\title{
New Zealand Apartment Living: Developing a Liveability Evaluation Index
}

JESSICA BENNETT

VICTORIA UNIVERSITY OF WELLINGTON

APRIL 2010

A thesis submitted to the School of Architecture, Victoria University of Wellington in fulfilment of the requirements for the degree of Masters in Building Science 
New Zealand Apartment Living: Developing a Liveability Index 


\section{ABSTRACT}

Over the past decade there has been a major shift in the housing preferences of New Zealanders away from low density, suburban, stand-alone housing towards higher density, urban apartments. As more people experience this style of accommodation, liveability issues have become apparent. An international literature review has found a gap between the research-based academic knowledge and the expectations of prospective occupants as represented by the national, popular press. For occupants their crucial issues are readily assessable (e.g. spatial and visual design), but often these issues do not have direct or long term health effects. The academic literature minimises these issues while placing importance on health and liveability issues (e.g. thermal and acoustic environments).

This thesis presents the development of an assessment methodology to enable prospective buyers/tenants to easily and quickly evaluate and compare apartment liveability over a wide range of indicators, not just those of immediate concern. The New Zealand Apartment Liveability Index [NZ ALI] considers over 100 factors that influence liveability in higher density housing and presents this information in a simple, easily understandable format.

The indicators have been organised into a weighted hierarchal system divided into five main categories: Community; Configuration; Governance; Indoor Environmental Quality; and Quality. There are 332 components within the New Zealand Apartment Liveability Index and all are weighted in order to provide a simple Liveability Rating (single score) or Liveability Profile (performance profile). Six criteria were applied in the development of the New Zealand Apartment Liveability Index to ensure that it is fit for purpose. The development criteria considered relevancy to liveability, objectivity \& practicality of assessments, accuracy of evaluations, and generality \& user friendliness of the tool.

The New Zealand Apartment Liveability Index is intended to provide the public with a simple, easy to use tool to help them make informed decisions when purchasing or leasing apartments. It will also be of value to regulatory agencies to help better understand the minimum liveability standards for apartments, as well as to designers and developers to help them better meet the needs of their current clients and future building users.

\section{KEYWORDS}

Apartment; Building Quality Indices; Built Environment Assessment Tool; Comfort; Evaluation; Health; Hierarchy; High Density; Housing Performance; Inner City Living; Liveability; New Zealand; Performance Indicator; Performance Measurement \& Assessment; Quality; Ranking Scales; Residential Built Environment; Safety; Weightings; Well-being. 


\section{ACKNOWLEDGEMENTS}

Many thanks to everyone who has assisted this research and made this study possible. I would especially like to thank my supervisor Nigel Isaacs for all his help and continual encouragement. His feedback and guidance has proved invaluable.

I would like to acknowledge BRANZ and the Building Research Levy who provided financial assistance for this research.

I would like to thank all those who made this research possible, through their continued and interest in providing helpful information and support. I would especially like to thank Alexandra Hills, Jonathan Smith, Krystle Stewart and Lee Bint. Their feedback and continuing support has made this research realizable.

I would especially like to thank the 47 participants of the NZ ALI Survey. Without their willingness to participate and thorough responses to the survey this research would not have been feasible. I would also like to thank the six participants of the NZ ALI Trial and Critique. Without their honest discussion and feedback this research would not have been achievable.

Finally I would like to thank all my family and friends who have continually supported me during this research. Their willingness to listen and provide insightful ideas has proved invaluable. Special thanks to my mother and father; Karyn and Andrew Bennett who were sounding boards for much of the research and continually supported me. Thank also to my brother and sister; Samuel and Laura for their feedback and support. Special thanks also to Miranda Hill and Virginia Maddock whose continuing support made the research possible. 


\section{PREFACE}

This thesis was submitted as part of the requirements for the degree of Master of Building Science at the School of Architecture, Victoria University of Wellington.

Author:

Jessica Bennett

School of Architecture

Victoria University of Wellington

Email: jessbenorama@gmail.com

Primary Supervisor

Nigel Isaacs

Teaching and Research Fellow

School of Architecture

Victoria University of Wellington

Email: nigel.isaacs@vuw.ac.nz 
New Zealand Apartment Living: Developing a Liveability Index 


\section{TABLE OF CONTENTS}

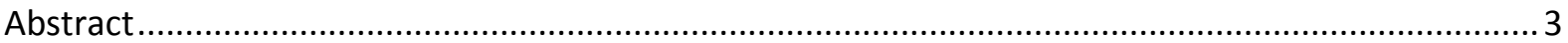

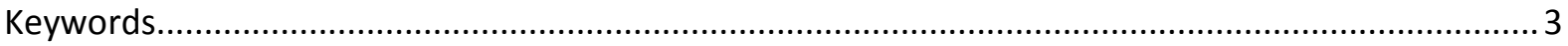

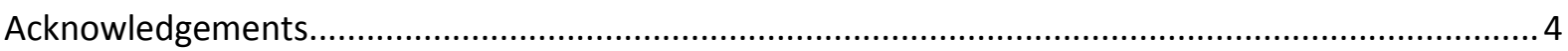

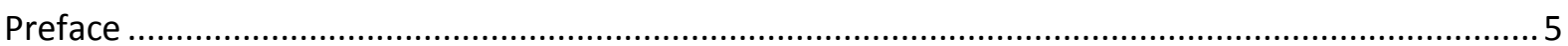

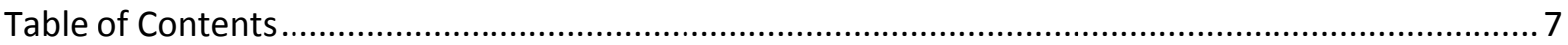

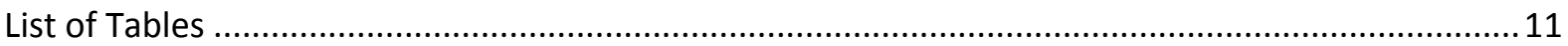

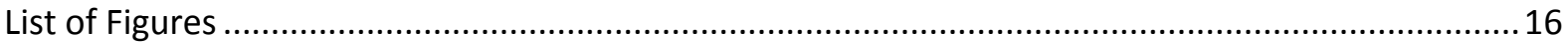

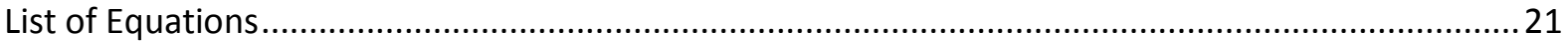

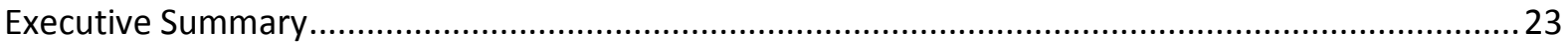

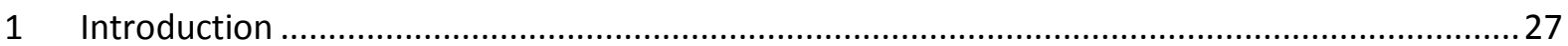

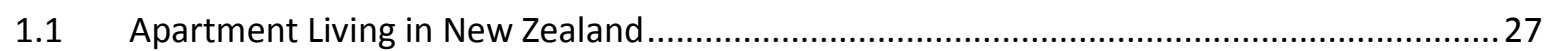

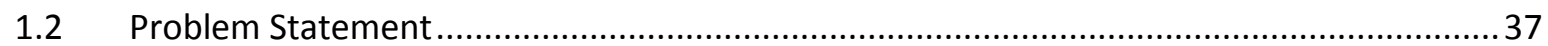

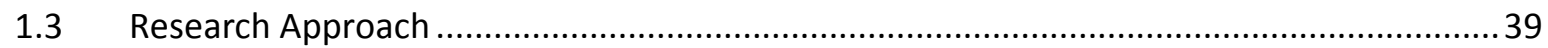

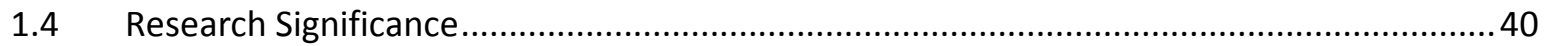

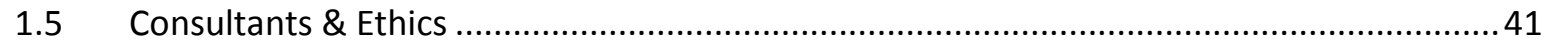

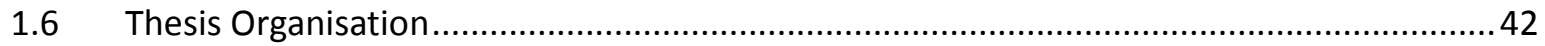

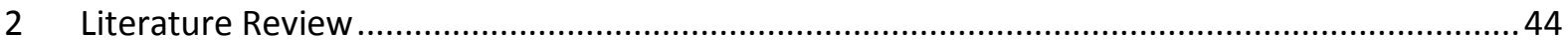

2.1 Liveability in the Residential Built Environment ................................................................ 44

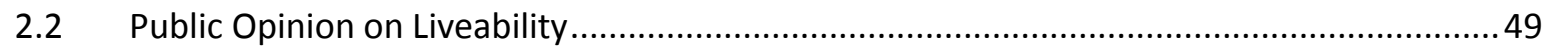

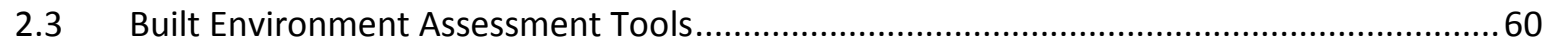

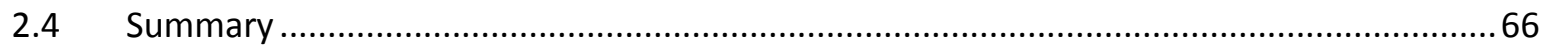

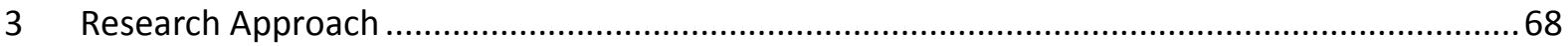

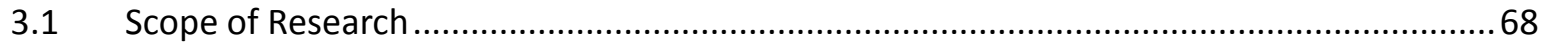

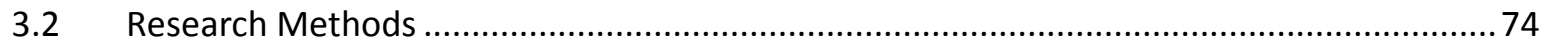

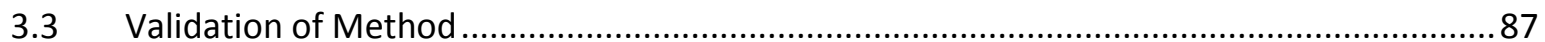




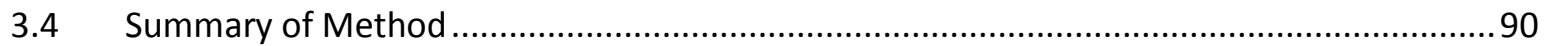

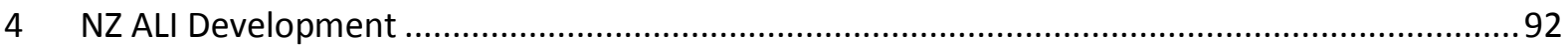

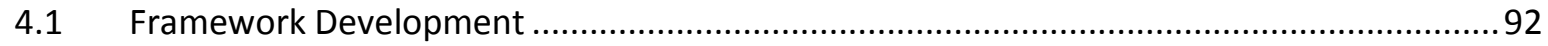

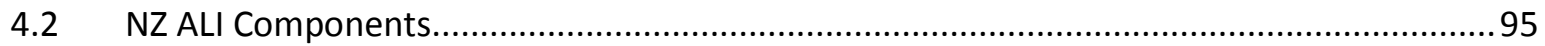

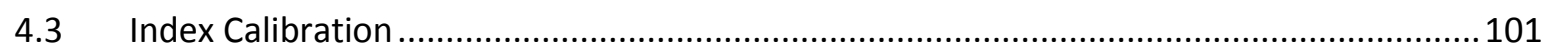

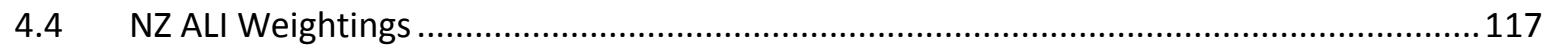

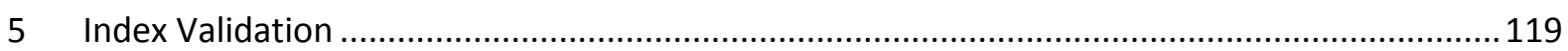

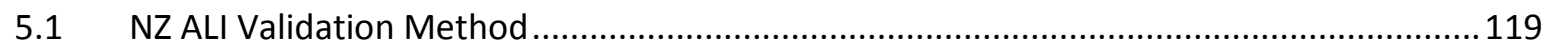

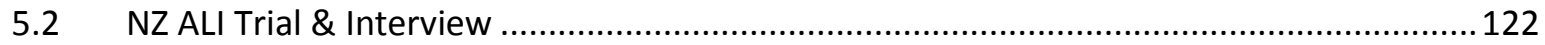

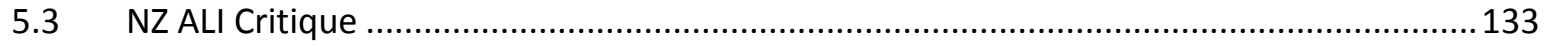

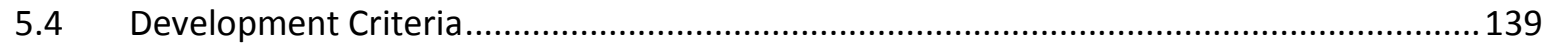

$6 \quad$ The New Zealand Apartment Liveability Index .................................................................. 142

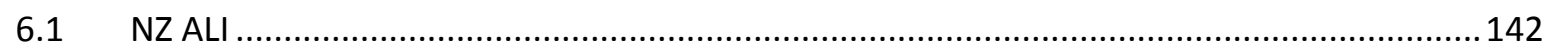

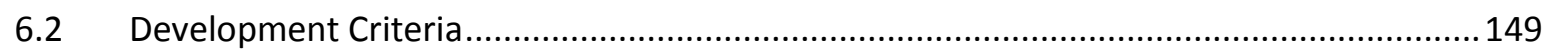

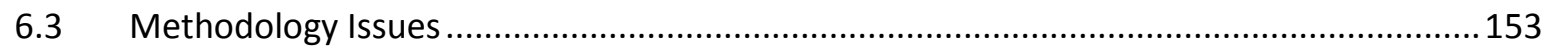

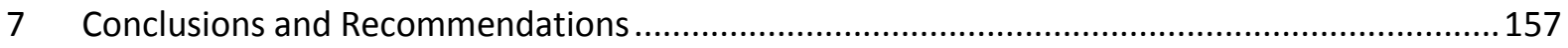

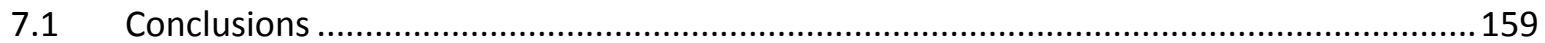

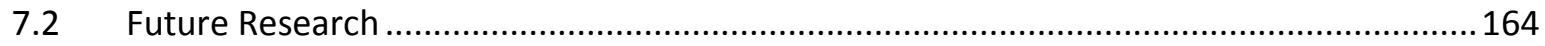

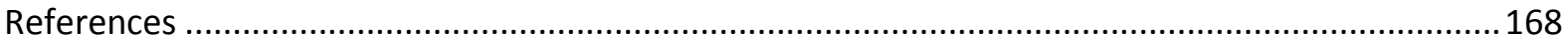

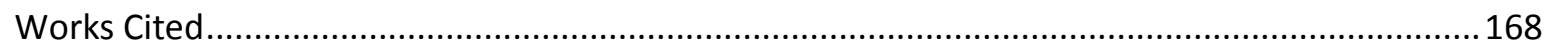

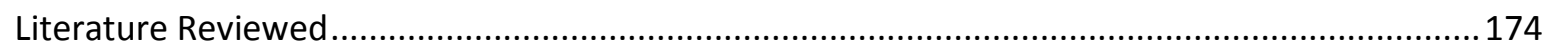

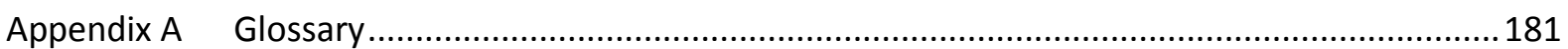

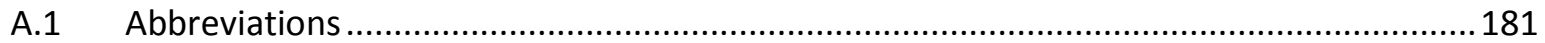

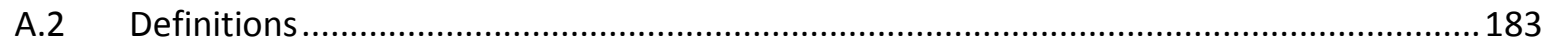

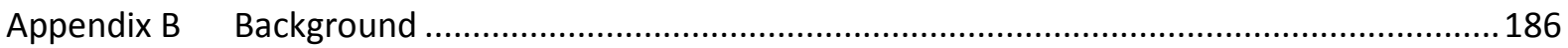

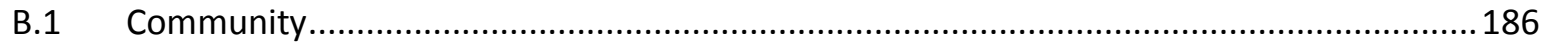

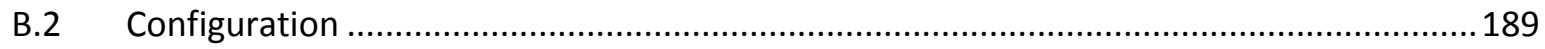


B.3 Governance 191

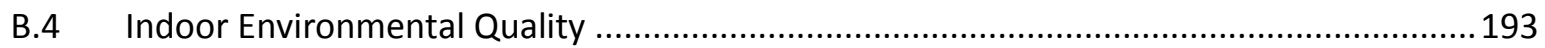

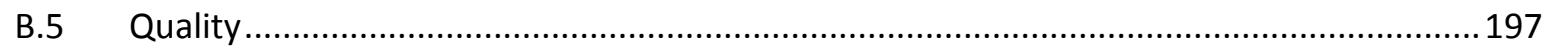

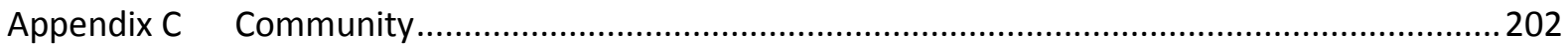

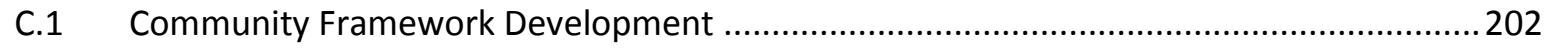

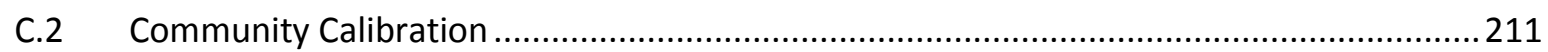

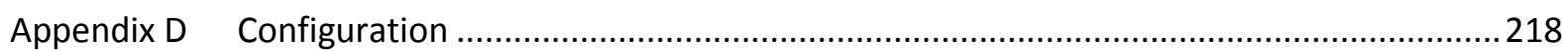

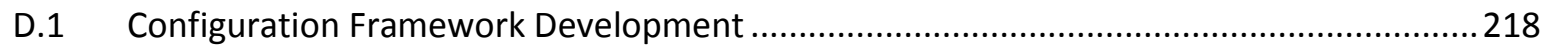

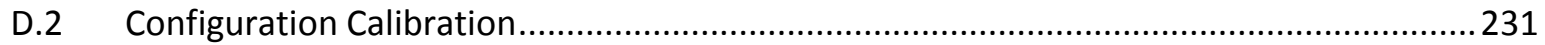

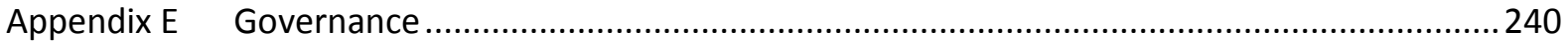

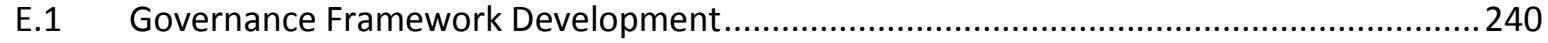

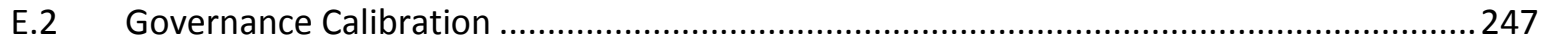

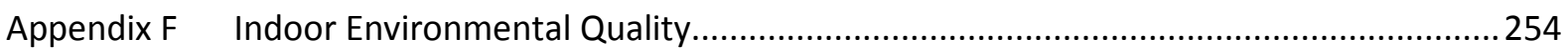

F.1 Indoor Environmental Quality Framework Development ...............................................2 254

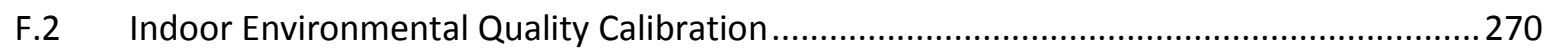

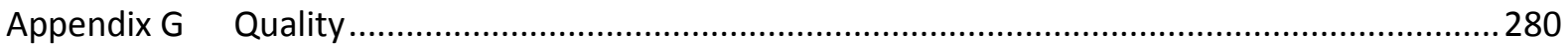

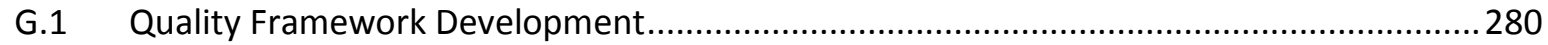

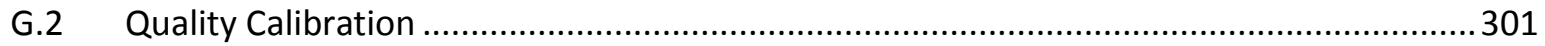

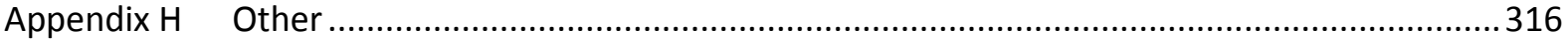

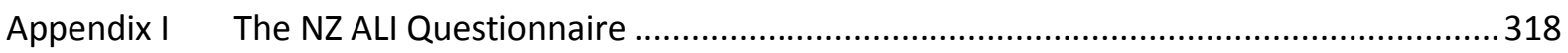

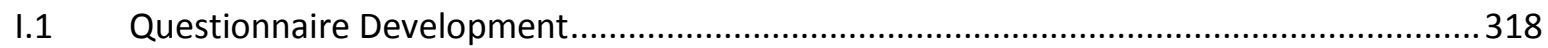

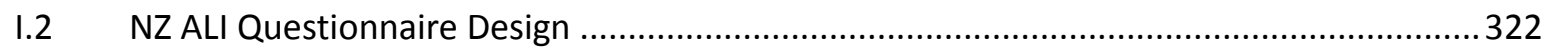

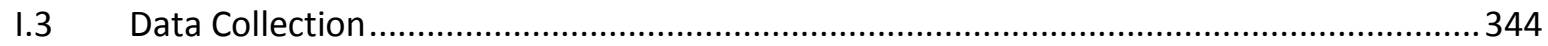

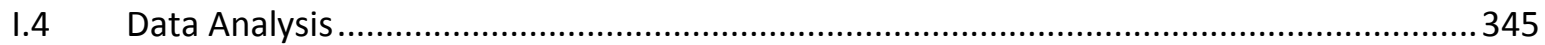

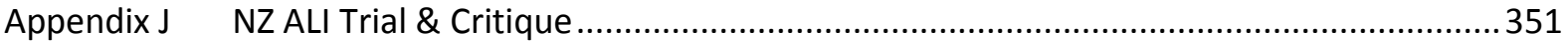

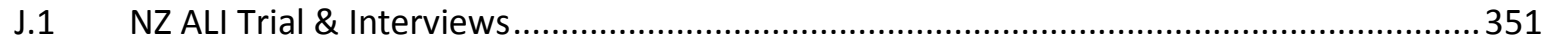

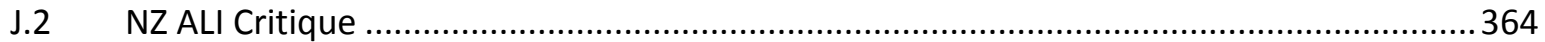


Appendix K

NZ ALI

Appendix L Victoria University of Wellington Ethics Approval 
LIST OF TABLES

Table 2-1, Example of the Literature Review Process ............................................................5 50

Table 2-2, Overview of the Literature Review Comparison ....................................................51

Table 2-3, Criterion Applied to the Development of Selected Recent BEAT ...................................65

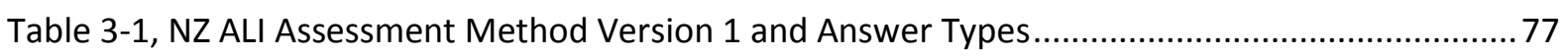

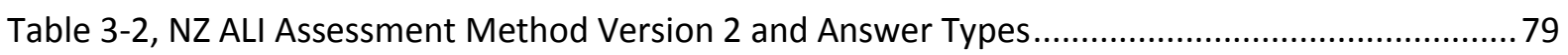

Table 3-3, Storage Assessment Method Version 1 Identification \& Assessment .............................. 79

Table 3-4, Storage Assessment Method Version 2 ........................................................... 79

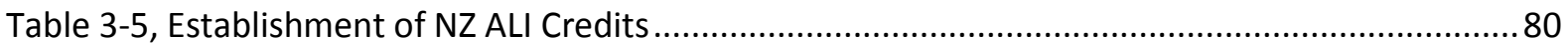

Table 3-6, Determination of Storage Credits ..................................................................... 81

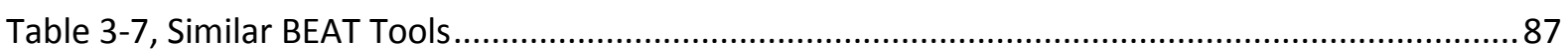

Table 3-8, AHP Method Pair-wise Comparison of each component in Spatiality............................88

Table 3-9, Ranking Method Ranking of each component in Spatiality .......................................89

Table 4-1, Weighting Applied to NZ ALI for Shape \& Configuration Aspects following Rule \#1........112

Table 4-2, Weightings Applied to NZ ALI Spatiality Aspects with more than one Indicator..............112

Table 4-3, Weightings for NZ ALI Storage Indicators ......................................................... 114

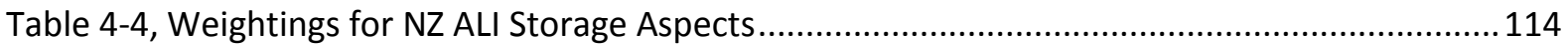

Table 4-5, Weightings for NZ ALI Spatiality Features............................................................... 115

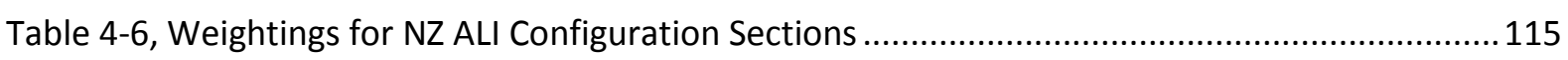

Table 4-7, Weightings for NZ ALI Categories ....................................................................... 115

Table 4-8, Weightings for NZ ALI Objective ..................................................................... 116

Table 4-9, NZ ALI Category Weightings and Associated Components...................................... 117

Table 4-10, NZ ALI Section Weightings and Associated Components ...................................... 117

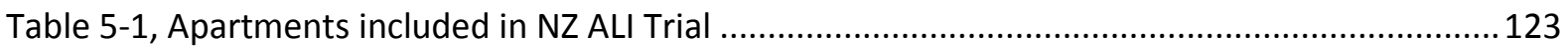

Table 5-2, Apartment Occupants who Participated in NZ ALI Trial \& Critique ............................... 124

Table 5-3, Summary of Key Issues determined from NZ ALI Interviews for NZ ALI Trial .................127 
Table 5-4, Summary of NZ ALI Critique regarding Usability 133

Table 5-5, Summary of NZ ALI Critique regarding Objectivity 134

Table 5-6, Summary of NZ ALI Critique regarding Practicality 135

Table C-1, Features Identified for Community 203

Table C-2, Aspects Identified for Environment 204

Table C-3, Aspects Identified for Neighbourhood 205

Table C-4, Indicators Identified for Community 206

Table C-5, Review of Assessment Methods Identified for Environment 207

Table C-6, Review of Assessment Methods Identified for Neighbourhood 208

Table C-7, Acceptability \& Awarding of Credits Identified for Environment 209

Table C-8, Acceptability \& Awarding of Credits Identified for Neighbourhood 210

Table C-9, Weighting Applied to NZ ALI for Safety Aspects 214

Table C-10, Component and Global Weightings for Community Indicators. 215

Table C-11, Component and Global Weightings for Community Aspects 216

Table C-12, Component and Global Weightings for Community Features. 216

Table C-13, Component and Global Weightings for Community Sections . 216

Table D-1, Features Identified for Configuration 219

Table D-2, Aspects Identified for Connections 220

Table D-3, Aspects Identified for Spatiality. 222

Table D-4, Indicators Identified for Configuration 223

Table D-5, Review of Assessment Methods Identified for Connections 225

Table D-6, Review of Assessment Methods Identified for Spatiality 226

Table D-7, Acceptability \& Awarding of Credits Identified for Connections. 227

Table D-8, Acceptability \& Awarding of Credits Identified for Spatiality. 229

Table D-9, Weightings Applied for NZ ALI Configuration Aspects with Two Indicators and One Assessment Method 234

Table D-10, Weightings Applied to NZ ALI Configuration Aspects with more than one Indicator .....235

Table D-11, Weightings Applied to NZ ALI Private Outdoor Access Aspects 235 
Table D-12, Component and Global Weightings for Configuration Indicators 236

Table D-13, Component and Global Weightings for Configuration Aspects 237

Table D-14, Component and Global Weightings for Configuration Features 238

Table D-15, Component and Global Weightings for Configuration Sections 238

Table E-1, Features Identified for Governance 241

Table E-2, Aspects Identified for Maintenance. 242

Table E-3, Aspects Identified for Management 242

Table E-4, Indicators Identified for Governance .243

Table E-5, Review of Assessment Methods Identified for Maintenance. 244

Table E-6, Review of Assessment Methods Identified for Management 244

Table E-7, Acceptability \& Awarding of Credits Identified for Maintenance. 245

Table E-8, Acceptability \& Awarding of Credits Identified for Management 246

Table E-9, Weightings Applied to NZ ALI Management Aspects 250

Table E-10, Component and Global Weightings for Governance Indicators .251

Table E-11, Component and Global Weightings for Governance Aspects. 251

Table E-12, Component and Global Weightings for Governance Features 252

Table E-13, Component and Global Weightings for Governance Sections. 252

Table F-1, Features Identified for Indoor Environmental Quality 255

Table F-2, Aspects Identified for Acoustics 256

Table F-3, Aspects Identified for Indoor Air Quality 257

Table F-4, Aspects Identified for Thermal Comfort 257

Table F-5, Aspects Identified for Visual Aspects 258

Table F-6, Indicators Identified for Indoor Environmental Quality..... 259

Table F-7, Review of Assessment Methods Identified for Acoustics 261

Table F-8, Review of Assessment Methods Identified for Indoor Air Quality 262

Table F-9, Review of Assessment Methods Identified for Thermal Comfort 263

Table F-10, Review of Assessment Methods Identified for Visual Aspects 265 
Table F-11, Acceptability \& Awarding of Credits Identified for Acoustics 266

Table F-12, Acceptability \& Awarding of Credits Identified for Indoor Air Quality 267

Table F-13, Acceptability \& Awarding of Credits Identified for Thermal Comfort 268

Table F-14, Acceptability \& Awarding of Credits Identified for Visual Aspects . 269

Table F-15, Weightings Applied to NZ ALI Indoor Environmental Quality Aspects with more than one Indicator 274

Table F-16, Component and Global Weightings for Indoor Environmental Quality Indicators. 275

Table F-17, Component and Global Weightings for Indoor Environmental Quality Aspects 277

Table F-18, Component and Global Weightings for Indoor Environmental Quality Features 278

Table F-19, Component and Global Weightings for Indoor Environmental Quality Sections 278

Table G-1, Features Identified for Quality 281

Table G-2, Aspects Identified for Building Quality 282

Table G-3, Aspects Identified for Building Services \& Amenities. 285

Table G-4, Aspects Identified for Materials Quality 286

Table G-5, Indicators Identified for Quality 286

Table G-6, Review of Assessment Methods Identified for Building Quality. 289

Table G-7, Review of Assessment Methods Identified for Building Services and Amenities 292

Table G-8, Review of Assessment Methods Identified for Materials Quality 294

Table G-9, Acceptability \& Awarding of Credits Identified for Building Quality 295

Table G-10, Acceptability \& Awarding of Credits Identified for Building Services \& Amenities. 297

Table G-11, Acceptability \& Awarding of Credits Identified for Materials Quality. 300

Table G-12, Weightings Applied to NZ ALI Quality following Rule \#1 305

Table G-13, Weightings Applied to NZ ALI Quality following Rule \#2 306

Table G-14, Weightings Applied to Building Services \& Amenities Aspects. 308

Table G-15, Component and Global Weightings for Building Quality Indicators 310

Table G-16, Component and Global Weightings for Building Services \& Amenities Indicators 311

Table G-17, Component and Global Weightings for Materials Quality Indicators 312

Table G-18, Component and Global Weightings for Quality Aspects 312 
Table G-19, Component and Global Weightings for Quality Features 314

Table G-20, Component and Global Weightings for Quality Sections 314

Table I-1, Online Survey Tool Requirements 319

Table I-2, Response Rate for End-User and Stakeholder Groups 345

Table J-1, NZ ALI Liveability Ratings for NZ ALI Trial Apartments 351

Table J-2, NZ ALI Category Liveability Profiles for NZ ALI Trial Apartments 351

Table J-3, NZ ALI Section Liveability Profiles for NZ ALI Trial Apartments 352

Table J-4, NZ ALI Interview, Discussion Topics \& Prompts 353

Table J-5, NZ ALI Interview Occupant A Statistical Questions 354

Table J-6, NZ ALI Interview Occupant A Liveability Questions 355

Table J-7, NZ ALI Interview Occupant B\&C Statistical Questions. 357

Table J-8, NZ ALI Interview Occupant B\&C Liveability Questions 358

Table J-9, NZ ALI Interview Occupant D Statistical Questions 359

Table J-10, NZ ALI Interview Occupant D Liveability Questions. 360

Table J-11, NZ ALI Interview Occupant E\&F Statistical Questions 361

Table J-12, NZ ALI Interview Occupant E\&F Liveability Questions. 362

Table J-13, NZ ALI Critique, Usability 365

Table J-14, Summary of Usability Issues 366

Table J-15, NZ ALI Critique, Objectivity. 367

Table J-16, Summary of Objectivity Issues 367

Table J-17, NZ ALI Critique, Practicality 368

Table J-18, Summary of Practicality Issues 369 


\section{LIST OF FIGURES}

Figure 1-1, Comparison of Building Consents issued nationwide for Apartments and All Residential Buildings

Figure 1-2, Comparison of Census Night Population Counts for New Zealand, Cities and Districts..... 29

Figure 1-3, Comparison of Urban Intensification in Auckland City, Wellington City and Christchurch from 19912006

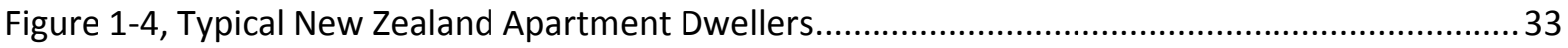

Figure 2-1, Six Human Requirements in the Residential Built Environment ....................................45

Figure 2-2, Categories Developed from Identified Factors ................................................................52

Figure 2-3, Community Associated Sections \& Factors …..........................................................53

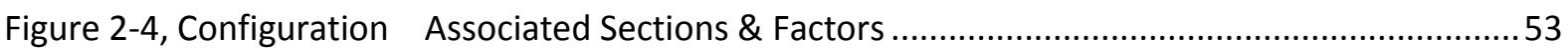

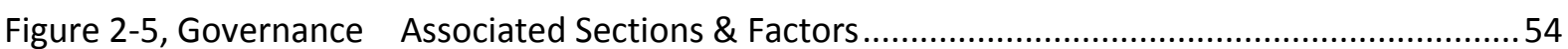

Figure 2-6, Indoor Environmental Quality Associated Sections \& Factors ........................................54

Figure 2-7, Quality Associated Sections \& Factors....................................................................... 55

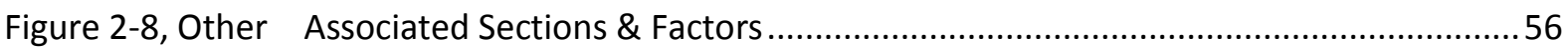

Figure 2-9, Comparison of Perceived Category Importance .............................................................57

Figure 2-10, Comparison of Perceived Section Importance ............................................................57

Figure 3-1, Potential End-Users and Benefits of NZ ALI............................................................. 70

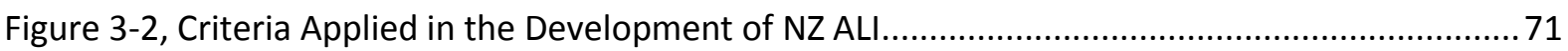

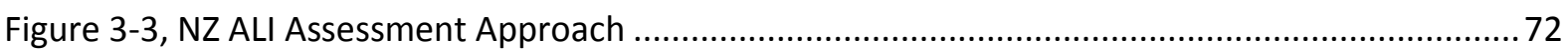

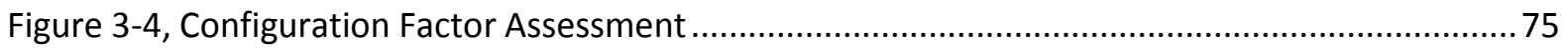

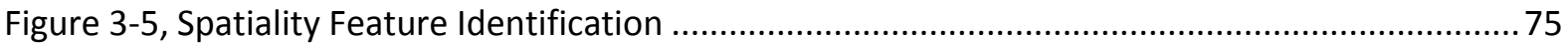

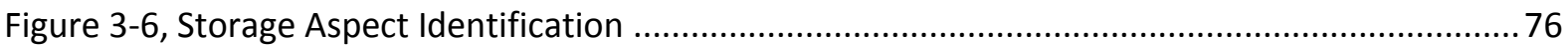

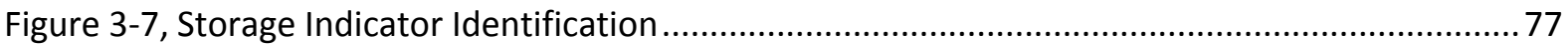

Figure 3-

Questionnaire Results 83

Figure 3-9, Ranking Variation for Spatiality Features, NZ ALI Questionnaire Results 83

Figure 3-10, Weightings Determined for Spatiality Features, NZ ALI Questionnaire Results .84 
Figure 4-1, Objective, Categories \& Sections Identified in Literature Review 93

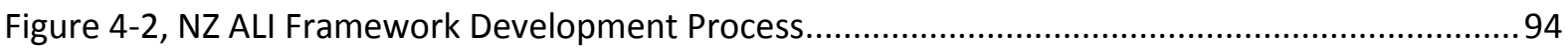

Figure 4-3, NZ ALI Components within Community to Aspect Level .................................................95

Figure 4-4, NZ ALI Components within Configuration to Aspect Level.............................................96

Figure 4-5, NZ ALI Components within Governance to Aspect Level .............................................97

Figure 4-6, NZ ALI Components within Indoor Environmental Quality to Aspect Level .......................98

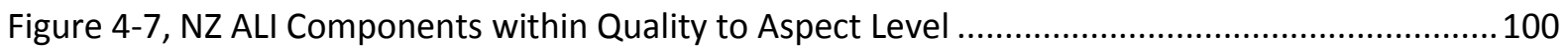

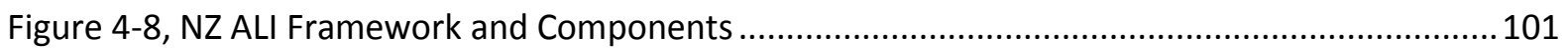

Figure 4-9, NZ ALI Questionnaire, Part 1 Aspects \& Features Example Spatiality ...........................103

Figure 4-10, NZ ALI Questionnaire, Part 2 Sections Example Configuration ................................... 104

Figure 4-11, NZ ALI Questionnaire, Part 3 Categories Example ～NZ ALI.......................................... 104

Figure 4-12, NZ ALI Questionnaire, Part 4 Statistical Questions Example ......................................... 104

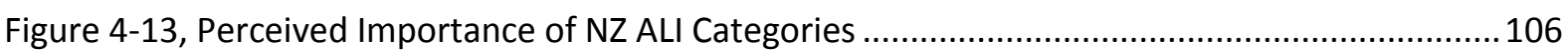

Figure 4-14, Perceived Importance of NZ ALI Categories - End-User and Stakeholder Group

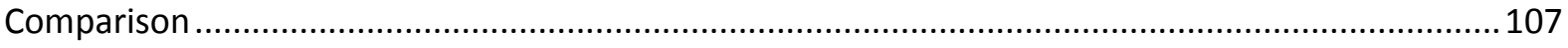

Figure 4-15, NZ ALI Category Ranking - End-User and Stakeholder Group Comparison .................... 108

Figure 4-16, Perceived Importance of NZ ALI Categories Dwelling History Comparison..................109

Figure 4-17, NZ ALI Category Ranking Dwelling History Comparison ............................................110

Figure 5-1, NZ ALI Ratings for Apartments included within NZ ALI Trial .......................................125

Figure 5-2, NZ ALI Category Profiles for Apartments included within NZ ALI Trial............................126

Figure 5-3, NZ ALI Section Profiles for Apartments included within NZ ALI Trial ..............................126

Figure 6-1, NZ ALI for Existing Buildings, Introduction \& General Questions Worksheet ...................143

Figure 6-2, NZ ALI for New Buildings, Introduction \& General Questions Worksheet .......................144

Figure 6-3, NZ ALI for Existing Buildings, Spatiality Worksheet .................................................. 145

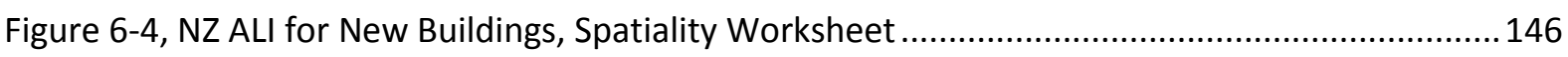

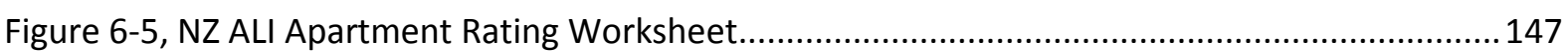

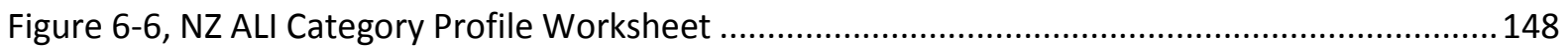

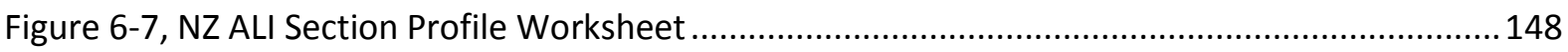


Figure B-1, Liveability Effects: Environment 186

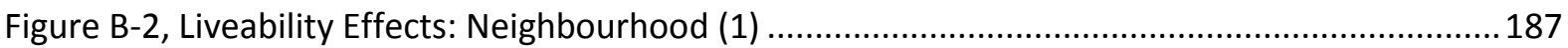

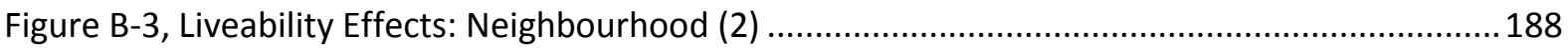

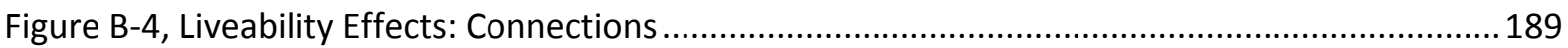

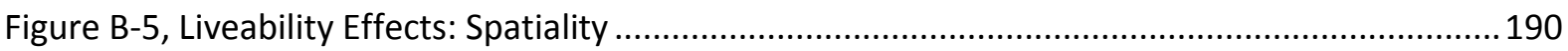

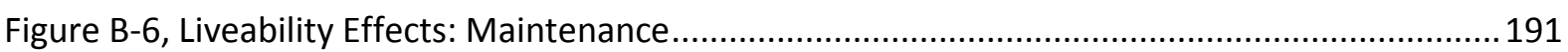

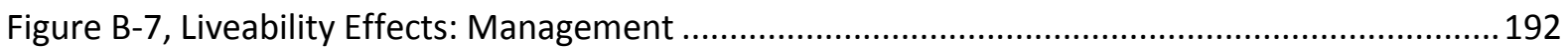

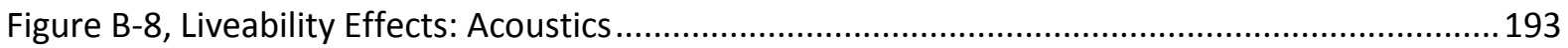

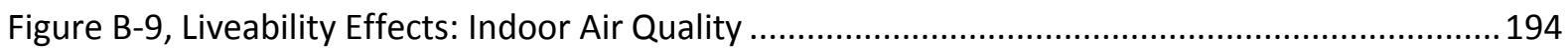

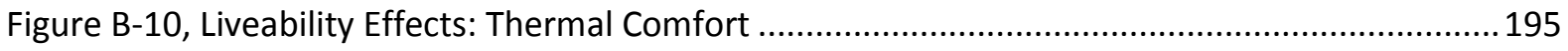

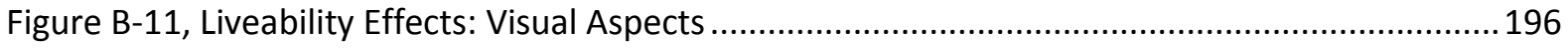

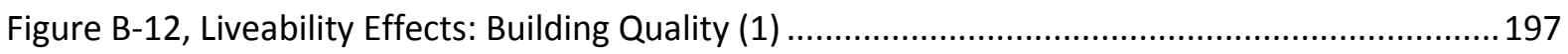

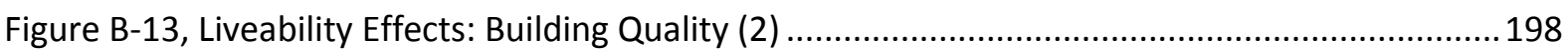

Figure B-14, Liveability Effects: Building Services \& Amenities ..................................................... 199

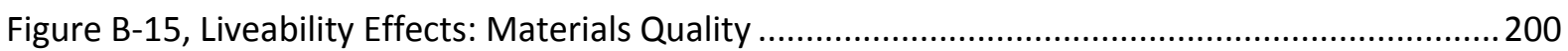

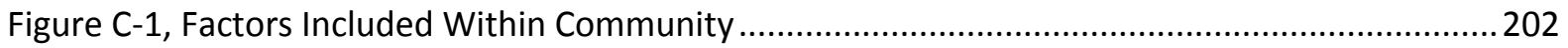

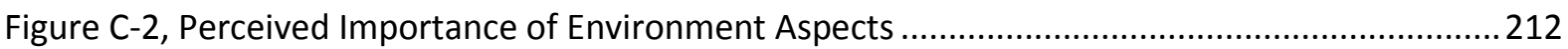

Figure C-3, Perceived Importance of Neighbourhood Aspects.....................................................212

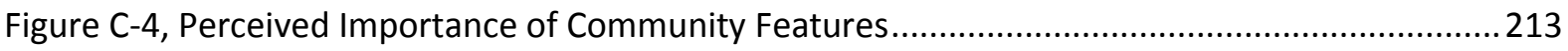

Figure C-5, Perceived Importance of Community Sections ........................................................213

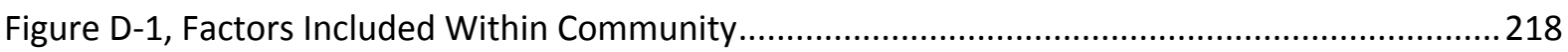

Figure D-2, NSCC Headroom Recommendations from the Good Solutions Guide for Apartments ... 229

Figure D-3, Perceived Importance of Connections Aspects...........................................................232

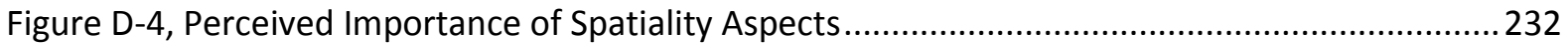

Figure D-5, Perceived Importance of Configuration Features ....................................................233

Figure D-6, Perceived Importance of Configuration Sections............................................................233

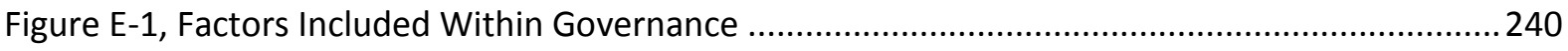




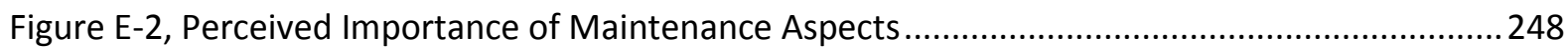

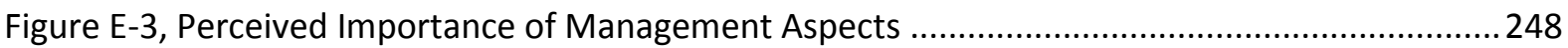

Figure E-4, Perceived Importance of Governance Features ..........................................................249

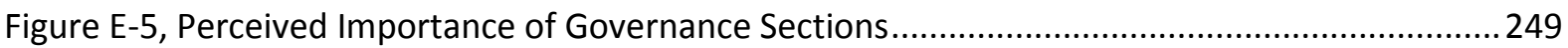

Figure F-1, Factors Included Within Indoor Environmental Quality .............................................25

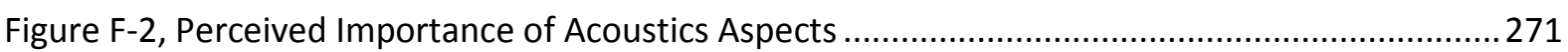

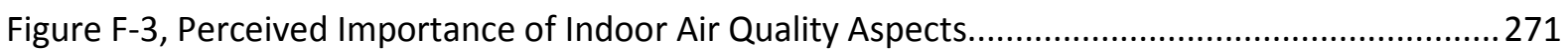

Figure F-4, Perceived Importance of Thermal Comfort Aspects.....................................................272

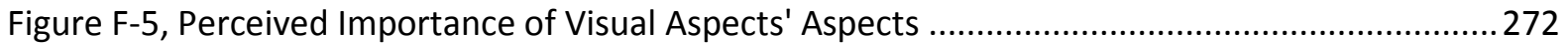

Figure F-6, Perceived Importance of Indoor Environmental Quality Features................................273

Figure F-7, Perceived Importance of Indoor Environmental Quality Sections ..................................273

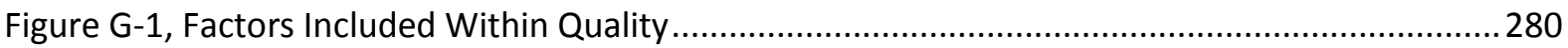

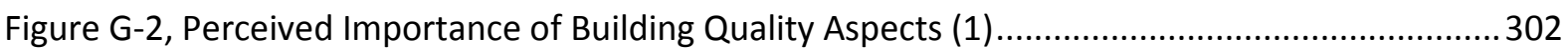

Figure G-3, Perceived Importance of Building Quality Aspects (2) ..................................................302

Figure G-4, Perceived Importance of Building Services \& Amenities Aspects (1) ...............................303

Figure G-5, Perceived Importance of Building Services \& Amenities Aspects (2) .............................303

Figure G-6, Perceived Importance of Materials Quality Aspects .......................................................304

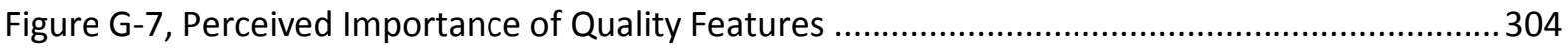

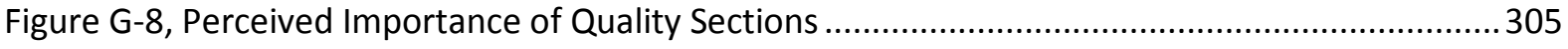

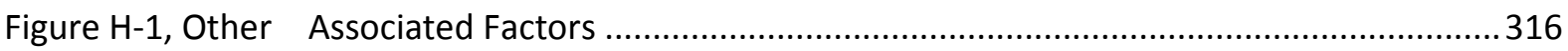

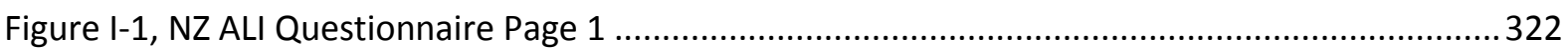

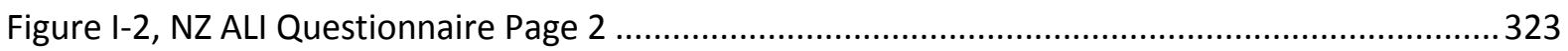

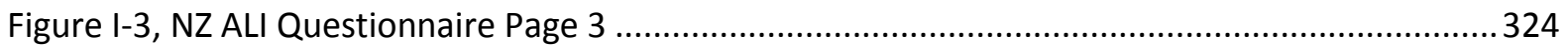

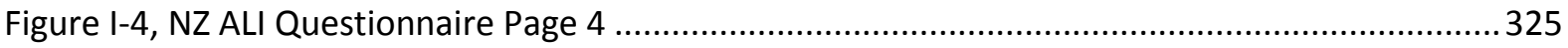

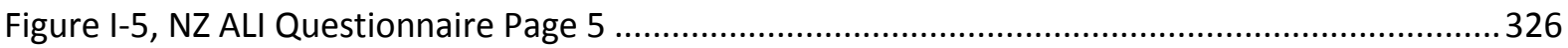

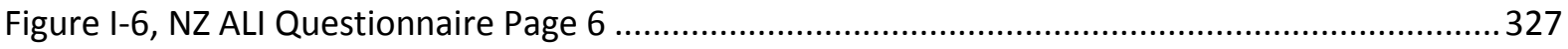

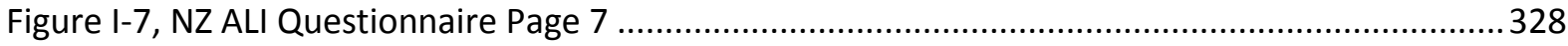




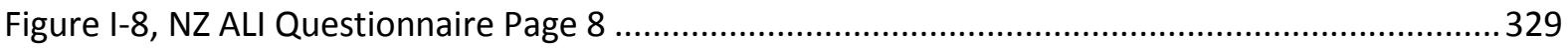

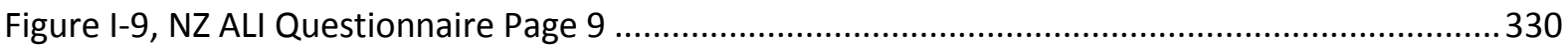

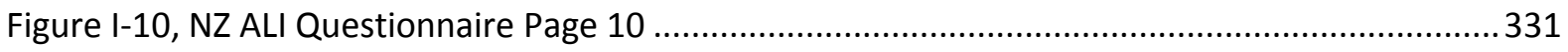

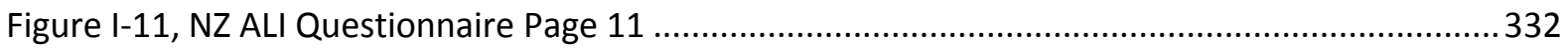

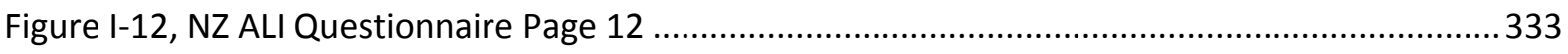

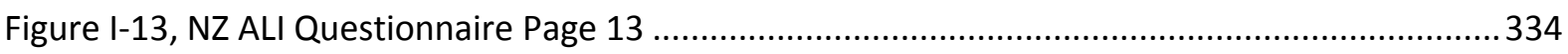

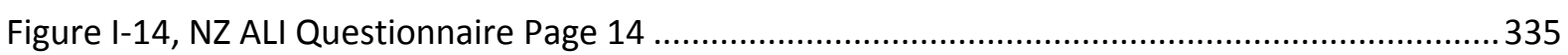

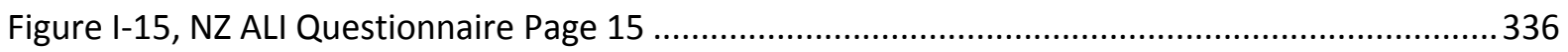

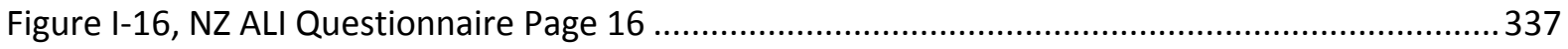

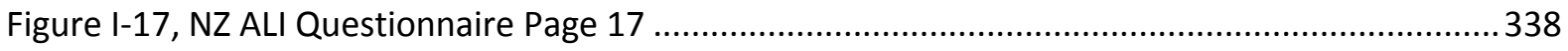

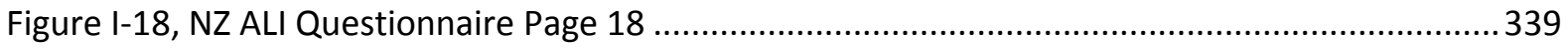

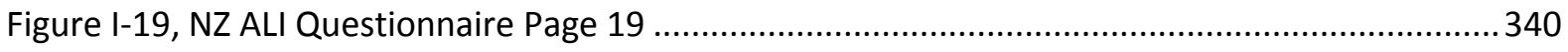

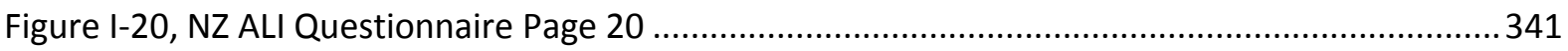

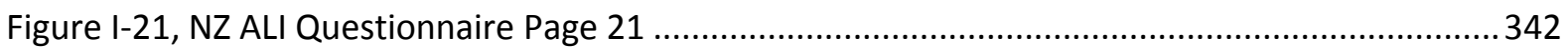

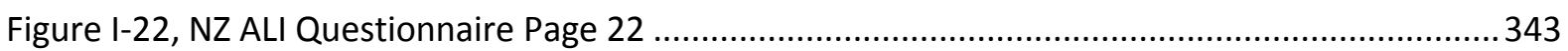

Figure I-23, Survey Responses by End User and Stakeholder Groups .............................................346

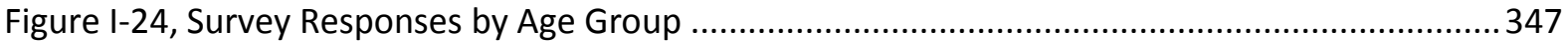

Figure I-25, Survey Responses by Current Dwelling Type............................................................348

Figure I-26, Survey Responses by Apartment Dwelling History...................................................... 349

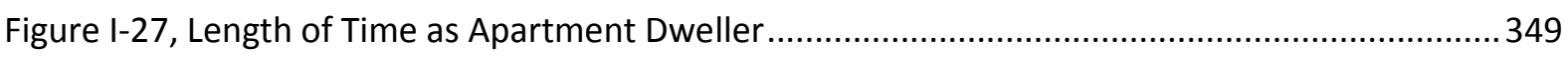

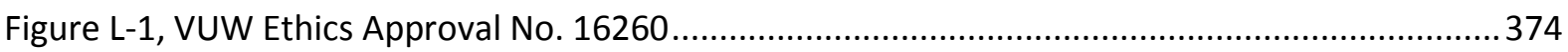

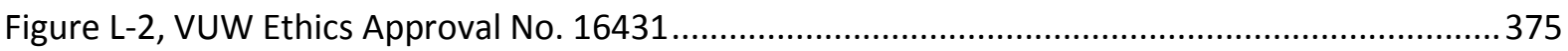


LIST OF EQUATIONS

Equation 3-1, Cumulative Percentage ... .84

Equation 4-1, Cumulative Percentage .... 105

Equation 4-2, Section Global Weighting .

Equation 4-3, Feature Global Weighting 113

Equation 4-4, Aspect Global Weighting .... 113

Equation 4-5, Indicator Global Weighting 113 
New Zealand Apartment Living: Developing a Liveability Index 
Over the past decade there has been a shift in the housing preferences of New Zealanders away from low density, suburban, stand-alone housing towards higher-density, urban apartments. Since 1991 the number of building consents issued for new apartment buildings has risen by over $2000 \%$. This urban intensification has been most prolific in Auckland City and Wellington City.

Unfortunately despite the rapid rise in this type of construction and lifestyle in recent years a number of liveability issues have come to light as a result of poor construction and a building code that is ill equipped to deal with this type of building. Inadequate natural light, poor noise control, limited outdoor access, inadequate ventilation, small unit sizes and inadequate storage provisions are just some of the issues with liveability in New Zealand apartments.

Housing and liveability are inherently related to each other. There are a number of factors that -being and safety (liveability) when in their home. An apartment offers a different type of lifestyle that many New Zealanders do not understand. Unlike buying electronic goods or a new car, when buying an apartment there is little information available concerning its suitability or liveability. As many people make apartment purchasing or tenancy decisions only a few times in their lives, it is important that they understand the differences in apartment design and living, and make informed decisions when purchasing or leasing. Currently this information is not readily available in an easy to use and understand format.

The overall aim of this research was to investigate apartment living in New Zealand and how it affects occupant liveability. It was hypothesized that it is possible to develop an assessment method that will provide prospective apartment occupants in New Zealand with a simple, easy way to compare and evaluate apartment liveability over a wide range of indicators, not just those of immediate concern.

The specific objectives of the research were:

- To develop a comprehensive set of factors that affect lives in the residential built environment, particularly in higher density, high-rise housing,

- To investigate the issues the New Zealand public considers important regarding liveability of the residential built environment,

- To develop a Built Environment Assessment Tool [BEAT] that is capable of evaluating liveability of New Zealand apartments across a wide range of factors,

- To test the research approach used to develop other similar evaluation tools Building Quality Assessment [BQA], Building Quality Indicator [BQI] and Housing Performance Evaluation Model for Multi-family Residential Buildings [HPMFRB ] in developing an apartment liveability evaluation tool for New Zealand,

- To determine what different groups of end-users and stakeholders perceive to be important in regards to peoples liveability in higher density, high-rise housing. 
To meet the first two objectives an international literature review was conducted. It found:

- Over 100 factors in the residential built environment that can affect liveability in various ways. Six main requirements were identified access to community amenities, connections to the outdoors, satisfying indoor environments (visually, aurally, thermally and spatially), privacy \& sanctuary, well-built buildings (e.g. occupants) and social capita \& interactions (e.g. social inclusion),

- Academic knowledge and public opinion (represented by the New Zealand popular press) showed disparity when placing importance on factors that can affect occupant liveability. The public places importance on issues that can easily be assessed (i.e. views and outdoor access) whereas academia places value on factors that often affect liveability through longer term exposure (i.e. air quality and acoustics), and cannot easily be assessed. This disparity suggests that the public makes purchasing or tenancy decisions based on readily assessed information ignoring other issues and shows that there is a real need for a better method of evaluating the liveability of higher-density housing.

A BEAT has been developed to evaluate the occupant liveability of New Zealand apartments The New Zealand Apartment Liveability Index [NZ ALI]. The development of NZ ALI follows the research methods used to develop BQA (a New Zealand developed office and retail evaluation tool), BQI (a health and safety evaluation tool for high density living developed in Hong Kong) and HPMFRB (a health and comfort evaluation tool for high density living developed in South Korea). These BEAT are based on a weighted hierarchy of building features and indicators which can be used to provide a single overall score and a set of sub-scores (or performance profile).

Two versions of NZ ALI were developed, one for existing buildings and one for new buildings. The tools adhered to six development criteria to ensure fitness-for-purpose. These were:

1. Relevant

The factors considered should be directly related to the health, comfort, wellbeing and safety of occupants, users and visitors

2. Objective

Assessed factors should be measureable and verifiable to minimise the amount of subjectivity in use

3. Practical

Evaluation procedure should be simple and information easily acquired. It should not require measurement instruments and/or sophisticated/specialist knowledge

4. Accurate

Results provided should be representative of how the apartment's liveability may affect most people.

5. General

The index should be applicable to different environments and typical New Zealand apartments at present and in near future

6. User Friendly

The tool should be easy to use, easy to understand and straightforward for users

NZ ALI was developed using the factors identified in the literature review as a hierarchy. These were grouped into five overall Categories with 13 Sections beneath these. At this stage Criterion \#1 was 
applied. Overall there are six levels to the hierarchy of NZ ALI: Objective; Category; Section; Feature; Aspect; and finally Indicator. The hierarchy was developed into an index by including Assessment Methods and Credits for the different answers. At this stage Criteria \#2 and \#3 were applied. The index was then calibrated so that each of the $332 \mathrm{NZ} \mathrm{ALI} \mathrm{components} \mathrm{were} \mathrm{weighted} \mathrm{in} \mathrm{order} \mathrm{to}$ provide an overall Liveability Rating (percentage rating) and Liveability Profile (similar to a performance profile over the Category and Section levels).

Calibration of the index was undertaken through a survey that was conducted which questioned six groups of people (Building Management, Building Owners/Developers, Designers, Occupants, Academics/Researchers and Governmental Organisations) regarding what they consider to be important in relation to liveability in higher density housing.

The working NZ ALI was then validated to ensure that its evaluations were acceptability accurate, the tool easy to use and general as required by the development criteria \#4, \#5 and \#6. Validation of NZ ALI was completed by trialling the tool on four apartments and comparing the results to occupant interviews. The same occupants then also trialled the tool themselves to ensure it met the requirements of Criterion \#6.

It was found that the research method utilized in BQA, BQI and HPMFRB was appropriate in developing a BEAT for New Zealand apartments. The literature review found that there was disparity between academic knowledge and public opinion regarding liveability in higher density housing. The tool developed following these research methods is able to provide a quick and easy liveability evaluation bridging the knowledge gap between academia and the public.

This evaluation tool will be able to provide people with information that will enable them to make informed decisions and potentially demand a higher standard of apartment design, construction and living. However it will not only be of use to occupants, but also to designers, developers, building managers, and governmental organisations. It will also be of value to regulatory agencies to help better understand the minimum liveability standards for New Zealand apartments and to designers and developers to help them better meet the needs of their clients and building users.

In the longer term, such a tool may have the potential to drive market prices up (or down) where liveability is shown to be of a high (or low) standard as the apartment occupant demands better standards of living. Building management, developers and owners will benefit from this as it will allow them to easily see where a higher rate of return can be found and where upgrades or retrofits will provide the best benefits.

Currently NZ ALI has been developed as a pilot study to determine whether such a BEAT can be developed for New Zealand apartments. To develop a fully functioning and validated NZ ALI, more comprehensive calibration would be required to ensure that weightings applied to NZ ALI components are representative and accurate. 
New Zealand Apartment Living: Developing a Liveability Index 


\section{INTRODUCTION}

The connection between health and the dwelling of the population is one of the most important that exists Florence Nightingale quoted in (Lowry, 1991).

The World Health Organisation reports that people spend up to two thirds of their lives in their homes (Ranson, 1991). All homes should therefore provide healthy, comfortable and safe environments. Un-sanitary and unhealthy dwellings have the potential to put at risk the health of occupants.

In recent years there has been a rapid rise in apartment living in New Zealand. The effect of this phenomenon has been to highlight liveability issues that previously were not a problem in standalone houses (such as adequate daylight, views, ventilation and acoustics). This shift from standalone houses has forced an uninformed society to deal with lifestyle and health issues within higher density living.

This thesis will examine the changes in New Zealand housing preferences over the last two decades, apartment assessment and evaluation tool was developed as a potential way to bridge the gap between academic and public knowledge.

This introductory chapter will discuss the background, motivation, and significance of this research project.

\subsection{APARTMENT LIVING IN NEW ZEALAND}

For some time, New Zealanders have preferred to live in stand-alone housing sited on a quarter acre section. This is referred to as the quarter acre dream because of the ability to have gardens and privacy from neighbours (Mitchell, 1972). This has its beginnings in both the early years of English

Zealanders away from traditional stand-alone houses towards higher density, urban apartment living. Today higher density housing is often seen as more affordable, convenient and secure than traditional housing for both younger and older generations of New Zealanders. This section will discuss the rise of apartment living in New Zealand and current issues with this type of living in New Zealand to provide a background to the research undertaken in this thesis. 


\subsubsection{RISE OF APARTMENT LIVING}

Since 1991 building consents issued for new apartment buildings have risen significantly. In 1991 building consents for new apartment buildings represented just $0.6 \%$ of all building consents issued for residential buildings ${ }^{1}$. However in 2008 consents issued for new apartment buildings represented 12.5\% (Statistics New Zealand, 2009). Figure 1-1 compares the number of building consents issued nationwide for new apartment buildings ${ }^{2}$ to all new residential buildings ${ }^{3}$ from $19912008^{4}$. The figures for all residential buildings also include figures for apartment buildings.

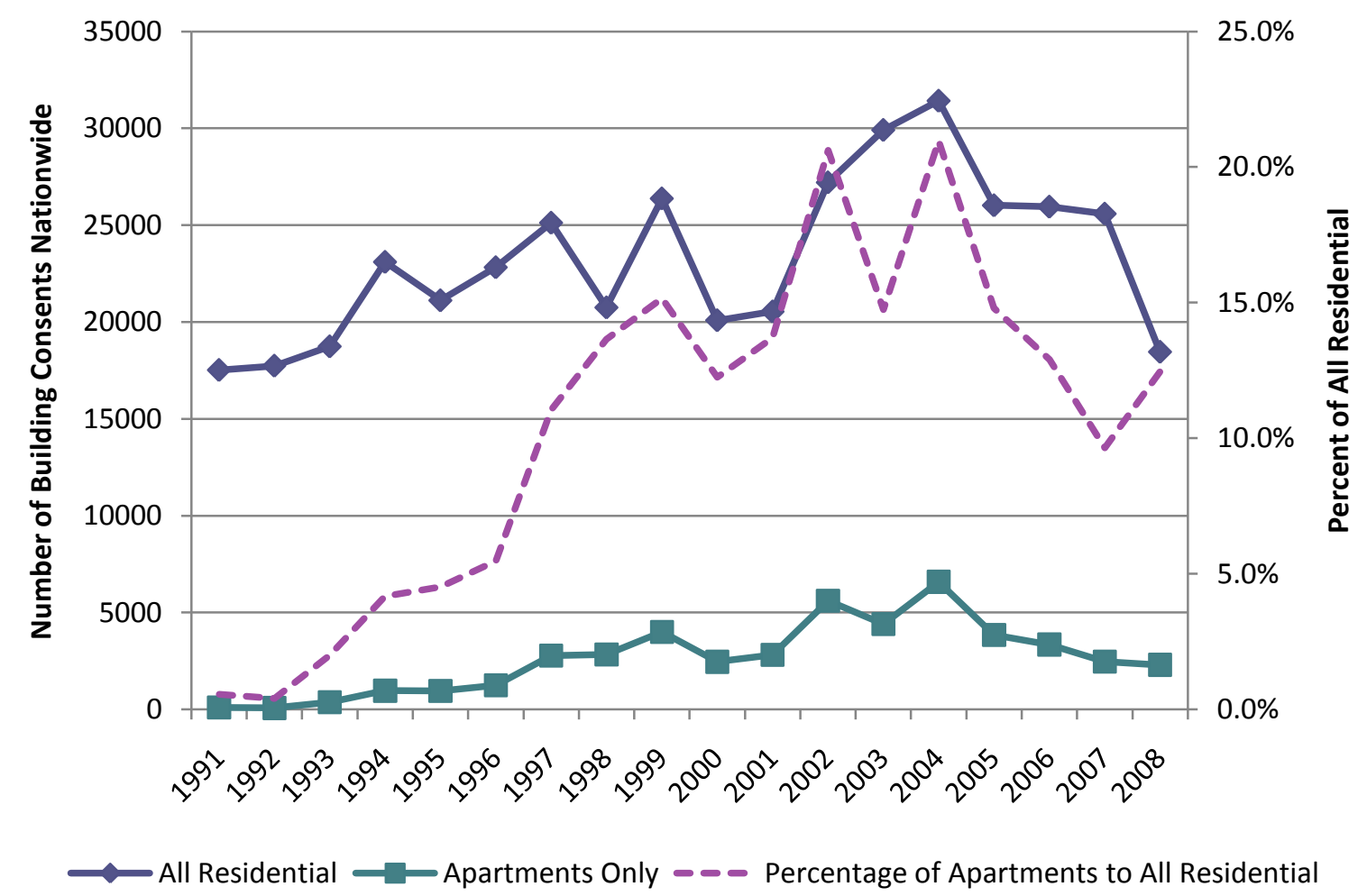

Figure 1-1, Comparison of Building Consents issued nationwide for Apartments and All Residential Buildings

Figure 1-1 shows that building consents issued nationwide for new apartment buildings have followed similar trends to all residential buildings in that they increased and peaked in 1997, 1999 and again in 2004 with rapid drops in the intervening years and a steady decline from 2004 to 2008.

\footnotetext{
${ }^{1}$ Statistics New Zealand began recording regional data on apartment buildings in July 1990 and before this data is only available at a national level from the beginning of 1990.

${ }^{2}$ Statistics New Zealand compile figures for new apartment buildings from consents that have 10 or more attached new dwelling units this means that figures for ten or more horizontally or vertically attached dwellings are included in the data. The reported figures are for the number of buildings containing apartments, not the total number of apartment units.

${ }^{3}$ Statistics New Zealand classes residential buildings as 'all dwellings', meaning construction that is built for habitation. This does not include hostels, boarding houses, hotels, motels and nursing homes

${ }^{4}$ These figures are for building consents issued for new buildings only and do not include building consents issued for alterations to buildings.
} 
Building consents for all residential buildings more than doubled in 2004 in comparison to figures for 1991 but by 2008 had dropped again to levels similar to 1991.

In comparison, building consents for new apartment buildings have not dropped to the same extent. In 1991 these consents were just $0.6 \%$ of all residential building consents (shown in Figure 1-1 with a dashed line). By 2004 the number of consents issued had risen by over $6000 \%$ and were $21 \%$ of all residential building consents. Since 2004 there has been a steady drop in the number of apartment consents issued, however unlike all residential they have not dropped to 1991 levels. In 2008 they were still $13 \%$ of all residential building consents.

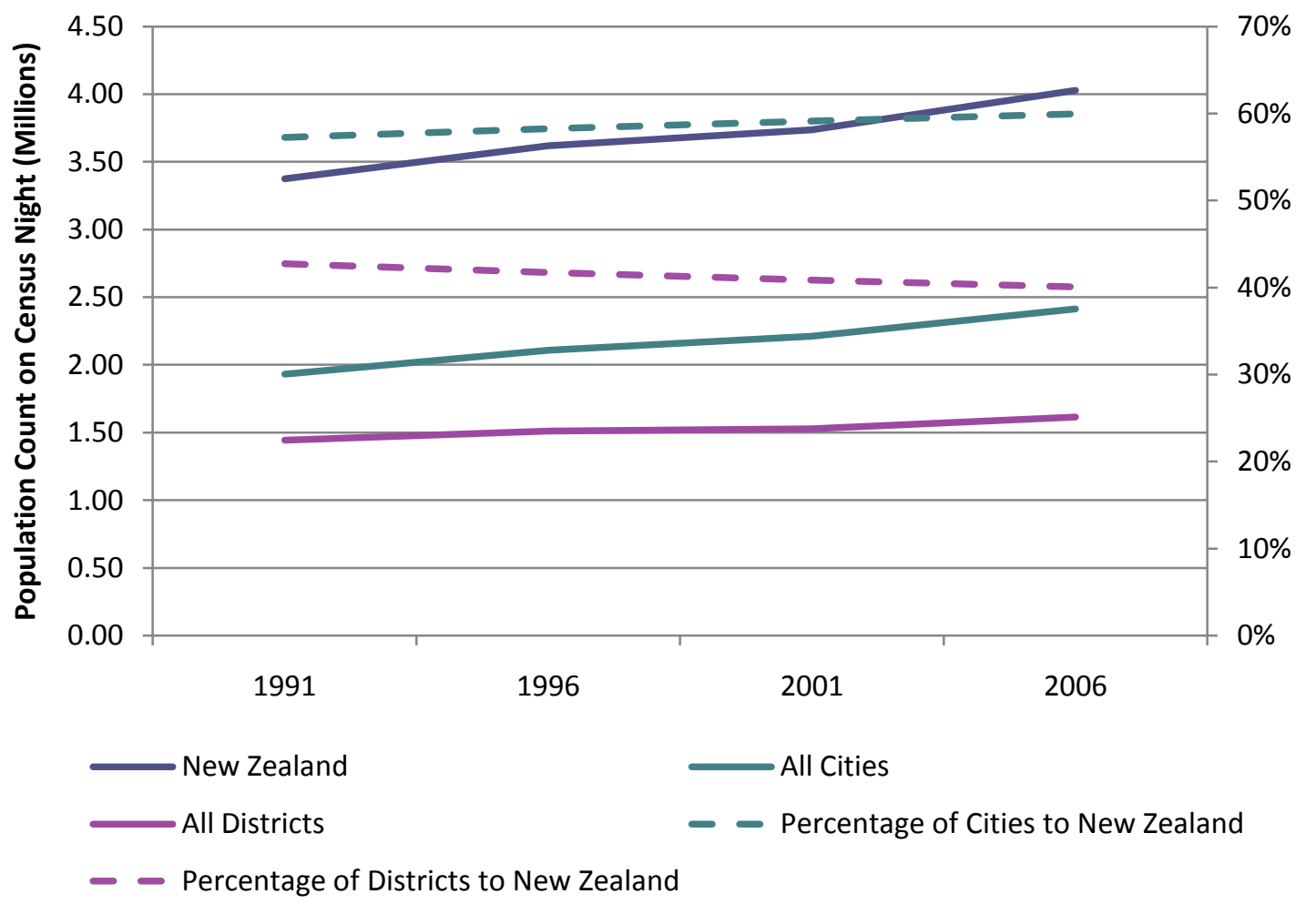

Figure 1-2, Comparison of Census Night Population Counts for New Zealand, Cities and Districts

Figure 1-2 compares the population counts recorded by Statistics New Zealand from the four latest publications (Statistics New Zealand, 2009). The data compares population changes nationwide, in cities ${ }^{5}$ and in districts ${ }^{6}$. Since 1991 there has been a $19 \%$ increase in the nations population and as the data shows this has been predominantly in the higher density urban areas (cities) which have seen a $25 \%$ population increase compared to just $11 \%$ in districts. In 2006

ese statistics

\footnotetext{
${ }^{5}$ Statistics New Zealand classifies a city as a territorial authority area which has a minimum population of 50,000 , is predominantly urban in character, and is a distinct entity and a major centre of activity within its parent region. Currently there are 16 cities nationwide.

${ }^{6}$ Statistics New Zealand classifies a district as a territorial authority that is neither wholly urban nor wholly rural and which is under the jurisdiction of a district council. There are 57 districts nationwide.
} 
shows that there has been urban intensification due to the higher population increases of these areas.

\subsubsection{URBAN INTENSIFICATION}

Statistics New Zealand data shows that of the 73

issued building consents for new apartment buildings from

1991 2008. Ten

buildings from $19912008^{7}$

apartment buildings from 1991 2008; Auckland City (48\%) and Wellington City (13\%). North Shore City issued $7 \%$ and Christchurch and Waitakere Cities issued 5\% each.

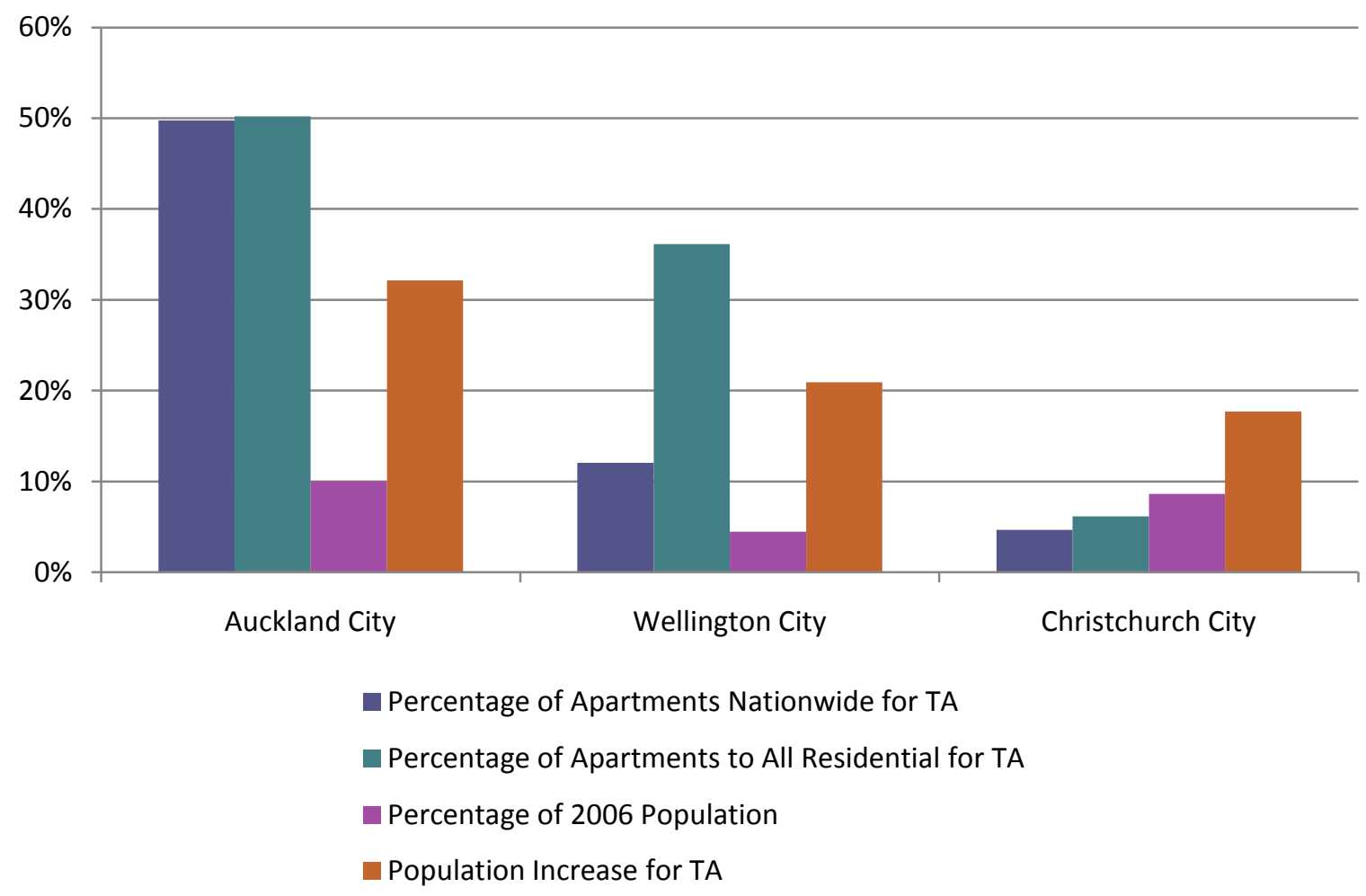

Figure 1-3, Comparison of Urban Intensification in Auckland City, Wellington City and Christchurch from $1991-2006$

Figure 1-3 compares the urban intensification of New Zealand three major cities from 19912006. The data shows that urban intensification is occurring more rapidly in two cities Auckland and Wellington due to population increases and the growth of higher density living. Christchurch (New ification to

\footnotetext{
${ }^{7}$ Eight were cities - North Shore City, Waitakere City, Auckland City, Manukau City, Hamilton City, Tauranga City, Wellington City and Christchurch City. Only two were districts Rodney District and Queenstown-Lakes District.
} 
the same degree. Wellington City is actually only the sixth largest city in New Zealand ${ }^{8}$ however it has experienced much more urban intensification most probably due to the fact that it is the capital city and there are terrain constraints.

\subsubsection{TRIGGERS \& DRIVERS OF APARTMENT LIVING}

The intensification of higher-density development, particularly in the inner city areas, reflects a significant change away from the traditional New Zealand residential property to a higher density more urban lifestyle (DTZ Research, 2004). Crockers (2005) state that the kiwi quarter-acre pavlova paradise of the sixties is not only out of reach for many that the next generation actually want as they try to balance busy work lives with more active lifestyles. Crockers (2005) identify four major triggers of higher-density housing development from society: social changes, land use demands, lifestyle changes and the property market. Studies undertaken in Auckland and Wellington have identified five main personal drivers for people to move towards higher-density inner-city living: affordability; convenience \& lifestyle; maintenance; security and transport. (Criscillo \& Tong, 1999) (DTZ Research, 2003) (Morrison \& McMurray, 1999) (Statistics New Zealand, 2005). The societal triggers and personal drivers are naturally related to each other and have been grouped under: land use demands; lifestyle changes; property market; security and social changes.

Land Use Demands: Two factors have placed restrictions on land use in New Zealand. The first comes from restrictions on urban sprawl. This comes from both terrain restrictions (for example in the hilly landscape of Wellington where the terrain restricts the amount of building) and from restrictions from Territorial Authorities on urban and suburban sprawl (for example the North Shore City Council ${ }^{9}$ ). The second factor is from the drive to become more sustainable and make better use of infrastructure. Higher density living is seen as one solution to this problem, because of the ability to centralise services, share facilities and lower heating energy use compared to standalone housing. (Crockers Property Group, 2005).

Lifestyle Changes: Changing lifestyles, particularly of younger generations, is a key trigger towards higher-density inner-city living. As people try to balance busier work lives (longer hours, increased stress etc) with more active and social personal lives, the convenience and lifestyle that apartment living can offer is a much more attractive option than stand alone housing (Crockers Property Group, 2005). There are two main issues with lifestyle changes and why

\footnotetext{
${ }^{8}$ Wellington is ranked sixth after (in order of population size), Auckland City, Christchurch City, Manukau City, North Shore City and Waitakere City.

${ }^{9}$ The North Shore City Council [NSCC] promotes good urban design, urban intensification and higher-density housing as one way of responding to urban growth in a coherent and sustainable manner. The Urban Design Protocol Action Plan addresses issues of urban sprawl, creating sustainable communities, efficiently using infrastructure and public services and efficiently managing waste. Increasing urban density is seen as one way of attaining sustainable development, and apartments are necessary for achieving desired density. The NSCC therefore promotes apartment living as a viable option for long-term housing for a greater number of people in urban areas (North Shore City Council, 2007). As part of this the NSCC has developed a series of Good Solution Guides for Apartments apartment design (Thompson, 2007).
} 
apartment can offer a more convenient lifestyle than suburban standalone housing: proximity to amenities and reduced maintenance.

The close location of amenities encourages social \& economic interaction and minimises the movement of people and goods. It also reduces commuting times which allows people to spend less time in transit and more time at work or at play. Closer proximity to work and public transport reduces the need for the private car and time spent in transit.

Younger generations tend to value their leisure time and are not prepared to look after larger properties. Due to the smaller size and the provision of building management services, higher density inner-city housing requires reduced time and cost spent on maintenance. This allows residents more time to do what they want to instead of spending extra time maintaining a larger home.

Property Market: Finally, the property market has also played a huge role in the shift towards higher-density inner-city living. Since 1991, stand alone housing has more than doubled in price as the size of these houses has increased by up to a third (Crockers Property Group, 2005). In contrast, the value of higher density housing has fluctuated in a much narrower band. The smaller size of apartments mean that they are often a much more affordable and attractive option for four groups of people: first home buyers; investment buyers; people wishing to downsize (such as people entering retirement) and those needing a second home in the central city.

Security: The closer proximity of other people in higher-density housing and at times the greater sense of community allows for a heightened sense of security, particularly amongst younger people, single women and the elderly. This is often cited as a key personal driver towards higher-density inner-city living.

Social Changes: Over the last few decades New Zealand has experienced many social changes that have changed household composition and increased the demand for housing. These include increased family break-ups, smaller households, longer life expectancies, an increase in dual working couples, and more adults living alone, marrying and having children later in life (Crockers Property Group, 2005).

\subsubsection{APARTMENT DWELLERS IN NEW ZEALAND}

Studies by Statistics New Zealand [Statistics NZ], DTZ Research, Auckland UniServices, Criscillo \& Tong, Morrison \& McMurray, and the Wellington City Council [WCC] provide an insight on who typical apartment dwellers might be in New Zealand. Because apartment living suits a wide variety of people it is difficult to pinpoint one typical type of person however Figure 1-4 provides some insight to who typically lives in an apartment in New Zealand.

In short most apartment dwellers can be expected to be:

- 2554 years of age,

- Single or couples without children,

- Most likely NZ European and professionals employed in white collar jobs. 


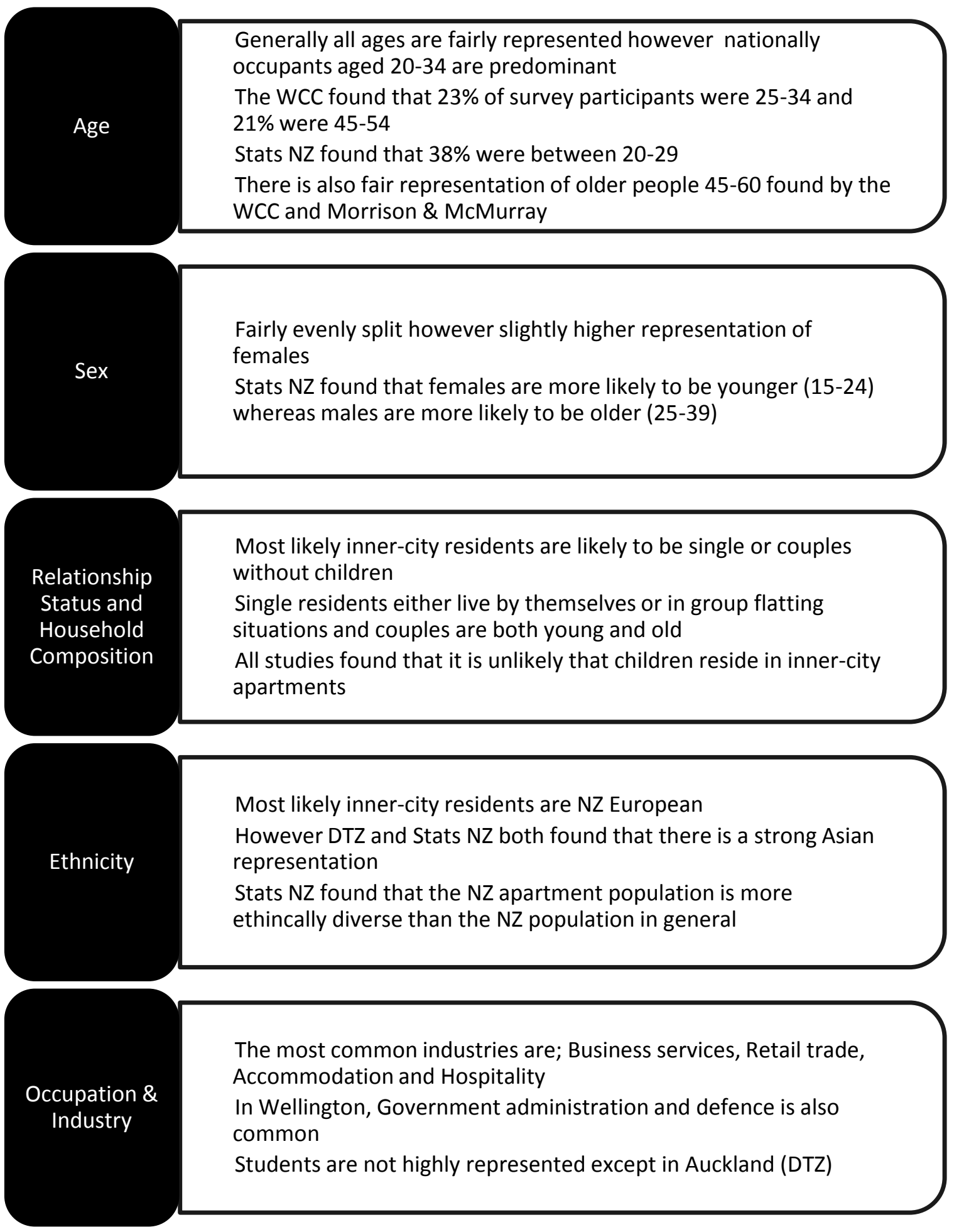

Figure 1-4, Typical New Zealand Apartment Dwellers

\subsubsection{ISSUES WITH APARTMENT LIVING}

Apartment living in New Zealand is still a relatively new phenomenon compared with international experience, i.e. in Europe, Asia and America. The rapid rise in this type of construction and living, and a building code that is ill equipped for this type of building has meant that a number of issues 
have become apparent in recent years. This section discusses the inadequacies of parts of the New Zealand Building Code [NZBC] for addressing higher density housing and examines current issues with this type of housing that have arisen from inadequate building controls.

\subsubsection{THE NEW ZEALAND BUILDING CODE}

The New Zealand Building Code [NZBC] is a performance-based code developed to ensure that all New Zealand buildings are of an acceptable standard for health, safety and well-being. The NZBC considers aspects such as stability, fire safety, access, moisture, user safety, services \& facilities and energy efficiency in 35 technical clauses which are implemented through Compliance Documents. These set out Acceptable Solutions and Verification Methods which can be used to show compliance with the NZBC. Compliance Documents are one way of complying with the requirements of the NZBC there may be other ways of complying which are called Alternative Solutions.

For example, the Compliance Document for NZBC Clause G4 Ventilation contains the technical clauses (G4.1 G4.3.5), the Verification Method G4/VM1, and the Acceptable Solution G4/AS1. A design that follows G4/AS1, or shows compliance through G4/VM1 is deemed to comply with the requirements of G4 (Department of Building \& Housing, 2009).

Under the NZBC, requirements for housing apply to buildings or uses where there is self care and service (internal management). There are three types of housing defined in NZBC Clause A1 (Department of Building \& Housing, 2009)

- Detached Dwellings: a building or use where a group of people live as a single household or family. Examples: a holiday cottage, boarding house accommodating fewer than 6 people, dwelling or hut

- Multi-unit Dwellings: a building or use which contains more than one separate household or family. Examples: an attached dwelling, flat or multi-unit apartment

- Group Dwellings: a building or use where groups of people live as one large extended family. Examples: within a commune or marae.

All building types are required to comply with each relevant clause of the NZBC. However in some clauses, Acceptable Solutions and/or Verification Methods are not applicable to some building types. Currently there are 8 Acceptable Solutions ${ }^{10}$ within the NZBC which multi-unit dwellings are outside of the scope of they must find another way to prove NZBC Compliance for those particular sections of the NZBC. There are:

- NZBC C/AS1 Fire Safety (Part 1 Fire Safety, Part 7 Fire ratings of adjacent walls and Appendix A Fire alarm systems),

- NZBC D1/AS1 Access Routes (Access requirements),

- NZBC F4/AS1 Safety from Falling (Minimum barrier heights for stairs, ramps, landings, balconies and decks),

- NZBC G1/AS1 Personal Hygiene (Provisions for sanitary facilities),

- NZBC G2/AS1 Laundering (Provisions for laundry facilities),

\footnotetext{
${ }^{10}$ This may be all of, or only one part of, a Acceptable Solution
} 
- NZBC G4/AS1 Ventilation (Single sided household units ${ }^{11}$ are specifically excluded from using the current method of compliance,

- NZBC G12/AS1 Water Supplies (Water supply to individual units),

- NZBC G15/AS1 Solid Waste (Solid waste collection and removal).

Other than these specific requirements and/or exclusions from particular compliance methods, multi-unit dwellings are treated the same as housing and detached dwellings. However, this has led to some poorly designed apartment buildings. For example NZBC G7 Natural Light requires that a minimum illuminance of 30 Lux is provided for $75 \%$ of the standard year in housing (Department of Building \& Housing, 2009) but this is deemed to have been achieved if the Acceptable Solution is followed. This has led to some issues in apartment buildings where this minimum illuminance may not actually be met (Stewart \& Donn, 2008). There are different design issues when looking at apartment buildings compared to detached dwellings that are not currently addressed by the NZBC Acceptable Solutions. For natural light, this includes the number of external walls, the density of the area, orientation, and vertical location of an apartment and so on.

In its current form the NZBC is more focused on stand-alone houses than on apartment buildings. For example, the Acceptable Solution G7/AS1 for NZBC Clause G7 Natural Light calls for a minimum window area of $10 \%$ of the floor area in order to provide adequate illuminance levels ( 30 Lux) on the floor for safety and orientation (Department of Building \& Housing, 2009). While this Acceptable Solution may work adequately for stand-alone housing, it is not appropriate for use on apartments. There are many more factors (such as reflectance from opposite buildings, vertical location, reduced window to wall ratios, and surrounding urban density) to take into account when providing adequate natural light in higher density, urban environments (Stewart \& Donn, 2008). However despite this inadequate compliance method, multi-unit dwellings are still able to use G7/AS1 to show NZBC Clause G7 Compliance and as a consequence there are a number of apartments that have very little natural light (Stewart \& Donn, 2008).

The overall objective of the NZBC is to safeguard user health, safety and wellbeing (The Building Act 2004). However in the NZBC Compliance documents (through which the NZBC is most commonly implemented) there is little consideration of the unique issues with apartment buildings compared to stand-alone housing. Reviews of apartment living have highlighted various issues regarding liveability in higher-density housing (Auckland UniServices Ltd, 2004) (Criscillo \& Tong, 1999) (DTZ Research, 2003) (Lyne \& Moore, 2004) (Morrison \& McMurray, 1999) (Waghorn, 2006). Some of these are a result of an inadequate building code or TA bylaws ${ }^{12}$ and some are a result of poor design and construction. The issues that are currently apparent are concerned with:

- Natural Light \& Views,

\footnotetext{
${ }^{11}$ Single sided household units refer to apartments with only one external wall that is able to provide natural ventilation

12

the NZBC. TA bylaws are region specific and therefore are subject to change around the country. In the Auckland region for example there are minimum apartment sizes (Auckland City Council, 2009) (North Shore City Council, 2007). Wellington City Council despite being the second largest issuer of apartment building consents does not have any comparable requirements.
} 
- Noise,

- Outdoor Access \& Balconies,

- Parking,

- Privacy,

- Rubbish \& Recycling,

- Safety, Security \& Access,

- Space \& Storage,

- Ventilation.

The rapid increase of apartment building construction has not been matched by suitably focused controls. Currently parts of the NZBC are inadequate to control poor quality apartment buildings or encourage higher quality designs. Such legislation is only now being introduced by various local authorities in order to try to ensure that the health, comfort and well-being of apartment occupants are not compromised. One example of this is the Good Solution Guide for Apartments developed by the North Shore City Council in conjunction with the Auckland, Waitakere and Manukau City Councils, the Auckland Regional Council and the Ministry for Environment (Thompson, 2007). Although it is only a guideline for apartment design the Auckland City Council [ACC] goes further and specifies minimum apartment sizes (Auckland City Council, 2009) . 


\subsection{PROBLEM STATEMENT}

Reviews of apartment living in New Zealand have revealed a number of liveability issues some a result of inadequacies with the NZBC, some with building management and some with inadequate TA bylaws. Considering the number of New Zealanders that now live in apartment buildings, the amount of time that people spend in their home (WHO suggests that we spend up to two thirds of our lives at home) and how intrinsically related our well-being and homes are it is important that this type of housing is adequate and liveable. Prospective buyers and tenants in New Zealand do not currently have access to information that will help them make informed decisions about this relationship, particularly in apartments.

A consumer intending to buy electronic goods can access consumer guides and reviews which provide information to help them make informed decisions. However when buying a home, and in particular an apartment, there is little guidance of this kind relating to health, comfort and wellbeing. A purchaser could obtain reports and assessments regarding land information, property information and energy use ${ }^{13}$ but these aspects do not relate to liveability. Considering the connection between health and housing, it seems important that potential buyers and occupants should have access to this type of information to help them make informed decisions to ensure their well-being.

Apartment buildings are very different from traditional detached housing in New Zealand. This is not only because of location, but also due to increased density, reduced privacy, noise control, spatial issues and so on. Prospective occupants are already at a disadvantage if when choosing an apartment they are looking at a whole new style of living. It is important that they are able to understand the differences in apartment design and living in order to make informed decisions when purchasing or leasing.

\subsubsection{HYPOTHESIS, AIMS \& OBJECTIVES}

The hypothesis for this research is that:

It is possible to develop an assessment method that will provide prospective apartment occupants in New Zealand with a simple, easy method to compare and evaluate apartment liveability over a wide range of indicators, not just those of current concern.

The primary aim of the research is to develop a method of evaluating liveability in New Zealand apartments. The secondary aim was to test the research method used for developing BQA, BQI and

\footnotetext{
${ }^{13}$ Reports such as a Land Information Memorandum [LIM], a Project Information Memorandum [PIM], a Home Energy Rating Scheme assessment [HERS] all provide home owners with information regarding land use, historical information, zoning, energy use etc, however they do not provide information on health and wellbeing aspects.
} 
HPMFRB in developing an apartment liveability evaluation tool for New Zealand. Therefore five research objectives were also identified which were:

environment, particularly in higher density, high-rise housing,

- To investigate the issues the New Zealand public considers important regarding liveability of the residential built environment,

- To develop a Built Environment Assessment Tool [BEAT] that is capable of evaluating liveability of New Zealand apartments across a wide range of factors,

- To test the research approach used to develop other similar evaluation tools Building Quality Assessment [BQA], Building Quality Indicator [BQI] and Housing Performance Evaluation Model for Multi-family Residential Buildings [HPMFRB ] in developing an apartment liveability evaluation tool for New Zealand,

- To determine what different groups of end-users and stakeholders perceive to be important in regards to peoples liveability in higher density, high-rise housing. 


\subsection{RESEARCH APPROACH}

The development of NZ ALI followed the methodology of three similar tools:

Building Quality Assessment [BQA] was developed for assessments of health and safety in New Zealand office and retail buildings (Baird, Gray, Isaacs, Kernohan, \& Mclndoe, 1995):

Building Quality Index [BQI] was developed in Hong Kong for assessing health and safety in apartments (Wong, Cheung, Yau, Ho, \& Chau, 2006).

Housing Performance Evaluation Model for Multi-Family Residential Buildings [HPMFRB] was developed in South Korea to evaluate housing environment, function and comfort in multiunit residential buildings (Kim, Yang, Yeo, \& Kim, 2005).

These three tools are based on a weighted hierarchy of building features and indicators providing both a single overall score and a set of sub-scores (or performance profile). Myhr and Johansson (2008) state that hierarchies are preferred when there are many levels of data, as they allow each issue to be explored independently without losing sight of the overall objective.

These tools underwent a similar development process the hierarchy and indicators were established first, then weightings and credits were applied. BQI and HPMFRB used the Analytic Hierarchy Process [AHP] to set weightings, whereas BQA used a ranking system.

The development of NZ ALI is only intended to be a pilot study. Initially it was proposed that the AHP method of pair-wise comparisons would be applied to NZ ALI but it was found that the large number of pairs would make such a survey extremely time consuming. Instead a ranking system, similar to that used for BQA has been used for NZ ALI.

The methodology used in the development of NZ ALI is as follows:

- Hierarchy Development based on findings from the literature review,

- Index Development extension of hierarchy, including assessment methods for each indicator,

- Index Calibration development of weightings for indicators from survey with stakeholders and end-users,

- Index Validation consultation with end-users and use of NZ ALI to ensure that results are valid and accurate. 


\subsection{RESEARCH SIGNIFICANCE}

Buildings are among the largest, most complex and long lasting products that humans create. However customers for these products are often at a disadvantage because they make a purchase or sign a lease only a few times in their life - often without a consumer report to guide them. (Baird, Gray, Isaacs, Kernohan, \& McIndoe, 1995)

New Zealand currently has no process for prospective apartment occupants to adequately evaluate the liveability of an apartment and its surroundings. As Myhr (2008) states, building evaluation is not a new field. These tools are able to provide people with the information they require to make informed decisions, and can help bridge the gap between academic knowledge and public needs.

As discussed further in Section 3.1, NZ ALI is intended as a labelling tool so that it can provide objective information on the strengths and weaknesses of a building. This is useful for providing guidance to users. These types of tools serve as drivers for encouraging initiative towards better housing performance (Kim, Yang, Yeo, \& Kim, 2005).

$\mathrm{BQA}, \mathrm{BQI}$ and HPMFRB are tools that provide information on building design, health, comfort, safety and usability. In New Zealand and particularly for higher density residential buildings, this type of evaluation tool would be beneficial to a wide range of stakeholders and end users in apartment design and living.

As discussed in Section 3.1 further, six stakeholder groups or end-users have been identified that would benefit from the use of this tool. These are: prospective occupants; developers \& building owners; designers \& architects; building management; governmental organisations and academics \& researchers.

A tool such as the one developed by this research has the potential to change the housing market around apartments in New Zealand. As occupants use the tool, they would also begin to demand better quality living and apartments. This in turn would drive market prices, which would affect how developers and designers design and market new apartments. Similarly, building management and owners would begin to consider how they might better run, maintain and upgrade their buildings in order to attract occupants. Finally, the tool could potentially influence the design and planning of higher density residential apartment buildings by becoming a minimum requirement (i.e. a design must score a certain percentage in particular categories in order to get building consent) should DBH 


\subsection{CONSULTANTS \& ETHICS}

The development of NZ ALI needed the opinions, experience and knowledge of experts within the New Zealand Building Industry and apartment occupants to ensure that it was accurately developed to meet the needs of all stakeholders and end-users.

In order to survey a suitable variety of people, ethical consent was obtained from the Victoria University of Wellington Human Ethics Committee. The first approval was obtained for the initial survey conducted for the development of weightings (Ethics Approval No. 16260). The second approval was obtained for the interviews conducted with occupants (Ethics Approval No. 16431, see Appendix L). Due to ethical restrictions, those people who were consulted in part of this research, or who participated in surveys and interviews cannot be named or identified. 


\subsection{THESIS ORGANISATION}

This thesis is organised into 7 chapters. This introductory chapter discusses the background to the research, the methodology used and the significance of the research into order to provide an understanding of the motivation and aims for the work.

Chapter 2 reviews and discusses literature on Building Evaluation and Assessment Tools [BEAT], as

wellbeing all of which contribute to liveability.

Chapter 3 discusses an overview of the methodology used for this research in apartment liveability in New Zealand. It will look at how NZ ALI was developed, calibrated through the use of a survey and validated through the use of site visits and interviews with apartment occupants.

Chapter 4 reviews the development of NZ ALI focusing on the development of the framework, hierarchy and assessment methods. The NZ ALI calibration is also discussed where consultation with end-users and stakeholders was utilised to develop component weightings.

Chapter 5 discusses how NZ ALI was validated to ensure that liveability evaluations are accurate and that the tool is fit for purpose.

Chapter 6 then presents the final version of NZ ALI.

Conclusions, key findings and recommendations that arose from the research are discussed in Chapter 7. The chapter concludes with future research possibilities and implications for the building and real estate industries.

References and appendices are found at the back of the document, providing further information on the research, and further reading. Glossary provides a glossary of key terms and definitions used throughout the research. Background provides further information and reading on the primary literature review topics and findings. Community through to Other provides detailed information on the development of each of the NZ ALI Categories and associated components (these are also discussed in brief in Chapter 4).

The NZ ALI Questionnaire presents further information on the NZ ALI Questionnaire used to calibrate and weight the tools components (discussed in brief Chapter 4. NZ ALI Trial \& Critique provides additional information on NZ ALI Validation discussed in Chapter 5. NZ ALI contains a CD with a working example of NZ ALI and Victoria University of Wellington Ethics Approval provides copies of Ethical Approvals. 


\section{LITERATURE REVIEW}

Chapter 2 reviews and discusses literature concerning liveability in the residential built environment, and Built Environment Evaluation Tools. Specific evidence is cited and its relationship to this research is discussed. The chapter is divided into four sections:

- Section 2.1 investigates how occupants can be affected by the liveability of the residential built environment, with particular focus on higher-density urban environments

- Section 2.2 investigates differences between academic knowledge and public opinion regarding liveability of higher-density urban living

- Section 2.3 discusses international Built Environment Evaluation Tools [BEAT], what they can contribute and development procedures

- Section 0 provides a summary discussion of the literature focusing on the key writings that support this research

\subsection{LIVEABILITY IN THE RESIDENTIAL BUILT ENVIRONMENT}

A literature review was conducted that investigated occupant health, comfort, safety and well-being issues in the residential built environment. The focus was on higher density, urban living and the main human requirements in the residential built environment.

There has been a vast amount of research into the topic of health and safety in the built environment, particularly in the workplace. Recent years have seen a renewal of interest in the links between housing quality and public health, with several reviews showing many links between health (both physical and mental) and housing quality (Jacobs, 2006). The built environment can affect health in many different ways: directly and indirectly; physically, mentally and emotionally; psychologically and psychosocially. In 1946, the World Health Organisation [WHO] defined health as:

... not merely the absence of disease or infirmity, but a state of complete physical, mental and social well-being. The enjoyment of the highest attainable standard of health is one of the fundamental rights of every human being without distinction of race, religion, and political belief, economic or social condition.(World Health Organisation, 2006)

The literature review illustrates that there are six basic human requirements that when met help to provide healthy, comfortable, safe and liveable built environments. These are outlined in Figure 2-1. When these are provided to an adequate level, a

(World Health Organisation, 2006).

The literature review found that there are over 100 variables that influence liveability and the six basic human requirements in the residential built environment. In addition to the large number, these variables are all interrelated and often influence more than one of the six basic human 
requirements. For these reasons, discussion of each specific variable and its liveability effect is beyond the scope of this report. A summarised discussion of the six basic requirements and the major contributing variables is presented in Background.

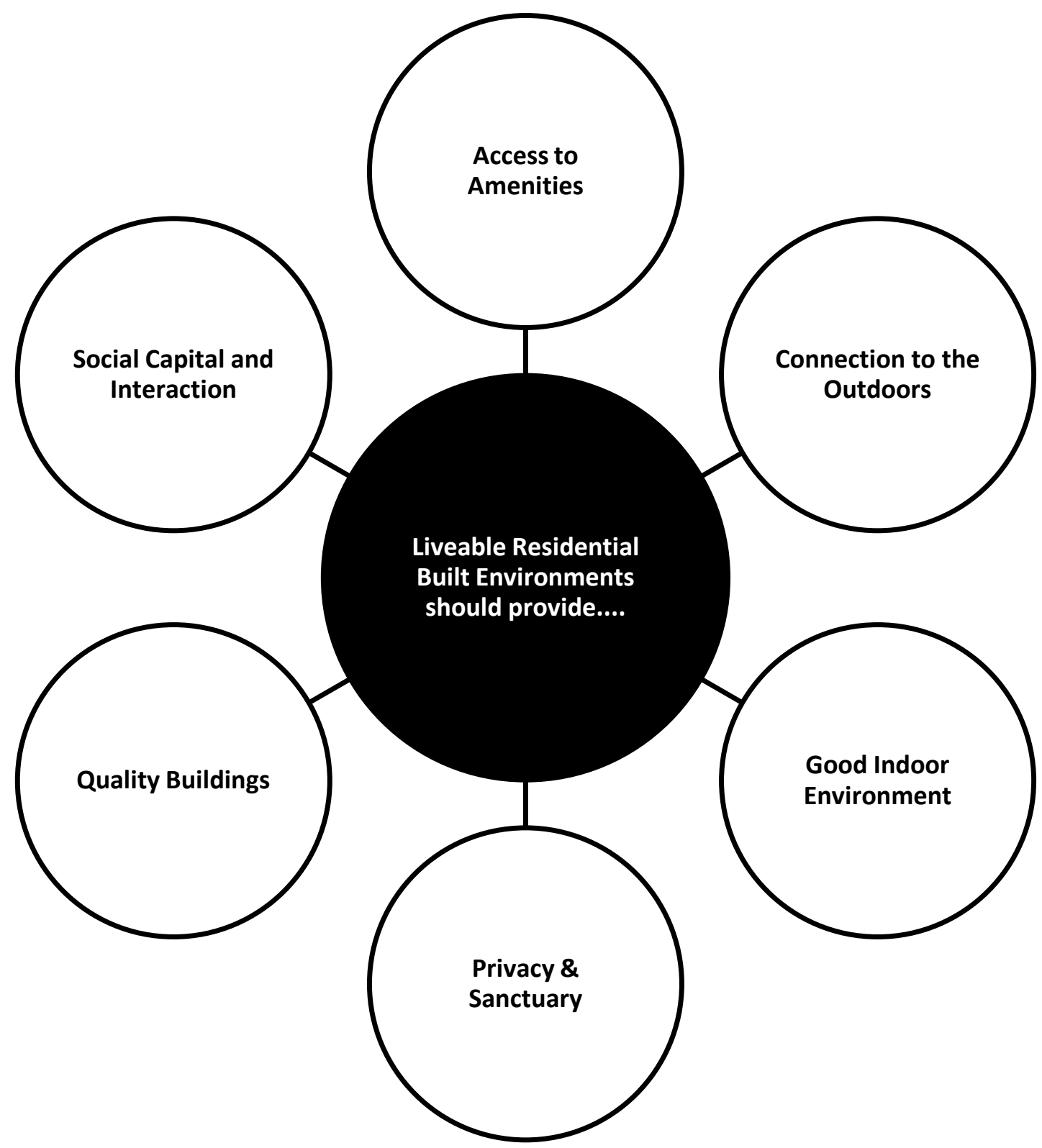

Figure 2-1, Six Human Requirements in the Residential Built Environment

\section{Access to Amenities}

The ability to access amenities within a neighbourhood and community is considered to be vital for a -being. Amenities such as public buildings, landmarks, supermarkets, swimming pools, shops and entertainment venues are all important within a community. Similarly, good orientation and visual landmarks assist people in way-finding. All these elements help provide people with a sense of ease, comfort, safety and a sense of belonging in society (Jackson, 2003). 


\section{Connection to the Outdoors}

\section{Biophilia}

life-like processes (Frumkin, 2001). The human relationship with nature and the idea that this might be a component of good health have a long history. The Whole Building Design Guide [WBDG] states that there is a growing body of research that shows that built environments that connect people to nature are more supportive of human emotional wellbeing and cognitive performance, than environments that lack in these features (Whole Building Design Guide, 2007)

Green Spaces: Access to green spaces is extremely important. There is a large body of research into how physical activity, health and mental well-being are increased through access to green spaces. It not only encourages more walking and exercise but also allows for opportunities for informal social contact and interaction. (Rao, Prasad, Adshead, \& Tissera, 2007) (Whole Building Design Guide, 2007) Green spaces such as parks, gardens and landscaping have been noted for their restorative effects both mentally and physically, similarly they provide a place for people to experience nature. However, natures presence can also come from daylight, fresh air, sunlight, indoor plants, views, and changing aural stimuli. A wide range of research has identified the positive impacts on people from these outdoor connections (Whole Building Design Guide, 2007).

Windows are an important part of the built environment and they are significant for both mental and physical health. A windowless space does not deprive a person of all sensory stimuli, but it does reduce the amount of visual, auditory and thermal input received from the outside world and can be considered a milder form of deprivation (Raw, Aizlewood, \& Hamilton, 2001). In studies of windowless environments, a consistent finding is concern over the loss of information about time and weather. Raw, Aizlewood \& Hamilton (2001) do not suggest that windows are essential for optimum health, rather for well-being and comfort because passive viewing of nature through windows promotes positive moods and reduces stress.

\section{Good Indoor Environment}

A good indoor environment will be able to provide a person with a space that is visually, thermally and aurally satisfying while also providing the person with a spatially comfortable place to undertake different activities and tasks. Raw, Aizlewood \& Hamilton (2001) state that visually there are a number of factors that need to be taken into consideration in order to provide a usually comfortable space.

Aural Comfort: Noise can arise in dwellings from a number of sources, both external and internal.

Generally noise is a nuisance which may cause loss of sleep, stress, frustration and difficulty in hearing and conducting conversation (Raw, Aizlewood, \& Hamilton, 2001). The only direct health effect is the possibility of hearing loss: however the extent of damage is related to the length and size of exposure.

Thermal Comfort: Influenced by a range of factors including: metabolic rate (activity), clothing (personal insulation), air temperature, radiant temperature of surroundings, rate of air 
movement and atmospheric humidity (Ruck, 1989). It is also affected by other factors such as surroundings, location, and culture.

- Uncomfortable air temperatures can cause defence mechanisms such as shivering or sweating (Raw, Aizlewood, \& Hamilton, 2001)

- Inadequate ventilation and air movement and excess moisture contribute to asthma, mouldinduced illnesses, carbon monoxide poisoning, poor indoor air quality [IAQ], etc (Raw, Aizlewood, \& Hamilton, 2001)

- Humidity contributes to dampness, moisture accumulation, and dust mite and mould growth. Low humidity can result in drying and chapping of skin, while higher humidity can cause moisture accumulation and mould growth (Raw, Aizlewood, \& Hamilton, 2001)

Visual Comfort: There are many variables that affect visual comfort including daylighting, views, glare, artificial lighting (including flicker, colour and humming), emergency lighting and general task lighting (Raw, Aizlewood, \& Hamilton, 2001).

- Daylighting or natural light provides exposure to ultraviolet radiation, permitting the body to manufacture vitamin $D$ and melatonin, which influence circadian rhythms (i.e. sleeping \& waking and mood states) and promote healthy bone development (Raw, Aizlewood, \& Hamilton, 2001). As discussed previously, natural light and views also help provide connections to the outdoors influencing moods and stress.

- Glare reflected from other objects can cause either discomfort or disability depending on vision interference. Discomfort can contribute to eye strain and headaches whereas disability affects safety when vision is directly impaired (Raw, Aizlewood, \& Hamilton, 2001). Glare can be caused by natural or artificial lighting.

- Artificial lighting can present issues with flicker (causing distractions for most people and convulsions in flicker sensitive people), colour (where some tasks may be difficult or unsafe if colours are not accurately represented under certain lamp colours), and humming (where headaches and annoyance may occur) (Raw, Aizlewood, \& Hamilton, 2001).

- Emergency lighting is critical in way-finding in emergency situations and can cause serious safety concerns if inadequate (Raw, Aizlewood, \& Hamilton, 2001).

- Task lighting is important because visual acuity increases with increased light levels (Raw, 2001) and unsafe conditions can be created from inadequate task lighting. In orientation low lighting often causes increased collisions, trips and falls (Raw, Aizlewood, \& Hamilton, 2001).

Spatial Comfort: Adequate space allocation for users of spaces in essential to ensure that overcrowding does not occur which can increase stress levels, spread of illnesses and social withdrawal (Raw, Aizlewood, \& Hamilton, 2001). Spaces need to be adequately designed to ensure flexibility of tasks and the ability to seek sanctuary and personal territory (Evans, 2003).

\section{Privacy}

Privacy and the ability to identify (and maintain) personal and private territory is very important for all people (Raw, Aizlewood, \& Hamilton, 2001). Crowding, density and inadequate space allocation for people within the built environment can often have a detrimental impact on health and wellbeing (Evans, 2003). This can be through the transmission of infectious diseases in crowded 
situations, through social withdrawal in the need for personal space and privacy, and through increased stress in cramped or over-crowded situations. The ability of people to define their own territory allows people to feel more comfortable, secure and at ease.

\section{Quality Buildings}

Building quality is important when considering liveability because of the wide range of factors it includes. Airtightness, orientation, building use, safety, security, drainage, parking, water supply, emergency escape, materials, maintenance, cleanliness etc can all affect liveability (Raw, Aizlewood, \& Hamilton, 2001). Issues with these factors can lead to stress, poor mental health, the spread of infectious diseases and so on.

\section{Social Capital and Interaction}

While it is very important for people to be able to have privacy and solitude, research also shows that it is just as important for people to be able to socially interact with other members of the community whether this is the neighbourhood at large or within a building. Research shows that high-rise living can often place restrictions in social networking and neighbourly interactions (Evans, 2003).

Jackson (2003) states, social capital considers the transition between the building and the neighbourhood. As a gregarious species, people benefit emotionally and physically from interpersonal relationships and society at large benefits from the participation of its members in different organisations, associations and activities as increased familiarity among individuals promotes mutual aid, empathy and belonging (Jackson, 2003). 


\subsection{PUBLIC OPINION ON LIVEABILITY}

Jackson (2003) reports that there has been an immense amount of research into health and safety in the built environment. However, as discussed in Section 1.2, when a prospective apartment occupant in New Zealand is looking to buy or lease an apartment there is little guidance or information that will help them to consider affects on their liveability. The knowledge that academics have developed in recent years is vast. However, as shown in Chapter 0 , it seems that this knowledge has not been made available to the public.

The second research objective was to investigate what the New Zealand public considers to be the important factors relating to liveability in the New Zealand residential built environment. A review of the popular press and academic literature was undertaken to investigate whether there are any differences in what the public perceives to be important compared to academic knowledge with respect to liveability in the residential built environment. The literature that was reviewed covered the period from 19982008 inclusive, and compared both academic literature and the popular New Zealand press ${ }^{14}$.

\subsubsection{LITERATURE REVIEW METHOD}

\section{Popular Press}

The popular press articles that were reviewed were taken from a search of the Index New Zealand (INNZ) $^{15}$, a National Library of New Zealand database (National Library of New Zealand, 2009). The search was undertaken using the words apartment and design, and was limited to articles in the last ten years (i.e. from 1998 to the 2008). Although 188 articles were found, only 54 articles were sourced and deemed applicable for the review ${ }^{16}$.

14

access to on a day to day basis e.g. newspapers (e.g. The New Zealand Herald) and magazines (e.g. New Zealand House \& Garden or Architecture New Zealand). This search excluded academic literature such as formal journals, conference proceedings, books, or research reports undertaken or commissioned by relevant research bodies.

${ }^{15}$ INNZ includes over half a million articles published in New Zealand over the last 20 years. The titles indexed range from popular magazines such as North and South and Consumer to more specialised journals such as New Zealand Law Review and Art New Zealand. INNZ is updated daily and approximately 2,500 documents are added monthly. Subjects covered include general interest material, social research, current affairs, the arts and humanities.

${ }^{16}$ Only 54 articles were used either because the rest could not be found or because once read the other articles were not actually applicable to this study despite them having the apartment and design keywords in INNZ. 


\section{Academic Literature}

The academic literature reviewed was taken from both New Zealand and International academic literature including academic journals, theses, conference proceedings, internet sources and books. A total of 36 publications were reviewed. The primary databases used to source the academic literature were ScienceDirect (Elsevier Publishers, 2009) and Scopus (Elsevier Publishers, 2009).

In general Building Science was the realm of academia reviewed. However some sociology, policy, health and psychology work was reviewed also such as Butterworth (2000), Stewart (2005) and Rao, Prasad, Adshead \& Tissera (2007).

\section{Process}

The review process involved taking detailed notes for each identified item where apartment liveability factors were identified. These were generally design features, dwelling and occupants preferences or liveability issues. Counts were recorded of the number of times each factor was mentioned. This allowed an investigation into what was mentioned regularly (and what was not), how often different factors were mentioned and ultimately where importance and value was placed in respect to apartment liveability.

Table 2-1 provides an example of how literature was reviewed and the results recorded. This example is a newspaper article from the popular press review. These results were stored electronically for ease of analysis of factor counts.

Table 2-1, Example of the Literature Review Process

\begin{tabular}{|l|l|}
\hline Author & Venter, N. (Venter, 2006) \\
\hline Title & The Second Wave \\
\hline Publication & The Dominion Post \\
\hline Issue Number & 11/11/06; p.E1 2 \\
\hline Abstract & $\begin{array}{l}\text { Reports on a second wave of building of apartments in the central city [of } \\
\text { Wellington]. Talks to some recent converts to apartment living about the } \\
\text { benefits for them and their families. }\end{array}$ \\
\hline Notes/Keywords & $\begin{array}{l}\text { Location; Size Shoebox apartments particularly rented by international } \\
\text { students; Wellington is very much owner/occupier scenario due to lifestyle } \\
\text { choices: Car parking; Civil/local amenities such as cafes; Acoustics and noise } \\
\text { have been an issue in the past; Lifestyle; Lack of outdoor spaces good in terms } \\
\text { of maintenance; Big windows; Light; Views; Ability to walk to work }\end{array}$ \\
\hline Factors Identified & $\begin{array}{l}\text { Acoustics; Lifestyle; Local amenities; Location; Maintenance; Parking; Size; Small } \\
\text { apartments; Views; Windows }\end{array}$ \\
\hline
\end{tabular}




\subsubsection{FACTOR CATEGORIES}

A total of 107 factors were identified from 90 publications and 840 counts recorded as shown in Table 2-2. Please refer to the Literature Reviewed for both Academic Literature and Popular Press reference lists used for this review.

Table 2-2, Overview of the Literature Review Comparison

\begin{tabular}{|l|r|r|r|}
\hline & Academic Literature & Popular Press & Combined Review \\
\hline Pieces of Literature Reviewed & $36^{17}$ & 54 & 90 \\
\hline Number of Factors Identified & 79 & 28 & 107 \\
\hline Number of Counts Recorded & 530 & 317 & 847 \\
\hline
\end{tabular}

In order to easily assess the factors they were grouped into six Categories depending on the type of factors and similarities. It was initially thought that factors should be grouped in relation to the six requirements discussed in Figure 2-1. However, this created a challenge because often a factor can influence more than one of these requirements. Instead six Categories were developed: Community, Configuration, Governance, Indoor Environmental Quality and Other. Further grouping of factors into 13 Sections was also possible within the Categories as shown and outlined in Figure 2-2. This provides a brief outline of each Category and lists Sections identified within each Category also. Detail on each Category and Section is provided following Figure 2-2.

${ }^{17} 38$ publications were assessed, however 3 papers discussed the same study, and so they counts from these three publications were combined into one set of counts for that study, with only one to the Literature Reviewed for these papers. 


\section{COMMUNITY}

Site, Neighbourhood, Location and

Surrounding Area

Environment

Neighbourhood

\section{GOVERNANCE}

Running and organisation of a building, management, cleanliness and maintenance

Maintenance

Management

\section{QUALITY}

Quality of a building including in construction, materials, building services and amenities

Building Quality

Building Services \& Amenities

Materials Quality

\section{CONFIGURATION}

The design of a space, use of a space, social interaction and privacy

Connections

Spatiality

\section{OTHER}

Reasons people may choose a building such as affordability, sustainability and energy efficiency

Other

Figure 2-2, Categories Developed from Identified Factors

\section{Community}

Factors within this Category consider site, neighbourhood, location and surrounding area. Factors included within Community are fixed when the site is chosen and are only changeable slowly over a period of time. The Factors were grouped into two Sections: Environment and Neighbourhood, shown in Figure 2-3. This provides an overview of the two Sections and associated factors grouped within them. The Factors within Community are concerned with three of the six human requirements: access to amenities; connection to the outdoors and social capital \& interaction. 


\section{Environment}

Considers the immediate surroundings or environment of the building and site

Location

Outdoor Air Quality

Site Shading

Site Typology

Wind Environment

\begin{tabular}{|l|}
\hline Neighbourhood \\
Considers the neighbourhood at large, local \\
services available and safety \\
Convenience \\
Emergency Services \\
Graffiti/Crime \\
Green Spaces \\
Local Amenities \\
Neighbourhood/Community \\
Public Transport \\
Safety \\
Surrounding Use
\end{tabular}

Figure 2-3, Community - Associated Sections \& Factors

\section{Configuration}

Factors within Configuration are related to how the design of a space affects usability; social interactions \& inclusion; the ability to gain privacy; and outdoor access. Unlike Community these factors can be altered during the design stage of the building, as once built these factors are generally fixed. Factors were grouped into two Sections: Connections and Spatiality as shown in Figure 2-4. The Factors within Configuration are related to four of the basic human requirements: connection to the outdoors; good indoor environments; privacy \& sanctuary and social capital \& interaction.

\section{Connections}

Considers the outdoor provision \& access, social connections \& interactions and privacy

High-rise living (and vertical location) Outdoor Provision

Privacy

Spatiality
Considers the size, shape, layout and spatial
organisation
Crowding
Density
Headroom
Occupancy
Shape (of Unit)
Size (of Unit)
Spatial Organisation
Storage

Figure 2-4, Configuration - Associated Sections \& Factors

\section{Governance}

Factors associated with Governance consider the running and organisation of a building, its management, cleanliness, maintenance and pets. This is the only Category that includes factors that can be changed or affected after the site has been chosen and the building designed and built. This is because it is affected by building users and managements whose practices and organisation can be 
changed if required. Two Sections were used to further group factors: Maintenance and Management as shown in Figure 2-5. The Factors within Governance are connected to only one of the six human requirements: quality buildings.

Maintenance
Considers the upkeep of a building
Cleanliness
Maintenance
Pests

Figure 2-5, Governance - Associated Sections \& Factors

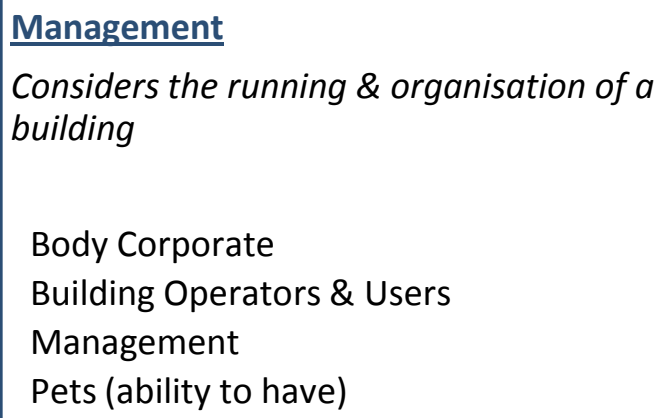

Acoustics
Considers internal and external noise
disturbances, acoustic vibrations and sound
insulation
External Disturbances
Internal Disturbances
Sound Insulation
Reverberation
Vibration

\section{Thermal Comfort}

Considers the thermal comfort and hygrothermal conditions of a space

Cooling Quality/Capabiity

Heating Quality/Capability

Humidity

Indoor Temperature

Moisture, Dampness \& Mould

Orientation

Seasonal Variations

Sun

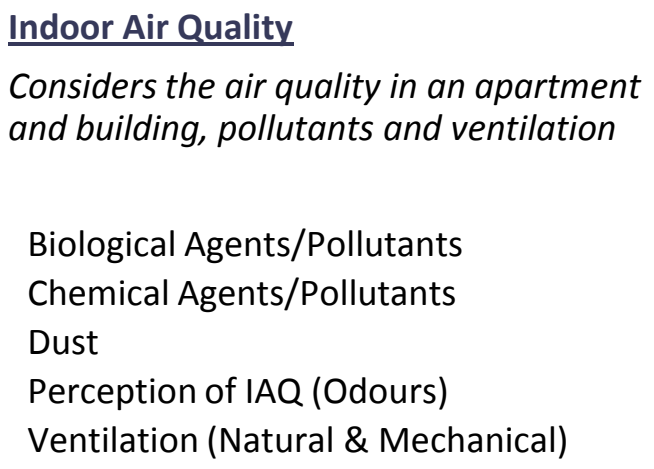

\section{Visual Aspects}

Considers the artificial and natural light, views and windows

Artificial Light

Internal Bedrooms (bedrooms without windows)

Natural Light

Views \& Aspect

Windows (size \& shading of)

Figure 2-6, Indoor Environmental Quality - Associated Sections \& Factors

\section{Indoor Environmental Quality}

Factors related to Indoor Environmental Quality consider the environmental aspects within a space such as acoustics and thermal comfort. This Category is similar to Configuration as the factors are fixed in a building after design and construction as they are inherently tied to a buildings 
construction, materials and envelope perhaps more so than Configuration. For example the layout of a space could be changed during a retrofit although the amount of daylight available in a space is tied to the building envelope and the number \& design of fenestrations (windows). Four Sections were identified: Acoustics, Indoor Air Quality, Thermal Comfort and Visual Aspects as shown in Figure 2-6. The Factors within Indoor Environmental Quality are primarily concerned with only one basic human requirement: good indoor environments. Some Factors are also concerned with connection to the outdoors.

\section{Quality}

Factors associated with Quality consider the quality of construction, materials, building services and amenities. In general most factors are unchangeable and fixed after design and construction as for Configuration and Indoor Environmental Quality. Although some are more easily changeable than others (e.g. such as rubbish \& recycling facilities), in most cases changing these factors after construction will require an expensive retrofit. Three Sections were identified to group factors within Quality: Building Quality, Building Services \& Amenities and Materials Quality, shown in Figure 2-7. Factors within Quality are concerned with only one basic human requirement: quality buildings.

Building Quality
Considers the quality of construction and
design
Airtightness (Draughts)
Communal Areas
Electrical Safety
Injury Prevention and Safety (from slips,
trips, falls and collisions)
Security
Structural Safety

Building Services \& Amenities
Considers the services, amenities and
utilities provided for building users
Drainage
Emergency Egress
Fire Safety Features
Lifts
Parking
Rubbish \& Recycling
Utilities
Waste
Water

Materials Quality
Considers quality of materials used in
construction and finishing of a building
Construction Materials
Finishings
Internal Furnishings

Figure 2-7, Quality - Associated Sections \& Factors 


\section{Other}

Factors within this Category are related to the many other reasons people may choose a particular building such as affordability, sustainability and energy efficiency. Unlike the other five Categories these Factors may have little direct influence on liveability. Only one Section was used to group these factors as shown in Figure 2-8.

\begin{tabular}{|l|}
\hline Other \\
Considers non building, design or site related \\
factors \\
Affordability \\
Availability \\
Energy Efficiency/Use \\
Finance \\
Lifestyle \\
Sustainability
\end{tabular}

Figure 2-8, Other - Associated Sections \& Factors

\subsubsection{RESULTS}

This section will discuss the findings of the literature comparison. Figure 2-9 compares the percentage of counts that were assigned to each category between the Popular Press (representing the New Zealand Public) and Academic Literature. Figure 2-10 compares the counts assigned to the sections underneath these categories. It should be noted that factor counts do not necessarily reflect the concern about a particular issue by an author of an article but only provides some form of analysis about issues raised.

\section{The New Zealand Public}

The category that the New Zealand Public placed the most importance on was Configuration, with one third of the counts recorded within this category (33\%). This is not surprising as this category includes both outdoor access such as balconies, issues dealing with space and size and privacy. Indeed, both the sections included under this category Spatiality and Connections received the most counts and were ranked first and second equal ( $17 \%$ and $15 \%$ respectively).

Indoor Environmental Quality ranked second in the category level on one hand, this is not surprising considering that this includes Visual Aspects, ranked second equal with Connections with $15 \%$ of the counts. However all three of the other sections, Acoustics, Thermal Comfort and Indoor Air Quality received only 7\% of the counts between them. This is surprising considering that there have been many recorded issues with both Acoustics and Indoor Air Quality in apartments from a variety of surveys conducted on apartment dwelling in New Zealand. 


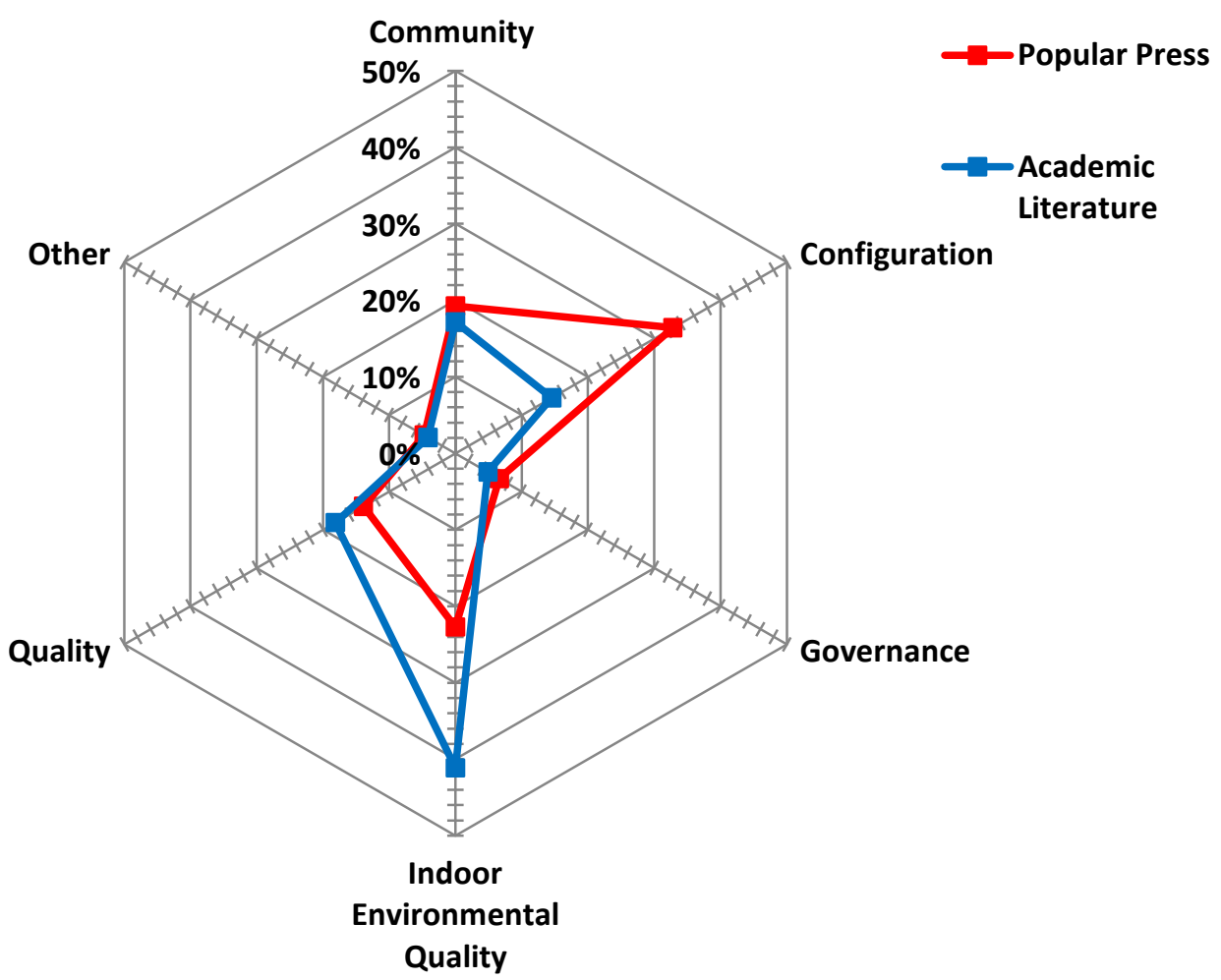

Figure 2-9, Comparison of Perceived Category Importance

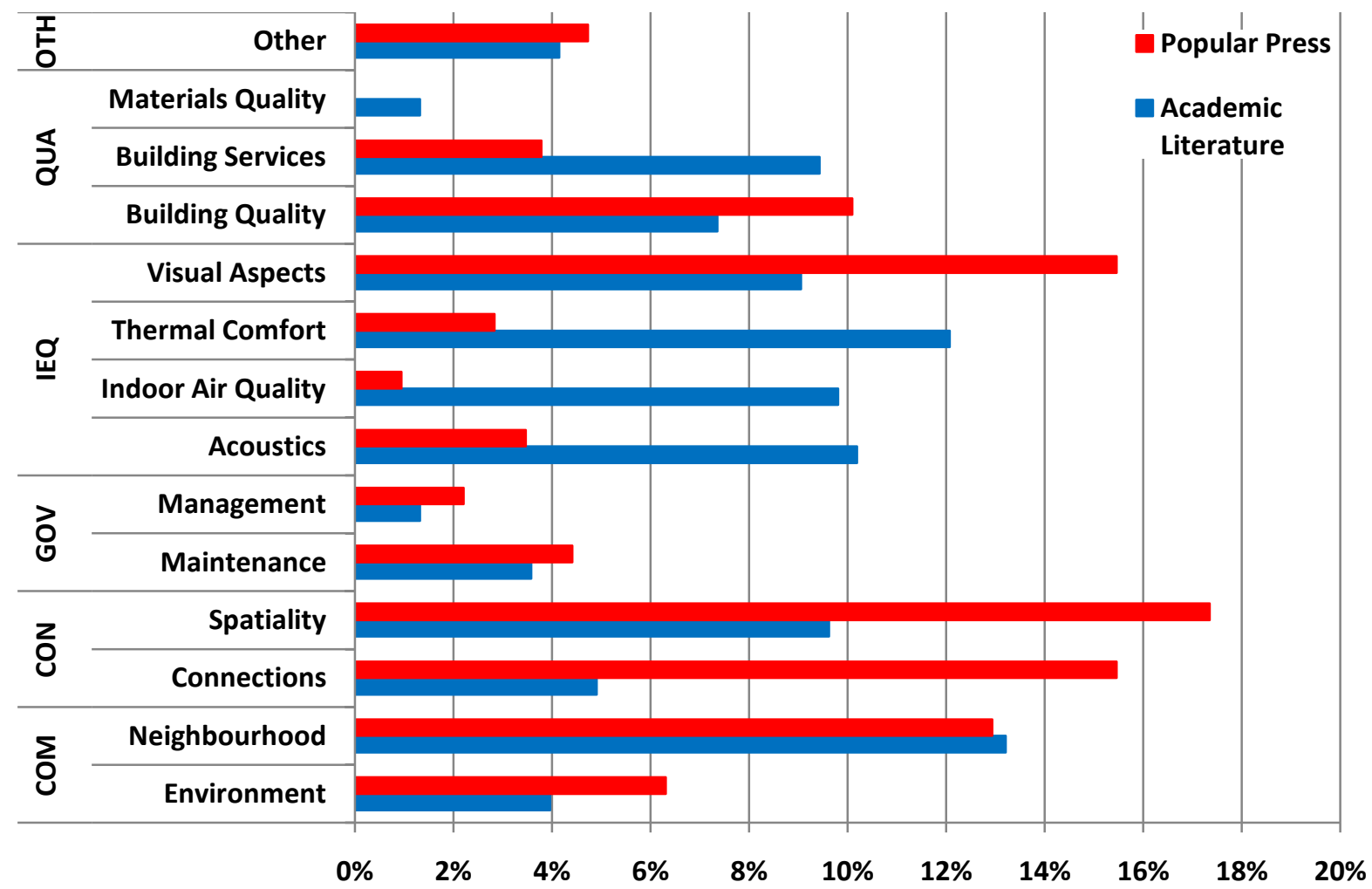

Figure 2-10, Comparison of Perceived Section Importance 
Little importance was placed on Quality or Governance in comparison to the other categories (14\% and $7 \%$ respectively). Community however received $19 \%$ of the counts and was ranked third in the categories. Other received only $4 \%$.

Only five sections received more than $10 \%$ of the counts. In addition to the ones already mentioned is Neighbourhood ranked fourth (13\%) and Building Quality (10\%). These five sections all include issues and factors that would seem to be more easily assessable liveability issues than those that are not perceived as important. This means that issues with these factors are more easily assessable by prospective occupants when looking at plans or having a walk through for example spatial design, connections to the outdoors and neighbourhood quality. These issues often do not directly affect health, and those that do are often harder to immediately assess unless they become apparent after longer exposures (i.e. noise).

\section{Academia}

Indoor Environmental Quality was shown to be the most important category in the academic literature, receiving $41 \%$. Considering the many direct and indirect health and well-being consequences that Thermal Comfort, Indoor Air Quality, Acoustics and Visual Aspects can create, it is not surprising to see that academic researchers place such a high importance on these issues in comparison to the other four categories.

Quality, Community and Configuration were ranked second, third and fourth (18\%, $17 \%$ and $15 \%$ respectively), lower than Indoor Environmental Quality. Governance, similarly to public opinion was ranked second to last with $5 \%$ as was Other ranked last with just $4 \%$.

Similarly to the popular press, five sections also received over $10 \%$ of the counts each Neighbourhood, Thermal Comfort, Acoustics, Indoor Air Quality and Spatiality (13\%, 12\%, 10\%, 10\% and $10 \%$ respectively). However Building Services \& Amenities and Visual Aspects were also very close behind with $9 \%$ each. Academic researchers seem to place importance on things that seem to have more direct affects on health, and that often require longer exposure to become a problem.

\subsubsection{COMPARISON}

Figure 2-9 compares the percentage of counts each category received between the academic literature and popular press. Three categories Quality, Governance and Community were perceived to be similarly important for each group. However, the responses for Configuration and Indoor Environmental Quality were quite different. Figure 2-10 compares the percentage of counts each section received between the academic literature and popular press. Compared to the category level, there was much more variance between the levels of importance placed on each section between the two groups.

The result of the analysis of the literature review shows a clear difference between what the two groups consider important. It would seem that the public places importance on those issues that they can readily assess but these do not have long term health effects. Academic research values those cate 
mental health). While both groups clearly value access to amenities, good indoor environments, privacy and social capital \& interactions, only the public places any real importance on connections to the outdoors (both visually and physically). Again, this emphasises that the public places importance on issues that can be easily assessed without a lot of information (i.e. during an open home). For example, Visual Aspects are able to be easily assessed with minimal information access to daylight can be readily assessed visually, as can window sizes and the adequacy of task lighting. The same is true for Spatiality and Connections where size, layout, privacy and outdoor access can all be assessed visually. In contrast noise disturbances (Acoustics) may often not be identified in a visit and definitely not from design plans.

This comparison has shown that the public places importance on those issues that are easily measureable or assessable onsite or from construction drawings. However, the academic literature places greater importance and value on those issues which have more direct effects on health and liveability. There is a difference between the knowledge of academia with respect to liveability, and what prospective buyers and/or tenants perceive to be important and place value on when considering how a new house or apartment. It is clear that the public do not have access to useful information when considering buying or renting apartments.

This would suggest that different methods of evaluating, assessing and even comparing housing design with respect to occupant liveability need to be developed. Such an assessment or evaluation method will enable the knowledge gained through academic research to be passed on to the public, so that they are able to make informed decisions when purchasing or signing a lease for a new apartment. There is clearly a need for accessible information that will allow people to make informed decisions and the method developed in this research is one possible answer to this problem. 


\subsection{BUILT ENVIRONMENT ASSESSMENT TOOLS}

This section provides an overview of selected building evaluation and assessment tools and methods. It discusses what building evaluation is, why it is useful and how it may be applied to residential buildings. Methods for built environment evaluation and assessment are also summarised, as well as current tools available both nationally and worldwide. Finally different criterion and requirement for tools that have been developed are also summarised.

\subsubsection{BUILDING EVALUATION IMPORTANT OR USEFUL?}

Building evaluation is the systematic assessment of building performance relative to defined objectives and requirements (Baird, Gray, Isaacs, Kernohan, \& McIndoe, 1995). Building evaluation and assessment tools are intended to provide a wide range of people with information concerning the building performance in a wide range of areas such as: energy efficiency, user satisfaction and environmental impacts. Assessment tools, as they are a type of measurement, try to convert empirical observations into values which are possible to assess, evaluate or to compare to other observations (Myhr, 2008).

Buildings are among the largest, most complex and long-lasting "products" that we humans create. Their purpose is to provide shelter for human activities; therefore, they are responding to what is, after food, one of the primary human needs... "Customers" for these "products", unless they are on the staff of large organisations, are at a disadvantage. They probably make a buy decision or sign a lease for this product only a few times in their life and have no Consumer Report to guide them. (Baird, Gray, Isaacs, Kernohan, \& Mclndoe, 1995)

buildings (such as building owners, building management, purchasers, users or tenants) with information about a given building and how it will effect satisfaction, the environment, how energy efficient the design is, and so on. In addition building evaluation is a useful driver in helping to improve the ways in which buildings are designed, managed and used, both environmentally and also with respect to user expectations.

Myhr (2008)

be that building evaluation can help provide information that the building performs well from a financial perspective. While financial aspects are rarely included in building evaluation, environmental issues often are which can be very effective in terms of leasing a building. In purchasing situations Myhr (2008) states that purchasers can use building evaluation and assessment to obtain/provide information about the environmental condition of the property. This also allows investors to understand any environmental liabilities which may potentially affect its financial performance. For occupants (the users and tenants of a building) the main focus is towards comfort, health, safety, well-being, satisfaction and maintenance. Building assessment and evaluation is able to provide users with this type of information to help make informed decisions. Finally Myhr (2008) also notes that building evaluation and assessment is also useful for government bodies. Currently some tools are already 
being used by governments

One example of this is the voluntary New Zealand Home Energy Rating Scheme [HERS] which rates New Zealand homes on their energy use out of ten (Energy Efficiency and Conservation Authority, 2009). Another example of this type of BEAT in New Zealand is Green Star which is a comprehensive, voluntary environmental rating scheme which evaluates the environmental attributes and performance on non-residential buildings (New Zealand Green Building Council, 2008).

Building evaluation and assessment tools are important because they are able to provide the public with information that is otherwise not readily available or understood by them. People are able, through evaluation and assessment to get commercial, organisation, operational and design intelligence and they are able to make confident, successful decisions about building and operations within buildings (Baird, Gray, Isaacs, Kernohan, \& McIndoe, 1995).

BEAT are considered potent and effective vehicle in improving the environmental performance of buildings and in promoting higher demands and expectations. BEAT have emerged in the conceptual gap between the academic desire for objective, scientifically relevant and stringent indicators and the sector's desire for practical, transparent and foremost, easily understandable indicators that are easy to communicate. (Myhr, 2008)

\subsubsection{BUILDING EVALUATION FOR RESIDENTIAL BUILDING}

In the last ten years, there has been a growing awareness of health, housing and environmental health, especially since the outbreak of Severe Acute Respiratory Syndrome [SARS] in several Asian countries and Canada in 2003 (Ho, et al., 2004). Ranson (1991) states that we spend up to two thirds of our lives at home, therefore the health of all individuals is potentially at risk from unsanitary or unhealthy home environments. Ho, et al. states (2004) that until relatively recently, building evaluation and assessment tools were only available for commercial buildings (i.e. offices) but these schemes are not applicable to apartments because of different design and management settings (i.e. offices have HVAC issues whereas residential buildings are generally naturally ventilated). It is for this reason that it is useful to develop assessment schemes for apartment buildings.

Nowadays with the improvement of living standards, occupants are demanding better residential environments (Kim, Yang, Yeo, \& Kim, 2005). Building evaluation and assessment schemes for residential buildings (and especially high-density apartment buildings) are a valuable source of information for a wide range of user groups. For the building tenant and occupants, assessment schemes provide useful tools for the evaluation of different aspects of the building that may affect their health, safety and hygiene; for the developers and building owners, assessment schemes encourage the construction and maintenance of healthy buildings; for architects and designers, tools are useful for checking and improving the quality of health and safety aspects of new building designs and for the government and territorial authorities, building evaluation and assessment schemes can be used as criteria for implementing urban renewal and/or mandatory inspection, maintenance and rehabilitation schemes. Building evaluation and assessment tools are extremely valuable to the community, profession and the government (Ho, et al., 2004). 
Currently there are two assessment schemes that have been developed that consider aspects of health, safety, hygiene, comfort and well-being in terms of the design and management of residential apartment buildings. These are:

- The Building Quality Index [BQI], developed in Hong Kong, comprising two modules including aspects of health and safety in design and management (Wong, Cheung, Yau, Ho, \& Chau, 2006),

- Housing Performance of Multi-Family Residential Buildings [HPMFRB] developed in South Korea, including aspects of housing environment, function and comfort (Kim, Yang, Yeo, \& Kim, 2005).

These assessment tools will be discussed in further detail in following sections. They are criteriabased, weighted hierarchical schemes designed to give both a single score quality indicator and a performance profile of an apartment. Each tool can be easily used by a range of user groups and can easily help compare different apartment buildings (and single apartments) in terms of quality and performance for the occupants.

Three other notable BEAT have been developed in recent years: Building Quality Assessment [BQA]; the Healthy Housing Checklist [HHC] and the Serviceability Tools and Methods [STM]. While only the $\mathrm{HHC}$ is applicable for housing, all of these provide useful insights into evaluating building quality in relation to well-being and usability.

- BQA was developed for assessments of health and safety in New Zealand office and retail buildings (Baird, Gray, Isaacs, Kernohan, \& McIndoe, 1995). Similar to BQI and HPMFRB, it is criteria based weighted hierarchy scheme that provides single scores and performance profiles.

- HHC was developed for assessing health hazards in Dutch homes and for indicating improvement measures (Hasselaar, 2006). It is an unweighted checklist scheme and the evaluation outcome is a report listing hazards (of both empty and occupied buildings) and possible improvements for householders.

- STM was developed as a way to assess and compare the serviceability of office buildings in North America (E 1700 - 95, 1995), (E 1701 - 95, 1995). It is an American Society for Testing Materials (ASTM) standard. STM considers the capability of a building to perform as required from both a management aspect and a structure \& building envelope aspect (Baird, Gray, Isaacs, Kernohan, \& McIndoe, 1995). STM is a criteria-based checklist system which uses scales to provide comparable scores for building users and management.

\subsubsection{METHODS FOR EVALUATING/ASSESSING THE BUILT ENVIRONMENT}

There is a sizable amount of literature on the different methods or types of building evaluation and assessment. This can be divided into two types: the assessment method and the assessment type of tool. The assessment method considers the types of assessment strategies used when undertaking an evaluation and the type of assessment framework required to present information. The assessment tool type on the other hand considers how the tool will be used and who might use it. 


\subsubsection{ASSESSMENT METHOD}

\section{Assessment Strategy}

Baird, Gray, Isaacs, Kernohan \& McIndoe (1995) state that there are several strategies or concepts to consider when planning, developing and managing evaluations. There are four concepts to consider when planning an evaluation of a building. These consider: the depth of the evaluation; the presentation of evaluation outcomes; the focus of the evaluation and; who should provide evaluation judgements.

Exploratory Level vs. Focused Level: This considers how in-depth an evaluation should be. A General level evaluation is characterised by open-ended discussions about what works and what does not. A focused level evaluation usually gathers more in-depth and precise information and support detailed analysis.

Performance as a Single Score vs. Performance as a Profile: Evaluation outcomes can be presented either as an aggregated single score or as separated scores for different issues. A single score is like a total value, however this hides more than it reveals about a buildings performance. Profiling is a group of scores for different qualities, similar to a personality profile. While a single score can be useful in quickly comparing different buildings it shows little about the evaluation. For example, two entirely different buildings maybe evaluated and both receive the same single score, despite Building A scoring higher in Category 1 and lower in Category 2 than Building B. This type of information is hidden in a single score however a performance profile is able to provide insight on these sorts of differences.

Qualitative Focus vs. Quantitative Focus: A quantitative evaluation allows for more precise and specific performance evaluation providing objective information while a qualitative evaluation provides subjective information Ideally a qualitative focus should be complimentary and in agreement with quantitative or objective information.

Expert Evaluation vs. User Evaluation: When considering who should provide judgements, either experts or users can provide good evaluation. Expert evaluation is useful when considering technical issues about a buildings performance. Conversely user evaluation is also extremely useful when assessing their building, as they know the most about using the building.

\section{Assessment Framework}

Myhr and Johansson (2008) discuss the different frameworks that can be used to organise assessment tools. Current assessment schemes can be organised into the Checklist, Matrix or Hierarchy groups. Checklists and Hierarchies are also discussed by Myhr (2008).

Checklists: A checklist is a straightforward way of ordering information where the issues or indicators considered are simply listed. Each indicator is described and target levels assigned. No weightings are assigned to indicators in a checklist and as a result there is no consideration or indication of the significance of how indicators relate to each other and to the overall objective of the tool. Hasselaa

(Hasselaar, 2004). 
Matrices: The arrangement of indicators in rows and columns within a table like format. The relationship between two categories of indicators that are relevant to the aspects in the matrix is inherently shown. Matrices are often used in risk assessment or environmental impact assessment. Risks may be related to various features to be aggregated, resulting in a risk score for the building. One example of this is the Risk Matrix used in E2/AS1, the NZBC Clause E2 External Moisture Acceptable Solution (Department of Building \& Housing, 2009).

Hierarchies: Theoretical constructions that allow for the examination of the interaction between different parts of a building and the building as a whole. When there are many levels of data this framework is preferred as it allows users to focus on one indicator at a time, without losing sight of the overall objective of the assessment. At the top of a hierarchy is usually the overall objective (i.e. health), but each level down the hierarchy becomes more concrete with increasing levels of detail (i.e. noise, acoustics). At the very bottom of the hierarchy are the measureable variables (i.e. measure of sound transmission through the building fabric). The advantage of a hierarchical structure is that it creates an overview of the whole evaluation, where different indicators of the same issue are brought together step-by-step by the use of a weighting system. Weighting is a way to model the relationship between the significance of different criteria or problems it is a way to relate the significance of various impacts to each other and also in relation to the overall evaluation objective. BQA, BQI and HPMFRB are examples of weighted hierarchical assessment frameworks.

\subsubsection{BEAT TYPE}

It is important to consider how a BEAT might be used and who might use it to ensure that the type of BEAT that is developed is fit for the purpose and is usable. BEAT generally have one of two end uses: building certification or labelling (Kim, Yang, Yeo, \& Kim, 2005).

Building Certification: This type of BEAT evaluates a building performance at the design stage and is often used for certification and/or endorsement of a design. Both HERS and Green Star are examples of these for green building in New Zealand. HERS provides New Zealanders with a water and energy efficiency rating (out of 10) for their homes. While a HERS rating is not mandatory it does help to provide New Zealanders with the knowledge they need to make informed decisions about improving the energy efficiency of their homes. Green Star rates non-residential buildings out of six over nine categories and similarly to HERS is not mandatory but allows for endorsement of green design. Certification tools evaluate a in comparison to a reference building or other similar buildings, and are usually developed by government authorities. This type of BEAT is normally used for evaluating buildings with performance beyond the statutory value (i.e. comparison against building regulations). Certification tools cannot generally be considered an adequate

building designers, developers, regulatory bodies or building owners to certify buildings, or provide guidance as to how to improve a building that does not achieve the compliance performance level.

Building Labelling: This type of BEAT assesses the in-use performance of a building compared with that of similar buildings. It is used for comparison and decision making. One example of this 
in New Zealand is BQA. A labelling BEAT objectively and relatively compares a building to a self-selected reference or some other similar building. Some evaluated buildings may be superior, while others inferior to the reference building. Because they are developed for su $s$ and decision-making on purchase, leasing or renting, a labelling BEAT supplies objective information on the strengths and weaknesses of a building.. These tools can also serve as a driver for encouraging initiatives toward achieving better housing performance.

\subsubsection{CRITERION AND REQUIREMENTS}

Over the years many building evaluation and assessment tools have been developed. As part of the development, criteria and requirements have been applied to ensure that the tools have been robustly designed and are applicable, accurate and ultimately appropriate for use. A summary of 12 criteria relevant to the type of tool developed in this research which were applied in three recently developed BEAT is shown in Table 2-3. Eight of these are relevant to many BEAT (\#1 \#8) whereas $\# 9$ to \#12 are applicable only depending on the scope of a proposed tool and therefore are not necessarily relevant to the type of tool investigated in this research.

Table 2-3, Criterion Applied to the Development of Selected Recent BEAT

\begin{tabular}{|c|c|c|c|}
\hline & $\begin{array}{l}\text { BQI } \\
\text { (Ho, et al., } \\
2004 \text { ) }\end{array}$ & $\begin{array}{l}\text { HHC } \\
\text { (Hasselaar, } \\
\text { 2004) }\end{array}$ & $\begin{array}{l}\text { NZBC G7 } \\
\text { Compliance } \\
\text { Tool } \\
\text { (Stewart \& } \\
\text { Donn, 2008) }\end{array}$ \\
\hline 1. Reasonably accurate & & & \\
\hline 2. Easy, simple and straightforward & & & \\
\hline 3. Easily implemented & & & \\
\hline $\begin{array}{l}\text { 4. Representative of typical apartments (now } \\
\text { and in future) }\end{array}$ & & & \\
\hline 5. Applicable to different environments & & & \\
\hline $\begin{array}{l}\text { 6. Objective assessment methods to minimise } \\
\text { subjectivity }\end{array}$ & & & \\
\hline $\begin{array}{l}\text { 7. Practical assessment methods relevant to } \\
\text { skill of user }\end{array}$ & & & \\
\hline 8. Relevant to issue at hand & & & \\
\hline 9. Related to maintenance policies & & & \\
\hline 10. Promotes action & & & \\
\hline $\begin{array}{l}\text { 11. Supports communication and dissemination } \\
\text { of knowledge }\end{array}$ & & & \\
\hline 12. Promotes better understanding of issues & & & \\
\hline
\end{tabular}




\subsection{SUMMARY}

Two of the key research objectives were investigated in the literature to provide a basis and background to the research undertaken. In summary:

- Over 100 factors have been identified in the residential built environment that can affect liveability. Six main requirements were identified that indicate liveability (1) access to community amenities, (2) connections to the outdoors, (3) satisfying indoor environments (visually, aurally, thermally and spatially), (4) privacy \& sanctuary, (5) well-built buildings

(6) social capita \& interactions (social inclusion):

- Academic knowledge and public opinion (represented by the New Zealand popular press) place different importance on factors that can affect occupant liveability. The public places importance on issues that can easily be assessed (i.e. views and outdoor access) whereas academia is more concerned with factors that cannot easily be assessed and often affect liveability through longer term exposure (e.g. air quality). This suggests that the public makes purchasing or tenancy decisions based on readily assessed information, ignoring other issues. It also shows that there is a real need for a better method of evaluating how higher-density housing may affect liveability.

The role of BEATs was also investigated in order to be able to determine what form an apartment evaluation tool should take and where it may fit in relation to other BEAT already developed. It was found that they are important because they can provide the public with information that is otherwise not readily available or understood (Baird, Gray, Isaacs, Kernohan, \& McIndoe, 1995). BEAT are useful in two ways: they assist people to make well informed purchasing and operation decisions (Baird, Gray, Isaacs, Kernohan, \& McIndoe, 1995); and are effective in improving performance and promoting higher expectations of users (Myhr, 2008).

There are a number of aspects to consider when planning an evaluation or developing a BEAT. These include: assessment strategy; assessment framework; type of tool and end-users.

Five BEAT have been identified that provide a useful insight into the evaluation of buildings in regards to quality, well-being and usability. Only BQI and HPMFRB have been developed for use on high-density multi-family buildings. However for the purposes of this research BQA, BQI and HPMFRB will be used as a reference point in developing an apartment evaluation tool for New Zealand because of the way they have been developed, their framework, assessment strategy and evaluation outcomes (this is discussed further in Section 3.1).

These three tools are based on weighted hierarchy frameworks which can provide both single scores and performance profiles meaning that information is available in whatever depth is required. They assess buildings at a focused quantitative level. All are designed to be used by experts and are labelling tools that provide the ability to compare buildings. In order for BEAT to be designed properly so they are fit for purpose and are usable, development criteria must be applied. A review of three recently developed tools identified 12 development criteria that could be applied, although not all criteria are relevant to all uses. 


\section{RESEARCH APPROACH}

This chapter describes the research design of this study. Section 3.1 first outlines the scope of the research including the aim and hypothesis as well as the scope and requirements of the proposed evaluation tool. Section 3.2 outlines the research methods used to develop the proposed tool hierarchy and assessment methods. It will also discuss the use of consultation with end users to both calibrate and validate the tool. Section 3.3 provides discussion and validation of the research approach by comparison to other BEAT previously developed. Section 3.4 summarises the research approach used in this research.

\subsection{SCOPE OF RESEARCH}

The initial literature review revealed a significant gap between the knowledge of the public and academia with respect to how apartment living can affect liveability of occupants. The public (as represented by the popular press) places importance or value on issues that are seemingly easily assessable on site (i.e. spatial design and visual aspects). However academia places importance on issues that have more direct health and comfort affects such as thermal comfort and acoustics. There is a need for better methods of evaluating, assessing and even comparing apartment design with respect to occupant liveability over a wide range of issues. A more comprehensive evaluation method will provide the prospective occupants with the information they are currently lacking in order to make full informed purchasing or tenancy decisions making the currently unasked, measureable.

This section discusses the scope of the proposed tool, the criteria required to ensure that it is developed acceptably, the assessment method, and potential end-users.

\subsubsection{NZ ALI SCOPE}

The aim of this research is to determine if it is possible to develop a BEAT that will simply and easily evaluate liveability in New Zealand apartments. The literature surrounding BEAT suggest that there are five considerations when developing a BEAT:

- Purpose,

- End Users \& Benefits,

- Development Criterion,

- Assessment Method,

- Type.

prospective apartment may be for potential occupants. It should have the ability to deliver both 
single score and performance profile results depending on the user requirements. It will bridge the gap between academic knowledge, public opinion and current liveability issues with respect to apartment design, construction and lifestyle. It will provide prospective occupants with the ability to make informed purchasing/tenancy decisions with respect to how a potential apartment may affect their health, comfort and well-being. This section will outline the scope of the proposed BEAT for liveability in New Zealand apartments. The BEAT developed in this research has been named The New Zealand Apartment Liveability Index [NZ ALI].

\subsubsection{BEAT PURPOSE}

The purpose of the proposed NZ ALI is to provide an insight into how an apartment may affect liveability for occupants. Therefore NZALI must encompass everything that is included under

The term liveable as defined by the Oxford English Dictionary (Oxford English Dictionary, 2009) as generally meaning that something (e.g. a dwelling) is conducive to comfortable living and that life can be lived, made bearable or is supported.

Liveability considers the suitability of a house for habitation and the capacity it has to offer comfortable living (Oxford English Dictionary, 2009). Liveability considers the quality of life and wellbeing felt by an individual or group and encompasses both physical aspects such as health, diet and safety and psychological elements such as stress, worry and happiness. This is different to the standard of living and is not able to be measured directly or accurately as liveability is highly dependent on personal needs or wants.

With this definition of liveability in mind, NZ ALI must be able to cover a wide range of issues surrounding liveability in the residential built environment. Because liveability is subjective it is not expected that a liveability evaluation will be perfectly suited to all individuals. However, it should be able to provide a general evaluation and guidance on liveability in apartments for a majority of users. It will only be applicable to apartments, but should be applicable to both existing and new apartments.

\subsubsection{END USERS \& BENEFITS}

A tool such as NZ ALI has the potential to change the apartment property market. Six potential enduser or stakeholder groups have been identified that could benefit from the proposed tool and are outlined in Figure 3-1. Four of these groups were identified as End-Users as they would potentially use the tool for their own personal benefit. While end-user groups may benefit in a variety of ways, the leading benefit would be financially driven as more liveable apartments should be expected to deliver a higher rate of return. The largest benefit to Building Occupants would be a more liveable environment that better suits their needs. NZ ALI is primarily designed for Building Occupants due to current issues with apartment design and living, coupled with the demand that the use of the tool could potentially create for higher quality, liveable apartments. 


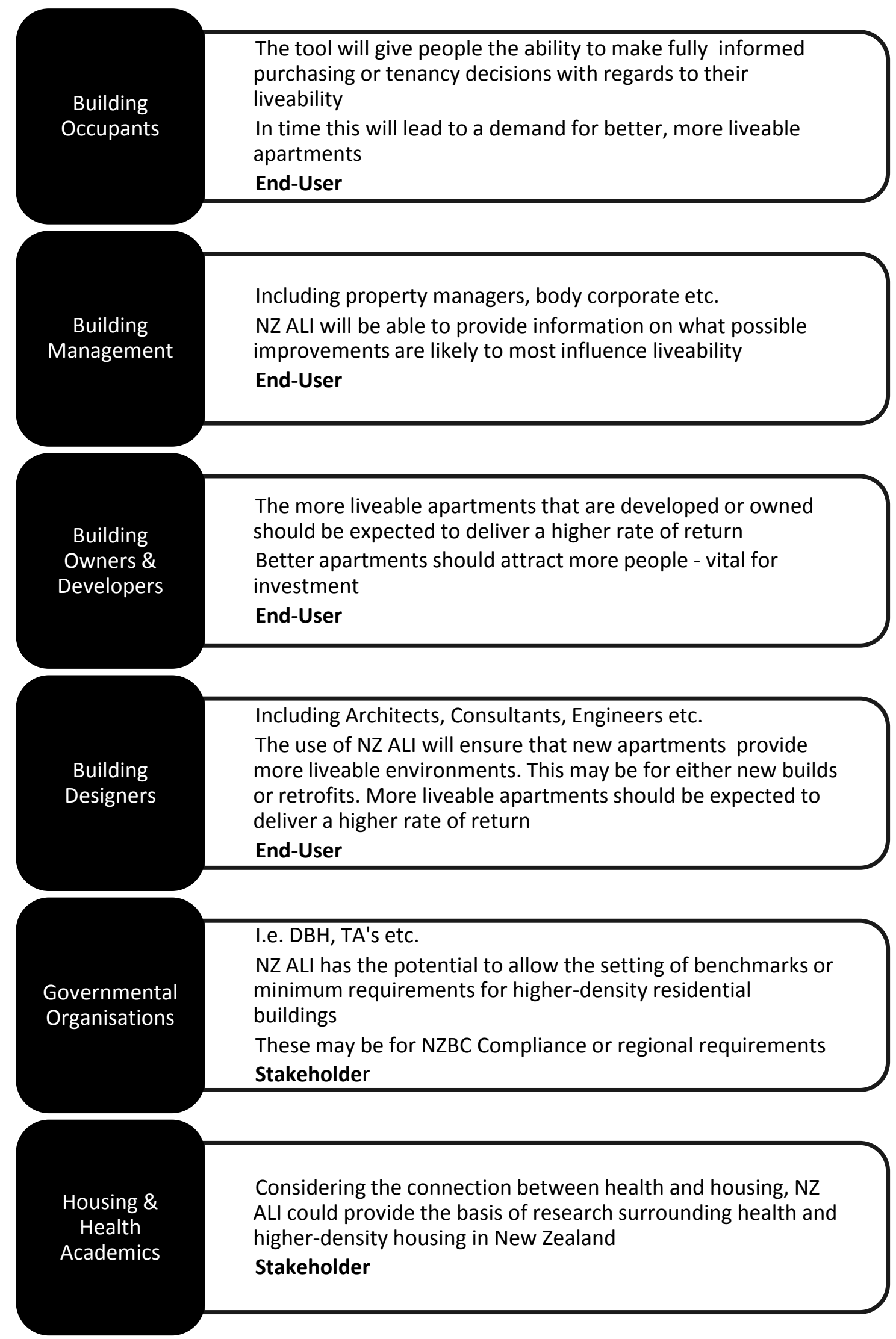

Figure 3-1, Potential End-Users and Benefits of NZ ALI 
Two of the groups identified in Figure 3-1 were considered to be Stakeholders Governmental Organisations and Housing \& Health Academics. Unlike End-users, Stakeholders are considered to be groups or individuals who may have an interest in NZ ALI, but would not use the tool for their own personal benefit. For example the Department of Building and Housing [DBH] could potentially use the tool as a basis NZBC Compliance, either through benchmarking or setting of minimum requirements. The use of the tool by a stakeholder would not see them make any personal gain from using or implementing it, whereas an end-user would see some kind of personal gain.

\subsubsection{DEVELOPMENT CRITERIA}

The literature review found many different criteria that have been applied in the development of different tools internationally. From these, 6 criteria have been set to be applied in the development of this tool as outlined in Figure 3-2.

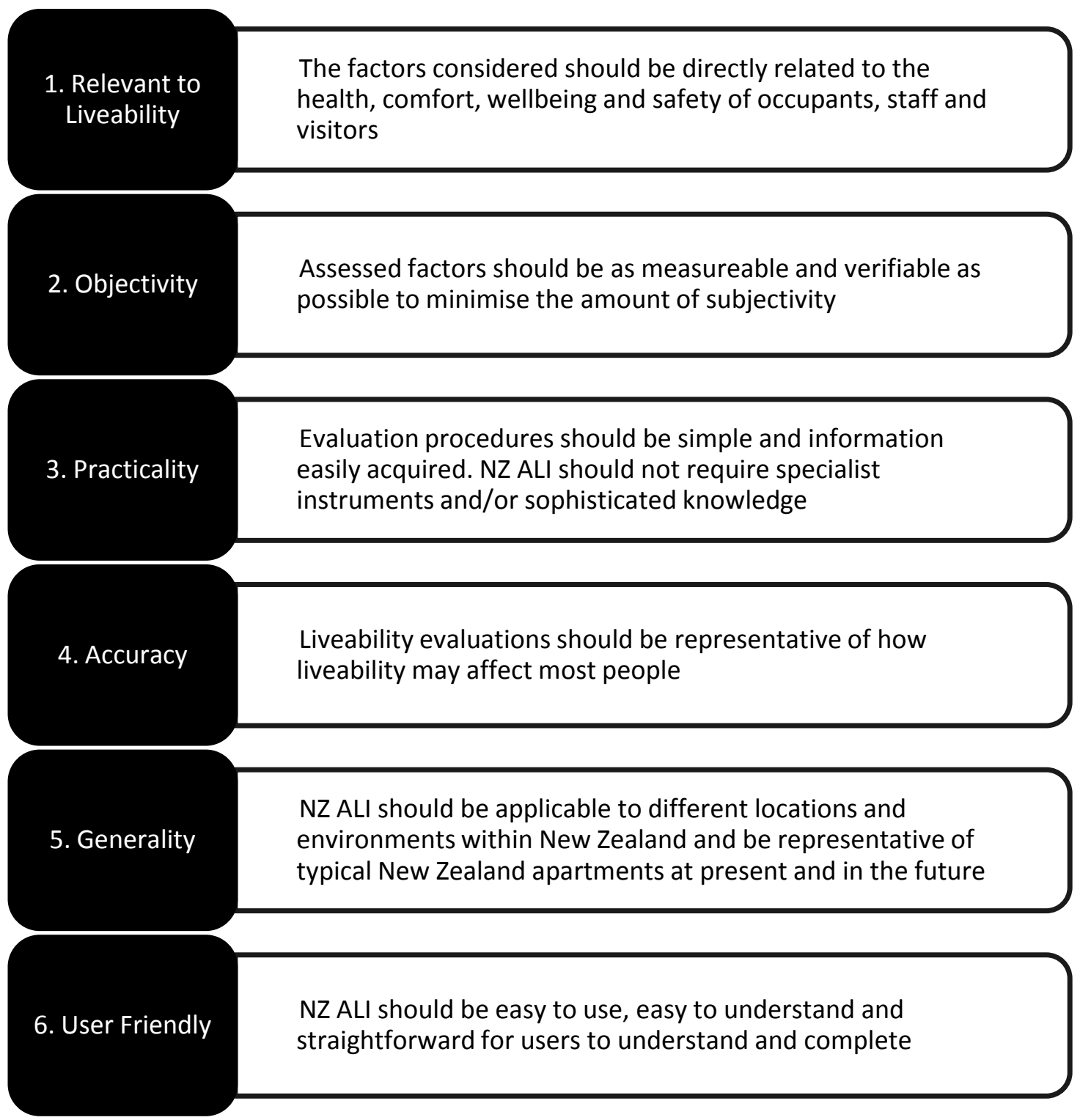

Figure 3-2, Criteria Applied in the Development of NZ ALI 
While it is expected that the proposed liveability evaluation tool will adhere to these six criteria, it is understood that two Criteria may at times be in conflict with each other \#2 Objectivity and \#3 Practicality. Because liveability is highly subjective, is it anticipated that it may be difficult to identify objective assessments for all parts of the tool. Also where objective assessments may be identified they may conflict with the requirement to be practical for users to undertake. It is accepted that some trade-offs may occur between these two criteria because if NZ ALI is to be used widely, then it will need to be easy to use without special measuring instruments and able to be understood by a wide range of people whether or not they have sophisticated knowledge. If these issues should occur, practicality should always be the primary concern because if users cant undertake or understand an assessment the tool will not be usable for its intended users.

\subsubsection{NZ ALI ASSESSMENT APPROACH}

The literature shows that there are a number of factors to consider when developing a BEAT. These include strategy, assessment type, framework and type of BEAT. Figure 3-3 outlines the assessment approach applied to NZ ALI.

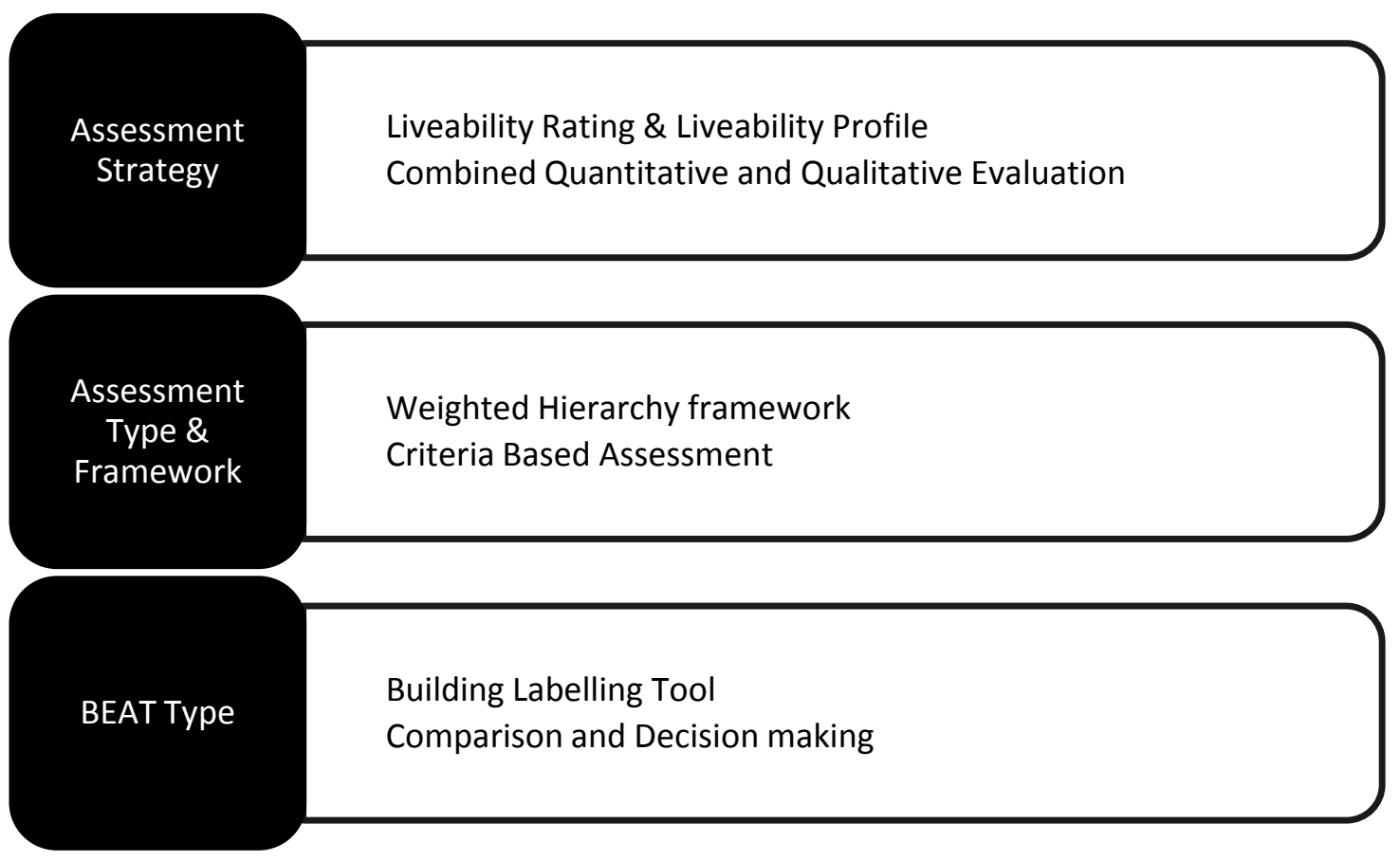

Figure 3-3, NZ ALI Assessment Approach

\section{Assessment Strategy}

It was considered important that NZ ALI be able to provide both single ratings and a more detailed profile or an apartment. Single ratings can often hide more than they reveal about the qualities of a building (Baird, Gray, Isaacs, Kernohan, \& McIndoe, 1995) so it is important that users have access to as much information as possible. Two levels of liveability profiles will be provided the Category level and the Section level Liveability Profile, as shown in Chapter 6.

Because of the subjective nature of liveability and the requirement to be as objective as possible, NZ ALI will have a combined Qualitative and Quantitative focus. 


\section{Assessment Type \& Framework}

$B Q A, B Q I$ and HPMFRB are evaluation tools which are based on weighted hierarchies and consist of criteria based assessments. NZ ALI will also be based on a weighted hierarchy of liveability factors. Each of these factors will be individually assessed against set criteria. As Myhr (2008) explains, the advantage of hierarchical structure is that they create an overview of the whole evaluation with different indicators of the same issue being brought together step-by-step by the use of weightings. Users are able to focus on one indicator or assessment at a time, without losing sight of the overall objective. Liveability is such a broad issue and there are a number of factors that affect liveability. Therefore it was considered that basing NZ ALI on a weighted hierarchy with assessments of each factor would be the best method to develop a comprehensive liveability evaluation tool. This would ensure that all factors are considered and contribute appropriate credits to the overall evaluation.

\section{BEAT Type}

Kim, Yang, Yeo and Kim (2005) discuss the different types of BEAT. NZ ALI is viewed as an evaluation and labelling tool because of its intended purpose.

labelling model, which supplies objective information and guidance on both the strengths and the weaknesses of a building, would be more useful for comparisons and decision making when leasing or purchasing a unit in one of these buildings (Kim, Yang, Yeo, \& Kim, 2005). This model also serves as a tool for encouraging initiatives toward achieving better housing performance and it is envisaged that NZ ALI will also be useful for this purpose. 


\subsection{RESEARCH METHODS}

This section will outline the research methods used to develop the proposed apartment evaluation tool NZ ALI. As will be discussed in detail in Section 3.3 (and already discussed briefly in Section 1.3, NZ ALI follows the research methods of two similar tools Building Quality Assessment [BQA] and Building Quality Index [BQI]. Both tools are based on weighted hierarchies of different building features that can provide both a single overall score or a set of sub-scores (a performance profile). Both of these tools underwent a similar development process the hierarchy and indicators were established first, then weightings and credits were applied. The methodology used in the development of NZ ALI is as follows:

- Framework development of NZ ALI,

- Use of ranking method in obtaining weights to be applied to components of NZ ALI index,

- Consultation with end users to ensure that NZ ALI fulfils all Criteria and is fit for purpose.

\subsubsection{FRAMEWORK DEVELOPMENT}

This section will outline the development of the NZ ALI framework, using one Category (Configuration) as an example.

1. Factor Assessment

The initial literature review identified 107 factors that academia and the New Zealand public consider important regarding liveability in New Zealand apartments. These factors have been grouped into six Categories and 13 Sections as part of the literature review. Step one of the framework development required each of the identified Factors be assessed for two reasons:

- To remove any repetition between the initially identified Factors,

- Compliance with Criterion \#1, Relevant to Liveability.

Rather than document all the changes, this section uses one Category as an example. Figure 3-4 outlines the Factor assessment of the Configuration Category. Factors in blue are those identified in the academic literature, in red are those from the popular press. Green Factors show where repetition occurred between the two sets of Factors. Five factors were identified in Connections however two were repeated (shown in green in Figure 3-4) Outdoor Provision and Privacy. 12 Factors were initially identified in Spatiality and two were found to be repeated Apartment Size and Storage. There were no Factors in Spatiality that did not comply with Criterion \#1 and so 10 Factors remained in Spatiality.

Of the 107 Factors initially identified, 29 were removed due to either repetition or irrelevance to Liveability. All Factors that were not relevant to liveability were part of the Other Category which meant that this Category was removed entirely, as discussed in Other. 


\section{CONFIGURATION}

\section{CONNECTIONS}

High-Rise/Vertical Location

Outdoor Provision

Privacy

\author{
SPATIALITY \\ Crowding \\ Density \\ Headroom \\ Occupancy \\ Shape (Of Unit) \\ Size (Of Unit) \\ Space Organisation \\ Spatiality \\ Storage
}

Figure 3-4, Configuration Factor Assessment

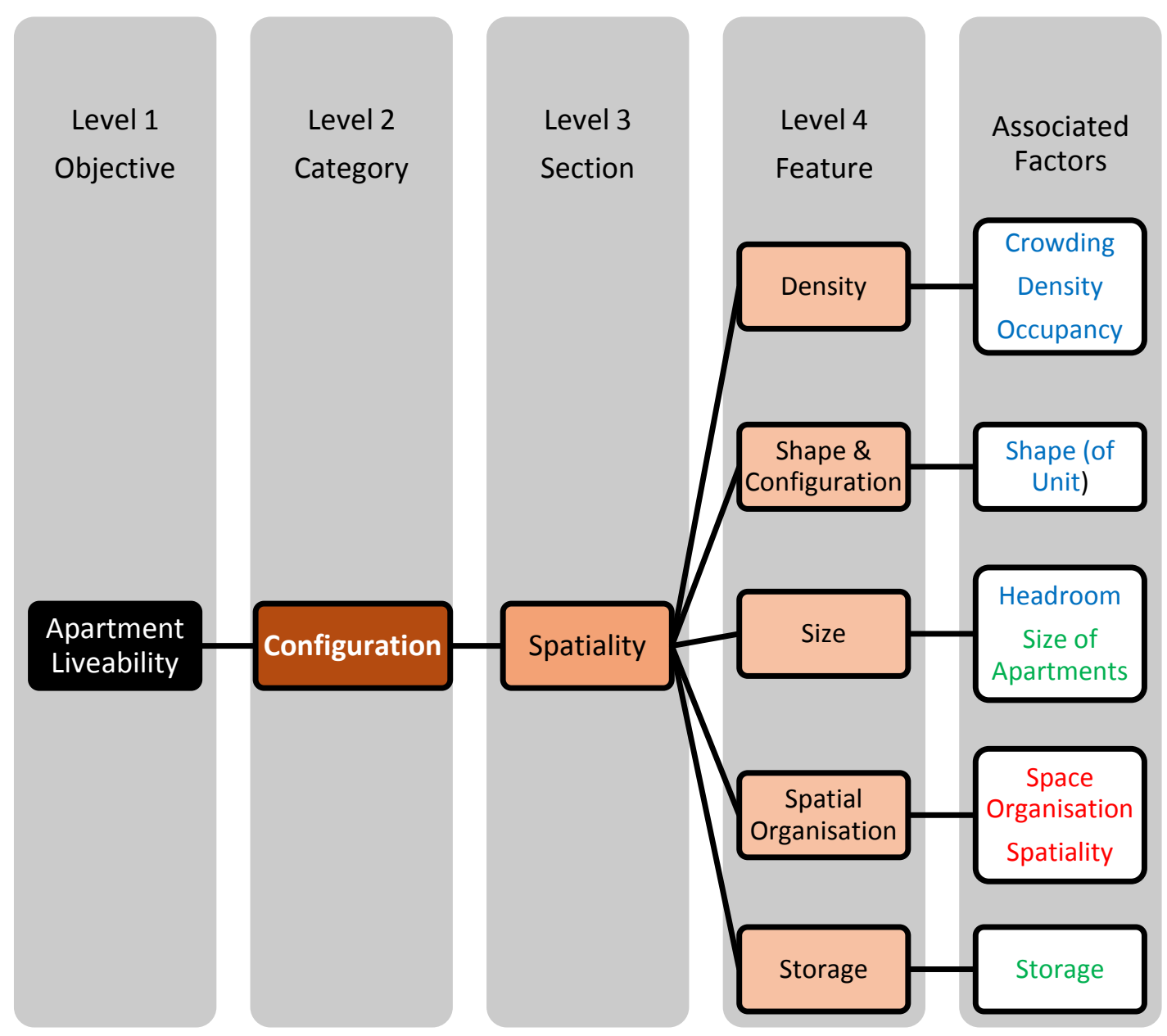

Figure 3-5, Spatiality Feature Identification 
2. Feature Identification

Following the Factor assessment, five Categories, 13 Sections and 77 Factors remained. A hierarchical structure was already apparent, with the Categories and Sections becoming the $2^{\text {nd }}$ and $3^{\text {rd }}$ levels (respectively) of a hierarchy. The Objective (Liveability in New Zealand Apartments) is the $1^{\text {st }}$ or top level. The Factors grouped beneath the Sections were re-grouped again and these groupings became the $4^{\text {th }}$ level of the hierarchy Features. 45 Features were identified and Figure 3-5 shows the Features and associated Factors identified for Spatiality.

\section{Aspect Identification}

Aspects of each Feature that affect liveability in an apartment were then identified. The Aspects became the $5^{\text {th }}$ level of the hierarchy. Most Features are represented by one Aspect while some are represented by two or more (see Figure 3-6). 120 Aspects were identified across the 5 Categories. Figure 3-6 outlines the four Aspects identified for Storage, one Feature within Spatiality.

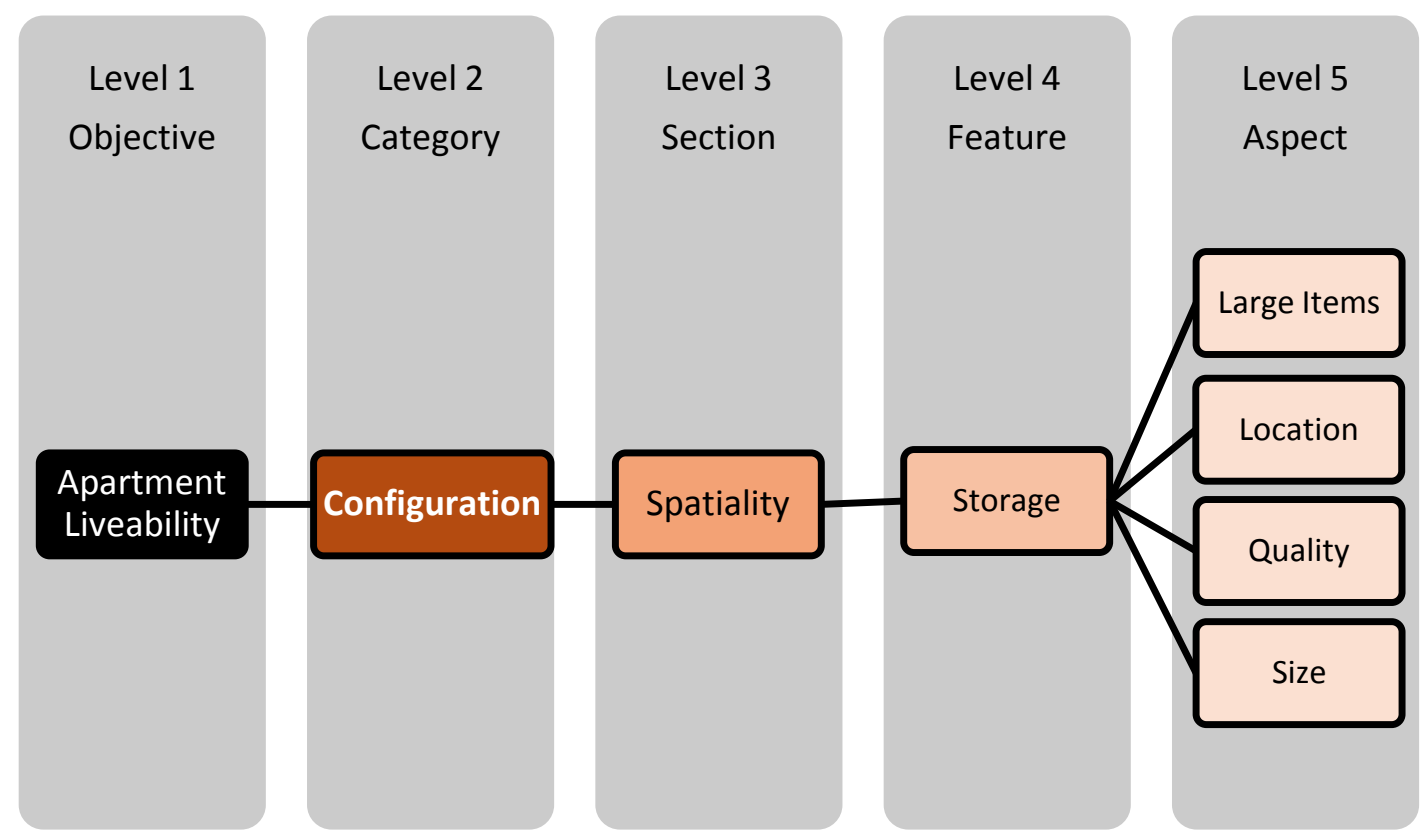

Figure 3-6, Storage Aspect Identification

4. Indicator Identification

Indicators of each Aspect were then identified to become the $6^{\text {th }}$ level of the hierarchy. Indicators

Indicators were identified for the 115 Aspects. Most Aspects only required one Indicator although some required two or more. Figure 3-7 outlines the Indicators identified for the Aspects associated with Storage. 


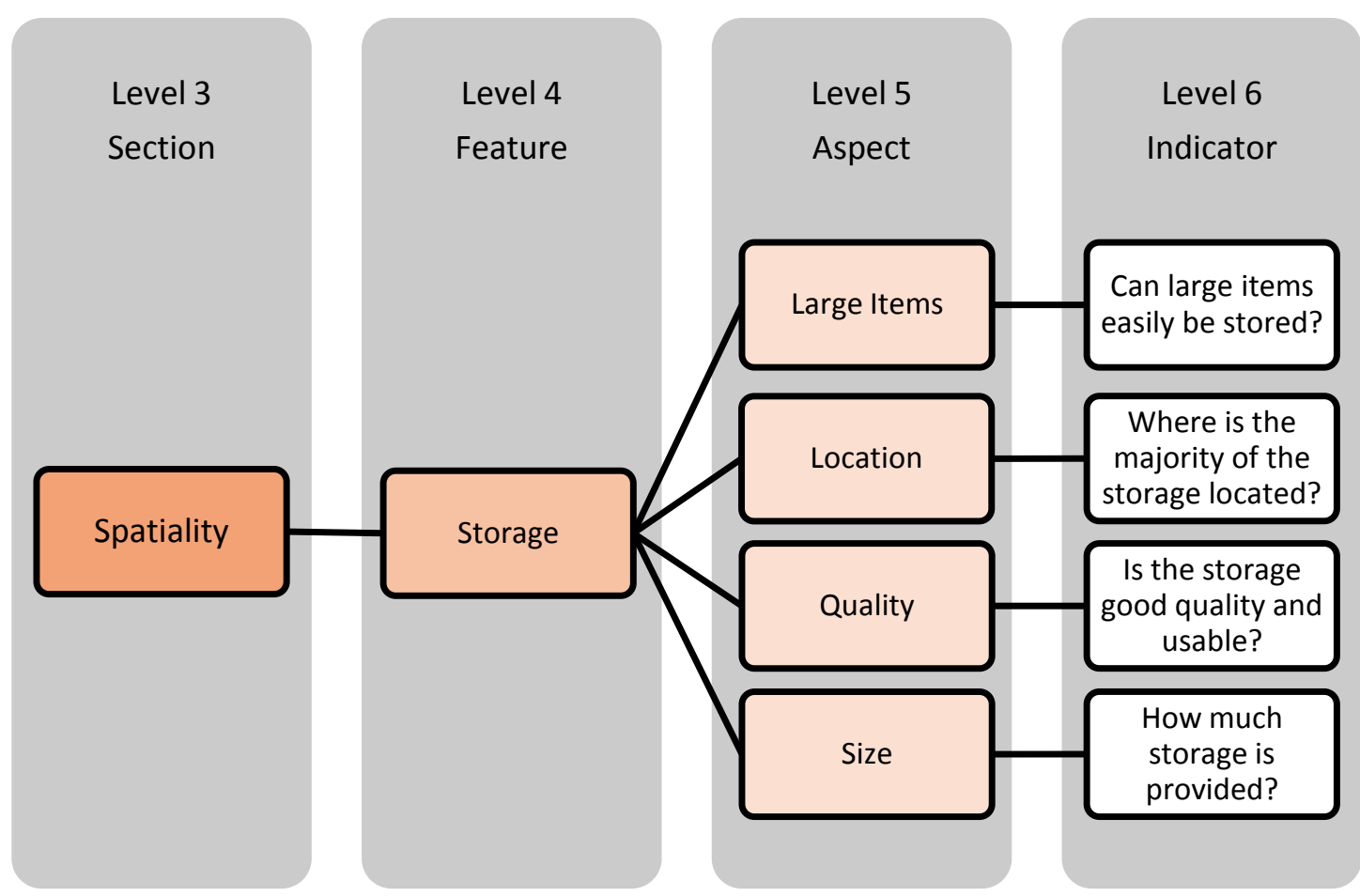

Figure 3-7, Storage Indicator Identification

\section{Assessment Method Identification \& Review}

Each of the 153 Indicators are considered as Assessment Questions . Each of these required an Assessment Method [AM] so that all components of the tool are appropriately considered by users. To ensure that all indicators were initially assessed in the most accurate way, Criteria \#2 and \#3 were not considered at this stage. Five assessment methods were considered for all 153 Indicators, outlined in Table 3-1.

Table 3-1, NZ ALI Assessment Method Version 1 and Answer Types

\begin{tabular}{|l|l|}
\hline Assessment & $\begin{array}{l}\text { An assessment of some type (i.e. air quality or wind environment) is required to } \\
\text { determine the acceptability of the Indicator. }\end{array}$ \\
\hline $\begin{array}{l}\text { Choose } \\
\text { Yes/No }\end{array}$ & The user is required to answer Yes or No to the assessment question. \\
\hline Measurement & $\begin{array}{l}\text { A measurement of some kind (i.e. distance, floor area, illuminance levels etc) is } \\
\text { required to determine the acceptability of the Indicator. }\end{array}$ \\
\hline $\begin{array}{l}\text { Personal } \\
\text { Perception }\end{array}$ & The user makes a personal judgement of the acceptability of the Indicator. \\
\hline Statement & The user is required to state an answer (e.g. location, orientation, building use, etc) \\
\hline
\end{tabular}


Assessment Methods initially identified for the Indicators were then reviewed against Criteria \#2 (Practicality) and \#3 (Objectivity). Any that did not meet the requirements were reworked. None were removed to ensure that a complete liveability evaluation was able to be performed.

\section{Criterion \#2 - Practicality}

- All assessments should be practical for users to make. No specialist knowledge, tools or information should be needed to make any of the assessments ${ }^{18}$

- An assessment method might be considered impractical due to a lack of skills or expertise of intended users or due to wording that intended users may not understand.

\section{Criterion \#3 - Objectivity}

- Where possible assessment should be measureable and verifiable to minimise subjectivity

- An assessment method is considered objective if it relies on defined or known information and not on user opinions or perceptions

- Because liveability is a very personal subject, everybody will have slightly differing liveability requirements. It is accepted that in some cases objective measurements would not be compatible with practical measurements. In these cases practical measurements were considered of higher importance

Where it was not possible to propose both practical and objective assessments for an Indicator, notes and comments were recorded so that users would have guidance on how to make an assessment. This way, users of the end tool could make an informed decision and answer the question within the correct parameters and therefore minimise the subjectivity of the assessment.

One example of this conflict is with adequate task lighting. An objective assessment of task lighting would require users to personally measure lighting levels with an illuminance meter. However this is an impractical assessment because users may not have access to this equipment or understand what to do. Instead a more practical assessment was proposed where users are asked to consider whether they believe they could easily perform a range of tasks (i.e. walk safely, read a book, prepare a meal etc) in a room which would give an indication of how adequate lighting levels would be. In this case, this assessment was considered acceptable because adequate lighting levels change for different people particularly for the elderly and visually impaired. What one person may consider perfect lighting to read a book, a visually impaired person may find too dark for reading in.

During the assessment of the proposed assessment methods, it was determined that in order to make NZ ALI user friendly (Criterion \#6) there would be only four assessment methods and answer types. These are outlined in Table 3-2.

assessment methods (outlined in Table 3-1) remained

Table 3-2

used instead for some modified assessment methods. Table 3-3 and Table 3-4 provide an example of the Assessment Method Identification and Review for Aspect Storage Quality within Spatiality.

\footnotetext{
${ }^{18}$ Information beyond that which would be given in either an open home, a visit to a show room, a simple internet search (e.g. Google Street View) and walk around the neighbourhood
} 
Table 3-2, NZ ALI Assessment Method Version 2 and Answer Types

\begin{tabular}{|l|l|}
\hline List & $\begin{array}{l}\text { The user is required to pick the best fit or most appropriate answer from a list } \\
\text { provided. }\end{array}$ \\
\hline Yes/No & The user is required to answer Yes or No to the assessment question. At times, when \\
\hline Scale & $\begin{array}{l}\text { The user is required to nominate a number from } 1 \quad 10 \text { (1 being the lowest, } 10 \text { being } \\
\text { the highest) depending on how well it meets the requirements. }\end{array}$ \\
\hline Number & The user is required to input a number or measurement to answer the question. \\
\hline
\end{tabular}

Table 3-3, Storage Assessment Method Version 1 Identification \& Assessment

\begin{tabular}{|l|l|l|l|l|l|}
\hline \multirow{2}{*}{ Indicator } & AM 1 & \multicolumn{2}{l|}{ C\#2 Practicality } & \multicolumn{2}{l|}{ C\#3 Objectivity } \\
\cline { 3 - 6 } & Relevant? & Why? & Relevant? & Why? \\
\hline $\begin{array}{l}\text { Quality of } \\
\text { Storage }\end{array}$ & $\begin{array}{l}\text { Personal } \\
\text { Perception }\end{array}$ & No & $\begin{array}{l}\text { Impractical } \\
\text { due to } \\
\text { wording }\end{array}$ & No & $\begin{array}{l}\text { Subjective as it } \\
\text { relies on user } \\
\text { perceptions }\end{array}$ \\
\hline
\end{tabular}

Table 3-4, Storage Assessment Method Version 2

\begin{tabular}{|l|l|l|l|}
\hline Indicator & Assessment Question & AM 2 & Guidance \\
\hline Quality of Storage & $\begin{array}{l}\text { How good is the } \\
\text { storage provided? }\end{array}$ & Scale & $\begin{array}{l}\text { Please consider } \\
\text { dampness, mould, } \\
\text { accessibility, shelving } \\
\text { etc }\end{array}$ \\
\hline
\end{tabular}

\section{Credit Establishment}

The final step in developing the framework of NZ ALI was to determine how credits would be awarded depending on the

Table 3-2 can award credits differently as shown in Table 3-5.

Acceptability of answers was taken from various sources including the NZBC, New Zealand Standards and apartment design guidelines (this is discussed in greater detail in Appendices Community, Configuration, Governance, Indoor Environmental Quality and Quality.) Credits could then be awarded depending on the acceptability of an answer:

- Each Indicator could provide up to $100 \%$ of its weighting (weighting to be determined during the Index Calibration stage of the research),

- Depending on an answers acceptability a credit was awarded anywhere between $0100 \%$,

- Once weightings were determined then these credits could be applied so that NZ ALI was a functioning evaluation tool,

- Depending on the assessment method and answer type, credits were given in different ways as Table 3-5 shows, 
- Table 3-6 shows the credit establishment for the Indicators associated with the Storage Feature.

Table 3-5, Establishment of NZ ALI Credits

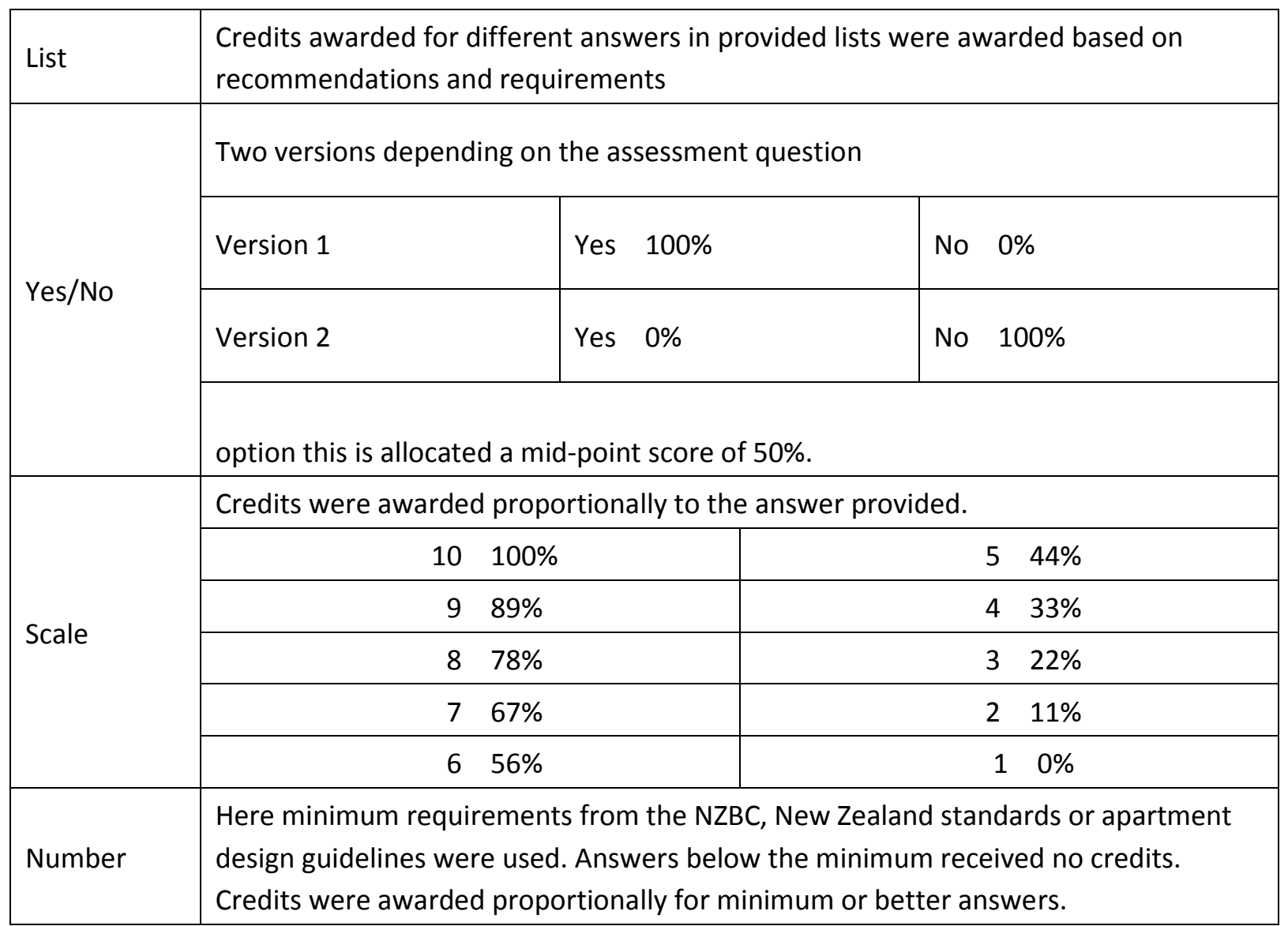


Table 3-6, Determination of Storage Credits

\begin{tabular}{|c|c|c|c|c|c|}
\hline Feature & Aspect & Indicator & $\begin{array}{c}\text { Assessment } \\
\text { Method (AM) \#2 }\end{array}$ & Answer Possibilities & $\begin{array}{l}\text { Percentage } \\
\text { of Credit } \\
\text { Awarded }\end{array}$ \\
\hline \multirow{18}{*}{ Storage } & \multirow[b]{2}{*}{ Large Items } & \multirow{2}{*}{$\begin{array}{c}\text { Can large } \\
\text { items easily be } \\
\text { stored? }\end{array}$} & \multirow[b]{2}{*}{ Yes/No } & Yes & $100 \%$ \\
\hline & & & & No & $0 \%$ \\
\hline & \multirow{3}{*}{ Location } & \multirow{3}{*}{$\begin{array}{l}\text { Where is the } \\
\text { majority of the } \\
\text { storage } \\
\text { located? }\end{array}$} & \multirow{3}{*}{ List } & $\begin{array}{l}\text { Internal Storage (In } \\
\text { Apartment) }\end{array}$ & $100 \%$ \\
\hline & & & & $\begin{array}{l}\text { External Storage (In } \\
\text { Building, i.e. } \\
\text { basement) }\end{array}$ & $75 \%$ \\
\hline & & & & $\begin{array}{l}\text { External Storage } \\
\text { (Onsite i.e. separate } \\
\text { building) }\end{array}$ & $50 \%$ \\
\hline & \multirow{10}{*}{ Quality } & \multirow{10}{*}{$\begin{array}{l}\text { Is the storage } \\
\text { good quality } \\
\text { and usable? }\end{array}$} & \multirow{10}{*}{ Scale } & 10 & $100 \%$ \\
\hline & & & & 9 & $89 \%$ \\
\hline & & & & 8 & $78 \%$ \\
\hline & & & & 7 & $67 \%$ \\
\hline & & & & 6 & $56 \%$ \\
\hline & & & & 5 & $44 \%$ \\
\hline & & & & 4 & $33 \%$ \\
\hline & & & & 3 & $22 \%$ \\
\hline & & & & 2 & $11 \%$ \\
\hline & & & & 1 & $0 \%$ \\
\hline & \multirow{3}{*}{ Size } & \multirow{3}{*}{$\begin{array}{l}\text { How much } \\
\text { storage is } \\
\text { provided? }\end{array}$} & \multirow{3}{*}{ Number } & $\begin{array}{l}\text { Greater than or equal } \\
\text { to twice minimum } \\
\text { requirement }\end{array}$ & $100 \%$ \\
\hline & & & & $\begin{array}{l}\text { Greater than or equal } \\
\text { to minimum } \\
\text { requirement }\end{array}$ & $50 \%$ \\
\hline & & & & $\begin{array}{l}\text { Less than minimum } \\
\text { requirement }\end{array}$ & $0 \%$ \\
\hline
\end{tabular}




\subsubsection{INDEX CALIBRATION}

The second stage in the development of NZ ALI required the components within the tool to be calibrated. Calibration allows NZ ALI to become a useful evaluation tool to provide an apartment liveability rating and performance profile.

In order to obtain weightings for each of NZ ALI components, a questionnaire was used to survey different groups of people who have experience and knowledge of New Zealand apartments to determine what they consider to be important in relation to liveability. This approach is similar to that used by BQA where a user opinion survey is used to determine weightings (Baird, Gray, Isaacs, Kernohan, \& McIndoe, 1995).

Five groups of people were surveyed from the same six groups identified Figure 3-1 as end users and stakeholders. In total 47 respondents completed the questionnaire. Two groups from Figure 3-1 were combined due to low response rates Building Management and Building Owners \& Developers became one group in the survey. All other groups remained the same.

The results from the survey provided the basis for the weightings to be applied to the NZ ALI components. Questionnaire respondents were required to either nominate components they considered to be the most important (at Aspect level) or rank components in order of importance (at Feature, Section and Category level) in regards to apartment liveability. Limited data on each respondent was also obtained so that the results could be analysed by stakeholder group and dwelling history. Ethics Approval was given for this section of the work from the Victoria University of Wellington Human Ethics Committee Ethics Approval No. 16260 (see Victoria University of Wellington Ethics Approval).

The results from the survey were used to determine how much each of NZ ALI components should be weighted. Weightings were determined by how important the respondents rated each of the components within that set. Each set of components were assigned a total of $100 \%$ (i.e. each set of Aspects under a Feature, each set of Features under a Section).

\section{Aspects}

Weightings for Aspects were determined based on how important the participants believed they were. For the Aspects, participants were asked to nominate one Aspect they considered to be most important. Figure 3-8 shows the percentage of nominations each Aspect within Storage received. These percentages were then used for the weightings. Therefore, Quality is the most important Aspect for Storage, contributing $40.4 \%$ of the credit awarded for Storage. Location, ranked second, contributes $31.9 \%$, Size contributes $23.4 \%$ and Large Item Storage contributes only $4.3 \%$.

\section{Features, Sections \& Categories}

For Features, Sections, and Categories, participants were asked to rank all components, with one being the lowest or least important. Rankings were not immediately obvious as they were for Aspects because inevitably rankings were varied across components, as Figure 3-9 shows for the Features shown within Spatiality the number of respondents giving a 1, 2, 3, 4, or 5 . 
A cumulative percentage was used to determine the weightings that would be applied to NZ ALI (shown in Equation 3-1).

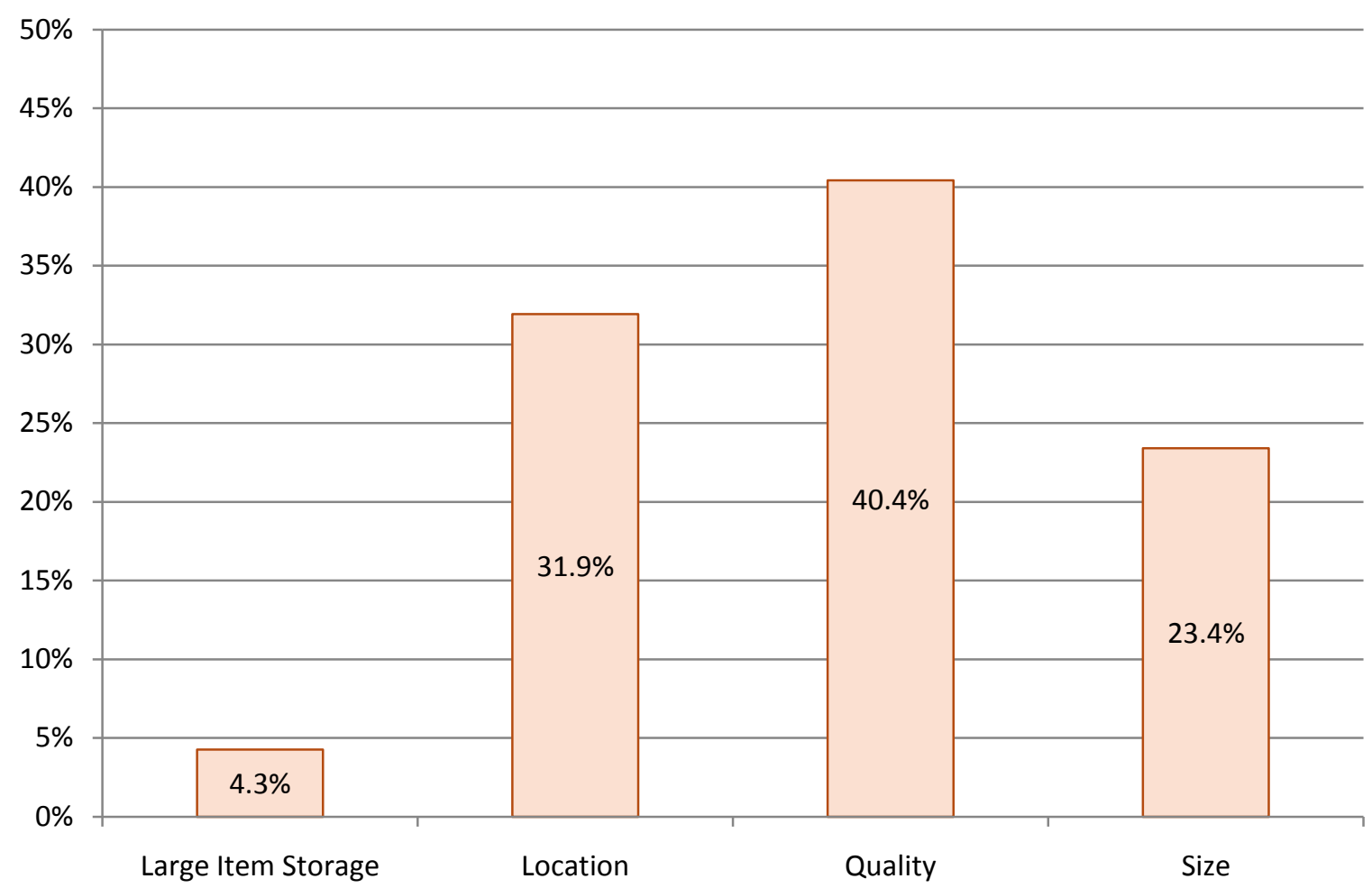

Figure 3-8, Percentage of 'Most Important' Counts for Storage, NZ ALI Questionnaire Results

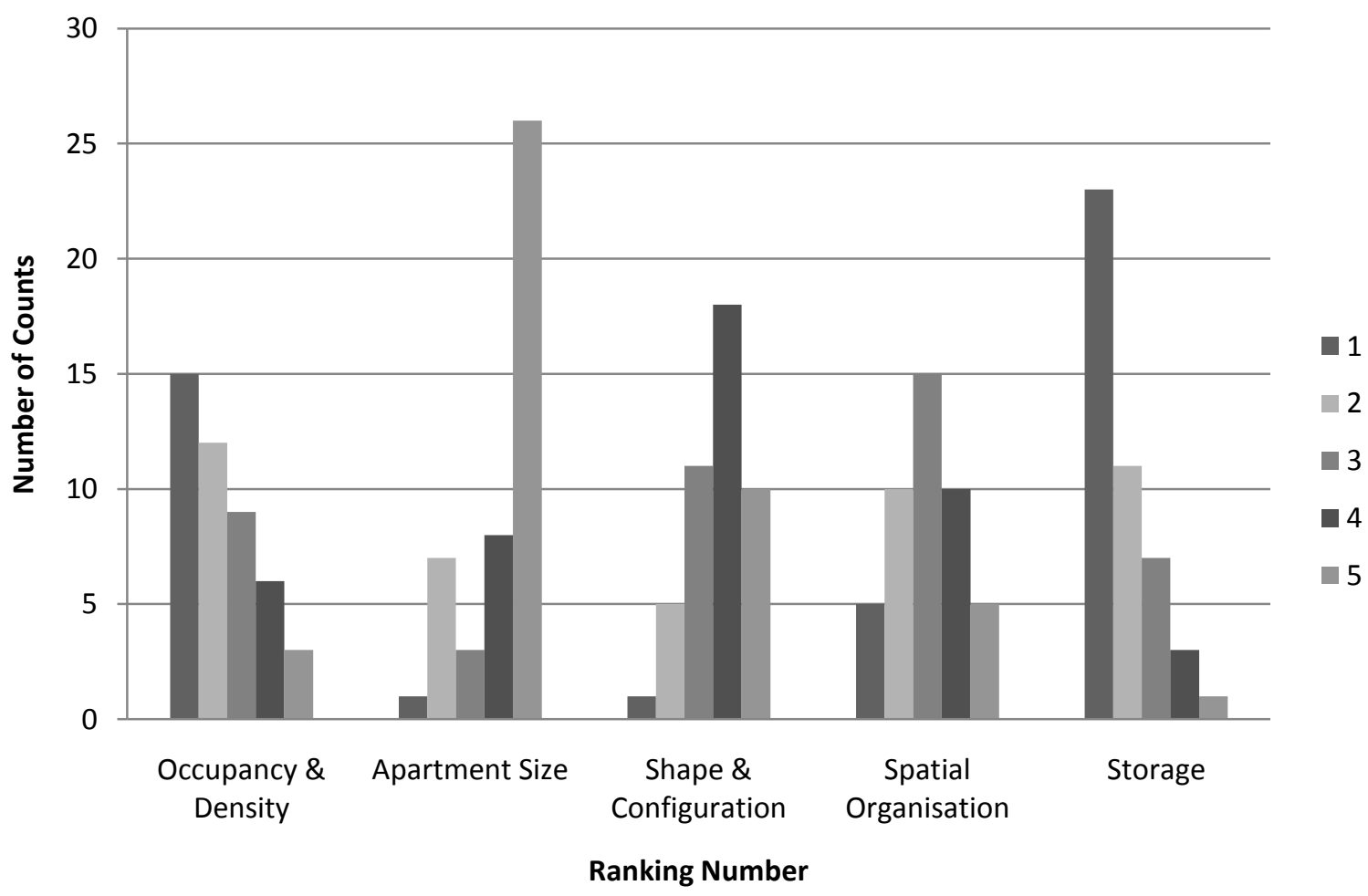

Figure 3-9, Ranking Variation for Spatiality Features, NZ ALI Questionnaire Results 
Equation 3-1, Cumulative Percentage

$$
W=\frac{C R}{T R} \times 100
$$

Where $W$ is the component weighting, $C R$ is the sum of all component rankings and $T R$ is the sum of all component rankings within set. For Storage, $C R$ was determined to be 83; TR for the Spatiality features was determined to be 675 . Therefore the Cumulative Percentage $(W)$ was determined to be $12.3 \%$.

Figure 3-10 shows the weightings determined for the Spatiality Features by using Equation 3-1. Storage (ranked least important) contributes only $12.3 \%$ of the credit awarded to Spatiality. Size is the most important, contributing 27.6\%; Shape \& Configuration contributes $24.6 \%$, Spatial Organisation $20.0 \%$ and Density $15.6 \%$.

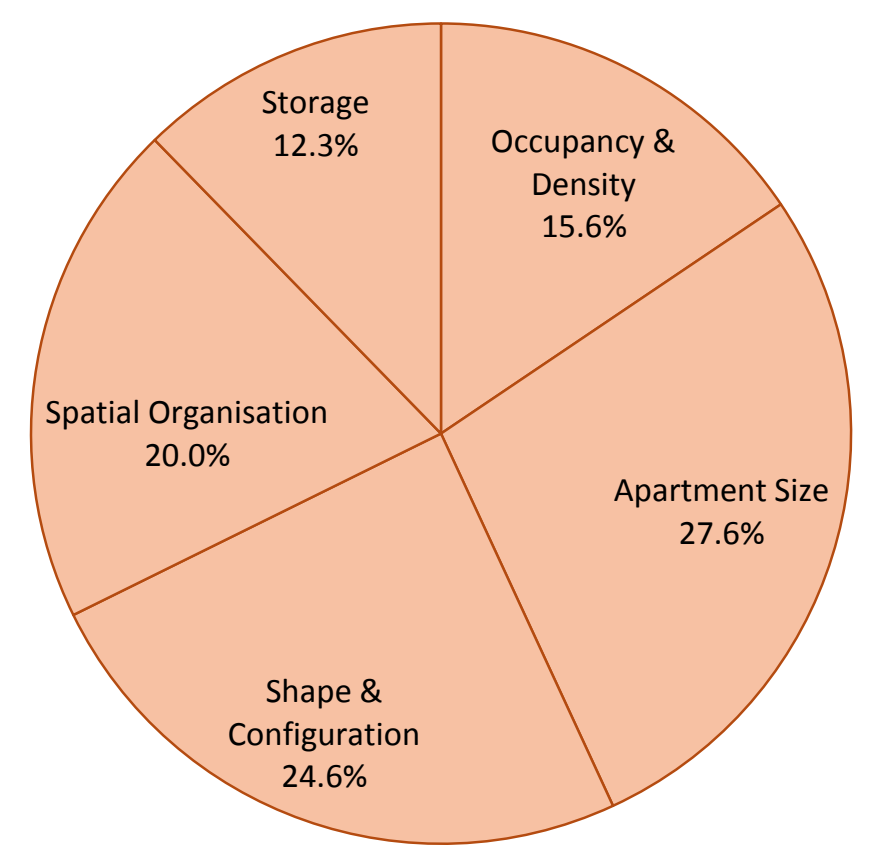

Figure 3-10, Weightings Determined for Spatiality Features, NZ ALI Questionnaire Results

In this way, weightings were determined from the survey data for each of the Aspects, Features, Sections and Categories. At this stage NZ ALI was a usable, but unvalidated, tool able to provide either a single score, or Liveability Rating and a set of sub-scores, or a Performance Profile of an apartment. 


\subsubsection{INDEX VALIDATION}

The final stage in the development of NZ ALI was to validate the tool and its liveability evaluations this occurred in three ways:

- The first was to ensure that the results that NZ ALI provided were reasonably accurate and therefore adhering to Criterion \#4,

- The second was to ensure that the tool was representative of typical New Zealand apartments and could be applied to different environments within New Zealand (Criterion \#5),

- The third was to ensure that the tool met the requirements of Criterion \#6 User friendliness.

Validation of NZ ALI was undertaken in three stages: trialling the tool on existing apartments; interviews with the occupants; and finally critiquing of the tool by a selected group of apartment occupants. The interviews with occupants focused on how they believed their liveability had been affected in their apartment. The comparison of the NZ ALI Trial and Interviews quantified the tool accuracy in predicting how the liveability of the apartment.

The tool was also tested by the same occupants and the comments received were used to determine how user friendly the tool is. Index Validation was undertaken on four apartments of differing quality, size, location and price to determine how well the tool met Criterion \#5. Six occupants from the four apartments were involved. Ethics Approval was given for this section of the work from the Victoria University of Wellington Human Ethics Committee Ethics Approval No. 16431 (see Victoria University of Wellington Ethics Approval).

\section{Criterion \#4 - Accuracy}

When the results from the interviews and open discussion were compared to the NZ ALI Trial results, a high level of correlation between the two was evident. Generally, where occupants stated that certain things annoyed them, or they disliked them, in the open discussion that followed the NZ ALI Trial, the tool results agreed ${ }^{19}$. Similarly, the tool picked up and scored highly those areas that occupants favoured. It was decided that there would no need to change or re-assess any of the weightings as the trial results were acceptably.

\section{Criterion \#5 - Generality}

In general it was found that NZ ALI was able to be applied to a range of different environments representative of typical New Zealand apartments. One occupant stated that although the tool was rather long to complete ide range of making the tool relatively easy to use. The answer lists were intended from the beginning to be able to provide a response for almost every conceivable answer although most probably generalised.

\footnotetext{
${ }^{19}$ The trial of NZ ALI was conducted by the researcher as an experienced user.
} 
There were two issues identified in relation to Criterion \#5. First it was harder to find appropriate answers for apartments that had no internal access, and therefore few internal communal areas. To

Quality Category to determine whether the building had these areas, and if it did not then the respondents were not required to answer any more of those types of questions.

in an

they suggested that two versions of the tool be developed: one for when you buy off plans and one for when you buy as built as some answers would be hard to determine in the first scenario.

\section{Criterion \#6 - User Friendliness}

The apartment occupants were asked four questions as part of their critique of NZ ALI. These were

1.

2. How straight forward is it to use?

3. How objective do you feel the questions and answers are? Are they easily measureable?

4. How practical is NZ ALI? Is the procedure simple and information easily acquired? Is the information too specialist in any way?

Generally, the participants found that NZ ALI was simple and straightforward to use. They commented that it was generally very easy to understand except for technical words (e.g. Emissions and Egress). All occupants commented that it was very long and that it became a bit boring towards the end however as the provided responses covered most scenarios, there was not

Generally they found the question types very easy particularly the drop down lists and Yes/No questions. One occupant did not like the 10 point scale that was initially used as it not have a

$\mathrm{F}$

specifically mentioned specialist words or questions were re-worded; the 10 point scale was changed to a 7 point scale, with 4 as a neutral similar to an ASHRAE scale (Auliciems \& Szokolay, 1997). 


\subsection{VALIDATION OF METHOD}

The research approach to NZ ALI follows the same approach that was used to develop three similar tools Building Quality Assessment [BQA] (Baird, Gray, Isaacs, Kernohan, \& McIndoe, 1995), Building Quality Assessment [BQI] (Ho, et al., 2008), (Wong, Cheung, Yau, Ho, \& Chau, 2006), and Housing Performance of Multi-Family Residential Building tool [HPMFRB] (Kim, Yang, Yeo, \& Kim, 2005). Table 3-7 outlines these tools.

The method used to develop NZ ALI has already been used to develop building assessment tools: it was used for BQA first in 1990. Both BQI and HPMFRB used this method in 2003 and 2005 (respectively). The only difference between the research approaches is how weightings were developed. In following these methods, people who had knowledge and experience within the appropriate fields were asked for their opinions (based on knowledge, experience and expertise) on different criteria in order to determine/develop weightings for each of the levels within NZ ALI. BQA used a simple ranking approach to determine the weightings from the consultation, whereas BQI and HPMFRB both used the Analytic Hierarchy Process [AHP] process.

Table 3-7, Similar BEAT Tools

\begin{tabular}{|l|l|l|l|}
\hline & BQA & BQI & HPMFRB \\
\hline $\begin{array}{l}\text { Scope of } \\
\text { Tool }\end{array}$ & $\begin{array}{l}\text { Developed for New } \\
\text { Zealand and Australian } \\
\text { office and retail spaces. } \\
\text { Assessment of health and } \\
\text { safety. }\end{array}$ & $\begin{array}{l}\text { Developed for high } \\
\text { density apartment living } \\
\text { in Hong Kong. } \\
\text { Two modules within BQI } \\
\text { looking separately at } \\
\text { health and safety (BHHI } \\
\text { and BSCI }{ }^{20} \text { ). }\end{array}$ & $\begin{array}{l}\text { Developed for high density } \\
\text { apartment living in South } \\
\text { Korea. } \\
\text { Assessment of housing } \\
\text { environment, function and } \\
\text { comfort. }\end{array}$ \\
\hline $\begin{array}{l}\text { Assessment } \\
\text { Method \& }\end{array}$ & $\begin{array}{l}\text { Criteria based, weighted hierarchical scheme. } \\
\text { Type }\end{array}$ & $\begin{array}{l}\text { Able to provide single score/rating and performance profile. } \\
\text { Building labelling tool. }\end{array}$ & \\
\hline Research & Hierarchy and components established through literature review. \\
\cline { 2 - 4 } Approach & $\begin{array}{l}\text { Weightings determined } \\
\text { through consultation with } \\
\text { industry professionals } \\
\text { use of ranking system to } \\
\text { determine weightings }\end{array}$ & $\begin{array}{l}\text { Weightings determined through consultation with } \\
\text { industry professionals } \\
\text { Process [AHP] to determine weightings. }\end{array}$ \\
\cline { 2 - 4 } & Credits applied to develop functioning evaluation tool. \\
\hline
\end{tabular}

${ }^{20} \mathrm{BHHI}$ Building Health and Hygiene Index, BSCl Building Safety and Conditions Index 
The AHP has been used widely for many different applications. It is based on three basic principles: decomposition; comparative judgements; and hierarchic composition or synthesis of priorities (Forman \& Gass, 2001). First, decomposition is applied so that the problem or issue is structured as a hierarchy of clusters, sub-clusters, and sub-sub clusters, etc (Forman \& Gass, 2001). Pair-wise comparisons are then used to comparatively judge all elements within a cluster with respect to the parent of that cluster. These comparisons are then used to derive priorities of the elements within the cluster. Finally, synthesis is applied to multiply the local priorities of the elements in a cluster by

Simply speaking, components within a hierarchy are compared against each of the other components within its cluster. Weightings and consistency ratios can be determined from there, which can then be applied to the components of the hierarchy. Internationally AHP has been widely accepted and used since developed by Saaty in the

(Forman \& Gass, 2001).

The ranking system used for BQA is similar to AHP in that each component of the hierarchy is analysed within its cluster. However components are ranked against each other as a group (not compared individually) and then weightings are determined from these results. This provides a simpler and shorter process than AHP to determine weightings.

Initially it was proposed to use AHP to develop the weightings for NZ ALI. However, in investigating the AHP, it was determined that for this research the process would be too time consuming and costly. For example, all participants would be required to undertake pair-wise comparisons on all components of $\mathrm{NZ} \mathrm{ALI,} \mathrm{meaning} \mathrm{approximately} 400$ survey questions would be required, compared to the 88 questions that were finally used.

An example comparison of the Spatiality Section is provided below for each method to show the difference in complexity and time required Table 3-8 give the AHP and Table 3-9 the ranked hierarchy approaches.

Table 3-8, AHP Method - Pair-wise Comparison of each component in Spatiality

\begin{tabular}{|c|l|l|l|}
\hline Question Number & Component A & Vs. & Component B \\
\hline 1. & Occupancy \& Density & Vs. & Size \\
\hline 2. & Occupancy \& Density & Vs. & Shape \\
\hline 3. & Occupancy \& Density & Vs. & Spatiality \\
\hline 4. & Occupancy \& Density & Vs. & Storage \\
\hline 5. & Size & Vs. & Shape \\
\hline 6. & Size & Vs. & Spatiality \\
\hline 7. & Size & Vs. & Storage \\
\hline 8. & Shape & Vs. & Spatiality \\
\hline 9. & Shape & Vs. & Storage \\
\hline 10. & Spatiality & Vs. & Storage \\
\hline
\end{tabular}


Table 3-9, Ranking Method - Ranking of each component in Spatiality

\begin{tabular}{|l|l|l|}
\hline Question Number & Component & Rank \\
\hline \multirow{3}{*}{1.} & Occupancy \& Density & \\
\cline { 2 - 3 } & Size & \\
\cline { 2 - 3 } & Shape & \\
\cline { 2 - 3 } & Spatiality & \\
\hline & Storage & \\
\hline
\end{tabular}

While both methods are equally valid in determining the weightings for ALI, the ranking method was chosen as the best fit for NZALI for the following reasons:

- Early research showed a wide disparity between what the public and academics believed to be important, or placed value on,

- The AHP involved a large number of questions, and could potentially be quite time consuming for participants (particularly if consistency ratios were unacceptable),

- While AHP was used to develop BQI, this only took into account expertise of building professionals. For New Zealand, it was clear that the difference in opinions is great and therefore opinions of different groups should be taken into consideration,

- The ranking method has considerably less questions, is easier to understand and would also be less time consuming,

- The ranking method would allow for a larger participant group and a wider range of participants due to the lower

The development of NZ ALI therefore broadly followed the development method of all three tools; but used ranking to determine component weightings. 


\subsection{SUMMARY OF METHOD}

To summarise, the development of NZ ALI follows the method of three previously developed BEAT $B Q A, B Q I$ and HPMFRB. Each of these BEAT is based on a weighted hierarchy of building features and indicators which are able to provide a single overall score and a set of sub-scores (or performance profile).

Four stages occurred in the development of NZ ALI:

- Framework development

- Factors that influence liveability identified in the literature review were expanded upon and organised into a six level hierarchical framework

- The six levels are Objective, Categories, Sections, Features, Aspects and Indicators

- There are 332 components in total.

- Criterion \#1 was applied.

- Index development

- Assessment methods and the range of answers were determined for each of the 153 Indicators

- Criteria \#2 \& \#3 were applied.

- Index Calibration

- A survey was conducted with 47 participants from identified stakeholder and enduser groups to determine the component weightings

- Index Validation

- A functioning NZ ALI was tested on four apartments and the evaluation results compared to interviews with the apartment occupants regarding how the apartment has affected their liveability

○ Criteria \#4, \#5 and \#6 were applied. 


\section{NZ ALI DEVELOPMENT}

This chapter discusses the development process of the New Zealand Apartment Liveability Index and is presented in three sections. Section 4.1 discusses the six steps of the NZ ALI framework development. Section 4.2 presents the major components of NZ ALI and Section 4.3 discusses the calibration of the tool and presents the weightings determined for the three highest ranking levels of

components of the tool.

\subsection{FRAMEWORK DEVELOPMENT}

The development of the NZ ALI framework was conducted in six steps and this section will outline these steps and shows the important components of the tool. From the literature review along with comparison of academic knowledge and public opinion, six Categories of liveability factors were identified. In total 107 Factors were identified that affect occupant liveability in some way. Within the six Categories the Factors were then grouped into 13 Sections and these became the basis of the NZ ALI structure and are the $2^{\text {nd }}$ and $3^{\text {rd }}$ levels of the hierarchy as shown in Figure $4-1$. The process of developing the initial Factors and groupings produced the framework and required assessments for NZ ALI. Six steps were required in this process as outlined in Figure 4-2. Further detail on how this was applied to each of the Categories and their development can be found in Appendices $\mathrm{C} H$.

Each of the Factors identified from the literature review was firstly re-assessed to ensure that there was no repetition between Factors identified in the academic literature and those from the popular

components of the tool were relevant. At this stage the sixth Category Other was removed from the assessment because the factors associated with it were deemed not relevant to liveability. The factors were then re-grouped and expanded to develop three more levels to the hierarchy: Features; Aspects; and Indicators $\left(4^{\text {th }}, 5^{\text {th }}\right.$, and $6^{\text {th }}$ respectively). There are 332 components in total across the six levels of the hierarchy.

Assessment Methods for each Indicator were identified. Because assessments had to be both practical for users and as objective as possible they were assessed against Criteria

assessments were not possible, it was considered that practical assessments were more important as users would have little expertise and ultimately a liveability assessment has a level of subjectiveness. The final step in the framework development, as shown in Figure 4-2, was to establish how credits would be awarded. This required determining acceptable answers for each assessment that was identified for each indicator. Credits were then awarded depending on the type of assessment and the acceptability of possible answers. Further information on this process is available in Chapter 3 and Appendices $C$ G provides detailed information on the development of each of the five Categories. Appendix $\mathrm{H}$ discusses the sixth Category Other which was removed. 


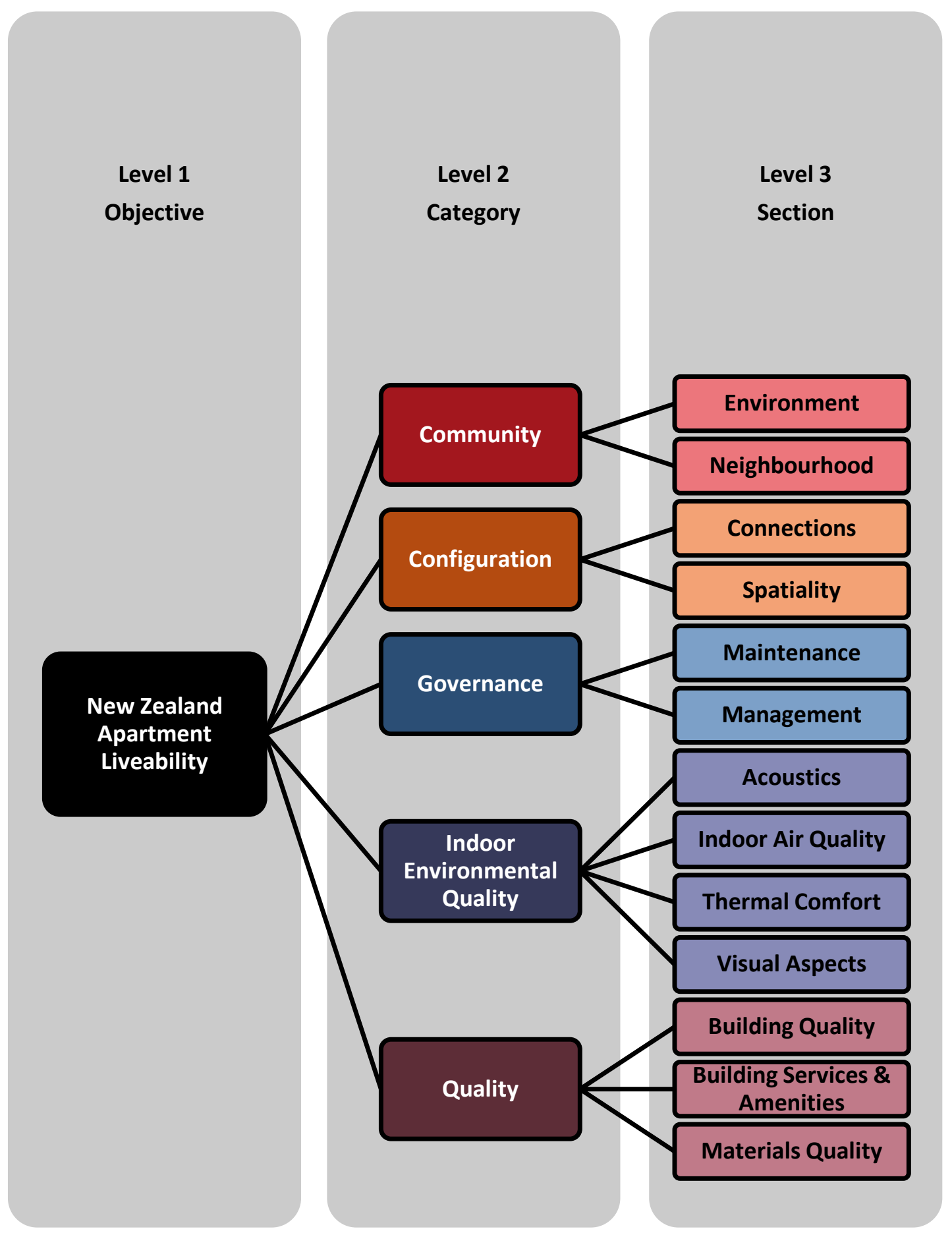

Figure 4-1, Objective, Categories \& Sections Identified in Literature Review 


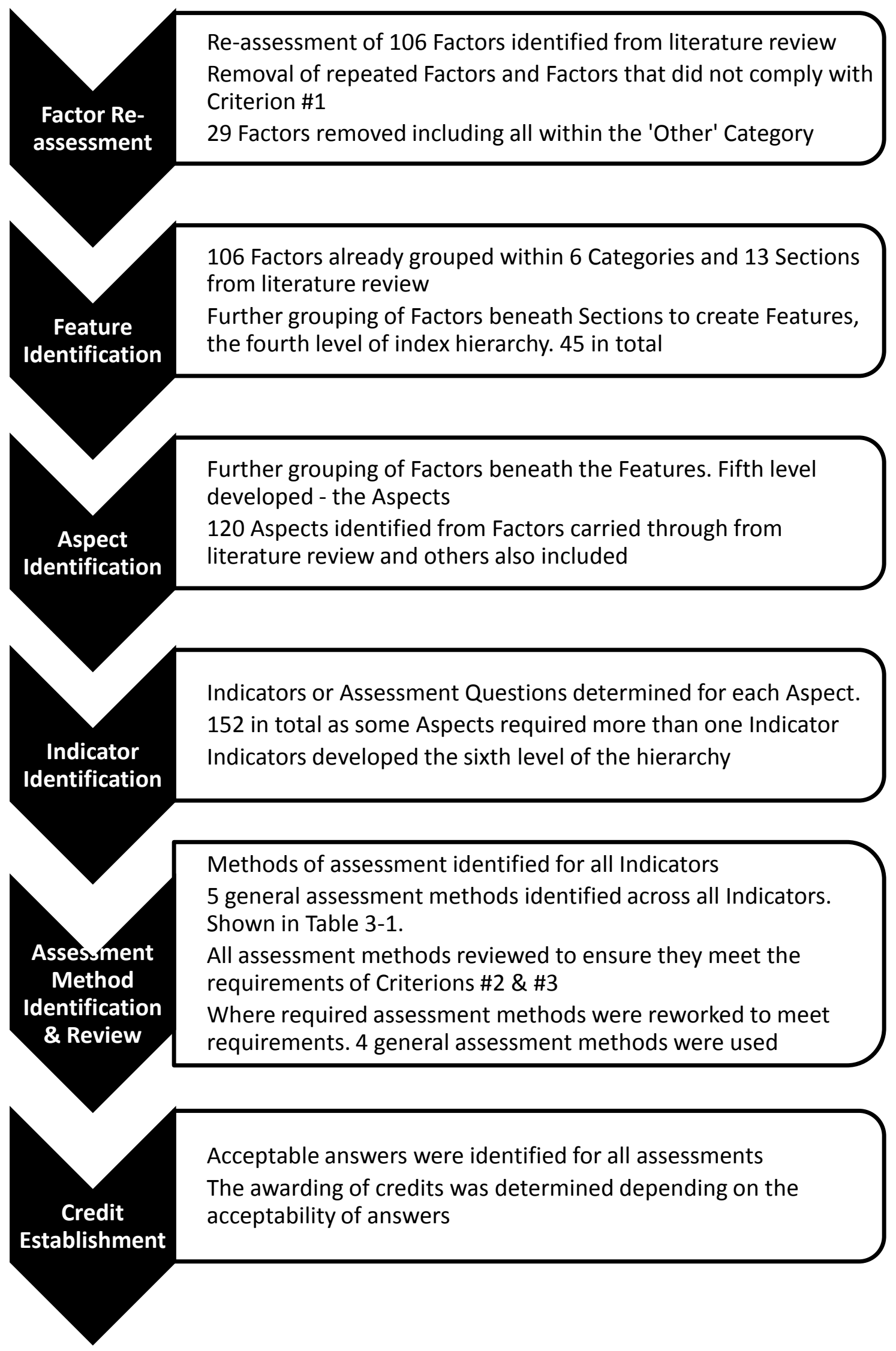

Figure 4-2, NZ ALI Framework Development Process 


\subsection{NZ ALI COMPONENTS}

After the completion of the framework development process the tool comprises 332 components. There are six levels within the hierarchy (from Objective to Indicator) as well as two assessment levels within the Index for each Indicator. Figure 4-3 to Figure 4-7 outlines the major components of

Table 4-9 and Table 4-10 summarise this information outlining the number of associated components and weightings determined from the Index Calibration (discussed in 4.3). Further detail on each of the Categories and their development to the lowest level can be found in Appendices A $\mathrm{H}$.

Community considers factors that deal with the site, the neighbourhood, location and surrounding area shown in Figure 4-3. Factors initially grouped in this Category were re-grouped into two Sections Environment and Neighbourhood. There are a total of $35^{21}$ components within Community. Generally the Community Category was considered to be fixed. Once a site has been chosen for a building, an architect or building user cannot change or affect these factors. Community contributes $13 \%$ of credits to NZ ALI making it the least important Category (refer to Table 4-9).

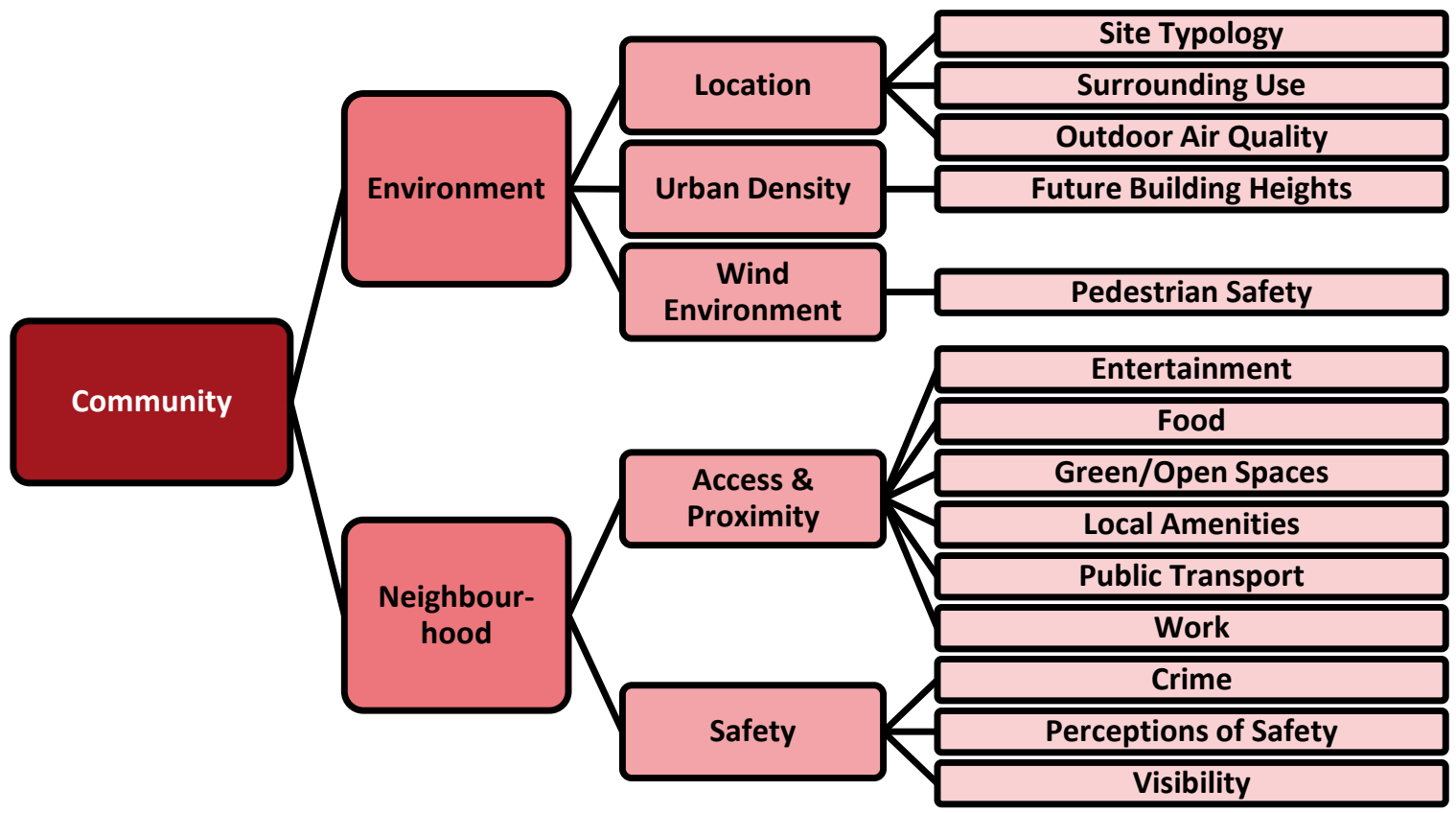

Figure 4-3, NZ ALI Components within Community to Aspect Level

Environment considers issues with the immediate surrounding or environment of a site such as site typology, surrounding use, air quality, urban density and the pedestrian level wind environment. There are 13 components within this Section which contribute up to 53\% of

\footnotetext{
${ }^{21}$ Figure 4-3 depicts only 21 components within Community. However there are another 14 components beneath Aspects within the Indicator Level. This is the same for all components discussed in Section 4.2.
} 
the Community credits. Globally this Section contributes up to $6.9 \%$ of credits to the overall Liveability Rating (Table 4-10).

Neighbourhood is concerned with issues to do with the neighbourhood at large compared to the immediate surroundings. These include safety in the neighbourhood and access to surrounding facilities such as entertainment venues, food services, public transport and work. There are 20 components that contribute up to $47 \%$ locally within Community and $6.1 \%$ globally within the index (Table 4-10).

Configuration takes into account the way that the design of a space affects how a user uses the space, their social interactions and privacy. This is outlined in Figure 4-4. There are 59 components within Configuration which were grouped into two Sections: Connections and Spatiality. Unlike Community, this category is affected during the design phase of the building, but is also fixed once the building has been constructed. Configuration encompasses provision of outdoor space, apartment size, the ability to have privacy as well as interact with other building users as shown in Figure 4-4. It contributes $20 \%$ of credits.

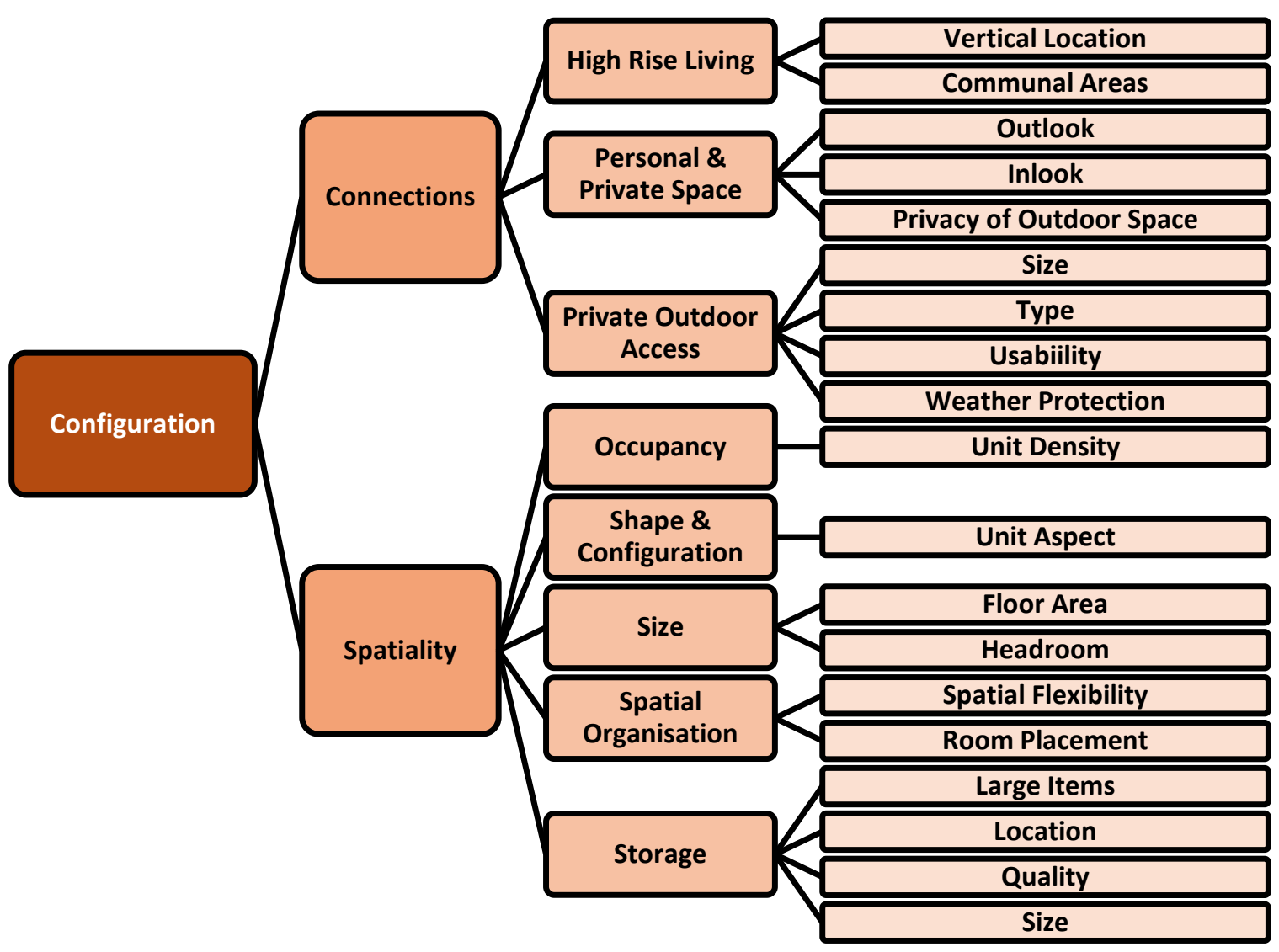

Figure 4-4, NZ ALI Components within Configuration to Aspect Level

Connections deals with_outdoor connections, social connections \& interactions and privacy. There are 24 components within this Section which contribute up to $40 \%$ of Configuration credits and $8 \%$ of all credits globally. 
Spatiality is concerned with issues associated with the size, shape, layout and organisation of the space within the individual apartment unit. There are 33 components within Spatiality that contribute $60 \%$ of Configuration credits and $12 \%$ of credits globally within the index.

Governance is the third NZ ALI Category and encompasses factors associated with the day to day running of a building, its management, organisation, maintenance and cleanliness as shown in Figure 4-5. This is the only category that includes factors that can be changed or affected after the site has been chosen and the building designed and built. This category can be changed because it is the consequence of the practices and organisation of building users and management which can be changed if required. Two Sections were used to re-group the Governance factors Maintenance and Management. Governance contributes $17 \%$ of credits (Table 4-9).

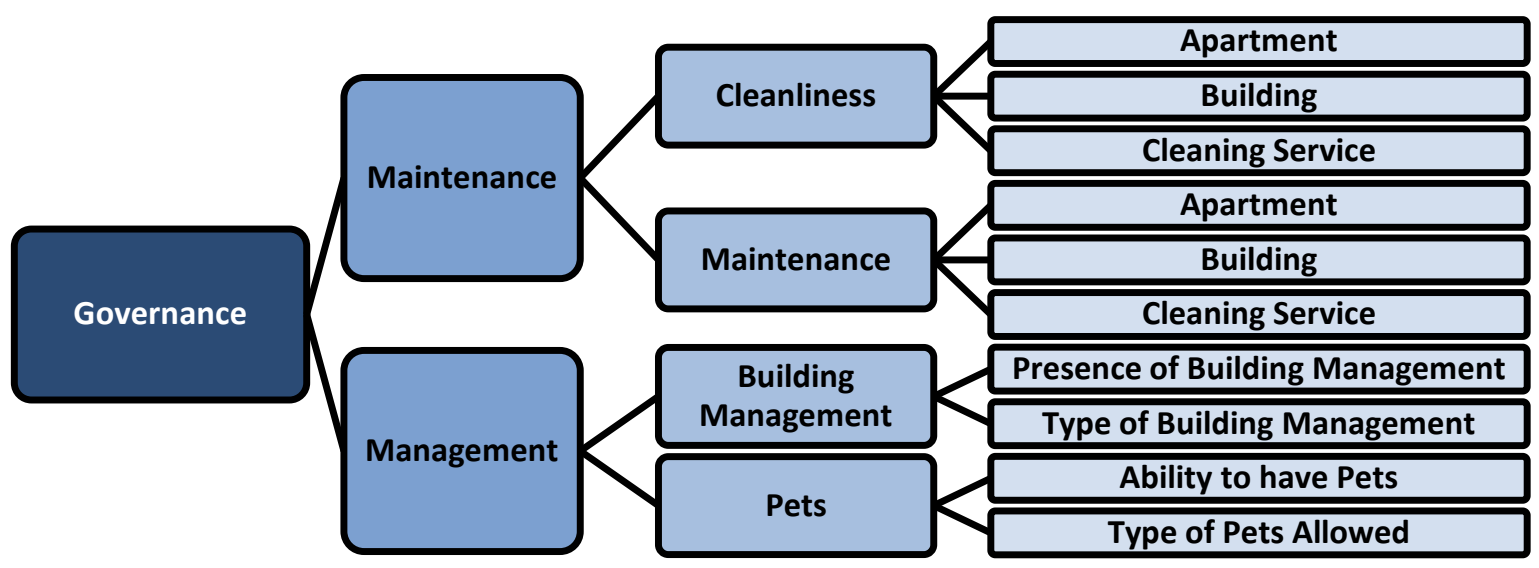

Figure 4-5, NZ ALI Components within Governance to Aspect Level

Maintenance deals with issues surrounding the upkeep of the building and has 14 components associated with it. This Section makes up 57\% of the credits awarded to Governance and contributes $9.7 \%$ to the overall Liveability Rating (Table 4-10).

Management considers issues regarding the running of a building and the management. There are 8 components within this Section which contribute $43 \%$ of credits to Governance and $7 \%$ of credits globally (Table 4-10).

Indoor Environmental Quality [IEQ] considers all aspects of the indoor environment including Acoustics, Indoor Air Quality [IAQ], Thermal Comfort and Visual Aspects (shown in Figure 4-6). Similarly to Configuration, the credits received in the IEQ Category are fixed once a building is designed and built. There is no ability to increase credits in this Category without a retrofit, as the factors considered in IEQ are often tied to the building envelope (i.e. orientation, control of sound, natural lighting). In total there are 78 components within IEQ from the Category level down to the Indicators which have been grouped into four Sections: Acoustics, Indoor Air Quality [IAQ], Thermal Comfort and Visual Aspects. IEQ contributes $25 \%$ of credits. 
Acoustics considers the control of sound, and noise disturbances from inside the building and outside the building. There are 16 components within Acoustics which attribute $27 \%$ of the IEQ credits and $6.8 \%$ of the global credits.

Indoor Air Quality deals with issues surrounding air quality, contamination and ventilation in the individual apartment unit. The 17 components within IAQ represent $25 \%$ of IEQ credits and $6.3 \%$ of credits globally.

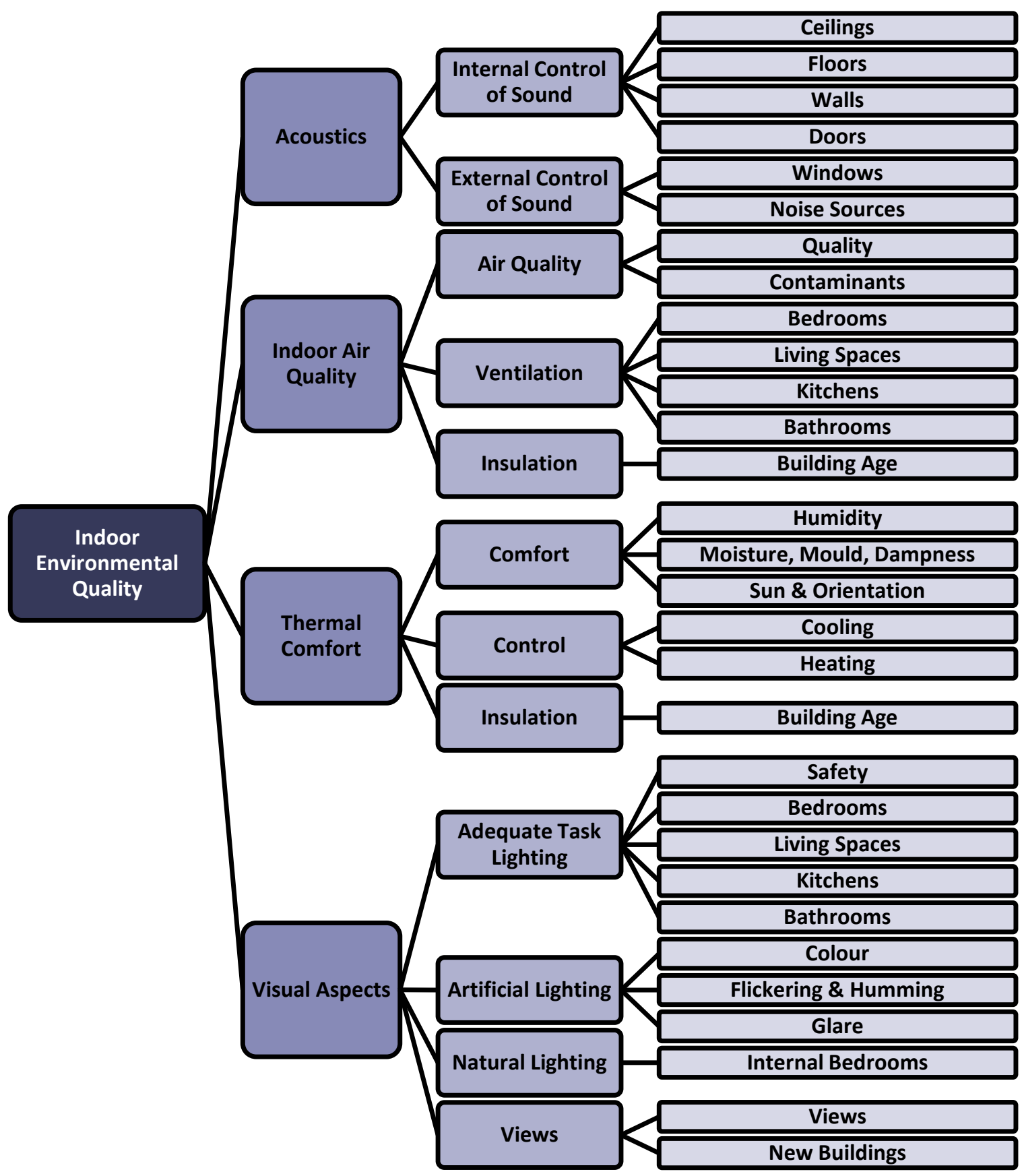

Figure 4-6, NZ ALI Components within Indoor Environmental Quality to Aspect Level

Thermal Comfort considers issues with thermal comfort and personal control over thermal comfort. There are 15 components which contribute up to $30 \%$ of credits to the IEQ Category and $7.5 \%$ to the global Liveability Rating (Table 4-10). 
Visual Aspects, the final Section within IEQ, contributes 26 components and contribute $18 \%$ locally to IEQ and $4.5 \%$ globally to the Liveability Rating. This Category considers issues surrounding the ability to undertake different tasks, artificial lighting, natural lighting and views outlined in Figure 4-6.

Quality is the fifth and final Category within NZ ALI and it considers factors that are concerned with the quality of a building i.e. the construction, materials, building services or facilities that are provided. Like Configuration and Indoor Environmental Quality, Quality is unchangeable once the building is designed and built unless building owners are prepared to pay for an upgrade or retrofit. Quality (shown in Figure 4-7) has 130 components which are grouped into three Sections: Building Quality; Building Services \& Amenities; and Materials Quality. Quality contributes 25\% of credits jointly making it the most important Category along with IEQ (Table 4-9).

Building Quality has 47 components and contributes $41 \%$ of Quality's credits, while globally it contributes $10.3 \%$. It considers the quality of the construction and design of the building such as Airtightness and Safety.

Building Services \& Amenities looks at the services, amenities and facilities that are provided in the building such as communal outdoor areas, lifts and parking. The 67 components within BS\&A contribute $31 \%$ of credits to Quality and $7.8 \%$ globally.

Materials Quality considers issues with the materials and furnishings in a building such as toxic materials and emissions from materials. There are 13 components which provide up to $28 \%$ of credits to Quality and up to $7 \%$ of credits globally. 


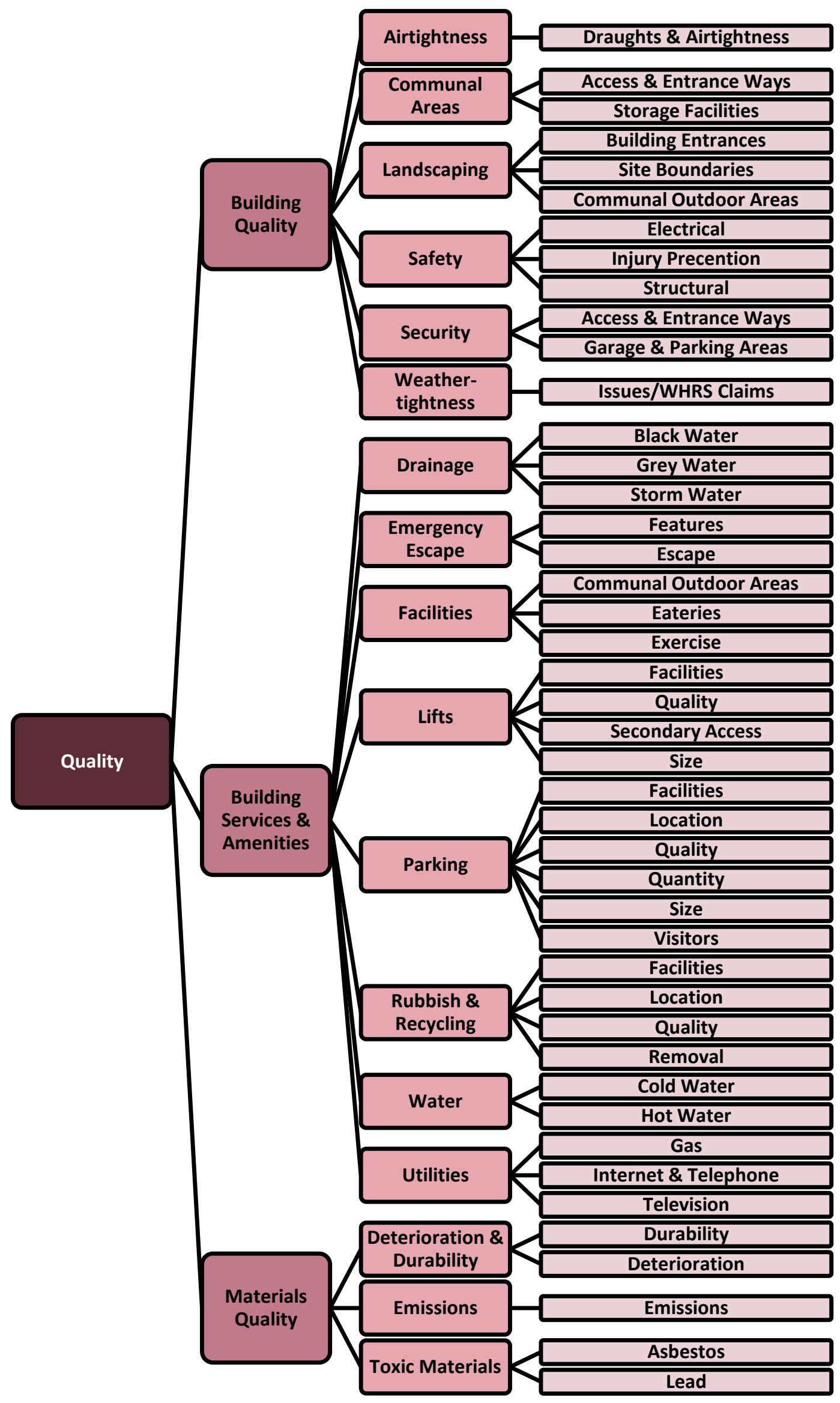

Figure 4-7, NZ ALI Components within Quality to Aspect Level 


\subsection{INDEX CALIBRATION}

six levels nested within the hierarchy and a total of 334 components across the six levels as shown below in Figure 4-8.

- Objective (1 component $N Z A L I)$

○ Category (5 components, i.e. Configuration)

- Section (13 components, i.e. Spatiality)

- Feature (45 components, i.e. Storage)

$\circ \quad$ Aspect (115 components, i.e. Size)

- Indicator (153 components, i.e. Storage Floor Area)

Figure 4-8, NZ ALI Framework and Components

There are a large number of components that need to be assessed in some way, and as a result a large amount of information that needs to be evaluated and then, as Cole notes (1999) once the assessment of a building is complete, the results need to be summarised and communicated to the user. As discussed in Section 3.1 NZ ALI is intended as a building labelling tool to be used for comparison and decision making. Therefore as outlined in Figure 3-1, to ensure that the information provided is relevant both a single score (Liveability Rating) and a performance profile (Liveability Profile) will be used to summarise the evaluation. The advantage of providing both these evaluation options is that a user can have as much or as little information as they need to compare apartments. To achieve this, the index needs to be weighted so that the evaluation can easily be communicated to end-users. Weighting is the mechanism by which a very large number of performance criteria are reduced to a smaller and more manageable number. Myhr (2008) states that

Weighting, as it is an expression of the fundamental values and consequently the overall objective of a tool, is a way to model the relationship between the significance of different criteria or problems, i.e. it is a way to relate the significance of various impacts to each other and in relation to the selected overall objective.

own requirements to the information provided by NZ ALI would make it little more than a framework of assessments that consider liveability in New Zealand apartments. In order to make the tool a simple, effective and user friendly evaluation tool, the components would need to be weighted so that end users could efficiently evaluate and compare different apartments based on a common assessment. By using weighted components within NZ ALI end users could potentially compare apartments either with a single score (Liveability Rating) or a set of sub scores (Liveability Profile). The weighting of the components will effectively calibrate the index turning it from a framework of assessments to a comparative evaluation tool.

In following the approach used in the development and calibration of the BQA, BQI and HPMFRB tools, people who had knowledge and experience within the appropriate fields were asked for their opinions (based on knowledge, experience and expertise) on NZ ALI components in order to develop 
component weightings and calibrate NZ ALI into a functioning BEAT.. All three BEAT consulted with experts or potential end users who undertook surveys that questioned them on their opinions, knowledge, experiences and expertise.

However, the statistical method used for BQA was different to that of BQI and HPMFRB. BQA used a simple Ranking method, whereas BQI \& HPMFRB used the AHP method. As discussed in Section 3.3, the calibration of NZ ALI used a simple Ranking method, similar to that of BQA due to time constraints, survey questions and participant effort required. There are many ways to gauge opinions of knowledgeable and experienced individuals, but a computer based survey was deemed the most appropriate for reasons including anonymity, lack of bias and the large number of participants and information that could potentially be collected.

\subsubsection{NZ ALI QUESTIONNAIRE}

In order to obtain weightings for each of NZ ALI components, a questionnaire was used to survey different groups of people who have experience and knowledge of New Zealand apartments to determine what they consider to be important in relation to liveability. Five groups of people were surveyed from the same six groups identified as end users and stakeholders (refer to Figure 3-1). In total 47 respondents completed the questionnaire. The five participant groups were:

- Building Management, Owners \& Developers [BMOD],

- Designers, Architects \& Consultants [ARCH],

- Regulatory Bodies \& Government Agencies [GOVT],

- Current and previous apartment occupants [OCPT],

- Academics [ACDM].

Figure 3-1 shows that Building Managements and Owners \& Developers are considered to be different stakeholder groups; however for this section of work they have been analysed jointly due to low representation of both groups. Refer to The NZ ALI Questionnaire for more information.

The survey was split into three parts. In Part 1, participants were asked to first consider the Aspect level and choose one Aspect they considered to be the most important for each Feature. They were then asked to consider the Feature level and were required to rank in order of importance each of the Features within a Section (an example is shown in Figure 4-9). Part 2 asked participants to consider the Section level and rank each Section in order of importance within each Category (Figure 4-10). In Part 3, participants were required to do the same again, but ranking the Categories with NZ ALI as shown in Figure 4-11. Part 4 consisted of statistical questions, some are these are shown in Figure 4-12. Ethics Approval was given for this section of the work from the Victoria University of Wellington Human Ethics Committee Ethics Approval No. 16260. Further information on the survey can be found in The NZ ALI Questionnaire and Victoria University of Wellington Ethics Approval which includes the NZ ALI Questionnaire and statistical analysis. 


\section{SPATIALITY}

For the following questions, please select the one Aspect you believe to be the most important when you consider liveability in apartments

This is the fifth level of NZ ALI - the Aspects.

\section{OCCUPANCY \& DENSITY}

Number of occupants per unit

Number of occupants within building

\section{APARTMENT SIZE}

Floor Area

Headroom (floor to ceiling height)

\section{SHAPE \& CONFIGURATION}

Number of external walls $(1,2,3 \ldots)$

Number of external walls with windows $(1,2,3 \ldots)$

\section{SPATIAL ORGANISATION}

Apartment Layout

Proximity of Living Spaces to Kitchens and Bathrooms

\section{STORAGE}

Location (within apartment, within building or offsite)

Quality (free of mould, well ventilated)

Size

Large Item Storage (excess furniture)

For the following question, please rank each in order of importance. 1 is the most important and 5 is the least important. Select $N / A$ if you believe an Aspect has no importance.

This is the fourth level of NZ ALI - the Features.

\begin{tabular}{|l|l|l|l|l|l|l|}
\hline \multicolumn{1}{|c|}{ 6. SPATIALITY } & $\mathbf{1}$ & $\mathbf{2}$ & $\mathbf{3}$ & $\mathbf{4}$ & $\mathbf{5}$ & N/A \\
\hline Occupancy \& Density & & & & & & \\
\hline Apartment Size & & & & & & \\
\hline Shape \& Configuration & & & & & & \\
\hline Spatial Organisation & & & & & & \\
\hline Storage & & & & & &
\end{tabular}

Please include any other additional features you feel effect the SPATIALITY of an apartment building

\section{SPATIALITY}

Figure 4-9, NZ ALI Questionnaire, Part 1 Aspects \& Features Example - Spatiality 


\begin{tabular}{|c|c|c|}
\hline 2. CONFIGURATION & 1 & 2 \\
\hline \multicolumn{3}{|l|}{ Connections } \\
\hline Spatiality & & \\
\hline
\end{tabular}

Figure 4-10, NZ ALI Questionnaire, Part 2 Sections Example - Configuration

\begin{tabular}{|l|c|c|c|c|c|}
\hline \multicolumn{1}{|c|}{$\mathbf{1 .}$ NZ ALI } & $\mathbf{1}$ & $\mathbf{2}$ & $\mathbf{3}$ & $\mathbf{4}$ & $\mathbf{5}$ \\
\hline Community & & & & & \\
\hline Configuration & & & & & \\
\hline Governance & & & & & \\
\hline Indoor Environmental Quality & & & & & \\
\hline Quality & & & & & \\
\hline
\end{tabular}

Figure 4-11, NZ ALI Questionnaire, Part 3 Categories Example - NZ ALI

1. Please circle your age group

\begin{tabular}{|ll|ll|ll|ll|ll|l}
\hline 18 & 24 & 25 & 34 & 35 & 44 & 45 & 54 & 55 & 64 & $65+$ \\
\hline
\end{tabular}

2. Please circle your gender

\begin{tabular}{l|l}
\hline Male & Female \\
\hline
\end{tabular}

3. Please state your city/region in New Zealand

4. Please state your current occupation

5. How long have your worked in that job/industry? (years)

6. Please circle your current dwelling type

\begin{tabular}{|l|l|l|}
\hline Detached & Terraced Housing & Apartment \\
\hline
\end{tabular}

7. How long have you lived in your current dwelling? (years)

Figure 4-12, NZ ALI Questionnaire, Part 4 Statistical Questions Example

\subsubsection{RESULTS AND ANALYSIS}

This section will discuss the perceived importance of the NZ ALI Categories and analysis of stakeholder group data as well as dwelling history data. Further information on the data obtained regarding the NZ ALI Section to Indicator level can be found in Appendices C G.

The data obtained from the NZ ALI Questionnaire was used to determine the weighting of each of components within NZ ALI. Weights were determined by the average importance allocated to each 
component by the correspondents. Each set of components were assigned a total of $100 \%$, e.g. if considering the 3 Aspects under Safety, together they can contribute up to $100 \%$ to Safety. Safety and Access \& Proximity can also contribute up to $100 \%$ to Neighbourhood.

\section{Aspects}

Aspect weightings were based on how the percentage of people who choose an Aspect as being the (refer to

Figure 3-8).

\section{Features, Sections \& Categories}

For Features, Sections, and Categories, participants were asked to rank all components, with one being the lowest or least important. Rankings were not immediately obvious as they were for Aspects because inevitably rankings were varied across components. Therefore because of the ranking variance, a cumulative percentage Equation 4-1 was used to determine the weightings that would be applied to NZ ALI, refer to Figure 3-9 and Figure 3-10.

Equation 4-1, Cumulative Percentage

$$
C W=\frac{C R}{T R} \times 100
$$

$\mathrm{CW}=$ Component weighting

$\mathrm{CR}=$ Sum of all component rankings

$T R=$ Sum of all total rankings (from all components within set)

\subsubsection{NZ ALI CATEGORIES}

Perceived importance was determined for each of the five Categories within NZ ALI ( ${ }^{\text {nd }}$ level of the hierarchy) from Equation 4-1. These are shown in Figure 4-13. Participants placed the highest level of importance on Indoor Environmental Quality with a weighting of $26 \%$ determined from Equation 4-1. Second most important was Quality with $25 \%$ followed by Configuration with $20 \%$. Governance was weighted $17 \%$ and Community was least important with $13 \%$.

The resultant rankings of each of the Categories generally align with the rankings that were anticipated. It was expected that participants would consider Indoor Environmental Quality an important Category due to current issues with acoustics, natural light, views and ventilation in New Zealand apartments. Similarly Quality and Configuration were also anticipated to be important Categories due to the issues that are associated with them. However it was expected that Community would be considered more important than it was because it considers location, the surrounding use and proximity to local amenities which is often cited as a reason people move to higher density urban housing or a reason people enjoy living there. It was expected that Governance would be considered the least important Category but it would appear that participants consider the day to day running and upkeep of a building more important than anticipated. 


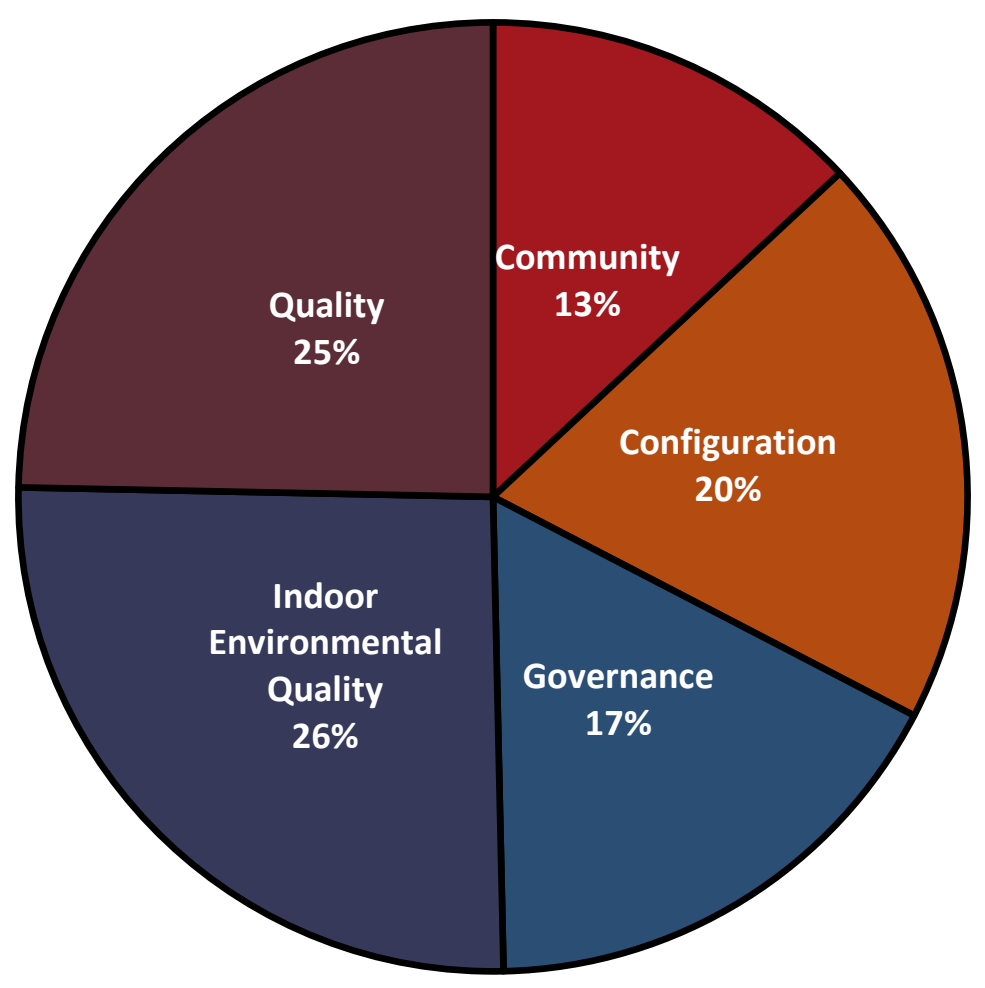

Figure 4-13, Perceived Importance of NZ ALI Categories

The results of the NZ ALI Category ranking show that participants place importance on issues that associated with parts of an apartment building itself rather than issues surrounding the running and upkeep of a building, its site and the location.

\subsubsection{END USER AND STAKEHOLDER GROUP COMPARISON}

The NZ ALI Questionnaire data was also analysed by End-user and Stakeholder groups to determine where any similarities between the five groups occurred and what each of the groups placed importance on. Figure 4-14 shows the perceived importance of each of the NZ ALI Categories analysed by participant groups. For comparison the first column shows the perceived importance of the NZ ALI Categories from all data. There is little difference in the perceived importance of the NZ Ali Categories (determined from Equation 4-1) across the five participant groups. The five participant groups had very similar responses and there is little variance $( \pm 3 \%)$ in perceived importance to the averaged NZ ALI Weighting. 


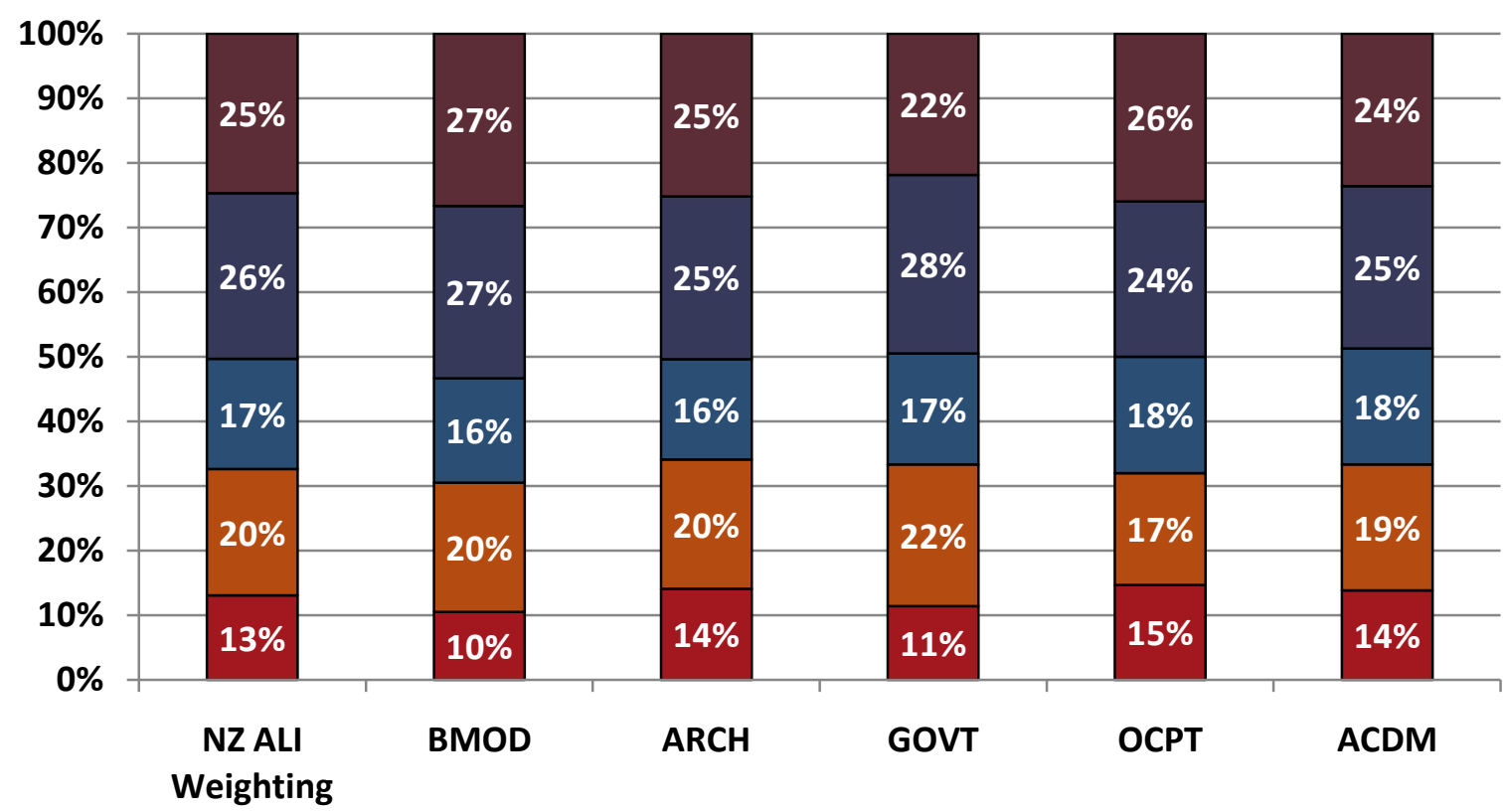

Participant End-User Group

$\square$ Community $\square$ Configuration $\square$ Governance $\square$ Indoor Environmental Quality $\square$ Quality

Figure 4-14, Perceived Importance of NZ ALI Categories - End-User and Stakeholder Group Comparison

Figure 4-15 shows the NZ ALI Category rankings across the five End-user and stakeholder participant groups. A ranking of 1 is the highest and 5 is the lowest. In general the Category rankings are similar between the five groups. All groups found that Community was the least important Category. Perceived importance of Community ranged between $10 \quad$ 15\% with the NZ ALI Weighting $13 \%$.

Governance was ranked fourth by all participant groups except OCPT which found it to be more important and ranked it third. Perceived importance of Governance ranged between $16 \quad 18 \%$. The NZ ALI Weighting was $17 \%$ and the OCPT $18 \%$. GOVT also ranked this at $17 \%$.

Configuration was ranked third from the NZ ALI Questionnaire data with a perceived importance of 20\%. Rankings from the participant groups aligned with this except for GOVT and OCPT. GOVT placed higher importance on Configuration and it was found to be ranked second most important by this group. OCPT on the other hand found Configuration to be less important and ranked it fourth. Perceived importance of Configuration ranged between 17 22\% across the groups with the NZ ALI Weighting sitting at the middle of the range, $20 \%$. GOVT ranked this Category at $22 \%$ and OCPT at $17 \%$. 


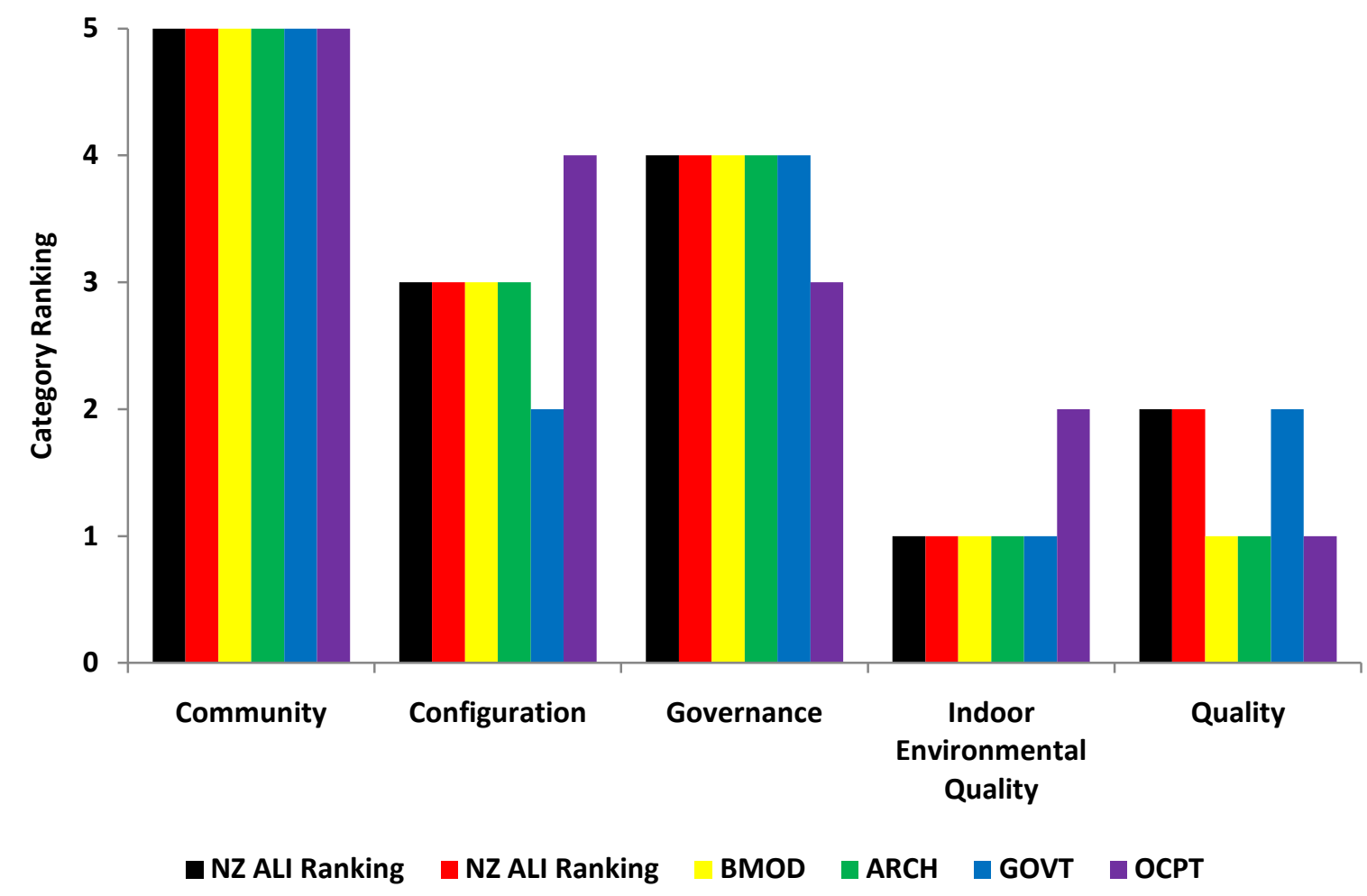

Figure 4-15, NZ ALI Category Ranking - End-User and Stakeholder Group Comparison

Ranked second in the five Categories from the NZ ALI Weighting was Quality. Only two participant groups aligned with this ranking GOVT and ACDM. BMOD, ARCH and OCPT all found this Category to be the most important Category in NZ ALI. GOVT placed equal importance on Configuration and Quality and ranked them both second. This participant group did not have a Category ranked third as a result. The perceived importance of Quality ranged between $22 \quad 27 \%$. The NZ ALI Weighting was $25 \%$, BMOD 27\%, ARCH 25\% and OCPT 26\%.

The NZ ALI Weighting placed Indoor Environmental Quality as the most important Category within NZ ALI. All participant groups except OCPT aligned with this ranking. Both BMOD and ARCH found Indoor Environmental Quality and Quality to be equally most important and did have a Category ranked second. OCPT found Indoor Environmental Quality to be second most important, ranking Quality first instead. The perceived importance of Indoor Environmental Quality ranged between 24 $28 \%$ with the NZ ALI Weighting being $26 \%$, and OCPT $24 \%$.

In general the analysis found that the differing opinions, experiences and knowledge of the five enduser and stakeholder participant groups did not overly affect the importance placed on the five NZ ALI Categories. Perceived importance of each of the categories did not differ significantly across the groups from the NZ ALI weighting. Most of the weightings were within $13 \%$ of the overall average.

Some of these slight differences did however affect the rankings of some Categories across the participant groups. The most affected were the rankings from the OCPT group with ranking differences for all Categories except Community. As the perceived importance of Categories was so similar to the NZ ALI Weightings it is difficult to say whether this group showed any particular difference in opinions due to their experiences of living in apartments. 
All groups did show that, from their experiences, they place the least importance on the Community and the most importance on either Indoor Environmental Quality and/or Quality. This shows that across the groups people find that the surrounding environment and neighbourhood they live in affects their liveability the least, however the indoor environment and quality of a building are the most important things in relation to liveability.

\subsubsection{DWELLING HISTORY COMPARISON}

The NZ ALI Questionnaire data was also analysed by respondent dwelling history to determine where any similarities or differences may occur depending on whether they had lived in apartments before. Figure 4-16 shows the perceived importance of the five NZ ALI Categories analysed by dwelling history, where the participant provided an answer to that question. Three groups are analysed here, participants who had previously lived in an apartment, those who were currently living in an apartment and those who had never lived in an apartment. For comparison the first column shows the perceived importance of the NZ ALI Categories from all data.

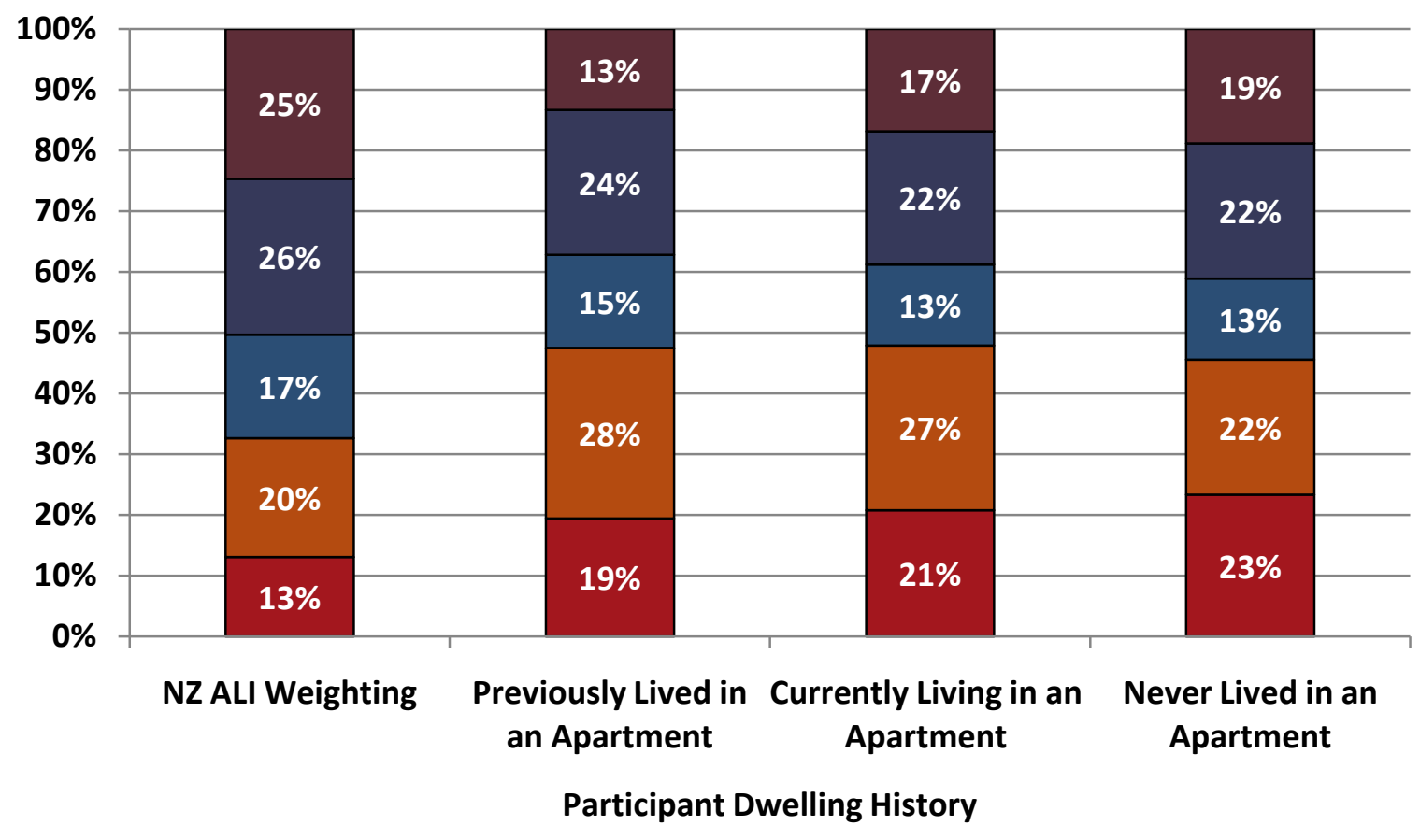

$\square$ Community $\square$ Configuration $\square$ Governance $\square$ Indoor Environmental Quality $\square$ Quality

Figure 4-16, Perceived Importance of NZ ALI Categories - Dwelling History Comparison

Unlike the weightings determined for each of the participant groups, the weightings determined for the dwelling history groups do not align with the overall NZ ALI Weightings. While the ranges of Category weightings across the groups are relatively small the overall NZ ALI Weighting is always either above or below this range depending on the Category as shown in Figure 4-16. 


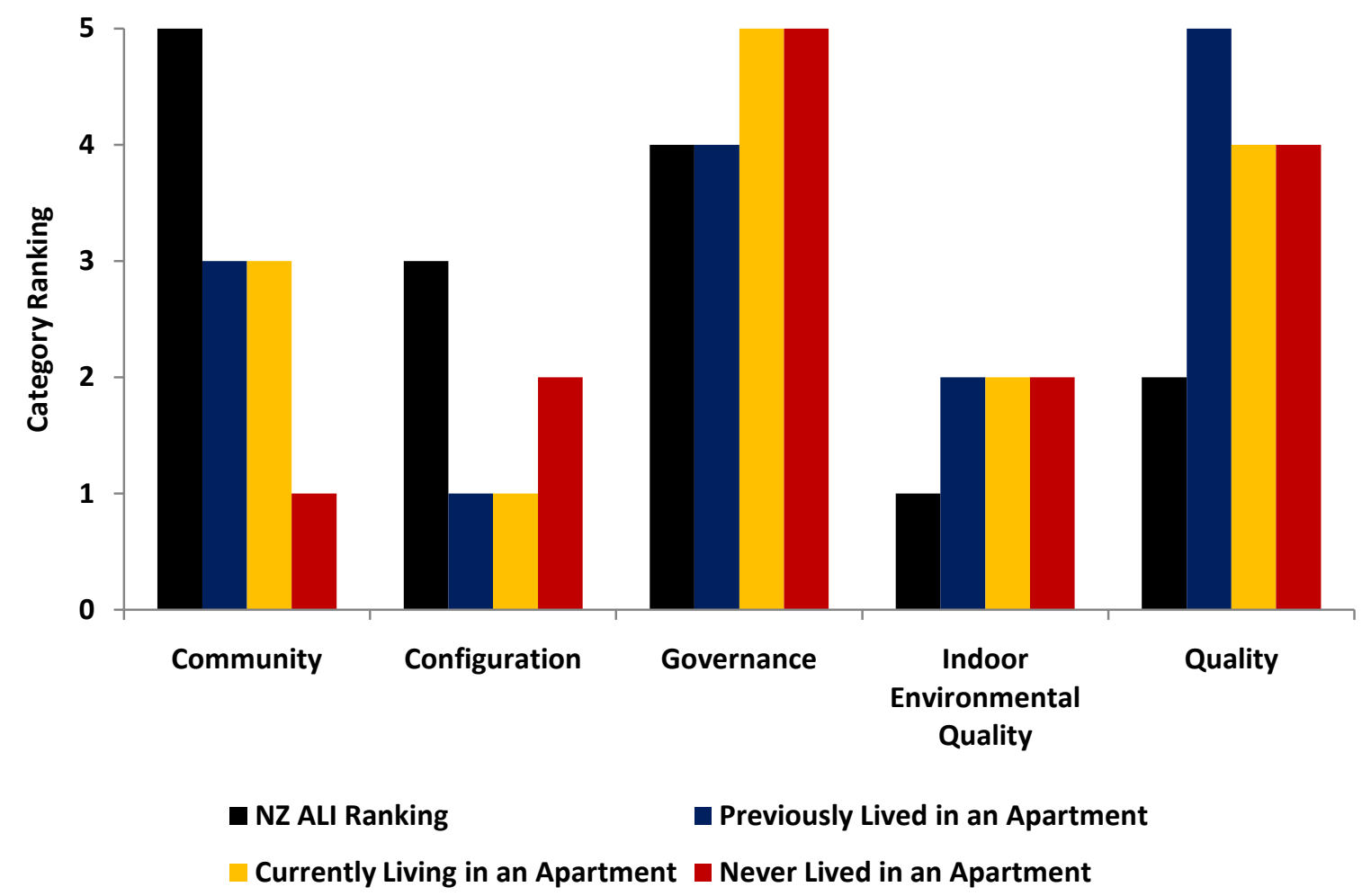

Figure 4-17, NZ ALI Category Ranking - Dwelling History Comparison

Figure 4-17 shows the rankings each Category was placed in from the perceived importance weightings of each dwelling history group. Similarly to the perceived importance the Category rankings were also very different from the NZ ALI Rankings. Community was found to be the least important Category from the NZ ALI Rankings. None of the three dwelling history groups aligned with this ranking. Both current and previous apartment dwellers found Community to be more important and ranked it third. However those participants who have never lived in an apartment found this to be the most important Category. The NZ ALI Weighting for this Category was 13\% but the range between the dwelling history groups was $1923 \%$.

While Governance was ranked fourth through the NZ ALI Rankings, only previous apartment dwellers agreed with this ranking. Both current apartment dwellers and people who have never lived in an apartment found this category to be the least important. The perceived importance weightings ranged from $13 \quad 15 \%$ for Governance while the NZ ALI Weighting for this Category was 17\%.

Ranked third from the NZ ALI Rankings was Configuration. However, all the groups found this Category to be more important. Both current and previous apartment dwellers ranked this as the most important. Those who had never lived in an apartment ranked this as second most important. The range for this Category was $22 \quad 28 \%$. The NZ ALI weighting was $20 \%$.

Quality was found to be the second most important Category from the NZ ALI Questionnaire. However none of these groups align with this all considered this to be much less important. PREVS ranked it as least important and current apartment dwellers and people who have never lived in an apartment ranked it fourth. The range for Quality was $13 \quad 19 \%$ but overall NZ ALI weighted it as $25 \%$. 
Indoor Environmental Quality was found to be the most important Category within NZ ALI. The dwelling history groups found this to be slightly less important with all ranking it second. People who have never lived in an apartment found it to be equally important to Configuration and so ranked no Categories third. The range for this Category was $22 \quad 24 \%$ and overall NZ ALI weighted it as $26 \%$.

When analysed by dwelling history the perceived of each of the NZ ALI Categories is markedly different to the initial overall NZ ALI Weightings determined. Few of the weightings and subsequent rankings align. However it is interesting to note that people who have lived in or are currently living in, an apartment place similar levels of importance on Categories. Both current and previous apartment dwellers ranked Configuration and Indoor Environmental Quality first or second and Community third. They then ranked Governance and Quality fourth or fifth as did people who have never lived in an apartment. These participants however ranked Community as the most important Category and Configuration and Indoor Environmental Quality second. It should be noted however, that, due to the small percentage of participants that made up people who have never lived in an apartment these results are in no way conclusive. It is not surprising that current and previous apartment dwellers both consider Configuration and Indoor Environmental Quality to be the most important Categories as they would have experience and knowledge of the issues associated with these Categories. Also it is understandable that Community was considered the third most important Category as issues associated with Category are often reasons why people choose to live in higher-density urban environments.

These results differ significantly from the overall NZ ALI Weightings and Rankings. They show that people who have lived in apartments before have a different understanding of how they work and

Quality was

perceived to be one of the least important Categories it is not surprising that participants placed the most importance on Configuration and Indoor Environmental Quality due to the apartment issues associated with them.

\subsubsection{APPLICATION OF PERCEIVED IMPORTANCE AS WEIGHTINGS}

Once the NZ ALI Questionnaire was complete, the data was used to apply weightings to each of the NZ ALI Components. In general the perceived importance of NZ ALI components (determined from NZ ALI Questionnaire) was applied to the appropriate components as the weighting. However in some cases the weighting had to be modified. Appendix $\mathrm{C} \quad \mathrm{H}$ provides a detailed explanation of the weightings applied to the NZ ALI components.

Three rules were used in applying weightings to NZ ALI:

- Perceived Importance of less than 3\%

- Indicator Weightings

- Modified Components 


\section{Rule \#1 - Perceived Importance of less than 3\%}

Where a perceived importance was $3 \%$ or less, the component was removed from the index and the remaining weighting distributed evenly among the remaining components. An example of this is the Aspect External Walls without Windows that was initially in the Spatiality Feature Shape \&

Configuration. This received a perceived importance of $2 \%$ in the NZ ALI Questionnaire and External Walls with Windows received $98 \%$. Therefore the former was removed and the latter was given a weighting of $100 \%$ and was renamed Unit Configuration to consider how many walls were external and had windows. This is shown in Table 4-1.

Table 4-1, Weighting Applied to NZ ALI for Shape \& Configuration Aspects following Rule \#1

\begin{tabular}{|l|l|l|}
\hline Shape \& Configuration Aspects & Perceived Importance & NZ ALI Weighting \\
\hline $\begin{array}{l}\text { External Walls with } \\
\text { Windows/Unit Configuration }\end{array}$ & $98 \%$ & $100 \%$ \\
\hline $\begin{array}{l}\text { External Walls without } \\
\text { Windows }\end{array}$ & $2 \%$ & $0 \%$ (removed from NZ ALI) \\
\hline
\end{tabular}

\section{Rule \#2 - Indicator Weightings}

As Indicators were not evaluated in the NZ ALI Questionnaire, the percent of credits they were awarded was based on the number of Indicators within an Aspect. An example of this are Indicators associated with the Apartment Size and Spatial Organisation Features within Spatiality. There are 3 Indicators within Headroom so each received a weighting of $33 \%$ as stipulated by Rule \#2. The four Indicators within Room Placement each receive $25 \%$ as shown in Table 4-2.

Table 4-2, Weightings Applied to NZ ALI Spatiality Aspects with more than one Indicator

\begin{tabular}{|l|l|l|l|}
\hline Feature & Aspect & Indicator & Indicator Weighting \\
\hline \multirow{2}{*}{ Apartment Size } & \multirow{2}{*}{ Headroom } & Habitable spaces & $33 \%$ \\
\cline { 3 - 4 } & & Mezzanine spaces & $33 \%$ \\
\cline { 3 - 4 } & Non-Habitable spaces & $33 \%$ \\
\hline \multirow{2}{*}{ Spatial Organisation } & \multirow{2}{*}{ Room Placement } & Living Room Placement & $25 \%$ \\
\cline { 3 - 4 } & Bedroom Placement & $25 \%$ \\
\hline & $\begin{array}{l}\text { Doors Separating } \\
\text { Toilets \& Kitchens }\end{array}$ & $25 \%$ \\
\cline { 3 - 4 } & $\begin{array}{l}\text { Circulation Spaces \& } \\
\text { Kitchens }\end{array}$ & $25 \%$ \\
\hline
\end{tabular}

\section{Rule \#3 - Modified Components}

Where NZ ALI components were modified, perceived importance was used where possible and any remaining weightings distributed evenly. Within Spatiality one Feature was modified following the NZ ALI Questionnaire Occupancy \& Density. Initially this had two Aspects, Unit Occupancy and 
Building Occupancy however the latter was removed because of similarity to Urban Density. It was determined that this was a pre-made decision to live in a certain density. Unit Occupancy was the only Aspect within this Feature and it received a weighting of $100 \%$ instead of $47 \%$ that was determined from the NZ ALI Questionnaire as required by Rule \#3. Further information on how this affected NZ ALI components can be found in Appendices $\mathrm{C} \mathrm{H}$.

\subsubsection{NZ ALI COMPONENT WEIGHTINGS}

The weightings applied to NZ ALI can be looked at in two ways firstly the Component Weighting and secondly the Global Weighting.

The Component Weighting [CW] is the weighting applied to a component at that level and is generally equivalent to the perceived importance determined from the NZ ALI Questionnaire unless modified.

The Global Weighting is the overall weighting of a component within the index as it contributes to the overall objective.

For example, if Component $\mathrm{A}$ had a $\mathrm{CW}$ of $30 \%$ within the third level of a hierarchy and its parent had a CW of $40 \%$ then its GW would be $12 \%$ - or it contributes $12 \%$ of the final rating because its parent modifies the $\mathrm{CW}(30 \%$ of $40 \%=12 \%)$. Each level of the hierarchy requires a slightly different equation to determine the GW and these are outlined below. The GW of components in the first two levels of NZ ALI (Objective and Categories) is the same as their CW and therefore do not need equations because their parent component does not modify their CW.

Equation 4-2, Section Global Weighting

$$
S . G W=S . C W \times C . C W
$$

Equation 4-3, Feature Global Weighting

$$
F . G W=F . C W \times S . C W \times C . C W
$$

Equation 4-4, Aspect Global Weighting

$$
\text { A. } G W=A . C W \times F . C W \times S . C W \times C . C W
$$

Equation 4-5, Indicator Global Weighting

$$
I . G W=I . C W \times A . C W \times F . C W \times S . C W \times C . C W
$$

Where:

GW = Global Weighting

$\mathrm{CW}=$ Component weighting

$\mathrm{C}=$ Category

$S=$ Section 
$\mathrm{F}=$ Feature

$A=$ Aspect

$I=$ Indicator

Using these four equations Global Weightings were determined for all components within NZ ALI. An example of this is shown for one line of the NZ ALI hierarchy, from Indicator to Objective level within Spatiality and Storage. Note that the associated components of this line in the hierarchy are in bold in the following tables.

Table 4-3, Weightings for NZ ALI Storage Indicators

\begin{tabular}{|c|c|c|c|c|c|c|c|}
\hline $\begin{array}{l}\text { Level } 1 \\
\text { Objective }\end{array}$ & $\begin{array}{l}\text { Level } 2 \\
\text { Category }\end{array}$ & $\begin{array}{l}\text { Level } 3 \\
\text { Section }\end{array}$ & $\begin{array}{l}\text { Level } 4 \\
\text { Feature }\end{array}$ & $\begin{array}{l}\text { Level } 5 \\
\text { Aspect }\end{array}$ & $\begin{array}{l}\text { Level } 6 \\
\text { Indicator }\end{array}$ & $\begin{array}{l}\text { Component } \\
\text { Weighting }\end{array}$ & $\begin{array}{l}\text { Global } \\
\text { Weighting }\end{array}$ \\
\hline \multirow{5}{*}{ NZ ALI } & \multirow{5}{*}{ Configuration } & \multirow{5}{*}{ Spatiality } & \multirow{5}{*}{ Storage } & Location & Location & $100 \%$ & $0.46 \%$ \\
\hline & & & & \multirow[t]{2}{*}{ Size } & Bedrooms & $50 \%$ & $0.17 \%$ \\
\hline & & & & & Size & $50 \%$ & $0.17 \%$ \\
\hline & & & & $\begin{array}{l}\text { Large } \\
\text { Items }\end{array}$ & $\begin{array}{l}\text { Large } \\
\text { Items }\end{array}$ & $100 \%$ & $0.07 \%$ \\
\hline & & & & Quality & Usability & $100 \%$ & $0.58 \%$ \\
\hline
\end{tabular}

Table 4-4, Weightings for NZ ALI Storage Aspects

\begin{tabular}{|l|l|l|l|l|l|l|l|}
\hline $\begin{array}{l}\text { Level 1 } \\
\text { Objective }\end{array}$ & $\begin{array}{l}\text { Level 2 } \\
\text { Category }\end{array}$ & $\begin{array}{l}\text { Level 3 } \\
\text { Section }\end{array}$ & $\begin{array}{l}\text { Level 4 } \\
\text { Feature }\end{array}$ & $\begin{array}{l}\text { Level 5 } \\
\text { Aspect }\end{array}$ & $\begin{array}{l}\text { Component } \\
\text { Weighting }\end{array}$ & $\begin{array}{l}\text { Global } \\
\text { Weighting }\end{array}$ & $\begin{array}{l}\text { Level 6 } \\
\text { Indicators }\end{array}$ \\
\hline \multirow{2}{*}{ NZ ALI } & \multirow{2}{*}{ Configuration } & \multirow{3}{*}{ Spatiality } & \multirow{2}{*}{ Storage } & Location & $32 \%$ & $0.46 \%$ & 1 \\
\cline { 4 - 8 } & & & Size & $23 \%$ & $0.33 \%$ & 2 \\
\cline { 4 - 8 } & & & $\begin{array}{l}\text { Large } \\
\text { Items }\end{array}$ & $5 \%$ & $0.07 \%$ & 1 \\
\cline { 4 - 8 } & & & Quality & $40 \%$ & $0.58 \%$ & 1 \\
\hline
\end{tabular}

Table 4-3 and Table 4-4 show that where Aspects have only one Indicator the Global Weighting remains the same for both Indicator and Aspect (e.g. Large Items). This is also the same when a Feature has only one associated Aspect and Indicator one example of this is Shape \& Configuration which has only one Aspect Unit Configuration which has only one Indicator as discussed in Section 4.3.3. All three of these components have a Global Weighting of $2.88 \%$, shown in As already discussed, the Global Weightings of the Objective and five Categories stay the same as the Component Weighting. Because the Objective is the top level of NZ ALI it has no parent which modifies its CW, meaning its CW and GW are both $100 \%$. Therefore because the CW of the Objective is $100 \%$ it cannot influence the GW of the Categories. Thus the CW and the GW of a Category is the same as shown in Table 4-7and Table 4-8.

Table 4-5. Storage was considered to be the least important Feature within Configuration receiving a Component Weighting of just $12 \%$; therefore its relative importance to NZ ALI is also small with a Global Weighting of just $1.44 \%$. 
Table 4-6 shows that Spatiality has a large relative importance to NZ ALI with a Global Weighting of $12 \%$. Considering there are thirteen Sections within NZ ALI this is proportionally very high. Spatiality has the highest Global Weighting of all Sections and therefore is able to influence the evaluation the most.

As already discussed, the Global Weightings of the Objective and five Categories stay the same as the Component Weighting. Because the Objective is the top level of NZ ALI it has no parent which modifies its $\mathrm{CW}$, meaning its $\mathrm{CW}$ and $\mathrm{GW}$ are both $100 \%$. Therefore because the $\mathrm{CW}$ of the Objective is $100 \%$ it cannot influence the GW of the Categories. Thus the CW and the GW of a Category is the same as shown in Table 4-7and Table 4-8.

Table 4-5, Weightings for NZ ALI Spatiality Features

\begin{tabular}{|c|c|c|c|c|c|c|c|}
\hline $\begin{array}{l}\text { Level } 1 \\
\text { Objective }\end{array}$ & $\begin{array}{l}\text { Level } 2 \\
\text { Category }\end{array}$ & $\begin{array}{l}\text { Level } 3 \\
\text { Section }\end{array}$ & $\begin{array}{l}\text { Level } 4 \\
\text { Feature } \\
\end{array}$ & $\begin{array}{l}\text { Component } \\
\text { Weighting }\end{array}$ & $\begin{array}{l}\text { Global } \\
\text { Weighting }\end{array}$ & $\begin{array}{l}\text { Level } 5 \\
\text { Aspect } \\
\end{array}$ & $\begin{array}{l}\text { Level } 6 \\
\text { Indicators }\end{array}$ \\
\hline \multirow{5}{*}{ NZ ALI } & \multirow{5}{*}{ Configuration } & \multirow{5}{*}{ Spatiality } & Occupancy & $16 \%$ & $1.92 \%$ & 1 & 2 \\
\hline & & & $\begin{array}{l}\text { Shape \& } \\
\text { Configuration }\end{array}$ & $24 \%$ & $2.88 \%$ & 1 & 1 \\
\hline & & & Size & $28 \%$ & $3.36 \%$ & 2 & 5 \\
\hline & & & $\begin{array}{l}\text { Spatial } \\
\text { Organisation }\end{array}$ & $20 \%$ & $2.40 \%$ & 2 & 5 \\
\hline & & & Storage & $12 \%$ & $1.44 \%$ & 4 & 5 \\
\hline
\end{tabular}

Table 4-6, Weightings for NZ ALI Configuration Sections

\begin{tabular}{|l|l|l|l|l|l|l|l|}
\hline $\begin{array}{l}\text { Level 1 } \\
\text { Objective }\end{array}$ & $\begin{array}{l}\text { Level 2 } \\
\text { Category }\end{array}$ & $\begin{array}{l}\text { Level 3 } \\
\text { Section }\end{array}$ & $\begin{array}{l}\text { Component } \\
\text { Weighting }\end{array}$ & $\begin{array}{l}\text { Global } \\
\text { Weighting }\end{array}$ & $\begin{array}{l}\text { Level 4 } \\
\text { Feature }\end{array}$ & $\begin{array}{l}\text { Level 5 } \\
\text { Aspect }\end{array}$ & $\begin{array}{l}\text { Level 6 } \\
\text { Indicators }\end{array}$ \\
\hline \multirow{2}{*}{ NZ ALI } & \multirow{2}{*}{ Configuration } & Connections & $40 \%$ & $8.00 \%$ & 3 & 10 & 11 \\
\cline { 3 - 9 } & & Spatiality & $\mathbf{6 0 \%}$ & $12.00 \%$ & $\mathbf{5}$ & $\mathbf{1 0}$ & $\mathbf{1 8}$ \\
\hline
\end{tabular}

Table 4-7, Weightings for NZ ALI Categories

\begin{tabular}{|c|c|c|c|c|c|c|c|}
\hline $\begin{array}{l}\text { Level } 1 \\
\text { Objective }\end{array}$ & $\begin{array}{l}\text { Level } 2 \\
\text { Category }\end{array}$ & $\begin{array}{l}\text { Component } \\
\text { Weighting }\end{array}$ & $\begin{array}{l}\text { Global } \\
\text { Weighting }\end{array}$ & $\begin{array}{l}\text { Level } 3 \\
\text { Section }\end{array}$ & $\begin{array}{l}\text { Level } 4 \\
\text { Feature }\end{array}$ & $\begin{array}{l}\text { Level } 5 \\
\text { Aspect }\end{array}$ & $\begin{array}{l}\text { Level } 6 \\
\text { Indicators }\end{array}$ \\
\hline \multirow{5}{*}{ NZ ALI } & Community & $13 \%$ & $13.00 \%$ & 2 & 5 & 14 & 14 \\
\hline & Configuration & $20 \%$ & $20.00 \%$ & 2 & 8 & 20 & 29 \\
\hline & Governance & $17 \%$ & $17.00 \%$ & 2 & 4 & 8 & 10 \\
\hline & $\begin{array}{l}\text { Indoor } \\
\text { Environmental } \\
\text { Quality }\end{array}$ & $25 \%$ & $25.00 \%$ & 4 & 11 & 29 & 34 \\
\hline & Quality & $25 \%$ & $25.00 \%$ & 3 & 17 & 44 & 66 \\
\hline
\end{tabular}


Table 4-8, Weightings for NZ ALI Objective

\begin{tabular}{|l|l|l|l|l|l|l|l|}
\hline $\begin{array}{l}\text { Level } 1 \\
\text { Objective }\end{array}$ & $\begin{array}{l}\text { Component } \\
\text { Weighting }\end{array}$ & $\begin{array}{l}\text { Global } \\
\text { Weighting }\end{array}$ & $\begin{array}{l}\text { Level 2 } \\
\text { Category }\end{array}$ & $\begin{array}{l}\text { Level 3 } \\
\text { Section }\end{array}$ & $\begin{array}{l}\text { Level 4 } \\
\text { Feature }\end{array}$ & $\begin{array}{l}\text { Level 5 } \\
\text { Aspect }\end{array}$ & Level 6 \\
\hline Indicators
\end{tabular}




\subsection{NZ ALI WEIGHTINGS}

Table 4-9 and Table 4-10 present the weightings and associated components for the NZ ALI Categories and Sections. The Category with the most components is Quality (130) followed by IEQ with 78. Building Services \& Amenities has the highest number of associated components (67) followed by Building Quality (47). It should be noted that the number of associated components within a Category or Section does not relate to the component or global weightings. These were determined as part of the Index Calibration discussed in Section 4.3. It is interesting to note that Governance has the potential to drastically change Liveability Ratings because of firstly the low number of associated components (24) and secondly it is the only Category that can easily change

Quality and IEQ are less likely to significantly affect an evaluation because they have considerably more associated components (with lower global

Table

4-10 where the global weightings of Sections are outlined.

Table 4-9, NZ ALI Category Weightings and Associated Components

\begin{tabular}{|l|r|r|r|r|r|r|}
\hline \multirow{2}{*}{$\begin{array}{l}\text { Level } 2 \\
\text { Category }\end{array}$} & \multicolumn{2}{|l|}{ Weightings } & Associated Components & \multicolumn{2}{l|}{} \\
\cline { 2 - 8 } & Component & Global & Section & Feature & Aspect & Indicator \\
\hline Community & $13 \%$ & $13 \%$ & 2 & 5 & 14 & 14 \\
\hline Connections & $20 \%$ & $20 \%$ & 2 & 8 & 20 & 29 \\
\hline Governance & $17 \%$ & $17 \%$ & 2 & 4 & 8 & 10 \\
\hline IEQ & $25 \%$ & $25 \%$ & 4 & 11 & 29 & 34 \\
\hline Quality & $25 \%$ & $25 \%$ & 3 & 17 & 44 & 66 \\
\hline
\end{tabular}

Table 4-10, NZ ALI Section Weightings and Associated Components

\begin{tabular}{|l|l|r|r|r|r|r|}
\hline \multirow{2}{*}{$\begin{array}{l}\text { Level 2 } \\
\text { Category }\end{array}$} & Level 3 & \multicolumn{2}{|l|}{ Weightings } & \multicolumn{3}{|c|}{ Associated Components } \\
\cline { 2 - 7 } & Section & Component & Global & Feature & Aspect & Indicator \\
\hline \multirow{3}{*}{ Community } & Environment & $53 \%$ & $6.89 \%$ & 3 & 5 & 5 \\
\cline { 2 - 7 } & Neighbourhood & $47 \%$ & $6.11 \%$ & 2 & 9 & 9 \\
\hline \multirow{3}{*}{ Connection } & Configuration & $40 \%$ & $8.00 \%$ & 3 & 10 & 11 \\
\cline { 2 - 7 } & Spatiality & $60 \%$ & $12.00 \%$ & 5 & 10 & 18 \\
\hline \multirow{3}{*}{ Governance } & Maintenance & $57 \%$ & $9.69 \%$ & 2 & 6 & 6 \\
\cline { 2 - 7 } & Management & $43 \%$ & $7.31 \%$ & 2 & 2 & 4 \\
\hline \multirow{3}{*}{ IEQ } & Acoustics & $27 \%$ & $6.75 \%$ & 2 & 6 & 8 \\
\cline { 2 - 7 } & Indoor Air Quality & $25 \%$ & $6.25 \%$ & 2 & 6 & 9 \\
\cline { 2 - 7 } & Thermal Comfort & $30 \%$ & $7.50 \%$ & 3 & 6 & 6 \\
\cline { 2 - 7 } & Visual Aspects & $18 \%$ & $4.50 \%$ & 4 & 11 & 11 \\
\hline \multirow{2}{*}{ Quality } & Building Quality & $41 \%$ & $10.25 \%$ & 6 & 12 & 29 \\
\cline { 2 - 7 } & Building Services \& & $31 \%$ & $7.75 \%$ & 8 & 27 & 32 \\
\cline { 2 - 7 } & Amenities & $28 \%$ & $7.00 \%$ & 3 & 5 & 5 \\
\cline { 2 - 7 } & Materials Quality & & & & \\
\end{tabular}


New Zealand Apartment Living: Developing a Liveability Index 


\section{INDEX VALIDATION}

This chapter outlines the method used to validate NZ ALI. Validation of the tool is required to ensure the tool is fit for purpose by meeting the development criteria. This stage of the research ensured that the methodology is appropriate for developing an apartment liveability evaluation tool for New Zealand. Section 5.1 outlines the validation method and the development criteria assessed in this stage of the research. Section 5.2 discusses the NZ ALI Validation results and Section 0 discusses how each of the applicable development criteria were assessed and met.

\subsection{NZ ALI VALIDATION METHOD}

The development process required that the NZ ALI tool be validated to ensure that it is fit for purpose and able to provide accurate, useful evaluations of how liveability may be affected in New Zealand apartments. Six development criteria were applied to the tool to ensure that it is usable and applicable for end users. As discussed in the previous chapter (4), three of these Criteria have already been applied (Criteria \#1, \#2 and \#3 Relevant, Objective and General). The purpose of the NZ ALI validation was to ensure that it meet the remaining development criteria. These are:

4. Accurate

Results provided should be representative of how liveability may affect most people.

5. General

The index should be applicable to different environments within New Zealand and representative of typical New Zealand apartments at present and in the near future

6. User Friendly

The tool should be easy to use, easy to understand and straightforward for users

The purpose of the NZ ALI Validation was two-fold. Firstly it was to trial the tool and to determine whether the resulting evaluation and rating of an apartment correlated with how the occupants feel their liveability has been affected (Criterion \#4). This involved both a trial of the tool on an apartment and an occupant interview to discuss liveability. Criterion \#5 was also assessed in the trial. The second purpose of the $v$ needs (Criterion \#6) which was assessed through a user critique.

\subsubsection{NZ ALI TRIAL}

The trial looked at how effective the tool is in meeting the requirements of Criteria \#4 and \#5 (Accurate and General). The method used was firstly to trial the tool on a variety of apartments to evaluate how liveability may be affected by them. The tool was trialled on each of the apartments by the author. 
perceived their

lives had been affected by their apartment. The interview was conducted in two parts first a series of statistical questions about the occupants. Questions pertaining to the occupants such as demographics were asked as well as questions about dwelling history of occupants and features of the apartments. There was then an open discussion with the occupants where they were given topics to consider and discuss. Each of the 13 NZ ALI Sections was discussed in turn with prompts and guidance given only from Features and Aspects. It was important to have each personal views and experiences discussed.

From both the trial and interview it was possible to evaluate how accurate the tool was at predicting how liveability may be affected in an apartment. Similarly it was also possible to determine how general the tool s questions were and whether they were applicable to a range of apartments, locations and environments. NZ ALI Trial \& Critique provides full details on the validation method, interview and results of the NZ ALI Validation.

\section{Criterion \#4 - Accurate}

Accuracy of NZ ALI was assessed by comparing how well the trial and interview results aligned where issues were identified in the interview they had to also be identified in the liveability

profiles that the NZ ALI Trial predicted should closely relate to what the occupants discussed in the Interviews. The tool should be able to highlight any liveability issues (e.g. ventilation) which should also align with occupants issues, like or dislikes. Because liveability is a very personal issue, it was not expected that the tool predictions would be perfectly accurate for every occupant. However, NZ ALI should be able to provide a general evaluation of an apartment liveability and guidance on how people may be affected. If the right components have been selected and included within NZ $A L I$, then the resulting evaluation from the trial should provide similar results to the open discussion with occupants in the interview.

\section{Criterion \#5 - General}

Generality of NZ ALI was assessed by applying the tool to a range of apartment types in the trial and analysing how well it could be applied to all these apartments i.e. how well the questions and possible answers covered all aspects the tool must be capable of being applied to a range of different environments and to a range of apartment types. For example, this would include retrofits, existing buildings, new buildings, evaluations from plans and documentation, three storey buildings to twenty storey buildings and so on.

\subsubsection{NZ ALI CRITIQUE}

The second stage of the validation required the tool to be critiqued by end-users to ensure that it met the requirements of Criterion \#6 User Friendly. The NZ ALI Critique used the same apartment occupants from the NZ ALI Interviews to trial the tool then provide feedback on the

- The usability of the tool 
- Objectivity of questions

- Practicality of NZ ALI

Further information on the NZ ALI Critique can be found in NZ ALI Trial \& Critique including Critique questions asked and results.

\section{Criterion \#6 - User Friendly}

straightforward. All the components, including Questions and Assessment Methods, should be easily understood by users. Similarly required answers should be easily acquired and not specialised in any way. Users should be able to make any required measurements themselves and understand resulting ratings, evaluations and predicted liveability effects. 


\subsection{NZ ALI TRIAL \& INTERVIEW}

This section will discuss the NZ ALI Trial and Interview conducted as part of the NZ ALI Validation. Participants of the NZ ALI interview and critique are outlined as well as the apartments included within the trial. The NZ ALI trial results and interview discussions are presented and then compared to determine how well the NZ ALI evaluation aligns with the occupant discussions about the liveability of their apartments. The NZ ALI trial was also assessed to determine how easily it can be applied to a range of apartments. This was an essential step in the tool development as it helped to ensure accuracy in the liveability predictions and evaluations and to assess the generality of the tool.

\subsubsection{PARTICIPANTS AND APARTMENTS}

The NZ ALI Validation Assessment was conducted on four apartments, with all six of the occupants

A high-end apartment is considered to be of better quality, more expensive and luxurious. A low-end apartment is by comparison a cheaper, less expensive and lower quality apartment

Ethics Approval was given for this section of the research from the Victoria University of Wellington Human Ethics Committee Ethics Approval No. 16431 (refer to Victoria University of Wellington Ethics Approval). Table 5-1 and Table 5-2 provide summaries of the apartments used for the NZ ALI Trial and the participants who took part in both the NZ ALI Trial and NZ ALI Critique. The NZ ALI Validation was carried out in May 2009. 
Table 5-1, Apartments included in NZ ALI Trial

\begin{tabular}{|c|c|c|c|c|}
\hline Key for Graphs & Apartment 1 & Apartment 2 & Apartment 3 & Apartment 4 \\
\hline $\begin{array}{l}\text { Year Built/Last } \\
\text { Refurbished }\end{array}$ & 1995 & 1990 & 1990 & 2000 \\
\hline No. Bedrooms & 1 & 2 & 6 & 3 \\
\hline Size & $35 m^{2}$ & $95 \mathrm{~m}^{2}$ & $150 \mathrm{~m}^{2}$ & $150 \mathrm{~m}^{2}$ \\
\hline No. Occupants & 1 & 3 & 6 & 2 \\
\hline $\begin{array}{l}\text { Occupants } \\
\text { Interviewed }\end{array}$ & Occupant A & $\begin{array}{l}\text { Occupant B } \\
\text { Occupant C }\end{array}$ & Occupant D & $\begin{array}{l}\text { Occupant E } \\
\text { Occupant F }\end{array}$ \\
\hline Apartment Type & Low end & Mid range & Low end & High end \\
\hline Rent/week ${ }^{22}$ & $\$ 240$ & $\$ 400$ & $\$ 660$ & $\$ 600$ \\
\hline Surrounding Use & Residential & Commercial & Commercial & Entertainment \\
\hline Vertical Location & Ground Floor & First Third Floor & First Third Floor & $\begin{array}{l}\text { Fourth Sixth } \\
\text { Floor }\end{array}$ \\
\hline Outdoor Access? & No & Yes & No & Yes \\
\hline Aspect & Double & Single & Triple & Double \\
\hline $\begin{array}{l}\text { Building } \\
\text { Management? }\end{array}$ & Yes & Yes & No & Yes \\
\hline Acoustics Issues? & Yes & Yes & No & No \\
\hline IAQ Issues? & Yes & No & Yes & No \\
\hline Main Orientation & East & West & West & North \\
\hline $\begin{array}{l}\text { Adequate } \\
\text { Natural Light }\end{array}$ & Yes & No & No & Yes \\
\hline Access Type & $\begin{array}{l}\text { Key only with } \\
\text { unrestricted, } \\
\text { individual and } \\
\text { horizontal access }\end{array}$ & $\begin{array}{l}\text { Pin \& Key with } \\
\text { unrestricted, } \\
\text { communal and } \\
\text { horizontal access }\end{array}$ & $\begin{array}{l}\text { Key only with } \\
\text { unrestricted, } \\
\text { individual and } \\
\text { vertical access }\end{array}$ & $\begin{array}{l}\text { Pin \& Key with } \\
\text { unrestricted, } \\
\text { communal and } \\
\text { horizontal access }\end{array}$ \\
\hline
\end{tabular}

\footnotetext{
${ }^{22}$ For the apartments that were not rented, occupants were asked to estimate how much they might rent their apartment for per week
} 
Table 5-2, Apartment Occupants who Participated in NZ ALI Trial \& Critique

\begin{tabular}{|c|c|c|c|c|c|c|}
\hline$\stackrel{\text { ì }}{\frac{\hat{k}}{3}}$ & 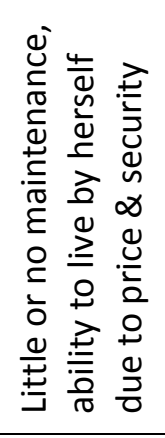 & 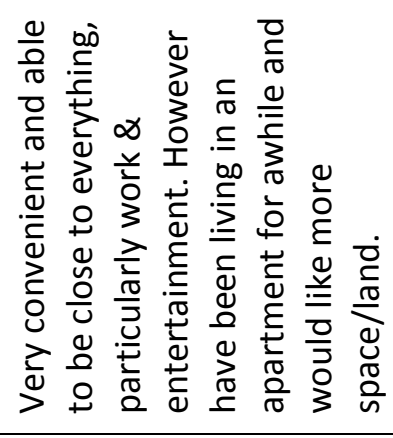 & 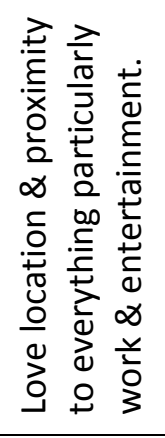 & 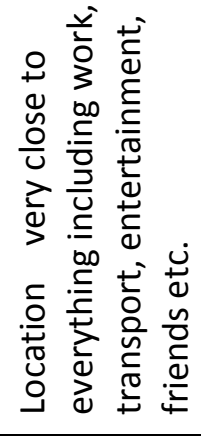 & 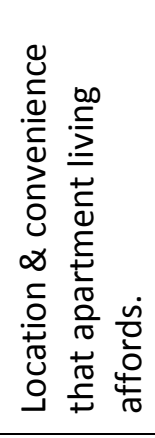 & 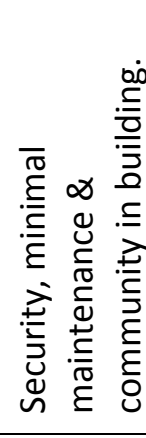 \\
\hline 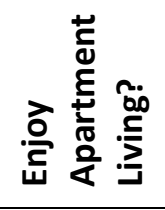 & $\stackrel{\Perp}{\nu}$ & $\begin{array}{l}2 \\
2 \\
0 \\
\frac{0}{\pi} \\
y \\
\stackrel{y}{\nu}\end{array}$ & $\stackrel{\Perp}{\nu}$ & $\stackrel{\check{\Perp}}{\rightleftharpoons}$ & $\stackrel{\check{\Perp}}{\rightleftharpoons}$ & $\stackrel{\check{\Perp}}{\rightleftharpoons}$ \\
\hline 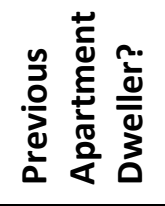 & 우 & 2 & 2o & 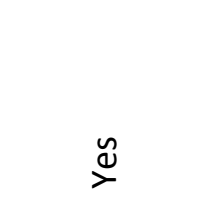 & z & 2o \\
\hline 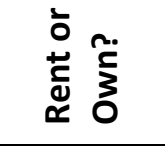 & $\begin{array}{l}\overrightarrow{\widetilde{\varpi}} \\
\propto \\
\propto\end{array}$ & క్ & క & $\begin{array}{l}\tilde{\bar{\varpi}} \\
\propto\end{array}$ & క్ & $\widehat{\jmath}$ \\
\hline 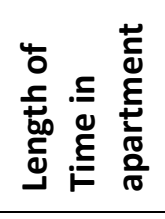 & 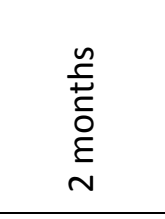 & $\begin{array}{l}\stackrel{n}{\pi} \\
\stackrel{N}{\Perp} \\
\end{array}$ & $\begin{array}{l}\frac{n}{\pi} \\
\stackrel{\varpi}{\Perp} \\
m\end{array}$ & 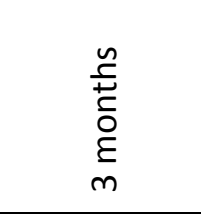 & $\begin{array}{l}\stackrel{n}{\pi} \\
\stackrel{N}{\Perp} \\
\end{array}$ & 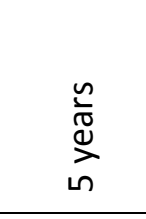 \\
\hline 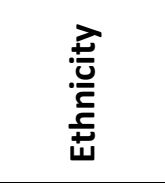 & N & 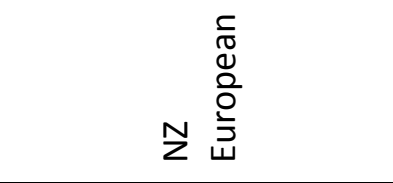 & 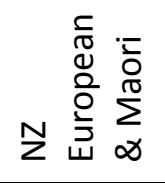 & 之 & № & 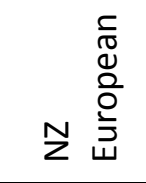 \\
\hline 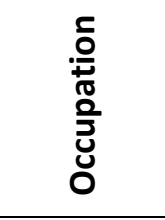 & $\begin{array}{l}\frac{\pi}{0} \\
\frac{\pi}{\pi} \\
\frac{\pi}{\pi} \\
\frac{\pi}{\alpha} \\
\frac{\pi}{\alpha}\end{array}$ & 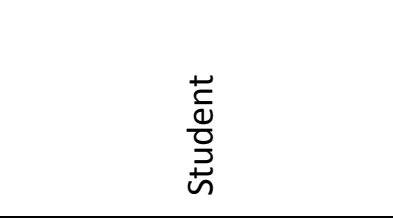 & 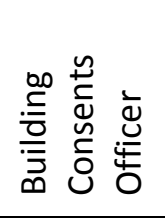 & 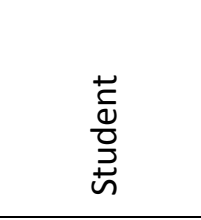 & 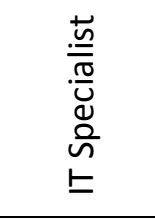 & $\begin{array}{l}\frac{0}{E} \\
\frac{0}{0} \\
\frac{\pi}{4}\end{array}$ \\
\hline 品 & $\stackrel{\sim}{\sim}$ & q & $\stackrel{m}{m}$ & $\stackrel{m}{\sim}$ & 8 & 㶽 \\
\hline 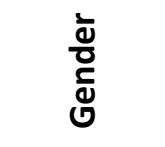 & 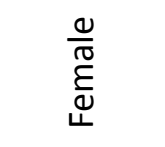 & $\frac{\frac{\varrho}{\pi}}{\sum \frac{\pi}{\pi}}$ & 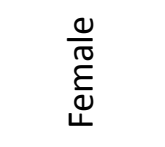 & 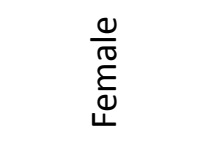 & $\frac{\frac{0}{\pi}}{\sum \frac{\pi}{\pi}}$ & 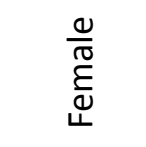 \\
\hline 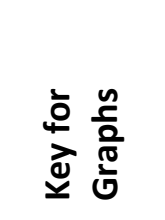 & 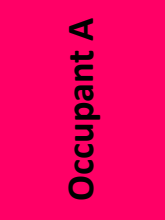 & 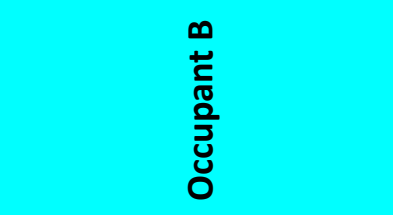 & 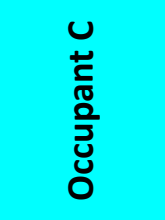 & 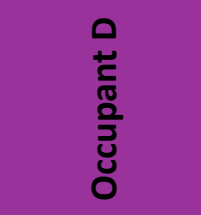 & 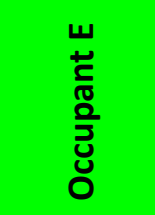 & 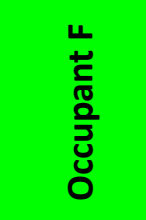 \\
\hline
\end{tabular}




\subsubsection{NZ ALI TRIAL \& INTERVIEW RESULTS}

NZ ALI was first trialled on each of the four apartments. Figure 5-1 shows the overall Liveability Rating for each apartment. Figure 5-2 shows the NZ ALI Category profile for each apartment. Figure 5-1 shows the NZ ALI Section profile for each apartment. Apartment 1 is shown in pink, apartment 2 in blue, apartment 3 in purple and apartment 4 in green in all figures.

The six apartment occupants were then involved in an open discussion about the apartments, particularly concentrating on how they feel their liveability has been affected by living in their apartment. A summary of these discussions can be found in NZ ALI Trial \& Critique. Table 5-3 outlines the key issues determined from each of the interviews.

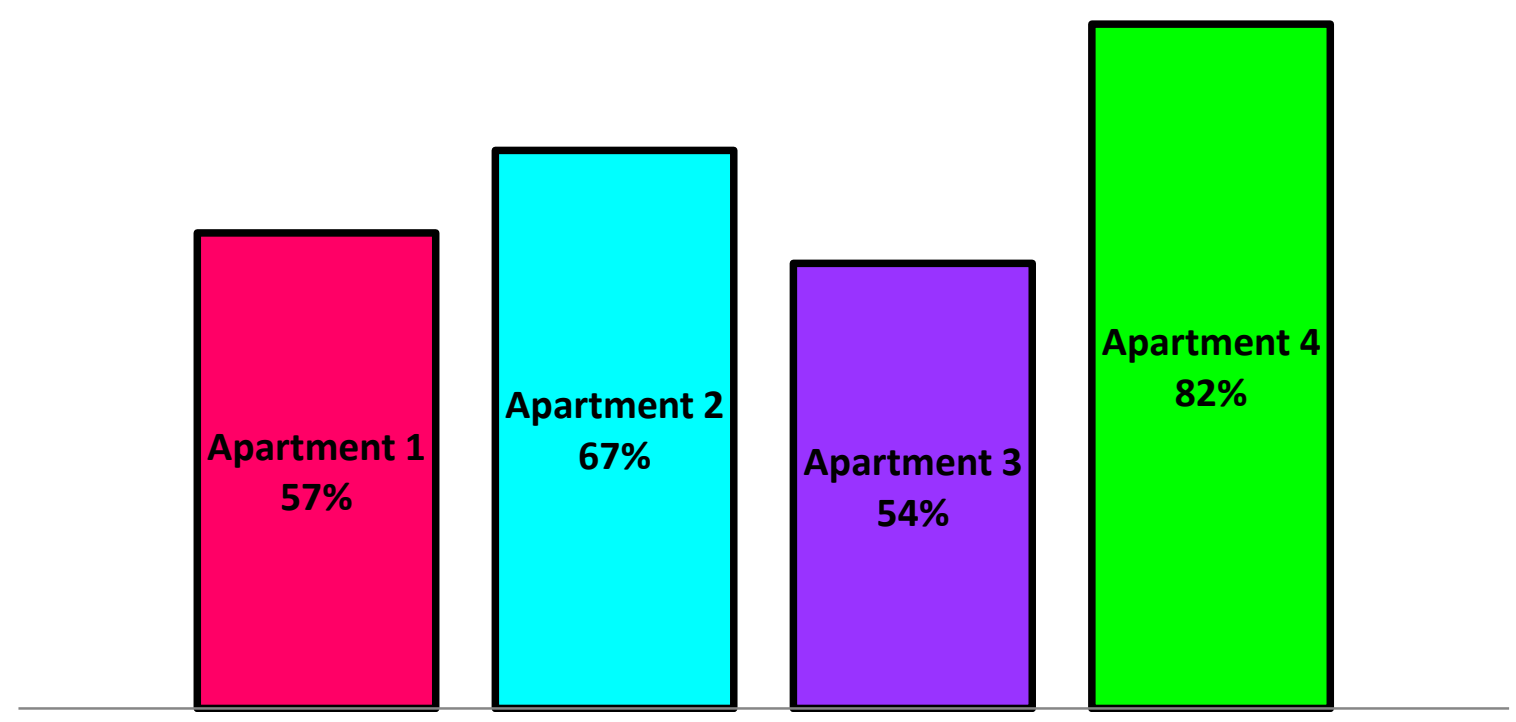

NZ ALI Liveablity Profile

Figure 5-1, NZ ALI Ratings for Apartments included within NZ ALI Trial 


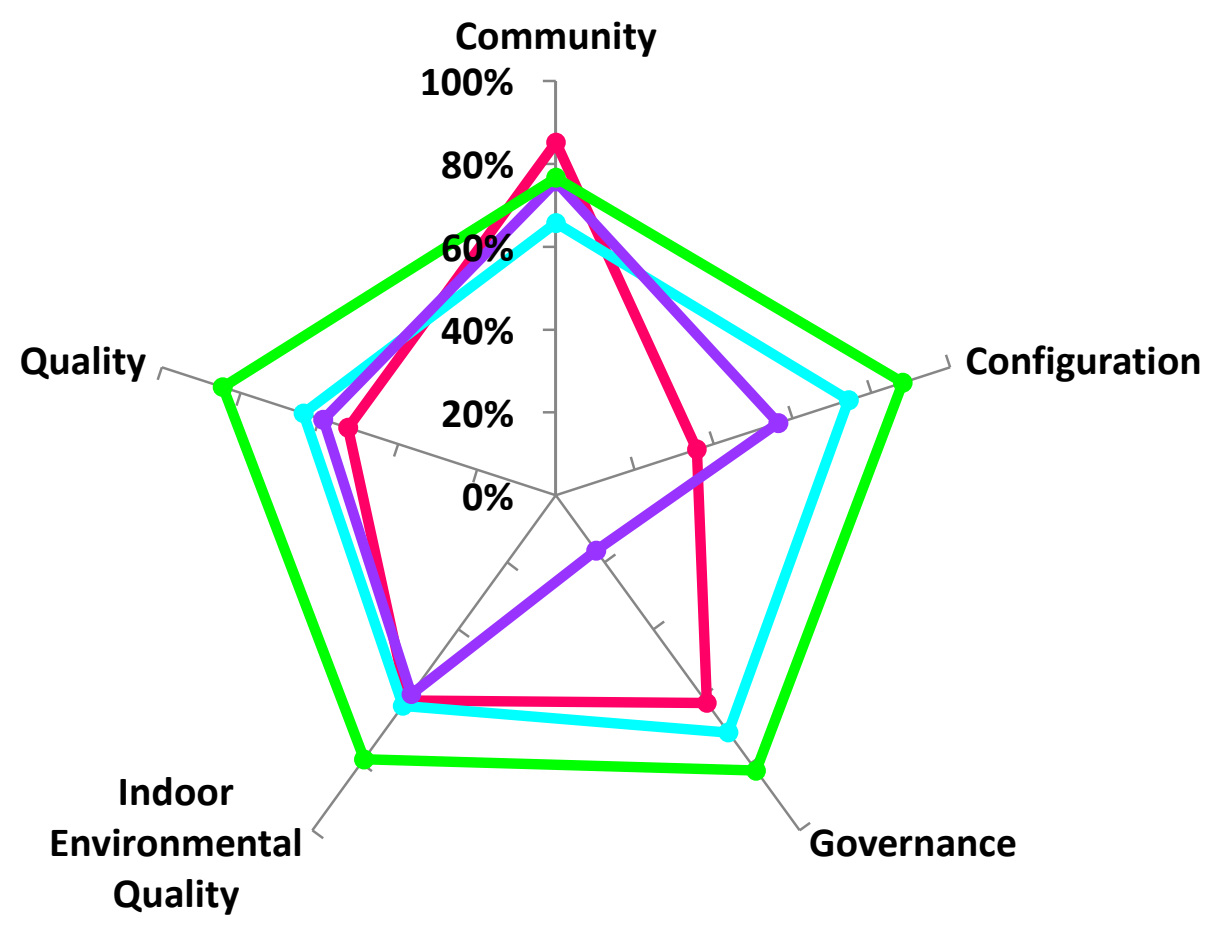

Figure 5-2, NZ ALI Category Profiles for Apartments included within NZ ALI Trial

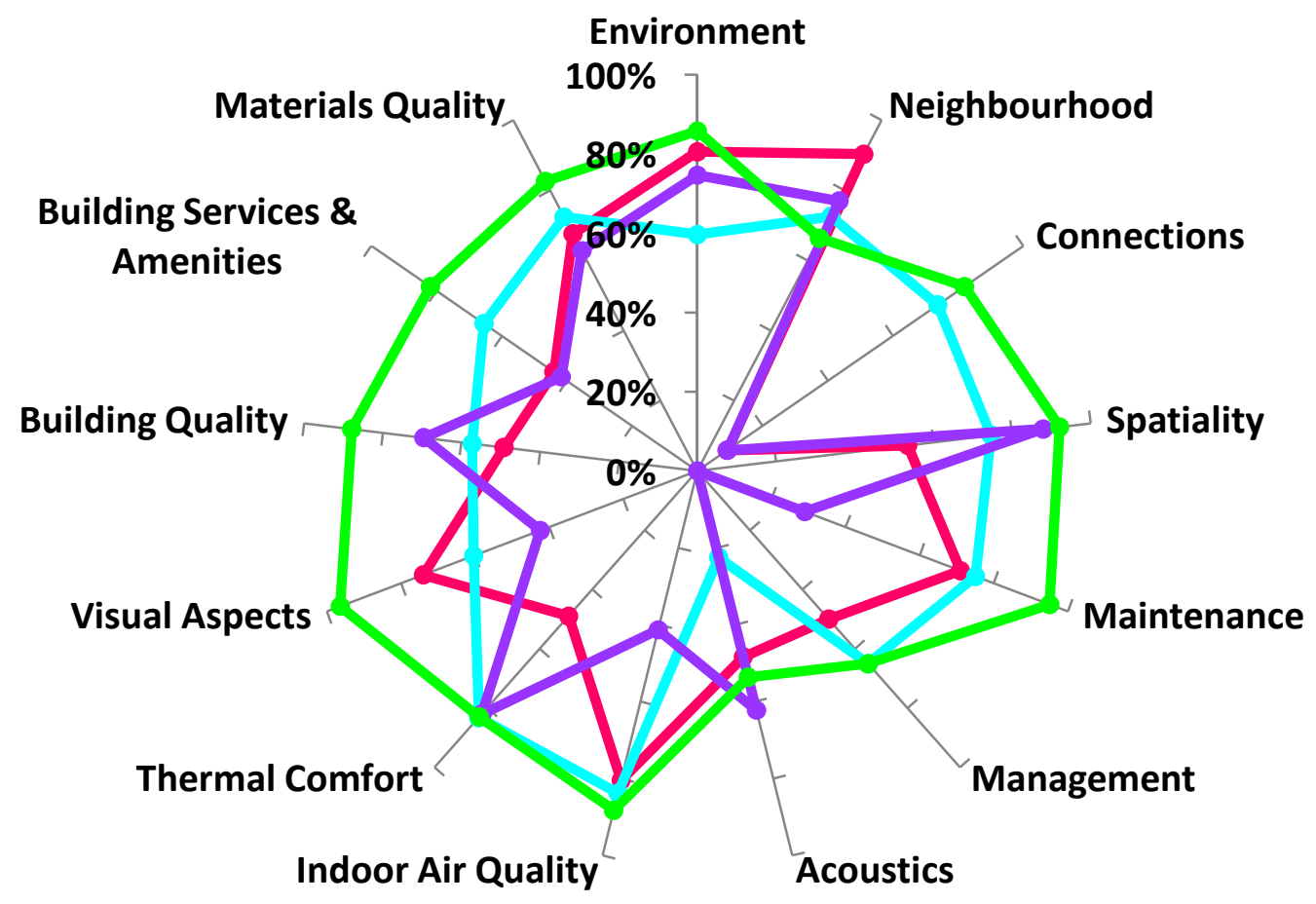

Figure 5-3, NZ ALI Section Profiles for Apartments included within NZ ALI Trial 
Table 5-3, Summary of Key Issues determined from NZ ALI Interviews for NZ ALI Trial

\begin{tabular}{|c|c|c|c|}
\hline Apartment & $\begin{array}{l}\text { Most liked features of } \\
\text { apartment }\end{array}$ & $\begin{array}{l}\text { Most disliked features } \\
\text { of apartment }\end{array}$ & $\begin{array}{l}\text { Key Issues } \\
\text { determined from } \\
\text { discussion }\end{array}$ \\
\hline $\begin{array}{l}\text { Apartment } 1 \\
\text { (Occupant A) }\end{array}$ & $\begin{array}{l}\text { - } \text { Size } \\
\text { - } \text { Modern Fittings } \\
\text { - } \\
\text { Proximity to } \\
\text { motorway (for work) } \\
\text { and entertainment }\end{array}$ & $\begin{array}{ll}\text { - } & \text { Noise } \\
\text { - } & \text { Lack of sunlight } \\
\text { - } & \text { Front door } \\
\text { (coldness, security } \\
\text { and draughts) }\end{array}$ & $\begin{array}{ll}\text { - } & \text { Poor noise control } \\
\text { - } & \text { Lack of sunlight } \\
\text { - } & \text { Poor views } \\
\text { - } & \text { Poor security } \\
\text { - } & \text { IAQ issues } \\
\text { - } & \text { Lack of outdoor }\end{array}$ \\
\hline $\begin{array}{l}\text { Apartment } 2 \\
\text { (Occupants B \& C) }\end{array}$ & $\begin{array}{ll}\text { - } & \text { Convenience \& } \\
\text { - } & \text { Size } \\
\text { - } & \text { Warmth \& Aspect } \\
\text { - } & \text { Outdoor provision } \\
\text { - } & \text { Comfortable }\end{array}$ & 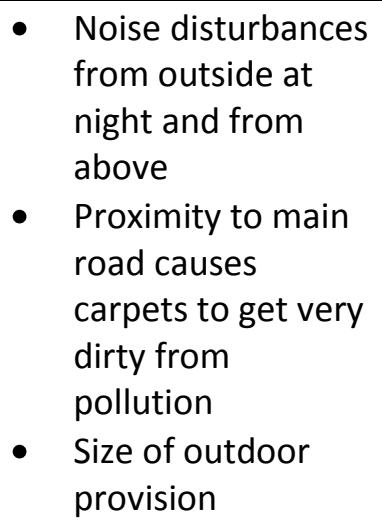 & $\begin{array}{ll}\text { - } & \text { Poor noise control } \\
\text { - } & \text { Lack of visitor } \\
\text { - } & \text { Securing } \\
\text { - } & \text { Outdoor Air } \\
& \text { Quality \& Traffic } \\
\text { - } & \text { Natural Light } \\
\text { - } & \text { Storage } \\
\text { - } & \text { Deterioration of } \\
& \text { materials with age } \\
& \text { and maintenance }\end{array}$ \\
\hline $\begin{array}{l}\text { Apartment } 3 \\
\text { (Occupant D) }\end{array}$ & $\begin{array}{ll}\text { - } & \text { Location } \\
\text { - } & \text { Sunlight } \\
\text { - } & \text { Size }\end{array}$ & $\begin{array}{l}\text { - } \\
\text { - } \text { from outse disturbances } \\
\text { - } \\
\text { - } \text { Draughtment Density } \\
\text { windows }\end{array}$ & $\begin{array}{ll}\text { - } & \text { Poor noise control } \\
\text { - } & \text { Airtightness } \\
\text { - } & \text { Age, materials \& } \\
& \text { maintenance } \\
\text { - } & \text { No outdoor access } \\
\text { - } & \text { Storage } \\
\end{array}$ \\
\hline $\begin{array}{l}\text { Apartment } 4 \\
\text { (Occupants E \& F) }\end{array}$ & $\begin{array}{ll}\text { - } & \text { Location } \\
\text { - } & \text { No maintenance } \\
\text { - } & \text { Size } \\
\text { - } & \text { Outdoor Access } \\
\text { - } & \text { Storage } \\
\text { - } & \text { Light }\end{array}$ & $\begin{array}{ll}\text { - } & \text { Proximity to bars \& } \\
\text { subsequent noise } \\
\text { - } & \text { Poor noise control } \\
\text { from outside }\end{array}$ & $\begin{array}{l}\text { - Noise control for } \\
\text { area }\end{array}$ \\
\hline
\end{tabular}

\subsubsection{COMPARISON TO OCCUPANT ISSUES}

This section will discuss the comparison of the NZ ALI Trial and the NZ ALI Interview results for each apartment. The comparison focuses on how well the Liveability Evaluation aligns with the issues identified by the occupants during the NZ ALI Interview and whether the tool predictions for each Category corresponded to what was expected for each apartment. Three types of ratings are discussed here: Liveability Ratings, Category Ratings and Section Ratings. The first represents the overall NZ ALI rating (Figure 5-1), the second represents the rating a Category received and contributes towards the Category Profiles for each apartment (Figure 5-2). The third represents the rating a Section received and contributes towards the Section Profiles for each apartment (Figure $5-3)$. 


\subsubsection{APARTMENT 1}

Apartment 1 was considered a low-end apartment and this is shown in the overall Liveability Rating (Figure 5-1) which was just 57\%. The strongest Category for this apartment was Community with a Category Rating of $85 \%$ (Figure 5-2). One of the most liked aspects of the apartment stated by Occupant A (the sole occupant) was the proximity to the motorway as she works out of town and it is very convenient for her to get to most things she needs (such as shops, entertainment venues and so on). This is reflected in the high score for this Category. Occupant A said she felt very safe in the area and she very much liked the location of the apartment.

Governance was ranked $2^{\text {nd }}$ with a Category Rating of $62 \%$. This appears to align with the discussion with Occupant $A$ as she had few issues with the Building Management and found that in general the building was well maintained. The lower score reflects issues that she had with maintenance in her apartment particularly with seals around windows and the front door. Indoor Environmental Quality was ranked $3^{\text {rd }}$ with a Category Rating of $61 \%$. Occupant A was particularly concerned with issues within this Category especially surrounding noise ${ }^{23}$, sunlight, views and indoor air quality ${ }^{24}$. These were all key issues identified from the discussion and as a result it was expected that Indoor Environmental Quality would score much lower than it did in the trial. Quality was ranked $4^{\text {th }}$ with a Category Rating of 53\%. The apartment building has few communal facilities, poor parking and Occupant A was particularly concerned with security as her front door was fully glazed. Because of the poor security and lack of services and amenities it was expected that the Category Rating for Quality would be as low as predicted by the tool.

Configuration with a rating of $36 \%$. The occupant had many issues with the components within this Category, in particular the lack of outdoor space, the lack of privacy, the minimal storage (currently her broom and vacuum cleaner are stored in her bedroom wardrobe) and issues she has with the layout of the apartment. She did comment that she felt the size of the apartment $\left(35 \mathrm{~m}^{2}\right)$ was generous, although in comparison to minimum recommendations (set by the ACC) it is smaller than should be expected $\left(45 \mathrm{~m}^{2}\right)$ (Auckland City Council, 2009).

Overall the NZ ALI Liveability Rating closely matched the results of the occupant interview, suggesting it was fairly accurate for this apartment. In all Categories except Indoor Environmental Quality, the Category Rating and Profile corresponded with the comments made by Occupant A. One unexpected finding was that Indoor Environmental Quality was given a higher rating considering the number and type of issues reported by Occupant A. Based on this apartment some modification to the weightings of the IEQ components would be recommended (modifications to the tool are discussed in Section 0). Apartment 1 was the only apartment that had solely external access. It was also one of only two apartments evaluated that had minimal communal facilities. However despite these differences it was found that NZ ALI could be relatively easily applied without too much difficulty due to the range of possible answers within the tool.

\footnotetext{
${ }^{23}$ Occupant $A$ is often disturbed by her upstairs neighbours, particularly late at night when she states she often cannot sleep due to them playing the piano.

${ }^{24}$ A result of the poor spatial organization and lack of a mechanical extract fan in the open plan kitchen and living room
} 


\subsubsection{APARTMENT 2}

Apartment 2 was considered to be a middle range apartment. The overall Liveability Rating from NZ ALI was 67\% (Figure 5-1). Unlike Apartment 1, the Category rankings of Apartment 2 were more evenly spread and ranged from $63 \%$ to $74 \%$ (Figure 5-2). The strongest Category for Apartment 2 was Configuration with a rating of $74 \%$. This was expected as Occupant $B$ and $C$ both commented on how much they liked the size of the apartment, privacy and outdoor spaces the apartment provided. One issue Occupant $\mathrm{C}$ had with Apartment 2 was the lack of good storage. She commented that they

storage at the end of their car park as was the case for many other occupants in the building.

Governance was ranked second with a rating of $71 \%$ which is understandable considering that the building is relatively well maintained and was reported to have good Building Management. Community was ranked third with a rating of $66 \%$ due to the fact that both Occupant B and C felt quite safe in the area and felt the proximity of the apartment to nearby amenities was very good. The only negative issue with this Category was the proximity to heavy traffic which resulted in poor Outdoor Air Quality which they believe makes their carpet very dirty due to traffic pollution. This is an issue for both Community and Governance because of the Surrounding Use and Outdoor Air Quality (Community) and Cleanliness and Maintenance issues (Governance).

Quality was ranked fourth with a rating of $64 \%$. Overall the building provided many services and amenities, including parking, rubbish $\&$ recycling and good access. The low rating of this Category is attributed to some security issues with the building which the occupants attributed more to other . They commented that security breaches were often due to occupants letting strangers into the building without realizing. They also felt that the lack of visitor parking was a key issue. Only one visitor car park is provided for the entire building of fifty apartments which results in many visitors receiving parking tickets. Both occupants also commented on the deterioration of materials but noted that the building was already 20 years old without any major renovations during that time, so this deterioration should be attributed to normal wear and tear and not poor quality materials.

The weakest Category for Apartment 2 was Indoor Environmental Quality which received a rating of $63 \%$. Occupant $B$ and $C$ both found that they had issues with adequate noise control, both from occupants above and from outside. They also commented on the lack of natural light as an issue the apartment is relatively deep with a recessed balcony which reduces the amount of natural light entering the apartment. There is also an internal bedroom which lacks even borrowed external light.

Overall the Liveability Rating that NZ ALI awarded to Apartment 2 seemed to be fairly accurate. Both Occupant $B$ and $C$ had similar issues with the apartment and building and the Liveability Profile that NZ ALI determined seemed to highlight these same issues. The Category ratings for Apartment 2 were more evenly spread than Apartment 1. NZ ALI was able to be easily applied to Apartment 2. There were no parts of the tool that could not be evaluated and no issues arose as a result. 


\subsubsection{APARTMENT 3}

Apartment 3 was considered to be a low end apartment and the NZ ALI Liveability Rating was 55\% (Figure 5-1). Similarly to Apartment 1 (which was also a low end apartment) the Category ratings were widely spread from $17 \%$ - 76\% (Figure 5-2). The highest ranked Category for Apartment 3 was Community (76\%). Occupant $\mathrm{D}$ stated that the location of the apartment and its proximity to many local amenities and services was her most liked feature of the apartment. Neighbourhood was ranked lower than Environment (Figure 5-3) which matched the concerns expressed by Occupant D about the safety of the area particularly late at night.

Both Indoor Environmental Quality and Quality were ranked second equal in the Liveability Profile with ratings of $59 \%$ each. Occupant $D$ had many issues with both of these Categories including poor noise control (particularly at night), poor air quality ${ }^{25}$, poor views, internal bedrooms, poor task lighting, the need to constantly heat, draughts, old and deteriorating materials and , few facilities $^{26}$ and poor fire safety features. From the discussion with Occupant $D$ about these Categories it was anticipated that both would score relatively low. NZ ALI was able to pick up each of the issues raised by Occupant $D$ and the resulting Category Rating for was representative of these issues.

Configuration was ranked fourth with a Category Rating of 56\%. Considering that the apartment had no private outdoor access or storage ${ }^{27}$ it is unsurprising Apartment 3 had a Community Category Rating of just $56 \%$. Occupant $D$ felt that for the number of bedrooms and occupants, the size of the apartment was adequate and that the spatial configuration and layout was adequate however she did believe that bedrooms and living areas were not all placed appropriately to make full use of sun, daylight and noise control. The NZ ALI Configuration Category Rating seemed to match the occupant raised issues.

Governance was the weakest Category at 17\%. From the NZ ALI assessment, the building and apartment seemed to be poorly maintained, which matched an Occupant $D$ statement that this was one thing she most disliked about the apartment ${ }^{28}$. Building Management was only provided through a Property Manager who Occupant $D$ felt did a good job. It is understandable then that Governance had such a low Category Rating, showing the tool to fairly accurately match the issues raised by Occupant $\mathrm{D}$.

The trial on Apartment 3 found the NZ ALI outputs fairly accurately matched the issues identified by Occupant D. The overall Liveability Rating for NZ ALI reflects the type of apartment, quality, upkeep and location of the building a low Liveability Rating for a low-end apartment. It was possible for NZ

\footnotetext{
${ }^{25}$ The occupant did state that she was not sure that the poor IAQ within the apartment was because of poor natural ventilation or from poor hygiene of other flatmates

${ }^{26}$ No parking, lifts, rubbish \& recycling facilities

${ }^{27}$ Apart from the kitchen cupboards and hot water cupboard all other storage was brought in by other occupants

${ }^{28}$ Particularly windows that were badly deteriorated and draughty
} 
few communal facilities and was only a two-storey building. However the tool, its questions and answers indicated that it is able to provide a reasonable assessment each time.

\subsubsection{APARTMENT 4}

Apartment 4 was considered a high end apartment and was included in the NZ ALI Validation due its high specification finish, price and location. This was reflected in the overall Liveability Rating from NZ ALI 82\% (Figure 5-1). Like Apartment 2 the Category ratings were less widely spread from $88 \%$ $73 \%$. The strongest Category for Apartment 4 was Configuration with a rating of $88 \%$. Apartment 4 was large with good quality storage, good outdoor access and good spatial design and layout. Both Occupants $\mathrm{E}$ and $\mathrm{F}$ commented how much they appreciate these features of the apartment and felt that the apartment was very private despite its location in the central city. The NZ ALI evaluation seemed to identify these highly valued aspects and appropriately rated Configuration highly (88\%).

Quality was rated second for Apartment 4 with a rating of $85 \%$. This was not surprising as this apartment building offers many services $\&$ facilities. There is secure parking, spacious lifts, efficient access, good security, and amenities provided are well maintained. Both Occupants $E$ and $F$ commented that they felt the quality of the building was high and they felt very comfortable in the building due to its high spec design. The Quality Category Rating seems to mirror this. Both occupants commented that they appreciated the services that the building was able to provide but also understood that the price they paid for the apartment reflected the higher quality building.

Ranked third from NZ ALI for Apartment 4 was Governance (82\%, Figure 5-2). As Figure 5-3 shows, Maintenance received a very high $95 \%$ but Management received only $65 \%$. Both occupants were very happy with the maintenance and cleanliness of the building and were very happy with the Building Management particularly as Occupant E was on the Body Corporate. While the building did not allow pets they were not concerned with this as they commented that not only did they not want pets but also felt that it was unfair to have pets such as cats or dogs in an apartment building with no ground floor access and limited outdoor provision in the form of a recessed balcony. The Section Rating for Maintenance reflects the discussion with the occupants. However the same cannot be said for Management mainly because of the issue surrounding pets.

Indoor Environmental Quality was ranked fourth in the NZ ALI Category Profile at 79\%. Both occupants only had one issue with IEQ which was the poor noise control and sound transmission reduction from the outside. This was of particular concern for them as the apartment building is located in a very central area and not too far from the main entertainment district. Both occupants were very pleased with the thermal environment, their visual comfort and the air quality ${ }^{29}$ in both the apartment and the building. The Section Ratings for the IEQ Sections (shown in Figure 5-3) aligns with the discussion with the occupants as all except Acoustics were predicted to have a high Section Rating. Acoustics only received $54 \%$ as the building is located near both heavy traffic and entertainment venues. These findings seem to correspond to the discussion with the occupants regarding their liveability and the indoor environment.

\footnotetext{
${ }^{29}$ Occupant F noted that they hardly get any cooking smells in the hallways due to the placement of kitchens, entrances to apartments and extract fans in all kitchens
} 
The lowest rating Category for Apartment 4 was Community with a Category Rating of $73 \%$.

Occupant $\mathrm{F}$ commented that she loved the location of the apartment and the setting of the building in regards to neighbouring building $s^{30}$. Occupant $E$ said he felt comfortable in the area and that while there are some crime issues due to bars and intoxicated people in the area, he generally felt fairly safe due to police presence and the WCC alk Wise . The Section Rating for both Environment and Neighbourhood scores match the discussions with both Occupants $\mathrm{E}$ and $\mathrm{F}$. The only real concern that either occupants had was regarding some known crime issues in the area which were picked up in NZ ALI and reflected in the lower Neighbourhood score.

The Liveability Rating and Profile for Apartment 4 seems to closely match the NZ ALI Interview undertaken with Occupants $E$ and F. Apartment 4 scored very well on the Liveability Index which fits with expectations for a high end apartment. Good and bad aspects of the apartment discussed by both occupants were highlighted in the NZ ALI evaluation and where expected Apartment 4 scored higher or lower. There were also no concerns about applying NZ ALI to Apartment 4 even though it was considered to be a higher end apartment compared to the other trial apartments.

\subsubsection{DISCUSSION}

Comparing the trial of NZ ALI on four apartments and the showed that in general NZ ALI evaluations were reasonably accurate. Where there were issues identified from the occupant interviews these were also identified in the corresponding NZ ALI evaluations of their apartments (and vice versa for good aspects of the apartments). The only issue identified was with the Indoor Environmental Quality component weightings specifically with the results from Apartment 1. The Indoor Environmental Quality component weightings seemed to predict a higher Category Rating for Apartment 1 than was expected from issues raised by Occupant A with surrounding noise, sunlight, views and IAQ.

NZ ALI was able to be readily applied to the range of apartment types in the trial. The four apartments were selected for in the trial due to the many differences between them (e.g. low to high end apartments, a range of access types and differing services provided).

\footnotetext{
${ }^{30}$ She was able to easily access many things in the area including public transport, supermarkets and open space. Although it is only an average height building in the area, the building in front of theirs did not interfere with views and sunlight access into the apartment
} 


\subsection{NZ ALI CRITIQUE}

This section discusses the NZ ALI Critique that was conducted as part of the NZ ALI Validation. The critique results are presented and discussed to identify issues with NZ ALI, particularly surrounding the usability, objectivity and practicality of the tool. This was an essential step in the completion of the development of the tool to ensure that it met the development criteria and was fit for purpose. Participants of the NZ ALI Interview and the trialled apartments are outlined in Section 5.2.1.

\subsubsection{NZ ALI CRITIQUE RESULTS}

Each of the six apartment occupants interviewed in the first part of the NZ ALI Validation also participated in a critique of the tool. They were asked to trial the use of the tool and look over the results. They were then they were asked eight questions regarding the usability, objectivity and practicality of NZ ALI. NZ ALI Trial \& Critique provides the full results of this critique. Table 5-4, Table 5-5, and Table 5-6 provide a summary of the six critiques and the main issues identified.

\section{Usability}

Table 5-4, Summary of NZ ALI Critique regarding Usability

\begin{tabular}{|c|c|c|c|c|c|}
\hline \multicolumn{3}{|l|}{ Questions } & Summary & Negative Points & Positive Points \\
\hline \multirow{3}{*}{ Usability } & a) & $\begin{array}{l}\text { How user- } \\
\text { friendly is NZ ALI? }\end{array}$ & Yes & $\begin{array}{l}\text { Length of evaluation } \\
\text { Evaluation interface }\end{array}$ & $\begin{array}{l}\text { Definitely very user- } \\
\text { friendly }\end{array}$ \\
\hline & b) & $\begin{array}{l}\text { How easy is NZ } \\
\text { ALI to } \\
\text { understand? }\end{array}$ & Yes & 110 Scale & $\begin{array}{l}\text { Instructions, guidance, } \\
\text { types of questions \& } \\
\text { answers make it very } \\
\text { easy to use \& } \\
\text { understand }\end{array}$ \\
\hline & c) & $\begin{array}{l}\text { How straight } \\
\text { forward is NZ ALI } \\
\text { to use? }\end{array}$ & Yes & Layout & $\begin{array}{l}\text { Hierarchy is clearly } \\
\text { defined through layout } \\
\text { Despite the length there } \\
\text { is not a lot of 'thinking' } \\
\text { required due to drop } \\
\text { down menus and broad } \\
\text { range of possible } \\
\text { answers }\end{array}$ \\
\hline
\end{tabular}

All apartment occupants stated that they found that NZ ALI was fairly usable user-friendly, understandable and straightforward to use. However there were negative points about the usability of the tool despite the general consensus that it is fairly user-friendly. Some comments from the participants about this were: 
- It was very long and got a bit boring towards the end (Occupant A)

- The

- The 110 scale was hard to understand and use because of the lack of a neutral option (Occupants B \& F)

- Although it was long the types of questions \& answers provided made it very easy to use as particularly with the drop down menus(Occupant D)

- The instructions and guidance provided made the tool very easy to follow (Occupant E)

- The layout needs to be clearer but the boxes are good (Occupant C)

- The layout is good, and the hierarchy is clearly defined (Occupant F)

The main issues identified regarding the usability and user-friendliness of NZ ALI were:

- Layout,

- Length of Evaluation,

- Program/Interface,

- Scale.

\section{Objectivity}

Table 5-5, Summary of NZ ALI Critique regarding Objectivity

\begin{tabular}{|c|c|c|c|c|c|}
\hline \multicolumn{3}{|l|}{ Questions } & Summary & Negative Points & Positive Points \\
\hline \multirow{2}{*}{ Objectivity } & a) & $\begin{array}{l}\text { How objective do } \\
\text { you feel the } \\
\text { questions } \\
\text { answers required } \\
\text { in NZ ALI are? }\end{array}$ & $\begin{array}{l}\text { Seems } \\
\text { fairly } \\
\text { objective }\end{array}$ & $\begin{array}{l}\text { Some very obviously } \\
\text { subjective questions }\end{array}$ & $\begin{array}{l}\text { Instructions \& guidelines } \\
\text { help to limit subjectivity }\end{array}$ \\
\hline & b) & $\begin{array}{l}\text { Are NZ ALI } \\
\text { components } \\
\text { easily } \\
\text { measureable? }\end{array}$ & $\begin{array}{l}\text { In general } \\
\text { yes }\end{array}$ & $\begin{array}{l}1 \text { - } 10 \text { Scale } \\
\text { Clarity of instructions } \\
\text { at times these are } \\
\text { confusing }\end{array}$ & $\begin{array}{l}\text { Clarity of instructions } \\
\text { generally these explain } \\
\text { what is required }\end{array}$ \\
\hline
\end{tabular}

When questioned about the objectivity of the NZ ALI evaluation the NZ ALI Critique participants generally commented that the questions asked in the NZ ALI evaluation seemed objective, although both Occupant $\mathrm{C}$ and $\mathrm{F}$ commented that some questions (particularly those concerning quality) were very subjective as users have to choose a number on a scale rather than use a defined number (e.g. floor area). Occupant $C$ however did comment that the instructions and guidelines that are given for each Indicator were very helpful and seemed to limit the amount of subjectivity in answering.

The six participants also stated that generally the NZ ALI components are easily measureable. Occupant $A$ and $F$ both commented on difficulties they found with the 110 scale, particularly as . They stated that this made the scale a bit hard to apply and therefore some components were hard to measure. Occupant $\mathrm{B}$ and $\mathrm{C}$ also commented that 
while the components are generally measureable, when the instructions are not very clear this made it hard to easily report on some components of NZ ALI.

The main issues identified regarding the objectivity of NZ ALI were:

- Clarity of Instructions \& Guidelines,

- Scale.

\section{Practicality}

Table 5-6, Summary of NZ ALI Critique regarding Practicality

\begin{tabular}{|c|c|c|c|c|c|}
\hline \multicolumn{3}{|l|}{ Questions } & Summary & Negative Points & Positive Points \\
\hline \multirow{3}{*}{ Practicality } & a) & $\begin{array}{l}\text { How practical is } \\
\text { NZ ALI? }\end{array}$ & Yes & $\begin{array}{l}\text { Length of evaluation } \\
\text { Confusing technical } \\
\text { terms } \\
\text { Repeated assessments }\end{array}$ & Very practical \\
\hline & b) & $\begin{array}{l}\text { Are the } \\
\text { assessment } \\
\text { procedures } \\
\text { simple and any } \\
\text { information } \\
\text { required easily } \\
\text { acquired? }\end{array}$ & $\begin{array}{l}\text { Yes, } \\
\text { seems to } \\
\text { be }\end{array}$ & $\begin{array}{l}\text { Some unknown } \\
\text { information } \\
\text { Some assessments } \\
\text { difficult for new } \\
\text { apartment dwellers }\end{array}$ & $\begin{array}{l}\text { Simple assessment } \\
\text { procedures }\end{array}$ \\
\hline & c) & $\begin{array}{l}\text { Is any of the } \\
\text { information } \\
\text { required for NZ } \\
\text { ALI too specialist } \\
\text { in any way? }\end{array}$ & No & $\begin{array}{l}\text { Confusing technical } \\
\text { terms }\end{array}$ & $\begin{array}{l}\text { Most factors could be } \\
\text { understood by } \\
\text { anybody }\end{array}$ \\
\hline
\end{tabular}

The feedback given by the NZ ALI Critique participants concerning practicality of the tool showed that NZ ALI is a practical tool, the required information is generally easily acquired and little of the information required is too specialist for the intended end-users. Some of the comments and feedback regarding practicality of NZ ALI were:

- Except for the issue with length, the tool is very practical, particularly because the different assessments are very simple (Occupant A),

- It is confusing and repetitive to have things assessed in more than one worksheet e.g. communal areas, and this contributes to the length issue (Occupant $A$ ),

- Although I have no background in the building industry I am sure that most of the questions and factors in the tool could be understood by anybody (Occupant E),

- A few of the terms are too technical for my understanding and really confused me emissions and egress (Occupant D), 
- I have lived in an apartment for quite a while but some of the questions asked would be very hard to answer or understand if you had never lived in an apartment before or were buying from plans (Occupant C),

- I think I would be able to find all the information really easily except for the question about the future building heights in the area, how would I find this out? (Occupant F).

The main issues identified regarding the practicality of NZ ALI were:

- Confusing Technical Terms,

- Difficulty for new apartment dwellers and for buying from plans,

- Length of Evaluation,

- Repeated assessments,

- Unknown information.

\subsubsection{MODIFICATIONS}

The NZ ALI Critique allowed the tool to be trialled and tested by end-users and then modified to ensure that the final version of the tool fits within all development criteria and is fit for purpose. The general consensus of the six NZ ALI Critique participants was that the tool is usable, user-friendly, objective and practical to a certain degree. However for NZ ALI to be fully functional and able to be used as intended some modifications are required. Nine issues have been identified that require the tool to be modified in some way. These are discussed below with modification proposals for NZ ALI.

\section{Layout}

Some participants found that the layout made the tool less straightforward to use whereas some found that it made the hierarchical structure clear and easy to follow through the tool. Because of the inconsistency of this issue between participants the layout has been revised to ensure that it is clear, easy to follow and defines the hierarchical structure of NZ ALI. Style and formatting of the tool has been refined to make the tool more straightforward.

\section{Length of Evaluation and Repeated assessments}

To ensure that NZ ALI is practical and user-friendly it was determined that an assessment should

an assessment but is still in-depth to provide them with useful information. For one occupant, the time it took to complete an evaluation with NZ ALI was too long (around 45 minutes) and they found this made the tool less user-friendly and impractical, especially because of repeated assessments of factors between sections (i.e. communal areas, storage etc). For this participant the apartment building did not provide many of the communal facilities that are assessed multiple times. To combat this, a rule has been included in the tool to first ascertain whether an apartment has the factor in question and if not further questions regarding it are disregarded and automatically awarded zero credits. Another way to streamline the evaluation was to include another worksheet within the tool where those factors that are assessed across more than one Section are brought 
together in one worksheet. These two modifications to the tool have helped to streamline the evaluation process requiring less time thus making it more usable and practical.

\section{Program/Interface}

One occupant also had issues with the computer program that was used to create NZ ALI Microsoft Excel. However as this is only a pilot study the interface of NZ ALI is not considered to be an issue as this would most likely change as the tool is fully developed. NZ ALI is ultimately intended to be an online evaluation tool so the final program/interface used could change in the future.

\section{Scale}

Two of the participants had concerns with the 110 scale when users are required to make personal perception judgements of Indicators particularly quality Indicators. The main issue was

scale was too large to easily make a judgement. As a result the scale was changed to a 17 scale where a 4 provides a neutral option. ASHRAE commonly uses a 7 point scale which ranges from -3 3 (Auliciems \& Szokolay, 1997). -3 represents strongly disagree, 0 represents neutral and 3 represents strongly agree. Because the NZ ALI scale was changed to a similar scale (where 1 represents extremely poor, 4 is neutral and 7 is extremely good quality) this brings it more into line with a rating scale that is used internationally for thermal comfort assessments (Auliciems \& Szokolay, 1997). A 17 scale was felt to be more user friendly to input rather than a $-3+3$ scale.

\section{Clarity of Instructions \& Guidelines}

Comments were made about the clarity of instructions and guidelines for some components of NZ $\mathrm{ALI}$ and how they limit the measurability of some components. While generally all components were found to be easily measureable, at times it was found that the instructions were confusing for participants. All instructions and guidelines for the use of the tool have been reviewed and simplified to ensure that all components can be easily assessed and understood.

\section{Confusing Technical Terms}

It was found that most of the components within NZ ALI were understood by most participants. However one participant did not understand two terms (egress and emissions) which made it difficult for her to assess these issues. To ensure that this is not a problem for any other users of the tool these terms have been modified. Egress has been changed to escape. Emissions have not been changed but the assessment question has been changed to better explain this Indicator. The original assessment question was Are there any emissions from materials? The modified assessment question is Are things like substances, odours, particles etc being emitted, discharged or ejected from furnishings?

\section{Difficulty for new apartment dwellers and for buying from plans (Practicality)}

The issue was raised by one participant that new apartment dwellers and those that are buying new apartments from plans may struggle to use NZ ALI in its current form. The review of the instructions and guidelines has helped to ensure that new apartment dwellers will be able to use the tool regardless of their lack of experience with this type of housing. A second version of the tool has also 
been developed for new-builds as some questions will not be applicable (such as questions regarding maintenance, building age, weathertightness and so on). Two versions of NZ ALI have now been developed: NZ ALI for Existing Apartments and NZ ALI for New Apartments.

\section{Unknown information}

The issue was raised that information regarding the future heights of buildings in the area may not be easy to find. While it de this information, the ability to Are the maximum allowable building heights (as set by the local council) likely to change in the future?) which is awarded $50 \%$ of the credits respectively. 


\subsection{DEVELOPMENT CRITERIA}

This section discusses each of the three development criteria assessed in the NZ ALI Validation work. NZ ALI has been assessed to determine how well it meets the requirements of the three criteria and where required modifications have been proposed to ensure that NZ ALI is fit for purpose.

\section{Criterion \#4 - Accurate}

NZ ALI is required to be able to provide accurate evaluations of liveability in New Zealand apartments. Because liveability is such a personal and very subjective issue, the tool is not expected to provide perfect liveability evaluations for each user but it should be able to identify where liveability issues may occur.

Across the four NZ ALI trialled apartments it was found that NZ ALI can provide reasonably accurate evaluations of liveability. The Liveability Ratings

the high end apartment received the highest rating, followed by the middle end apartment and then the two low end apartments. The only concern

Indoor

Environmental Quality Liveability Profile determined for Apartment 1. Because of the issues

discussed by Occupant A such as poor sunlight access, poor noise control, and lack of views and poor indoor air quality, it was expected that the Liveability Profile for Indoor Environmental Quality would be much lower than $61 \%$ and initially it was proposed that these weightings assigned to the Indoor Environmental Quality Sections (Acoustics 27\%, Indoor Air Quality 25\%, Thermal Comfort 30\% and Visual Aspects $18 \%$ - discussed in Appendices C H) be modified.

No other apartments seemed to experience any issues with this the Indoor Environmental Quality component weightings. NZ ALI is not expected to provide a liveability evaluation perfectly tailored to each individual, but does provide a general liveability evaluation. For this reason modification of NZ ALI components weightings was deemed unnecessary as NZ ALI is currently able to provide a fairly accurate evaluation of liveability. It does not and is not expected to provide a liveability evaluation that is perfectly suited to every individual. It does however provide guidance on where liveability may be affected in an apartment. No weightings have been modified.

\section{Criterion \#5 - General}

NZ ALI is required to be able to be applied to a wide range of apartments commonly found in New Zealand. It should also be able to deal with typical apartments now and in the future. The

trialled were considered to range from low to high end. The buildings and apartments ranged in size, price, location, density, aspect, surrounding uses, orientation, and so on. NZ ALI was easily applied to all of these without any major issues arising.

Two issues arose during the NZ ALI Critique that were not initially anticipated: the assessments of repeated factors such as communal facilities; and the use of NZ ALI by new apartment dwellers and for new apartments brought off plans. While neither of these issues means that NZ ALI cannot be used in these situations, they do however mean that it was harder to use, more tedious and confusing for some users. Modifications discussed in Section 5.3.2 have addressed these issues. 
NZ ALI is capable of being applied to a range of different apartments within New Zealand both at present and in the future. This is possible because when the questions, Assessment Methods and possible answers were developed, care was taken to ensure that a range of possibilities were covered particularly with questions that required users to choose an appropriate answer from a list. With the development of two versions of NZALI it is possible for anybody to evaluate any type of apartment in New Zealand whether it has already been built or is to be constructed after purchase.

\section{Criterion \#6 - User Friendly}

From the NZ ALI Critique it was found that most participants found the tool to be useable. Some issues were found concerning:

- Layout

- Length of Evaluation and Repeated assessments

- Program/Interface

- Scale

- Clarity of Instructions \& Guidelines

- Confusing Technical Terms

- Difficulty for new apartment dwellers and for buying from plans (Practicality)

- Unknown information

However modifications outlined in Section 5.3.2 have helped to make NZ ALI more user-friendly. Now both versions of the tool are user-friendly, straightforward, simple and fit for purpose as required by the scope and development criteria of the tool. 


\section{THE NEW ZEALAND APARTMENT LIVEABILITY INDEX}

This chapter presents the final version of NZ ALI. Section 6.1 presents the tool in

6.2 discusses the development criteria and how NZ ALI meets the development requirements. Finally Section 6.3 discusses the research methodology used to develop NZ ALI.

\subsection{NZ ALI}

The New Zealand Apartment Liveability Index has been initially developed in Microsoft Excel as an automated spreadsheet. A further refinement would be to develop an automated online tool. There are 15 worksheets that users complete to achieve a liveability evaluation. The first worksheet provides an introduction and guidance on using the tool, as shown in Figure 6-1 and Figure 6-2. It also asks general questions concerning the Building Age and Number of Bedrooms (which are required for more than one Section).

The remaining fourteen worksheets are based on each of the thirteen Sections within the tool, plus within Quality ${ }^{31}$. Figure 6-3 and Figure 6-4 show the Spatiality worksheets for both the NZ ALI New Buildings and NZ ALI Existing Buildings. There is little difference between the two except for wording of Assessment Questions. NZ ALI provides a CD with working examples of both versions of the tool. Both require Microsoft Excel 2007.

Indicators, Assessment Questions and Assessment Methods are presented on each worksheet with formatting used to imply structure. Answering instructions and guidance are also provided for each question. Users are required to input appropriate answers in the empty cells. Macros are used to efficiently direct users back and forward through NZ ALI.

On completion of the tool, users are directed through the macros to the final three worksheets. The first presents the overall Liveability Rating as a percentage (Figure 6-5). Users can also evaluate the Category and Section Ratings and Profiles in the following two worksheets (Figure 6-6 and Figure 6-7).

\footnotetext{
${ }^{31}$ Following the Index Validation it was determined that requiring users to answer questions about Communal Areas across two spreadsheets was confusing and time consuming. The questions pertaining to Communal Areas were then amalgamated into one spreadsheet so that users were required to think about and answer questions on these Communal Areas once only.
} 


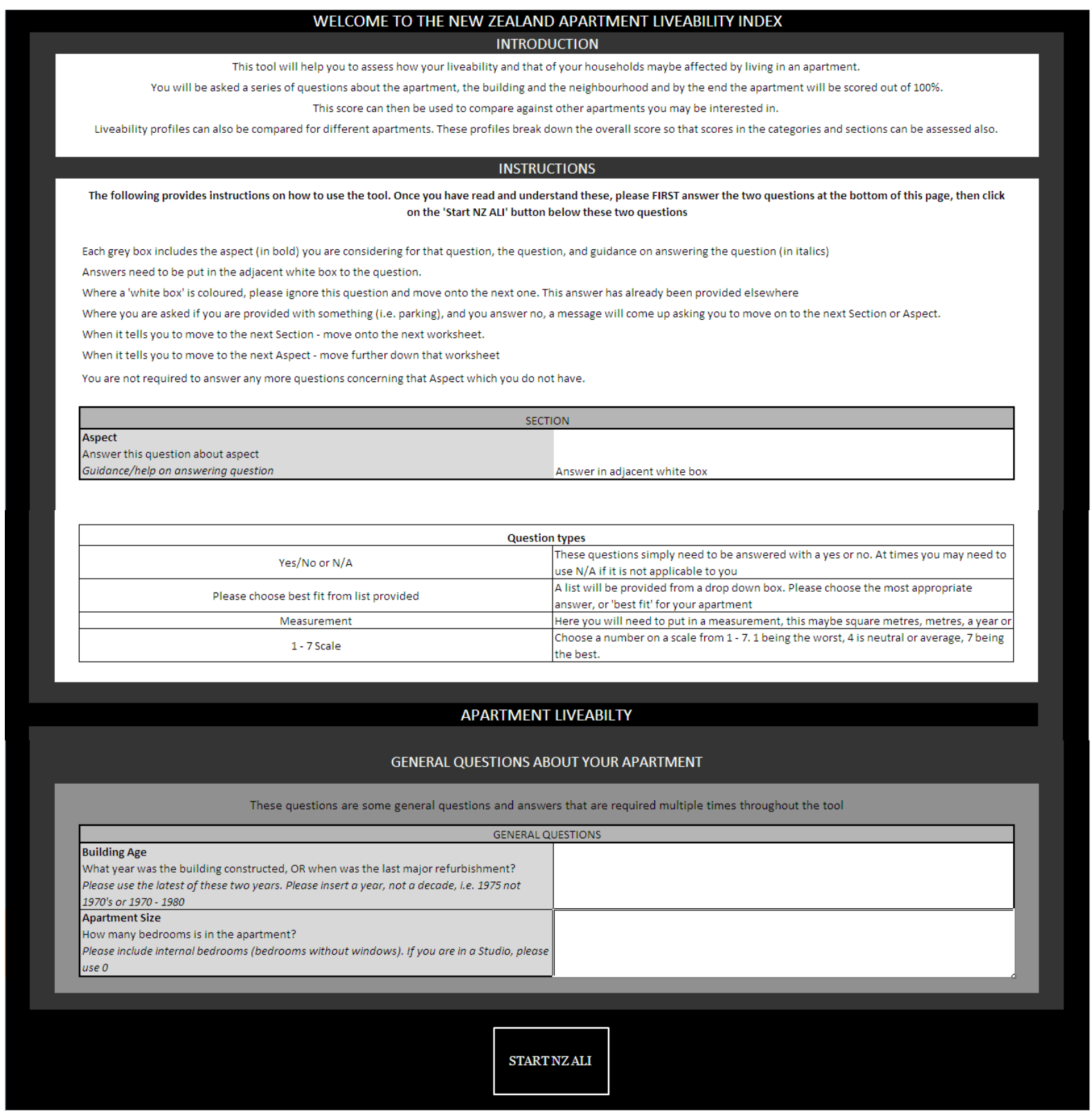

Figure 6-1, NZ ALI for Existing Buildings, Introduction \& General Questions Worksheet 


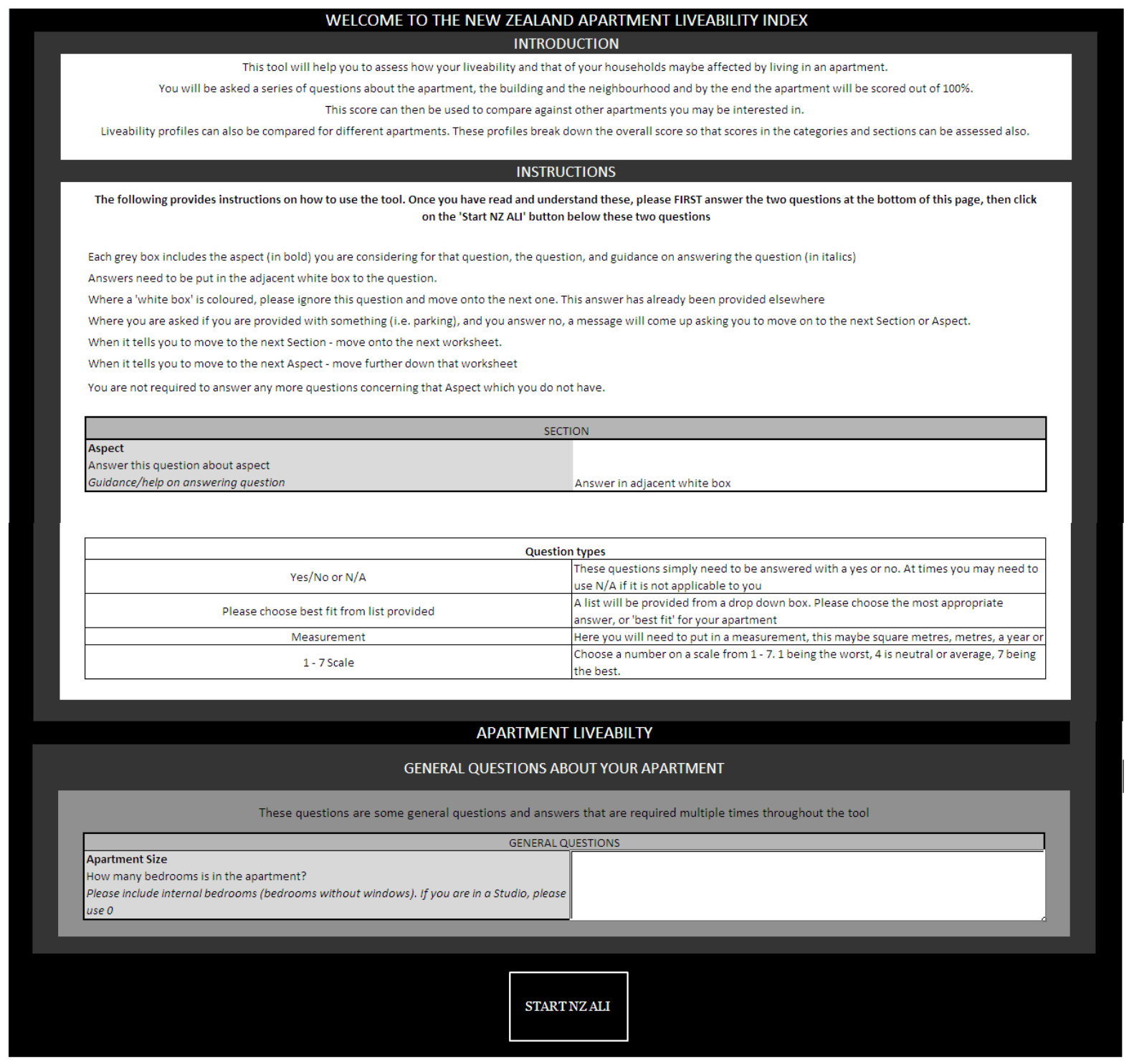

Figure 6-2, NZ ALI for New Buildings, Introduction \& General Questions Worksheet 


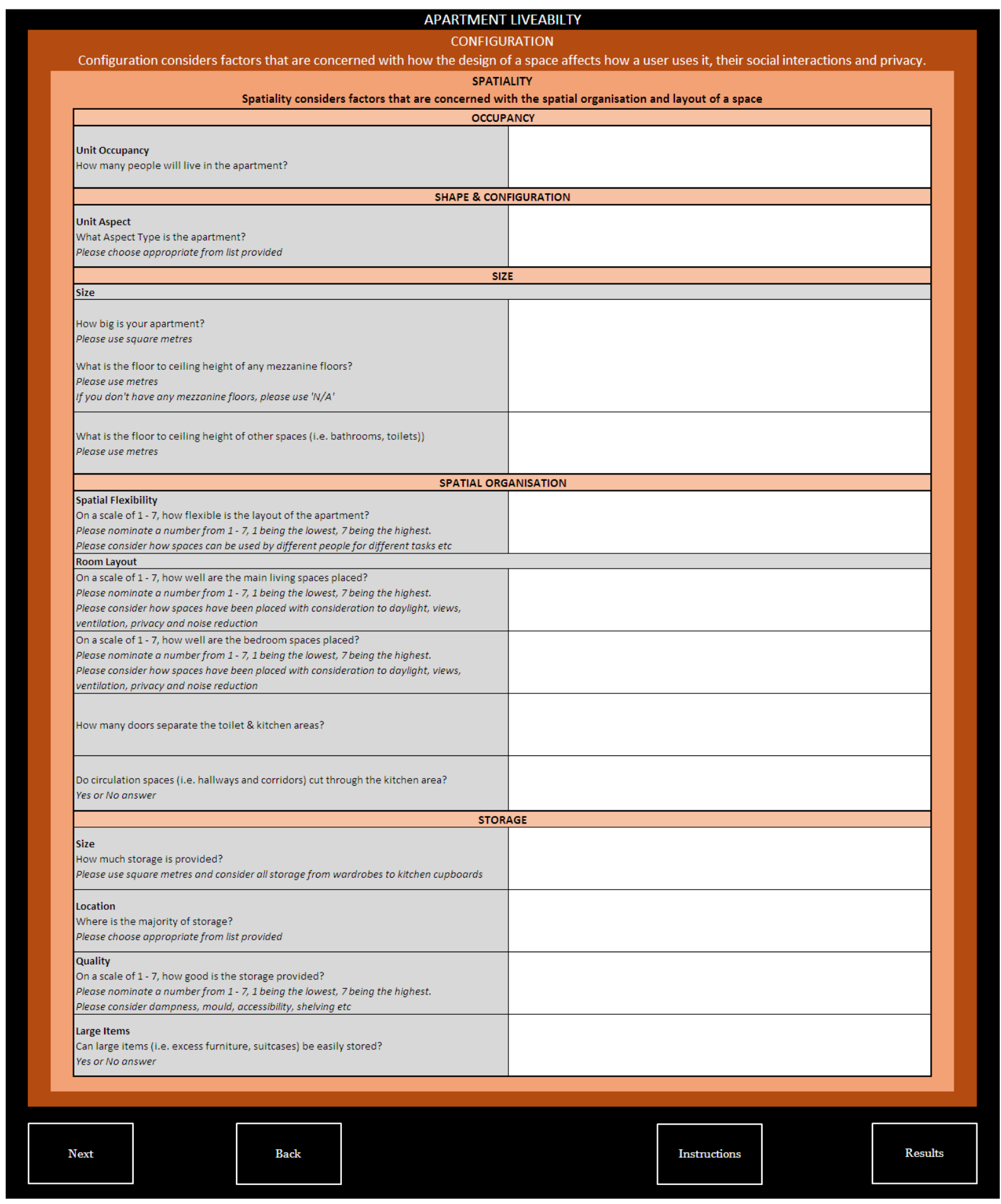

Figure 6-3, NZ ALI for Existing Buildings, Spatiality Worksheet 


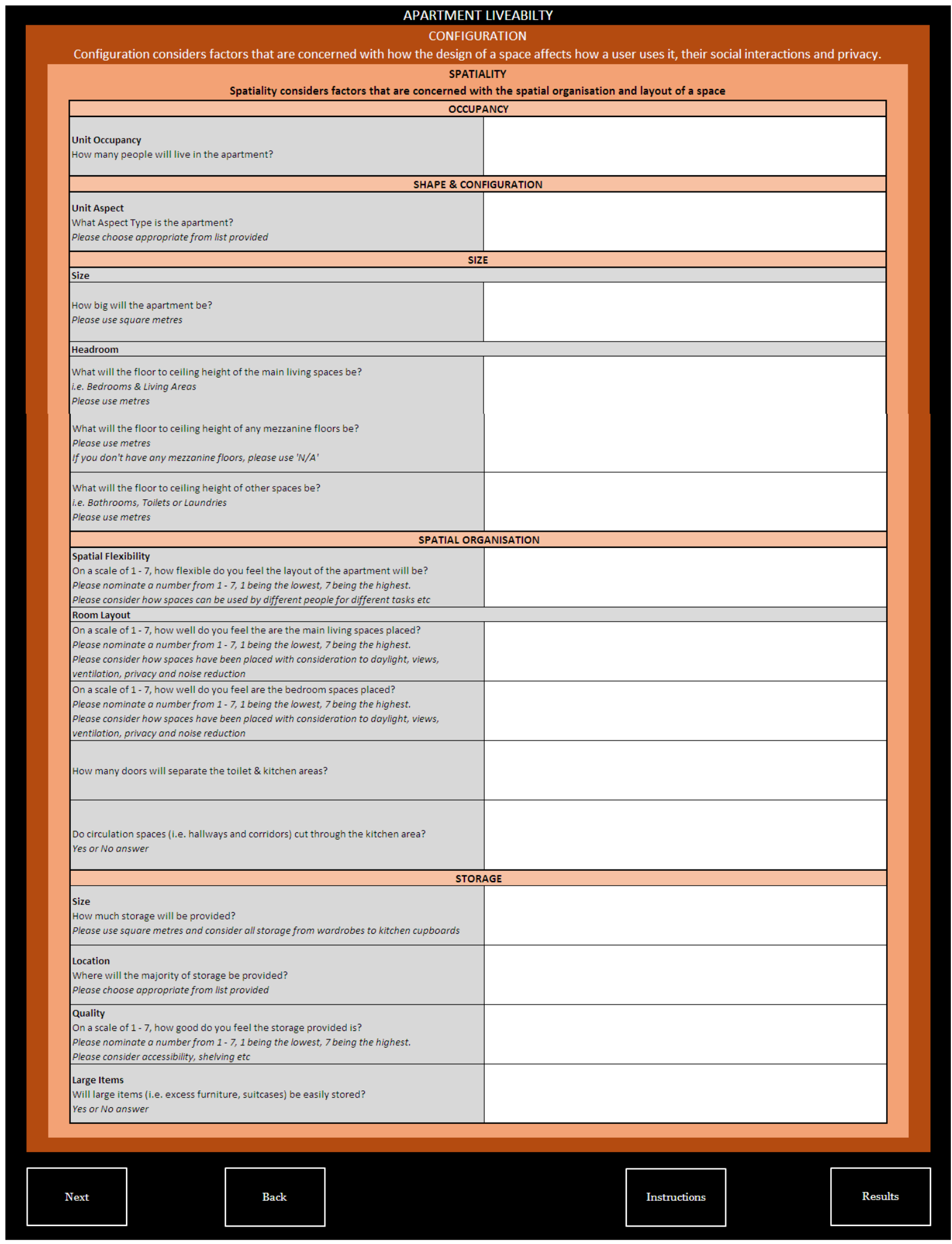

Figure 6-4, NZ ALI for New Buildings, Spatiality Worksheet 


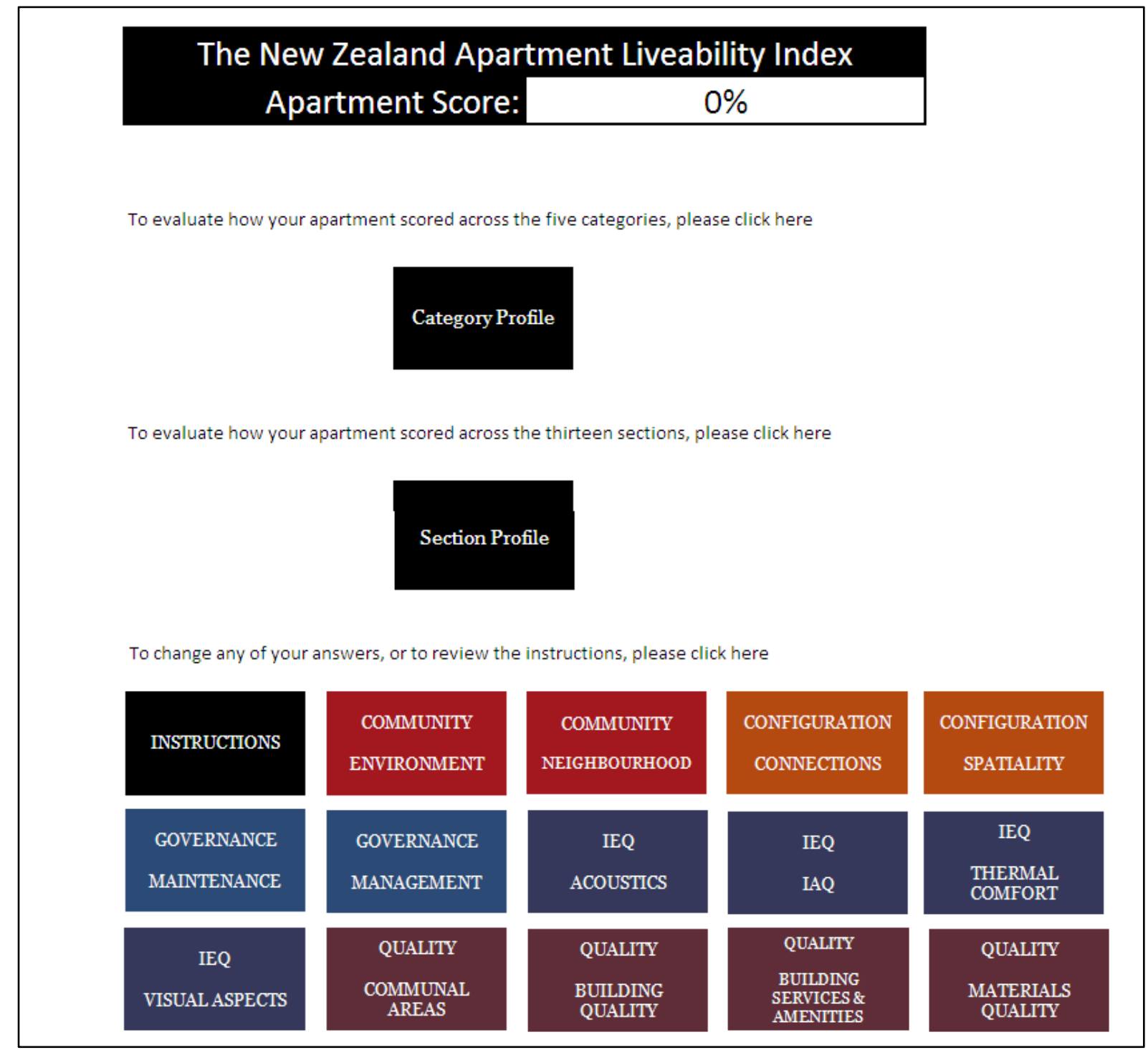

Figure 6-5, NZ ALI Apartment Rating Worksheet 


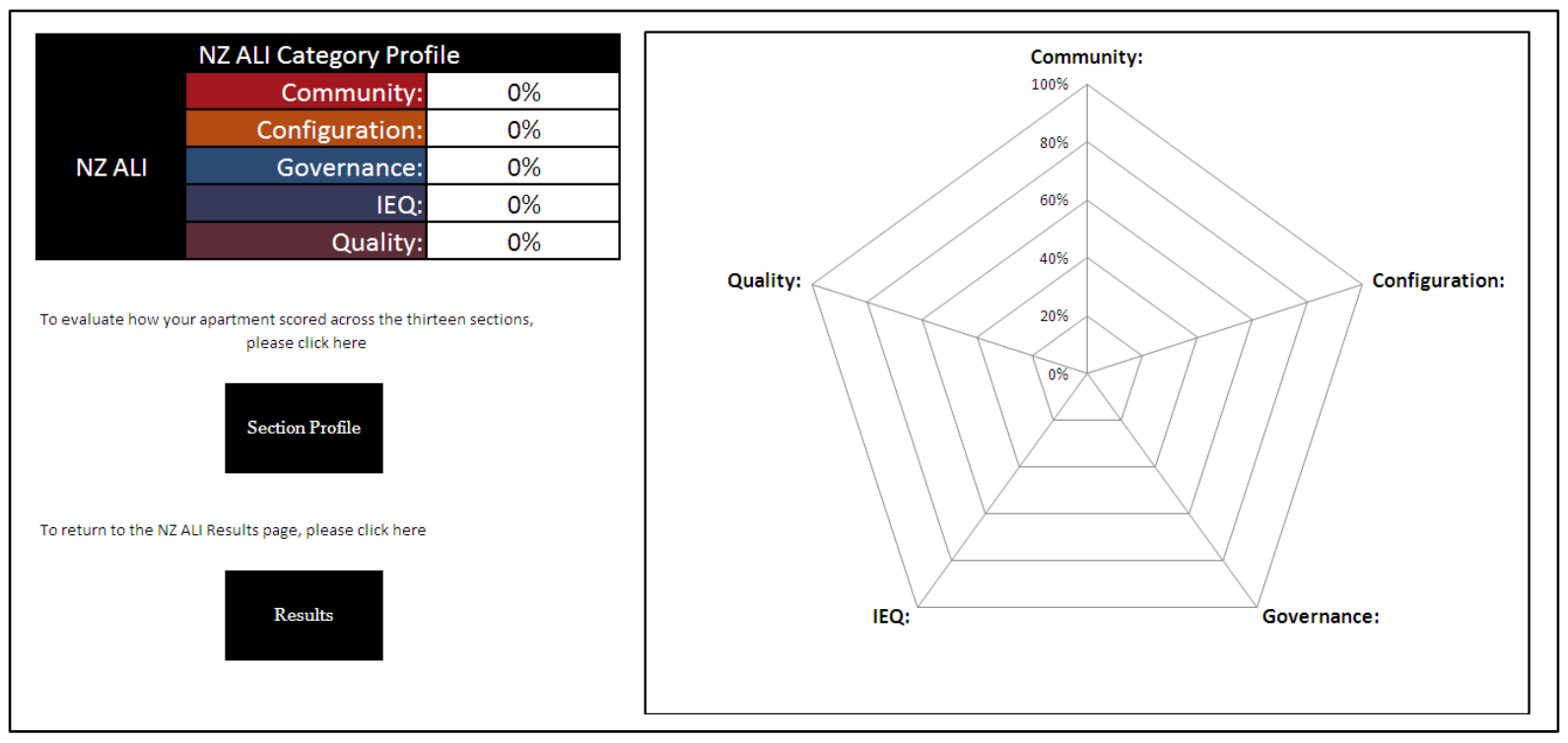

Figure 6-6, NZ ALI Category Profile Worksheet

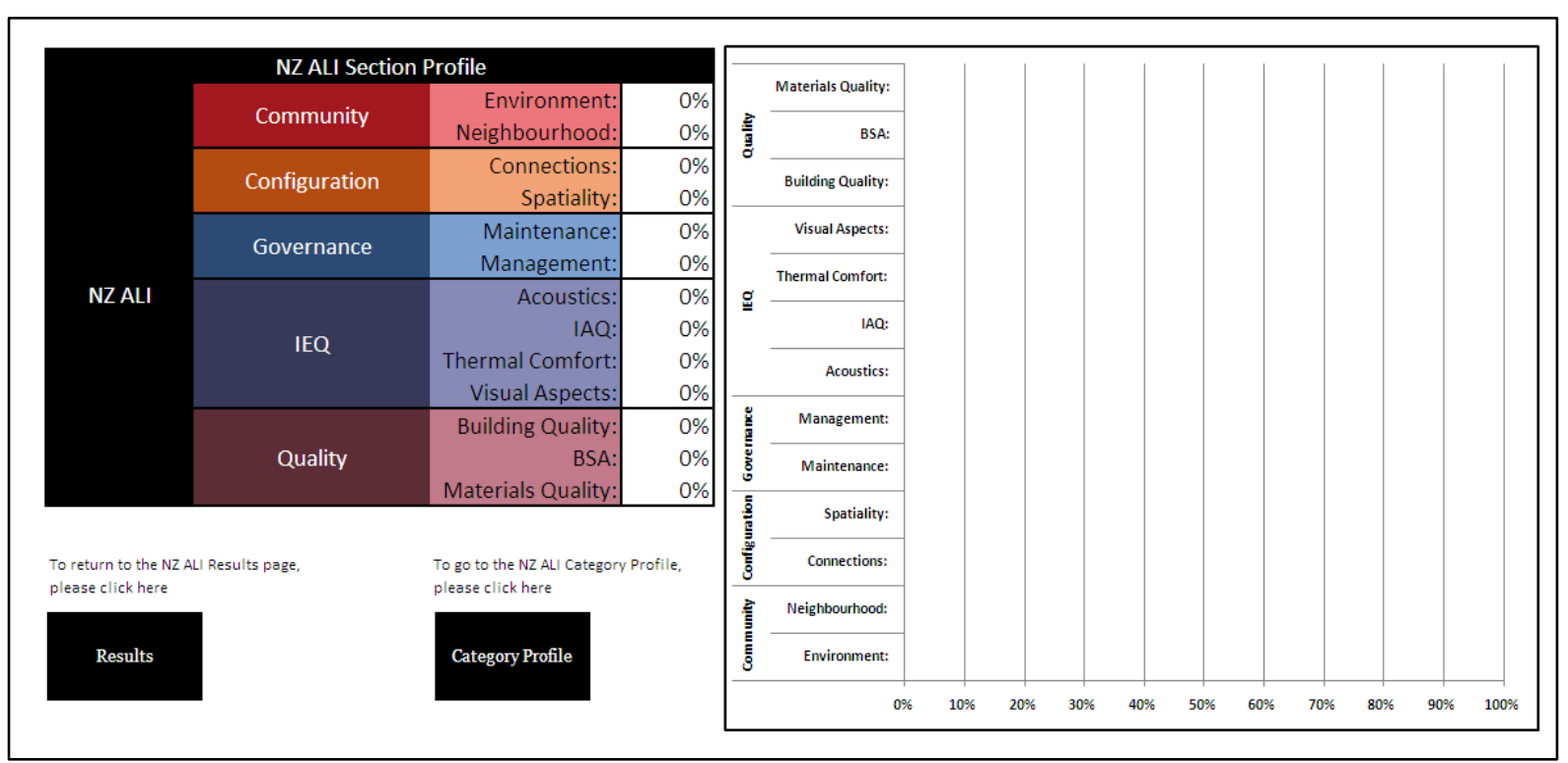

Figure 6-7, NZ ALI Section Profile Worksheet 


\subsection{DEVELOPMENT CRITERIA}

The New Zealand Apartment Liveability Index was required to be developed to meet six development criteria. This section discusses how NZ ALI meets each of these requirements.

\subsubsection{CRITERION \#1 RELEVANT}

The first criterion that NZ ALI was required to adhere to was that all components within the tool and everything that is assessed should be directly related to health, comfort, safety and well-being of apartment occupants, users and visitors. The tool should be relevant to liveability.

1. Relevant

The factors considered should be directly related to the health, comfort, wellbeing and safety of occupants, users and visitors

As discussed in Section 4.1, the first stage of the hierarchy development was to reassess all the 107 factors that were determined to be important from the literature review and ensure that they were directly relevant to liveability. In total all except six factors were found to be relevant to liveability and were ultimately included in NZ ALI for Existing Buildings (refer to Section 3.2 and Other). When NZ ALI for New Buildings was developed it was found that 27 components were not ultimately suited to being assessed for liveability in new buildings, so only 126 Indicators from the NZ ALI for Existing Buildings were included within the version for New Buildings.

\subsubsection{CRITERION \#2 OBJECTIVE}

The second criterion was that all assessed factors needed to be measureable and verifiable to minimise subjectivity in the tools evaluation. The assessed factors within NZ ALI must be Objective.

2. Objective

Assessed factors should be measureable and verifiable to minimise the amount of subjectivity

This criterion was addressed in the development of the index when Assessment Methods were applied to each of the Indicators developed in the initial NZ ALI Hierarchy (refer to Section 3.2). Once Assessment Methods were identified for each of the Indicators, they were then re-assessed to ensure that they met the requirements of this Criterion. An AM was judged as Objective if it relied on defined or known information, but it was considered subjective if it relied on user perceptions and opinions. Liveability is a very personal issue and every person will have different views on how liveable something is. Due to conflicting issues with Criterion \#3 Practical, it was expected that at times an AM would be identified that would be Objective but Impractical. In these cases it was accepted that to meet the requirements of Criterion \#3 to provide a more Practical AM would also require a more Subjective AM. When this occurred and a Subjective AM was required to meet Criterion \#3 instructions and guidance were provided to minimise the 
were found to be too subjective when they were reassessed. These were reworked and reworded to minimise subjectivity for users.

\subsubsection{CRITERION \#3 PRACTICAL}

The third criterion that NZ ALI was required to meet was that the evaluation procedure and assessment methods should be practical. This means that the information that is needed to complete an evaluation should be simple easily accessible or acquirable and it should not need specialist instruments or knowledge. This was to ensure that potential end users would be able to easily use the tool and complete evaluations by themselves without specialist input.

\section{Practical}

The evaluation procedure should be simple and information easily acquired. It should not require instruments and/or sophisticated/specialist knowledge

Criterion \#3 was addressed in the Index Development at the same time as Criterion \#2 (refer to Section 3.2). AMs that were initially identified for the index were reassessed to ensure that they were practical and met the requirements of the tool. An AM was judged impractical if it was too specialist (i.e. knowledge or equipment required) due to wording, lack of skills or expertise. In total

Criterion \#2 and Criterion \#3. Although times there was conflict in the requirements of these two criteria, it was determined that as Liveability is a very personal and subjective issue, practicality of the tool and its AMs would be considered more important.

\subsubsection{CRITERION \#4 ACCURATE}

The fourth development criterion concerned accuracy. The personal and subjective nature of liveability means that the issues that affect one occupant may not have the same impact on another occupant. Therefore, NZ ALI was not expected to be capable of providing an evaluation or assessment of liveability in apartments that would be completely suited or $100 \%$ accurate for each and every person who used the tool. It was expected however that the evaluation and predicted Liveability Rating that the tool provides should be representative of how liveability affects the majority of people.

\section{Accurate}

Results provided should be representative of how liveability may affect most people.

Criterion \#4 was focused on during the Index Validation (refer to Section 0) where NZ ALI was trialled and the predicted Liveability Ratings compared to occupant interviews regarding how they feel their liveability has been affected. Four apartments were investigated and six apartment occupants from the four apartments were interviewed. Although the sample numbers were small, in general the liveability predictions from NZ ALI correlated closely with occupant interviews. The tool was able to provide acceptably accurate liveability profiles for the four apartments. Only one apartment had a 
liveability result that did not completely match the occupant discussion this was regarding issues surrounding Indoor Environmental Quality. While the tool was able to predict similar issues to those raised by the occupant, it was felt that the tool was not adequately weighted for this apartment. However as NZ ALI is required to provide evaluations that are representative for most people (i.e. not personally suited to or representative of all people), it was considered that as the tool does provide a reasonable assessment.

\subsubsection{CRITERION \#5 GENERAL}

The fifth development criterion that NZ ALI was required to meet was generality NZ ALI should be able to be applied to a range of apartments found in a range of environments and locations within New Zealand including existing apartments and new apartments in the future. This criterion was addressed during the Index Validation stage (refer to Section 0 ) at the same time as Criterion \#4. Part of the NZ ALI Trial and Critique was to determine how well the tool met Criterion \#5. The tool was applied to four different types of apartments and was trialled by different people to see how well it met Criterion \#5.

\section{General}

The index should be applicable to different environments within New Zealand and representative of typical New Zealand apartments at present and in near future

In general it was found that NZ ALI was able to be easily applied to a range of different apartment types, regardless of location, construction, size and so on. However, two issues were highlighted with the tool in regards to this criterion during the Index Validation (refer to Section 0). These were:

- Repeated component assessment

- Ability to use NZ ALI for both existing and new buildings

The first issue was addressed by incorporating an increased number meant that if a component is assessed across two or three Sections (e.g. Parking) then a provision question is used to initially determine if this component is available and if not then stop the user from being given these questions. This made the tool easier to use for apartments that did not incorporate these components.

The second issue was addressed by developing two versions of NZ ALI. The first NZ ALI for Existing Buildings assesses all the $153 \mathrm{NZ}$ ALI Indicators. The second NZ ALI for New Buildings assesses only 126 Indicators as 27 were determined to be irrelevant for new buildings. Five were modified so that they could be assessed in new buildings also (e.g. Ventilation Indicators).

It was found that, with these modifications the final NZ ALI is capable of being applied to a wide range of apartment types. The tool is not region specific as the region (e.g. Auckland or Wellington) is a predetermined factor (discussed in detail in Community). Where applicable, answers were provided to cover a range of choices to ensure that NZ ALI is generally applicable to as many types as possible. Should more answers be required at a later date, then NZ ALI has been developed to easily incorporate changes into the automated Microsoft Excel spreadsheet. 


\subsubsection{CRITERION \#6 USER FRIENDLY}

The sixth and final development criterion that NZ ALI was required to meet was that it should be easy to use, to understand and be straightforward. NZ ALI was required to be user friendly and able to be used by anybody regardless of expertise, knowledge or past experience.

\section{User Friendly}

The tool should be easy to use, easy to understand and straightforward for users

Criterion \#6 was tested during the Index Validation stage during the NZ ALI Critique. Here six apartment occupants were asked to use and test NZ ALI and were then asked a series of questions regarding the user friendliness, practicality and objectivity of the tool, the evaluation procedure and the results/outcomes. It was found that in general users felt that NZ ALI was user friendly due to the wide range of answers, types of assessments required and ease of use. Some parts of the tool did require modification (i.e. instructions, some wordings, scales and so on), but it was felt that these

, all the six occupants who took part in the NZ ALI

Critique were pleased with the tool, and found it to be user friendly, practical and objective. 


\subsection{METHODOLOGY ISSUES}

This section discusses the research approach used to develop NZ ALI. It identifies some of the methodological issues found during the development of NZ ALI. It also identifies improvements and adjustments for further research on these topics.

The only issues uncovered with the research approach used to develop NZ ALI were in relation to the survey used to calibrate NZ ALI. Calibration of the tool was required so that each of the NZ ALI components could be weighted and so that the tool could in turn provide a Liveability Rating or Profile. In essence, calibration of the tool ensured that NZ ALI is more than a set or checklist of components and is instead an evaluation tool. Two main issues were identified with the survey used to calibrate NZ ALI. These were:

- Survey Participation

- Survey Design

\subsubsection{SURVEY PARTICIPATION}

Survey participation was found to be a major issue in the NZ ALI research methodology. Three issues associated with it were:

- Participation,

- Random Sample,

- Incentives.

In general it was very hard to get an adequate number of participants and a fair representation of the end-user and stakeholder groups. Out of the 64 people sent the questionnaire or the on-link line, only 47 took part. One group (Building Owners \& Property Managers) had only two respondents and so this group was amalgamated with the Building Management group which also had a relatively low response rate of only 5 people. For this reason the survey results will most likely be skewed due to the low representation of these two groups in comparison to the other four groups. Before NZ ALI is fully deplored, it is recommended that a large number of stakeholder and end user groups are surveyed to ensure that the tool is adequately weighted and calibrated.

Because it was difficult to find an adequate number of respondents within the time frame of the research, the survey sample was not a fully random selection. In some cases people known to the researchers who fitted with a low represented group were asked directly to ensure that there was a reasonable representation of these groups. Despite these steps, as noted before there was still low representation of both Building Management and Building Owners/Developers.

It is felt for future development of NZ ALI, it would be important to offer incentives to encourage participation and increase survey response. Many surveys use incentives such as a Lotto ticket, grocery voucher, book voucher, petrol voucher and so on. In hindsight, such incentives would have probably helped to increase survey response. The result of this would be better survey response, 
greater representation of stakeholder and end-user groups, more accurate components weightings and finally a better calibrated tool.

\subsubsection{SURVEY DESIGN}

The second major issue with the NZ ALI research methodology and in particular with the NZ ALI Survey was the survey design. The two main issues regarding survey design were:

- Question Design,

- Survey Interface.

The main issue with the NZ ALI Survey design was concerned with the design of the questions, particularly wording and choices. Some respondents found that at times they struggled with the wording of some questions and answer choices. Either they found that some words were too technical and they did not understand them (particularly for the apartment occupant group), or they found that in some cases answer choices were very similar. For example Air Leakage and Draughts were the two choices for the Airtightness question, which many occupants found were too similar to distinguish between.

The NZ ALI Survey was designed using two interfaces a web-based instrument and a hardcopy/postal version. Both presented different issues: The web-based survey had issues surrounding the number of options respondents could choose for particular questions. Some respondents found that they could not adequately consider or choose between options when they were only able to pick one option (e.g. for Aspect questions). At times they wanted to choose more than one option as they were equally important to them but the design of the web-based survey did not allow them to do this which they reported as being highly frustrating.

In comparison, the hard-copy postal survey did not have limits incorporated in question answering. Despite clear instructions to choose the one most important option for the Aspect questions some postal respondents chose more than one option. When the first option was entered by default, it is had they been restricted in their choices and forced to choose between the different possible answers.

A second issue regarding the hard-copy postal surveys was partial completion. Because the webbased survey did not allow respondents to move on from a question until it had been answered correctly (i.e. only one option chosen for Aspect questions or for Feature, Section and Category questions rankings only used once) respondents were forced to make decisions in order to move on. The hard-copy postal survey did not put these restrictions on respondents. These people were able to choose more than one option, rank inappropriately, only partially complete questions and even not do some questions. Where this occurred, the first option was chosen and in the case of ranking questions missing rankings were included in alphabetical order. Where questions were not completed no answers were entered. In total there were 8 postal surveys and 4 of these were considered incomplete. Only one was completely unusable. 
The issues surrounding the survey design of the NZ ALI Survey pose an interesting dilemma. The aim of the survey was to weight each of the components and calibrate the index. Because of this it was felt necessary to force users to choose the options they considered the most important from their experiences and knowledge of apartments so that perceived importance of each component could be applied as weightings for calibration. It is understandable that some respondents found it difficult to choose one option over another. The purpose though was to ensure that appropriate weightings could be applied. For future development of NZ ALI or for future research using this methodology it is recommended to still force respondents to choose options, but it may helpful to allow two choices or less restrictive rankings where appropriate. Clarification of terms, a better understanding of the aim of the survey and also clearer instructions would also help to address these issues. It is not felt that these issues greatly affected the outcome of the survey, however some modification of the survey for future use would be beneficial to ensure that these issues do not occur again. 
New Zealand Apartment Living: Developing a Liveability Index 


\section{CONCLUSIONS AND RECOMMENDATIONS}

The overall aim of this research was to develop a method of evaluating liveability in New Zealand apartments. The research aimed to develop an evaluation tool that would enable prospective apartment buyers or tenants to easily and quickly evaluate and compare apartment liveability over a wide range of factors and not just those of current concern. The secondary aim of the research was to test the methodology of BQA, BQI and HPMFRB to develop a tool for New Zealand.

The specific objectives of the NZ ALI research were:

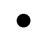

environment, particularly in higher density, high-rise housing,

- To investigate the issues the New Zealand public considers important regarding liveability of the residential built environment,

- To develop a Built Environment Assessment Tool [BEAT] that is capable of evaluating liveability of New Zealand apartments across a wide range of factors,

- To test the research approach used to develop other similar evaluation tools Building Quality Assessment [BQA], Building Quality Indicator [BQI] and Housing Performance Evaluation Model for Multi-family Residential Buildings [HPMFRB ] in developing an apartment liveability evaluation tool for New Zealand,

- To determine what different groups of end-users and stakeholders perceive to be important in regards to peoples liveability in higher density, high-rise housing.

The research approach employed to investigate these aims and objectives was trialled from methods used to develop similar evaluation tools both in New Zealand (BQA) and internationally (BQI and HPMFRB). Four stages of work were required to develop NZ ALI as follows:

- Hierarchy Development based on findings from the literature review,

- Index Development extension of hierarchy, including assessment methods for each indicator,

- Index Calibration development of weightings for NZ ALI components from survey with stakeholders and end-users,

- Index Validation consultation with end-users and use of NZ ALI to ensure that results are valid and accurate.

The research was found to be a success with a useable liveability evaluation tool being developed that evaluates liveability over a wide range of factors. Some issues surrounding the survey used to calibrate the tool were identified, particularly with survey participation and the survey design. However as the research is only intended as a pilot study of the research approach and the tool, these were not considered to have substantially affected the outcome.

The results of this research will be beneficial in understanding how people liveability can be affected in the residential built environment. There are many studies that show that health and housing are closely related Florence Nightingale is quoted as saying that the connection between health and the dwelling of the population is one of the most important that exists (Lowry, 1991) and research 
undertaken by WHO shows that we can spend up to two thirds of our lives at home (Ranson, 1991). It is important then that people understand how they can be affected by this relatively new type of housing in New Zealand. This research will help improve this understanding of higher density living in New Zealand, particularly in regards to why people want to live in this type of housing and what they consider important for their liveability.

As Baird et al. (1995) discusses, buildings are some of the longest lasting and complex products that people create but people are often at a disadvantage when making purchasing or leasing decisions about buildings. The liveability evaluation tool developed in this research, NZ ALI will enable prospective apartment tenants and buyers to easily and quickly evaluate and compare apartment liveability over a wide range of issues not just those that are currently of concern.

As well as helping to improve buying or tenancy decisions, a tool such as NZ ALI also has the potential to change the apartment market in New Zealand. Through the use and implementation of NZ ALI people will be able to demand a better quality of living in apartments. This in turn would be instrumental in driving market prices of apartments up or down where appropriate. The effect of this would mean that developers and designers would be required to design and market better apartments in New Zealand with occupant liveability in mind seeing a higher return for better quality.

NZ ALI will also be beneficial to building management and building owners as they would be able to consider how they might manage, maintain and upgrade apartments more effectively in order to attract occupants. NZ ALI has the potential to influence the minimum regulatory requirements of apartments in New Zealand where compliance with the NZBC could be contingent on specified scores in specific categories of NZ ALI.

This research could serve to enhance and improve the quality of living in New Zealand apartments. It has the ability to influence a range of people and disciplines and their decisions regarding New Zealand apartment living, design, quality and regulations. It provides an understanding of what is considered important, who these apartment dwellers are and why they want to live in apartments It Is vital in ensuring that New Zealand apartments are so designed as to be capable of providing highly liveable and quality dwellings. 


\subsection{CONCLUSIONS}

This section outlines the main findings and conclusions in relation to the specific aims and objectives of the research.

\subsubsection{LIVEABILITY IN HIGHER DENSITY HOUSING}

The first research objective in this study was to develop a comprehensive set of factors that affect liveability in the residential built environment, particularly in higher density, high-rise housing. From the literature review approximately 107 factors were identified that affect liveability in some way in higher density housing. The literature showed that the residential built environment is capable of affecting liveability in a variety of ways: it can affect physical health e.g. through the spread of infectious diseases from over-crowding or through structural collapse; it can affect mental wellbeing e.g. through increased stress caused by fears over security and crime; it can affect comfort e.g. from poor acoustic environments. It was determined from the results of the literature review that there are six main human requirements that when met provide liveable housing and each of the 107 factors determined align with one or more of these requirements.

- Amenity Access the ability to access certain amenities and landmarks within a community provide people with a sense of ease, comfort, safety and a sense of belonging. Amenities such as public buildings, landmarks, supermarkets, swimming pools, shops and entertainment venues are all important within a community.

- Connections to the Outdoors -like processes (biophilia) means that access or at least connection to the outdoors is essential for emotional well-being and cognitive performance. This may come through direct access to the outdoors or connections such as aural, visual, thermal or greenery stimuli

- Indoor Environment providing people with spaces that are visually, thermally, aurally and spatially satisfying and comfortable is vital. Good indoor environments allow people to be comfortable, happy and healthy

- Privacy the ability to identify territory or personal space is very important as crowding, density and inadequate space can be detrimental to health and well-being through increased stress, social withdrawal and physical health impacts such as transmission of infectious diseases. Privacy allows people to feel comfortable, safe and secure

- Quality Buildings factors such as airtightness, orientation, maintenance and emergency escape can be detrimental to liveability through increased stress, poor mental health, poor physical health

- Social Capital and Interactions social inclusion is very important for liveability as people benefit emotionally and physically from interpersonal relationships. Similarly the community benefits from the participation of its members as increased familiarity among people promotes mutual aid, empathy and a sense of belonging. 


\subsubsection{ACADEMICS VS THE PUBLIC}

The second research objective investigated factors that the New Zealand public considers important regarding liveability in the residential built environment. A review of academic literature (representing academic knowledge) and popular press (representing public opinion) was undertaken to determine what possible differences there may be between public opinion and academic knowledge. In total 90 pieces of literature were reviewed 36 from academia and 54 from the popular press. 840 counts for each of the 107 factors determined previously were recorded across both sets of literature.

This literature review and comparison showed that there is a clear difference between what academia values in higher density housing compared to what the public places value on. The public tends to place importance on issues that can be easily assessed (e.g. views, outdoor access and large windows) and that do not generally have any long term direct physical health effects. In contrast, academia places importance on issues that cannot easily be assessed and often affect liveability through longer term exposure (e.g. indoor air quality and acoustics).

The results show that the issues that the public believe are important (or are lead to feel are important through publicity in the popular press) can be easily assessed without a lot of information

e.g. in an open home. The review showed that there is a clear disparity between what both groups believe is important. The public (perhaps considered the less informed) makes purchasing or tenancy decisions based on readily assessed information whereas academia disregards these types of issues and places importance instead on issues that are less readily assessed and often have longer term liveability effects.

There is a gap between the knowledge of academia and what is considered important by the average person in New Zealand when considering how their liveability is likely to be affected in higher density housing. This gap shows that there needs to be a better method of evaluating the liveability of higher density housing so that academic knowledge may be passed on to the public to ensure they are able to make informed purchasing or tenancy decisions. It is clear that the public do not have access to useful information when considering buying or renting apartments. There is clearly a need for accessible information that will allow people to make informed decisions and NZ $\mathrm{ALI}$ is one possible answer to this problem.

\subsubsection{EVALUATING LIVEABILITY IN NEW ZEALAND APARTMENTS}

The third objective of this research was to develop a Built Environmental Assessment Tool [BEAT] that is capable of evaluating liveability of New Zealand apartments across a wide range of factors. Because the literature showed that there is a gap between the knowledge of academia and what is considered important by the general public, it was considered important that such a tool should be able to be primarily used by the general public and specifically by prospective apartment occupants.

An apartment liveability evaluation tool was developed in this research called NZ ALI. Two versions were developed, one for existing buildings and one for new buildings. 
The tool adhered to six development criteria to ensure that it was fit for purpose (as discussed in Section 6.2). These were:

1. Relevant

The factors considered should be directly related to the health, comfort, wellbeing and safety of occupants, users and visitors

2. Objective

Assessed factors should be measureable and verifiable to minimise the amount of subjectivity

3. Practical

The evaluation procedure should be simple and information easily acquired. It should not require instruments and/or sophisticated/specialist knowledge

4. Accurate

Results provided should be representative of how liveability may affect most people.

5. General

The index should be applicable to different environments within New Zealand and representative of typical New Zealand apartments at present and in near future

6. User Friendly

The tool should be easy to use, easy to understand and straightforward for users

NZ ALI was developed using the 107 factors identified in the literature review as a hierarchy. These were grouped into five overall Categories with a total of 13 Sections beneath them. At this stage Criterion \#1 was applied. Overall there are six levels to the hierarchy of NZ ALI, starting from the Objective (Liveability), Category (Configuration), Section (Spatiality), Feature (Storage), Aspect (Storage Size) and finally Indicator (Floor Area).

The hierarchy was developed into an index by including Assessment Methods and Credits for acceptable answers. At this stage Criteria \#2 and \#3 were applied. The index was then calibrated so that each of the $332 \mathrm{NZ}$ ALI components was weighted to enable NZ ALI to provide a Liveability Rating (percentage rating) and Liveability Profile (similar to a performance profile over the Category and Section levels). Calibration of the index was done through a survey which questioned six groups of people (Building Management, Building Owners/Developers, Designers, Occupants, Academics/Researchers and Governmental Organisations) regarding what they consider to be important in relation to liveability in higher density housing.

Once NZ ALI had been developed to a working stage it was then validated to ensure that its liveability evaluations matched occupant responses and the tool easy to use and general as per the development criteria \#4 \#6.

Validation of NZ ALI occurred by trialling the tool on four apartments and comparing the results to occupant interviews regarding how their liveability has been affected in the related apartment. The same occupants then also trialled using the tool to critique it and ensure it met the requirements of Criterion \#6. 


\subsubsection{TESTING OF METHODOLOGY}

The fourth research objective was to test the research approach used to develop other similar evaluation tools (BQA, BQI and HPMFRB) in developing an apartment liveability evaluation tool for New Zealand. The methodology used to develop NZ ALI followed very closely methods used to develop similar tools in New Zealand (BQA) and internationally (BQI and HPMFRB). In each of these tools a comprehensive set of factors and assessment were developed which were presented in the form of a weighted hierarchy or index that could provide both a Performance Rating and Performance Profile.

In both BQI and HPMFRB the AHP method of weighting the index components was used to develop a working index. In BQA however a simple ranking system was used. Both required user and stakeholder surveys for this. Due to time and participation constraints, the NZ ALI component weightings were determined through a ranking system similar to BQA. It was felt that due to the range of people needed to complete the survey and the number of questions that would be required with AHP it was more feasible to use a ranking system of determining weightings for NZ ALI rather than the AHP method.

Overall it was found that the method tested to develop an apartment liveability evaluation tool for New Zealand was appropriate. The tool developed (NZ ALI) is able to provide a quick and easy evaluation of liveability in New Zealand apartments over a comprehensive set of factors. This will ensure that prospective apartment occupants can easily assess and compare how different apartments may affect their liveability over a wider range of issues and not just those of current concern as portrayed in the popular press.

The one area of concern with the methodology tested in this research was with the survey used to develop NZ ALI component weightings. Due to low survey participation it was difficult to ensure that each of the six end user and stakeholder groups were adequately represented in the survey respondents. Also there were issues surrounding the questionnaire design and survey interface as some respondents found it hard to appropriately choose the best options. These issues are not related specifically to the methodology tested but rather to the survey itself. It is considered that the method used to develop NZ ALI was appropriate for developing such a tool for New Zealand apartments. Because of the limited survey sample size more work is needed in the future to ensure that component weightings applied to NZ ALI are representative of all stakeholder and end-user groups.

\subsubsection{PERCEIVED IMPORTANCE}

The fifth and final research objective of this study was to investigate whether different end user and stakeholder groups had differing views regarding what they felt was important for liveability in New Zealand apartments. This objective was investigated during the NZ ALI survey which was used to calibrate and weight the NZ ALI components.

Due to limited sample size and particularly low representation of two of the groups Building Management and Building Owners/Developers it is hard to accurately ascertain whether there is any 
difference in perceived importance of different NZ ALI components between the groups. Similarly because the NZ ALI Survey was on a relatively small scale (a total of 47 participants) due to the research being a pilot study testing the methodology, it is also hard to draw any significant conclusions concerning perceived importance.

However the analysis of the NZ ALI survey data showed that the differing opinions, experiences and knowledge of apartments in New Zealand between the groups did not differ significantly when considering perceived importance of the NZ ALI components. All groups showed that they considered the Community Category and its associated components to be the least important set of components within NZ ALI. This may be because these deal with the site and neighbourhood, so once the site has been determined they are fixed and unchangeable by the designer or building users.

The two Categories that all groups placed the highest importance on were Indoor Environmental Quality and Quality. Both of these Categories are only fixed after the design and construction of the apartment.

Because of the issues surrounding the NZ ALI Survey, particularly the low response rate and representation, it is hard to draw any significant conclusions regarding where different groups place importance for liveability. It was hoped that some trends may have been shown but this was not the case. In order to investigate this objective further a full scale, more comprehensive survey of all six end user and stakeholder groups is recommended. 


\subsection{FUTURE RESEARCH}

Over the last two decades there has been a rapid rise in apartment living in New Zealand. Since 1991 the number of building consents issued for new apartment buildings has risen from $1 \%$ of all residential buildings consents issued nationwide to $12 \%$. In 2004 consents for apartment buildings peaked at $21 \%$ of all residential building consents nationwide. Auckland City has experienced the largest urban intensification in New Zealand, with nearly 50\% of all consents issued from 1991 2008. Wellington has experienced the second highest level with $12 \%$ of all consents issued from the Wellington City Council. This rapid increase in higher density living and a building code that is currently inappropriate for apartment buildings has allowed the building of apartments with less than desirable levels of liveability. There are currently many issues with apartments in New Zealand surrounding indoor environmental quality, outdoor access, spatial design, storage provision and building amenities, to name a few.

The primary aim of this research was to develop an apartment liveability evaluation tool that will allow prospective occupants (buyers or tenants) to easily and quickly evaluate (and compare) how their liveability may be affected by a particular apartment or apartments. The tool that has been developed enables people to evaluate liveability over a comprehensive set of liveability factors and not just those of current concern. NZ ALI provides a way to bridge the gap between academic knowledge and what is considered important by the general public, and as a result enables people to make informed purchasing or tenancy decisions.

The secondary aim of the research was to test the research method used for developing BQA, BQI and HPMFRB. This research was a pilot study testing this methodology to see whether such a tool could be developed and whether the methodology was appropriate for New Zealand apartments. The research found that such a tool could be developed and that the method adopted from BQA, $\mathrm{BQI}$ and HPMFRB was appropriate for New Zealand apartments. Because the aim was not to develop a fully developed or finalised version of NZ ALI, the research has highlighted a number of areas for further research.

\subsubsection{NZ ALI}

The tool developed as part of this research into liveability in New Zealand apartments was developed as a pilot study testing both the methodology and ability to develop such a tool. NZ ALI is intended to be used by prospective apartment occupants primarily but also for use by building management, designers, regulatory agencies and real estate agents. Currently it is not fully developed for use by any of the potential end users because of issues with the survey used for calibration, minimal consultation and validation.

The survey used to determine the weightings of the NZ ALI components was limited in its size, as it was felt that it was unnecessary within the time constraints to undertake a full survey with equal representation of all six end user and stakeholder groups. In order for NZ ALI to begin to become a fully functional tool and be as accurate as possible a full survey would need to be undertaken that 
has an acceptably representative sample size. This will ensure that the knowledge, experience and opinions of all six end user and stakeholder groups are accurately represented in the NZ ALI component weightings.

NZ ALI is intended for use by prospective occupants, but also for regulatory agencies, designers and management. As well as undertaking a complete calibration survey, consultation and collaboration with these groups is recommended. Consultation (particularly with apartment occupants) will ensure that NZ ALI will meet their needs and is developed to meet their requirements. During this research consultation was only undertaken with a small group of current apartment occupants and not with any of the other five end user or stakeholder groups. It would be necessary to consult with all groups fully to ensure that the tool can be potentially used by all.

As well as further calibration of NZ ALI and end user/stakeholder consultation it is also recommended that NZ ALI undergoes further validation. This will ensure that the tool provides accurate liveability predictions and meets the requirements of users. While validation did occur as part of this research, it was limited due to the time constraints and nature of the work. Further validation of NZ ALI should be undertaken on a wider range of apartments nationally to ensure that the tool can be applied to a variety of apartments, used by all potential end users and is accurate. It is recommended that validation is on going to ensure that as higher density housing changes and evolves NZ ALI is still capable of delivering accurate and reliable liveability evaluations that are based on occupant requirements.

\subsubsection{PERCEIVED IMPORTANCE}

One of the secondary aims of this research was to investigate the potentially differing opinions of the end user and stakeholder groups in regards to liveability in New Zealand apartments. It was intended that the results from the NZ ALI Survey would be able to provide some insight to this. However due to issues surrounding low participation and representation of these groups in the survey it was difficult to ascertain whether there are any differing opinions between the groups that may have arisen from their experience and knowledge of New Zealand apartments. While it was not expected that a small survey such as this would be able to provide conclusive results, it was hoped that some trends could be suggested.

It would be of value to the building industry to fully investigate any potential differences in perceived importance of factors that influence liveability in apartments so that apartments are designed and constructed with the liveability of occupants in mind and not making a quick profit.

It is recommended that a full investigation of potential differences in perceived importance of factors that influence liveability in apartments is undertaken. Research into this would be particularly valuable to the New Zealand public and the building industry. It would ensure that New Zealand apartments are designed and constructed with the liveability of apartment occupants in mind rather than current concerns such as monetary benefits. It would also ensure that issues that are currently of concern in apartments (such as poor acoustics and visual environments) are minimised. Considering that the WHO suggested that people spend up to two thirds of their lives at home (Ranson, 1991) it is of vital importance that apartments in New Zealand are safe, healthy and 
comfortable for occupants. Investigation into the perceived importance of liveability factors would help to overcome current issues with liveability in New Zealand apartments.

\subsubsection{POTENTIAL END USE}

NZ ALI has been developed so that it is of most use for its primary end users prospective apartment occupants (buyers and tenants). However this tool will also benefit other areas of the building industry. It is suggested that widespread use of the tool could potentially influence market prices, with a premium in exchange for higher liveability. Further investigation of this potential benefit is recommended to ensure widespread and beneficial use of a fully developed tool.

Currently the compliance methods for the NZBC are generally inappropriate for use with apartments. It is understood that the NZBC is currently undergoing a major review and due to changing housing preferences it is also understood that more appropriate compliance methods for apartments will also be investigated. A fully developed NZ ALI could potentially be beneficial for New Zealand regulatory agencies (such as the Department of Building and Housing or Territorial Authorities) in developing minimum requirements for New Zealand apartments. Should the tool become widespread in use, it will help to influence the design and planning of New Zealand apartments. It will help to develop public expectations for apartment liveability, providing realistic guidance to a type of housing that is currently poorly served with quality information. 


\section{REFERENCES}

WORKS CITED

Assefa, G., Glaumann, M., Malmqvist, T., Kindembe, B., Hult, M., Myhr, U., et al. (2007).

Environmental Assessment of Building Properties - Where Natural and Social Sciences Meet: The Case of EcoEffect. Building and Environment, 42 (3), 14581464.

Auckland City Council. (2009). Appendix 12: Minimum Residential Apartment Standards. Retrieved November 2, 2009, from Auckland City Council:

http://www.aucklandcity.govt.nz/Council/documents/central/pdfs/appendix12.pdf

Auckland UniServices Ltd. (2004). Living the Highlife? A Review of Apartment Living in Inner City Auckland. A report prepared for the Building Industry Authority. Auckland: Auckland UniServices Ltd.

Auliciems, A., \& Szokolay, S. (1997). Thermal Comfort. Brisbane: PLEA in association with Department of Architecture, University of Queensland.

Baird, G., Gray, J., Isaacs, N., Kernohan, D., \& McIndoe, G. (1995). Building Evaluation Techniques. Wellington: McGraw-Hill.

Bluyssen, P. (2000). EPIQR and IEQ: Indoor Environment Quality in European Apartment Buildings. Energy and Buildings, 31 (2), 103110.

BRANZ Ltd. (N.D.). Health and Safety - Lead Paint. Retrieved November 9, 2009, from Level: http://www.level.org.nz/health-and-safety/lead-paint/

BRANZ Ltd. (N.D.). Passive Design, Insulation. Retrieved November 4, 2009, from Level: http://www.level.org.nz/passive-design/insulation/

Braubach, M. (2004). Residential Conditions and their Impact on Health and Residential Satisfaction Results of the WHO LARES Study. 2nd WHO Housing \& Health Symposium. Vilnius: WHO.

Bullen, C., Kearns, R., Clinton, J., Laing, P., Mahoney, F., \& McDuff, I. (2008). Bringing Health Home: Householder and Provider Perspectives on the Healthy Housing Programme in Auckland, New Zealand. Social Sciences \& Medicine, 66 (5), 1185-1196.

Burton, E. (2000). The Compact City: Just or Just Compact? Urban Studies, 37 (11), 1969-2001.

Butterworth, I. (2000). The Relationship between the Built Environment and Well-Being. A Literature Review. A report prepared for the Victorian Health Promotion Foundation, Melbourne.

Cole, R. (1999). Building Environmental Assessment Methods: Clarifying Intention. Building Research \& Information, 27 (4/5), 232-246.

Consumer NZ. (2003, March). Living in the City. Consumer, 423, pp. 17-19. 
Criscillo, V., \& Tong, H. (1999). Wellington City Apartments: The Survey: "What Type of Apartments do you Really Want?". Wellington: Moore Warburton Ltd.

Crockers Property Group. (2005). Crockers Corner Issue 27 July 2005. Retrieved October 31, 2009, from Crockers Property Group:

http://www.crocker.co.nz/tp/download/18339/60e6ecda2f69cba0035c7d675fdd9c7c/cc-july05.pdf\%20-

Department of Building \& Housing. (2009, October 22). About the Building Code. Retrieved October 28, 2009, from Department of Building \& Housing: http://www.dbh.govt.nz/bcr-about-the-buildingcode

Department of Building \& Housing. (2007). Building Code Review Report. Retrieved November 4, 2009, from Department of Building \& Housing:

http://www.dbh.govt.nz/UserFiles/File/Building/building-code-review/pdf/Building-Code-reviewreport.pdf

Department of Building \& Housing. (2009, September 1). NZBC Clause E2 External Moisture Compliance Document. Retrieved October 1, 2009, from Department of Building \& Housing: http://www.dbh.govt.nz/UserFiles/File/Publications/Building/Compliance-documents/E2-ExternalMoisture-effective-1-May-2008.pdf

Department of Building \& Housing. (2009, September 1). NZBC Clause G12 Water Supplies Compliance Document. Retrieved November 9, 2009, from Department of Building \& Housing: http://www.dbh.govt.nz/UserFiles/File/Publications/Building/Compliance-documents/clause-G12water-supplies.pdf

Department of Building \& Housing. (2009, September 1). NZBC Clause G4 Ventilation Compliance Document. Retrieved October 28, 2009, from Department of Building \& Housing:

http://www.dbh.govt.nz/UserFiles/File/Publications/Building/Compliance-documents/clause-g4.pdf

Department of Building \& Housing. (2009, September 1). NZBC Clause G7 Natural Light Compliance Document. Retrieved October 28, 2009, from Department of Building \& Housing:

http://www.dbh.govt.nz/UserFiles/File/Publications/Building/Compliance-documents/clause-G7.pdf

Department of Building \& Housing. (2009, September 1). NZBC Clause H1 Energy Efficiency Compliance Document. Retrieved November 4, 2009, from Department of Building \& Housing: http://www.dbh.govt.nz/UserFiles/File/Publications/Building/Compliance-documents/clause-H1.pdf

Department of Building \& Housing. (2009, September 1). NZBC Handbook 3rd Edition. Retrieved October 28, 2009, from Department of Building \& Housing:

http://www.dbh.govt.nz/UserFiles/File/Publications/Building/Compliance-documents/buildingcode-handbook.pdf

DTZ Research. (2003). Auckland Inner City Living Survey, Executive Summary. Retrieved October 31, 2009, from Auckland City Council:

http://www.aucklandcity.govt.nz/council/projects/cbdproject/docs/executivesummary.pdf 
DTZ Research. (2004). Changes in the Structure of the New Zealand Housing Market Executive Summary. A report prepared for the Centre for Housing Research, Aotearoa New Zealand. Wellington: DTZ Research.

E 1700 - 95. (1995). Standard Classification for Serviceability of an Office Facility for Structure and Building Envelope. United States of America: ASTM International.

E 1701 - 95. (1995). Standard Classification for Serviceability of an Office Facility for Manageability. United States of America: ASTM International.

Elsevier Publishers. (2009). ScienceDirect. Retrieved December 2, 2009, from ScienceDirect: www.sciencedirect.com

Elsevier Publishers. (2009). Scopus. Retrieved December 2, 2009, from Scopus:

http://www.scopus.com/home.url

Energy Efficiency and Conservation Authority. (2009). Home Energy Ratings [HERS]. Retrieved October 31, 2009, from Energy Efficiency and Conservation Authority: http://www.eeca.govt.nz/eeca-programmes-and-funding/programmes/homes/home-energy-ratings Evans, G. (2003). The Built Environment and Mental Health. Journal of Urban Health, 80 (4), 536-555. Forman, E., \& Gass, S. (2001). The Analytic Hierarchy Process - An Exposition. Operations Research, 49 (4), 469-486.

Frumkin, H. (2001). Beyond Toxicity - Human Health in the Natural Environment. American Journal of Preventative Medicine, 20 (3), 234-240.

Gray, A. (2001). Definitions of Crowding and the Effects of Crowding on Health. A report prepared for the NZ Ministry of Social Policy. Gray Matter Research.

Hasselaar, E. (2004). Checklist Healthy Housing for Tenants and Home Owners. 2nd WHO International Housing and Health Symposium (pp. 93-103). Vilnius: World Health Organisation.

Hasselaar, E. (2006). Health Performance of Housing. Indicators and Tools (Sustainable Urban Areas). Amsterdam: Delft University Press.

Ho, D., Chau, K., Cheung, A., Yau, Y., Wong, S., Leung, H., et al. (2008). A Survey of the Health and Safety Conditions of Apartment Buildings in Hong Kong. Building and Environment, 43 (5), 764-775.

Ho, D., Leung, H., Wong, S., Cheung, A., Lau, S., Wong, W., et al. (2004). Assessing the Health and Hygiene Performance of Apartment Buildings. Facilities, 22 (3), 58-69.

Jackson, L. (2003). The Relationship of Urban Design to Human Health and Condition. Landscape and Urban Planning, 64 (4), 191-200.

Jacobs, D. (2006). A Qualitative Review of Housing Hazard Assessment Protocols in the United States. Environmental Research, 102 (1), 13-21. 
Kim, S., Yang, I., Yeo, M., \& Kim, K. (2005). Development of a Housing Performance Evaluation Model for multi-Family Residential Buildings in Korea. Building and Environment, 40 (8), 1103-1116.

Lowry, S. (1991). Housing. British Medical Journal, 838-840.

Lyne, N., \& Moore, R. (2004). The Potential Health Effects of Residential Intensification in Auckland City. Auckland: Auckland University of Technology.

Mitchell, A. (1972). The Half Gallon, Quarter Acre, Pavlova Paradise. Christchurch: Whitcombe and Tombs.

Moore, M., Gould, P., \& Keary, B. (2003). Global Urbanization and Impact on Health. International Journal of Hygiene and Environmental Health, 206 (4-5), 269-287.

Morrison, P., \& McMurray, S. (1999). The Inner-city Apartment versus the Suburb: Housing Sub Markets in a New Zealand City. Urban Studies, 36 (2), 377-397.

Myhr, U. (2008). Property-level Environmental Assessment Tools for Outdoor Areas. PhD Thesis. Swedish University of Agricultural Sciences.

Myhr, U., \& Johansson, R. (2008). EcoEffect for Outdoor Environments: the Process of Tool Development. Environmental Impact Assessment Review, 28 (7), 439-454.

National Library of New Zealand. (2009). Index New Zealand. Retrieved December 2, 2009, from Index New Zealand: http://innz.natlib.govt.nz/content/index.html

New Zealand Green Building Council. (2008). Green Star New Zealand. Retrieved December 2, 2009, from New Zealand Green Building Council: http://www.nzgbc.org.nz/main/greenstar

Niu, J. (2004). Some Significant Environmental Issues in High-Rise Residential Building Design in Urban Areas. Energy and Buildings, 36 (12), 1259-1263.

North Shore City Council. (2007). Urban Design: Apartment Developments. Retrieved October 31, 2009, from North Shore City Council:

http://www.northshorecity.govt.nz/YourCouncil/Planning/UrbanDesign/Pages/UrbanDesignApartm entDevelopments.aspx

NZS 4303: 1990. (1990, September 14). Ventilation for acceptable indoor air quality. Standards New Zealand.

Oxford English Dictionary. (2009, June). Livability. Retrieved October 28, 2009, from Oxford English Dictionary Online:

http://dictionary.oed.com.helicon.vuw.ac.nz/cgi/entry/50134420/50134420spg1?single=1\&query t ype=misspelling\&queryword=liveability\&first $=1 \& \max$ to show $=10 \&$ hilite $=50134420$ spg 1

Oxford English Dictionary. (2009, September). Livable. Retrieved October 28, 2009, from Oxford English Dictionary Online:

http://dictionary.oed.com.helicon.vuw.ac.nz/cgi/entry/50134421/50134421spg1?single=1\&query t ype=misspelling\&queryword=liveable\&first $=1 \& \max$ to show $=10 \&$ hilite $=50134421$ spg 1 
Rankine, J. (2005). The Housing and Health in Auckland: A Summary of Selected Research. A report prepared for the Auckland Regional Public Health Service of the Auckland District Health Board, Auckland.

Ranson, R. (1991). Healthy Housing - A Practical Guide. London: E \& F.N. Spon.

Rao, M., Prasad, S., Adshead, F., \& Tissera, H. (2007). The Built Environment and Health. The Lancet, 370 (9593), 1111-1113.

Raw, G., Aizlewood, C., \& Hamilton, R. (Eds.). (2001). Building Regulation, Health and Safety BR417. Watford: Building Research Establishment.

Roulet, C. (2001). Indoor Environment Quality in Buildings and Its Impact on Outdoor Environment. Energy and Buildings, 33 (3), 183-191.

Ruck, N. (Ed.). (1989). Building Design and Human Performance. New York: Van Nostrand Reinhold.

Singh, J. (1996). Review: Health, Comfort and Productivity in the Indoor Environment. Indoor and Built Environment, 5 (1), 22-33.

Smartt, P. (2004). Mortality, Morbidity and Asbestosis in New Zealand: The Hidden Legacy of Asbestos Exposure. Journal of New Zealand Medical Association, 117 (1205).

Statistics New Zealand. (2009, October 28). 2006 Census: Final Counts Tables. Retrieved October 28, 2009, from Statistics New Zealand: http://www.stats.govt.nz/census/2006-census-data/2006census-reports/final-counts-tables.aspx

Statistics New Zealand. (2009, August 20). Building Consents Statistics for New Apartment Buildings 1991 - 2008. Wellington, New Zealand: Accessed from Infoshare database.

Statistics New Zealand. (2005). Downtown Dwellers 2005. Retrieved October 31, 2009, from Statistics New Zealand: http://www.stats.govt.nz/ /media/statistics/publications/analyticalreports/downtown-dwellers/downtown-dwellers-2005.aspx

Statistics New Zealand. (2006). Reducing Energy Use. Retrieved November 4, 2009, from Statistics New Zealand: http://www.standards.co.nz/news/Media+archive/July++ Sept+06/Reducing+Energy+Use.htm

Stewart, K., \& Donn, M. (2008). New Zealand Daylight Code Compliance Tool: Development and Implementation. PLEA 2008 - 25th Conference on Passive and Low Energy Architecture. Dublin: Passive and Low Energy Architecture.

Sullivan, M. (2006). Sounds like Conflict. Retrieved November 4, 2009, from Resource Management Law Association of New Zealand:

http://www.google.co.nz/url?sa=t\&source=web\&ct=res\&cd=5\&ved=0CB8QFjAE\&url=http\%3A\%2F\% 2Fwww.rmla.org.nz\%2Fpublications 2006\%2F1530\%2520Michael\%2520Sullivan.ppt\&ei=J7fwSuCXG 42wsgOrjLjyBQ\&usg=AFQjCNFurFILUhNTV2ALnCuL2pkvitxaAw\&sig2=QUp Ejtd8ZnjM27CINcW3A

The Building Act 2004. (2004, August 24). The Building Act 2004 No. 72. New Zealand: Parliamentary Government Office. 
Thompson, W. (2007, March 20). Urban Design: Blueprint for Better Apartment Design. The New Zealand Herald, p. A7.

Unit Titles Act. (2008, February). Unit Titles Bill (Draft). New Zealand: Parliamentary Government Office.

Venter, N. (2006, November 11). The Second Wave. The Dominion Post, pp. E1-2.

Waghorn, B. (2006, April/May). Apartments that don't make the grade. BUILD, pp. 58-60.

Wellington City Council. (2009). Central City Apartment Dwellers Survey - a summary of results.

Retrieved October 31, 2009, from Wellington City Council:

http://www.wellington.govt.nz/services/urban/pdfs/apartment-survey-report.pdf

Whole Building Design Guide. (2007). Psychosocial Value of a Space. Retrieved October 31, 2009, from Whole Building Design Guide: http://www.wbdg.org/resources/psychspace value.php

Wong, S., Cheung, A., Yau, Y., Ho, D., \& Chau, K. (2006). Are our residential buildings healthy and safe? A survey in Hong Kong. Structural Safety, 24 (1), 77-86.

World Health Organisation. (2006). Constitution of the World Health Organisation. Retrieved October 31, 2009, from World Health Organisation:

http://www.who.int/governance/eb/who constitution en.pdf

ZapSurvey. (2009). ZapSurvey. Retrieved November 1, 2009, from ZapSurvey:

http://www.zapsurvey.com/ 


\section{LITERATURE REVIEWED}

The following two reference lists provide details on the literature reviewed to compare academic knowledge and public opinion.

ACADEMIC LITERATURE

Assefa, G., Glaumann, M., Malmqvist, T., Kindembe, B., Hult, M., Myhr, M., et al. (2007).

Environmental Assessment of Building Properties Where Natural and Social Sciences Meet: The Case of EcoEffect. Building and Environment, 42(3), 14581464.

Auckland UniServices Ltd. (2004). Living the Highlife? A Review of Apartment Living in Inner City Auckland. Report Prepared for the Building Industry Authority.

Bierre, S., Cunningham, C., Cunningham, M., Baker, M., Robinson, J., Kennedy, M., et al. (2004, September 29 October 1). A Healthy Housing Index: A Collaborative Approach to Measuring Housing Condition. Paper presented at the $20042^{\text {nd }}$ WHO Housing and Health Symposium, Vilnius, Lithuania.

Bluyssen, P.M. (2000). EPIQR and IEQ: Indoor Environmental Quality in European Apartment Buildings. Building and Environment, 31(2), 103110.

Braubach, M. (2004, September 29 October 1). Residential Conditions and Their Impact on Health and Residential Satisfaction - Results of the WHO LARES Study. Paper presented at the $20042^{\text {nd }}$ WHO Housing and Health Symposium, Vilnius, Lithuania.

Bullen, C., Kearns, R.A., Clinton, J., Laing, P., Mahoney, F., \& McDuff, I. (2008). Bringing Health Home: Householder and Provider Perspectives on the Healthy Housing Programme in Auckland, New Zealand. Social Sciences \& Medicine, 66(5), 11851196.

Burton, E. (2000). The Compact City: Just or Just Compact? A Preliminary Analysis. Urban Studies, 37(11), 19692001

Butterworth, I. (2000). The Relationship between the Built Environment and Well-Being: A Literature Review. Report prepared for the Victorian Health Promotion Foundation, Melbourne, Australia.

Chau, C.K., Yung, H.K., Leung, T.M., \& Law, M.Y. (2006). Evaluation of Relative Importance of Environmental Issues Associated with a Residential Estate in Hong Kong. Landscape and Urban Planning, 77(1-2), $67 \quad 79$.

Criscillo, V., \& Tong, H. (1999). Wellington City Apartments: The Survey: "What Type of Apartments do you Really Want?". Wellington, New Zealand; Moore Warburton Ltd.

Evans, G.W. (2003). The Built Environment and Mental Health. Journal of Urban Health, 80(4), 536 555 
Gray, A. (2001). Definitions of Crowding and the Effects of Crowding on Health: A Literature Review. Report prepared for the Ministry of Social Policy, Wellington, New Zealand.

Guite, H.F., Clark, C., \& Ackrill, G. (2006). The Impact of the Physical and Urban Environment on Mental Well-Being. Public Health, 120(12), 11171126.

Hasselaar, E. (2004, September 29 October 1). Checklist Healthy Housing for Tenants and Home Owners. Paper presented at the $20042^{\text {nd }}$ WHO Housing and Health Symposium, Vilnius, Lithuania.

Isaacs, N.I. (1999, September 14). Building Science, Regulations and Health. Paper presented at the 1999 EECA Seminar

New Zealand.

Jackson, L.E. (2003). The Relationship of Urban Design to Human Health and Condition. Landscape and Urban Planning, 64(4), 191200.

Jacobs, D.E. (2006). A Qualitative Review of Housing Hazard Assessment Protocols in the United States. Environmental Research, 102(1), 1321.

Kim, S.S., Yang, I.H., Yeo, M.S., \& Kim, K.W. (2005). Development of a Housing Performance Evaluation Model for Multi-Family Residential Buildings in Korea. Building and Environment, 40(8), 11031116.

Lawrence, R.J. (2004). Housing and Health: From Interdisciplinary Principles to Transdisciplinary Research and Practice. Futures, 36(4), 487502.

Lutzkendorf, T., \& Speer, T.M. (2005). Alleviating Asymmetric Information in Property Markets: Building Performance and Product Quality as Signals for Consumers. Building Research and Information, 33(2), 182195.

Lyne, M., \& Moore, R. (2004). The Potential Health Impacts of Residential Intensification in Auckland City. Report prepared for EnHealth, Auckland, New Zealand.

Moore, M., Gould, P., \& Keary, B.S. (2003). Global Urbanization and Impact on Health. International Journal of Hygiene and Environmental Health, 206(4 - 5), 269287.

Morrison, P.S., \& McMurray, S. (1999). The Inner-city Apartment versus the Suburb: Housing Sub Markets in a New Zealand City. Urban Studies 36(2). 377397.

Myhr, U., \& Johansson, R. (2008). EcoEffect for Outdoor Environments; the Process of Tool Development. Environmental Impact Assessment Review, 28(7), 439-454.

$\mathrm{Ng}$, E. (2003). Studies on daylight design and regulation of high-density residential housing in Hong Kong. Lighting Research and Technology, 35(2), 127139.

Niu, J. (2004). Some Significant Environmental Issues in High-Rise Residential Building Design in Urban Areas. Energy and Buildings, 36(12), 12591263.

Ormandy, D. (2004, September 29 October 1). Safe as Houses? A Review of the Causes of Home Accidents. Paper presented at the $20042^{\text {nd }}$ WHO Housing and Health Symposium, Vilnius, Lithuania. 
Rankine, J. (2005). The Housing and Health in Auckland: A Summary of Selected Research. Report prepared for the Auckland Regional Public Health Service of the Auckland District Health Board, Auckland, New Zealand.

Rao, M., Prasad, S., Adshead, F., \& Tissera, H. (2007). The Built Environment and Health. The Lancet, 370(9593), 11111113.

Raw, G.J., Aizlewood, C.E., \& Hamilton, R.M. (Eds). (2001). Building Regulation, Health and Safety. Watford, England; Building Research Establishment (BRE).

Richardson, G., Eick, S.A., \& Shaw, S.R. (2006). Designing a Simple Tool Kit and Protocol for the Investigation of the Indoor Environment in Homes. Indoor and Built Environment, 15(5), 411424.

Roulet, C.A. (2001). Indoor Environment Quality in Buildings and its Impact on Outdoor Environment. Energy and Buildings, 33(3), 183191.

Stewart, J. (2005). A Review of UK Housing Policy: Ideology and Public Health. Public Health, 119(6), 525534.

Whole Building Design Guide (WBDG). (2006). Promote Health and Well-Being. Retrieved April 30, 2008 from http://www.wbdg.org/design/promote health.php

Whole Building Design Guide (WBDG). (2007). Psychosocial Value of a Space. Retrieved April 30, 2008 from http://www.wbdg.org/resources/psychspace value.php

The following publications all discuss $\mathrm{BQI}$. The $\mathrm{BQI}$ is the amalgamation of the $\mathrm{BHHI}$ and the $\mathrm{BSCl}$. The counts identified in these three papers were combined into one count set for this work in order to ensure that there was not an over-representation of this study (and the authors) in the final count. This set of counts for the Hong Kong BQI research was then attributed to one publication.

Ho, D.C.W., Chau, K.W., Cheung, A.K.C., Yau, Y., Wong, S.K., Leung, H.F., et al. (2008). A Survey of the Health and Safety Conditions of Apartment Buildings in Hong Kong. Building and Environment, 43(5), 764775 .

Ho, D.C.W., Leung, H.F., Wong, S.K., Cheung, A.K.C., Lau, S.S.Y., Wong, W.S., et al. (2004). Assessing the Health and Hygiene Performance of Apartment Buildings. Facilities, 22(3), 5869.

Wong, S.K., Cheung, A.K.C., Yau, Y., Ho, D.C.W., \& Chau, K.W. (2006). Are our residential buildings healthy and safe? A Survey in Hong Kong. Structural Survey, 24(1), 7786. 
POPULAR PRESS

Barker, L. (2005, Spring). Three times a charm. Urbis, 29, p. 5862.

Dominion Post, p. F16 17.

Budd, S. (2000, October). What goes around. New Zealand Management, 47(9), p. 5861.

Clement, D. (2007, August). New build versus conversions swings and roundabouts. New Zealand Property Magazine, 45, p. 2832.

Clement, D. (2007, January). Bones of apartment market may be worth picking over. New Zealand Property Magazine, 38, p. 3033.

Consumer NZ. (2003, March). Living in the city. Consumer, 423, p.17 19.

Cumming, G., Ried, G., \& Watkin, T. (2003, November 1). The big squeeze. New Zealand Herald, p. B1 5.

Dekker, D. (2006, February). A rest from the fest. NZ House \& Garden, 138, p. 3840.

Fraser, S. (1999, Winter). Top level performance. Urbis, 4, p. 2833.

Gamble, W. (2001, May 5). Up among the bright lights. New Zealand Herald, B5.

Gawith, A. (2000, February). Property Business, 6, p. 12.

Gibson, A. (2005, October 1). Rooms with an overcast view. New Zealand Herald, p. B6.

Greene, K. (2005, April 12). Be wary of apartment risks. Press, p. D4.

Harvey, C. (2007, October 6). Wall on the wild side. New Zealand Herald, p. Sup 3436.

Harwood, L., \& Mitchell, I. (2003, April). Intensification marches on; central city transformed.

Property Business, 24, p.12 \& 2426.

Holt, J. (2007, August). Making the move to high rise apartment living. New Zealand Property Magazine, 45, p. 3031.

Huse, S. (2004, Winter). Height of sophistication. Urbis, 24, p. 8085.

Huse, S. (2004, Winter). The finer point. Urbis, 24, p. 130135.

Hutching, C. (2004, April). Nelson boom resonates. Property Business, 31, p. 2426.

Johnson, A. (2004, June 5). Downtown living is still on the up and up. Dominion Post, p. A10.

Jones, P. (2004, Winter). Branded awareness. Urbis, 24, p. 6268.

Kennedy, F. (1999, Spring). Bring it on home. Urbis, 5, p. 7680.

Kitchin, R. (2004, June 12). Inner sanctum. Dominion Post, p. E14. 
Lloyd-Jenkins, D. (2000, August 9). Urban links. New Zealand Herald, p. G3.

Lloyd-Jenkins, D. (2004, Spring). Cintra of gravity. Heritage New Zealand, 94, p. 4445.

Louisson, J. (2000/2001, Summer). A perfect entrance. Urbis, 10, p. 8890.

Magill, J. (2006, December). The middle ground. NZ House \& Garden, 148, p. 110117.

inner city. Metro (Auckland), 315, p. 119

121.

Markman, T. (2003/2004, Summer). Marriage of old and new. Urbis, 22, p. 140144.

Marriage, G. (2000/2001, Summer). Up on the roof. Urbis, 10, p. 8084.

Mayo, F. (1999, Autumn). Style statesman. Urbis, 3, p. 7175.

Mayo, F. (2000/2001, Summer). Paradise regained. Urbis, 10, p. 3238.

McLeod, J. (2005, Autumn). Southern comfort. Urbis, 27, p. 148153.

Nation, D. (2004, July). Journey to the interior. NZ House \& Garden, 119, p. 2838.

Neville, P. (2006, November). Extremes of style. NZ House \& Garden, 147, p. 106113.

Nichol, R. (2002, December 12). Fifties chic. Dominion Post, p. F20.

Nichol, R. (2003, November 1). A kowhai in the city. Dominion Post, p. E16 17.

Nichol, R. (2004, August 23). Windows on Wellington. Dominion Post, P. F14.

Oakley, J. (2000, February 5). View from the top. New Zealand Herald, p. G1.

Olsen, R. (2008, April 17). Tower for II Casino Site. The Wellingtonian, p. 1 \& 24.

woes. Hospitality, 42(8), p. 1415.

Packer, A. (2002, December 21). Settling in the valley. Dominion Post, p. F12.

Packer, A. (2004, January 31). Art décor. Dominion Post, E12 13.

-density housing. New Zealand Herald,

p. A17.

Philp, M. (2007, February 10). Drawing a blank on housing. Press, p. D3.

Revell, F. (2000, April 9). Growing up. Sunday Star Times, p. D3

Sye, A. (2003/2004, Summer). A wool to survive. Urbis, 22, p. 8490.

Thompson, W. (2007, March 20). Blueprint for better apartment design. New Zealand Herald, p. A7

Venter, N. (2006, November 11). The second wave. Dominion Post, p. E1 2. 
Von Grondelle, C. (1999/2000 Summer). Inner city kids. Urbis, 6, p. 134138

Waghor

BUILD, 194, p. 5860 .

Wakefield, A. (2003, September). When education takes over. Planning Quarterly, 150, p.24 26.

Walsh, J. (2004, Spring). Viaduct declamation. Urbis, 25, p. 120124.

Wells, V. (2007, May). Doing your apartment homework. New Zealand Property Magazine, 42, p. 7. 
New Zealand Apartment Living: Developing a Liveability Index 
APPENDIX A GLOSSARY

\section{A.1 ABBREVIATIONS}

ACC: Auckland City Council

ACDM: Academics and Researchers (End User/Stakeholder Group)

AHP: The Analytical Hierarchy Process

AM: Assessment Method

ARCH: Architects, Designers and Engineers (End User/Stakeholder group)

BEAT: Built Environmental Assessment Tools

BMOD: Building Management, Owners and Developers (End User/Stakeholder group)

BQA: Building Quality Assessment

BQI: Building Quality Indicator

BHHI: Building health \& Hygiene Index

BSCI: Building Safety and Conditions Index

$\underline{\mathrm{CW}}$ : Component Weighting

DBH: Department of Building and Housing

GOVT: Governmental Organisation (End User/Stakeholder group)

HERS: Home Energy Rating Scheme

HHC: Healthy Housing Checklist

HPMFRB: Housing Performance Evaluation Model for Multi-family Residential Buildings

IAQ: Indoor Air Quality

IEQ: Indoor Environmental Quality

LIM: Land Information Memorandum

PIM: Project Information Memorandum

NSCC: North Shore City Council

NZBC: New Zealand Building Code

Jessica Bennett 
NZ ALl: The New Zealand Apartment Liveability Index

OCPT: Apartment Occupants (End User/Stakeholder group)

SARS: Severe Acute Respiratory Syndrome

Statistics NZ: Statistics New Zealand

STM: Serviceability Tools and Method

: Territorial Authorities

: Volatile Organic Compounds

WBDG: Whole Building Design Guide

WCC: Wellington City Council

WHO: The World Health Organisation

WHRS: Weathertightness Homes Resolution Service 


\section{A.2 DEFINITIONS}

\section{NZ ALI Terminology}

Aspect: Fifth level in the NZ ALI hierarchy, representing an issue for each Feature that needs to be addressed

Assessment Method: Method of assessing each of the Indicators

Assessment Question: The question to be answered for each Indicator

Category: Second level of the NZ ALI hierarchy, representing the five main areas in the evaluation to be considered

Component: A part or constituent of NZ ALI across any level of the hierarchy, i.e. a Category, Feature and Aspect are all components of NZ ALI

Credit: Percentage of weight awarded for a given answer

Criterion/Criteria: Requirements for the development of NZ ALI

Feature: Fourth level of the NZ ALI hierarchy, representing issues for each Section that needs to be addressed

Factors: Issues identified in the literature review that became the basis of the NZ LI hierarchy framework

Hierarchy: The framework structure of NZ ALI where the different levels allow users to focus on different issues without losing sight of the evaluation purpose

Indicator: Sixth level of the NZ ALI hierarchy, representing what will be assessed for each Aspect

Objective: First level of the NZ ALI hierarchy, representing the evaluation purpose

Section: Third level of the NZ ALI hierarchy, representing the main issues covered in the Categories

\section{General Terminology}

Amenity: Something that makes life more pleasant or comfortable

Apartment: A dwelling unit that is located in a building occupied by more than one household/dwelling unit. Generally have one or more inter-tenancy walls

Apartment Building: A building with ten or more dwelling units, usually more than two storeys with shared communal facilities and configured vertically

Comfort: A condition or feeling of pleasurable ease, well-being, and contentment 
Detached Dwelling/Stand=alone Housing: A dwelling unit where a group live as a single household. The building contains only one dwelling unit and there are no inter-tenancy walls

Health:

infirmity, but a state of complete physical, mental and social well-

Liveability: The suitability of a house for habitation and the capacity of offer comfortable living

Services:

water supplies, drainage, refuse disposal, fire services, electrical systems, etc

Terraced House: A dwelling unit located in a building with more than one dwelling unit, usually configured horizontally with only one or two inter-tenancy walls

Utility: A commodity or service, such as electricity, water, or public transportation that is provided by a public utility

Well-being: A good or satisfactory condition of existence; a state characterized by health, happiness, and prosperity; welfare 


\section{APPENDIX B BACKGROUND}

Further explanation of the liveability effects identified in the literature review is provided here. Liveability effects have been grouped by the NZ ALI Categories and Sections.

\section{B.1 COMMUNITY}

\section{B.1.1 ENVIRONMENT}

\section{Location}

Location is an important determinate of both health and well-being. It ties into many other issues such as IAQ (external variables), crime, safety and security, aesthetics of place, neighbourhood, and happiness with surroundings and so on

\section{Outdoor Air Quality}

Contaminanta and pollutants in outdoor air come from traffic, combustion and waste. The risk of inhalation of these in the outdoor air while it can not be avoided can be minimised.

Short-term increase are associated with increase mortality and morbidity rates, and long term effects include cardiopulmonary disease, reduced lung function, respiratory illness and possibly cancer (Raw, Aizlewood, \& Hamilton, 2001)

\section{Site Shading}

Outdoor shading is important because it allows people to use outdoor areas without adverse health affects (i.e. sunburn and heat stroke etc). It is often noted that residents prefer trees providing shade over particular areas utilised for outdoor activities (Myhr \& Johansson, 2008).

\section{Site Typology}

The type of site a building is located in can affect livability for example through sunniness or hilliness and so on. Similarly hilly sites can affect physical activity both adversly and negatively.

Land can become contaminated through industrial processes, landfill activities and agricultural uses. Naturally occurring contaminants can also contaminate land. Many contaminants are toxic or carcinogenic which raises many health issues when building on contaminated sites (Raw, Aizlewood, \& Hamilton, 2001).

\section{Wind Environment}

The wind in an around the built environment can affect liveability in a variety of ways.

It can affect sleeping through noise (Assefa, et al., 2007) and is also affects ventilation and indoor comfort (Niu, 2004).

Building design affects how the wind moves through a space and so can affect pedestrian safety when wind speeds become too high. On the other hand buildings provide protection from wind (Roulet, 2001)

Figure B-1, Liveability Effects: Environment 


\section{B.1.2 NEIGHBOURHOOD}

\section{Graffiti \& Crime}

Buildings and their immediate surroundings are directly involved in the majority of crimes; commonly burglary, vandalism, car crime and arson. Health risks are either direct (i.e. injuries caused during the criminal act), or indirect due to peoples fear/perception of crime. Fear of crime can lead to people modifying their lifestyle and living preferences reducing their willingness to participate in external activities, leading to a spiral of decline in communities and neighbourly links (Raw, Aizlewood, \& Hamilton, 2001).

\section{Green Spaces}

Access to green spaces is extremely important, both physically and visually. It increases physical activity and mental well-being because sustained exercise is incorporated into daily routines. By providing access to green spaces, this encourages more walking and cycling and opportunities for informal social contact and interaction. (Rao, Prasad, Adshead, \& Tissera, 2007). Jackson (2003) discusses the effect that parks and gardens have on mental and physical health, particularly due to biophilia.

\section{Neighbourhood \& Community}

Similarly to location, neighbourhood and community is very important to health \& mental wellbeing. Crime, security, safety, happiness, walking, transport etc are all affected. Also affected are social networking, social participation and inclusion/exclusion of which it is very important to ensure that loneliness does not occur.

People benefit emotionally and physically from interpersonal relationships and society at large benefits from the participation of its members in organisations, activities, associations etc because increased familiarity between individuals promotes mutual air and empathy. There is compelling evidence that any illnesses (including colds, heart attacks and cancers) are inversely related to social and family ties and group membership. Poor social capital may be as bad as or worse than smoking, obesity, elevated blood pressure or physical inactivity for human health (Jackson, 2003).

Jackson (2003) states that research shows increasing social capital has positive effects on the community, particularly as crime is reduced and people are more likely to be happier in their surroundings. Increasing informal contact between people in the community is the best way to increase social capital and the best way to do this is to increase the amount of green spaces to allow for informal contact.

inhibits physical activity. Physical features such as bicycle paths and footpaths not only need to exist, but must be sufficiently wide, maintained, attractive, well-lit, and networked to other resources, such as other paths and well-maintained, regular public transport. Physical activity is also

capacity in preserving important community resources such as parks and community centres (Butterworth, 2000).

Research participants identified that their physical activity was also affected by their sense of community, their sense of safety, and their sense of collective political capacity in preserving important community resources such as parks and community centres. People who jogged or walked regularly around their neighbourhood reported their enhanced awareness of, and concern -being as they began to get to know people on their rounds, and found

Schools were seen as providing a nexus for community life. A diversity of ages was seen to add to the sense of community (Butterworth, 2000).

Figure B-2, Liveability Effects: Neighbourhood (1) 
Proximity to Emergency Services, Local Amenities ,Landmarks and Public Buildings

Orientation is very important in the built environment. Visual landmarks and logical transit pathways assist people in reaching destinations and in way-finding. These elements provide a sense of ease, comfort and safety. Civic amenities (public buildings such as libraries, churches, and community centres) serve as havens from urban noise and traffic and also provide a sense of belonging in society (Jackson, 2003).

Urban planning, design and development are very important in that communities need to foster or

Sense of community has been found to be enhanced by urban planning that encourages visual coherence, diversity and attractiveness of houses and other buildings; affords sufficient privacy; ensures residents have easy access to amenities, parks, recreation facilities and a town or neighbourhood centre; offers pedestrian-friendly spaces; provides streetscapes so that houses have views of the surrounding neighbourhood; encourages open verandas and low fences in order to encourage social interaction; and restricts motor traffic.

Communities that encourage interaction between strangers have been shown to strongly develop community spirit. Interaction is encouraged through networking and neighbourly behaviour by ensuring that homes are close to town centres and public spaces and buildings (such as shops); provision of parks, recreation and sporting facilities in such a way that their availability, positioning and informal design encouraged fraternizing amongst strangers (Butterworth, 2000).

Proximity to Work

Closer proximity to work has the potential to reduce the separation between home and work and thus the time and money spent on commuting, resulting in less stress and higher levels of physical activity (Burton, 2000).

Long commutes have been associated to adverse health affects (including pollution generation) higher absenteeism, accidents at work, commuting also decreases community involvement which affects social capital. Also, non-commuters are also discouraged from community activities when many of their neighbours (who are commuters) are absent.

Driving in heavy traffic also commonly causes stress, aggression (road rage) and fatalities (Jackson, 2003).

Safety in the Vicinity

Crime, graffiti, safety, security and perceptions/feelings of these things greatly affect human health.

The perception of fear in the neighbourhood or vicinity of a building leads to a high level of dissatisfaction among resident which in turn has a powerful impact on the lives of residents and strongly affects social behaviours (Braubach, 2004).

Fear and perceived danger represent a very personal and emotional threat to health (Braubach, 2004).

Safety and Security can be affected by a number of things from crime, security, safety, graffiti, fear etc. Generally they lead to feelings of insecurity, enhanced stress from fear of crime, reduced social cohesion as people venture outdoors less (especially in women and the elderly)

People often feel unsafe walking around at night, and often feel unsafe around abandoned, poorly maintained or empty areas. Crime rates can be influenced not only by poverty, drug use, and social cohesion but also the built environment. Windows need to be large enough to allow for natural surveillance and clear visibility is required down and around streets. Diverse activiites throughout a neighbouthood also helps to promote prosocial behaviours (Butterworth, 2000).

Figure B-3, Liveability Effects: Neighbourhood (2) 


\section{B.2 CONFIGURATION}

\section{B.2.1 CONNECTIONS}

\section{High-Rise Living (Vertical Location)}

Social isolation of mothers and restricted play opportunities for children are suspected reasons for the links between high-rise living and psychological distress. Often in high-rise buildings, insufficient resources are allotted to spaces that allow for the development and maintenance of social networks (i.e. lobbies and lounges). Often women report loneliness in high-rise buildings, and parents often keep young children inside in larger multi-unit dwellings. These restrictions heighten interfamilial conflict, minimise play opportunities and remove the ability of neighbourly interaction (Evans, 2003).

Studies show that residence on upper floors of high-rise buildings is often associated with lower physical activity, behavioural problems, and respiratory illnesses in children, and with neuroticism and social isolation in stay-at-home mothers and military wives. Restricted to the outdoors maybe the key factor in these adverse health effects (Jackson, 2003).

\section{Outdoor Provision/Access}

As with access to green spaces and windows, a connection to the outdoors is vital to ensuring health, comfort and well-being. It helps to satisfy the basic human needs surrounding biophilia and allows us to be connected to be physically connected to the outdoors rather than just aurally or visually as in with windows.

\section{Privacy}

People need both privacy and social interaction. Physical environments can help or hinder our need

$$
\begin{gathered}
\text { behaviour, and substance abuse. Environments need to be designed which are responsive to } \\
\text { (Butterworth, 2000). }
\end{gathered}
$$

People need to be able to regulate the desired degree of social interaction (Whole Building Design Guide, 2007) because while privacy is very important the ability to have social interactions is just as important

Figure B-4, Liveability Effects: Connections 


\section{B.2.2 SPATIALITY}

Crowding, Density \& Occupancy

It is unlikely that there is a simple cause-effect relationship between the amount of space in a building and the health of its occupants. Space requirements are related to two primary factors, population density and crowding.

Adverse effects of crowding can be explained by the needs for personal space (territory) and for privacy (freedom from unwanted contact or observation), as well as the transmittance of infectious diseases (spread through close contact and the air) (Raw, Aizlewood, \& Hamilton, 2001).

People may feel that they have less personal control in higher-density, crowded situations, causing reduced privacy and stress. This may also result in social withdrawal (Evans, 2003).

Occupancy is related to density, crowding, privacy, management, cleanliness etc. High occupancy levels create crowding which in turns can result in the transmission of infectious diseases etc. Privacy and psychological distress is also heightened etc.

\section{Headroom, Shape, Size \& Storage}

This connects with crowding, occupancy and privacy. It has both mental and physical health affects physical is connected to the crowding issues. However mentally this connects to privacy and wellbeing issues.

People often feel cramped in smaller dwellings as there is not enough room to carry out day-to-day tasks comfortably (well-being and comfort) (Lyne \& Moore, 2004). This can lead to dissatisfaction and distress which may lead to lowered physical health

Storage is also very important as it affects the amount of space that people have to carry out day-today tasks. This is also a safety and hazard issue for physical safety and health as objects which can not be stored elsewhere can become hazards in day-to-day life and emergencies.

Figure B-5, Liveability Effects: Spatiality 


\section{B.3 GOVERNANCE}

\section{B.3.1 MAINTENANCE}

\section{Cleanliness}

Poor cleanliness can have both direct and indirect health affects it can encourage pests and infestation as well as provide breeding grounds for bacteria and mould.

\section{Maintenance}

Maintenance affects housing quality. Maintenance is affected by cleanliness, management, occupants, lack of communication and cultural aspects (Singh, 1996). Poor maintenance affects health (through poor cleanliness, and IAQ), mental well-being (through greater psychological distress (Evans, 2003) and safety through poor maintenance of potential hazards (i.e. structural safety, electrical safety etc).

\section{Pests}

Disease carrying pests such as rats, flies, and cockroaches can be a risk to health. They can crawl over garbage, animal excrement, food and storage surfaces etc. This creates a risk of crosscontamination and infection. People also get worried and upset by having pests and vermin in the home (Raw, Aizlewood, \& Hamilton, 2001).

The presence of cockroaches in dwellings is significant to occupants because they may; carry disease causing organisms, induce allergy and other allergic conditions, cause psychological distress and the accidental indigestion of or contact with control chemicals may cause illness (Raw, Aizlewood, \& Hamilton, 2001).

Figure B-6, Liveability Effects: Maintenance 


\section{B.3.2 MANAGEMENT}

\section{Building Operators \& Users}

Building operators and users can affect health due to their activities (such as smoking) and behaviours such as the accumulation of moisture, level of cleanliness etc. A range of potential sources of contaminants can be introduced by occupants or emanate from occupant activities in the indoor environment; water vapour, carbon dioxide and particulates, tobacco smoking, and emission of a range of organic compounds.

\section{Management}

Management ties into housing quality, maintenance and cleanliness. It is up to management to ensure that there are effective and adequate maintenance \& cleaning schedules in place to ensure occupant health and well-being (Singh, 1996).

Apartment buildings often run smoother with the presence and skill of building managers. They help to provide security for occupants, a good sense of community and help upkeep apartment building standards. Occupants feel better knowing that there is smooth, well-organised running of their building (Auckland UniServices Ltd, 2004).

Household pets such as cats and dogs are the source of toxoplasmosis, toxocariasis and campylobacteriosos. These can be contracted by handling litter or soil contaminated with faeces (Raw, Aizlewood, \& Hamilton, 2001).

Figure B-7, Liveability Effects: Management 


\section{B.4 INDOOR ENVIRONMENTAL QUALITY}

\section{B.4.1 ACOUSTICS}

\section{General Noise Disturbances}

Noise inside dwellings arising from external sources (transportation, people, and animals) or from nearby or adjoining buildings (neighbours voices or activities). Noise sufficiently intense and prolonged to cause physical damage to the hearing apparatus would occur in residential situations, so non-auditory effects are generally considered. Generally noise contributes to total stress and therefore affects a range of health outcomes indirectly.

Common noise sources include amplified music, voices, children, barking dogs and neighbours vehicles, generally from ht neighbouring building in the evening and night or an inadequate level of sound insulation between rooms

\section{Liveability Effects}

Physical effects or noise induced hearing loss the extent of damage is related to the level of noise and the length of exposure

Psychological effects are related to nuisance noise and annoyance through interference with communication, and sleep disturbance (causing delayed lack of alertness and motivation)

Non-auditory effectsNuisance noise can raise the levels of biochemical indicators of stress, which in turn creates other delayed health issues

\section{Reverberation}

Reverberation conisiders the amount of time taken for sound emitted from a source to reach the listener. There is little evidence to show that there are any direct health effects however there maybe comfort and psychological effects.

When reverberation time is too short or long echoes can occur which may mean that speech can be inaudible causing discomfort, annoyance, strain and headaches.

However reverberation is not generally an issue in most buildings, except where the acoustic environment needs to be high quality for example in a concert hall.

\section{Vibration}

High frequency sounds are often absorbed by the atomsphere however low frequency noise is not. For that reason deeper bass sounds (i.e. base music and trucks) can transmit through a building envelope causing perceptible vibrations due to the longer wave lengths.

Building vibrations are not only cvaused by low frequency noise but also by traffic and wind Generally vibrations in a building do not have any direct health effects (except if a building is structurally unsound and causes collapse or structural damage). Psychological effects such as stress, motion sickness, increased fear of heights etc are common effects of vibration in buildings.

Figure B-8, Liveability Effects: Acoustics 


\section{B.4.2 INDOOR AIR QUALITY}

Air Quality

Having good, clean air to breathe is very important as there are a wide range of potential air pollutants and a large number of ways these can affect liveability. Depending on the type of pollutant (or mixture of pollutants) and the length of exposure physical health, mental health, comfort and well-being can all be affected. In some cases death can occur quite rapidly (i.e. carbon monoxide poisoning) or headaches can occur.

Air pollutants can come from a variety of sources and it is estimated that there are over 80 airborne pollutants that can have adverse affects on human health (Ranson, 1991). The most common of these are carbon dioxide, carbon monoxide, nitrogen oxides, odours, formaldehydes, tobacco smoke, water vapour, airborne allergens, asbestos and other mineral fibres, airborne pathogens, and toxic emissions from polymers and consumer goods.

Air pollutants can come from building materials, construction, services \& controls, spatial design, occupants, environmental factors and maintenance \& management (Singh, 1996).

Biological Pollutants

Biological agents have not only a serious impact on the maintenance and repair of the national housing stock but also cause great concern about the health of occupants. The main biological factors causing building-related sickness are moulds, fungi, bacteria, viruses, protozoa, pollens, house dust mites, insect pests, algae, pigeons and rodents (Singh, 1996).

\section{Chemical Pollutants}

Causal agents of illnesses and stress in buildings may be chemical, physical, biological, psychosomatic or the synergistic effects of one or all of these agents. A number of common

inorganic (gas, liquid or particulates) (Singh, 1996).

\section{Gaseous Combustion Products}

Gaseous Combustion Products such as those listed below are the product of using unflued combustion appliances on homes. They are extremely bad for human health and today these types of heating appliances are not allowed within homes without adequate ventilation (Raw, Aizlewood, \& Hamilton, 2001).

Carbon Monoxide: Colourless, Odourless gas which is highly toxic and a major cause of accidental death due to poisoning. CO displaces oxygen from the haemoglobin in the blood causing carboxyhaemoglobin

Nitrogen Oxides: The effects are mostly on the respiratory system, causing damage to the lining of the airways. Generally studies have been undertaken in industrial settings where nitrogen oxides levels are much larger than will ever be found in the home.

Sulphur Dioxide: Highly soluble in water, able to irritate the mist mucous membranes of the eyes, nose, throat and upper airways.

Environmental Tobacco Smoke: Tobacco smoke contains over 3800 different chemical constituents, both gases and particles. There are some links to passive smoking and lung cancer (Raw, Aizlewood, \& Hamilton, 2001).

\section{Ventilation}

Air movement and ventilation is very important for a number of reasons; to remove indoor air pollutants and improve IAQ (including indoor moisture) and to decrease the room temperature on hot days (due to insolation, indoor temperatures are generally higher than outdoor temperatures) (Niu, 2004).

Inadequate ventilation as well as over-crowding increases moisture in the home (Bullen, Kearns, Clinton, Laing, Mahoney, \& McDuff, 2008). Today, inadequate ventilation and air movement and excess moisture contribute to asthma, mould-induced illnesses, carbon monoxide poisoning and so on (Jacobs, 2006)

Figure B-9, Liveability Effects: Indoor Air Quality 


\section{B.4.3 THERMAL COMFORT}

\section{Indoor Microclimates}

Thermal comfort is influenced by a range of factors including; metabolic rate (activity), clothing (personal insulation), air temperature, radiant temperature of surroundings, rate of air movement and atmospheric humidity. It is also affected by other factors such as surroundings, location, and culture (Ruck, 1989).

\section{Air Movement \& Ventilation}

Having good air movement and ventilation throughout a space is vital in removing air pollutants and cleaning air but also helps to decrease room temperature on hot days.

\section{Humidity}

Humidity contributes to dampness, moisture accumulation, and dust mite and mould growth. NZS $60 \%$ to minimise

which results in drying and chapping of skin (NZS 4303: 1990, 1990).

more difficult to heat and a poorly heated dwelling more susceptible to damp. Cold air has a higher relative humidity, increasing the risk of condensation indoors and providing a more favourable environment for the growth of moulds and micro-organisms. Dust mites, tiny parasites that live in carpets and mattresses, are an asthma trigger. Dust mites need moisture to breed and rarely survive under $50 \%$ humidity. Asthmatics that live in damp housing have more asthma attacks, use more asthma drugs and have to go to the hospital more often (Rankine, 2005).

\section{Dust/Dust Mites}

Levels of mite infestations depend on the temperature and humidity of habitats, as well as the age, cleanliness and usage of the furnishings. Mites feed on human skin scales. Mite allergens can trigger Type I (immediate hypersensitivity) allergic reactions particularly asthma. House dust allergies may also contribute to perennial allergic rhinitis and eczema patients also often show higher sensitivity to mite allergens (Raw, Aizlewood, \& Hamilton, 2001).

Moisture, Mould and Dampness

Allergy to mould spores is the major health risk, primarily Type I (immediate hypersensitivity) and Type III (extrinsic allergic alveolitis) allergies. Other health effects are carcinogenic, toxic and psychological effects, and fungal infections. Mould/Fungi growth is entirely dependant on the humidity in the indoor environment, this generally occurs in winter when there is less ventilation, more moisture generation and cooler surfaces. Mould growth generally does not occur in newer homes due to; better insulation, cavity walls, good ventilation and air circulation, good heating, no use of unflued combustion appliances, and a good state of repair (Raw, Aizlewood, \& Hamilton, 2001).

Temperature

$1824^{\circ}$

${ }^{\circ} \mathrm{C}$ is considered too cold and unhealthy. Outside this range, thermal stress increase progressively, and defence mechanisms such as shivering and sweating come into play (Raw, Aizlewood, \& Hamilton, 2001).

Figure B-10, Liveability Effects: Thermal Comfort 
B.4.4 VISUAL ASPECTS

\section{Lighting}

Visual acuity increases as illuminance levels increase and hazardous situations can be caused due to inadequate lighting (including insufficient light sources, glare, gloom and shadows). Accidents such as slips, trips, falls, and collisions are often associated with low lighting levels (Raw, Aizlewood, \& Hamilton, 2001).

Artificial Lighting

Colour: Different lighting types can affect the colour. Safety can be affected where colour judgement is required (i.e. electrical work). Some colour combinations may not be acceptable to visually impaired people when dealing with the internal environment.

Emergency Light: Emergency lighting must be adequate to help people finish of any required/urgent tasks as well as way-finding out of a building/situation (Raw, Aizlewood, \& Hamilton, 2001).

Flicker: There is a wide variation in individual sensitivity to flicker. For most people flicker is not medically troublesome, although it maybe annoying and/or distracting. Some people can be triggered into convulsions often thought of as epilepsy. Headaches and eyestrain can also be brought on by flicker at particularly frequencies (Raw, Aizlewood, \& Hamilton, 2001).

Daylight

appears to have special significance both physiologically and psychologically (Raw, Aizlewood, \& Hamilton, 2001).

There is an anatomical link between the optic pathway and the pineal gland in the brain. Light is one of the factors influencing the pineal secretion of melatonin into the bloodstream. Melatonin is thought to influence circadian rhythms, sleeping, waking and mood states. Seasonal Affective Disorder (SAD), as well as changes in production of adrenal steroids is also thought to be linked to either the intensity of light or the spectral quality of light

Ultraviolet radiation [UV] plays a major role in the synthesis of the skin of Vitamin D, which promotes healthy bone development through calcium metabolism. Deficiency of Vitamin D can lead to skeletal disorders such as rickets in children and osteomalacia in adults. Short daily exposures to natural light throughout the year assure the maintenance of Vitamin D metabolism (Raw, Aizlewood, \& Hamilton, 2001).

Glare occurs when one part of the visual field is much brighter than the average brightness. Where there is a direct interference with vision, this is known as disability glare. Discomfort glare is when the vision is not directly impaired but there is annoyance or distraction. Disability glare is relevant to safety, whereas discomfort glare contributes to eye strain and headaches (Raw, Aizlewood, \& Hamilton, 2001).

Glare can be caused by artificial or natural lighting depending on the circumstances and line of vision.

Windows

Provision of windows is commonly believed to be significant for physical and mental health. Being in an unchanging environment affects mood, the emotions and physiological arousal leading to adverse emotional states. Psychosomatic and stress symptoms. Little influence on intellectual functioning or skilled performance. A windowless space does not deprive a person of all sensory stimuli; it does reduce the amount of visual, auditory and thermal input received from the outside world and can be considered a milder form of deprivation (Raw, Aizlewood, \& Hamilton, 2001). In studies of windowless environments, a consistent finding is concern over the loss of information about time and weather. It has also been shown that passive viewing of nature through windows promotes positive moods and reduces stress (Whole Building Design Guide, 2007). 
B.5 QUALITY

\section{B.5.1 BUILDING QUALITY}

\section{Airtightness}

Airtightness contributes to the ventilation of the home. It is the natural infiltration and removal of air through cracks in the building fabric. It helps to passively vent a home, removing polluted air and dampness. Buildings that are too airtight will not allow for infiltration and maybe cause poor indoor air quality, whereas buildings that are not airtight enough may cause draughts and people may be too cold.

\section{Design \& Construction}

Poor building design and construction contribute to building-related health problems. The following factors should be taken into consideration to improve the indoor air quality: location, orientation, shading, views; passive solar heating; organisation of space, vertical transportation; building use, special industrial processes, number of employees and hours of occupation; public transport, vehicle access and parking; social facilities: disabled, rest rooms, crèche, canteen, coffee machines, fitness facilities, toilets; waste disposal; commissioning and initial air change/water control (Singh, 1996).

Poor housing is associated with poor physical health, safety issues and poor mental wellbeing/health.

Some health-threatening aspects of poor housing have less to do with the intrinsic characteristics of the dwelling, but rather are contingent on their use (Bullen, Kearns, Clinton, Laing, Mahoney, \& McDuff, 2008)

Dampness and cold are the most common health hazards of poor housing (Rankine, 2005)

Poor housing increases the risk of injury from lack of fencing, unflued gas heaters and exposed heating sources, unprotected high windows, balconies and stairs, faulty wiring or appliances, poor storage, breakable window glass, flammable materials and lack of functioning smoke alarms.

Parents in poor housing are more apt to contend with safety hazards including insufficient safety protection (e.g., smoke detectors, hot water temperature regulators), close proximity to higher volume street traffic, and a greater number of housing code violations, all of which contribute to childhood injury rates (Evans, 2003).

The longer people live in poor housing, the more it affects their mental and physical health; children are particularly vulnerable (Rankine, 2005).

Long periods in poor housing during childhood has a negative effect on adult health (Rankine, 2005).

There is an association between poor housing conditions as a child and death from common adult diseases that is independent from other social and economic deprivation (Rankine, 2005).

\section{Electrical Safety}

Electrical accidents are not a major cause of accidental deaths in buildings; however damaged or defective wiring may cause fire and/or electrocution. Electrical dangers come from shock, burns, electrical explosion or arcing, mechanical movements and fire and explosion initiated by electricity. Electrical injuries have low mortality rates but very high rates of short- and long-term morbidity. Electric current causes damage by thermally heating body tissues, by disregulating autonomously functioning organ systems (i.e. respiratory and circulatory systems) or by stimulation nerves and striated muscles (Raw, Aizlewood, \& Hamilton, 2001).

Figure B-12, Liveability Effects: Building Quality (1) 


\section{Building Safety}

Explosion in Buildings: Explosions in buildings generally tend to be catastrophic because people are often injured/killed, as well as the size of building damage. Risk to building occupants from an explosion range from either debris generated from the blast or partial or total collapse of the building (Raw, Aizlewood, \& Hamilton, 2001).

Collision and Entrapment with building features: Collision and entrapment accidents involve building users making direct contact with objects such s doors, windows or walls or jamming and pinching themselves in trapping points. The majority if accidents are nonfatal (Raw, Aizlewood, \& Hamilton, 2001).

Structural Safety: Both physically and mentally, structural safety (quality, soundness etc) is very important in terms of liveability. Not only can poor structural quality be a hazard (i.e. collapse), but it can cause great psychological distress due to uncertainty and worry. This links to quality, maintenance and management (Evans, 2003) (Jacobs, 2006).

\section{Injury Prevention}

Burns \& Scalds: Burns and scalds occur when people contact a hot source. People most at risks are the young and the elderly, partly due to their difficulty in escaping from fires, and also due to low registry of burning and scalding (Raw, Aizlewood, \& Hamilton, 2001).

Slips, Trips \& Falls: A major cause of accidents around the home. They can occur on the level, on stairs, escalators and ramps, between levels and around baths and showers (Raw, Aizlewood, \& Hamilton, 2001).

Being Hit by Falling Objects: The nature of this hazard depends on the particular object and contact made by the individual. Objects may fall from within or outside; there maybe a failure of building components or a structural collapse that may result in someone being hit (Raw, Aizlewood, \& Hamilton, 2001).

Figure B-13, Liveability Effects: Building Quality (2) 


\section{B.5.2 BUILDING SERVICES \& AMENITIES}

\section{Drainage}

Similarly with water and waste, adequate drainage is required to ensure the removal of grey and black water and no resulting infectious diseases being transmitted.

Emergency Escape

Emergency access and utilities are very important in terms of escape from fire etc. This ties into lighting, structural and fire safety.

\section{Fire Safety Features}

Every fire is unique, but almost all cause injury or fatalities. Fire scenarios are; smouldering/nonflaming fires, early, well ventilated flaming fires, small vitiated flaming fires in closed rooms and fully developed/post-flashover fires.

The risks to help include; impaired vision due to smoke, respiratory and breathing difficulties, narcosis from inhalation of toxic gases resulting in confusion and loss of consciousness, pathological changes to the brain and pain to exposed skin and the upper respiratory tract followed by burns and/or hyperthermia (Raw, Aizlewood, \& Hamilton, 2001).

Lifts are important for access to different floors of apartment buildings. There are often issues with lack of lifts/access and/or maintenance. They are also very important for the disabled and impaired. This is both a liveability issue as well as comfort issue as people will not wish to walk up many/any flights of stairs to get access to their particular floor.

A lack of lifts in apartment buildings that can cause significant problems especially when it breaks down or being maintained. Lifts are considered part of the quality of the building. Some also noted a lack of service lifts is a problem particularly when people are moving furniture. This can means there can be a conflict in usage and passenger lifts can be damaged if used (Auckland UniServices Ltd, 2004).

Parking

While parking itself does not directly affect health the safety and security issues surrounding it can cause undue stress and affect mental health. Similarly stress surrounding finding parks can be minimised if parking is provided with a dwelling.

\section{Waste, Rubbish \& Recycling}

Toilet Facilities: Inadequate toilet and sanitary facilities can result in the transmission of Sonne dysentery (shigellosis); this illness generally results in diarrhoea and colic (Raw, Aizlewood, \& Hamilton, 2001).

Waste Disposal: As far as disease transmission is concerned, garbage and refuse are relatively unimportant as long as they are not left uncollected. They do however contribute to the unaesthetic and degrading environment in slum areas and can be a source of infection however. The control of wastes is relevant to community health (Raw, Aizlewood, \& Hamilton, 2001).

\section{Water}

Poor water filtering and/or systems can lead to bacteria growth and infections such as Legionnaires disease a severe type of pneumonia. In homes, some hot water systems store water below $50^{\circ} \mathrm{C}$ (at which temperatures organisms can multiply) which can assist in the spread of the disease (Raw, Aizlewood, \& Hamilton, 2001).

Figure B-14, Liveability Effects: Building Services \& Amenities 


\section{B.5.3 MATERIALS QUALITY}

\section{Biocides}

Biocides are used in a range of materials in buildings to prevent biological deterioration. Generally biocides are intended for preservation, or eradication of infestations. By their nature, biocides are intended to have effects on certain organisms, and there is a potential for effects on other nontarget organisms. The main risk to health is through inhalation (Raw, Aizlewood, \& Hamilton, 2001).

Older paintwork may contain lead which can be taken into the body when chewed. Lead can also be found in drinking water if it passes through lead pipes. The main concern is the neurological development affect in childhood. The effects on blood enzymes causing anaemia is also a major health risk from lead (lead poisoning) (Raw, Aizlewood, \& Hamilton, 2001).

\section{Particles \& Fibres}

Airborne particles in buildings come in both solid and liquid forms. Particles generally come from the external environment, whereas fibres can come from materials such as insulation etc. The risk of inhalation of these while it can not be avoided can be minimised. Short-term increase are associated with increase mortality and morbidity rates, and long term effects include cardiopulmonary disease, reduced lung function, respiratory illness and possibly cancer (Raw, Aizlewood, \& Hamilton, 2001).

Radon

A natural, odourless and colourless gas formed from the radioactive decay of uranium and radium. These are often found in soil and masonry materials. If inhaled, they irradiate tissues in the body. Often this may lead to lung cancer because the largest does of radon is generally delivered to the lungs an the lining of the bronchi (Raw, Aizlewood, \& Hamilton, 2001).

\section{Volatile Organics Compounds}

metabolic products of people, animals and plants to building materials, treatments and services.

of malaise. However the size of the effect is highly dependant on individual sensitivities (Raw, Aizlewood, \& Hamilton, 2001).

Figure B-15, Liveability Effects: Materials Quality 


\section{APPENDIX C COMMUNITY}

This Appendix will present the development of the Community Category. This will include the Community framework development from factor assessment to credit establishment, and Calibration of the Community Components.

\section{C.1 COMMUNITY FRAMEWORK DEVELOPMENT}

The framework development discussed here follows the same process as that discussed in Section 3.2, Section 4.1 and Figure 4-2.

\section{Factor Assessment}

As discussed Community was made up originally of factors that concerned with the immediate surroundings, location and neighbourhood of the building and its site. A total of 19 factors were initially included within this Category, these can be seen in Figure C-1. The preliminary Factor assessment highlighted that there were five repeated factors across the two sets of literature Green Spaces (\& Proximity to), Location, Local Amenities (\& Proximity to), Neighbourhood \& Community and Transport. There were no factors in this Category that did not meet the requirements of Criterion \#1. Two Sections were identified (Environment and Neighbourhood) as discussed in Section 2.2.

\section{COMMUNITY}

\section{ENVIRONMENT}

Geographical Distribution

Outside Air Quality

Shade (Outdoor)

Wind
Location

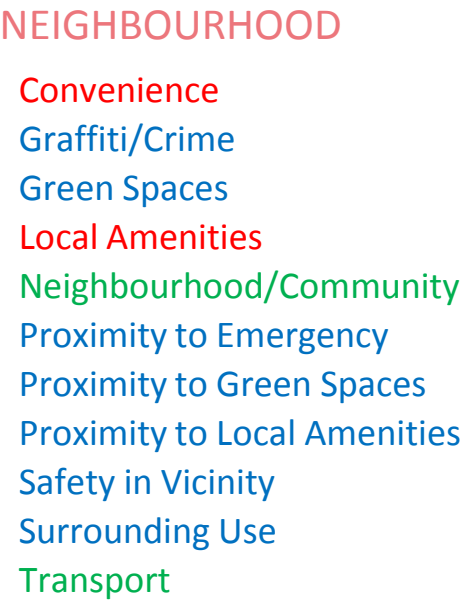

Figure C-1, Factors Included Within Community 


\section{Feature Identification}

Community had two Sections Environment and Neighbourhood beneath it. The Section titled Environment included factors that were concerned with the immediate surroundings or environment of the site and building. Within this Section, two main Features were also identified Location (Features that considered the physical location of the building) and Wind (the pedestrian level wind environment around the building and site). Neighbourhood included factors that were concerned with issues to do with the neighbourhood at large compared with the immediate surroundings. Two main Features were also indentified within this Section Access \& Proximity (Features that considered what amenities were accessible in the neighbourhood) and Safety (factors that considered the safety and security within the neighbourhood). Table C-1 shows the make up of these new levels with the hierarchy under Community.

Table C-1, Features Identified for Community

\begin{tabular}{|c|c|c|c|}
\hline $\begin{array}{l}\text { Level } 2 \\
\text { Category }\end{array}$ & $\begin{array}{l}\text { Level } 3 \\
\text { Section }\end{array}$ & $\begin{array}{l}\text { Level } 4 \\
\text { Feature }\end{array}$ & Associated Factors \\
\hline \multirow[t]{4}{*}{ Community } & \multirow[t]{2}{*}{ Environment } & Location & $\begin{array}{l}\text { - } \quad \text { Geographical Distribution } \\
\text { - Location } \\
\text { - Outside Air Quality } \\
\text { - Shade (Outdoor) }\end{array}$ \\
\hline & & Wind & - Wind \\
\hline & \multirow[t]{2}{*}{ Neighbourhood } & $\begin{array}{l}\text { Access \& } \\
\text { Proximity }\end{array}$ & $\begin{array}{l}\text { - } \text { Convenience } \\
\text { - Green Spaces } \\
\text { - Local Amenities } \\
\text { - Neighbourhood/Community } \\
\text { - Proximity to Emergency } \\
\text { - Transport } \\
\end{array}$ \\
\hline & & Safety & $\begin{array}{l}\text { - } \text { Graffiti/Crime } \\
\text { - Safety in Vicinity } \\
\text { - } \text { Surrounding Use }\end{array}$ \\
\hline
\end{tabular}

\section{Aspect Identification}

Each of the factors that were associated with the Features was then further investigated to develop Aspects of the Features that affected liveability. In total, 17 Aspects were developed with Community.

\section{Environment}

Within Location, two Aspects were identified Site Typology and Outdoor Air Quality. Site Typology considered the type of site the building is located in, i.e. terrain issues such as hills, waterfront etc, how sunny a site is etc. Outdoor Air Quality considers the acceptability of the air within the area.

Under the Feature of Wind, only one Aspect was identified Pedestrian Level Wind Environment, how safe the pedestrian level wind environment is in the area. Table C-2 shows all Aspects identified Environment. 
An additional Feature was also included at this stage Urban Density and Building Heights. This Feature was included not to take into consideration how dense the immediate surroundings were, but to acknowledge the role that the regions council has to play in this issue i.e. by setting maximum allowable building heights. Occupants should be aware that Councils are able to increase these maximum heights, which may adversely affect them is they reside in such an area. One Aspect was therefore identified here Future Building Heights. It was not considered that the built environment density in the area needed to be questioned in NZ ALI simply because of peop preference. For example if a person did not want to live in a high density area they would not look for a place to live there. It is an Aspect of the Location that is pre- determined by someone looking for a place to live.

Similarly, while geographical location or region in the country was identified as a Factor originally, it was not included in the hierarchy. This is a pre-determined Aspect. For example, someone looks for an apartment in Auckland or Wellington because they already know they want to or need to live there.

Table C-2, Aspects Identified for Environment

\begin{tabular}{|l|l|l|}
\hline \multirow{2}{*}{$\begin{array}{l}\text { Level } 3 \\
\text { Section }\end{array}$} & $\begin{array}{l}\text { Level } 4 \\
\text { Feature }\end{array}$ & $\begin{array}{l}\text { Level } 5 \\
\text { Aspect }\end{array}$ \\
\hline \multirow{3}{*}{ Environment } & Location & Site Typology \\
\cline { 2 - 3 } & & Outdoor Air Quality \\
\cline { 2 - 3 } & Urban Density & Building Heights in Area \\
\cline { 2 - 3 } & Wind & Wind Effects in the Area at Pedestrian Level \\
\hline
\end{tabular}

\section{Neighbourhood}

Within Access \& Proximity, eight Aspects were originally identified. There were either taken from already identified Factors, or from surveys where occupants had stated why they enjoyed or preferred living in an apartment. These Aspects were proximity to:

- education facilities (for all ages from pre-school through to tertiary),

- emergency services (fire, police, doctors),

- entertainment (such as bars, theatres etc),

- food and eateries (like restaurants, cafes and supermarkets),

- green spaces (such as parks or waterfront areas)

- local amenities (such as libraries, councils, swimming pools)

- public transport (including buses, trains, taxis, trams, airports etc)

- work places

Within Safety, five Aspects were identified. Crime issues within the area, Graffiti issues within the area, Perceptions of Safety (i.e. how safe do people feel walking around), Surrounding Use (i.e. is it mainly commercial, residential, industrial etc) and Visibility (i.e. how open is an area, can one naturally survey down paths and roads to determine safety). Refer to Table C-3 for all Aspects identified for Neighbourhood. 
Table C-3, Aspects Identified for Neighbourhood

\begin{tabular}{|c|c|c|}
\hline $\begin{array}{l}\text { Level } 3 \\
\text { Section }\end{array}$ & $\begin{array}{l}\text { Level } 4 \\
\text { Feature } \\
\end{array}$ & $\begin{array}{l}\text { Level } 5 \\
\text { Aspect }\end{array}$ \\
\hline \multirow[t]{13}{*}{ Neighbourhood } & \multirow[t]{8}{*}{ Access \& Proximity } & Education Facilities \\
\hline & & Emergency Services \\
\hline & & Entertainment \\
\hline & & Food Services \\
\hline & & Green Spaces \\
\hline & & Local Amenities \\
\hline & & Public Transport \\
\hline & & Work Places \\
\hline & \multirow[t]{5}{*}{ Safety } & Crime Issues in the Area \\
\hline & & Graffiti Issues in the Area \\
\hline & & Perceptions of Safety in the Area \\
\hline & & Surrounding Use of the building \\
\hline & & Visibility (Natural Surveillance down paths and roads) \\
\hline
\end{tabular}

4. Indicator Identification

Each of the Aspects was then assigned an Indicator or Assessment Question. In this Category, each Aspect had only 1 Indicator. Table C-4 outlines each of these for Community. 
Table C-4, Indicators Identified for Community

\begin{tabular}{|c|c|c|c|}
\hline $\begin{array}{l}\text { Level } 3 \\
\text { Section }\end{array}$ & $\begin{array}{l}\text { Level } 4 \\
\text { Feature }\end{array}$ & $\begin{array}{l}\text { Level } 5 \\
\text { Aspect }\end{array}$ & $\begin{array}{l}\text { Level } 6 \\
\text { Indicator }\end{array}$ \\
\hline \multirow[t]{4}{*}{ Environment } & \multirow[t]{2}{*}{ Location } & Site Typology & $\begin{array}{l}\text { What type of site is the building } \\
\text { Located in? }\end{array}$ \\
\hline & & Outdoor Air Quality & $\begin{array}{l}\text { How acceptable is the outdoor air } \\
\text { quality? }\end{array}$ \\
\hline & Urban Density & $\begin{array}{l}\text { Building Heights in } \\
\text { Area }\end{array}$ & $\begin{array}{l}\text { Will the maximum allowable } \\
\text { building heights change in the } \\
\text { future? }\end{array}$ \\
\hline & Wind & $\begin{array}{l}\text { Wind Effects in the } \\
\text { Area }\end{array}$ & $\begin{array}{l}\text { Are the pedestrian level wind } \\
\text { conditions unsafe in the area? }\end{array}$ \\
\hline \multirow[t]{13}{*}{ Neighbourhood } & \multirow[t]{8}{*}{ Access \& Proximity } & Education Facilities & $\begin{array}{l}\text { How close is the building to any } \\
\text { required education facilities? }\end{array}$ \\
\hline & & Emergency Services & $\begin{array}{l}\text { How close is the building to } \\
\text { emergency services? }\end{array}$ \\
\hline & & Entertainment & $\begin{array}{l}\text { How close is the building to } \\
\text { entertainment places? }\end{array}$ \\
\hline & & Food Services & $\begin{array}{l}\text { How close is the building to food } \\
\text { services? }\end{array}$ \\
\hline & & Green Spaces & $\begin{array}{l}\text { How close is the building to green } \\
\text { spaces? }\end{array}$ \\
\hline & & Local Amenities & $\begin{array}{l}\text { How close is the building to local } \\
\text { amenities }\end{array}$ \\
\hline & & Public Transport & $\begin{array}{l}\text { How close is the building to public } \\
\text { transport }\end{array}$ \\
\hline & & Work Places & How close is the building to work? \\
\hline & \multirow[t]{5}{*}{ Safety } & $\begin{array}{l}\text { Crime Issues in the } \\
\text { Area }\end{array}$ & $\begin{array}{l}\text { Are there known crime issues in } \\
\text { the area? }\end{array}$ \\
\hline & & $\begin{array}{l}\text { Graffiti Issues in the } \\
\text { Area }\end{array}$ & $\begin{array}{l}\text { Are there known graffiti issues in } \\
\text { the area? }\end{array}$ \\
\hline & & $\begin{array}{l}\text { Perceptions of Safety } \\
\text { in the Area }\end{array}$ & $\begin{array}{l}\text { How safe does the area feel to } \\
\text { walk in? }\end{array}$ \\
\hline & & $\begin{array}{l}\text { Surrounding Use of } \\
\text { the building }\end{array}$ & $\begin{array}{l}\text { What is the surrounding use of the } \\
\text { building? }\end{array}$ \\
\hline & & $\begin{array}{l}\text { Visibility (Natural } \\
\text { Surveillance down } \\
\text { paths and roads) } \\
\end{array}$ & How open and visible is the area? \\
\hline
\end{tabular}




\section{AM Identification \& Review}

\section{Environment}

Table C-5

Environment. Two of these were statements, two were assessments and only one was a yes or no choice. These are shown in the column

skills and knowledge barriers (shown in blue cells under Assessment Method Version 1 Table C-5). These were the two assessments for Outdoor Air Quality and the Pedestrian Wind Environment.

shown in Table C-5 under Assessment Method Version 2. While these can be considered to be highly subjective, they were considered to be appropriate because of the expected skill and expertise level of primary end-users and subjectivity issues with liveability.

Table C-5, Review of Assessment Methods Identified for Environment

\begin{tabular}{|c|c|c|c|c|}
\hline $\begin{array}{l}\text { Level } 4 \\
\text { Feature }\end{array}$ & $\begin{array}{l}\text { Level } 5 \\
\text { Aspect }\end{array}$ & $\begin{array}{l}\text { Level } 6 \\
\text { Indicator-Assessment } \\
\text { Question }\end{array}$ & $\begin{array}{l}\text { Assessment } \\
\text { Method } \\
\text { Version } 1 \\
\end{array}$ & $\begin{array}{l}\text { Modified } \\
\text { Assessment } \\
\text { Method } \\
\end{array}$ \\
\hline \multirow{3}{*}{ Location } & $\begin{array}{l}\text { Site } \\
\text { Typology }\end{array}$ & $\begin{array}{l}\text { What type of site is the } \\
\text { building Located in? }\end{array}$ & $\begin{array}{l}\text { Statement } \\
\text { (Location) }\end{array}$ & List \\
\hline & $\begin{array}{l}\text { Surrounding } \\
\text { Use }\end{array}$ & $\begin{array}{l}\text { What is the surrounding use } \\
\text { of the building? }\end{array}$ & $\begin{array}{l}\text { Statement } \\
\text { (Surrounding } \\
\text { Use) }\end{array}$ & List \\
\hline & $\begin{array}{l}\text { Outdoor Air } \\
\text { Quality }\end{array}$ & $\begin{array}{l}\text { How acceptable is the } \\
\text { outdoor air quality? }\end{array}$ & $\begin{array}{l}\text { Assessment (Air } \\
\text { Quality) }\end{array}$ & Scale \\
\hline $\begin{array}{l}\text { Urban } \\
\text { Density }\end{array}$ & $\begin{array}{l}\text { Building } \\
\text { Heights in } \\
\text { Area }\end{array}$ & $\begin{array}{l}\text { Will the maximum allowable } \\
\text { building heights change in } \\
\text { the future? }\end{array}$ & Choose Yes or No & Yes/No \\
\hline Wind & Wind Effects & $\begin{array}{l}\text { Are the pedestrian level } \\
\text { wind conditions unsafe in } \\
\text { the area? }\end{array}$ & $\begin{array}{l}\text { Assessment } \\
\text { (Wind) }\end{array}$ & Scale \\
\hline
\end{tabular}

\section{Neighbourhood}

Table C-6

Neighbourhood (shown in Assessment Method

Version 1). All Indicators for Access \& Proximity had Assessment Methods applied that were measurements of distance away. Two Indicators within Safety Methods and two had Personal Perceptions.

The Assessment Methods applied to the Access \& Proximity Indicators were all judged to be both practical and objective assessments. However it was decided for ease of use and user friendliness that users should be required to choose from a list rather than determining a distance and inputting this into the tool. This change of AM can be seen in Table C- 6 
Of the four Indicators within Safety

Criteria \#2

and \#3. These were Perceptions of Safety and Visibility. Both of these initially required Personal

Perceptions of these issues by users. These Personal Perceptions were considered to be impractical (shown in light orange) for users due to a possible confusion or misunderstanding over wordings i.e. natural surveillance and visibility). Similarly these Assessment Methods were considered too subjective (as shown in red text) because they required users to make personal judgements.

Table C-6, Review of Assessment Methods Identified for Neighbourhood

\begin{tabular}{|c|c|c|c|c|}
\hline $\begin{array}{l}\text { Level } 4 \\
\text { Feature }\end{array}$ & $\begin{array}{l}\text { Level } 5 \\
\text { Aspect }\end{array}$ & $\begin{array}{l}\text { Level } 6 \\
\text { Indicator-Assessment } \\
\text { Question }\end{array}$ & $\begin{array}{l}\text { Assessment } \\
\text { Method } \\
\text { Version } 1 \\
\end{array}$ & $\begin{array}{l}\text { Modified } \\
\text { Assessment } \\
\text { Method } \\
\end{array}$ \\
\hline \multirow{8}{*}{$\begin{array}{l}\text { Access \& } \\
\text { Proximity }\end{array}$} & $\begin{array}{l}\text { Education } \\
\text { Facilities }\end{array}$ & $\begin{array}{l}\text { How close is the building to } \\
\text { any required education } \\
\text { facilities? }\end{array}$ & $\begin{array}{l}\text { Measurement } \\
\text { (Distance) }\end{array}$ & List \\
\hline & $\begin{array}{l}\text { Emergency } \\
\text { Services }\end{array}$ & $\begin{array}{l}\text { How close is the building to } \\
\text { emergency services? }\end{array}$ & $\begin{array}{l}\text { Measurement } \\
\text { (Distance) }\end{array}$ & List \\
\hline & Entertainment & $\begin{array}{l}\text { How close is the building to } \\
\text { entertainment places? }\end{array}$ & $\begin{array}{l}\text { Measurement } \\
\text { (Distance) }\end{array}$ & List \\
\hline & Food Services & $\begin{array}{l}\text { How close is the building to } \\
\text { food services? }\end{array}$ & $\begin{array}{l}\text { Measurement } \\
\text { (Distance) }\end{array}$ & List \\
\hline & Green Spaces & $\begin{array}{l}\text { How close is the building to } \\
\text { green spaces? }\end{array}$ & $\begin{array}{l}\text { Measurement } \\
\text { (Distance) }\end{array}$ & List \\
\hline & $\begin{array}{l}\text { Local } \\
\text { Amenities }\end{array}$ & $\begin{array}{l}\text { How close is the building to } \\
\text { local amenities }\end{array}$ & $\begin{array}{l}\text { Measurement } \\
\text { (Distance) }\end{array}$ & List \\
\hline & $\begin{array}{l}\text { Public } \\
\text { Transport }\end{array}$ & $\begin{array}{l}\text { How close is the building to } \\
\text { public transport }\end{array}$ & $\begin{array}{l}\text { Measurement } \\
\text { (Distance) }\end{array}$ & List \\
\hline & Work Places & $\begin{array}{l}\text { How close is the building to } \\
\text { work? }\end{array}$ & $\begin{array}{l}\text { Measurement } \\
\text { (Distance) }\end{array}$ & List \\
\hline \multirow{4}{*}{ Safety } & $\begin{array}{l}\text { Crime Issues } \\
\text { in the Area }\end{array}$ & $\begin{array}{l}\text { Are there known crime } \\
\text { issues in the area? }\end{array}$ & Choose Yes or No & Yes/No \\
\hline & $\begin{array}{l}\text { Graffiti Issues } \\
\text { in the Area }\end{array}$ & $\begin{array}{l}\text { Are there known graffiti } \\
\text { issues in the area? }\end{array}$ & Choose Yes or No & Yes/No \\
\hline & $\begin{array}{l}\text { Perceptions of } \\
\text { Safety in the } \\
\text { Area }\end{array}$ & $\begin{array}{l}\text { How safe does the area feel } \\
\text { to walk in? }\end{array}$ & $\begin{array}{l}\text { Personal } \\
\text { Perception } \\
\text { (Safety) }\end{array}$ & Scale \\
\hline & $\begin{array}{l}\text { Visibility } \\
\text { (Natural } \\
\text { Surveillance } \\
\text { down paths } \\
\text { and roads) }\end{array}$ & $\begin{array}{l}\text { How open and visible is the } \\
\text { area? }\end{array}$ & $\begin{array}{l}\text { Personal } \\
\text { Perception } \\
\text { (Visibility) }\end{array}$ & Scale \\
\hline
\end{tabular}




\section{Credit Establishment}

Answer acceptability and credits were established for the Indicators of Environment. Outlines of these are shown in Table C-7.All Assessment Questions except Site Typology and Surrounding Use were reworded to accurately represent the Assessment Method and answer required.

Table C-7, Acceptability \& Awarding of Credits Identified for Environment

\begin{tabular}{|c|c|c|c|c|}
\hline $\begin{array}{l}\text { Level } 4 \\
\text { Feature }\end{array}$ & $\begin{array}{l}\text { Level } 5 \\
\text { Aspect }\end{array}$ & $\begin{array}{l}\text { Level } 6 \\
\text { Indicator - Modified } \\
\text { Assessment Question }\end{array}$ & Acceptability \& Awardin & redits \\
\hline \multirow{3}{*}{ Location } & $\begin{array}{l}\text { Site } \\
\text { Typology }\end{array}$ & $\begin{array}{l}\text { What type of site is the } \\
\text { building located in? }\end{array}$ & $\begin{array}{l}\text { Smallest Building } \\
\text { Average Height Building } \\
\text { Tallest Building } \\
\text { Cold/Damp } \\
\text { Sunny/Warm } \\
\text { Flat Terrain } \\
\text { Hilly Terrain }\end{array}$ & $\begin{array}{l}0 \% \\
100 \% \\
50 \% \\
0 \% \\
100 \% \\
100 \% \\
50 \% \\
\end{array}$ \\
\hline & $\begin{array}{l}\text { Surrounding } \\
\text { Use }\end{array}$ & $\begin{array}{l}\text { What is the surrounding use } \\
\text { of the building? }\end{array}$ & $\begin{array}{l}\text { Commercial } \\
\text { Entertainment } \\
\text { Industrial } \\
\text { Open Space } \\
\text { Residential } \\
\text { Other }\end{array}$ & $\begin{array}{l}50 \% \\
50 \% \\
0 \% \\
100 \% \\
100 \% \\
25 \% \\
\end{array}$ \\
\hline & $\begin{array}{l}\text { Outdoor Air } \\
\text { Quality }\end{array}$ & $\begin{array}{l}\text { On a scale of } 1 \quad 10 \text {, how } \\
\text { acceptable is the outdoor air } \\
\text { quality? }\end{array}$ & 110 Scale & \\
\hline $\begin{array}{l}\text { Urban } \\
\text { Density }\end{array}$ & $\begin{array}{l}\text { Building } \\
\text { Heights in } \\
\text { Area }\end{array}$ & $\begin{array}{l}\text { Are the maximum allowable } \\
\text { building heights (as set by } \\
\text { the local council) likely to } \\
\text { change in the future? }\end{array}$ & Yes/No Version 2, & \\
\hline Wind & Wind Effects & $\begin{array}{l}\text { On a scale of } 1 \quad 10 \text {, how } \\
\text { safe do you feel the } \\
\text { pedestrian level wind } \\
\text { conditions are? }\end{array}$ & 110 Scale & \\
\hline
\end{tabular}

Answers and Credits were then established for the Indicators and Assessment Methods in Neighbourhood. These are shown in Table C-8. All Assessment Questions except Crime and Graffiti Modified

Assessment Question 
Table C-8, Acceptability \& Awarding of Credits Identified for Neighbourhood

\begin{tabular}{|c|c|c|c|c|}
\hline $\begin{array}{l}\text { Level } 4 \\
\text { Feature }\end{array}$ & $\begin{array}{l}\text { Level } 5 \\
\text { Aspect }\end{array}$ & $\begin{array}{l}\text { Level } 6 \\
\text { Indicator - Modified } \\
\text { Assessment Question }\end{array}$ & \multicolumn{2}{|c|}{ Acceptability \& Awarding of Credits } \\
\hline \multirow{8}{*}{$\begin{array}{l}\text { Access \& } \\
\text { Proximity }\end{array}$} & $\begin{array}{l}\text { Education } \\
\text { Facilities }\end{array}$ & $\begin{array}{l}\text { How easy is it to get to } \\
\text { education facilities (i.e. pre- } \\
\text { school through to tertiary)? }\end{array}$ & \multirow{2}{*}{$\begin{array}{l}\text { Very Easy }(<10 \text { minutes } \\
\text { walk) } \\
\text { Easy }(10 \quad 15 \text { minutes walk })\end{array}$} & $100 \%$ \\
\hline & $\begin{array}{l}\text { Emergency } \\
\text { Services }\end{array}$ & $\begin{array}{l}\text { How easy is it to get to } \\
\text { emergency services (i.e. } \\
\text { hospital, police station)? }\end{array}$ & & $75 \%$ \\
\hline & $\begin{array}{l}\text { Entertainme } \\
\text { nt }\end{array}$ & $\begin{array}{l}\text { How easy is it to get to } \\
\text { entertainment services (i.e. } \\
\text { bars, theatres, and } \\
\text { cinemas)? }\end{array}$ & \multirow{2}{*}{$\begin{array}{l}\text { Moderate (15 } 20 \text { minutes } \\
\text { walk) } \\
\text { Difficult ( } 20 \quad 30 \text { minutes } \\
\text { walk) }\end{array}$} & $50 \%$ \\
\hline & $\begin{array}{l}\text { Food } \\
\text { Services }\end{array}$ & $\begin{array}{l}\text { How easy is it to get to food } \\
\text { services (i.e. cafes, } \\
\text { restaurants, and } \\
\text { supermarkets)? }\end{array}$ & & $25 \%$ \\
\hline & $\begin{array}{l}\text { Green } \\
\text { Spaces }\end{array}$ & $\begin{array}{l}\text { How easy is it to get to green } \\
\& \text { open spaces (i.e. parks, } \\
\text { lakes, waterfronts)? }\end{array}$ & \multirow{4}{*}{$\begin{array}{l}\text { Very Difficult ( } 30 \text { minutes } \\
\text { walk or more) }\end{array}$} & \\
\hline & $\begin{array}{l}\text { Local } \\
\text { Amenities }\end{array}$ & $\begin{array}{l}\text { How easy is it to get to local } \\
\text { amenities (i.e. council } \\
\text { buildings, libraries, } \\
\text { swimming pools)? }\end{array}$ & & $0 \%$ \\
\hline & $\begin{array}{l}\text { Public } \\
\text { Transport }\end{array}$ & $\begin{array}{l}\text { How easy is it to get to } \\
\text { public transport (i.e. buses, } \\
\text { trains, and trams)? }\end{array}$ & & $100 \%$ \\
\hline & Work Places & $\begin{array}{l}\text { How easy is it to get to your } \\
\text { work place? }\end{array}$ & & \\
\hline \multirow{4}{*}{ Safety } & $\begin{array}{l}\text { Crime Issues } \\
\text { in the Area }\end{array}$ & $\begin{array}{l}\text { Are there known crime } \\
\text { issues in the area? }\end{array}$ & \multicolumn{2}{|l|}{ Yes/No Version 2} \\
\hline & $\begin{array}{l}\text { Graffiti } \\
\text { Issues in the } \\
\text { Area }\end{array}$ & $\begin{array}{l}\text { Are there known graffiti } \\
\text { issues in the area? }\end{array}$ & \multicolumn{2}{|l|}{ Yes/No Version 2} \\
\hline & $\begin{array}{l}\text { Perceptions } \\
\text { of Safety in } \\
\text { the Area }\end{array}$ & $\begin{array}{l}\text { On a scale of } 1 \quad 10 \text {, how } \\
\text { safe do you feel the } \\
\text { surrounding area is? }\end{array}$ & \multicolumn{2}{|l|}{110 Scale } \\
\hline & $\begin{array}{l}\text { Visibility } \\
\text { (Natural } \\
\text { Surveillance } \\
\text { down paths } \\
\text { and roads) }\end{array}$ & $\begin{array}{l}\text { On a scale of } 1 \quad 10 \text {, how } \\
\text { open and visible do you feel } \\
\text { the area is? }\end{array}$ & \multicolumn{2}{|l|}{110 Scale } \\
\hline
\end{tabular}




\section{C.2 COMMUNITY CALIBRATION}

The information discussed here provides information on the Calibration of the Community Components. The data analysed and used to develop weightings for this Category is from the NZ ALI Questionnaire. The Calibration process follows that discussed in Section 4.3 and The NZ ALI Questionnaire.

\section{C.2.1 NZ ALI QUESTIONNAIRE RESULTS \& ANALYSIS}

\section{Aspects}

Environment: Figure C-2 shows the percentage of nominations that each of the Aspects within Environment received.

Neighbourhood: Figure C-3 shows the percentage of nominations that each of the Aspects within Neighbourhood received. Within Access \& Proximity two Aspects received no nominations Education Facilities and Emergency Services.

\section{Features}

Figure C-4 shows the weightings determined for the Community Features which were determined from Equation 4-1.

\section{Sections}

Figure C-5 shows the weightings determined for the Community Sections which were determined from Equation 4-1. 


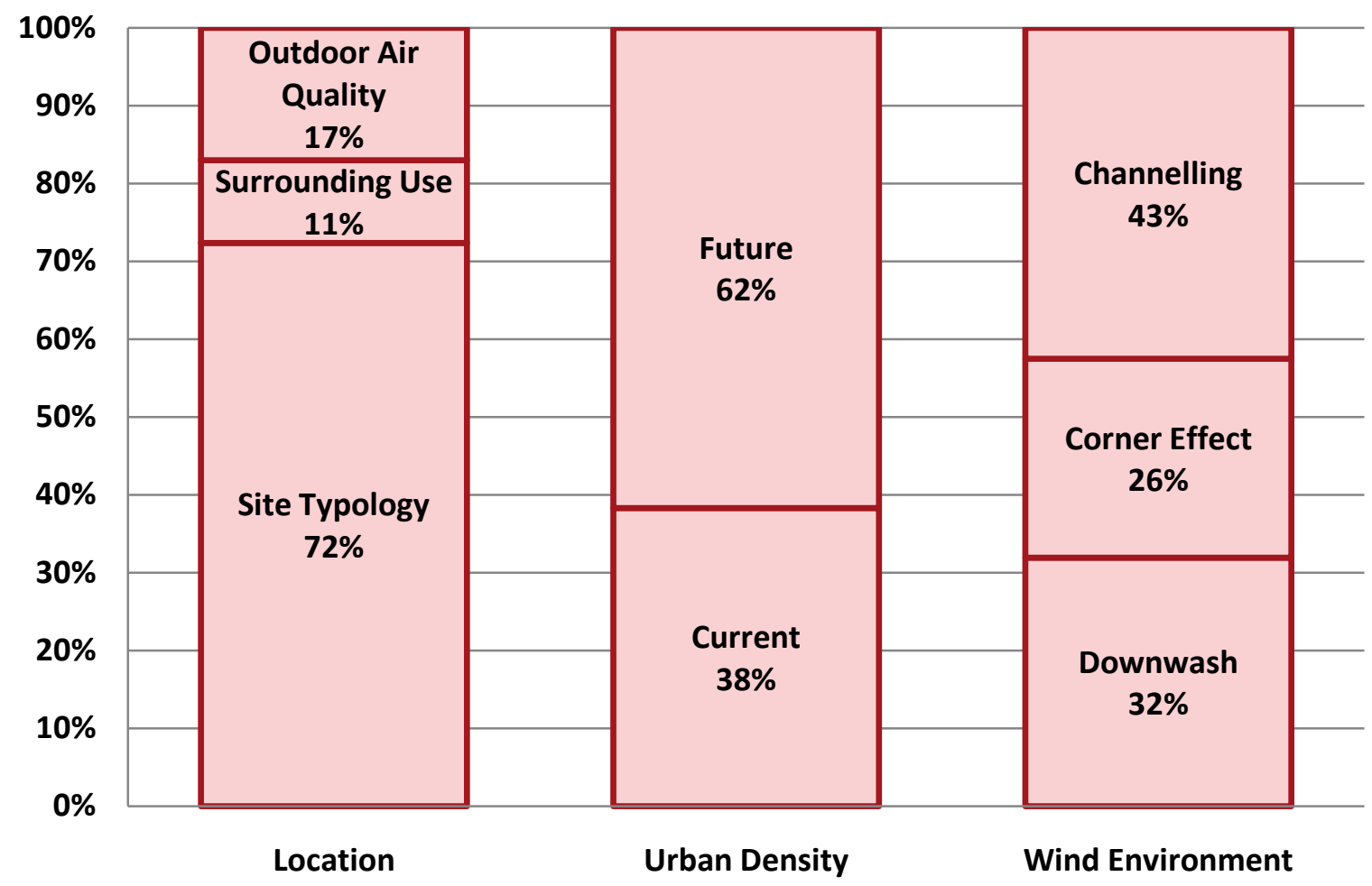

Figure C-2, Perceived Importance of Environment Aspects

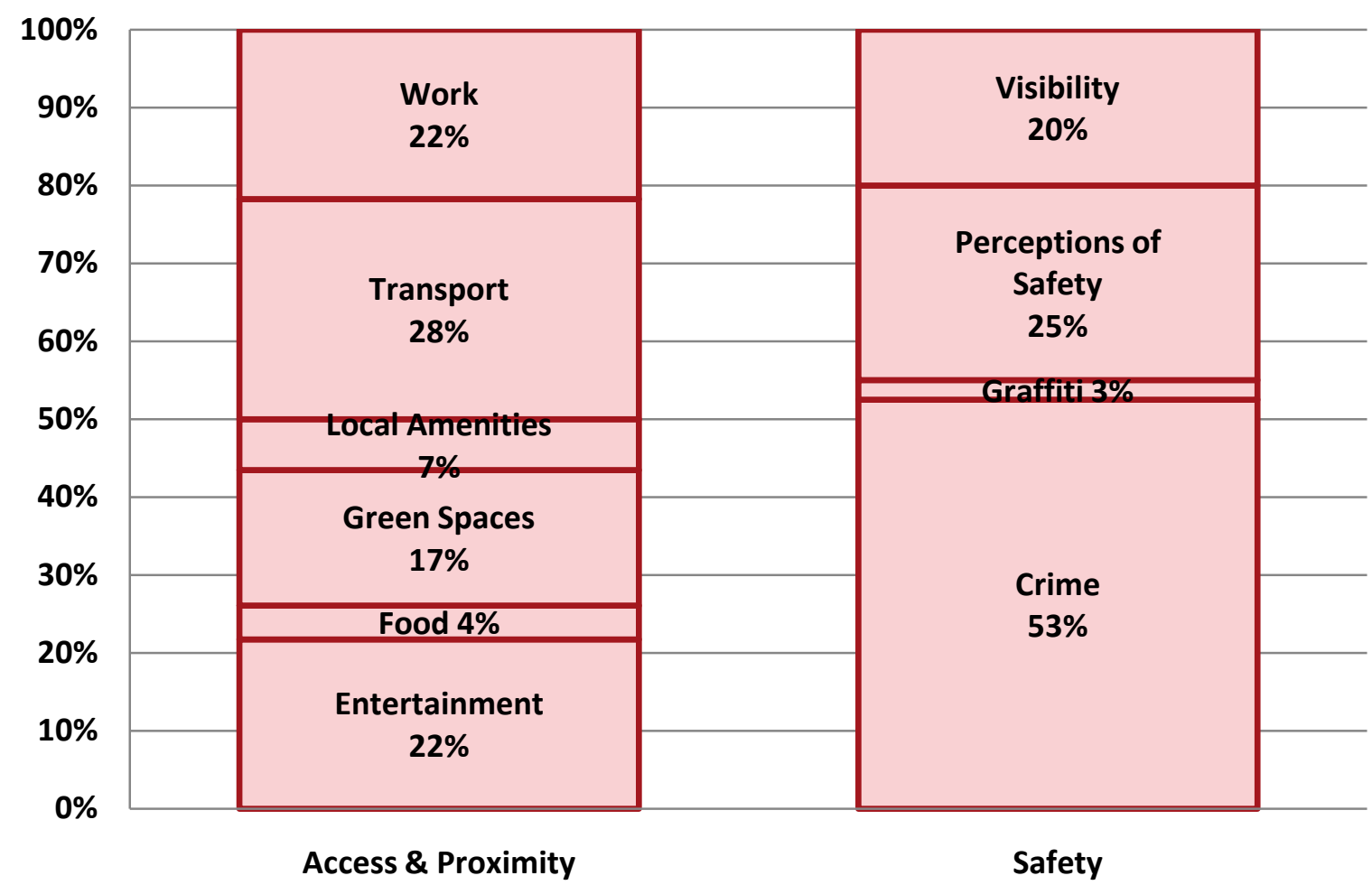

Figure C-3, Perceived Importance of Neighbourhood Aspects 


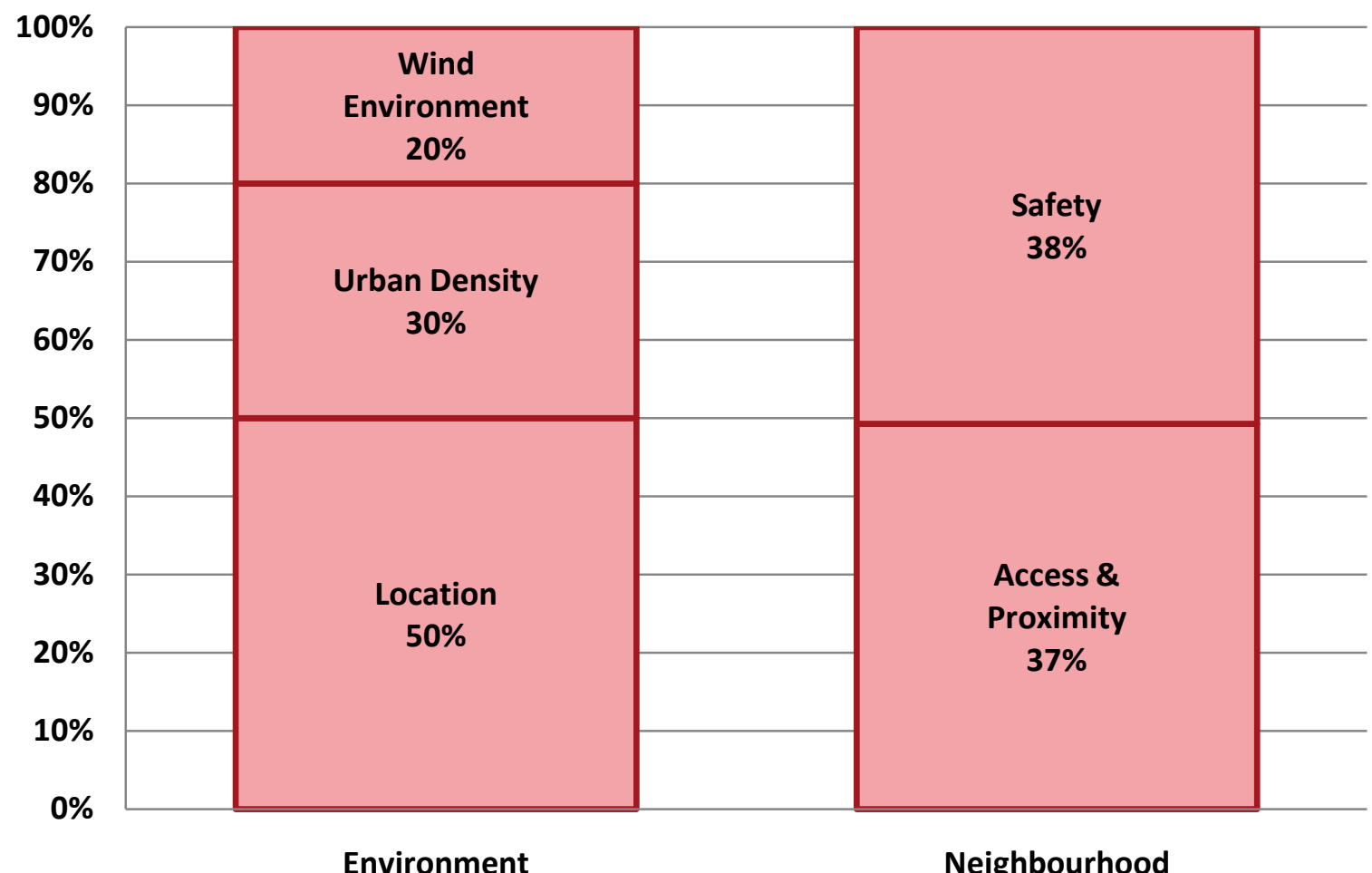

Figure C-4, Perceived Importance of Community Features

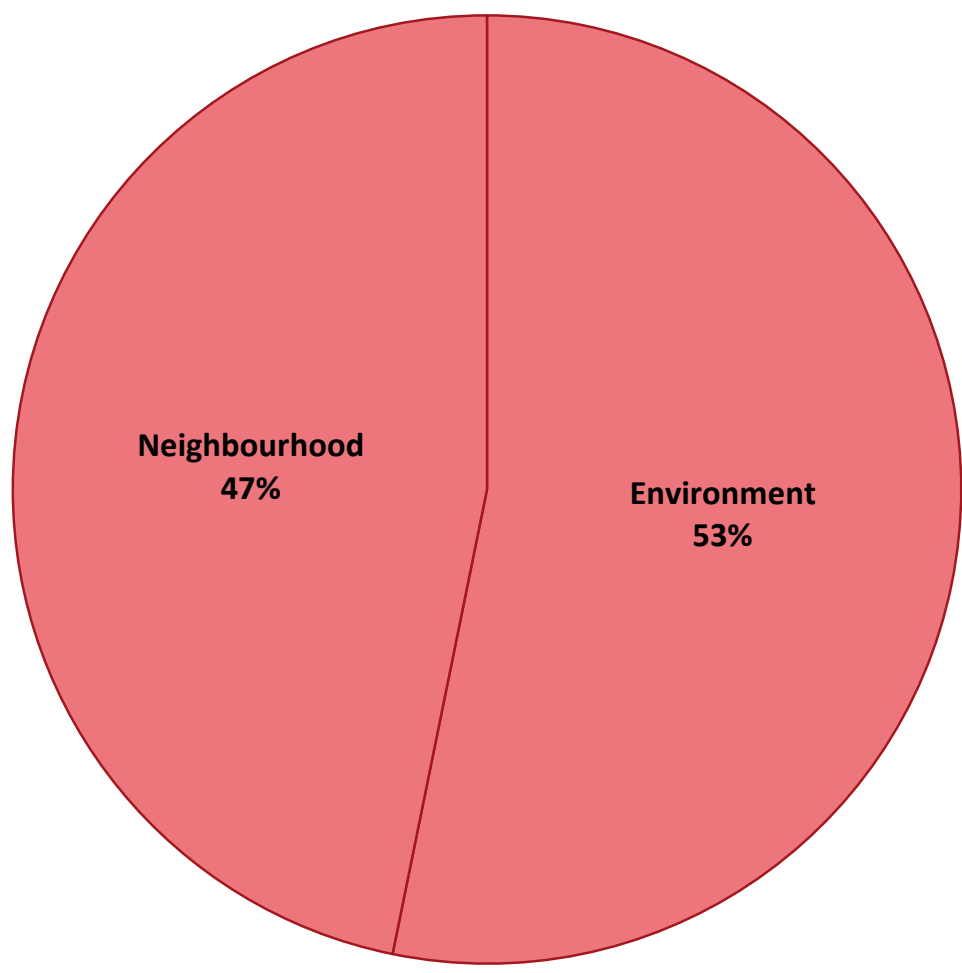

Figure C-5, Perceived Importance of Community Sections 


\section{C.2.2 APPLICATION OF PERCEIVED IMPORTANCE AS WEIGHTINGS}

\section{Rule \#1 - Perceived Importance of less than 3\%}

Within Community three components had perceived importance of less than $3 \%$ and were subsequently removed. These were

- Access to Education Facilities (0\%)

- Access to Emergency Services (0\%)

- Graffiti Issues (2.5\%)

\section{Rule \#2 - Indicator Weightings}

All Aspects within Community had only one Indicator associated with it so they were all weighted $100 \%$

\section{Rule \#3 - Modified Components}

In general the perceived importance of each component determined from the NZ ALI Questionnaire was applied to the components within Community. However four Features within Community were modified. Within Safety Graffiti was removed due to its low perceived importance so the weightings of the three remaining Aspects were modified as shown in Table C-9 below. As both Access to Education Facilities and Access to Emergency Services have perceived importance of $0 \%$, no modification was required to the weightings of the other six Aspects within Access \& Proximity.

Table C-9, Weighting Applied to NZ ALI for Safety Aspects

\begin{tabular}{|l|l|l|}
\hline Safety Aspects & Perceived Importance & NZ ALI Weighting \\
\hline Crime Issues & $52.5 \%$ & $53 \%$ \\
\hline Graffiti Issues & $2.5 \%$ & $0 \%$ \\
\hline Perceptions of Safety & $25.0 \%$ & $26 \%$ \\
\hline Visibility/Natural Surveillance & $20.0 \%$ & $21 \%$ \\
\hline
\end{tabular}

Two other Features were also modified within Environment Urban Density and Wind Environment. Initially Urban Density had two Aspects Current Building Heights and Future Building Heights. It was decided to remove Current Building Heights was an Aspects because it is a choice pre- made by the user to live in a particular urban density. The issue surrounding this would be when the area becomes higher density i.e. if building heights allowed in a District Plan are changed or increased. Future Building Heights was then awarded a weighting of $100 \%$.

Wind Environment initially had three Aspects associated with it Downwash, Corner Effect and Channelling. It was decided to remove these Aspects as the issue is pedestrian safety, not the type of wind effects in the area. One aspect then remained Wind Environment and Safety at Pedestrian Level which was awarded a weighting of $100 \%$. 


\section{C.2.3 COMMUNITY COMPONENT WEIGHTINGS}

The following tables present the final weightings applied to all Community components.

Table C-10, Component and Global Weightings for Community Indicators

\begin{tabular}{|c|c|c|c|c|c|c|}
\hline $\begin{array}{l}\text { Level } 2 \\
\text { Category }\end{array}$ & $\begin{array}{l}\text { Level } 3 \\
\text { Section } \\
\end{array}$ & $\begin{array}{l}\text { Level } 4 \\
\text { Feature } \\
\end{array}$ & $\begin{array}{l}\text { Level } 5 \\
\text { Aspect } \\
\end{array}$ & $\begin{array}{l}\text { Level } 6 \\
\text { Indicator }\end{array}$ & $\begin{array}{l}\text { Component } \\
\text { Weighting }\end{array}$ & $\begin{array}{l}\text { Global } \\
\text { Weighting }\end{array}$ \\
\hline \multirow{14}{*}{ Community } & \multirow{5}{*}{ Environment } & \multirow{3}{*}{ Location } & $\begin{array}{l}\text { Site } \\
\text { Typology }\end{array}$ & $\begin{array}{l}\text { Site } \\
\text { Typology }\end{array}$ & $100 \%$ & $2.48 \%$ \\
\hline & & & Surrounding & Surrounding & $100 \%$ & $0.38 \%$ \\
\hline & & & Air Quality & Air Quality & $100 \%$ & $0.59 \%$ \\
\hline & & $\begin{array}{l}\text { Urban } \\
\text { Density }\end{array}$ & Future & Future & $100 \%$ & $2.07 \%$ \\
\hline & & Wind & Wind & Wind & $100 \%$ & $1.38 \%$ \\
\hline & \multirow{9}{*}{ Neighbourhood } & \multirow{6}{*}{$\begin{array}{l}\text { Access \& } \\
\text { Proximity }\end{array}$} & $\begin{array}{l}\text { Enter- } \\
\text { tainment }\end{array}$ & Dist & $100 \%$ & $0.66 \%$ \\
\hline & & & Food & Dist & $100 \%$ & $0.12 \%$ \\
\hline & & & $\begin{array}{l}\text { Green } \\
\text { Spaces }\end{array}$ & Dist & $100 \%$ & $0.51 \%$ \\
\hline & & & $\begin{array}{l}\text { Local } \\
\text { Amenities }\end{array}$ & Dist & $100 \%$ & $0.21 \%$ \\
\hline & & & $\begin{array}{l}\text { Public } \\
\text { Transport }\end{array}$ & Dist & $100 \%$ & $0.84 \%$ \\
\hline & & & Work & Dist & $100 \%$ & $0.66 \%$ \\
\hline & & \multirow{3}{*}{ Safety } & Crime & Issues & $100 \%$ & $1.65 \%$ \\
\hline & & & Perceptions & Perceptions & $100 \%$ & $0.81 \%$ \\
\hline & & & Visibility & Visibility & $100 \%$ & $0.65 \%$ \\
\hline
\end{tabular}


Table C-11, Component and Global Weightings for Community Aspects

\begin{tabular}{|c|c|c|c|c|c|c|}
\hline $\begin{array}{l}\text { Level } 2 \\
\text { Category }\end{array}$ & $\begin{array}{l}\text { Level } 3 \\
\text { Section }\end{array}$ & $\begin{array}{l}\text { Level } 4 \\
\text { Feature }\end{array}$ & $\begin{array}{l}\text { Level } 5 \\
\text { Aspect }\end{array}$ & $\begin{array}{l}\text { Component } \\
\text { Weighting }\end{array}$ & $\begin{array}{l}\text { Global } \\
\text { Weighting }\end{array}$ & $\begin{array}{l}\text { Level } 6 \\
\text { Indicators }\end{array}$ \\
\hline \multirow{14}{*}{ Community } & \multirow{5}{*}{ Environment } & \multirow{3}{*}{ Location } & $\begin{array}{l}\text { Site } \\
\text { Typology }\end{array}$ & $72 \%$ & $2.48 \%$ & 1 \\
\hline & & & Surrounding & $11 \%$ & $0.38 \%$ & 1 \\
\hline & & & Air Quality & $17 \%$ & $0.59 \%$ & 1 \\
\hline & & $\begin{array}{l}\text { Urban } \\
\text { Density }\end{array}$ & Future & $100 \%$ & $2.07 \%$ & 1 \\
\hline & & Wind & Wind & $100 \%$ & $1.38 \%$ & 1 \\
\hline & \multirow{9}{*}{ Neighbourhood } & \multirow{6}{*}{$\begin{array}{l}\text { Access \& } \\
\text { Proximity }\end{array}$} & $\begin{array}{l}\text { Enter- } \\
\text { tainment }\end{array}$ & $22 \%$ & $0.66 \%$ & 1 \\
\hline & & & Food & $4 \%$ & $0.12 \%$ & 1 \\
\hline & & & $\begin{array}{l}\text { Green } \\
\text { Spaces }\end{array}$ & $17 \%$ & $0.51 \%$ & 1 \\
\hline & & & $\begin{array}{l}\text { Local } \\
\text { Amenities }\end{array}$ & $7 \%$ & $0.21 \%$ & 1 \\
\hline & & & $\begin{array}{l}\text { Public } \\
\text { Transport }\end{array}$ & $28 \%$ & $0.84 \%$ & 1 \\
\hline & & & Work & $22 \%$ & $0.66 \%$ & 1 \\
\hline & & \multirow{3}{*}{ Safety } & Crime & $53 \%$ & $1.65 \%$ & 1 \\
\hline & & & Perceptions & $26 \%$ & $0.81 \%$ & 1 \\
\hline & & & Visibility & $21 \%$ & $0.65 \%$ & 1 \\
\hline
\end{tabular}

Table C-12, Component and Global Weightings for Community Features

\begin{tabular}{|c|c|c|c|c|c|c|}
\hline $\begin{array}{l}\text { Level } 2 \\
\text { Category }\end{array}$ & $\begin{array}{l}\text { Level } 3 \\
\text { Section }\end{array}$ & $\begin{array}{l}\text { Level } 4 \\
\text { Feature }\end{array}$ & $\begin{array}{l}\text { Component } \\
\text { Weighting }\end{array}$ & $\begin{array}{l}\text { Global } \\
\text { Weighting }\end{array}$ & $\begin{array}{l}\text { Level } 5 \\
\text { Aspect }\end{array}$ & $\begin{array}{l}\text { Level } 6 \\
\text { Indicators }\end{array}$ \\
\hline \multirow{5}{*}{ Community } & \multirow{3}{*}{ Environment } & Location & $50 \%$ & $3.45 \%$ & 3 & 3 \\
\hline & & $\begin{array}{l}\text { Urban } \\
\text { Density }\end{array}$ & $30 \%$ & $2.07 \%$ & 1 & 1 \\
\hline & & Wind & $20 \%$ & $1.38 \%$ & 1 & 1 \\
\hline & \multirow[t]{2}{*}{ Neighbourhood } & $\begin{array}{l}\text { Access \& } \\
\text { Proximity }\end{array}$ & $49 \%$ & $2.99 \%$ & 6 & 6 \\
\hline & & Safety & $51 \%$ & $3.12 \%$ & 3 & 3 \\
\hline
\end{tabular}

Table C-13, Component and Global Weightings for Community Sections

\begin{tabular}{|l|l|l|l|l|l|l|}
\hline $\begin{array}{l}\text { Level 2 } \\
\text { Category }\end{array}$ & $\begin{array}{l}\text { Level 3 } \\
\text { Section }\end{array}$ & $\begin{array}{l}\text { Component } \\
\text { Weighting }\end{array}$ & $\begin{array}{l}\text { Global } \\
\text { Weighting }\end{array}$ & $\begin{array}{l}\text { Level 4 } \\
\text { Feature }\end{array}$ & $\begin{array}{l}\text { Level 5 } \\
\text { Aspect }\end{array}$ & $\begin{array}{l}\text { Level 6 } \\
\text { Indicators }\end{array}$ \\
\hline \multirow{2}{*}{ Community } & Environment & $53 \%$ & $6.89 \%$ & 3 & 5 & 5 \\
\cline { 2 - 7 } & Neighbourhood & $47 \%$ & $6.11 \%$ & 2 & 9 & 9 \\
\hline
\end{tabular}




\section{APPENDIX D CONFIGURATION}

This Appendix will present the development of the Configuration Category. This will include the Configuration framework development from factor assessment to credit establishment, and Calibration of the Configuration Components.

\section{D.1 CONFIGURATION FRAMEWORK DEVELOPMENT}

The framework development discussed here follows the same process as that discussed in Section 3.2, Section 4.1 and Figure 4-2.

\section{Factor Assessment}

Configuration was created by grouping factors that are concerned with how the design of a space affects usability, social interactions and privacy. A total of 18 Factors were initially included within this Category, these can be seen in Figure 2-4. The preliminary Factor assessment highlighted that there were four repeated factors Outdoor Provision, Privacy, Size and Storage, shown in Figure D-1. There were no factors in Configuration that did not meet the requirements of Criterion \#1.

\section{CONFIGURATION}

\begin{tabular}{|l|l}
\hline CONNECTIONS & SPATIALITY \\
High-Rise/Vertical Location & Crowding \\
Outdoor Provision & Density \\
Privacy & Headroom \\
& Occupancy \\
& Shape (Of Unit) \\
& Size (Of Unit) \\
& Space Organisation \\
& Spatiality \\
& Storage
\end{tabular}

Figure D-1, Factors Included Within Community 


\section{Feature Identification}

The Factors that were initially grouped under Configuration were grouped within two Sections Connections and Spatiality. Factors within Connections were concerned with how the architecture and design of a space can facilitate with two types of connections that are required connections to the outdoors through private outdoor access and social connections and privacy. This Section also had three Features beneath it Private Outdoor Access, Privacy and High-Rise Living.

The second Section that was identified was Spatiality. Factors that were re-grouped within Spatiality were concerned with the size, shape, layout and organisation of the space within the apartment. Five Features were identified Occupancy (density and crowding), Shape \& Configuration, Size, Spatial Organisation and Storage. Table D-1 shows these new levels of the hierarchy under Configuration. In total, 2 Sections and 8 Features were identified.

Table D-1, Features Identified for Configuration

\begin{tabular}{|c|c|c|c|}
\hline $\begin{array}{l}\text { Level } 2 \\
\text { Category }\end{array}$ & $\begin{array}{l}\text { Level } 3 \\
\text { Section }\end{array}$ & $\begin{array}{l}\text { Level } 4 \\
\text { Feature }\end{array}$ & Associated Factors \\
\hline \multirow[t]{8}{*}{ Configuration } & \multirow[t]{3}{*}{ Connections } & High Rise Living & - High-Rise/Vertical Location \\
\hline & & Privacy & - $\quad$ Privacy \\
\hline & & $\begin{array}{l}\text { Private Outdoor } \\
\text { Access }\end{array}$ & $\begin{array}{l}\text { - Outdoor Provision, Outdoor } \\
\text { Areas and Balconies }\end{array}$ \\
\hline & \multirow[t]{5}{*}{ Spatiality } & Occupancy & $\begin{array}{ll}\text { - } & \text { Crowding } \\
\text { - } & \text { Density } \\
\text { - } & \text { Occupancy }\end{array}$ \\
\hline & & $\begin{array}{l}\text { Shape \& } \\
\text { Configuration }\end{array}$ & - Shape (of Unit) \\
\hline & & Size & $\begin{array}{l}\text { - } \quad \text { Headroom } \\
\text { - } \quad \text { Size of Apartments }\end{array}$ \\
\hline & & $\begin{array}{l}\text { Spatial } \\
\text { Organisation }\end{array}$ & $\begin{array}{ll}\text { - } & \text { Space Organisation } \\
\text { - } & \text { Spatiality }\end{array}$ \\
\hline & & Storage & - Storage \\
\hline
\end{tabular}

3. Aspect Identification

\section{Connections}

High-Rise Living affects occupants well-being in two ways by restricting physical exercise (depending on the floor an occupant lives on) and also be inhibiting social interactions with neighbours and other occupants. Because of this, two Aspects were identified that affect liveability Vertical Location (floor level of the apartment) and Communal Areas (how they prevent or encourage social interactions). 
The literature review showed that Privacy

If they feel

spaces then privacy or

be an issue. Three Aspects were identified for Privacy the outlook of the apartment, neighbours outlook (specifically if neighbours are perceived to be or able to look in) and the privacy of personal outdoor spaces.

review highlighted many issues with outdoor access. Studies of apartments highlighted that size was particularly important, as well as how usable it is and how well protected from the weather it may be. In a comparative study of potential health issues in standalone housing and high-medium density housing in Auckland, New Zealand, Lyne and Moore (1999, pg 4) found that:

While adverse weather conditions was the main reason occupants from both housing types did not use their outdoor spaces more frequently, more occupants of high-medium density homes (21\%) than single stand-alone dwellings (13\%) indicated that a lack of privacy was the next main reason of concern. This is probably due to the design of the complexes where outdoor living areas may be in full view of other residents and/or people passing by.

Five Aspects were identified for this Feature. These were:

- Provision of Private Outdoor Spaces i.e. whether or not an apartment has a balcony

- The Size of these spaces if provided

- The Type of private outdoor spaces i.e. a balcony, terrace, courtyard, rooftop access etc

- The Usability of private outdoor spaces i.e. the shape, whether outdoor furniture can easily be used, washing stands, how safe these spaces are etc

- Weather Protection spaces become better quality the more they are sheltered from rain and wind.

This Feature only considered personal outdoor spaces, not communal outdoor spaces as this is considered in the Quality Category. The 10 Aspects identified for Connections are shown in Table D-2

Table D-2, Aspects Identified for Connections

\begin{tabular}{|c|c|c|}
\hline $\begin{array}{l}\text { Level } 3 \\
\text { Section }\end{array}$ & $\begin{array}{l}\text { Level } 4 \\
\text { Feature } \\
\end{array}$ & $\begin{array}{l}\text { Level } 5 \\
\text { Aspect } \\
\end{array}$ \\
\hline \multirow[t]{10}{*}{ Connections } & \multirow[t]{2}{*}{ High Rise Living } & Vertical Location \\
\hline & & Social Interactions in Communal Areas \\
\hline & \multirow[t]{3}{*}{ Privacy } & Outlook of Unit \\
\hline & & Neighbours Outlook \\
\hline & & Privacy of Outdoor Spaces \\
\hline & \multirow{5}{*}{$\begin{array}{l}\text { Private Outdoor } \\
\text { Access }\end{array}$} & Provision of Private Spaces \\
\hline & & Size of Private Outdoor Spaces \\
\hline & & Type of Private Outdoor Access \\
\hline & & Usability of Private Outdoor Spaces \\
\hline & & Weather Protection \\
\hline
\end{tabular}




\section{Spatiality}

Occupancy, crowding and density is an issue that is very important for well-being. However it is also an issue that is very personal so issues arising from crowding within a home are different for everyone. As Gray (2001) discusses in her study into the effects of crowding on health, there is no

Similarly, there is no definitive measure of crowding. Crowding can be measured by occupancy rate, bedroom occupancy rate, the bedroom standard and many more. For this study, it was determined that in order to be in line with other research, the Aspect used to assess Occupancy in NZ ALI would bedroom $^{32}$ Unit Occupancy.

Shape and Configuration is a Feature that looks at how the apartment unit is configured with respect to aspect and external walls. This is an important Feature of Spatiality as it is influenced by site opportunities and constraints like views, orientation, sunlight access and building access (North Shore City Council, 2007). Apartment Aspect considers how many external walls (with windows) a unit has. For example Single Aspect has only one external wall, Dual Aspect has two opposite external walls and Corner Aspect has two adjacent external walls. Each of these apartment shapes

identified Unit Configuration ${ }^{33}$.

Size is also an important Feature of Spatiality. A review of apartment living in inner city Auckland in 2004 (Auckland UniServices Ltd, 2004) found that more than half the occupants found that the spaces within their apartment were not adequate for their requirements. Lyne and Moore (2004) found that occupants from high-medium density housing were more likely to perceive their indoor living areas as cramped in comparison to those from single, stand alone housing. They discuss that of high-medium density homes which are more compact so as to Occupants need adequate space so they can carry out day to day tasks and may feel dissatisfaction, distress and cramped in spaces that are too small for their needs. Therefore two Aspects were identified with Size Floor Area and Headroom (floor to ceiling height).

Spatial Organisation considers the apartment layout and organisation different to shape and internal layout of an apartment establishes the spatial arrangement of the rooms, circulation and privacy of rooms (North Shore City Council, 2007). Aspects of layout such as access to daylight, carry out day to day tasks and to socialise, feel safe and secure. The NSCC Good Solutions Guide to Apartment (2007) outlines four main ways to maximise apartment layout for liveability:

\footnotetext{
32 In 2001 Gray undertook a study that looked at definitions of crowding and the effects of crowding on health (Gray, 2001)

e.g. A bedroom, a habitable space, any room in a
}

and to minimize misunderstandings of the term. 
- Providing flexible layouts (to maximise privacy and to allow for different furniture arrangements and activities)

- Designing layouts to maximise daylight, views, ventilation, privacy and reducing noise disturbances

- Locating similar spaces (i.e. main living spaces near private outdoor spaces)

- Separating incompatible spaces (i.e. bathrooms and kitchens, circulation spaces and kitchens)

From this, two Aspects of Spatial Organisation were determined Flexibility of Spaces and Placement of Rooms.

The final Feature of Spatiality is Storage. Auckland UniServices (2004) found that storage is a major issue in many apartments in their surveys of apartment occupants and building management. Often there is inadequate storage for cleaning equipment and larger items such as bicycles and often it is located externally from the unit. Over half the occupants interviewed stated that they lacked sufficient storage space and cupboards. From this, four Aspects were identified for Storage the ability to store Large Items (like bicycles, excess furniture or suitcases), the Location of storage facilities, the Quality of storage (i.e. cupboards, shelves, dampness, hanging spaces etc) and finally Size or amount of storage provided. All Aspect identified for Spatiality are shown in Table D-3.

Table D-3, Aspects Identified for Spatiality

\begin{tabular}{|c|c|c|}
\hline $\begin{array}{l}\text { Level } 3 \\
\text { Section }\end{array}$ & $\begin{array}{l}\text { Level } 4 \\
\text { Feature }\end{array}$ & $\begin{array}{l}\text { Level } 5 \\
\text { Aspect }\end{array}$ \\
\hline \multirow[t]{10}{*}{ Spatiality } & Occupancy & Unit Occupancy \\
\hline & $\begin{array}{l}\text { Shape \& } \\
\text { Configuration }\end{array}$ & Unit Configuration \\
\hline & \multirow[t]{2}{*}{ Size } & Floor Area \\
\hline & & Headroom \\
\hline & \multirow[t]{2}{*}{ Spatial Organisation } & Flexibility of Spaces \\
\hline & & Room Placement \\
\hline & \multirow[t]{4}{*}{ Storage } & Large Items \\
\hline & & Location \\
\hline & & Quality \\
\hline & & Size \\
\hline
\end{tabular}

4. Indicator Identification

In total, 20 Aspects were identified for the 8 Features within Configuration. Table D-4 shows the Indicators that were then identified. Only one Aspect had more than one Indicator Room Placement due to the number of issues highlighted with this Aspect with regards to how to best utilise apartment layout. 
Table D-4, Indicators Identified for Configuration

\begin{tabular}{|c|c|c|c|}
\hline $\begin{array}{l}\text { Level } 3 \\
\text { Section }\end{array}$ & $\begin{array}{l}\text { Level } 4 \\
\text { Feature }\end{array}$ & $\begin{array}{l}\text { Level } 5 \\
\text { Aspect }\end{array}$ & $\begin{array}{l}\text { Level } 6 \\
\text { Indicator }\end{array}$ \\
\hline \multirow[t]{10}{*}{ Connections } & \multirow[t]{2}{*}{ High Rise Living } & Vertical Location & $\begin{array}{l}\text { What floor level(s) is the unit } \\
\text { situated on? }\end{array}$ \\
\hline & & $\begin{array}{l}\text { Social Interactions in } \\
\text { Communal Areas }\end{array}$ & $\begin{array}{l}\text { Do communal areas allow for } \\
\text { social interactions with } \\
\text { neighbours and other occupants? }\end{array}$ \\
\hline & \multirow[t]{3}{*}{ Privacy } & Outlook of Unit & $\begin{array}{l}\text { Do you look into other } \\
\text { private spaces? }\end{array}$ \\
\hline & & Neighbours Outlook & $\begin{array}{l}\text { Can other people look into your } \\
\text { private spaces? }\end{array}$ \\
\hline & & $\begin{array}{l}\text { Privacy of Outdoor } \\
\text { Spaces }\end{array}$ & $\begin{array}{l}\text { How private are your personal } \\
\text { outdoor spaces? }\end{array}$ \\
\hline & \multirow[t]{5}{*}{$\begin{array}{l}\text { Private Outdoor } \\
\text { Access }\end{array}$} & $\begin{array}{l}\text { Provision of Private } \\
\text { Spaces }\end{array}$ & $\begin{array}{l}\text { Are private outdoor spaces } \\
\text { provided? }\end{array}$ \\
\hline & & $\begin{array}{l}\text { Size of Private } \\
\text { Outdoor Spaces }\end{array}$ & $\begin{array}{l}\text { How big are private outdoor } \\
\text { spaces? }\end{array}$ \\
\hline & & $\begin{array}{l}\text { Type of Private } \\
\text { Outdoor Access }\end{array}$ & $\begin{array}{l}\text { What type of private outdoor } \\
\text { access do you have? }\end{array}$ \\
\hline & & $\begin{array}{l}\text { Usability of Private } \\
\text { Outdoor Spaces }\end{array}$ & $\begin{array}{l}\text { How usable are private outdoor } \\
\text { spaces? }\end{array}$ \\
\hline & & Weather Protection & $\begin{array}{l}\text { Are private outdoor spaces well } \\
\text { protected from the weather? }\end{array}$ \\
\hline \multirow[t]{13}{*}{ Spatiality } & Occupancy & Unit Occupancy & $\begin{array}{l}\text { What is the occupant per } \\
\text { bedroom ratio? }\end{array}$ \\
\hline & $\begin{array}{l}\text { Shape \& } \\
\text { Configuration }\end{array}$ & Unit Aspect & $\begin{array}{l}\text { What aspect type is the } \\
\text { apartment? }\end{array}$ \\
\hline & \multirow[t]{2}{*}{ Size } & Floor Area & How big is the apartment? \\
\hline & & Headroom & What is the floor to ceiling height? \\
\hline & \multirow[t]{5}{*}{ Spatial Organisation } & Flexibility of Spaces & Do spaces allow for flexibility? \\
\hline & & \multirow[t]{4}{*}{ Room Placement } & $\begin{array}{l}\text { Where are the main living spaces } \\
\text { placed? }\end{array}$ \\
\hline & & & Where are the bedrooms placed? \\
\hline & & & $\begin{array}{l}\text { How close are the kitchen and } \\
\text { bathroom spaces? }\end{array}$ \\
\hline & & & $\begin{array}{l}\text { Is the kitchen space located in or } \\
\text { close to circulation spaces? }\end{array}$ \\
\hline & \multirow[t]{4}{*}{ Storage } & Large Items & Can large items be easily stored? \\
\hline & & Location & $\begin{array}{l}\text { Where is the majority of the } \\
\text { storage located? }\end{array}$ \\
\hline & & Quality & $\begin{array}{l}\text { Is the storage good quality and } \\
\text { usable? }\end{array}$ \\
\hline & & Size & How much storage is provided? \\
\hline
\end{tabular}


5. AM Identification \& Review

\section{Connections}

Table D-5

Connections (under Assessment Method Version 1).

Vertical Location and Type of Private Outdoor Access) and one required Measurement (Size of Private Outdoor Space). Three required Personal Perceptions (Privacy, Usability and Weather Protection of Outdoor Spaces) and the remaining four Indicators required a Yes or No Choice.

Connections, three were determined to be impractical due to wording

- Privacy of Outdoor Spaces

- Usability of Private Outdoor Spaces

- Weather Protection of Private Outdoor Spaces

All

modified to become Scales as is shown in Table D-5.

\section{Spatiality}

Table D-6 outlines the initial Assessment Methods identified for Spatiality (under Assessment

Choices and the other four required Personal Perceptions.

Spatiality, four were found to not meet

the requirements of Criteria

following Indicators

- Flexibility of Spaces

- Placement of Main Living Spaces

- Placement of Bedrooms

- Storage Quality

Due to possible issues and misunderstanding of Indicator and Assessment Method wordings these were found to be impractical assessments. Similarly as they required personal judgements from users they were deemed to be highly subjective. The modified Assessment Methods for these four Indicators are shown in Table D-6 under Modified Assessment Method shown in purple. It was decided that allowing users to use a scale to rate these Indicators (with appropriate guidance) would be an appropriate way to practically assess these Indicators, while still allowing for some subjectivity. 
Table D-5, Review of Assessment Methods Identified for Connections

\begin{tabular}{|c|c|c|c|c|}
\hline $\begin{array}{l}\text { Level } 4 \\
\text { Feature }\end{array}$ & $\begin{array}{l}\text { Level } 5 \\
\text { Aspect }\end{array}$ & $\begin{array}{l}\text { Level } 6 \\
\text { Indicator-Assessment } \\
\text { Question }\end{array}$ & $\begin{array}{l}\text { Assessment } \\
\text { Method } \\
\text { Version } 1 \\
\end{array}$ & $\begin{array}{l}\text { Modified } \\
\text { Assessment } \\
\text { Method } \\
\end{array}$ \\
\hline \multirow[b]{2}{*}{$\begin{array}{l}\text { High Rise } \\
\text { Living }\end{array}$} & $\begin{array}{l}\text { Vertical } \\
\text { Location }\end{array}$ & $\begin{array}{l}\text { What floor level(s) is the unit } \\
\text { situated on? }\end{array}$ & $\begin{array}{l}\text { Statement (Floor } \\
\text { Level) }\end{array}$ & List \\
\hline & $\begin{array}{l}\text { Social } \\
\text { Interactions } \\
\text { in Communal } \\
\text { Areas }\end{array}$ & $\begin{array}{l}\text { Do communal areas allow } \\
\text { for social interactions with } \\
\text { neighbours and other } \\
\text { occupants? }\end{array}$ & Choose Yes or No & Yes/No \\
\hline \multirow{3}{*}{ Privacy } & $\begin{array}{l}\text { Outlook of } \\
\text { Unit }\end{array}$ & $\begin{array}{c}\text { Do you look into other } \\
\text { private spaces? }\end{array}$ & Choose Yes or No & Yes/No \\
\hline & $\begin{array}{l}\text { Neighbours } \\
\text { Outlook }\end{array}$ & $\begin{array}{l}\text { Can other people look into } \\
\text { your private spaces? }\end{array}$ & Choose Yes or No & Yes/No \\
\hline & $\begin{array}{l}\text { Privacy of } \\
\text { Outdoor } \\
\text { Spaces }\end{array}$ & $\begin{array}{l}\text { How private are your } \\
\text { personal outdoor spaces? }\end{array}$ & $\begin{array}{l}\text { Personal } \\
\text { Perception } \\
\text { (Privacy) } \\
\end{array}$ & Scale \\
\hline \multirow{5}{*}{$\begin{array}{l}\text { Private } \\
\text { Outdoor } \\
\text { Access }\end{array}$} & $\begin{array}{l}\text { Provision of } \\
\text { Private } \\
\text { Spaces }\end{array}$ & $\begin{array}{l}\text { Are private outdoor spaces } \\
\text { provided? }\end{array}$ & Choose Yes or No & Yes/No \\
\hline & $\begin{array}{l}\text { Size of } \\
\text { Private } \\
\text { Outdoor } \\
\text { Spaces }\end{array}$ & $\begin{array}{l}\text { How big are private outdoor } \\
\text { spaces? }\end{array}$ & $\begin{array}{l}\text { Measurement } \\
\text { (Floor Area) }\end{array}$ & Number \\
\hline & $\begin{array}{l}\text { Type of } \\
\text { Private } \\
\text { Outdoor } \\
\text { Access } \\
\end{array}$ & $\begin{array}{l}\text { What type of private } \\
\text { outdoor access do you have? }\end{array}$ & $\begin{array}{l}\text { Statement } \\
\text { (Outdoor Access) }\end{array}$ & List \\
\hline & $\begin{array}{l}\text { Usability of } \\
\text { Private } \\
\text { Outdoor } \\
\text { Spaces }\end{array}$ & $\begin{array}{l}\text { How usable are private } \\
\text { outdoor spaces? }\end{array}$ & $\begin{array}{l}\text { Personal } \\
\text { Perception } \\
\text { (Usability) }\end{array}$ & Scale \\
\hline & $\begin{array}{l}\text { Weather } \\
\text { Protection }\end{array}$ & $\begin{array}{l}\text { Are private outdoor spaces } \\
\text { well protected from the } \\
\text { weather? }\end{array}$ & $\begin{array}{l}\text { Personal } \\
\text { Perception } \\
\text { (Weather } \\
\text { Protection) }\end{array}$ & Scale \\
\hline
\end{tabular}


Table D-6, Review of Assessment Methods Identified for Spatiality

\begin{tabular}{|c|c|c|c|c|}
\hline $\begin{array}{l}\text { Level } 4 \\
\text { Feature }\end{array}$ & $\begin{array}{l}\text { Level } 5 \\
\text { Aspect }\end{array}$ & $\begin{array}{l}\text { Level } 6 \\
\text { Indicator-Assessment } \\
\text { Question }\end{array}$ & $\begin{array}{l}\text { Assessment } \\
\text { Method } \\
\text { Version } 1 \\
\end{array}$ & $\begin{array}{l}\text { Modified } \\
\text { Assessment } \\
\text { Method }\end{array}$ \\
\hline Occupancy & $\begin{array}{l}\text { Unit } \\
\text { Occupancy }\end{array}$ & $\begin{array}{l}\text { What is the occupant per } \\
\text { bedroom ratio? }\end{array}$ & $\begin{array}{l}\text { Measurement } \\
\text { (No. Bedrooms \& } \\
\text { No. Occupants) }\end{array}$ & Number \\
\hline $\begin{array}{l}\text { Shape \& } \\
\text { Configuration }\end{array}$ & Unit Aspect & $\begin{array}{l}\text { What aspect type is the } \\
\text { apartment? }\end{array}$ & $\begin{array}{l}\text { Statement } \\
\text { (Aspect) }\end{array}$ & List \\
\hline \multirow{2}{*}{ Size } & Floor Area & How big is the apartment? & $\begin{array}{l}\text { Measurement } \\
\text { (Floor Area) }\end{array}$ & Number \\
\hline & Headroom & $\begin{array}{l}\text { What is the floor to ceiling } \\
\text { height? }\end{array}$ & $\begin{array}{l}\text { Measurement } \\
\text { (Headroom) }\end{array}$ & Number \\
\hline \multirow{5}{*}{$\begin{array}{l}\text { Spatial } \\
\text { Organisation }\end{array}$} & $\begin{array}{l}\text { Flexibility of } \\
\text { Spaces }\end{array}$ & $\begin{array}{l}\text { Do spaces allow for } \\
\text { flexibility? }\end{array}$ & $\begin{array}{l}\text { Personal } \\
\text { Perception } \\
\text { (Flexibility) } \\
\end{array}$ & Scale \\
\hline & \multirow{4}{*}{$\begin{array}{l}\text { Room } \\
\text { Placement }\end{array}$} & $\begin{array}{l}\text { How well are the main living } \\
\text { spaces placed? }\end{array}$ & $\begin{array}{l}\text { Personal } \\
\text { Perception } \\
\text { (Placement) }\end{array}$ & Scale \\
\hline & & $\begin{array}{l}\text { How well the bedrooms } \\
\text { placed? }\end{array}$ & $\begin{array}{l}\text { Personal } \\
\text { Perception } \\
\text { (Placement) }\end{array}$ & Scale \\
\hline & & $\begin{array}{l}\text { How close are the kitchen } \\
\text { and bathroom spaces? }\end{array}$ & $\begin{array}{l}\text { Measurement } \\
\text { (Distance) }\end{array}$ & Number \\
\hline & & $\begin{array}{l}\text { Is the kitchen space located } \\
\text { in or close to circulation } \\
\text { spaces? }\end{array}$ & $\begin{array}{l}\text { Choose Yes or } \\
\text { No }\end{array}$ & Yes/No \\
\hline \multirow{4}{*}{ Storage } & Large Items & $\begin{array}{l}\text { Can large items be easily } \\
\text { stored? }\end{array}$ & $\begin{array}{l}\text { Choose Yes or } \\
\text { No }\end{array}$ & Yes/No \\
\hline & Location & $\begin{array}{l}\text { Where is the majority of the } \\
\text { storage located? }\end{array}$ & $\begin{array}{l}\text { Statement } \\
\text { (Location) }\end{array}$ & List \\
\hline & Quality & $\begin{array}{l}\text { Is the storage good quality } \\
\text { and usable? }\end{array}$ & $\begin{array}{l}\text { Personal } \\
\text { Perception } \\
\text { (Usability \& } \\
\text { Quality) }\end{array}$ & Scale \\
\hline & Size & $\begin{array}{l}\text { How much storage is } \\
\text { provided? }\end{array}$ & $\begin{array}{l}\text { Measurement } \\
\text { (Storage Floor } \\
\text { Area) }\end{array}$ & Number \\
\hline
\end{tabular}




\section{Credit Establishment}

\section{Connections}

Credits and Acceptability of Answers was then determined for the Connections Assessment Methods shown in Table D-7. All Assessment Questions were modified except Vertical Location, generally to tailor the question to the Assessment Method of NZ ALI.

During this stage of the Index Development, one Indicator in Neighbourhood was required to be modified so that credits could be appropriately applied Size of Private Outdoor Spaces. The ACC

(Auckland City Council,

2009) however these sizes are based on the number of bedrooms. The GSGA also recommends a minimum size for private outdoor space for apartments on the ground floor (North Shore City Council, 2007). As a result, 2 additional Indicators were identified for Size of Private Outdoor Spaces Vertical Location (i.e. whether or not it is on the ground floor) and the Number of Bedrooms. The Answer Acceptability is then based on the Floor Area of the private outdoor space and how well it meets the minimum sizes specified by the ACC and GSGA.

\section{Spatiality}

Table D-8 outlines the appropriate answers and credits determined for Spatiality. All Assessment Questions were modified except for Unit Aspect and Storage Location. Within this Section, four Indicators also had to be modified so that they could be adequately assessed. The first Unit Occupancy is assessed on the occupant per bedroom ratio. This required two Assessment Questions to be included for the Aspect the Number of Bedrooms and the Number of Occupants.

Two other Indicators that had to be modified were for Apartment Floor Area and Storage Floor Area. Similarly to Size of Private Outdoor Space, the ACC sets minimum size requirements for both of these based on the Number of Bedrooms. As a result, each Aspect included an additional Indicator (Number of Bedrooms) to accurately assess them as shown in Table D-8 under Level 6 Indicator Modified Assessment Question.

The final Aspect and relating Indicator that was modified was Headroom. The GSGA recommends two different floor to ceiling heights depending on the type of space shown in Figure D-2. From this, three Assessment Questions were included for Headroom the Floor to Ceiling Height of Habitable Spaces, the Floor to Ceiling Height of Mezzanine Floors and the Floor to Ceiling height of Non-Habitable Spaces.

Table D-7, Acceptability \& Awarding of Credits Identified for Connections

\begin{tabular}{|l|l|l|ll|}
\hline $\begin{array}{l}\text { Level 4 } \\
\text { Feature }\end{array}$ & $\begin{array}{l}\text { Level 5 } \\
\text { Aspect }\end{array}$ & $\begin{array}{l}\text { Level 6 } \\
\text { Indicator - Modified } \\
\text { Assessment Question }\end{array}$ & Acceptability \& Awarding of Credits \\
\hline High Rise & Vertical & What floor level is your & Ground Floor Third Floors & $100 \%$ \\
Living & Location & apartment located on? & Fourth - Sixth Floors & $80 \%$ \\
\cline { 1 - 3 } & & & Seventh - Ninth Floors & $60 \%$
\end{tabular}




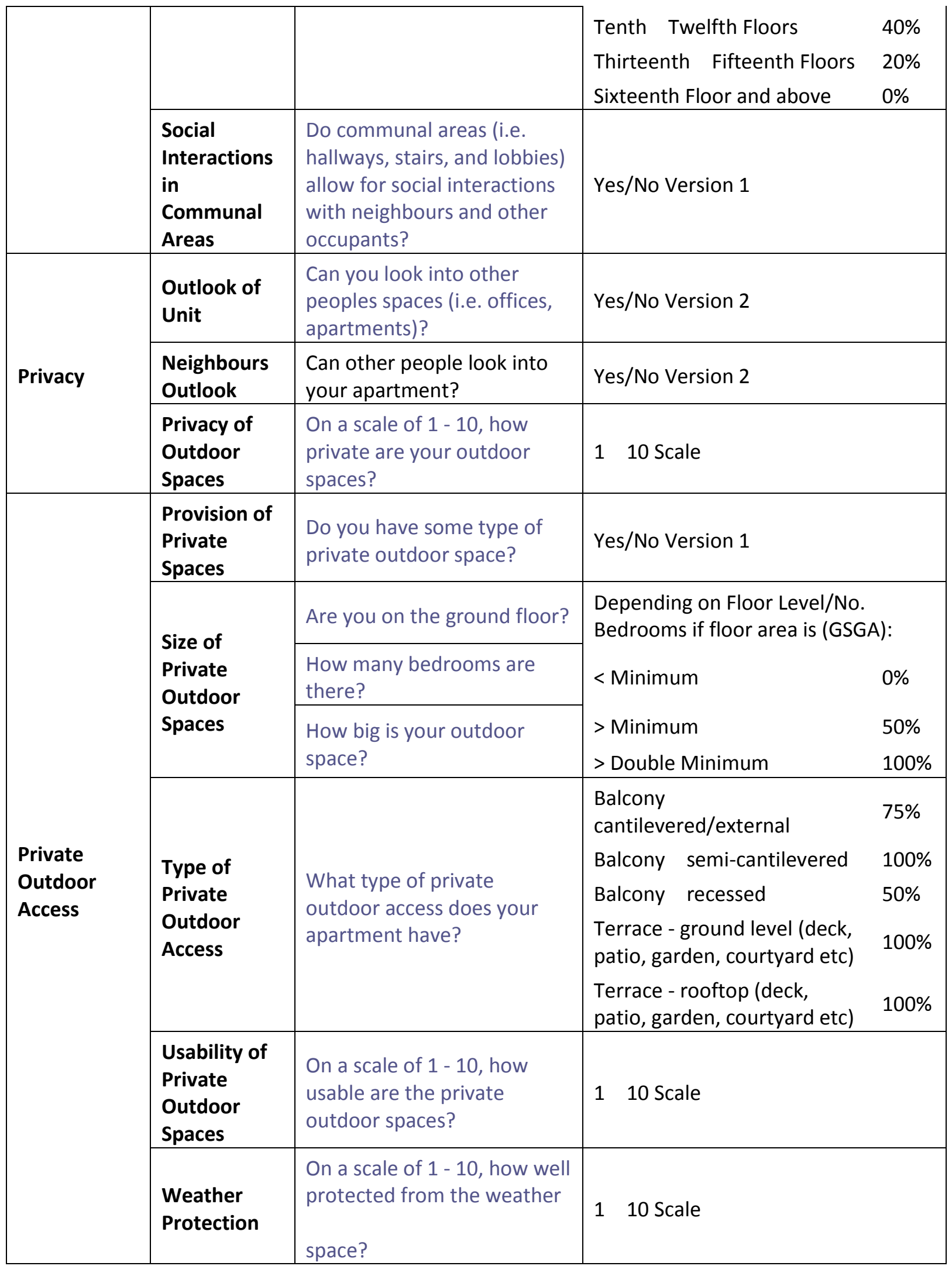




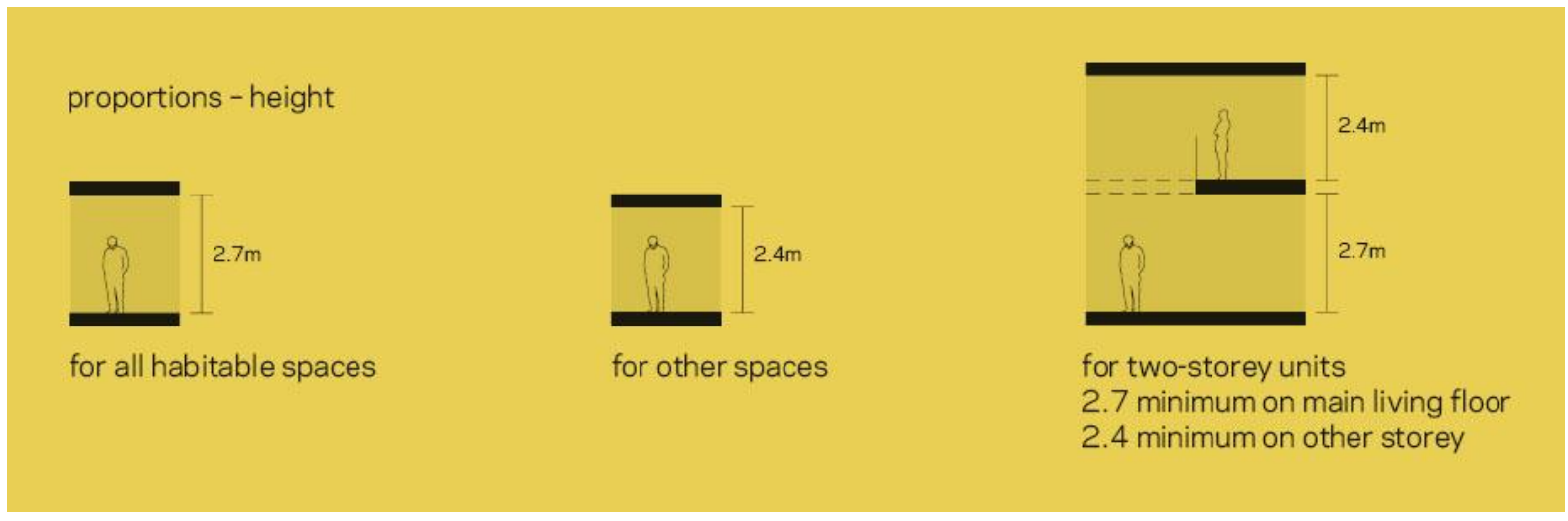

Figure D-2, NSCC Headroom Recommendations from the Good Solutions Guide for Apartments

Table D-8, Acceptability \& Awarding of Credits Identified for Spatiality

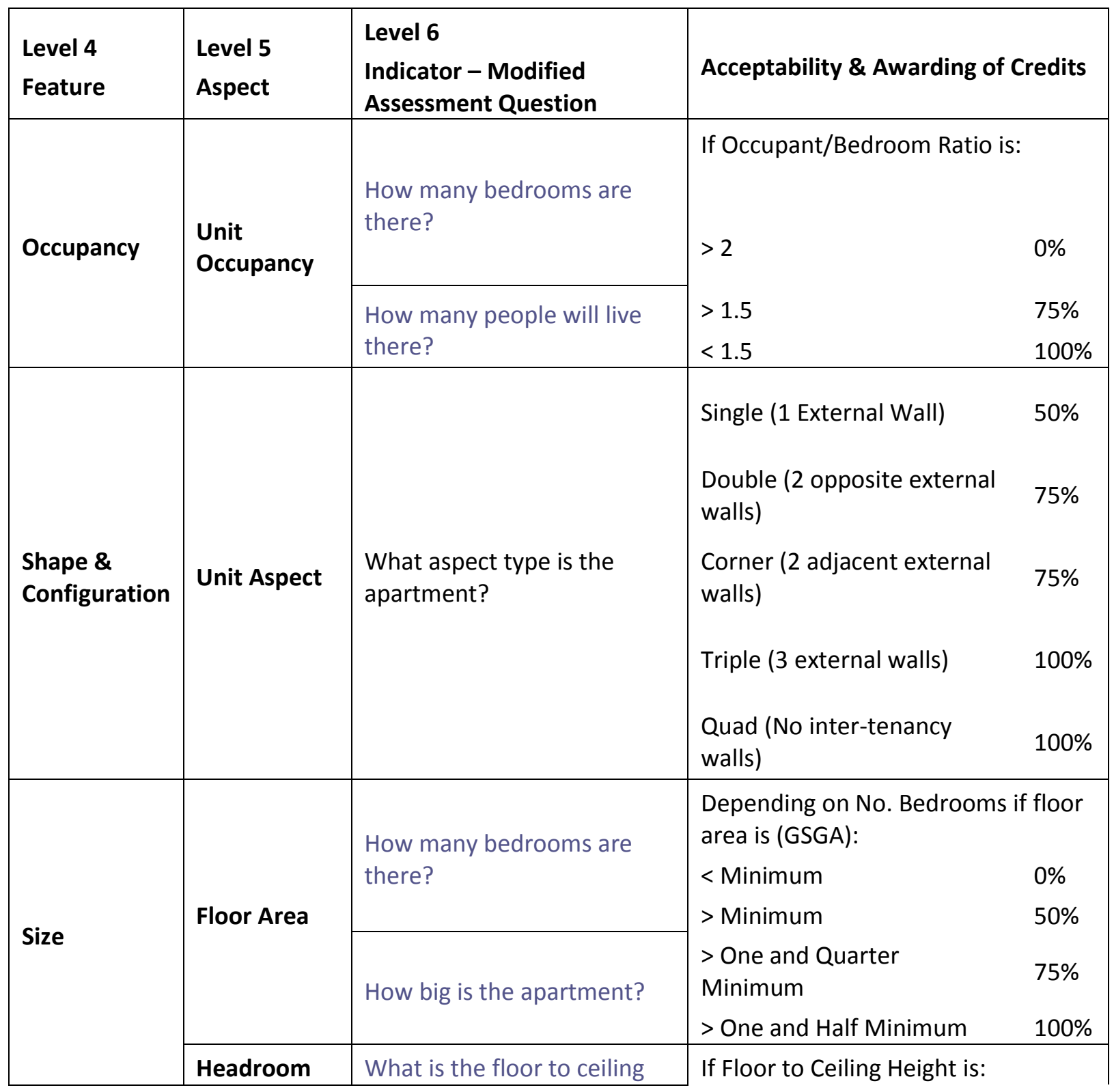




\begin{tabular}{|c|c|c|c|c|}
\hline & & height in habitable spaces? & $\begin{array}{l}>2.7 \mathrm{~m} \\
>2.4 \mathrm{~m} \\
<2.4 \mathrm{~m}\end{array}$ & $\begin{array}{l}100 \% \\
50 \% \\
0 \%\end{array}$ \\
\hline & & $\begin{array}{l}\text { What is the floor to ceiling } \\
\text { height on mezzanine floors? }\end{array}$ & \multirow{2}{*}{$\begin{array}{l}\text { If Floor to Ceiling Height is: } \\
>2.4 \mathrm{~m} \text { (or N/A) } \\
>2.3 \mathrm{~m} \\
<2.3 \mathrm{~m}\end{array}$} & \multirow{2}{*}{$\begin{array}{l}100 \% \\
50 \% \\
0 \%\end{array}$} \\
\hline & & $\begin{array}{l}\text { What is the floor to ceiling } \\
\text { height in non-habitable } \\
\text { spaces? }\end{array}$ & & \\
\hline \multirow{5}{*}{$\begin{array}{l}\text { Spatial } \\
\text { Organisation }\end{array}$} & $\begin{array}{l}\text { Flexibility of } \\
\text { Spaces }\end{array}$ & $\begin{array}{l}\text { On a scale of } 1-10 \text {, how } \\
\text { flexible is the layout of the } \\
\text { apartment? }\end{array}$ & 110 Scale & \\
\hline & \multirow{4}{*}{$\begin{array}{l}\text { Room } \\
\text { Placement }\end{array}$} & $\begin{array}{l}\text { On a scale of } 1-10 \text {, how well } \\
\text { are the main living spaces } \\
\text { placed? }\end{array}$ & 110 Scale & \\
\hline & & $\begin{array}{l}\text { On a scale of } 1-10 \text {, how well } \\
\text { are the bedroom spaces } \\
\text { placed? }\end{array}$ & 110 Scale & \\
\hline & & $\begin{array}{l}\text { How many doors separate } \\
\text { the toilet \& kitchen areas? }\end{array}$ & $\begin{array}{l}\text { If Number of Doors is: } \\
>1 \\
<1\end{array}$ & $\begin{array}{l}100 \% \\
0 \% \\
\end{array}$ \\
\hline & & $\begin{array}{l}\text { Do circulation spaces (i.e. } \\
\text { hallways and corridors) cut } \\
\text { through the kitchen area? }\end{array}$ & Yes/No Version 2 & \\
\hline \multirow{5}{*}{ Storage } & Large Items & $\begin{array}{l}\text { Can large items (i.e. excess } \\
\text { furniture, suitcases) be easily } \\
\text { stored? }\end{array}$ & Yes/No Version 1 & \\
\hline & Location & $\begin{array}{l}\text { Where is the majority of the } \\
\text { storage located? }\end{array}$ & $\begin{array}{l}\text { Internal Storage (In } \\
\text { Apartment) } \\
\text { External Storage (In Building, } \\
\text { i.e. basement) } \\
\text { External Storage (Onsite i.e. } \\
\text { separate building) }\end{array}$ & $\begin{array}{l}100 \% \\
75 \% \\
50 \%\end{array}$ \\
\hline & Quality & $\begin{array}{l}\text { On a scale of } 1-10 \text {, how } \\
\text { good is the storage } \\
\text { provided? }\end{array}$ & 110 Scale & \\
\hline & \multirow[t]{2}{*}{ Size } & $\begin{array}{l}\text { How many bedrooms are } \\
\text { there? }\end{array}$ & \multirow{2}{*}{\multicolumn{2}{|c|}{$\begin{array}{l}\text { Depending on No. Bedrooms if floor } \\
\text { area is: } \\
\text { < Minimum } \\
\text { > Minimum } \\
\begin{array}{ll}\text { > Double Minimum } & 50 \% \\
& 100 \%\end{array}\end{array}$}} \\
\hline & & $\begin{array}{l}\text { How much storage is } \\
\text { provided? }\end{array}$ & & \\
\hline
\end{tabular}




\section{D.2 CONFIGURATION CALIBRATION}

The information discussed here provides information on the Calibration of the Configuration Components. The data analysed and used to develop weightings for this Category is from the NZ ALI Questionnaire. The Calibration process follows that discussed in Section 4.3 and The NZ ALI Questionnaire.

\section{D.2.1 NZ ALI QUESTIONNAIRE RESULTS \& ANALYSIS}

\section{Aspects}

Connections: Figure D-3 shows the percentage of nominations that each of the Aspects within Connections received.

Spatiality: Figure D-4 shows the percentage of nominations that each of the Aspects within Spatiality received.

\section{Features}

Figure D-5 shows the weightings determined for the Configuration Features which were determined from Equation 4-1.

\section{Sections}

Figure D-6 shows the weightings determined for the Configuration Sections which were determined from Equation 4-1. 


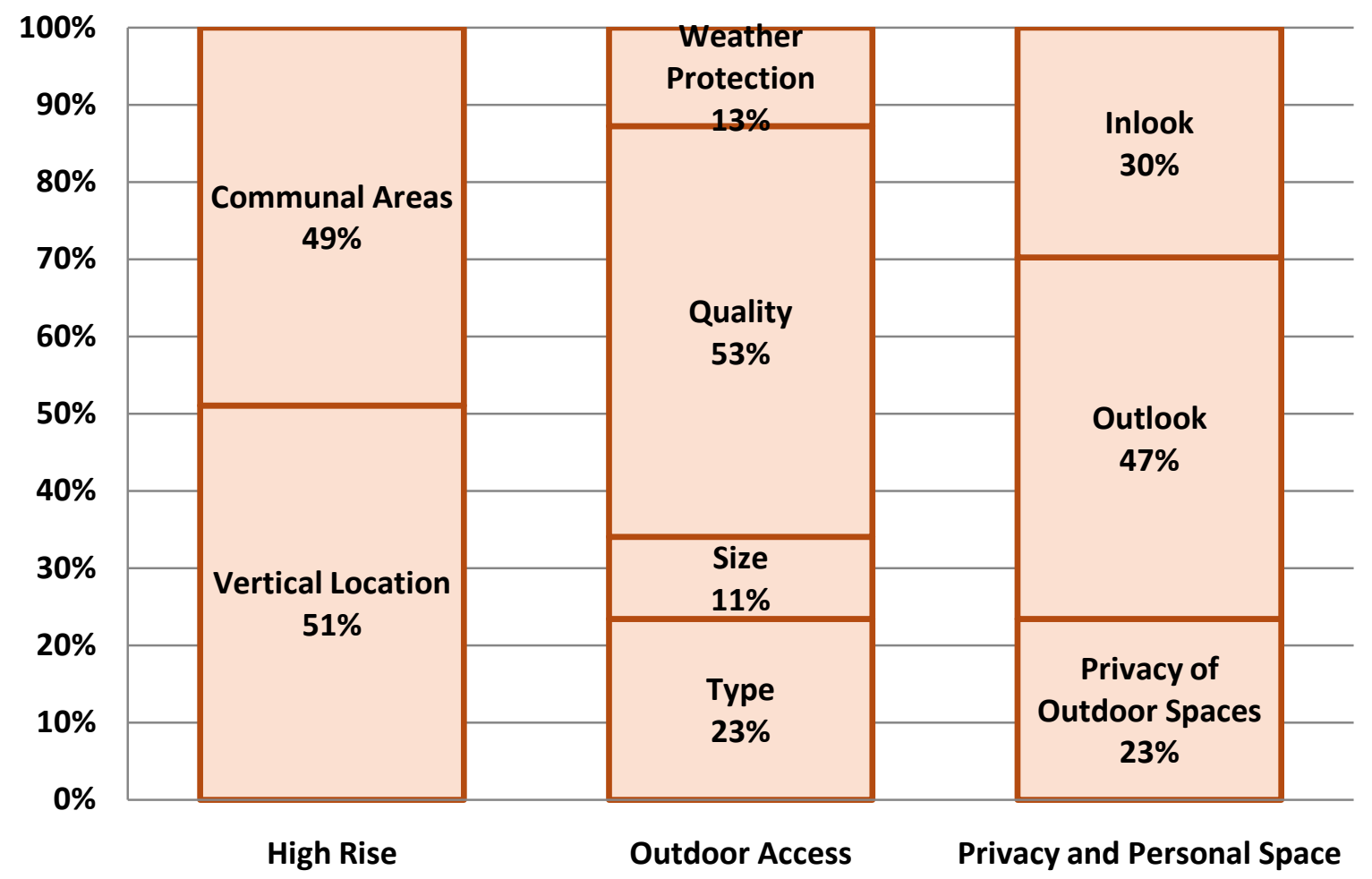

Figure D-3, Perceived Importance of Connections Aspects

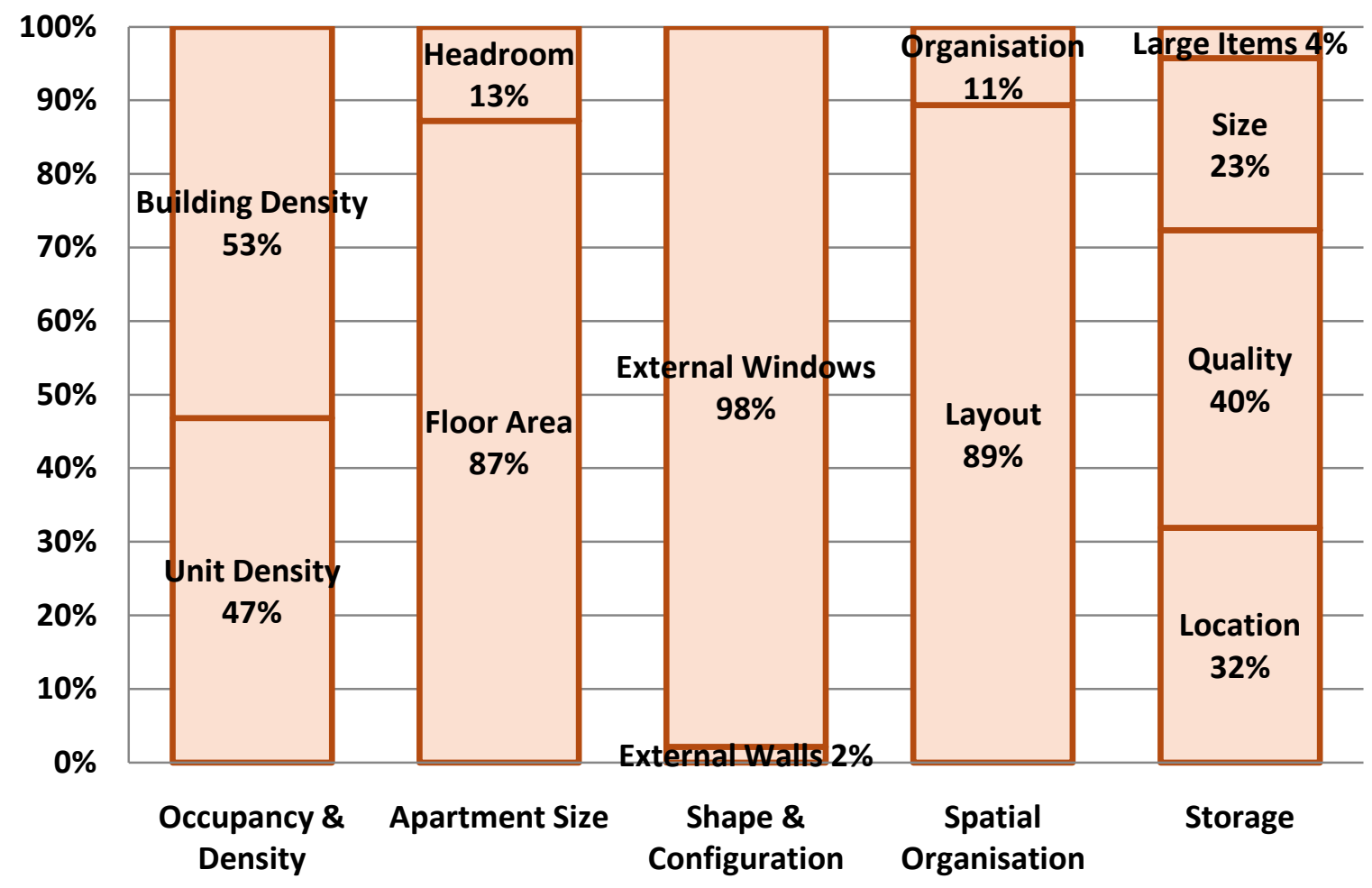

Figure D-4, Perceived Importance of Spatiality Aspects 


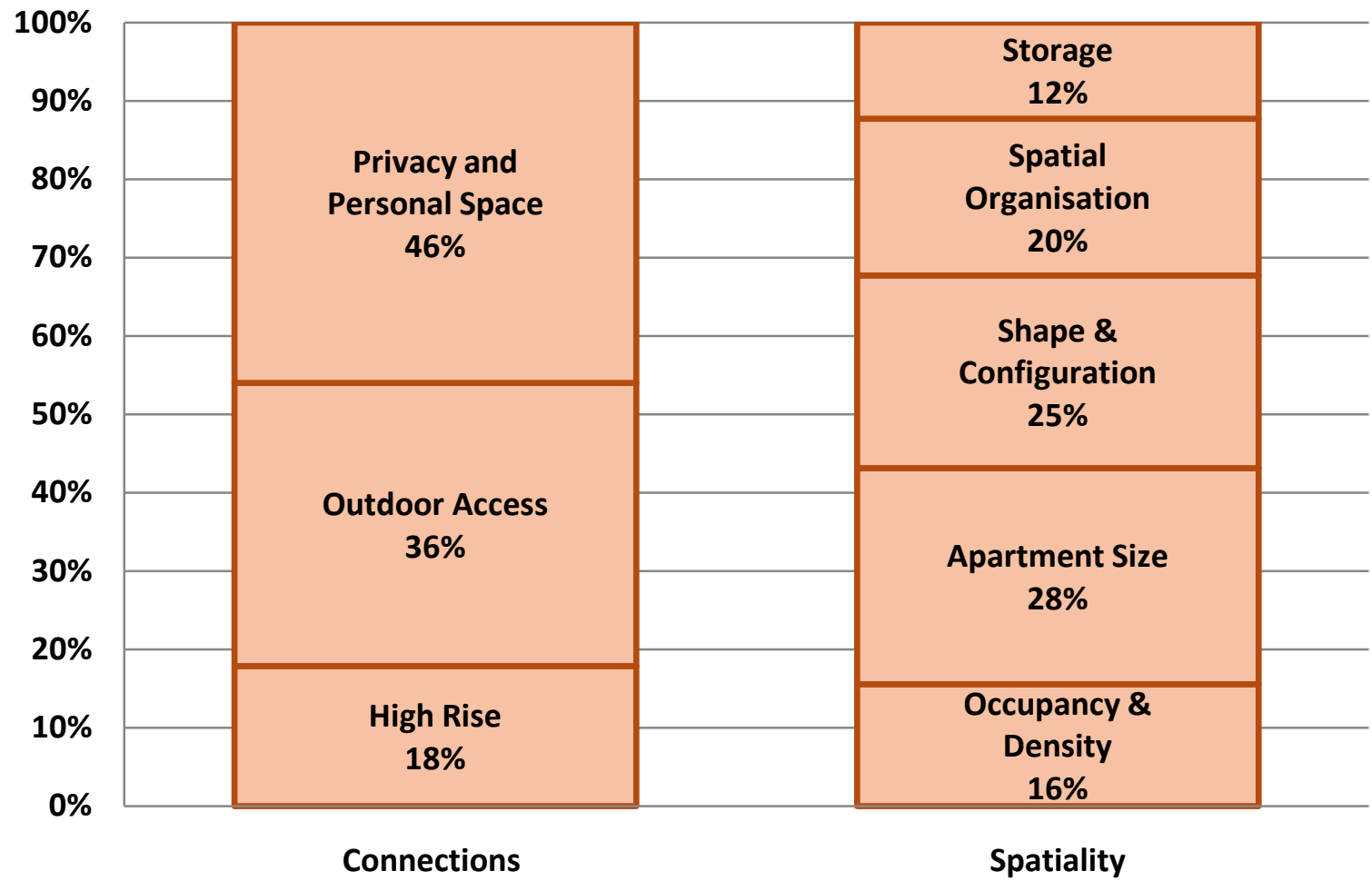

Figure D-5, Perceived Importance of Configuration Features

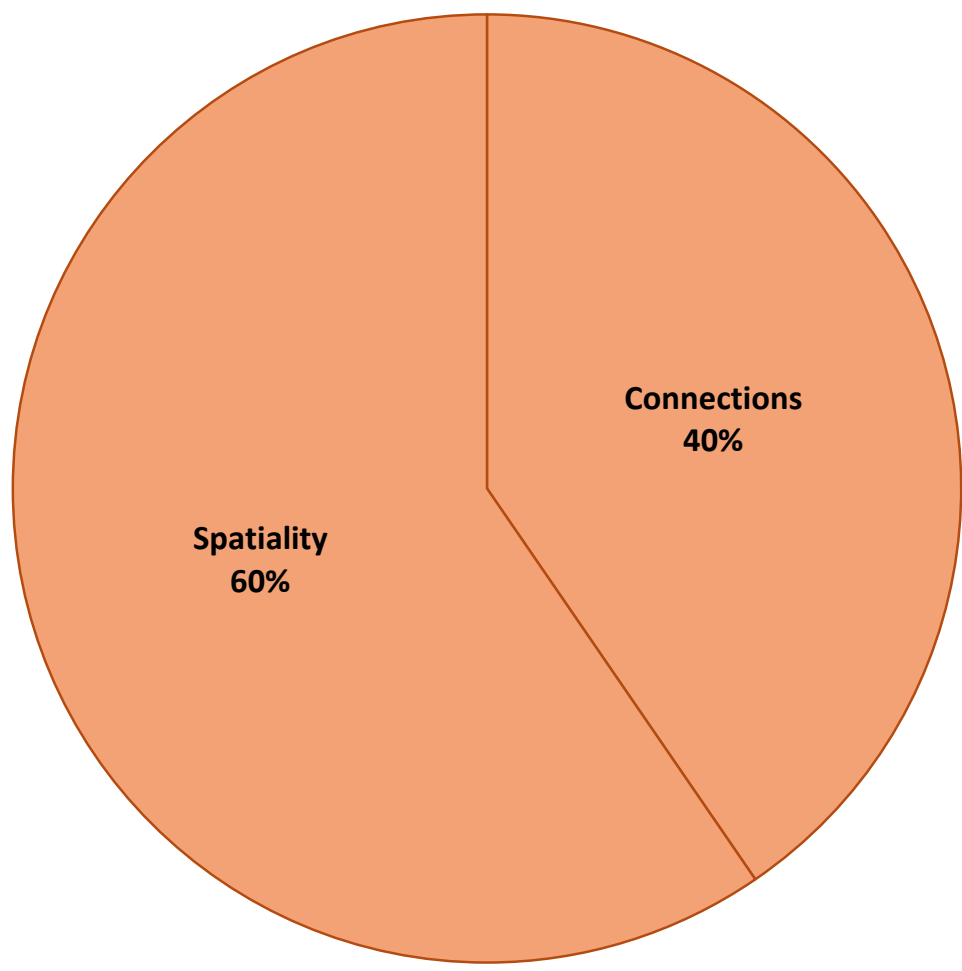

Figure D-6, Perceived Importance of Configuration Sections 


\section{D.2.2 APPLICATION OF PERCEIVED IMPORTANCE AS WEIGHTINGS}

\section{Rule \#1 - Perceived Importance of less than 3\%}

Within Configuration there was only one component that had a PI of less than 3\% - External Walls without Windows. This was removed and External Walls with Windows/Unit Aspect was awarded a weighting of $100 \%$. No other components had a PI of less than $3 \%$ so no other components needed to be removed. All other components were weighted with their perceived importance determined from the NZ ALI Questionnaire.

\section{Rule \#2 - Indicator Weightings}

Four Aspects within Configuration had two Indicators associated with them but credits were only awarded on the basis of one. However both were required in order to determine how acceptable an answer was. These Aspects were Size of Private Outdoor Spaces, Occupancy \& Density, Unit Floor Area, and Storage Size. Both Indicators were awarded $50 \%$ as they are both required in each case in order to assess an answer and award credits. Table D-9 below shows this.

Only two other Aspects had more than one Indicator Headroom and Room Placement. Headroom had three Indicators and Room Placement had four. As Table D-10 shows the weightings were split evenly between them.

Table D-9, Weightings Applied for NZ ALI Configuration Aspects with Two Indicators and One Assessment Method

\begin{tabular}{|l|l|l|l|l|}
\hline Aspect & Aspect Weighting & $\begin{array}{l}\text { Assessment } \\
\text { Method }\end{array}$ & Indicator & $\begin{array}{l}\text { Indicator } \\
\text { Weighting }\end{array}$ \\
\hline $\begin{array}{l}\text { Size of Private } \\
\text { Outdoor Spaces }\end{array}$ & $11 \%$ & $\begin{array}{l}\text { Floor Area } \\
\text { required per } \\
\text { bedroom }\end{array}$ & No. of Bedrooms & $50 \%$ \\
\cline { 3 - 5 } & & Size $\left(\mathrm{m}^{2}\right)$ & $50 \%$ \\
\hline $\begin{array}{l}\text { Occupancy \& } \\
\text { Density }\end{array}$ & $100 \%$ & Occupancy Ratio & No. of Bedrooms & $50 \%$ \\
\cline { 3 - 5 } & & No. Occupants & $50 \%$ \\
\hline Unit Floor Area & $87 \%$ & $\begin{array}{l}\text { Floor Area } \\
\text { required per } \\
\text { bedroom }\end{array}$ & No. of Bedrooms & $50 \%$ \\
\cline { 3 - 5 } & $23 \%$ & Size $\left(\mathrm{m}^{2}\right)$ & $50 \%$ \\
\hline Storage Size & $\begin{array}{l}\text { Floor Area } \\
\text { required per } \\
\text { bedroom }\end{array}$ & No. of Bedrooms & $50 \%$ \\
\cline { 3 - 5 } & & Size $\left(\mathrm{m}^{2}\right)$ & $50 \%$ \\
\hline
\end{tabular}


Table D-10, Weightings Applied to NZ ALI Configuration Aspects with more than one Indicator

\begin{tabular}{|l|l|l|l|}
\hline Feature & Aspect & Indicator & Indicator Weighting \\
\hline \multirow{2}{*}{ Apartment Size } & \multirow{2}{*}{ Headroom } & Habitable spaces & $33 \%$ \\
\cline { 3 - 4 } & & Mezzanine spaces & $33 \%$ \\
\cline { 3 - 4 } & \multirow{2}{*}{ Spatial Organisation } & Non-Habitable spaces & $33 \%$ \\
\hline \multirow{2}{*}{} & & Living Room Placement & $25 \%$ \\
\cline { 3 - 4 } & & Bedroom Placement & $25 \%$ \\
\cline { 3 - 4 } & & $\begin{array}{l}\text { Doors Separating } \\
\text { Toilets \& Kitchens }\end{array}$ & $25 \%$ \\
\cline { 3 - 4 } & & $\begin{array}{l}\text { Circulation Spaces \& } \\
\text { Kitchens }\end{array}$ & $25 \%$ \\
\hline
\end{tabular}

\section{Rule \#3 - Modified Components}

One Feature was modified within Configuration Occupancy \& Density. Initially Occupancy \& Density had two Aspects, Unit Occupancy and Building Occupancy. The latter was removed because similar to Urban Density it was determined that this was a pre-made decision to in a certain density. Unit Occupancy was the only Aspect within this Feature and it received a weighting of $100 \%$.

Within Private Outdoor Access there was one Aspect that was not included within the NZ Ali Questionnaire Provision of Outdoor Spaces. This Aspect was a Yes/No AM so if a user of NZ ALI

were skipped and no credits were awarded for this Feature as is shown in Table D-11 below.

Table D-11, Weightings Applied to NZ ALI Private Outdoor Access Aspects

\begin{tabular}{|c|c|c|c|c|}
\hline $\begin{array}{l}\text { Private Outdoor } \\
\text { Access Aspects }\end{array}$ & Weighting & Indicator & $\begin{array}{l}\text { Possible Credits } \\
\text { if 'No' }\end{array}$ & $\begin{array}{l}\text { Possible Credits } \\
\text { if 'Yes' }\end{array}$ \\
\hline $\begin{array}{l}\text { Provision of } \\
\text { Outdoor Spaces }\end{array}$ & $0 \%$ & $\begin{array}{l}\text { Are private } \\
\text { outdoor spaces } \\
\text { provided? }\end{array}$ & \multirow{5}{*}{$0 \%$} & N/A \\
\hline $\begin{array}{l}\text { Size of Outdoor } \\
\text { Spaces }\end{array}$ & $11 \%$ & $\begin{array}{l}\text { How big are } \\
\text { private outdoor } \\
\text { spaces? }\end{array}$ & & $11 \%$ \\
\hline $\begin{array}{l}\text { Type of Outdoor } \\
\text { Spaces }\end{array}$ & $23 \%$ & $\begin{array}{l}\text { What type of } \\
\text { private outdoor } \\
\text { access do you } \\
\text { have? }\end{array}$ & & $23 \%$ \\
\hline $\begin{array}{l}\text { Usability of } \\
\text { Outdoor Spaces }\end{array}$ & $53 \%$ & $\begin{array}{l}\text { How usable are } \\
\text { private outdoor } \\
\text { spaces? }\end{array}$ & & $53 \%$ \\
\hline $\begin{array}{l}\text { Weather } \\
\text { Protection }\end{array}$ & $13 \%$ & $\begin{array}{l}\text { Are private } \\
\text { outdoor spaces } \\
\text { well protected } \\
\text { from the } \\
\text { weather? }\end{array}$ & & $13 \%$ \\
\hline
\end{tabular}




\section{D.2.3 CONFIGURATION COMPONENT WEIGHTINGS}

The following tables present the final weightings applied to all Configuration components.

Table D-12, Component and Global Weightings for Configuration Indicators

\begin{tabular}{|c|c|c|c|c|c|c|}
\hline $\begin{array}{l}\text { Level } 2 \\
\text { Category }\end{array}$ & $\begin{array}{l}\text { Level } 3 \\
\text { Section }\end{array}$ & $\begin{array}{l}\text { Level } 4 \\
\text { Feature }\end{array}$ & $\begin{array}{l}\text { Level } 5 \\
\text { Aspect }\end{array}$ & $\begin{array}{l}\text { Level } 6 \\
\text { Indicator }\end{array}$ & $\begin{array}{l}\text { Component } \\
\text { Weighting }\end{array}$ & $\begin{array}{l}\text { Global } \\
\text { Weighting }\end{array}$ \\
\hline \multirow{27}{*}{ Configuration } & \multirow{11}{*}{ Connections } & \multirow{2}{*}{$\begin{array}{l}\text { High-Rise } \\
\text { Living }\end{array}$} & $\begin{array}{l}\text { Vertical } \\
\text { Location }\end{array}$ & Floor Level & $100 \%$ & $0.73 \%$ \\
\hline & & & $\begin{array}{l}\text { Communal } \\
\text { Areas }\end{array}$ & Interaction & $100 \%$ & $0.71 \%$ \\
\hline & & \multirow{3}{*}{$\begin{array}{l}\text { Personal } \\
\text { \&Private } \\
\text { Space }\end{array}$} & Outlook & Outlook & $100 \%$ & $1.73 \%$ \\
\hline & & & Inlook & Neighbours & $100 \%$ & $1.10 \%$ \\
\hline & & & $\begin{array}{l}\text { Private } \\
\text { Outdoor } \\
\text { Space }\end{array}$ & Privacy & $100 \%$ & $0.85 \%$ \\
\hline & & \multirow{6}{*}{$\begin{array}{l}\text { Private } \\
\text { Outdoor } \\
\text { Access }\end{array}$} & $\begin{array}{l}\text { Private } \\
\text { Outdoor } \\
\text { Access }\end{array}$ & Provided & $100 \%$ & $0.00 \%$ \\
\hline & & & Type & Type & $100 \%$ & $0.66 \%$ \\
\hline & & & \multirow{2}{*}{ Size } & Bedrooms & $50 \%$ & $0.16 \%$ \\
\hline & & & & Size & $50 \%$ & $0.16 \%$ \\
\hline & & & Usability & Usability & $100 \%$ & $1.53 \%$ \\
\hline & & & $\begin{array}{l}\text { Weather } \\
\text { Protection }\end{array}$ & Protection & $100 \%$ & $0.37 \%$ \\
\hline & \multirow{16}{*}{ Spatiality } & \multirow{2}{*}{ Occupancy } & \multirow{2}{*}{$\begin{array}{l}\text { Unit } \\
\text { Occupancy }\end{array}$} & Bedrooms & $50 \%$ & $0.96 \%$ \\
\hline & & & & People & $50 \%$ & $0.96 \%$ \\
\hline & & $\begin{array}{l}\text { Shape \& } \\
\text { Configuration }\end{array}$ & Aspect & Aspect & $100 \%$ & $2.88 \%$ \\
\hline & & \multirow{5}{*}{$\begin{array}{l}\text { Apartment } \\
\text { Size }\end{array}$} & \multirow{2}{*}{ Floor Area } & Bedrooms & $50 \%$ & $1.46 \%$ \\
\hline & & & & Size & $50 \%$ & $1.46 \%$ \\
\hline & & & \multirow{3}{*}{ Headroom } & Habitable & $33 \%$ & $0.15 \%$ \\
\hline & & & & Mezzanine & $33 \%$ & $0.15 \%$ \\
\hline & & & & $\begin{array}{l}\text { Non- } \\
\text { Habitable }\end{array}$ & $33 \%$ & $0.15 \%$ \\
\hline & & \multirow{5}{*}{$\begin{array}{l}\text { Spatial } \\
\text { Organisation }\end{array}$} & Flexibility & Flexibility & $100 \%$ & $0.26 \%$ \\
\hline & & & \multirow{4}{*}{$\begin{array}{l}\text { Room } \\
\text { Placement }\end{array}$} & Living & $25 \%$ & $0.53 \%$ \\
\hline & & & & Bedrooms & $25 \%$ & $0.53 \%$ \\
\hline & & & & Doors & $25 \%$ & $0.53 \%$ \\
\hline & & & & Circulation & $25 \%$ & $0.53 \%$ \\
\hline & & \multirow{3}{*}{ Storage } & Location & Location & $100 \%$ & $0.46 \%$ \\
\hline & & & \multirow{2}{*}{ Size } & Bedrooms & $50 \%$ & $0.17 \%$ \\
\hline & & & & Size & $50 \%$ & $0.17 \%$ \\
\hline
\end{tabular}




\begin{tabular}{|c|c|c|c|c|c|c|}
\hline & & & $\begin{array}{l}\text { Large } \\
\text { Items }\end{array}$ & Large Items & $100 \%$ & $0.07 \%$ \\
\hline & & & Quality & Usability & $100 \%$ & $0.58 \%$ \\
\hline
\end{tabular}

Table D-13, Component and Global Weightings for Configuration Aspects

\begin{tabular}{|c|c|c|c|c|c|c|}
\hline $\begin{array}{l}\text { Level } 2 \\
\text { Category }\end{array}$ & $\begin{array}{l}\text { Level } 3 \\
\text { Section }\end{array}$ & $\begin{array}{l}\text { Level } 4 \\
\text { Feature }\end{array}$ & $\begin{array}{l}\text { Level } 5 \\
\text { Aspect }\end{array}$ & $\begin{array}{l}\text { Component } \\
\text { Weighting }\end{array}$ & $\begin{array}{l}\text { Global } \\
\text { Weighting }\end{array}$ & $\begin{array}{l}\text { Level } 6 \\
\text { Indicators }\end{array}$ \\
\hline \multirow{20}{*}{ Configuration } & \multirow{10}{*}{ Connections } & \multirow{2}{*}{$\begin{array}{l}\text { High-Rise } \\
\text { Living }\end{array}$} & $\begin{array}{l}\text { Vertical } \\
\text { Location }\end{array}$ & $51 \%$ & $0.73 \%$ & 1 \\
\hline & & & $\begin{array}{l}\text { Communal } \\
\text { Areas }\end{array}$ & $49 \%$ & $0.71 \%$ & 1 \\
\hline & & \multirow{3}{*}{$\begin{array}{l}\text { Personal \& } \\
\text { Private Space }\end{array}$} & Outlook & $47 \%$ & $1.73 \%$ & 1 \\
\hline & & & Inlook & $30 \%$ & $1.10 \%$ & 1 \\
\hline & & & $\begin{array}{l}\text { Private } \\
\text { Outdoor } \\
\text { Space }\end{array}$ & $23 \%$ & $0.85 \%$ & 1 \\
\hline & & \multirow{5}{*}{$\begin{array}{l}\text { Private } \\
\text { Outdoor } \\
\text { Access }\end{array}$} & $\begin{array}{l}\text { Private } \\
\text { Outdoor } \\
\text { Access }\end{array}$ & $0 \%$ & $0.00 \%$ & 1 \\
\hline & & & Type & $23 \%$ & $0.66 \%$ & 1 \\
\hline & & & Size & $11 \%$ & $0.32 \%$ & 2 \\
\hline & & & Usability & $53 \%$ & $1.53 \%$ & 1 \\
\hline & & & $\begin{array}{l}\text { Weather } \\
\text { Protection }\end{array}$ & $13 \%$ & $0.37 \%$ & 1 \\
\hline & \multirow{10}{*}{ Spatiality } & Occupancy & $\begin{array}{l}\text { Unit } \\
\text { Occupancy }\end{array}$ & $100 \%$ & $1.92 \%$ & 2 \\
\hline & & $\begin{array}{l}\text { Shape \& } \\
\text { Configuration }\end{array}$ & Aspect & $100 \%$ & $2.88 \%$ & 1 \\
\hline & & \multirow{2}{*}{$\begin{array}{l}\text { Apartment } \\
\text { Size }\end{array}$} & Floor Area & $87 \%$ & $2.92 \%$ & 2 \\
\hline & & & Headroom & $13 \%$ & $0.44 \%$ & 3 \\
\hline & & \multirow{2}{*}{$\begin{array}{l}\text { Spatial } \\
\text { Organisation }\end{array}$} & Flexibility & $11 \%$ & $0.26 \%$ & 1 \\
\hline & & & $\begin{array}{l}\text { Room } \\
\text { Placement }\end{array}$ & $89 \%$ & $2.14 \%$ & 4 \\
\hline & & \multirow{4}{*}{ Storage } & Location & $32 \%$ & $0.46 \%$ & 1 \\
\hline & & & Size & $23 \%$ & $0.33 \%$ & 2 \\
\hline & & & $\begin{array}{l}\text { Large } \\
\text { Items }\end{array}$ & $5 \%$ & $0.07 \%$ & 1 \\
\hline & & & Quality & $40 \%$ & $0.58 \%$ & 1 \\
\hline
\end{tabular}


Table D-14, Component and Global Weightings for Configuration Features

\begin{tabular}{|c|c|c|c|c|c|c|}
\hline $\begin{array}{l}\text { Level } 2 \\
\text { Category }\end{array}$ & $\begin{array}{l}\text { Level } 3 \\
\text { Section }\end{array}$ & $\begin{array}{l}\text { Level } 4 \\
\text { Feature }\end{array}$ & $\begin{array}{l}\text { Component } \\
\text { Weighting }\end{array}$ & $\begin{array}{l}\text { Global } \\
\text { Weighting }\end{array}$ & $\begin{array}{l}\text { Level } 5 \\
\text { Aspect }\end{array}$ & $\begin{array}{l}\text { Level } 6 \\
\text { Indicators }\end{array}$ \\
\hline \multirow{8}{*}{ Configuration } & \multirow{3}{*}{ Connections } & $\begin{array}{l}\text { High-Rise } \\
\text { Living }\end{array}$ & $18 \%$ & $1.44 \%$ & 2 & 2 \\
\hline & & $\begin{array}{l}\text { Personal \& } \\
\text { Private Space }\end{array}$ & $46 \%$ & $3.68 \%$ & 3 & 3 \\
\hline & & $\begin{array}{l}\text { Private } \\
\text { Outdoor } \\
\text { Access }\end{array}$ & $36 \%$ & $2.88 \%$ & 5 & 6 \\
\hline & \multirow{5}{*}{ Spatiality } & Occupancy & $16 \%$ & $1.92 \%$ & 1 & 2 \\
\hline & & $\begin{array}{l}\text { Shape \& } \\
\text { Configuration }\end{array}$ & $24 \%$ & $2.88 \%$ & 1 & 1 \\
\hline & & $\begin{array}{l}\text { Apartment } \\
\text { Size }\end{array}$ & $28 \%$ & $3.36 \%$ & 2 & 5 \\
\hline & & $\begin{array}{l}\text { Spatial } \\
\text { Organisation }\end{array}$ & $20 \%$ & $2.40 \%$ & 2 & 5 \\
\hline & & Storage & $12 \%$ & $1.44 \%$ & 4 & 5 \\
\hline
\end{tabular}

Table D-15, Component and Global Weightings for Configuration Sections

\begin{tabular}{|l|l|l|l|l|l|l|}
\hline $\begin{array}{l}\text { Level } \mathbf{2} \\
\text { Category }\end{array}$ & $\begin{array}{l}\text { Level 3 } \\
\text { Section }\end{array}$ & $\begin{array}{l}\text { Component } \\
\text { Weighting }\end{array}$ & $\begin{array}{l}\text { Global } \\
\text { Weighting }\end{array}$ & $\begin{array}{l}\text { Level 4 } \\
\text { Feature }\end{array}$ & $\begin{array}{l}\text { Level 5 } \\
\text { Aspect }\end{array}$ & $\begin{array}{l}\text { Level 6 } \\
\text { Indicators }\end{array}$ \\
\hline \multirow{2}{*}{ Configuration } & Connections & $40 \%$ & $8.00 \%$ & 3 & 10 & 11 \\
\cline { 2 - 7 } & Spatiality & $60 \%$ & $12.00 \%$ & 5 & 10 & 18 \\
\hline
\end{tabular}




\section{APPENDIX E GOVERNANCE}

This Appendix will present the development of the Governance Category. This will include the Governance framework development from factor assessment to credit establishment, and Calibration of the Governance Components.

\section{E.1 GOVERNANCE FRAMEWORK DEVELOPMENT}

The framework development discussed here follows the same process as that discussed in Section 3.2, Section 4.1 and Figure 4-2.

1. Factor Assessment

\section{GOVERNANCE}

\begin{tabular}{|l|l}
\hline MAINTENANCE & MANAGEMENT \\
Cleanliness & Building Operators and Users \\
Maintenance & Management/Body Corporate \\
Pests & Pets
\end{tabular}

Figure E-1, Factors Included Within Governance

Governance was a Category developed from the literature review that included factors that consider the day to day running of a building, how it is maintained and managed. There were only 8 Factors identified initially within Governance as shown in Figure 2-5. However assessment of the factors showed that there were two repeated Factors Maintenance and Management/Body Corporate. There were no factors in this Category that did not meet the requirements of Criterion \#1. Figure E-1 shows the popular press factors in red, academic in blue, repeated factors in green). Two Sections were used to group the Governance factors Maintenance and Management. 
2. Feature Identification

Two Sections were identified within Governance Maintenance and Management. Maintenance included Factors that dealt with maintenance and cleanliness of the apartment and the building. Two Features were developed within Maintenance which were Cleanliness and Maintenance. Management concerned Factors that dealt with management issues and the running of the building. Two Features were identified here Management (including Management types, body corporate and associated issues) and Pets which is considered to be a management issue as to whether they are allowed in an apartment building.

Table E-1, Features Identified for Governance

\begin{tabular}{|c|c|c|c|}
\hline $\begin{array}{l}\text { Level } 2 \\
\text { Category }\end{array}$ & $\begin{array}{l}\text { Level } 3 \\
\text { Section }\end{array}$ & $\begin{array}{l}\text { Level } 4 \\
\text { Feature }\end{array}$ & Associated Factors \\
\hline \multirow[t]{4}{*}{ Governance } & \multirow[t]{2}{*}{ Maintenance } & Cleanliness & $\begin{array}{l}\text { - Cleanliness } \\
\text { - Pests }\end{array}$ \\
\hline & & Maintenance & - Maintenance \\
\hline & \multirow[t]{2}{*}{ Management } & Management & $\begin{array}{l}\text { - } \quad \text { Building Operators and Users } \\
\text { - Management and Body } \\
\text { Corporate }\end{array}$ \\
\hline & & Pets & - $\quad$ Pets \\
\hline
\end{tabular}

3. Aspect Identification

A total of 4 Features were identified in Governance, and 10 Aspects were developed that affect liveability.

\section{Maintenance}

reduced maintenance and lower maintenance costs) is an important facet of apartment living. DTZ Research (2003) found that lower maintenance costs was the fourth most important reason people in inner city Auckland choose to live in apartments. The WCC (2009) found the same for inner city dwellers in Wellington.

For both Maintenance and Cleanliness, three issues were identified the apartment, the building and regular services. Therefore, 3 Aspects were developed for each as is shown in Table E- 2 below. 
Table E-2, Aspects Identified for Maintenance

\begin{tabular}{|l|l|l|}
\hline \multirow{2}{*}{$\begin{array}{l}\text { Level } \mathbf{3} \\
\text { Section }\end{array}$} & $\begin{array}{l}\text { Level 4 } \\
\text { Feature }\end{array}$ & $\begin{array}{l}\text { Level 5 } \\
\text { Aspect }\end{array}$ \\
\hline \multirow{3}{*}{ Maintenance } & Cleanliness & Of Apartment \\
\cline { 3 - 3 } & & Of Building \\
\cline { 2 - 3 } & & Cleaning Services \\
\cline { 2 - 3 } & \multirow{2}{*}{ Maintenance } & Of Apartment \\
\cline { 3 - 3 } & & Of Building \\
\cline { 3 - 3 } & & Maintenance Schedule \\
\hline
\end{tabular}

\section{Management}

Management is an issue with apartment living that can make the day to day running of a building much easier. Auckland UniServices (2004) found that there are two issues with Management of apartment buildings. The first was that the presence of some type of building management, particularly a building manager was vital to the smooth running of an apartment building. The second was that helpful and effective building management is highly valued by occupants. Two Aspects were identified from this for Management whether there is any type of Building Management present, and if there is what Type of Building Management (it was noted that onsite/on-call managers are much more helpful).

I-being and mental health. Criscillo \& Tong (1999) found in their survey of Wellington apartment occupants that some people do want the provision to accommodate pets in apartments. However, household pets like cats and dogs can also be the cause of some allergens and diseases particularly when litter is handled or soil contaminated with faeces which may occur regularly in apartments. Two Aspects were identified for this Feature whether Pets Were Allowed in an apartment (to facilitate in good mental health) and what types of pets these were (to consider possible affects to health).

Table E-3, Aspects Identified for Management

\begin{tabular}{|l|l|l|}
\hline $\begin{array}{l}\text { Level } \mathbf{3} \\
\text { Section }\end{array}$ & $\begin{array}{l}\text { Level } \mathbf{4} \\
\text { Feature }\end{array}$ & $\begin{array}{l}\text { Level } \mathbf{5} \\
\text { Aspect }\end{array}$ \\
\hline \multirow{2}{*}{ Management } & Management & Presence of Building Management \\
\cline { 2 - 3 } & & Type of Building Management (if present) \\
\cline { 2 - 3 } & \multirow{2}{*}{ Pets } & Ability to have pets \\
\cline { 2 - 3 } & & Types of pets allowed \\
\hline
\end{tabular}

4. Indicator Identification

Table E-4 outlines each of the Indicators that were developed for the Aspects within Governance. No Aspects had more than one Indicator applied to it and 10 were identified in total. 
Table E-4, Indicators Identified for Governance

\begin{tabular}{|c|c|c|c|}
\hline $\begin{array}{l}\text { Level } 3 \\
\text { Section } \\
\end{array}$ & $\begin{array}{l}\text { Level } 4 \\
\text { Feature } \\
\end{array}$ & $\begin{array}{l}\text { Level } 5 \\
\text { Aspect }\end{array}$ & $\begin{array}{l}\text { Level } 6 \\
\text { Indicator }\end{array}$ \\
\hline \multirow[t]{6}{*}{ Maintenance } & \multirow[t]{3}{*}{ Cleanliness } & Of Apartment & Is the apartment clean? \\
\hline & & Of Building & Is the building clean? \\
\hline & & Cleaning Services & $\begin{array}{l}\text { Is there a regular cleaning service } \\
\text { for the building? }\end{array}$ \\
\hline & \multirow[t]{3}{*}{ Maintenance } & Of Apartment & Is the apartment well maintained? \\
\hline & & Of Building & Is the building well maintained? \\
\hline & & $\begin{array}{l}\text { Maintenance } \\
\text { Schedule }\end{array}$ & $\begin{array}{l}\text { Is there a regular maintenance } \\
\text { schedule for the building? }\end{array}$ \\
\hline \multirow[t]{4}{*}{ Management } & \multirow[t]{2}{*}{ Management } & $\begin{array}{l}\text { Presence of Building } \\
\text { Management }\end{array}$ & $\begin{array}{l}\text { Is there Building Management } \\
\text { provided? }\end{array}$ \\
\hline & & $\begin{array}{l}\text { Type of Building } \\
\text { Management (if } \\
\text { present) }\end{array}$ & $\begin{array}{l}\text { What type of Building } \\
\text { Management is provided? }\end{array}$ \\
\hline & \multirow[t]{2}{*}{ Pets } & Ability to have pets & Are pets allowed? \\
\hline & & $\begin{array}{l}\text { Types of pets } \\
\text { allowed }\end{array}$ & What types of pets are allowed? \\
\hline
\end{tabular}

5. AM Identification \& Review

\section{Maintenance}

Table E-5 outlines the Assessment Methods identified for Maintenance

Within Maintenance there were six Aspects and Indicators. Four of the Assessment Methods applied to these were determined to be both impractical (due to wording) and subjective (due to the requirement of Personal Judgements). The Assessment Methods were modified to Scales for these Indicators shown in Table E-5.

\section{Management}

Table E- 6 out

Management. Two Indicators received Yes

or No Choices and two required Statements.

\section{Management required any modifications as they were all}

considered to be both practical and

changed to Lists for ease of use and user friendliness, shown in Table E-6. 
Table E-5, Review of Assessment Methods Identified for Maintenance

\begin{tabular}{|c|c|c|c|c|}
\hline $\begin{array}{l}\text { Level } 4 \\
\text { Feature }\end{array}$ & $\begin{array}{l}\text { Level } 5 \\
\text { Aspect }\end{array}$ & $\begin{array}{l}\text { Level } 6 \\
\text { Indicator-Assessment } \\
\text { Question }\end{array}$ & $\begin{array}{l}\text { Assessment } \\
\text { Method } \\
\text { Version } 1 \\
\end{array}$ & $\begin{array}{l}\text { Modified } \\
\text { Assessment } \\
\text { Method } \\
\end{array}$ \\
\hline \multirow{3}{*}{ Cleanliness } & $\begin{array}{l}\text { Of } \\
\text { Apartment }\end{array}$ & Is the apartment clean? & $\begin{array}{l}\text { Personal } \\
\text { Perception } \\
\text { (Cleanliness) }\end{array}$ & Scale \\
\hline & Of Building & Is the building clean? & $\begin{array}{l}\text { Personal } \\
\text { Perception } \\
\text { (Cleanliness) }\end{array}$ & Scale \\
\hline & $\begin{array}{l}\text { Cleaning } \\
\text { Services }\end{array}$ & $\begin{array}{l}\text { Is there a regular cleaning } \\
\text { service for the building? }\end{array}$ & Choose Yes or No & Yes/No \\
\hline \multirow{3}{*}{ Maintenance } & $\begin{array}{l}\text { Of } \\
\text { Apartment }\end{array}$ & $\begin{array}{l}\text { Is the apartment well } \\
\text { maintained? }\end{array}$ & $\begin{array}{l}\text { Personal } \\
\text { Perception } \\
\text { (Maintainability) }\end{array}$ & Scale \\
\hline & Of Building & $\begin{array}{l}\text { Is the building well } \\
\text { maintained? }\end{array}$ & $\begin{array}{l}\text { Personal } \\
\text { Perception } \\
\text { (Maintainability) }\end{array}$ & Scale \\
\hline & $\begin{array}{l}\text { Maintenance } \\
\text { Schedule }\end{array}$ & $\begin{array}{l}\text { Is there a regular } \\
\text { maintenance schedule for } \\
\text { the building? }\end{array}$ & Choose Yes or No & Yes/No \\
\hline
\end{tabular}

Table E-6, Review of Assessment Methods Identified for Management

\begin{tabular}{|l|l|l|l|l|}
\hline $\begin{array}{l}\text { Level 4 } \\
\text { Feature }\end{array}$ & $\begin{array}{l}\text { Level 5 } \\
\text { Aspect }\end{array}$ & $\begin{array}{l}\text { Level 6 } \\
\text { Indicator-Assessment } \\
\text { Question }\end{array}$ & $\begin{array}{l}\text { Assessment } \\
\text { Method } \\
\text { Version 1 }\end{array}$ & $\begin{array}{l}\text { Modified } \\
\text { Assessment } \\
\text { Method }\end{array}$ \\
\hline \multirow{2}{*}{ Management } & $\begin{array}{l}\text { Presence of } \\
\text { Building } \\
\text { Management }\end{array}$ & $\begin{array}{l}\text { Is there Building } \\
\text { Management provided? }\end{array}$ & $\begin{array}{l}\text { Choose Yes or } \\
\text { No }\end{array}$ & Yes/No \\
\cline { 2 - 5 } & $\begin{array}{l}\text { Type of } \\
\text { Building } \\
\text { Management } \\
\text { (if present) }\end{array}$ & What type of Building & $\begin{array}{l}\text { Statement } \\
\text { (Management } \\
\text { Type) }\end{array}$ & List \\
\hline \multirow{3}{*}{ Pets } & $\begin{array}{l}\text { Ability to } \\
\text { have pets }\end{array}$ & Are pets allowed? & $\begin{array}{l}\text { Choose Yes or } \\
\text { No }\end{array}$ & Yes/No \\
\cline { 2 - 6 } & $\begin{array}{l}\text { Types of pets } \\
\text { allowed }\end{array}$ & $\begin{array}{l}\text { What types of pets are } \\
\text { allowed? }\end{array}$ & $\begin{array}{l}\text { Statement (Pet } \\
\text { Type) }\end{array}$ & List \\
\hline
\end{tabular}

\section{Credit Establishment}

Table E-7 shows the Acceptability and awarding of credits for the Assessment Methods associated with Maintenance. All of the Assessment Questions were modified (shown in blue text) to reflect the 
Table E-7, Acceptability \& Awarding of Credits Identified for Maintenance

\begin{tabular}{|c|c|c|c|}
\hline $\begin{array}{l}\text { Level } 4 \\
\text { Feature }\end{array}$ & $\begin{array}{l}\text { Level } 5 \\
\text { Aspect }\end{array}$ & $\begin{array}{l}\text { Level } 6 \\
\text { Indicator - Modified } \\
\text { Assessment Question }\end{array}$ & Acceptability \& Awarding of Credits \\
\hline \multirow{3}{*}{ Cleanliness } & $\begin{array}{l}\text { Of } \\
\text { Apartment }\end{array}$ & $\begin{array}{l}\text { On a scale of } 1 \text { - } 10 \text {, how } \\
\text { easy does the apartment } \\
\text { seem to be able to be kept } \\
\text { clean? }\end{array}$ & 110 Scale \\
\hline & Of Building & $\begin{array}{l}\text { On a scale of } 1-10 \text {, how } \\
\text { easy does the building seem } \\
\text { to be able to be kept clean? }\end{array}$ & 110 Scale \\
\hline & $\begin{array}{l}\text { Cleaning } \\
\text { Services }\end{array}$ & $\begin{array}{l}\text { Is there a regular cleaning } \\
\text { service for the communal } \\
\text { areas of the building? }\end{array}$ & Yes/No Version 1 \\
\hline \multirow{3}{*}{ Maintenance } & $\begin{array}{l}\text { Of } \\
\text { Apartment }\end{array}$ & $\begin{array}{l}\text { On a scale of } 1-10 \text {, how well } \\
\text { maintained does the } \\
\text { apartment seem to be? }\end{array}$ & 110 Scale \\
\hline & Of Building & $\begin{array}{l}\text { On a scale of } 1-10 \text {, how well } \\
\text { maintained does the building } \\
\text { seem to be? }\end{array}$ & 110 Scale \\
\hline & $\begin{array}{l}\text { Maintenance } \\
\text { Schedule }\end{array}$ & $\begin{array}{l}\text { Is there a regular } \\
\text { maintenance schedule for } \\
\text { the communal areas of the } \\
\text { building? }\end{array}$ & Yes/No Version 1 \\
\hline
\end{tabular}

Table E-8 outlines the Acceptability of Answers and Awarding of Credits for Management. The List for Type of Building Management was developed from results from the Auckland UniServices apartment occupant survey (2004), the Auckland Regional Council publication discussing body corporates (ARC, 2003) and New Zealand Governments Unit Titles Bill (Unit Titles Act, 2008). The List for Types of Pets Allowed was developed from Raw, Aizlewood \& Hamilton (2001).

Two of the Assessment Questions were modified (as shown in Table E-8) so that the wording was user friendly for inclusion in NZ ALI. 
Table E-8, Acceptability \& Awarding of Credits Identified for Management

\begin{tabular}{|c|c|c|c|c|}
\hline $\begin{array}{l}\text { Level } 4 \\
\text { Feature }\end{array}$ & $\begin{array}{l}\text { Level } 5 \\
\text { Aspect }\end{array}$ & $\begin{array}{l}\text { Level } 6 \\
\text { Indicator - Modified } \\
\text { Assessment Question }\end{array}$ & \multicolumn{2}{|c|}{ Acceptability \& Awarding of Credits } \\
\hline \multirow[b]{2}{*}{ Management } & $\begin{array}{l}\text { Presence of } \\
\text { Building } \\
\text { Management }\end{array}$ & $\begin{array}{l}\text { Is there some form of } \\
\text { Building Management? }\end{array}$ & Yes/No Version 1 & \\
\hline & $\begin{array}{l}\text { Type of } \\
\text { Building } \\
\text { Management } \\
\text { (if present) }\end{array}$ & $\begin{array}{l}\text { What type of Building } \\
\text { Management is provided? }\end{array}$ & $\begin{array}{l}\text { Body Corporate only } \\
\text { Building Manager (Full time, } \\
\text { appointed by Body } \\
\text { Corporate) } \\
\text { Building Manager (Part time, } \\
\text { appointed by Body } \\
\text { Corporate) } \\
\text { None (Less than } 9 \text { units on } \\
\text { site) } \\
\text { None (More than } 9 \text { units on } \\
\text { site) }\end{array}$ & $\begin{array}{l}100 \% \\
75 \% \\
25 \% \\
0 \%\end{array}$ \\
\hline \multirow[b]{2}{*}{ Pets } & $\begin{array}{l}\text { Ability to } \\
\text { have pets }\end{array}$ & $\begin{array}{l}\text { Are you allowed pets in the } \\
\text { building? }\end{array}$ & Yes/No Version 1 & \\
\hline & $\begin{array}{l}\text { Types of pets } \\
\text { allowed }\end{array}$ & $\begin{array}{l}\text { What types of pets are } \\
\text { allowed? }\end{array}$ & $\begin{array}{l}\text { Amphibian (including frog or } \\
\text { axolotl), Reptile (including } \\
\text { turtle, lizard), Fish } \\
\text { Bird, Cat, Dog (Small } \\
\text { Medium Sized) = } \\
\text { Dog (Large), Rabbit, Rodent } \\
\text { (including mouse, rat, } \\
\text { guinea pig, hamster or } \\
\text { gerbil) }\end{array}$ & $\begin{array}{l}100 \% \\
50 \%\end{array}$ \\
\hline
\end{tabular}




\section{E.2 GOVERNANCE CALIBRATION}

The information discussed here provides information on the Calibration of the Governance Components. The data analysed and used to develop weightings for this Category is from the NZ ALI Questionnaire. The Calibration process follows that discussed in Section 4.3 and The NZ ALI Questionnaire.

\section{E.2.1 NZ ALI QUESTIONNAIRE RESULTS \& ANALYSIS}

\section{Aspects}

Maintenance: Figure E-2 shows the percentage of nominations that each of the Aspects within Maintenance received.

Management: Figure E-3 shows the percentage of nominations that each of the Aspects within Management received.

\section{Features}

Figure E-4 shows the weightings determined for the Governance Features which were determined from Equation 4-1.

\section{Sections}

Figure E-5 shows the weightings determined for the Governance Sections which were determined from Equation 4-1. 


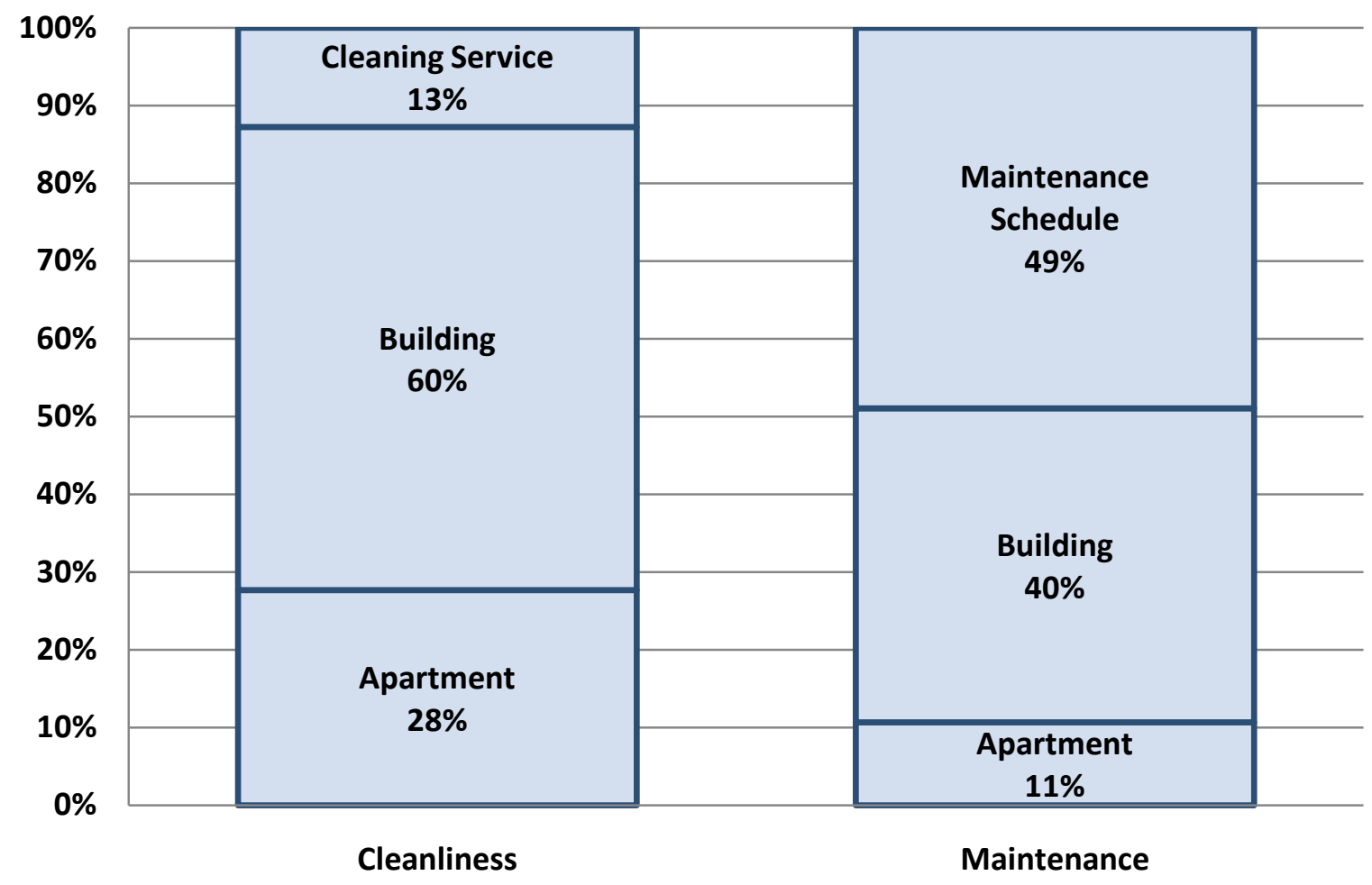

Figure E-2, Perceived Importance of Maintenance Aspects

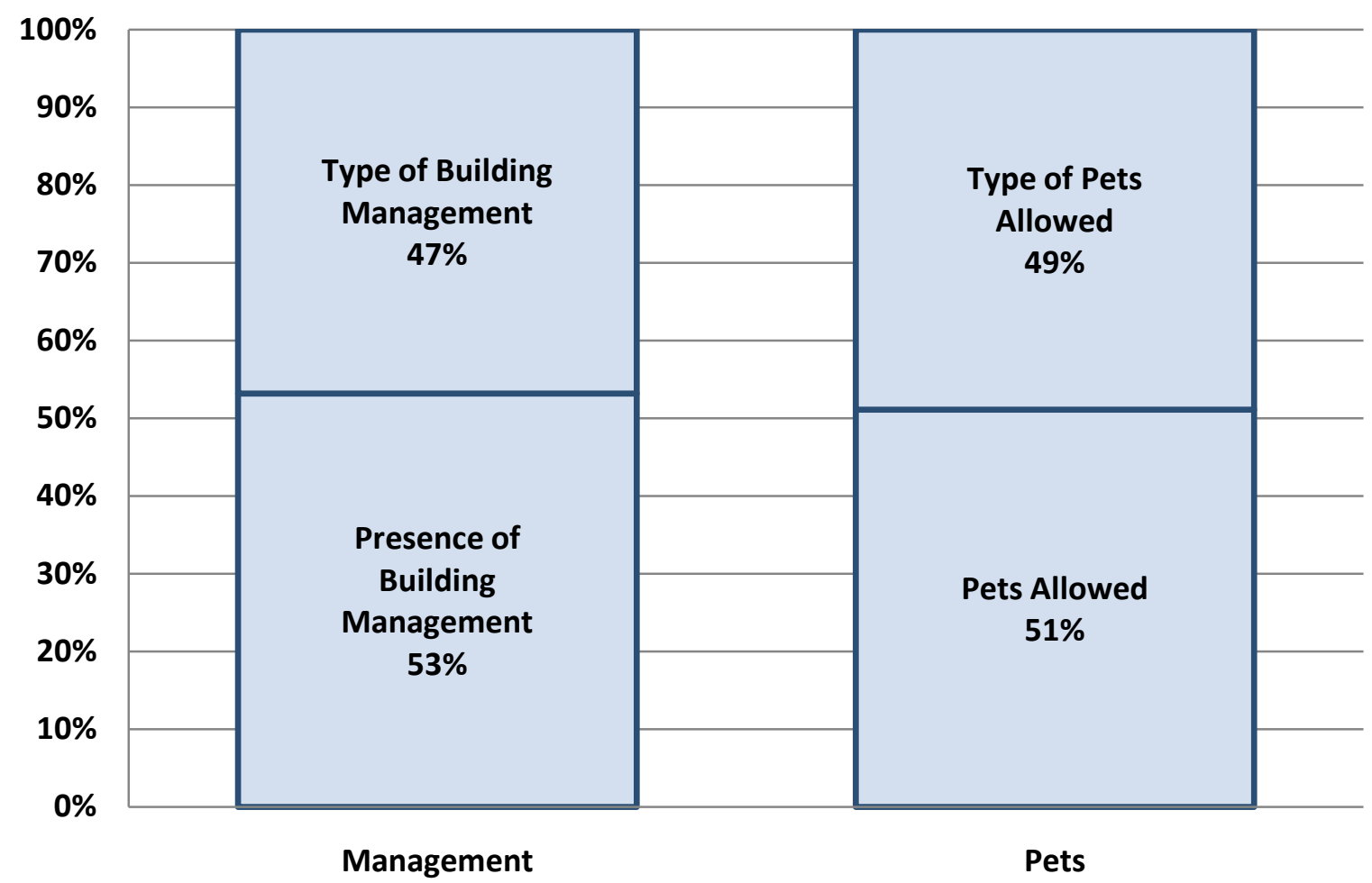

Figure E-3, Perceived Importance of Management Aspects 


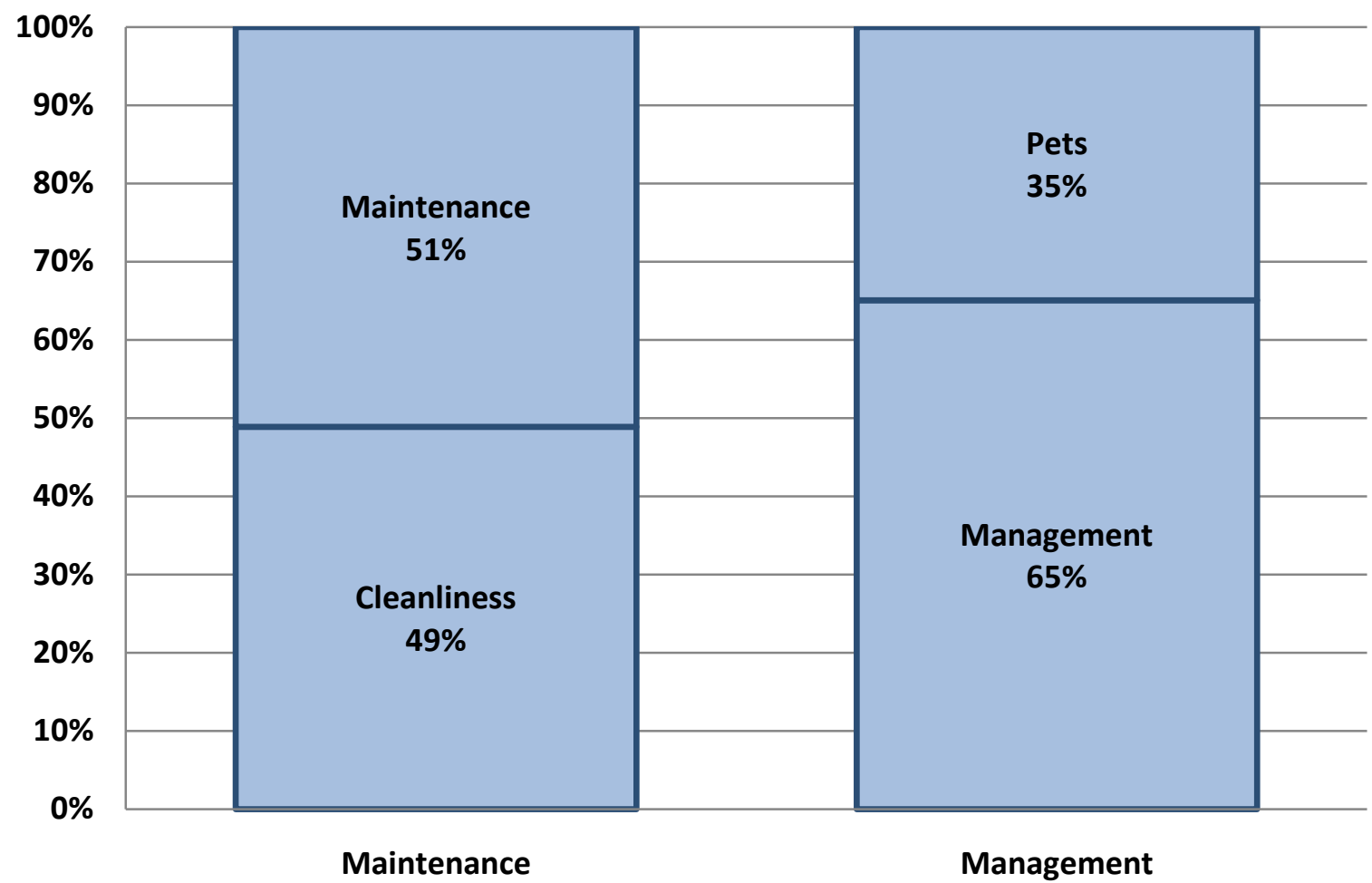

Figure E-4, Perceived Importance of Governance Features

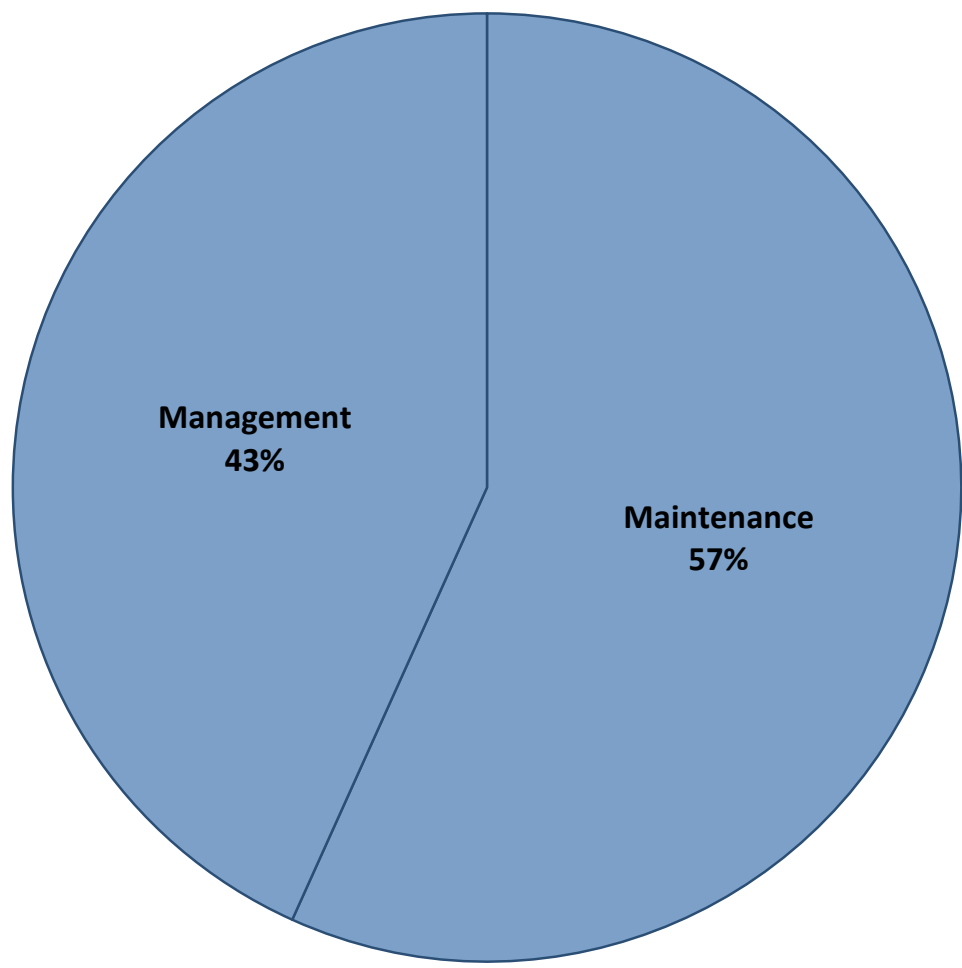

Figure E-5, Perceived Importance of Governance Sections 


\section{E.2.2 APPLICATION OF PERCEIVED IMPORTANCE AS WEIGHTINGS}

\section{Rule \#1 - Perceived Importance of less than 3\%}

Within Governance no components were perceived to have an importance of less than $3 \%$ from the NZ ALI Questionnaire.

\section{Rule \#2 - Indicator Weightings}

All Aspects within Governance had only one Indicator associated with them and so all received a full weighting of $100 \%$.

\section{Rule \#3 - Modified Components}

In the NZ ALI Questionnaire participants were required to evaluate all the Aspects within Building Management. Participants were required to evaluate whether they considered the Presence of Building Management and the Type of Building Management were important. However similarly to Provision of Outdoor Spaces Building Management was provided then no credits were awarded. All weighting for the Feature relied on Type of Building Management. The same occurred for Pets where weighting was only applied to Types of Pets Allowed. If pets are not allowed then no credits were awarded for the Feature as is shown in Table E-9.

No other components were changed within Governance and the perceived importances of each component determined from the NZ ALI Questionnaire were applied as weightings.

Table E-9, Weightings Applied to NZ ALI Management Aspects

\begin{tabular}{|l|l|l|l|l|l|}
\hline $\begin{array}{l}\text { Management } \\
\text { Feature }\end{array}$ & Aspects & Weighting & Indicator & $\begin{array}{l}\text { Possible } \\
\text { Credits if 'No' }\end{array}$ & $\begin{array}{l}\text { Possible } \\
\text { Credits if } \\
\text { 'Yes' }\end{array}$ \\
\hline $\begin{array}{l}\text { Building } \\
\text { Management }\end{array}$ & $\begin{array}{l}\text { Presence of } \\
\text { Building } \\
\text { Management }\end{array}$ & $0 \%$ & $\begin{array}{l}\text { Is there } \\
\text { Building } \\
\text { Management? }\end{array}$ & \multirow{2}{*}{$0 \%$} & N/A \\
\cline { 2 - 4 } & $\begin{array}{l}\text { Type of } \\
\text { Building } \\
\text { Management }\end{array}$ & $100 \%$ & $\begin{array}{l}\text { What type of } \\
\text { Building } \\
\text { Management } \\
\text { is there? }\end{array}$ & $100 \%$ \\
\cline { 1 - 3 } Pets & Pets Allowed & $0 \%$ & $\begin{array}{l}\text { Are pets } \\
\text { allowed? }\end{array}$ & \multirow{2}{*}{$0 \%$} & N/A \\
\cline { 2 - 4 } & Types of Pets & $100 \%$ & $\begin{array}{l}\text { What type of } \\
\text { pets? }\end{array}$ & $100 \%$ \\
\hline
\end{tabular}




\section{E.2.3 GOVERNANCE COMPONENT WEIGHTINGS}

The following tables present the final weightings applied to all Governance components.

Table E-10, Component and Global Weightings for Governance Indicators

\begin{tabular}{|c|c|c|c|c|c|c|}
\hline $\begin{array}{l}\text { Level } 2 \\
\text { Category }\end{array}$ & $\begin{array}{l}\text { Level } 3 \\
\text { Section }\end{array}$ & $\begin{array}{l}\text { Level } 4 \\
\text { Feature }\end{array}$ & $\begin{array}{l}\text { Level } 5 \\
\text { Aspect }\end{array}$ & $\begin{array}{l}\text { Level } 6 \\
\text { Indicator }\end{array}$ & $\begin{array}{l}\text { Component } \\
\text { Weighting }\end{array}$ & $\begin{array}{l}\text { Global } \\
\text { Weighting }\end{array}$ \\
\hline \multirow{10}{*}{$\begin{array}{l}\text { Gover- } \\
\text { nance }\end{array}$} & \multirow{6}{*}{ Maintenance } & \multirow{3}{*}{ Cleanliness } & Apartment & Clean & $100 \%$ & $1.28 \%$ \\
\hline & & & Building & Clean & $100 \%$ & $2.85 \%$ \\
\hline & & & $\begin{array}{l}\text { Cleaning } \\
\text { Service }\end{array}$ & Service & $100 \%$ & $0.62 \%$ \\
\hline & & \multirow{3}{*}{ Maintenance } & Apartment & Maintain & $100 \%$ & $0.54 \%$ \\
\hline & & & Building & Maintain & $100 \%$ & $1.98 \%$ \\
\hline & & & $\begin{array}{l}\text { Maintenance } \\
\text { Schedule }\end{array}$ & Schedule & $100 \%$ & $2.42 \%$ \\
\hline & \multirow{4}{*}{ Management } & \multirow{2}{*}{$\begin{array}{l}\text { Manage- } \\
\text { ment }\end{array}$} & $\begin{array}{l}\text { Building } \\
\text { Management }\end{array}$ & Management & $100 \%$ & $0.00 \%$ \\
\hline & & & $\begin{array}{l}\text { Type } \\
\text { Allowed }\end{array}$ & Management & $100 \%$ & $4.75 \%$ \\
\hline & & \multirow[b]{2}{*}{ Pets } & Pets & Allowed & $100 \%$ & $0.00 \%$ \\
\hline & & & $\begin{array}{l}\text { Type } \\
\text { Allowed }\end{array}$ & Type & $100 \%$ & $2.56 \%$ \\
\hline
\end{tabular}

Table E-11, Component and Global Weightings for Governance Aspects

\begin{tabular}{|c|c|c|c|c|c|c|}
\hline $\begin{array}{l}\text { Level } 2 \\
\text { Category }\end{array}$ & $\begin{array}{l}\text { Level } 3 \\
\text { Section }\end{array}$ & $\begin{array}{l}\text { Level } 4 \\
\text { Feature } \\
\end{array}$ & $\begin{array}{l}\text { Level } 5 \\
\text { Aspect } \\
\end{array}$ & $\begin{array}{l}\text { Component } \\
\text { Weighting }\end{array}$ & $\begin{array}{l}\text { Global } \\
\text { Weighting }\end{array}$ & $\begin{array}{l}\text { Level } 6 \\
\text { Indicators }\end{array}$ \\
\hline \multirow{10}{*}{$\begin{array}{l}\text { Gover- } \\
\text { nance }\end{array}$} & \multirow{6}{*}{ Maintenance } & \multirow{3}{*}{ Cleanliness } & Apartment & $27 \%$ & $1.28 \%$ & 1 \\
\hline & & & Building & $60 \%$ & $2.85 \%$ & 1 \\
\hline & & & $\begin{array}{l}\text { Cleaning } \\
\text { Service }\end{array}$ & $13 \%$ & $0.62 \%$ & 1 \\
\hline & & \multirow{3}{*}{ Maintenance } & Apartment & $11 \%$ & $0.54 \%$ & 1 \\
\hline & & & Building & $40 \%$ & $1.98 \%$ & 1 \\
\hline & & & $\begin{array}{l}\text { Maintenance } \\
\text { Schedule }\end{array}$ & $49 \%$ & $2.42 \%$ & 1 \\
\hline & \multirow{4}{*}{ Management } & \multirow{2}{*}{ Management } & $\begin{array}{l}\text { Building } \\
\text { Management }\end{array}$ & $0 \%$ & $0.00 \%$ & 1 \\
\hline & & & $\begin{array}{l}\text { Type } \\
\text { Allowed }\end{array}$ & $100 \%$ & $4.75 \%$ & 1 \\
\hline & & \multirow[b]{2}{*}{ Pets } & Pets & $0 \%$ & $0.00 \%$ & 1 \\
\hline & & & $\begin{array}{l}\text { Type } \\
\text { Allowed }\end{array}$ & $100 \%$ & $2.56 \%$ & 1 \\
\hline
\end{tabular}


Table E-12, Component and Global Weightings for Governance Features

\begin{tabular}{|l|l|l|r|l|r|r|}
\hline $\begin{array}{l}\text { Level 2 } \\
\text { Category }\end{array}$ & $\begin{array}{l}\text { Level 3 } \\
\text { Section }\end{array}$ & $\begin{array}{l}\text { Level 4 } \\
\text { Feature }\end{array}$ & $\begin{array}{l}\text { Component } \\
\text { Weighting }\end{array}$ & $\begin{array}{l}\text { Global } \\
\text { Weighting }\end{array}$ & $\begin{array}{l}\text { Level 5 } \\
\text { Aspect }\end{array}$ & $\begin{array}{l}\text { Level 6 } \\
\text { Indicators }\end{array}$ \\
\hline \multirow{3}{*}{$\begin{array}{l}\text { Gover- } \\
\text { nance }\end{array}$} & \multirow{2}{*}{ Maintenance } & Cleanliness & $49 \%$ & $4.75 \%$ & 3 & 3 \\
\cline { 3 - 8 } & \multirow{2}{*}{ Management } & Maintenance & $51 \%$ & $4.94 \%$ & 3 & 3 \\
\cline { 3 - 8 } & & Management & $65 \%$ & $4.75 \%$ & 1 & 2 \\
\cline { 3 - 8 } & Pets & $35 \%$ & $2.56 \%$ & 1 & 2 \\
\hline
\end{tabular}

Table E-13, Component and Global Weightings for Governance Sections

\begin{tabular}{|l|l|r|l|l|l|l|}
\hline $\begin{array}{l}\text { Level 2 } \\
\text { Category }\end{array}$ & $\begin{array}{l}\text { Level 3 } \\
\text { Section }\end{array}$ & $\begin{array}{l}\text { Component } \\
\text { Weighting }\end{array}$ & $\begin{array}{l}\text { Global } \\
\text { Weighting }\end{array}$ & $\begin{array}{l}\text { Level 4 } \\
\text { Feature }\end{array}$ & $\begin{array}{l}\text { Level 5 } \\
\text { Aspect }\end{array}$ & $\begin{array}{l}\text { Level 6 } \\
\text { Indicators }\end{array}$ \\
\hline \multirow{2}{*}{$\begin{array}{l}\text { Gover- } \\
\text { nance }\end{array}$} & Maintenance & $57 \%$ & $9.69 \%$ & 2 & 6 & 6 \\
\cline { 2 - 8 } & Management & $43 \%$ & $7.31 \%$ & 2 & 2 & 4 \\
\hline
\end{tabular}




\section{APPENDIX F INDOOR ENVIRONMENTAL QUALITY}

This Appendix will present the development of the Indoor Environmental Quality Category. This will include the Indoor Environmental Quality framework development from factor assessment to credit establishment, and Calibration of the Indoor Environmental Quality Components.

\section{F.1 INDOOR ENVIRONMENTAL QUALITY FRAMEWORK DEVELOPMENT}

The framework development discussed here follows the same process as that discussed in Section 3.2, Section 4.1 and Figure 4-2.

\section{Factor Assessment}

Indoor Environmental Quality considers all aspects of the internal environment in a space such as Acoustics, Indoor Air Quality, Thermal Comfort and Visual Aspects. 33 Factors were initially grouped in the Category as shown in Figure 2-6. However assessment of these 33 initial Factors found that there were many repetitions and similarities between them. 30 of the Factors were re-grouped into 8 Factors. Figure F-1 shows the 33 factors grouped in Indoor Environmental Quality 26 were from academic literature (in blue) and 7 were from the popular press (in red). Repeated factors are shown in green. No factors were removed as they are all relevant to liveability.

\section{Feature Identification}

Within Indoor Environmental Quality, there were four obvious Sections Acoustics, Indoor Air Quality [IAQ], Thermal Comfort and Visual Aspects. Similarly, the Features under these were obvious and able to be identified easily. With Acoustics, two Features were identified Internal Control of Sound and External Control of Sound.

It is well known that the $I A Q$ of a space is affected by ventilation and more than 80 pollutants have been identified that have adverse health effects depending on their toxicity, concentration and occurrence inside rooms (Ranson, 1991). Therefore, within $I A Q$, two Features were identified Air Quality and Ventilation.

Two Features were also initially identified with Thermal Comfort Comfort levels within the microclimate and Control over the microclimate. Two Features were also identified with Visual Aspects Adequate Lighting and Views. Table 4-13 show the make up of these new levels with the hierarchy under IEQ. 


\section{INDOOR ENVIRONMENTAL QUALITY}

\begin{tabular}{|c|c|c|c|}
\hline $\begin{array}{l}\text { ACOUSTICS } \\
\text { Acoustics } \\
\text { Noise - Exterior } \\
\text { Disturbance } \\
\text { Noise - General } \\
\text { Noise - Interior } \\
\text { Disturbance } \\
\text { Noise - Sound } \\
\text { Insulation } \\
\text { Vibration }\end{array}$ & $\begin{array}{l}\text { INDOOR AIR } \\
\text { QUALITY } \\
\text { Biological Agents } \\
\text { Chemical Agents } \\
\text { Dust } \\
\text { Indoor Air Quality } \\
\text { Indoor } \\
\text { Microclimates } \\
\text { Perception of IAQ } \\
\text { Ventilation }\end{array}$ & $\begin{array}{l}\text { THERMAL } \\
\text { COMFORT } \\
\text { Cooling } \\
\text { Quality/Capability } \\
\text { Heating } \\
\text { Quality/Capability } \\
\text { Humidity } \\
\text { Hygrothermal } \\
\text { Conditions } \\
\text { Indoor Temperature } \\
\text { Moisture, Damp, } \\
\text { Mould } \\
\text { Seasonal Variation } \\
\text { Sun } \\
\text { Thermal Comfort }\end{array}$ & $\begin{array}{l}\text { VISUAL ASPECTS } \\
\text { External Shading of } \\
\text { Windows } \\
\text { Light - Artificial } \\
\text { Light - Natural } \\
\text { Views \& Visual } \\
\text { Windows }\end{array}$ \\
\hline
\end{tabular}

Figure F-1, Factors Included Within Indoor Environmental Quality

Table F-1, Features Identified for Indoor Environmental Quality

\begin{tabular}{|c|c|c|c|}
\hline $\begin{array}{l}\text { Level } 2 \\
\text { Category }\end{array}$ & $\begin{array}{l}\text { Level } 3 \\
\text { Section }\end{array}$ & $\begin{array}{l}\text { Level } 4 \\
\text { Feature } \\
\end{array}$ & Associated Factors \\
\hline \multirow{8}{*}{$\begin{array}{l}\text { Indoor } \\
\text { Environmental } \\
\text { Quality }\end{array}$} & \multirow[t]{2}{*}{ Acoustics } & $\begin{array}{l}\text { Internal Control } \\
\text { of Sound }\end{array}$ & \multirow[t]{2}{*}{ - Acoustics } \\
\hline & & $\begin{array}{l}\text { External Control } \\
\text { of Sound }\end{array}$ & \\
\hline & \multirow[t]{2}{*}{ Indoor Air Quality } & Air Quality & - Indoor Air Quality \\
\hline & & Ventilation & - Ventilation \\
\hline & \multirow[t]{2}{*}{ Thermal Comfort } & Comfort & $\begin{array}{ll}\text { - } & \text { Hygrothermal Conditions \& } \\
& \text { Indoor Microclimates } \\
\text { - } & \text { Seasonal Variation } \\
\text { - } & \text { Sun } \\
\end{array}$ \\
\hline & & Control & $\begin{array}{ll} & \text { Cooling } \\
\text { - } & \text { Heating } \\
\end{array}$ \\
\hline & \multirow[t]{2}{*}{ Visual Aspects } & $\begin{array}{l}\text { Adequate Light } \\
\text { (artificial and/or } \\
\text { natural) }\end{array}$ & - Light \\
\hline & & Views & $\begin{array}{l}\text { - Views } \\
\text { - Windows }\end{array}$ \\
\hline
\end{tabular}


3. Aspect Identification

\section{Acoustics}

The Internal Control of Sound Feature considers how well noise disturbances are reduced through the building fabric between space to space specifically between apartments and communal areas. This does not consider control of noise within one apartment. Four Aspects were identified for this Feature which considers where internal noise may come from from apartments or spaces above, below or adjacent and from internal communal areas within the building (i.e. hallways, stair wells and lifts).

The External Control of Sound Feature considers how well noise disturbances are reduced through the building fabric from outside the building to the apartment in question. Two Aspects were identified for this Feature the control of noise from the outside and the nearest external noise source (i.e. a main road or a construction site). Refer to Table F-2 for all Acoustics Features identified.

Table F-2, Aspects Identified for Acoustics

\begin{tabular}{|l|l|l|}
\hline Level 3 & Level 4 & Level $\mathbf{5}$ \\
Section & Feature & Aspect \\
\hline Acoustics & Internal Control of & From Above (if not on top floor) \\
\cline { 3 - 3 } & Sound & From Below (if not on bottom floor) \\
\cline { 3 - 3 } & & From Adjacent Apartments \\
\cline { 3 - 3 } & & From Communal Areas \\
\cline { 2 - 3 } & \multirow{2}{*}{$\begin{array}{l}\text { External Control of } \\
\text { Sound }\end{array}$} & From Outside \\
\cline { 3 - 3 } & External noise sources \\
\hline
\end{tabular}

\section{Indoor Air Quality}

As stated above, there are a wide range of pollutants found in the air that have adverse health effects on occupants depending on their toxicity, concentration and occurrence. Common air pollutants are carbon dioxide, carbon monoxide, nitrogen oxides odours, tobacco smoke, water vapour, airborne allergens and pathogens as well as toxic emissions from polymers and consumer goods. Because of this, two Aspects were identified to assess the Air Quality of a space the Pollution in Air or air pollutants and Possible Contaminants and Sources (Table F-3).

Adequate ventilation, whether natural or mechanical is crucial to the good health of all people. Effective ventilation should provide a pure supply of air to occupied spaces and also remove odorous or polluted air. The Aspects which were identified for Ventilation look at each of the main room types found within an apartment Bedrooms, Living Areas, Kitchen \& Dining and Bathrooms and Toilets. Other spaces such as studies, laundries, and circulation spaces were not included because in an average apartment it is not likely that these would be separate rooms due to space constraints and they may only be found in higher end designs. 
Table F-3, Aspects Identified for Indoor Air Quality

\begin{tabular}{|l|l|l|}
\hline \multirow{2}{*}{$\begin{array}{l}\text { Level 3 } \\
\text { Section }\end{array}$} & $\begin{array}{l}\text { Level 4 } \\
\text { Feature }\end{array}$ & $\begin{array}{l}\text { Level 5 } \\
\text { Aspect }\end{array}$ \\
\hline \multirow{3}{*}{$\begin{array}{l}\text { Indoor Air } \\
\text { Quality }\end{array}$} & \multirow{2}{*}{ Air Quality } & Pollution in Air \\
\cline { 2 - 3 } & & Possible Contaminants and Sources \\
\cline { 2 - 3 } & \multirow{2}{*}{ Ventilation } & Bedrooms \\
\cline { 3 - 3 } & & Living Areas \\
\cline { 3 - 3 } & & Kitchen \& Dining \\
\cline { 3 - 3 } & & Bathrooms \& Toilets (and Laundries) \\
\hline
\end{tabular}

\section{Thermal Comfort}

Comfort, a Feature of Thermal Comfort considers how comfortable the indoor microclimate and hygrothermal conditions of a space are for an occupant. The hygrothermal conditions of a space are affected by humidity, dampness and air temperature. Three Aspects were identified to assess Comfort Humidity; Mould, Moisture \& Dampness; Temperature (Table F-4).

As Bluyssen (2000) states, there can be issues with the lack of control over heating and cooling within apartments. Often this is due to the type/lack of heating and/or cooling systems. Two Aspects were identified for Control within Thermal Comfort the control over Cooling and Heating.

At this stage, a third Feature was also included under Thermal Comfort Insulation. The Thermal Properties of Materials play an important role in helping maintain thermal comfort so this was identified as a Feature and Aspect that needs to be assessed.

Table F-4, Aspects Identified for Thermal Comfort

\begin{tabular}{|l|l|l|}
\hline Level 3 & Level 4 & Level 5 \\
Section & Feature & Aspect \\
\hline \multirow{3}{*}{$\begin{array}{l}\text { Thermal } \\
\text { Comfort }\end{array}$} & \multirow{2}{*}{ Comfort } & Humidity \\
\cline { 3 - 3 } & & Mould, Moisture, Dampness \\
\cline { 2 - 3 } & & Temperature \\
\cline { 2 - 3 } & \multirow{2}{*}{ Control } & Cooling \\
\cline { 2 - 3 } & & Heating \\
\cline { 2 - 3 } & Insulation & Thermal Properties of Materials \\
\hline
\end{tabular}

\section{Visual Aspects}

Originally adequate lighting had been grouped as one Feature within Visual Aspects which included both adequate task light, artificial light and natural light. However the decision was made to break this up into three Features Adequate Task Light, Artificial Light and Natural Light as each of these had different well-being issues surrounding them. Some of these issues include intensity, glare, flicker and spectrum of light (Raw, Aizlewood, \& Hamilton, 2001).

Adequate Task Lighting is required so that occupants of a space can safely and comfortably carry out a range of tasks. The intensity of light or illuminance affects what tasks can be carried out. Five 
Aspects were identified here whether there was adequate lighting for Safety (in circulation spaces), tasks in Bedrooms, Living Areas, Kitchen \& Dining areas and Bathrooms \& Toilets (Table F-5). There are a range of tasks that can be undertaken in these spaces, however adequate lighting e sight and so is a very personal issue.

In a study of health and safety issues within residential buildings, Raw found that Artificial Lighting can affect people through flicker, humming, glare and colour. Not everyone is affected by flicker although in some it may trigger convulsions similar to epilepsy (Raw, Aizlewood, \& Hamilton, 2001). Generally is causes distractions, similar to when humming occurs in electrical equipment and fixtures. Glare affects people either through disability glare where safety is affected through a direct interference with vision, or through discomfort glare when vision is not impaired but there is annoyance, often causing eye strains and/or headaches (Raw, Aizlewood, \& Hamilton, 2001). Lighting colour is an issue for certain tasks people may wish to undertake and it may be an issue for safety or the visually impaired. Three Aspects were identified for Artificial Lighting Colour, Flickering \& Humming and Glare (Table F-5).

Natural Light, $\mathrm{V}$

-being because as Raw, Aizlewood \& Hamilton (2001) states, being in an unchanging environment affects the mood, emotions and physiological arousal, leading to adverse emotional states, psychosomatic and stress symptoms. They help people to receive sensory stimuli through visual, auditory and thermal input received from the outside world, so the window helps in maintaining an optimal amount of stimulus variation to the brain. While there is little evidence that lack of natural light causes any major health impacts, There is evidence that exposure to ultraviolet radiation plays an essential role in producing Vitamin D which promotes healthy bone development (Raw, Aizlewood, \& Hamilton, 2001). Natural light also helps to influence circadian rhythms, sleeping and waking mood states through the production of melatonin. Often people who lack melatonin develop Seasonal affective disorder (SAD) is a form of depression that occurs in relation to the amount of exposure to daylight.

In order to assess these issues, two Aspects were identified for both the Features of Natural Light and Views. There are two issues with Natural Light Glare from external or internal objects (i.e. cars, windows, mirrors, water) and Internal Bedrooms (Table F-5). Internal Bedrooms are bedrooms without any windows and are often seen in apartments. For Views, the two Aspects were Views \& Outlook and New Construction (which may affect initial views).

Table F-5, Aspects Identified for Visual Aspects

\begin{tabular}{|c|c|c|}
\hline $\begin{array}{l}\text { Level } 3 \\
\text { Section }\end{array}$ & $\begin{array}{l}\text { Level } 4 \\
\text { Feature }\end{array}$ & $\begin{array}{l}\text { Level } 5 \\
\text { Aspect }\end{array}$ \\
\hline \multirow[t]{8}{*}{ Visual Aspects } & \multirow[t]{5}{*}{ Adequate Task Light } & Safety (within circulation spaces) \\
\hline & & Bedrooms \\
\hline & & Living Areas \\
\hline & & Kitchen \& Dining \\
\hline & & Bathrooms \& Toilets (and Laundries) \\
\hline & \multirow[t]{3}{*}{ Artificial Light } & Colour of Light \\
\hline & & Flickering \& Humming \\
\hline & & Glare from Lights \\
\hline
\end{tabular}




\begin{tabular}{|l|l|l|}
\hline \multirow{2}{*}{ Natural Light } & Glare \\
\cline { 2 - 3 } & \multirow{2}{*}{ Views } & Internal Bedrooms \\
\cline { 2 - 3 } & & Views \& Outlook \\
\cline { 2 - 2 } & New Construction \\
\hline
\end{tabular}

4. Indicator Identification

Each of the Aspects was then assigned an Indicator or Assessment Question. Table F-6 outlines each of these for Indoor Environmental Quality.

Table F-6, Indicators Identified for Indoor Environmental Quality

\begin{tabular}{|c|c|c|c|}
\hline $\begin{array}{l}\text { Level } 3 \\
\text { Section }\end{array}$ & $\begin{array}{l}\text { Level } 4 \\
\text { Feature }\end{array}$ & $\begin{array}{l}\text { Level } 5 \\
\text { Aspect }\end{array}$ & $\begin{array}{l}\text { Level } 6 \\
\text { Indicator }\end{array}$ \\
\hline \multirow[t]{8}{*}{ Acoustics } & \multirow[t]{4}{*}{$\begin{array}{l}\text { Internal Control of } \\
\text { Sound }\end{array}$} & $\begin{array}{l}\text { From Above (if not } \\
\text { on top floor) }\end{array}$ & $\begin{array}{l}\text { Is there adequate noise control } \\
\text { from upstairs? }\end{array}$ \\
\hline & & $\begin{array}{l}\text { From Below (if not } \\
\text { on bottom floor) }\end{array}$ & $\begin{array}{l}\text { Is there adequate noise control } \\
\text { from downstairs? }\end{array}$ \\
\hline & & $\begin{array}{l}\text { From Adjacent } \\
\text { Apartments }\end{array}$ & $\begin{array}{l}\text { Is there adequate noise control } \\
\text { from adjacent apartments? }\end{array}$ \\
\hline & & $\begin{array}{l}\text { From Communal } \\
\text { Areas }\end{array}$ & $\begin{array}{l}\text { Is there adequate noise control } \\
\text { from communal areas? }\end{array}$ \\
\hline & \multirow[t]{4}{*}{$\begin{array}{l}\text { External Control of } \\
\text { Sound }\end{array}$} & From Outside & $\begin{array}{l}\text { Is there adequate noise control } \\
\text { from outside? }\end{array}$ \\
\hline & & \multirow{3}{*}{$\begin{array}{l}\text { Nearest external } \\
\text { noise source }\end{array}$} & Is it located near heavy traffic? \\
\hline & & & $\begin{array}{l}\text { Is it located near construction } \\
\text { sites? }\end{array}$ \\
\hline & & & Is it located near bars? \\
\hline \multirow[t]{9}{*}{$\begin{array}{l}\text { Indoor Air } \\
\text { Quality }\end{array}$} & \multirow[t]{5}{*}{ Air Quality } & \multirow[t]{2}{*}{ Pollution in Air } & $\begin{array}{l}\text { Is the general air quality in the } \\
\text { apartment acceptable? }\end{array}$ \\
\hline & & & $\begin{array}{l}\text { Is the general air quality in the } \\
\text { building acceptable? }\end{array}$ \\
\hline & & \multirow{3}{*}{$\begin{array}{l}\text { Possible } \\
\text { Contaminants and } \\
\text { Sources }\end{array}$} & Is the apartment open plan? \\
\hline & & & $\begin{array}{l}\text { Is contamination from bathrooms } \\
\text { or toilets an issue? }\end{array}$ \\
\hline & & & $\begin{array}{l}\text { Is smoking allowed in the } \\
\text { apartment? }\end{array}$ \\
\hline & \multirow[t]{4}{*}{ Ventilation } & Bedrooms & $\begin{array}{l}\text { Is the ventilation adequate in } \\
\text { these rooms? }\end{array}$ \\
\hline & & Living Areas & $\begin{array}{l}\text { Is the ventilation adequate in } \\
\text { these rooms? }\end{array}$ \\
\hline & & Kitchen \& Dining & $\begin{array}{l}\text { Is the ventilation adequate in } \\
\text { these rooms? }\end{array}$ \\
\hline & & $\begin{array}{l}\text { Bathrooms \& Toilets } \\
\text { (and Laundries) }\end{array}$ & $\begin{array}{l}\text { Is the ventilation adequate in } \\
\text { these rooms? }\end{array}$ \\
\hline
\end{tabular}




\begin{tabular}{|c|c|c|c|}
\hline \multirow[t]{6}{*}{$\begin{array}{l}\text { Thermal } \\
\text { Comfort }\end{array}$} & \multirow[t]{3}{*}{ Comfort } & Humidity & $\begin{array}{l}\text { Is the humidity level acceptable } \\
\text { and healthy? }\end{array}$ \\
\hline & & $\begin{array}{l}\text { Mould, Moisture, } \\
\text { Dampness }\end{array}$ & $\begin{array}{l}\text { Does the apartment have mould } \\
\text { or dampness issues? }\end{array}$ \\
\hline & & Temperature & \\
\hline & \multirow[t]{2}{*}{ Control } & Cooling & $\begin{array}{l}\text { What cooling control is there for } \\
\text { occupants? }\end{array}$ \\
\hline & & Heating & $\begin{array}{l}\text { What heating control is there for } \\
\text { occupants? }\end{array}$ \\
\hline & Insulation & $\begin{array}{l}\text { Thermal Properties } \\
\text { of Materials }\end{array}$ & $\begin{array}{l}\text { What are the thermal properties } \\
\text { of the construction materials? }\end{array}$ \\
\hline \multirow[t]{12}{*}{ Visual Aspects } & \multirow[t]{5}{*}{ Adequate Task Light } & Safety & $\begin{array}{l}\text { Is there adequate lighting for } \\
\text { safety in walking and orientation? }\end{array}$ \\
\hline & & Bedrooms & $\begin{array}{l}\text { Is there adequate lighting for } \\
\text { different required tasks in this } \\
\text { room? }\end{array}$ \\
\hline & & Living Areas & $\begin{array}{l}\text { Is there adequate lighting for } \\
\text { different required tasks in this } \\
\text { room? }\end{array}$ \\
\hline & & Kitchen \& Dining & $\begin{array}{l}\text { Is there adequate lighting for } \\
\text { different required tasks in this } \\
\text { room? }\end{array}$ \\
\hline & & $\begin{array}{l}\text { Bathrooms \& Toilets } \\
\text { (and Laundries) }\end{array}$ & $\begin{array}{l}\text { Is there adequate lighting for } \\
\text { different required tasks in this } \\
\text { room? }\end{array}$ \\
\hline & \multirow[t]{3}{*}{ Artificial Light } & Colour of Light & $\begin{array}{l}\text { What is the colour output and is it } \\
\text { adequate for a range of daily } \\
\text { tasks? }\end{array}$ \\
\hline & & $\begin{array}{l}\text { Flickering \& } \\
\text { Humming }\end{array}$ & $\begin{array}{l}\text { Is there any flickering or humming } \\
\text { from artificial light sources? }\end{array}$ \\
\hline & & Glare from Lights & $\begin{array}{l}\text { Is there any glare from artificial } \\
\text { light sources? }\end{array}$ \\
\hline & \multirow[t]{2}{*}{ Natural Light } & Glare & $\begin{array}{l}\text { Is there any glare outside from the } \\
\text { sun on different objects? }\end{array}$ \\
\hline & & Shading & $\begin{array}{l}\text { Are there any major external } \\
\text { obstructions that cause } \\
\text { shadowing? }\end{array}$ \\
\hline & \multirow[t]{2}{*}{ Views } & Views \& Outlook & Is the view pleasant? \\
\hline & & New Construction & $\begin{array}{l}\text { Will new construction in the area } \\
\text { encroach on current views? }\end{array}$ \\
\hline
\end{tabular}




\section{AM Identification \& Review}

\section{Acoustics}

Table F-7 outlines the Assessment Methods Identified for Acoustics. Five of the eight Indicators required Assessments (Adequate Noise Control) and three required Yes or no Choices (External Noise Sources).

Acoustics were reviewed against the requirements of Criteria \#2 and \#3, five were determined to be inappropriate for NZ ALI. These were the assessments of STC rating (Sound Transmission Class) and noise control through the building fabric. While they were objective equired people to have an understanding of

often an issue within apartments and this assessment is not as accurate as assessing the STC rating of materials and the building fabric. However it was felt that it was appropriate to simplify this assessment so that all end-users could easily use the tool and have an understanding of issues to consider when considering an apartment. Table F-7

Table F-7, Review of Assessment Methods Identified for Acoustics

\begin{tabular}{|c|c|c|c|c|}
\hline $\begin{array}{l}\text { Level } 4 \\
\text { Feature }\end{array}$ & $\begin{array}{l}\text { Level } 5 \\
\text { Aspect }\end{array}$ & $\begin{array}{l}\text { Level } 6 \\
\text { Indicator-Assessment } \\
\text { Question }\end{array}$ & $\begin{array}{l}\text { Assessment } \\
\text { Method } \\
\text { Version } 1 \\
\end{array}$ & $\begin{array}{l}\text { Modified } \\
\text { Assessment } \\
\text { Method }\end{array}$ \\
\hline \multirow{4}{*}{$\begin{array}{l}\text { Internal } \\
\text { Control of } \\
\text { Sound }\end{array}$} & $\begin{array}{l}\text { From Above } \\
\text { (if not on top } \\
\text { floor) }\end{array}$ & $\begin{array}{l}\text { Is there adequate noise } \\
\text { control from upstairs? }\end{array}$ & $\begin{array}{l}\text { Assessment (STC } \\
\text { \& IIC Rating) }\end{array}$ & Yes/No \\
\hline & $\begin{array}{l}\text { From Below } \\
\text { (if not on } \\
\text { bottom } \\
\text { floor) }\end{array}$ & $\begin{array}{l}\text { Is there adequate noise } \\
\text { control from downstairs? }\end{array}$ & $\begin{array}{l}\text { Assessment (STC } \\
\text { Rating) }\end{array}$ & Yes/No \\
\hline & $\begin{array}{l}\text { From } \\
\text { Adjacent } \\
\text { Apartments }\end{array}$ & $\begin{array}{l}\text { Is there adequate noise } \\
\text { control from adjacent } \\
\text { apartments? }\end{array}$ & $\begin{array}{l}\text { Assessment (STC } \\
\text { Rating) }\end{array}$ & Yes/No \\
\hline & $\begin{array}{l}\text { From } \\
\text { Communal } \\
\text { Areas }\end{array}$ & $\begin{array}{l}\text { Is there adequate noise } \\
\text { control from communal } \\
\text { areas? }\end{array}$ & $\begin{array}{l}\text { Assessment (STC } \\
\text { Rating) }\end{array}$ & Yes/No \\
\hline \multirow{4}{*}{$\begin{array}{l}\text { External } \\
\text { Control of } \\
\text { Sound }\end{array}$} & $\begin{array}{l}\text { From } \\
\text { Outside }\end{array}$ & $\begin{array}{l}\text { Is there adequate noise } \\
\text { control from outside? }\end{array}$ & $\begin{array}{l}\text { Assessment (STC } \\
\text { Rating) }\end{array}$ & Yes/No \\
\hline & \multirow{3}{*}{$\begin{array}{l}\text { Nearest } \\
\text { external } \\
\text { noise source }\end{array}$} & $\begin{array}{l}\text { Are you located near traffic } \\
\text { (i.e. main roads, busy } \\
\text { intersections, motorways)? }\end{array}$ & Choose Yes or No & Yes/No \\
\hline & & $\begin{array}{l}\text { Are you located near } \\
\text { construction sites? }\end{array}$ & Choose Yes or No & Yes/No \\
\hline & & $\begin{array}{l}\text { Are you located near } \\
\text { entertainment venues such } \\
\text { as bars or stadia? }\end{array}$ & Choose Yes or No & Yes/No \\
\hline
\end{tabular}




\section{Indoor Air Quality}

Table F-8 outlines the nine Assessment Methods identified for Indoor Air Quality were Yes or No Choices (Indicators under Contaminants and Sources) required Air Quality or Ventilation assessment.

Of the nine Indicators identified for Indoor Air Quality three met the requirements of Criteria \#2 and \#3 and were determined to be acceptable. Six did not meet the requirements as shown in Table F-8

Air Pollution and

Ventilation. Because they were assessments of the Air Quality and Ventilation they were deemed impractical due to a possible lack of skills, equipment and knowledge by primary end-users. The

Air Pollution were modified to become scales so that end-users could make a structured and informed personal Indicators within Ventilation were modified to become Lists it is not likely that end=users could make an informed judgement about adequacy of Ventilation within different spaces on the basis of one open home or walk through so a List AM was deemed to be appropriate as it would provide guidance and help end-users make informed judgement on a complicated issue.

Table F-8, Review of Assessment Methods Identified for Indoor Air Quality

\begin{tabular}{|c|c|c|c|c|}
\hline $\begin{array}{l}\text { Level } 4 \\
\text { Feature }\end{array}$ & $\begin{array}{l}\text { Level } 5 \\
\text { Aspect }\end{array}$ & $\begin{array}{l}\text { Level } 6 \\
\text { Indicator-Assessment } \\
\text { Question }\end{array}$ & $\begin{array}{l}\text { Assessment } \\
\text { Method } \\
\text { Version } 1\end{array}$ & $\begin{array}{l}\text { Modified } \\
\text { Assessment } \\
\text { Method }\end{array}$ \\
\hline \multirow{5}{*}{ Air Quality } & \multirow{2}{*}{ Air Pollution } & $\begin{array}{l}\text { Is the general air quality in } \\
\text { the apartment acceptable? }\end{array}$ & $\begin{array}{l}\text { Assessment (Air } \\
\text { Quality) }\end{array}$ & Scale \\
\hline & & $\begin{array}{l}\text { Is the general air quality in } \\
\text { the building acceptable? }\end{array}$ & $\begin{array}{l}\text { Assessment (Air } \\
\text { Quality) }\end{array}$ & Scale \\
\hline & \multirow{3}{*}{$\begin{array}{l}\text { Contaminants } \\
\text { and Sources }\end{array}$} & Is the apartment open plan? & $\begin{array}{l}\text { Choose Yes or } \\
\text { No }\end{array}$ & Yes/No \\
\hline & & $\begin{array}{l}\text { Is contamination from } \\
\text { bathrooms or toilets an } \\
\text { issue? }\end{array}$ & $\begin{array}{l}\text { Choose Yes or } \\
\text { No }\end{array}$ & Yes/No \\
\hline & & $\begin{array}{l}\text { Is smoking allowed in the } \\
\text { apartment? }\end{array}$ & $\begin{array}{l}\text { Choose Yes or } \\
\text { No }\end{array}$ & Yes/No \\
\hline \multirow{4}{*}{ Ventilation } & Bedrooms & $\begin{array}{l}\text { Is the ventilation adequate in } \\
\text { these rooms? }\end{array}$ & $\begin{array}{l}\text { Assessment } \\
\text { (Ventilation) }\end{array}$ & List \\
\hline & Living Areas & $\begin{array}{l}\text { Is the ventilation adequate in } \\
\text { these rooms? }\end{array}$ & $\begin{array}{l}\text { Assessment } \\
\text { (Ventilation) }\end{array}$ & List \\
\hline & $\begin{array}{l}\text { Kitchen \& } \\
\text { Dining }\end{array}$ & $\begin{array}{l}\text { Is the ventilation adequate in } \\
\text { these rooms? }\end{array}$ & $\begin{array}{l}\text { Assessment } \\
\text { (Ventilation) }\end{array}$ & List \\
\hline & $\begin{array}{l}\text { Bathrooms \& } \\
\text { Toilets (and } \\
\text { Laundries) }\end{array}$ & $\begin{array}{l}\text { Is the ventilation adequate in } \\
\text { these rooms? }\end{array}$ & $\begin{array}{l}\text { Assessment } \\
\text { (Ventilation) }\end{array}$ & List \\
\hline
\end{tabular}




\section{Thermal Comfort}

Six Assessment Methods were identified for the Indicators within Thermal Comfort. Three required user statements (Sunlight \& Orientation, Cooling and Heating) and, one required a Personal Perception (Mould, Moisture \& Dampness). The AM identified for Humidity required an Assessment and Insulation required a Measurement of Material R-Values. Table F-9 shows these under the

Of the six Assessment Methods originally identified three were determined to not meet the requirements of NZ ALI Criteria \#2 and \#3. These were Humidity, Mould, Moisture \& Dampness and Insulation. Mould, Moisture \& Dampness initially required users to make a personal judgement about whether they believe there are any mould, moisture or dampness issues. This was deemed to be an impractical assessment due to confusion with wording. Similarly it was also considered too subjective. This AM was therefore modified to a Yes/No choice to make it practical and less subjective.

Table F-9, Review of Assessment Methods Identified for Thermal Comfort

\begin{tabular}{|l|l|l|l|l|}
\hline Level 4 & $\begin{array}{l}\text { Level 5 } \\
\text { Feature }\end{array}$ & $\begin{array}{l}\text { Level 6 } \\
\text { Indicator -Assessment } \\
\text { Question }\end{array}$ & $\begin{array}{l}\text { Assessment } \\
\text { Method } \\
\text { Version 1 }\end{array}$ & $\begin{array}{l}\text { Modified } \\
\text { Assessment } \\
\text { Method }\end{array}$ \\
\hline \multirow{5}{*}{ Comfort } & Humidity & $\begin{array}{l}\text { Is the humidity level } \\
\text { acceptable and healthy? }\end{array}$ & $\begin{array}{l}\text { Assessment } \\
\text { (Humidity) }\end{array}$ & List \\
\cline { 2 - 5 } & $\begin{array}{l}\text { Mould, } \\
\text { Moisture, } \\
\text { Dampness }\end{array}$ & $\begin{array}{l}\text { Does the apartment have } \\
\text { mould or dampness issues? }\end{array}$ & $\begin{array}{l}\text { Personal } \\
\text { Perception } \\
\text { (Mould, } \\
\text { Moisture \& } \\
\text { Dampness) }\end{array}$ & Yes/No \\
\cline { 2 - 6 } & $\begin{array}{l}\text { Sunlight \& } \\
\text { Orientation }\end{array}$ & $\begin{array}{l}\text { Which way do your main } \\
\text { living spaces face and how } \\
\text { much sun do you get during } \\
\text { the day? }\end{array}$ & $\begin{array}{l}\text { Statement } \\
\text { (Orientation) }\end{array}$ & List \\
\hline \multirow{5}{*}{ Control } & Cooling & $\begin{array}{l}\text { What cooling control is there } \\
\text { for occupants? }\end{array}$ & $\begin{array}{l}\text { Statement } \\
\text { (Cooling Control) }\end{array}$ & Yes/No \\
\cline { 2 - 6 } & Heating & $\begin{array}{l}\text { What heating control is } \\
\text { there for occupants? }\end{array}$ & $\begin{array}{l}\text { Statement } \\
\text { (Heating Control) }\end{array}$ & Yes/No \\
\hline \multirow{2}{*}{ Insulation } & $\begin{array}{l}\text { Thermal } \\
\text { Properties of } \\
\text { Materials }\end{array}$ & $\begin{array}{l}\text { What are the thermal } \\
\text { properties of the } \\
\text { construction materials? }\end{array}$ & $\begin{array}{l}\text { Measurement } \\
\text { (Materials R- } \\
\text { Values) }\end{array}$ & Number \\
\hline
\end{tabular}

The Humidity and Insulation Indicators required either Assessment or Measurement by end-users.

end-

but still

Humidity was applied an AM that required users to choose an answer from a list, and Insulation required the year of construction. 
The three other Indicators and Assessment Methods were also modified so that they were user friendly. Sunlight \& Orientation was changed to a list, and Heating and Cooling were changed to Yes/No choices, as is shown in Table F-9

\section{Visual Aspects}

Table F-10 outlines the Assessment Methods for Visual Aspects

urement or Assessment of some kind, three required Yes/No and one required a personal perception.

Only three of the Assessment Methods within Visual Aspects did not require any modification as they were considered to be both practical and objective assessments. The AM required for Views however was judged to be either practical or objective as it required a Personal Judgement about Views. This AM was therefore modified to become a Scale so that users could make practical assessments with some level of subjectivity as shown in Table F-10

As mentioned above, nine of the Indicators within Visual Aspects required wither Measurement or Assessment. These were not considered practical assessments due to a lack of knowledge, skills and equipment of end users they would not have the ability to carry out these Assessment Methods. These were all modified to become Yes or No Choices (as shown in Table F-10). For Adequate Task Light

While this is a highly subjective assessment, it was considered more practical because it cousld be easily determined and liveability is a very personal issue and what may be adequate task lighting for one person may be not be adequate for another (i.e. elderly or visually impaired). Similarly for Glare and Shading a Yes or No Choice was considered to be practical and sufficiently objective for different end users. 
Table F-10, Review of Assessment Methods Identified for Visual Aspects

\begin{tabular}{|c|c|c|c|c|}
\hline $\begin{array}{l}\text { Level } 4 \\
\text { Feature }\end{array}$ & $\begin{array}{l}\text { Level } 5 \\
\text { Aspect }\end{array}$ & $\begin{array}{l}\text { Level } 6 \\
\text { Indicator-Assessment } \\
\text { Question }\end{array}$ & $\begin{array}{l}\text { Assessment } \\
\text { Method } \\
\text { Version } 1 \\
\end{array}$ & $\begin{array}{l}\text { Modified } \\
\text { Assessment } \\
\text { Method } \\
\end{array}$ \\
\hline \multirow{5}{*}{$\begin{array}{l}\text { Adequate } \\
\text { Task Light }\end{array}$} & Safety & $\begin{array}{l}\text { Is there adequate lighting for } \\
\text { safety in walking and } \\
\text { orientation? }\end{array}$ & $\begin{array}{l}\text { Measurement } \\
\text { (Illuminance) }\end{array}$ & Yes/No \\
\hline & Bedrooms & $\begin{array}{l}\text { Is there adequate lighting for } \\
\text { different required tasks in } \\
\text { this room? }\end{array}$ & $\begin{array}{l}\text { Measurement } \\
\text { (Illuminance) }\end{array}$ & Yes/No \\
\hline & Living Areas & $\begin{array}{l}\text { Is there adequate lighting for } \\
\text { different required tasks in } \\
\text { this room? }\end{array}$ & $\begin{array}{l}\text { Measurement } \\
\text { (Illuminance) }\end{array}$ & Yes/No \\
\hline & $\begin{array}{l}\text { Kitchen \& } \\
\text { Dining }\end{array}$ & $\begin{array}{l}\text { Is there adequate lighting for } \\
\text { different required tasks in } \\
\text { this room? }\end{array}$ & $\begin{array}{l}\text { Measurement } \\
\text { (Illuminance) }\end{array}$ & Yes/No \\
\hline & $\begin{array}{l}\text { Bathrooms \& } \\
\text { Toilets (and } \\
\text { Laundries) } \\
\end{array}$ & $\begin{array}{l}\text { Is there adequate lighting for } \\
\text { different required tasks in } \\
\text { this room? }\end{array}$ & $\begin{array}{l}\text { Measurement } \\
\text { (Illuminance) }\end{array}$ & Yes/No \\
\hline \multirow{3}{*}{$\begin{array}{l}\text { Artificial } \\
\text { Light }\end{array}$} & $\begin{array}{l}\text { Colour of } \\
\text { Light }\end{array}$ & $\begin{array}{l}\text { What is the colour output } \\
\text { and is it adequate for a } \\
\text { range of daily tasks? }\end{array}$ & $\begin{array}{l}\text { Measurement } \\
\text { (Colour Output) }\end{array}$ & Yes/No \\
\hline & $\begin{array}{l}\text { Flickering \& } \\
\text { Humming }\end{array}$ & $\begin{array}{l}\text { Is there any flickering or } \\
\text { humming from artificial light } \\
\text { sources? }\end{array}$ & Choose Yes or No & Yes/No \\
\hline & $\begin{array}{l}\text { Glare from } \\
\text { Lights }\end{array}$ & $\begin{array}{l}\text { Is there any glare from } \\
\text { artificial light sources? }\end{array}$ & $\begin{array}{l}\text { Assessment } \\
\text { (Glare) }\end{array}$ & Yes/No \\
\hline \multirow{3}{*}{ Natural Light } & Glare & $\begin{array}{l}\text { Is there any glare outside } \\
\text { from the sun on different } \\
\text { objects? }\end{array}$ & $\begin{array}{l}\text { Assessment } \\
\text { (Glare) }\end{array}$ & Yes/No \\
\hline & $\begin{array}{l}\text { Internal } \\
\text { Bedrooms }\end{array}$ & $\begin{array}{l}\text { Are there any internal } \\
\text { bedrooms) }\end{array}$ & Choose Yes or No & Yes/No \\
\hline & Shading & $\begin{array}{l}\text { Are there any major external } \\
\text { obstructions that cause } \\
\text { shadowing? }\end{array}$ & $\begin{array}{l}\text { Assessment } \\
\text { (Shading) }\end{array}$ & Yes/No \\
\hline \multirow{2}{*}{ Views } & $\begin{array}{l}\text { Views \& } \\
\text { Outlook }\end{array}$ & Is the view pleasant? & $\begin{array}{l}\text { Personal } \\
\text { Perception } \\
\text { (Views) }\end{array}$ & Scale \\
\hline & $\begin{array}{l}\text { New } \\
\text { Construction }\end{array}$ & $\begin{array}{l}\text { Will new construction in the } \\
\text { area encroach on current } \\
\text { views? }\end{array}$ & Choose Yes or No & Yes/No \\
\hline
\end{tabular}


6. Credit Establishment

\section{Acoustics}

Table F-11 outlines the Acceptability of Answers and Awarding of Credits for Acoustics. As all Assessment Methods were Yes or No Choices no lists were required. Three Indicators also required choice because of where an apartment may be placed in relation to other apartments. These were Noise Control from Upstairs (Ceiling), Noise Control from Downstairs (Floor), and Noise Control from Internal Communal Areas (Doors). The four Assessment Questions were also modified to provide more guidance for end-users in NZ ALI.

Table F-11, Acceptability \& Awarding of Credits Identified for Acoustics

\begin{tabular}{|c|c|c|c|}
\hline $\begin{array}{l}\text { Level } 4 \\
\text { Feature }\end{array}$ & $\begin{array}{l}\text { Level } 5 \\
\text { Aspect }\end{array}$ & $\begin{array}{l}\text { Level } 6 \\
\text { Indicator - Modified } \\
\text { Assessment Question }\end{array}$ & Acceptability \& Awarding of Credits \\
\hline \multirow{4}{*}{$\begin{array}{l}\text { Internal } \\
\text { Control of } \\
\text { Sound }\end{array}$} & $\begin{array}{l}\text { From Above } \\
\text { (if not on top } \\
\text { floor) }\end{array}$ & $\begin{array}{l}\text { Is there adequate noise } \\
\text { control from upstairs } \\
\text { apartments? }\end{array}$ & $\begin{array}{l}\text { Yes/No Version } 1 \\
\text { and } N / A=100 \%\end{array}$ \\
\hline & $\begin{array}{l}\text { From Below } \\
\text { (if not on } \\
\text { bottom } \\
\text { floor) }\end{array}$ & $\begin{array}{l}\text { Is there adequate noise } \\
\text { control from downstairs } \\
\text { apartments? }\end{array}$ & $\begin{array}{l}\text { Yes/No Version } 1 \\
\text { and N/A }=100 \%\end{array}$ \\
\hline & $\begin{array}{l}\text { From } \\
\text { Adjacent } \\
\text { Apartments } \\
\end{array}$ & $\begin{array}{l}\text { Is there adequate noise } \\
\text { control from adjacent } \\
\text { apartments? }\end{array}$ & Yes/No Version 1 \\
\hline & $\begin{array}{l}\text { From } \\
\text { Communal } \\
\text { Areas }\end{array}$ & $\begin{array}{l}\text { Is there adequate noise } \\
\text { control from internal } \\
\text { communal areas (i.e. } \\
\text { hallways, lobbies, stairs) }\end{array}$ & $\begin{array}{l}\text { Yes/No Version } 1 \\
\text { and } N / A=100 \%\end{array}$ \\
\hline \multirow{4}{*}{$\begin{array}{l}\text { External } \\
\text { Control of } \\
\text { Sound }\end{array}$} & $\begin{array}{l}\text { From } \\
\text { Outside }\end{array}$ & $\begin{array}{l}\text { Is there adequate noise } \\
\text { control from outside? }\end{array}$ & Yes/No Version 1 \\
\hline & \multirow{3}{*}{$\begin{array}{l}\text { Nearest } \\
\text { external } \\
\text { noise source }\end{array}$} & $\begin{array}{l}\text { Are you located near traffic } \\
\text { (i.e. main roads, busy } \\
\text { intersections, motorways)? }\end{array}$ & Yes/No Version 2 \\
\hline & & $\begin{array}{l}\text { Are you located near } \\
\text { construction sites? }\end{array}$ & Yes/No Version 2 \\
\hline & & $\begin{array}{l}\text { Are you located near } \\
\text { entertainment venues such } \\
\text { as bars or stadia? }\end{array}$ & Yes/No Version 2 \\
\hline
\end{tabular}

\section{Indoor Air Quality}

Table F-12

Indoor Air Quality can be answered and how credits are awarded. Seven of the nine Assessment Questions were modified to be applied to NZ ALI. 
Table F-12, Acceptability \& Awarding of Credits Identified for Indoor Air Quality

\begin{tabular}{|c|c|c|c|c|}
\hline $\begin{array}{l}\text { Level } 4 \\
\text { Feature }\end{array}$ & $\begin{array}{l}\text { Level } 5 \\
\text { Aspect }\end{array}$ & $\begin{array}{l}\text { Level } 6 \\
\text { Indicator - Modified } \\
\text { Assessment Question }\end{array}$ & Acceptability \& Awarding of $C$ & redits \\
\hline \multirow{5}{*}{ Air Quality } & \multirow{2}{*}{$\begin{array}{l}\text { Pollution in } \\
\text { Air }\end{array}$} & $\begin{array}{l}\text { On a scale of } 1-10 \text {, how } \\
\text { acceptable is the general air } \\
\text { quality in the apartment? }\end{array}$ & \multicolumn{2}{|l|}{110 Scale } \\
\hline & & $\begin{array}{l}\text { On a scale of } 1-10 \text {, how } \\
\text { acceptable is the general air } \\
\text { quality in the building? }\end{array}$ & \multicolumn{2}{|l|}{110 Scale } \\
\hline & \multirow{3}{*}{$\begin{array}{l}\text { Possible } \\
\text { Contaminants } \\
\text { and Sources }\end{array}$} & Is the apartment open plan? & Yes/No Version 2 & \\
\hline & & $\begin{array}{l}\text { Are bathrooms/toilets } \\
\text { located directly off the main } \\
\text { living spaces (i.e. bedrooms } \\
\text { and living areas)? }\end{array}$ & \multicolumn{2}{|l|}{ Yes/No Version 2} \\
\hline & & $\begin{array}{l}\text { Is smoking allowed in the } \\
\text { apartment/building? }\end{array}$ & \multicolumn{2}{|l|}{ Yes/No Version 2} \\
\hline \multirow{4}{*}{ Ventilation } & Bedrooms & $\begin{array}{l}\text { Does the ventilation in this } \\
\text { room seem adequate? }\end{array}$ & \multicolumn{2}{|l|}{ The ventilation seems to be: } \\
\hline & Living Areas & $\begin{array}{l}\text { Does the ventilation in this } \\
\text { room seem adequate? }\end{array}$ & \multirow{2}{*}{$\begin{array}{l}\text { Yes - seems to be fine } \\
\text { Possibly - it seems a bit tight } \\
\text { and/or smelly }\end{array}$} & $100 \%$ \\
\hline & $\begin{array}{l}\text { Kitchen \& } \\
\text { Dining }\end{array}$ & $\begin{array}{l}\text { Does the ventilation in this } \\
\text { room seem adequate? }\end{array}$ & & $50 \%$ \\
\hline & $\begin{array}{l}\text { Bathrooms \& } \\
\text { Toilets (and } \\
\text { Laundries) } \\
\end{array}$ & $\begin{array}{l}\text { Does the ventilation in this } \\
\text { room seem adequate? }\end{array}$ & $\begin{array}{l}\text { No - very little air comes into } \\
\text { the space }\end{array}$ & $0 \%$ \\
\hline
\end{tabular}

\section{Thermal Comfort}

Table F-13 outlines the modified Assessment Questions and awarding of Credits for Thermal Comfort. The Assessment Methods for Cooling and Heating both needed to be modified also to accurately question end users and fit within NZ ALI. Humidity was split into two Indicators the Kitchen and the Bathroom and the type of ventilation available to deal with potential Humidity issues was assessed in the form of a List. The List developed for Sunlight \& Orientation was developed on which way the main living spaces faced and the amount of sunlight the spaces received. Insulation is now assessed by the year of construction and the NZBC requirements for thermal properties of materials at different years. 1978 was when these types of requirements were first introduced into the NZBC (Statistics New Zealand, 2006) and in 2007 the minimum requirements were substantially increased (Department of Building \& Housing, 2009). 
Table F-13, Acceptability \& Awarding of Credits Identified for Thermal Comfort

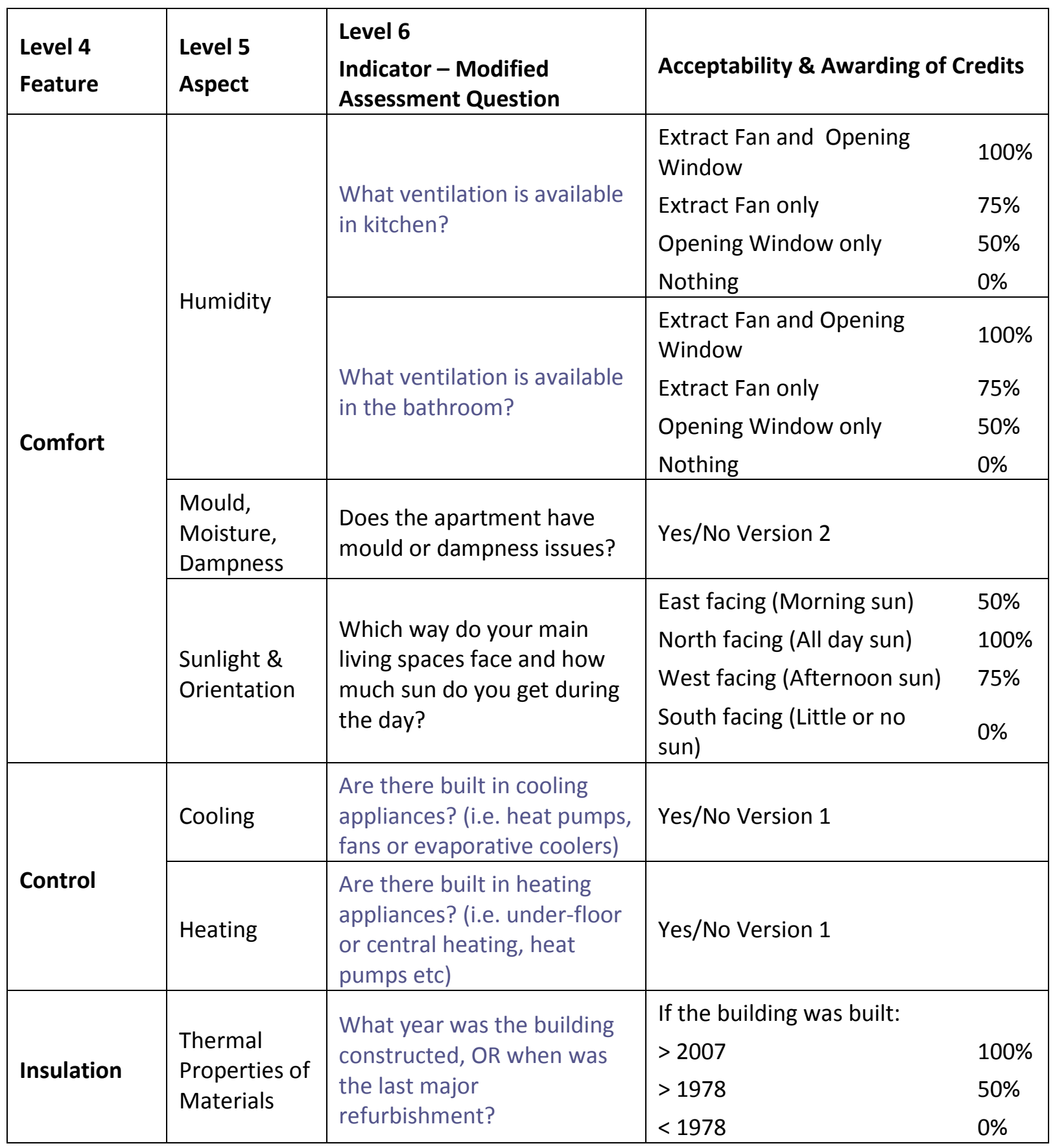

\section{Visual Aspects}

Table F-14 outlines the awarding of credits and possible answers for Visual Aspects. Eight Assessment Questions were modified to provide more information when applied to NZ ALI (as shown in blue text 
Table F-14, Acceptability \& Awarding of Credits Identified for Visual Aspects

\begin{tabular}{|c|c|c|c|}
\hline $\begin{array}{l}\text { Level } 4 \\
\text { Feature }\end{array}$ & $\begin{array}{l}\text { Level } 5 \\
\text { Aspect }\end{array}$ & $\begin{array}{l}\text { Level } 6 \\
\text { Indicator - Modified } \\
\text { Assessment Question }\end{array}$ & Acceptability \& Awarding of Credits \\
\hline \multirow{5}{*}{$\begin{array}{l}\text { Adequate } \\
\text { Task Light }\end{array}$} & Safety & $\begin{array}{l}\text { Is there adequate lighting for } \\
\text { safety when walking in the } \\
\text { apartment? }\end{array}$ & Yes/No Version 2 \\
\hline & Bedrooms & $\begin{array}{l}\text { Is there adequate lighting for } \\
\text { different tasks required in } \\
\text { this room? }\end{array}$ & Yes/No Version 1 \\
\hline & Living Areas & $\begin{array}{l}\text { Is there adequate lighting for } \\
\text { different tasks required in } \\
\text { this room? }\end{array}$ & Yes/No Version 1 \\
\hline & $\begin{array}{l}\text { Kitchen \& } \\
\text { Dining }\end{array}$ & $\begin{array}{l}\text { Is there adequate lighting for } \\
\text { different tasks required in } \\
\text { this room? }\end{array}$ & Yes/No Version 1 \\
\hline & $\begin{array}{l}\text { Bathrooms \& } \\
\text { Toilets (and } \\
\text { Laundries) } \\
\end{array}$ & $\begin{array}{l}\text { Is there adequate lighting for } \\
\text { different tasks required in } \\
\text { this room? }\end{array}$ & Yes/No Version 1 \\
\hline \multirow{3}{*}{$\begin{array}{l}\text { Artificial } \\
\text { Light }\end{array}$} & $\begin{array}{l}\text { Colour of } \\
\text { Light }\end{array}$ & $\begin{array}{l}\text { Is the colour output } \\
\text { adequate for a range of daily } \\
\text { tasks? }\end{array}$ & Yes/No Version 1 \\
\hline & $\begin{array}{l}\text { Flickering \& } \\
\text { Humming }\end{array}$ & $\begin{array}{l}\text { Is there any flickering or } \\
\text { humming from artificial light } \\
\text { sources? }\end{array}$ & Yes/No Version 2 \\
\hline & $\begin{array}{l}\text { Glare from } \\
\text { Lights }\end{array}$ & $\begin{array}{l}\text { Is there any glare from } \\
\text { artificial light sources? }\end{array}$ & Yes/No Version 2 \\
\hline \multirow{3}{*}{ Natural Light } & Glare & $\begin{array}{l}\text { Is there any glare outside } \\
\text { from different objects? }\end{array}$ & Yes/No Version 2 \\
\hline & $\begin{array}{l}\text { Internal } \\
\text { Bedrooms }\end{array}$ & $\begin{array}{l}\text { Are there any bedrooms } \\
\text { without windows to outside } \\
\text { the apartment? }\end{array}$ & Yes/No Version 1 \\
\hline & Shading & $\begin{array}{l}\text { Are there any major external } \\
\text { obstructions around } \\
\text { windows that cause } \\
\text { obstructions to sunlight and } \\
\text { shadows? }\end{array}$ & Yes/No Version 2 \\
\hline \multirow[b]{2}{*}{ Views } & $\begin{array}{l}\text { Views \& } \\
\text { Outlook }\end{array}$ & $\begin{array}{l}\text { On a scale of } 1-10 \text {, how } \\
\text { pleased are you with the } \\
\text { view? }\end{array}$ & 110 Scale \\
\hline & $\begin{array}{l}\text { New } \\
\text { Construction }\end{array}$ & $\begin{array}{l}\text { Are there construction sites } \\
\text { that when completed will } \\
\text { have a negative impact on } \\
\text { your views? }\end{array}$ & Yes/No Version 2 \\
\hline
\end{tabular}




\section{F.2 INDOOR ENVIRONMENTAL QUALITY CALIBRATION}

The information discussed here provides information on the Calibration of the Indoor Environmental Quality Components. The data analysed and used to develop weightings for this Category is from the NZ ALI Questionnaire. The Calibration process follows that discussed in Section 4.3and The NZ ALI Questionnaire.

\section{F.2.1 NZ ALI QUESTIONNAIRE RESULTS \& ANALYSIS}

\section{Aspects}

Acoustics: Figure F-2 shows the percentage of nominations that each of the Aspects within Acoustics received.

Indoor Air Quality: Figure F-3 shows the percentage of nominations that each of the Aspects within Indoor Air Quality received.

Thermal Comfort: Figure F-4 shows the percentage of nominations that each of the Aspects within Thermal Comfort received.

Visual Aspects: Figure F-5 shows the percentage of nominations that each of the Aspects within Visual Aspects received. Shading \& Shadowing received no nominations.

\section{Features}

Figure F-6 shows the weightings determined for the Indoor Environmental Quality Features which were determined from Equation 4-1.

\section{Sections}

Figure F-7 shows the weightings determined for the Indoor Environmental Quality Sections which were determined from Equation 4-1. 


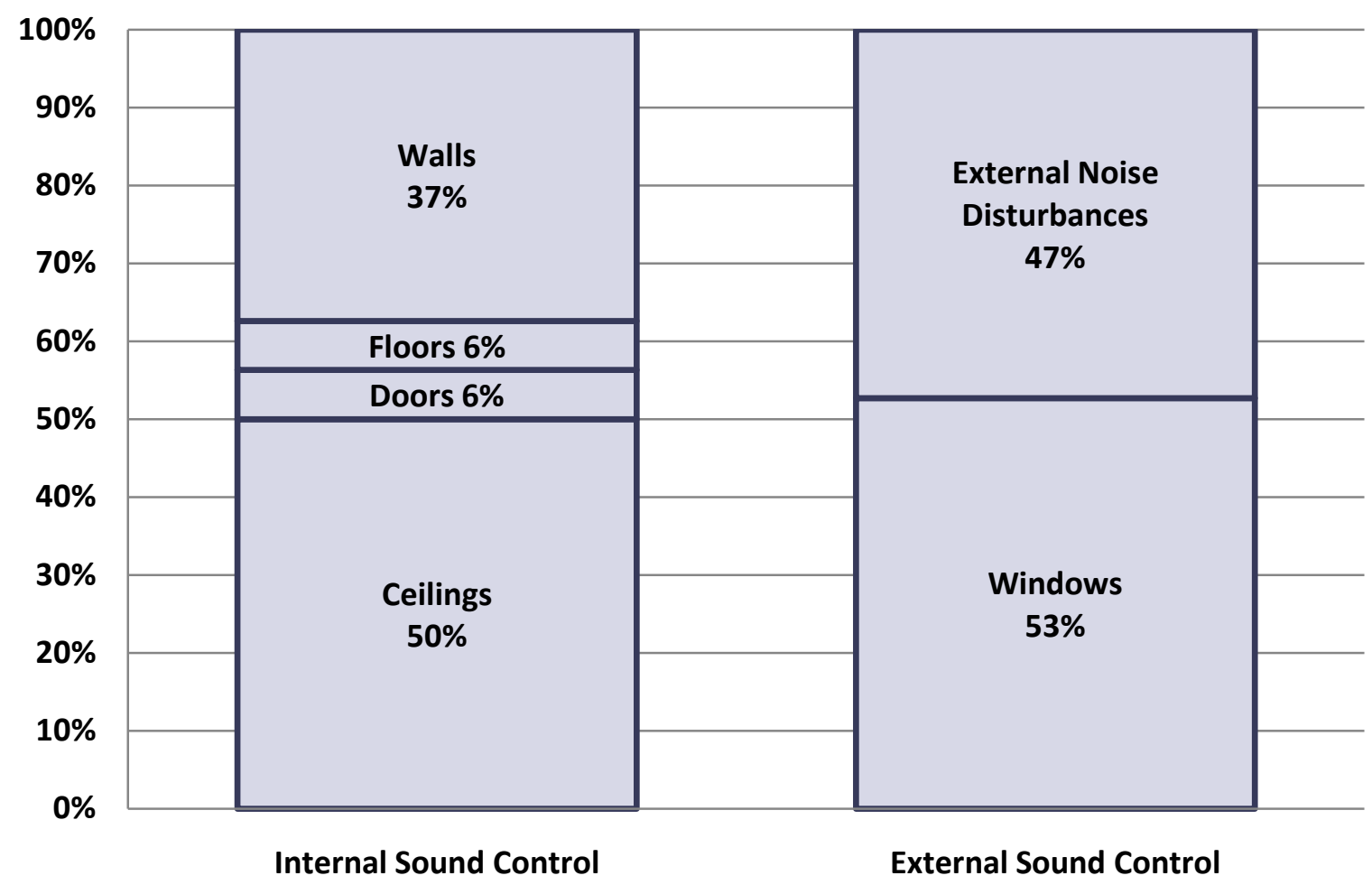

Figure F-2, Perceived Importance of Acoustics Aspects

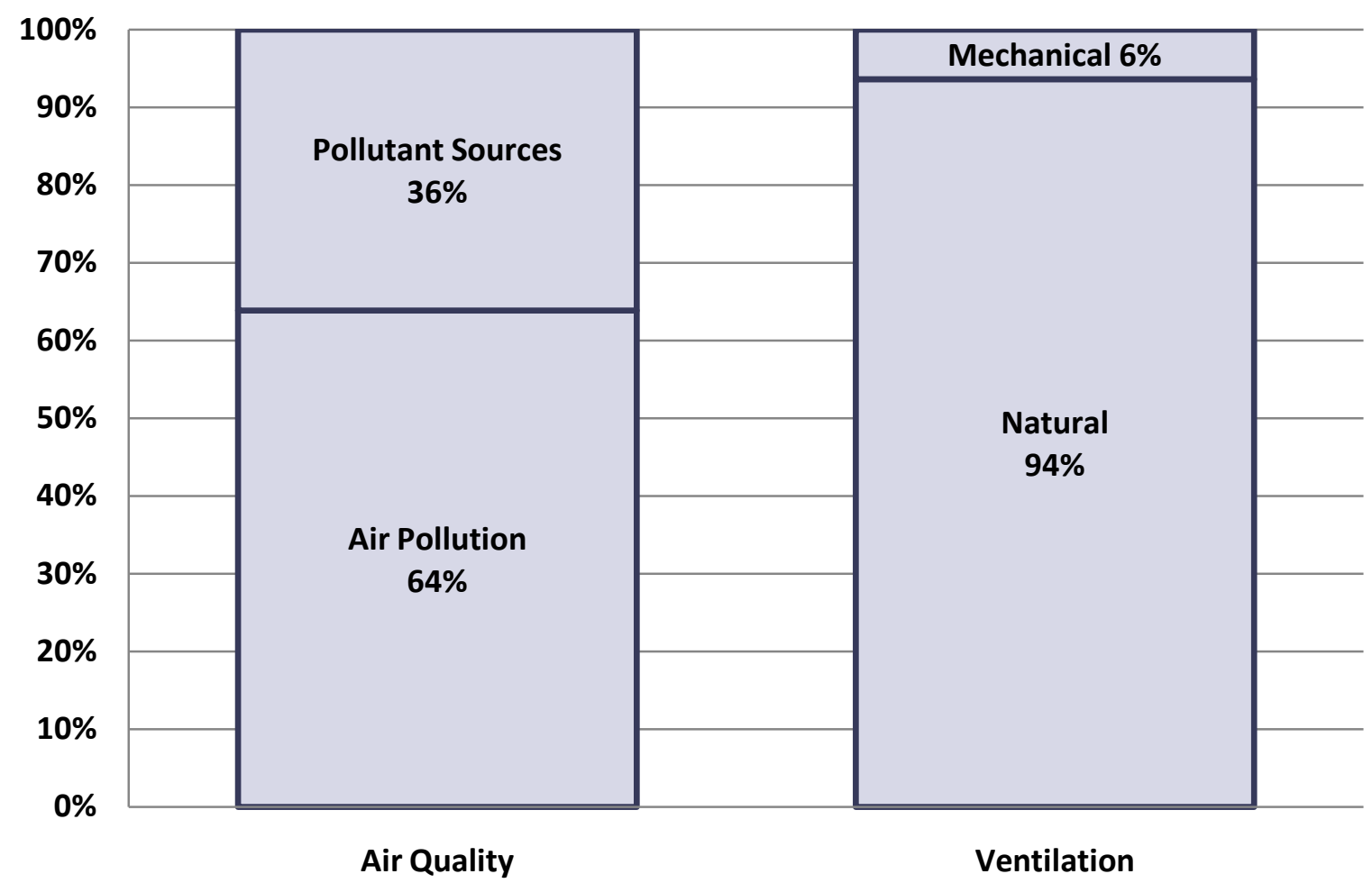

Figure F-3, Perceived Importance of Indoor Air Quality Aspects 


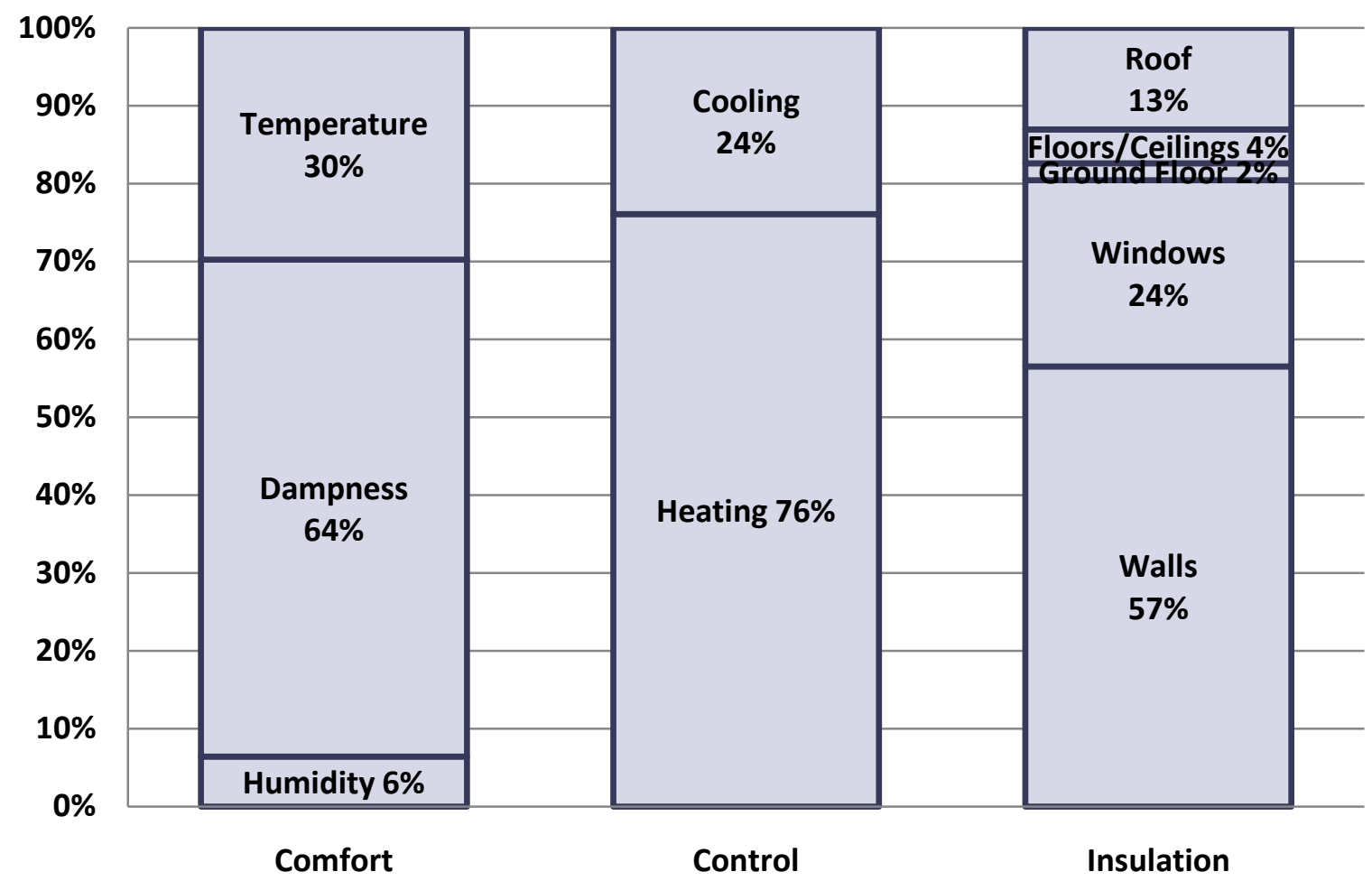

Figure F-4, Perceived Importance of Thermal Comfort Aspects

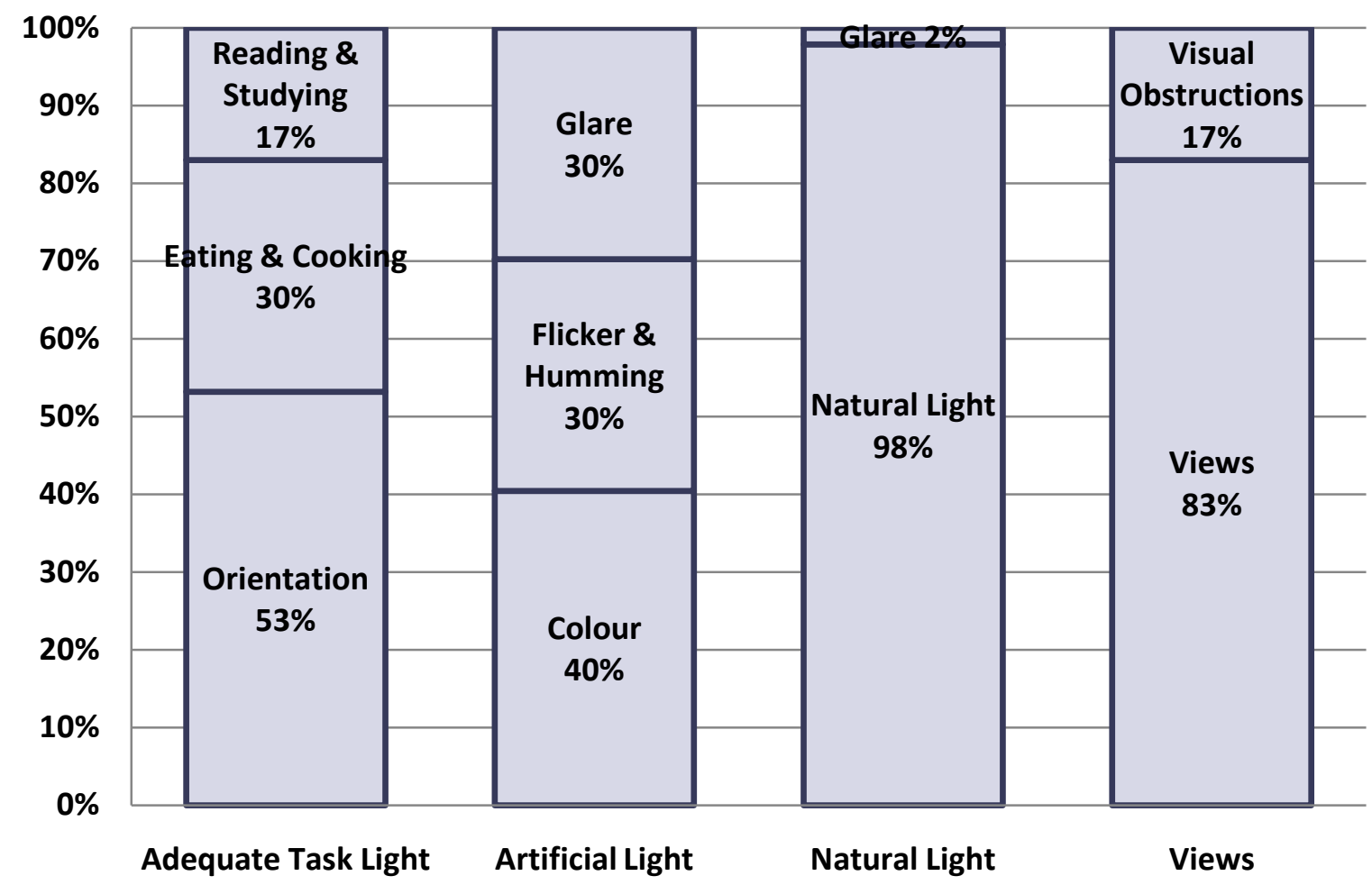

Figure F-5, Perceived Importance of Visual Aspects' Aspects 


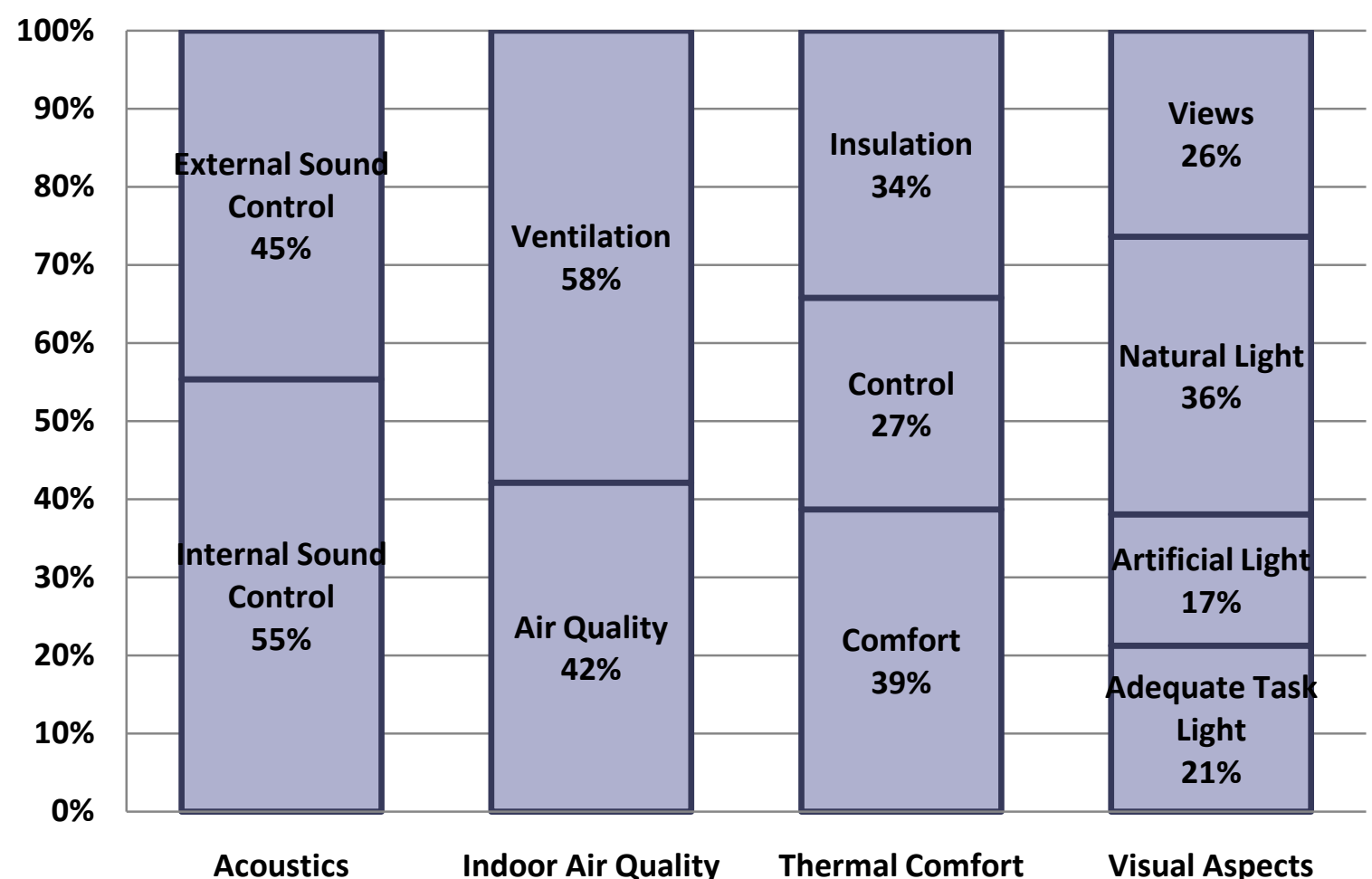

Figure F-6, Perceived Importance of Indoor Environmental Quality Features

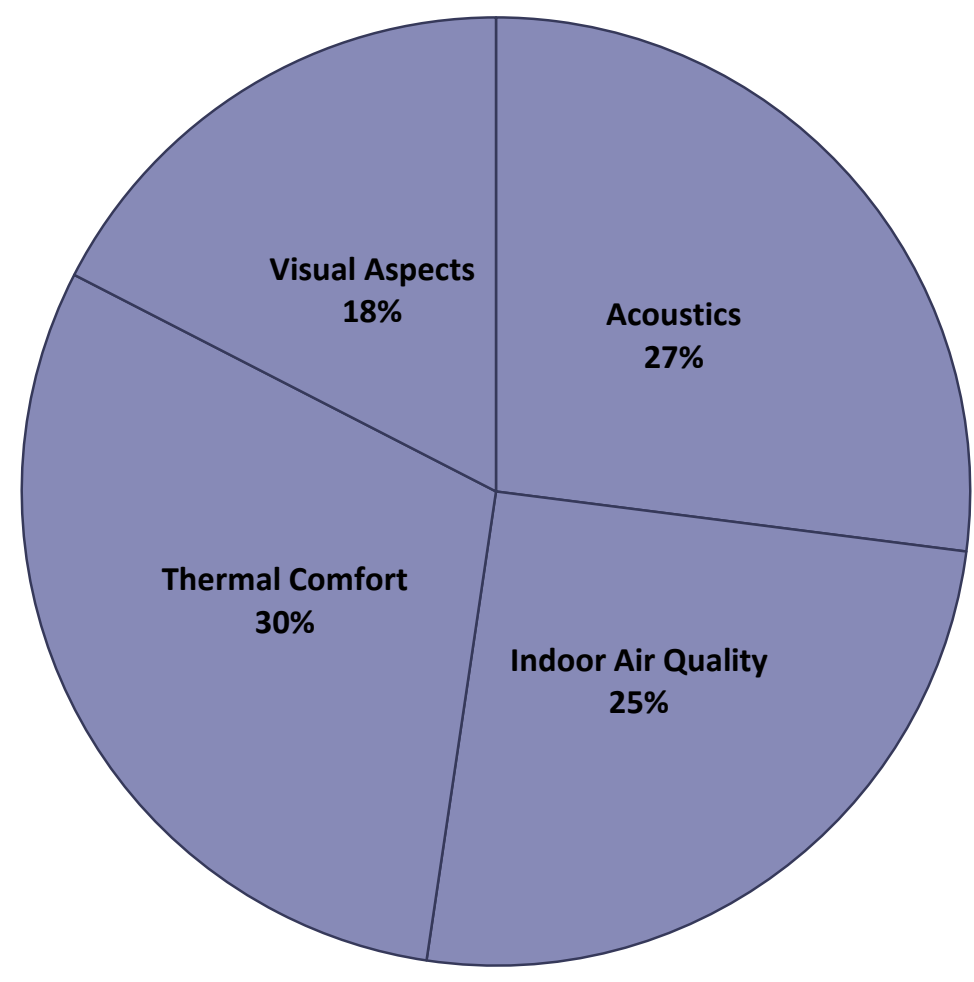

Figure F-7, Perceived Importance of Indoor Environmental Quality Sections 


\section{F.2.2 APPLICATION OF PERCEIVED IMPORTANCE AS WEIGHTINGS}

\section{Rule \#1 - Perceived Importance of less than 3\%}

Within Visual Aspects two Aspects were perceived to have an importance of less than $3 \%$ from the NZ ALI Questionnaire. These were both within Natural Light and were Glare and Shading. Shading was considered not important, and Glare was considered only $2 \%$ important with Natural Light/Internal Bedrooms receiving an importance of $98 \%$. Both of these low scoring Aspects were removed and Natural Light/Internal Bedrooms was given the full weighting of $100 \%$ for that Feature. No other components within Indoor Environmental Quality had a perceived importance of less than $3 \%$.

\section{Rule \#2 - Indicator Weightings}

Three Aspects within Indoor Environmental Quality had more than one Indicator associated with them. Weightings were spread evenly between them as shown in Table F-15. No other components were modified within Indoor Environmental Quality. Any unmodified components were awarded weightings matching that of their PI from the NZ ALI Questionnaire.

Table F-15, Weightings Applied to NZ ALI Indoor Environmental Quality Aspects with more than one Indicator

\begin{tabular}{|c|c|c|c|}
\hline Feature & Aspect & Indicator & Indicator Weighting \\
\hline \multirow[t]{3}{*}{$\begin{array}{l}\text { External Control of } \\
\text { Noise }\end{array}$} & \multirow[t]{3}{*}{ External Noise Sources } & $\begin{array}{l}\text { Are you located near } \\
\text { traffic? }\end{array}$ & $33 \%$ \\
\hline & & $\begin{array}{l}\text { Are you located near } \\
\text { construction sites? }\end{array}$ & $33 \%$ \\
\hline & & $\begin{array}{l}\text { Are you located near } \\
\text { bars? }\end{array}$ & $33 \%$ \\
\hline \multirow[t]{5}{*}{ Air Quality } & \multirow[t]{2}{*}{ Pollution in Air } & $\begin{array}{l}\text { Is the general air } \\
\text { quality in the } \\
\text { apartment acceptable? }\end{array}$ & $50 \%$ \\
\hline & & $\begin{array}{l}\text { Is the general air } \\
\text { quality in the building } \\
\text { acceptable? }\end{array}$ & $50 \%$ \\
\hline & \multirow[t]{3}{*}{$\begin{array}{l}\text { Possible Contaminants } \\
\text { and Sources }\end{array}$} & $\begin{array}{l}\text { Is the apartment open } \\
\text { plan? }\end{array}$ & $33 \%$ \\
\hline & & $\begin{array}{l}\text { Are bathrooms/toilets } \\
\text { located directly off the } \\
\text { main living spaces (i.e. } \\
\text { bedrooms and living } \\
\text { areas)? }\end{array}$ & $33 \%$ \\
\hline & & $\begin{array}{l}\text { Is smoking allowed in } \\
\text { the apartment? }\end{array}$ & $33 \%$ \\
\hline
\end{tabular}




\section{Rule \#3 - Modified Components}

Within Indoor Environmental Quality four Features were modified. Within Indoor Air Quality, one Feature was modified. Initially it was decided to assess Ventilation through either Natural Ventilation or Mechanical Ventilation. However as the acceptability of both of these are very complicated it was decided that the Aspects within Ventilation would be modified to assess the ventilation in different spaces within an apartment. Four new Aspects were then assessed within Ventilation Bedrooms, Living Areas, Kitchen \& Dining and Bathrooms \& Toilets. As these were not assessed in the NZ ALI Questionnaire they were each awarded a weighting of $25 \%$.

Within Thermal Comfort one Feature and its Aspects was modified Insulation. Initially this Feature was assessed with five Aspects Roof R-Value, Floor/Ceilings R-Value, Ground Floor R-Value, Windows $R$-Value and Wall R-Value. However it was decided that for ease of use and practicality, that only one Aspect would be assessed within Insulation the year the building was built or remodelled. This was then awarded a full weighting of $100 \%$.

One other Feature was also modified within Visual Aspects Adequate Task Light. Initially three Aspects were considered in the NZ ALI Questionnaire for this Feature Reading/Studying, Eating/Cooking and Safety/Orientation. As it was unclear how or where these were meant to be assessed (i.e. in which space) it was decided that for ease of use and better understanding that Adequate Task Light would be better assessed in each space, however Safety/Orientation was still kept within Adequate Task Light as this a minimum requirement for task light. The four new Aspects included were Bedrooms, Living Areas, Kitchen \& Dining and Bathrooms \& Toilets. Because Safety/Orientation was considered to be so important in the NZ ALI Questionnaire (PI of 53\%), it was decided to give a majority weighting of $40 \%$ to this Aspect and $15 \%$ to each of the other four.

\section{F.2.3 INDOOR ENVIRONMENTAL QUALITY COMPONENT WEIGHTINGS}

The following tables present the final weightings applied to all Indoor Environmental Quality components.

Table F-16, Component and Global Weightings for Indoor Environmental Quality Indicators

\begin{tabular}{|c|c|c|c|c|c|c|}
\hline $\begin{array}{l}\text { Level } 2 \\
\text { Category }\end{array}$ & $\begin{array}{l}\text { Level } 3 \\
\text { Section }\end{array}$ & $\begin{array}{l}\text { Level } 4 \\
\text { Feature }\end{array}$ & $\begin{array}{l}\text { Level } 5 \\
\text { Aspect }\end{array}$ & $\begin{array}{l}\text { Level } 6 \\
\text { Indicator }\end{array}$ & $\begin{array}{l}\text { Component } \\
\text { Weighting }\end{array}$ & $\begin{array}{l}\text { Global } \\
\text { Weighting }\end{array}$ \\
\hline \multirow{9}{*}{ IEQ } & \multirow{8}{*}{ Acoustics } & \multirow{4}{*}{$\begin{array}{l}\text { Internal } \\
\text { Control of } \\
\text { Sound }\end{array}$} & Ceiling & Noise & $100 \%$ & $1.52 \%$ \\
\hline & & & Floors & Noise & $100 \%$ & $0.18 \%$ \\
\hline & & & Wall & Noise & $100 \%$ & $1.15 \%$ \\
\hline & & & Door & Noise & $100 \%$ & $0.18 \%$ \\
\hline & & \multirow{4}{*}{$\begin{array}{l}\text { External } \\
\text { Control of } \\
\text { Sound }\end{array}$} & Window & Noise & $100 \%$ & $1.97 \%$ \\
\hline & & & \multirow{3}{*}{$\begin{array}{l}\text { Source of } \\
\text { External } \\
\text { Noise }\end{array}$} & Traffic & $33 \%$ & $0.58 \%$ \\
\hline & & & & Construction & $33 \%$ & $0.58 \%$ \\
\hline & & & & Bars & $33 \%$ & $0.58 \%$ \\
\hline & IAQ & Air Quality & Quality & Apartment & $50 \%$ & $0.84 \%$ \\
\hline
\end{tabular}




\begin{tabular}{|c|c|c|c|c|c|}
\hline & & & Building & $50 \%$ & $0.84 \%$ \\
\hline & & \multirow{3}{*}{ Contaminants } & Open Plan & $33 \%$ & $0.32 \%$ \\
\hline & & & Bathrooms & $33 \%$ & $0.32 \%$ \\
\hline & & & Smoking & $33 \%$ & $0.32 \%$ \\
\hline & \multirow{4}{*}{ Ventilation } & Bedroom & Adequate & $100 \%$ & $0.91 \%$ \\
\hline & & Living & Adequate & $100 \%$ & $0.91 \%$ \\
\hline & & Kitchen & Adequate & $100 \%$ & $0.91 \%$ \\
\hline & & Bathroom & Adequate & $100 \%$ & $0.91 \%$ \\
\hline \multirow{6}{*}{$\begin{array}{l}\text { Thermal } \\
\text { Comfort }\end{array}$} & \multirow{3}{*}{ Comfort } & Humidity & Air & $100 \%$ & $0.18 \%$ \\
\hline & & $\begin{array}{l}\text { Mould, } \\
\text { Moisture and } \\
\text { Dampness }\end{array}$ & Signs & $100 \%$ & $1.87 \%$ \\
\hline & & $\begin{array}{l}\text { Sunlight \& } \\
\text { Orientation }\end{array}$ & Orientation & $100 \%$ & $0.88 \%$ \\
\hline & \multirow{2}{*}{ Control } & Cooling & Control & $100 \%$ & $0.49 \%$ \\
\hline & & Heating & Control & $100 \%$ & $1.54 \%$ \\
\hline & Insulation & Age & Year & $100 \%$ & $2.55 \%$ \\
\hline \multirow{11}{*}{$\begin{array}{l}\text { Visual } \\
\text { Aspects }\end{array}$} & \multirow{5}{*}{$\begin{array}{l}\text { Adequate } \\
\text { Task } \\
\text { Lighting }\end{array}$} & Safety & Light & $100 \%$ & $0.47 \%$ \\
\hline & & Bedroom & Light & $100 \%$ & $0.12 \%$ \\
\hline & & Living & Light & $100 \%$ & $0.12 \%$ \\
\hline & & Kitchen & Light & $100 \%$ & $0.12 \%$ \\
\hline & & Bathroom & Light & $100 \%$ & $0.12 \%$ \\
\hline & \multirow{3}{*}{$\begin{array}{l}\text { Artificial } \\
\text { Lighting }\end{array}$} & Colour & Output & $100 \%$ & $0.31 \%$ \\
\hline & & $\begin{array}{l}\text { Flickering \& } \\
\text { Humming }\end{array}$ & Flicker Hum & $100 \%$ & $0.23 \%$ \\
\hline & & Glare & Glare & $100 \%$ & $0.23 \%$ \\
\hline & $\begin{array}{l}\text { Natural } \\
\text { Light }\end{array}$ & $\begin{array}{l}\text { Internal } \\
\text { Bedrooms }\end{array}$ & Internal & $100 \%$ & $1.62 \%$ \\
\hline & \multirow[b]{2}{*}{ Views } & View & View & $100 \%$ & $0.97 \%$ \\
\hline & & $\begin{array}{l}\text { New } \\
\text { Buildings }\end{array}$ & Construction & $100 \%$ & $0.20 \%$ \\
\hline
\end{tabular}


Table F-17, Component and Global Weightings for Indoor Environmental Quality Aspects

\begin{tabular}{|c|c|c|c|c|c|c|}
\hline $\begin{array}{l}\text { Level } 2 \\
\text { Category }\end{array}$ & $\begin{array}{l}\text { Level } 3 \\
\text { Section }\end{array}$ & $\begin{array}{l}\text { Level } 4 \\
\text { Feature } \\
\end{array}$ & $\begin{array}{l}\text { Level } 5 \\
\text { Aspect }\end{array}$ & $\begin{array}{l}\text { Component } \\
\text { Weighting }\end{array}$ & $\begin{array}{l}\text { Global } \\
\text { Weighting } \\
\end{array}$ & $\begin{array}{l}\text { Level } 6 \\
\text { Indicators }\end{array}$ \\
\hline \multirow{29}{*}{ IEQ } & \multirow{6}{*}{ Acoustics } & \multirow{4}{*}{$\begin{array}{l}\text { Internal } \\
\text { Control of } \\
\text { Sound }\end{array}$} & Ceiling & $50 \%$ & $1.52 \%$ & 1 \\
\hline & & & Floors & $6 \%$ & $0.18 \%$ & 1 \\
\hline & & & Wall & $38 \%$ & $1.15 \%$ & 1 \\
\hline & & & Door & $6 \%$ & $0.18 \%$ & 1 \\
\hline & & \multirow[b]{2}{*}{$\begin{array}{l}\text { External } \\
\text { Control of } \\
\text { Sound }\end{array}$} & Window & $53 \%$ & $1.97 \%$ & 1 \\
\hline & & & $\begin{array}{l}\text { Source of } \\
\text { External } \\
\text { Noise } \\
\end{array}$ & $47 \%$ & $1.74 \%$ & 3 \\
\hline & \multirow{6}{*}{ IAQ } & \multirow{2}{*}{ Air Quality } & Quality & $64 \%$ & $1.68 \%$ & 2 \\
\hline & & & Contaminants & $36 \%$ & $0.95 \%$ & 3 \\
\hline & & \multirow{4}{*}{ Ventilation } & Bedroom & $25 \%$ & $0.91 \%$ & 1 \\
\hline & & & Living & $25 \%$ & $0.91 \%$ & 1 \\
\hline & & & Kitchen & $25 \%$ & $0.91 \%$ & 1 \\
\hline & & & Bathroom & $25 \%$ & $0.91 \%$ & 1 \\
\hline & \multirow{6}{*}{$\begin{array}{l}\text { Thermal } \\
\text { Comfort }\end{array}$} & \multirow{3}{*}{ Comfort } & Humidity & $6 \%$ & $0.18 \%$ & 1 \\
\hline & & & $\begin{array}{l}\text { Mould, } \\
\text { Moisture and } \\
\text { Dampness }\end{array}$ & $64 \%$ & $1.87 \%$ & 1 \\
\hline & & & $\begin{array}{l}\text { Sunlight \& } \\
\text { Orientation }\end{array}$ & $30 \%$ & $0.88 \%$ & 1 \\
\hline & & \multirow{2}{*}{ Control } & Cooling & $24 \%$ & $0.49 \%$ & 1 \\
\hline & & & Heating & $76 \%$ & $1.54 \%$ & 1 \\
\hline & & Insulation & Age & $100 \%$ & $2.55 \%$ & 1 \\
\hline & \multirow{11}{*}{$\begin{array}{l}\text { Visual } \\
\text { Aspects }\end{array}$} & \multirow{5}{*}{$\begin{array}{l}\text { Adequate } \\
\text { Task } \\
\text { Lighting }\end{array}$} & Safety & $50 \%$ & $0.47 \%$ & 1 \\
\hline & & & Bedroom & $13 \%$ & $0.12 \%$ & 1 \\
\hline & & & Living & $13 \%$ & $0.12 \%$ & 1 \\
\hline & & & Kitchen & $13 \%$ & $0.12 \%$ & 1 \\
\hline & & & Bathroom & $13 \%$ & $0.12 \%$ & 1 \\
\hline & & \multirow{3}{*}{$\begin{array}{l}\text { Artificial } \\
\text { Lighting }\end{array}$} & Colour & $40 \%$ & $0.31 \%$ & 1 \\
\hline & & & $\begin{array}{l}\text { Flickering \& } \\
\text { Humming }\end{array}$ & $30 \%$ & $0.23 \%$ & 1 \\
\hline & & & Glare & $30 \%$ & $0.23 \%$ & 1 \\
\hline & & $\begin{array}{l}\text { Natural } \\
\text { Light }\end{array}$ & $\begin{array}{l}\text { Internal } \\
\text { Bedrooms }\end{array}$ & $100 \%$ & $1.62 \%$ & 1 \\
\hline & & \multirow[b]{2}{*}{ Views } & View & $83 \%$ & $0.97 \%$ & 1 \\
\hline & & & $\begin{array}{l}\text { New } \\
\text { Buildings }\end{array}$ & $17 \%$ & $0.20 \%$ & 1 \\
\hline
\end{tabular}


Table F-18, Component and Global Weightings for Indoor Environmental Quality Features

\begin{tabular}{|c|c|c|c|c|c|c|}
\hline $\begin{array}{l}\text { Level } 2 \\
\text { Category }\end{array}$ & $\begin{array}{l}\text { Level } 3 \\
\text { Section }\end{array}$ & $\begin{array}{l}\text { Level } 4 \\
\text { Feature }\end{array}$ & $\begin{array}{l}\text { Component } \\
\text { Weighting }\end{array}$ & $\begin{array}{l}\text { Global } \\
\text { Weighting }\end{array}$ & $\begin{array}{l}\text { Level } 5 \\
\text { Aspect }\end{array}$ & $\begin{array}{l}\text { Level } 6 \\
\text { Indicators }\end{array}$ \\
\hline \multirow{11}{*}{$\begin{array}{l}\text { Indoor } \\
\text { Environmental } \\
\text { Quality }\end{array}$} & \multirow{2}{*}{ Acoustics } & $\begin{array}{l}\text { Internal } \\
\text { Control of } \\
\text { Sound }\end{array}$ & $45 \%$ & $3.04 \%$ & 4 & 4 \\
\hline & & $\begin{array}{l}\text { External } \\
\text { Control of } \\
\text { Sound } \\
\end{array}$ & $55 \%$ & $3.71 \%$ & 2 & 4 \\
\hline & \multirow{2}{*}{$\begin{array}{l}\text { Indoor Air } \\
\text { Quality }\end{array}$} & Air Quality & $42 \%$ & $2.63 \%$ & 2 & 5 \\
\hline & & Ventilation & $58 \%$ & $3.63 \%$ & 4 & 4 \\
\hline & \multirow{3}{*}{$\begin{array}{l}\text { Thermal } \\
\text { Comfort }\end{array}$} & Comfort & $39 \%$ & $2.93 \%$ & 3 & 3 \\
\hline & & Control & $27 \%$ & $2.03 \%$ & 2 & 2 \\
\hline & & Insulation & $34 \%$ & $2.55 \%$ & 1 & 1 \\
\hline & \multirow{4}{*}{$\begin{array}{l}\text { Visual } \\
\text { Aspects }\end{array}$} & $\begin{array}{l}\text { Adequate } \\
\text { Task } \\
\text { Lighting } \\
\end{array}$ & $21 \%$ & $0.95 \%$ & 5 & 5 \\
\hline & & $\begin{array}{l}\text { Artificial } \\
\text { Lighting }\end{array}$ & $17 \%$ & $0.77 \%$ & 3 & 3 \\
\hline & & $\begin{array}{l}\text { Natural } \\
\text { Light }\end{array}$ & $36 \%$ & $1.62 \%$ & 1 & 1 \\
\hline & & Views & $26 \%$ & $1.17 \%$ & 2 & 2 \\
\hline
\end{tabular}

Table F-19, Component and Global Weightings for Indoor Environmental Quality Sections

\begin{tabular}{|c|c|c|c|c|c|c|}
\hline $\begin{array}{l}\text { Level } 2 \\
\text { Category }\end{array}$ & $\begin{array}{l}\text { Level } 3 \\
\text { Section }\end{array}$ & $\begin{array}{l}\text { Component } \\
\text { Weighting }\end{array}$ & $\begin{array}{l}\text { Global } \\
\text { Weighting }\end{array}$ & $\begin{array}{l}\text { Level } 4 \\
\text { Feature }\end{array}$ & $\begin{array}{l}\text { Level } 5 \\
\text { Aspect }\end{array}$ & $\begin{array}{l}\text { Level } 6 \\
\text { Indicators }\end{array}$ \\
\hline \multirow{4}{*}{$\begin{array}{l}\text { Indoor } \\
\text { Environmental } \\
\text { Quality }\end{array}$} & Acoustics & $27 \%$ & $6.75 \%$ & 2 & 6 & 8 \\
\hline & $\begin{array}{l}\text { Indoor Air } \\
\text { Quality }\end{array}$ & $25 \%$ & $6.25 \%$ & 2 & 6 & 9 \\
\hline & $\begin{array}{l}\text { Thermal } \\
\text { Comfort }\end{array}$ & $30 \%$ & $7.50 \%$ & 3 & 6 & 6 \\
\hline & $\begin{array}{l}\text { Visual } \\
\text { Aspects }\end{array}$ & $18 \%$ & $4.50 \%$ & 4 & 11 & 11 \\
\hline
\end{tabular}




\section{APPENDIX G QUALITY}

This Appendix will present the development of the Quality Category. This will include the Quality framework development from factor assessment to credit establishment, and Calibration of the Quality Components.

\section{G.1 QUALITY FRAMEWORK DEVELOPMENT}

The framework development discussed here follows the same process as that discussed in Section 3.2, Section 4.1 and Figure 4-2.

\section{Factor Assessment}

Quality was initially made up of factors that look at the quality of the building, from construction, materials, services and amenities. Initially 22 Factors from the two literature reviews were grouped in Quality. Assessment of the Factors showed that only one Factor was repeated Parking (shown in green in Figure G-1). There were no Factors that did not meet Criterion \#1.

\section{QUALITY}

\begin{tabular}{|l|l|l|}
\hline BUILDING QUALITY & BUILDING SERVICES \& & MATERIALS QUALITY \\
Airtightness & AMENITIES & $\begin{array}{l}\text { Construction Materials } \\
\text { Internal Furnishings }\end{array}$ \\
Common Areas & Drainage & \\
Electrical Safety & Emergency Access/Utilities & \\
Injury Prevention & Fire Safety & \\
Poor Housing & Lift & \\
Quality & Parking & \\
Safety in Building & Rubbish/Recycling & \\
Security & Utilities & \\
Structural Safety & Waste & \\
& Water Supply/Quality & \\
& & \\
& &
\end{tabular}

Figure G-1, Factors Included Within Quality 
2. Feature Identification

Assessment of the 21 factors showed that there were three over-riding Sections within Quality:

- Building Quality the quality of the construction and design,

- Building Services \& Amenities the quality of the services and amenities provided in a building,

- Materials Quality the quality of materials and furnishings.

Within Building Quality, four initial Features were identified from the original Factors. Building Services \& Amenities had seven Features and Materials Quality had only one. These are shown in Table G-1.

Table G-1, Features Identified for Quality

\begin{tabular}{|c|c|c|c|}
\hline $\begin{array}{l}\text { Level } 2 \\
\text { Category }\end{array}$ & $\begin{array}{l}\text { Level } 3 \\
\text { Section }\end{array}$ & $\begin{array}{l}\text { Level } 4 \\
\text { Feature }\end{array}$ & Associated Factors \\
\hline \multirow[t]{12}{*}{ Quality } & \multirow[t]{4}{*}{ Building Quality } & Airtightness & - Airtightness \\
\hline & & Communal Areas & - Common Areas \\
\hline & & Safety & $\begin{array}{ll}\text { - } & \text { Electrical Safety } \\
\text { - } & \text { Injury Prevention } \\
\text { - } & \text { Safety in Building } \\
\text { - } & \text { Structural Safety }\end{array}$ \\
\hline & & Security & - Security \\
\hline & \multirow{7}{*}{$\begin{array}{l}\text { Building Services } \\
\text { and Amenities }\end{array}$} & Drainage & - Drainage \\
\hline & & $\begin{array}{l}\text { Emergency } \\
\text { Escape }\end{array}$ & $\begin{array}{l}\text { - Emergency Access/Utilities } \\
\text { - Fire Safety }\end{array}$ \\
\hline & & Lifts & - Lift \\
\hline & & Parking & - Parking \\
\hline & & $\begin{array}{l}\text { Rubbish \& } \\
\text { Recycling }\end{array}$ & $\begin{array}{l}\text { - Rubbish/Recycling } \\
\text { - Waste }\end{array}$ \\
\hline & & Water & - Water Supply/Quality \\
\hline & & Utilities & - Utilities \\
\hline & Materials Quality & Materials & $\begin{array}{l}\text { - Construction Materials } \\
\text { - Internal Furnishings }\end{array}$ \\
\hline
\end{tabular}

3. Aspect Identification

\section{Building Quality}

Building Quality initially had only four Features: Airtightness, Communal Areas, Safety and Security. Airtightness affects people through unwanted draughts and air movement. Some air movement is good for effective passive ventilation, so houses that are too airtight can be bad, however houses that are not airtight enough can mean uncomfortable and noticeable draughts are apparent to occupants. As a result, the level of Airtightness became the only Aspect for this Feature. 
As the Good Solutions Guide to Apartments states (North Shore City Council, 2007), there are many Aspects of Communal Areas that affect their quality. Also, there are many types of Communal Areas Access \& Entrance Ways, Garage \& Parking Areas, Lifts \& Stairs and External Storage Areas. Two of these areas (Access \& Entrance Ways and External Storage Areas) then became the Aspects with affects such as presentability, light, ventilation and protection from the weather things to consider. The other two areas are considered in Building Services \& Amenities.

Four Factors were initially grouped within Safety: Electrical Safety, Injury Prevention, Safety in the Building and Structural Safety

encompasses all three other Factors. Electrical Safety, Injury Prevention and Structural Safety all became Aspects to consider taken from Raw, Aizlewood \& Hamilton (2001).

\section{Security}

-being and comfort. The Good

Solutions Guide to Apartments (North Shore City Council, 2007) states that security should be considered in all Communal Areas. The following areas became Aspects: Access \& Entrance Ways and Garage \& Parking Areas. Often occupants found that Mailboxes and Postal Facilities and External Storage Areas were lacking in security. Often people who were not occupants could access these areas without authorisation, security cameras did not function (or were non-existent) or there may not be a secure place for large parcels to be delivered to (Auckland UniServices Ltd, 2004). These two areas also became Aspects under Security.

The Good Solutions Guide to Apartments (North Shore City Council, 2007) also highlighted two other Features that needed to be added within Building Quality Landscaping and Weathertightness. Landscaping looked at the quality of Building \& Site Boundaries and Communal Outdoor Areas. Only one Aspect was identified for Weathertightness whether there had been any Weathertightness issues or claims to the Weathertightness Homes Resolution Service [WHRS].

Table G-2, Aspects Identified for Building Quality

\begin{tabular}{|c|c|c|}
\hline $\begin{array}{l}\text { Level } 3 \\
\text { Section }\end{array}$ & $\begin{array}{l}\text { Level } 4 \\
\text { Feature } \\
\end{array}$ & $\begin{array}{l}\text { Level } 5 \\
\text { Aspect } \\
\end{array}$ \\
\hline \multirow{13}{*}{$\begin{array}{l}\text { Building } \\
\text { Quality }\end{array}$} & Airtightness & Draughts \\
\hline & \multirow[t]{2}{*}{ Communal Areas } & Access \& Entrance Ways \\
\hline & & Storage Areas \\
\hline & \multirow[t]{2}{*}{ Landscaping } & Building \& Site Boundaries \\
\hline & & Communal Outdoor Areas \\
\hline & \multirow[t]{3}{*}{ Safety } & Electrical Safety \\
\hline & & Injury Prevention \\
\hline & & Structural Safety \\
\hline & \multirow[t]{4}{*}{ Security } & Access \& Entrance Ways \\
\hline & & Garage \& Parking Areas \\
\hline & & Mailbox \& Postal Facilities \\
\hline & & Storage Areas \\
\hline & Weathertightness & $\begin{array}{l}\text { Weathertightness Issues and/or Claims to } \\
\text { Weathertightness Homes Resolution Service }\end{array}$ \\
\hline
\end{tabular}




\section{Building Services \& Amenities}

Building Services \& Amenities initially had seven Features: Drainage, Emergency Escape, Lifts, Parking, Rubbish \& Recycling, Water and Utilities. There are three things to consider within Drainage the adequate removal from site of black, grey and storm water these all became Aspects.

Within Emergency Escape, the literature showed that there were three things to consider relating to emergencies and safety within a building. The first looked at what Fire Safety Features a building may have (such as fire alarms, fire extinguishers, or smoke detectors). The second looked at the adequacy of emergency lighting \& signage, and the third looked at egress routes particularly how well maintained these are and how clear and free of debris they are.

Many apartment buildings within New Zealand have lifts as one of their amenities (particularly if they are over two or three storeys tall). The first Aspect identified for Lifts was whether or not they were actually provided Criscillo \& Tong (1999) state that many occupants feel that lift access is very important .Auckland UniServices (2004) stated that some occupants indicated a lack of lifts can cause significant problems especially when they break down, or are being maintained. Similarly service lifts are needed, particularly when there is a conflict of usage (i.e. when moving furniture) and passenger lifts can be damaged at these times. From these occupant surveys, three further Aspects were identified Secondary Access (either by means of stairs and/or service lifts), the Size of lifts (i.e. for moving furniture) and the quality of lifts (maintenance, cleanliness, lighting, air quality etc).

The fourth Feature of Building Services \& Amenities was Parking and much of the literature showed that apartment occupants want easy access to secure, off-street and safe parking. Consumer NZ (2003) warns prospective apartment buyers to check how secure and how accessible off-street parking (i.e. how far groceries need to be carried). Waghorn (2006) states that while a lack of car parking spaces is often raised as an issue, this should be balanced with urban planning objectives to encourage walking, cycling and use of public transport. Auckland UniServices found that the lack of car parking is often an issue (for both occupants and visitors) and that often car parking is expensive to rent. They also found there were also safety and security issues in car parking and garage areas stating that it was often not difficult for strangers to access car parking areas and that these areas was the most common area targeted by thieves (Auckland UniServices Ltd, 2004). From this, five Aspects were identified to be included in the hierarchy Provision of Occupant parking, Location, the Quality (i.e. security, safety, weather protection, and accessibility), the number of parks provided or Quantity and Visitor Parking.

Auckland UniServices (2004) found that there were three main issues concerning Rubbish \& Recycling in apartments. The first was the availability of recycling facilities the survey found that rubbish recycling systems for apartment buildings varied and occupants where there was a general lack of these facilities often expressed disappointment. However they found that where these facilities were provided there was often a variety of recycling available including combinations of paper, cardboard, tin and aluminium cans and/or glass (pg 17). The second issue that Auckland UniServices found concerned the accessibility of the Rubbish \& Recycling facilities for both occupants (i.e. wheelie bin and wheelchair access) and rubbish collection (i.e. rubbish collection vehicles may have difficulty in accessing these areas). The third main issue regarding Rubbish \& Recycling in apartments fund by Auckland UniServices was in relation to the general design of the 
facilities (Auckland UniServices Ltd, 2004). They stated that it was clear that these areas had often not received much thought in terms of design, convenience or how they could be kept clean. Often they were small, narrow spaces that had little ventilation or were not well kept (Auckland UniServices Ltd, 2004). A fourth, more minor issue highlighted by the survey concerned the frequency of removal of rubbish \& recycling. From these findings from Auckland UniServices, four Aspects were identified for the Rubbish \& Recycling Feature Provision of Rubbish \& Recycling Facilities, Location of Facilities, Quality of Facilities and Frequency of Removal.

a severe type of pneumonia. It is caused by the inhalation of the Legionella bacterium, which lives in aquatic environments (Raw, Aizlewood, \& Hamilton, 2001)

stored below $50^{\circ} \mathrm{C}$ and therefore hot water is required to be stored at $60^{\circ} \mathrm{C}$ by Acceptable Solution G12/AS1 for NZBC Clause G12 Water Supply (Department of Building \& Housing, 2009). Moore, Gould \& Keary state that the lack of a direct water source to the home is strongly associated with gastrointestinal pathogens. Also the lack of a direct source of water limits hand washing, cleaning food and utensils, bathing and washing laundry. Studies of louse-borne diseases and scabies show a high association of the presence of these diseases in households with limited access to water (Moore, Gould, \& Keary, 2003). In New Zealand there is lower likelihood of houses lacking a direct source of water, however this is a fundamental hygiene and health issue for all homes. Singh found that the following should be taken into consideration in relation to improving domestic water systems and improving health related problems in buildings the type of system, storage, showers, delivery temperatures, fuel efficiency control strategy, system monitoring, operational strategy and disease control (1996). Two Aspects for Water Supply \& Quality were identified Cold Water Quality \& Supply and Hot Water Supply \& Storage.

There are two main Utilities that should be provided to all homes to provide a safe, healthy and comfortable home. These are power (i.e. electricity and gas) and telephone services. Criscillo \& Tong found in their survey of apartment dwellers in Wellington wanted $95 \%$ of participants wanted electricity as the preferred form of energy and $80 \%$ also wanted gas generally for cooking purposes (Criscillo \& Tong, 1999). Two other utilities internet and television services are also usually available in New Zealand homes in some form. The main issue with utilities in New Zealand is that there is often little choice in providers of utilities. For example it is often quite common for apartment buildings to be pre-wired for Sky Television services, but not other pay per view television services such as Saturn. Similarly telephone services may be limited, and at times gas may not be available in a building. Three Aspects were identified for Utilities Gas, Internet \& Telephone and Television. Electricity was not included as an Aspect as it was expected that electricity should always be available to any habitable building.

\section{Building}

Services \& Amenities - Facilities. They found that 39\% of the participants thought including a gymnasium in an apartment building as important and $36 \%$ a swimming pool. $24 \%$ saw a café as a good amenity, but few (5\%) wanted a restaurant (Criscillo \& Tong, 1999). Auckland UniServices (2004) also found that communal spaces particularly outdoor social and activity spaces were seen as an important part of liveability especially when apartments were small in size. From this, three Aspects were identified to be included under Facilities Communal Outdoor Areas, Eateries (i.e. cafés) and Exercise \& Health Facilities 
Table G-3, Aspects Identified for Building Services \& Amenities

\begin{tabular}{|c|c|c|}
\hline $\begin{array}{l}\text { Level } 3 \\
\text { Section }\end{array}$ & $\begin{array}{l}\text { Level } 4 \\
\text { Feature }\end{array}$ & $\begin{array}{l}\text { Level } 5 \\
\text { Aspect }\end{array}$ \\
\hline \multirow{28}{*}{$\begin{array}{l}\text { Building } \\
\text { Services and } \\
\text { Amenities }\end{array}$} & \multirow[t]{3}{*}{ Drainage } & Black Water \\
\hline & & Grey Water \\
\hline & & Storm Water \\
\hline & \multirow[t]{3}{*}{ Emergency Escape } & Fire Safety Features \\
\hline & & Emergency Lighting \& Signage \\
\hline & & Egress Routes \\
\hline & \multirow[t]{3}{*}{ Facilities } & Communal Outdoor Areas \\
\hline & & Eateries \\
\hline & & Exercise/Health Facilities \\
\hline & \multirow[t]{4}{*}{ Lifts } & Provision of Lifts \\
\hline & & Quality \\
\hline & & Secondary Access \\
\hline & & Size \\
\hline & \multirow[t]{6}{*}{ Parking } & Provision of Occupant Parking \\
\hline & & Location of Occupant Parking \\
\hline & & Quality of Occupant Parking \\
\hline & & Quantity of Occupant Parking \\
\hline & & Size of Occupant Parking \\
\hline & & Provision of Visitor Parking \\
\hline & \multirow[t]{4}{*}{ Rubbish \& Recycling } & Provision of Rubbish \& Recycling Facilities \\
\hline & & Location \\
\hline & & Quality \\
\hline & & Frequency of Removal \\
\hline & \multirow{2}{*}{$\begin{array}{l}\text { Water Supply \& } \\
\text { Quality }\end{array}$} & Cold Water Supply \\
\hline & & Hot Water Supply \& Storage \\
\hline & \multirow[t]{3}{*}{ Utilities } & Gas \\
\hline & & Internet \& Telephone \\
\hline & & Television \\
\hline
\end{tabular}

\section{Materials Quality}

Initially there was only one Feature developed from the literature review for Materials Quality. However studies by Raw, Aizlewood \& Hamilton (2001) show that there are many issues with internal furnishings, building and construction materials. There are many health issues in relation to biocides, Volatile Organic Compounds [VOC's], particles and fibres, asbestos, lead and radon all depending on the type of material, emissions, deterioration and durability. Three Aspects were then identified to assess Materials Deterioration \& Durability, Emissions and Toxic Materials (Table G-4). 
Table G-4, Aspects Identified for Materials Quality

\begin{tabular}{|l|l|l|}
\hline Level $\mathbf{3}$ & Level 4 & Level $\mathbf{5}$ \\
Section & Feature & Aspect \\
\hline Materials & Deterioration \& & Deterioration \& Durability \\
\cline { 2 - 3 } Quality & Durability & Emissions \\
\cline { 3 - 3 } & & Toxic Materials \\
\hline
\end{tabular}

4. Indicator Identification

Each of the Aspects was then assigned an Indicator or Assessment Question. In this Category, some Aspects had only 1 Indicator, whereas others had two or more. The most was 7 for Security within Access \& Entrance Ways. Table G-5 outlines each of these for Quality.

Table G-5, Indicators Identified for Quality

\begin{tabular}{|c|c|c|c|}
\hline $\begin{array}{l}\text { Level } 3 \\
\text { Section }\end{array}$ & $\begin{array}{l}\text { Level } 4 \\
\text { Feature } \\
\end{array}$ & $\begin{array}{l}\text { Level } 5 \\
\text { Aspect } \\
\end{array}$ & $\begin{array}{l}\text { Level } 6 \\
\text { Indicator }\end{array}$ \\
\hline \multirow{14}{*}{$\begin{array}{l}\text { Building } \\
\text { Quality }\end{array}$} & Airtightness & Draughts & Is the apartment airtight? \\
\hline & \multirow[t]{4}{*}{ Communal Areas } & \multirow[t]{3}{*}{$\begin{array}{l}\text { Access \& Entrance } \\
\text { Ways }\end{array}$} & $\begin{array}{l}\text { Are these areas nice and } \\
\text { presentable? }\end{array}$ \\
\hline & & & $\begin{array}{l}\text { Are these areas well protected } \\
\text { from the weather? }\end{array}$ \\
\hline & & & $\begin{array}{l}\text { Are these areas well lit and } \\
\text { ventilated? }\end{array}$ \\
\hline & & Storage Areas & $\begin{array}{l}\text { Are these areas nice and } \\
\text { presentable? }\end{array}$ \\
\hline & \multirow[t]{5}{*}{ Landscaping } & \multirow[t]{2}{*}{$\begin{array}{l}\text { Building \& Site } \\
\text { Boundaries }\end{array}$} & $\begin{array}{l}\text { Are these areas nice and } \\
\text { presentable? }\end{array}$ \\
\hline & & & $\begin{array}{l}\text { Is there a clear separation } \\
\text { between the site and public } \\
\text { boundaries? }\end{array}$ \\
\hline & & \multirow[t]{3}{*}{$\begin{array}{l}\text { Communal Outdoor } \\
\text { Areas }\end{array}$} & $\begin{array}{l}\text { Are these areas nice and } \\
\text { presentable? }\end{array}$ \\
\hline & & & $\begin{array}{l}\text { Are these areas well protected } \\
\text { from the weather? }\end{array}$ \\
\hline & & & $\begin{array}{l}\text { Are these areas regularly } \\
\text { maintained? }\end{array}$ \\
\hline & \multirow[t]{4}{*}{ Safety } & Electrical Safety & Are all electrical fixtures safe? \\
\hline & & \multirow[t]{3}{*}{ Injury Prevention } & $\begin{array}{l}\text { Are there any slippery or unsafe } \\
\text { surfaces? }\end{array}$ \\
\hline & & & $\begin{array}{l}\text { Are there adequate handrails } \\
\text { where required? }\end{array}$ \\
\hline & & & $\begin{array}{l}\text { Are there any windows that } \\
\text { people could fall from? }\end{array}$ \\
\hline
\end{tabular}




\begin{tabular}{|c|c|c|c|}
\hline & & Structural Safety & \\
\hline & Security & $\begin{array}{l}\text { Access \& Entrance } \\
\text { Ways }\end{array}$ & $\begin{array}{l}\text { What type of access is there for } \\
\text { occupants? }\end{array}$ \\
\hline & & & $\begin{array}{l}\text { What type of access is there for } \\
\text { visitors? }\end{array}$ \\
\hline & & & Is there restricted floor access? \\
\hline & & & Are there security cameras? \\
\hline & & & $\begin{array}{l}\text { Is it individual or communal } \\
\text { access? }\end{array}$ \\
\hline & & & Is it horizontal or vertical access? \\
\hline & & & Is it residential only? \\
\hline & & & Are front doors facing each other? \\
\hline & & $\begin{array}{l}\text { Garage \& Parking } \\
\text { Areas }\end{array}$ & $\begin{array}{l}\text { What type of access is there for } \\
\text { occupants? }\end{array}$ \\
\hline & & & Are there security cameras? \\
\hline & & $\begin{array}{l}\text { Mailbox \& Postal } \\
\text { Facilities }\end{array}$ & $\begin{array}{l}\text { What type of access is there for } \\
\text { occupants? }\end{array}$ \\
\hline & & & $\begin{array}{l}\text { Is there secure storage for large } \\
\text { post? }\end{array}$ \\
\hline & & Storage Areas & $\begin{array}{l}\text { What type of access is there for } \\
\text { occupants? }\end{array}$ \\
\hline & & & Are there security cameras? \\
\hline & Weathertightness & $\begin{array}{l}\text { Weathertightness } \\
\text { Issues and/or Claims } \\
\text { to Weathertightness } \\
\text { Homes Resolution } \\
\text { Service }\end{array}$ & $\begin{array}{l}\text { Are there any WT issues or claims } \\
\text { that have been made to WHRS? }\end{array}$ \\
\hline $\begin{array}{l}\text { Building } \\
\text { Services and }\end{array}$ & Drainage & Black Water & $\begin{array}{l}\text { Is black water adequately } \\
\text { removed from site? }\end{array}$ \\
\hline Amenities & & Grey Water & $\begin{array}{l}\text { Is grey water adequately removed } \\
\text { from site? }\end{array}$ \\
\hline & & Storm Water & $\begin{array}{l}\text { Is storm water adequately } \\
\text { removed from site? }\end{array}$ \\
\hline & Emergency Escape & Apartment & Are there smoke detectors? \\
\hline & & & Are there sprinklers? \\
\hline & & & Is there an alarm? \\
\hline & & & Are there switches? \\
\hline & & & $\begin{array}{l}\text { Are there fire extinguishers and/or } \\
\text { fire hose reels? }\end{array}$ \\
\hline & & $\begin{array}{l}\text { Emergency Lighting } \\
\text { \& Signage }\end{array}$ & $\begin{array}{l}\text { Is there emergency lighting \& } \\
\text { signage that is clear and } \\
\text { prominent? }\end{array}$ \\
\hline & & Egress Routes & $\begin{array}{l}\text { Are the egress routes clear and } \\
\text { well maintained? }\end{array}$ \\
\hline
\end{tabular}




\begin{tabular}{|c|c|c|c|}
\hline & \multirow[t]{3}{*}{ Facilities } & $\begin{array}{l}\text { Communal Outdoor } \\
\text { Areas }\end{array}$ & $\begin{array}{l}\text { Are there communal outdoor } \\
\text { areas? }\end{array}$ \\
\hline & & Eateries & \\
\hline & & $\begin{array}{l}\text { Exercise/Health } \\
\text { Facilities }\end{array}$ & $\begin{array}{l}\text { Are there exercise/health } \\
\text { facilities? }\end{array}$ \\
\hline & \multirow[t]{4}{*}{ Lifts } & Provision of Lifts & Are there lifts provided? \\
\hline & & Quality & Are the good quality? \\
\hline & & Secondary Access & Is there secondary access? \\
\hline & & Size & Are they an adequate size? \\
\hline & \multirow[t]{9}{*}{ Parking } & $\begin{array}{l}\text { Provision of } \\
\text { Occupant Parking }\end{array}$ & Is parking available? \\
\hline & & $\begin{array}{l}\text { Location of Occupant } \\
\text { Parking }\end{array}$ & Where is it located? \\
\hline & & $\begin{array}{l}\text { Quality of Occupant } \\
\text { Parking }\end{array}$ & Is it good quality parking? \\
\hline & & $\begin{array}{l}\text { Quantity of } \\
\text { Occupant Parking }\end{array}$ & How many parks are provided? \\
\hline & & $\begin{array}{l}\text { Size of Occupant } \\
\text { Parking }\end{array}$ & How big are parks? \\
\hline & & \multirow{4}{*}{$\begin{array}{l}\text { Provision of Visitor } \\
\text { Parking }\end{array}$} & Is visitor parking provided? \\
\hline & & & How many parks are provided? \\
\hline & & & How big are parks? \\
\hline & & & Where is it located? \\
\hline & \multirow[t]{4}{*}{ Rubbish \& Recycling } & $\begin{array}{l}\text { Provision of Rubbish } \\
\& \text { Recycling Facilities }\end{array}$ & $\begin{array}{l}\text { Are rubbish and recycling facilities } \\
\text { provided? }\end{array}$ \\
\hline & & Location & Where are they located? \\
\hline & & Quality & Are these areas good quality? \\
\hline & & $\begin{array}{l}\text { Frequency of } \\
\text { Removal }\end{array}$ & $\begin{array}{l}\text { How often is rubbish and recycling } \\
\text { removed? }\end{array}$ \\
\hline & \multirow[t]{2}{*}{ Water } & Water Supply & $\begin{array}{l}\text { How is water supplied to the } \\
\text { building? }\end{array}$ \\
\hline & & $\begin{array}{l}\text { Hot Water Supply \& } \\
\text { Storage }\end{array}$ & $\begin{array}{l}\text { How is hot water supplied and } \\
\text { stored? }\end{array}$ \\
\hline & \multirow[t]{3}{*}{ Utilities } & Gas & $\begin{array}{l}\text { Is gas available with a choice of } \\
\text { providers? }\end{array}$ \\
\hline & & $\begin{array}{l}\text { Internet \& } \\
\text { Telephone }\end{array}$ & $\begin{array}{l}\text { Is internet and telephone } \\
\text { available with a choice of } \\
\text { providers? }\end{array}$ \\
\hline & & Television & $\begin{array}{l}\text { Is television available with a } \\
\text { choice of providers? }\end{array}$ \\
\hline \multirow{4}{*}{$\begin{array}{l}\text { Materials } \\
\text { Quality }\end{array}$} & \multirow{2}{*}{$\begin{array}{l}\text { Deterioration \& } \\
\text { Durability }\end{array}$} & Durability & How durable are materials? \\
\hline & & Deterioration & Are materials deteriorating? \\
\hline & Emissions & Emissions & Are there any emissions? \\
\hline & Toxic Materials & Asbestos & Is there any asbestos? \\
\hline
\end{tabular}




\begin{tabular}{|l|l|l|l|}
\hline & & Lead & Is there any lead? \\
\hline
\end{tabular}

\section{AM Identification \& Review}

\section{Building Quality}

Table G-6 outlines the Assessment Methods originally identified for Building Quality. Of the 31 Indicators five had Assessment Methods that required some form of Assessment or Analysis, ten required Yes or No Choices, six required Personal Perceptions and ten required Statements. This is

Twenty of the Assessment Methods were determined to be appropriate for use within NZ ALI because they were both practical and objective Assessment Methods. However six were determined to be in appropriate because they were impractical assessments due to wording and also subjective.

Table G-6 these were either changed to

due to a lack in skills and knowledge. These were all changed to Yes/No Choices as is shown in Table G-6

from a List, a Yes/No Choice or a Number (year).

Table G-6, Review of Assessment Methods Identified for Building Quality

\begin{tabular}{|c|c|c|c|c|}
\hline $\begin{array}{l}\text { Level } 4 \\
\text { Feature }\end{array}$ & $\begin{array}{l}\text { Level } 5 \\
\text { Aspect }\end{array}$ & $\begin{array}{l}\text { Level } 6 \\
\text { Indicator-Assessment } \\
\text { Question }\end{array}$ & $\begin{array}{l}\text { Assessment } \\
\text { Method } \\
\text { Version } 1 \\
\end{array}$ & $\begin{array}{l}\text { Modified } \\
\text { Assessment } \\
\text { Method }\end{array}$ \\
\hline Airtightness & Draughts & Is the apartment airtight? & $\begin{array}{l}\text { Assessment } \\
\text { (Airtightness) }\end{array}$ & Yes/No \\
\hline \multirow{4}{*}{$\begin{array}{l}\text { Communal } \\
\text { Areas }\end{array}$} & \multirow{3}{*}{$\begin{array}{l}\text { Access \& } \\
\text { Entrance } \\
\text { Ways }\end{array}$} & $\begin{array}{l}\text { Are these areas nice and } \\
\text { presentable? }\end{array}$ & $\begin{array}{l}\text { Personal } \\
\text { Perception } \\
\text { (Niceness \& } \\
\text { Presentability) }\end{array}$ & Scale \\
\hline & & $\begin{array}{l}\text { Are these areas well } \\
\text { protected from the weather? }\end{array}$ & $\begin{array}{l}\text { Personal } \\
\text { Perception } \\
\text { (Weather } \\
\text { Protection) } \\
\end{array}$ & Yes/No \\
\hline & & $\begin{array}{l}\text { Are these areas well lit and } \\
\text { ventilated? }\end{array}$ & $\begin{array}{l}\text { Assessment } \\
\text { (Light \& } \\
\text { Ventilation) }\end{array}$ & Yes/No \\
\hline & $\begin{array}{l}\text { Storage } \\
\text { Areas }\end{array}$ & $\begin{array}{l}\text { Are these areas nice and } \\
\text { presentable? }\end{array}$ & $\begin{array}{l}\text { Personal } \\
\text { Perception } \\
\text { (Niceness \& } \\
\text { Presentability) }\end{array}$ & Scale \\
\hline
\end{tabular}




\begin{tabular}{|c|c|c|c|c|}
\hline \multirow{5}{*}{ Landscaping } & \multirow{2}{*}{$\begin{array}{l}\text { Building \& } \\
\text { Site } \\
\text { Boundaries }\end{array}$} & $\begin{array}{l}\text { Are these areas nice and } \\
\text { presentable? }\end{array}$ & $\begin{array}{l}\text { Personal } \\
\text { Perception } \\
\text { (Niceness \& } \\
\text { Presentability) }\end{array}$ & Scale \\
\hline & & $\begin{array}{l}\text { Is there a clear separation } \\
\text { between the site and public } \\
\text { boundaries? }\end{array}$ & Choose Yes or No & Yes/No \\
\hline & \multirow{3}{*}{$\begin{array}{l}\text { Communal } \\
\text { Outdoor } \\
\text { Areas }\end{array}$} & $\begin{array}{l}\text { Are these areas nice and } \\
\text { presentable? }\end{array}$ & $\begin{array}{l}\text { Personal } \\
\text { Perception } \\
\text { (Niceness \& } \\
\text { Presentability) } \\
\end{array}$ & Scale \\
\hline & & $\begin{array}{l}\text { Are these areas well } \\
\text { protected from the weather? }\end{array}$ & $\begin{array}{l}\text { Personal } \\
\text { Perception } \\
\text { (Weather } \\
\text { Protection) } \\
\end{array}$ & Yes/No \\
\hline & & $\begin{array}{l}\text { Are these areas regularly } \\
\text { maintained? }\end{array}$ & Choose Yes or No & Yes/No \\
\hline \multirow{6}{*}{ Safety } & $\begin{array}{l}\text { Electrical } \\
\text { Safety }\end{array}$ & $\begin{array}{l}\text { Are all electrical fixtures } \\
\text { safe? }\end{array}$ & $\begin{array}{l}\text { Assessment } \\
\text { (Electrical Safety) }\end{array}$ & Yes/No \\
\hline & \multirow{3}{*}{$\begin{array}{l}\text { Injury } \\
\text { Prevention }\end{array}$} & $\begin{array}{l}\text { Are there any slippery or } \\
\text { unsafe surfaces? }\end{array}$ & Choose Yes or No & Yes/No \\
\hline & & $\begin{array}{l}\text { Are there adequate handrails } \\
\text { where required? }\end{array}$ & Choose Yes or No & Yes/No \\
\hline & & $\begin{array}{l}\text { Are there any windows that } \\
\text { people could fall from? }\end{array}$ & Choose Yes or No & Yes/No \\
\hline & \multirow[b]{2}{*}{$\begin{array}{l}\text { Structural } \\
\text { Safety }\end{array}$} & $\begin{array}{l}\text { What year was the building } \\
\text { constructed, OR when was it } \\
\text { last majorly refurbished? }\end{array}$ & Statement (Year) & Number \\
\hline & & $\begin{array}{l}\text { Are there any degradation, } \\
\text { deformation and/or } \\
\text { vibrations in the structure of } \\
\text { the building? (i.e. floor } \\
\text { vibrations, squeaking, sag, } \\
\text { unevenness or sloping) }\end{array}$ & $\begin{array}{l}\text { Assessment } \\
\text { (Structural) }\end{array}$ & Yes/No \\
\hline \multirow{6}{*}{ Security } & \multirow{6}{*}{$\begin{array}{l}\text { Access \& } \\
\text { Entrance } \\
\text { Ways }\end{array}$} & $\begin{array}{l}\text { What type of access is there } \\
\text { for occupants? }\end{array}$ & $\begin{array}{l}\text { Statement } \\
\text { (Access) }\end{array}$ & List \\
\hline & & $\begin{array}{l}\text { What type of access is there } \\
\text { for visitors? }\end{array}$ & $\begin{array}{l}\text { Statement } \\
\text { (Access) }\end{array}$ & List \\
\hline & & $\begin{array}{l}\text { Is there restricted floor } \\
\text { access? (i.e. } \\
\text { occupants/visitors can only } \\
\text { access their floor) }\end{array}$ & $\begin{array}{l}\text { Statement } \\
\text { (Access) }\end{array}$ & Yes/No \\
\hline & & Are there security cameras? & Choose Yes or No & Yes/No \\
\hline & & $\begin{array}{l}\text { Is it individual or communal } \\
\text { access? }\end{array}$ & $\begin{array}{l}\text { Statement } \\
\text { (Access) }\end{array}$ & List \\
\hline & & $\begin{array}{l}\text { Is it horizontal or vertical } \\
\text { access? }\end{array}$ & $\begin{array}{l}\text { Statement } \\
\text { (Access) }\end{array}$ & List \\
\hline
\end{tabular}




\begin{tabular}{|c|c|c|c|c|}
\hline & & Is it residential only? & $\begin{array}{l}\text { Statement } \\
\text { (Building Use) }\end{array}$ & Yes/No \\
\hline & & $\begin{array}{l}\text { Are front doors facing each } \\
\text { other? }\end{array}$ & Choose Yes or No & Yes/No \\
\hline & $\begin{array}{l}\text { Garage \& } \\
\text { Parking }\end{array}$ & $\begin{array}{l}\text { What type of access is there } \\
\text { for occupants? }\end{array}$ & $\begin{array}{l}\text { Statement } \\
\text { (Access) }\end{array}$ & List \\
\hline & Areas & Are there security cameras? & Choose Yes or No & Yes/No \\
\hline & Mailbox \& & $\begin{array}{l}\text { What type of access is there } \\
\text { for occupants? }\end{array}$ & $\begin{array}{l}\text { Statement } \\
\text { (Access) }\end{array}$ & List \\
\hline & Facilities & $\begin{array}{l}\text { Is there secure storage for } \\
\text { large post? }\end{array}$ & Choose Yes or No & Yes/No \\
\hline & Storage & $\begin{array}{l}\text { What type of access is there } \\
\text { for occupants? }\end{array}$ & $\begin{array}{l}\text { Statement } \\
\text { (Access) }\end{array}$ & List \\
\hline & & Are there security cameras? & Choose Yes or No & Yes/No \\
\hline $\begin{array}{l}\text { Weather- } \\
\text { tightness }\end{array}$ & $\begin{array}{l}\text { Weather- } \\
\text { tightness } \\
\text { Issues } \\
\text { and/or } \\
\text { Claims to } \\
\text { Weather- } \\
\text { tightness } \\
\text { Homes } \\
\text { Resolution } \\
\text { Service }\end{array}$ & $\begin{array}{l}\text { Are there any WT issues or } \\
\text { claims that have been made } \\
\text { to WHRS? }\end{array}$ & $\begin{array}{l}\text { Assessment } \\
\text { (Weather- } \\
\text { tightness) or } \\
\text { WHRS Claims } \\
\text { investigation }\end{array}$ & Yes/No \\
\hline
\end{tabular}

\section{Building Services \& Amenities}

Table G-7 outlines the Assessment Methods initially identified for Building Services \& Amenities. Of

a Yes or No Choice, three required a Personal Perception and either required a statement of some

Of the 35 Assessment Methods initially applied to Building Services \& Amenities only nine were deemed to be inappropriate for use within NZ ALI. Three of these were impractical due to possible issues with wordings and subjective because they required a Personal Perception from the user. These were Quality of Lifts, Quality of Occupant parking and Quality of Rubbish \& Recycling Facilities. These three assessments were modified to become Scales as shown in Table G-7 sessment

The other nine inappropriate Assessment Methods were considered impractical due to issues with skills and knowledge. These Indicators were:

- Black Water

- Grey Water

- Storm Water

- Size of Lifts

- Size of Occupant Car Parks 
- Size of Visitor Car Parks

The two Car Parking Assessment Methods were modified to Lists and the rest to Yes or No Choices.

Eight other Assessment Methods were also modified to that they would be user friendly and easier to understand/answer for users. Where statements were required they were generally changed to a List except in the case of Location of Rubbish \& Recycling Facilities which was changed into a Scale AM because of a variety of accessibility issues that need to be considered. Also an exception was for the number of car parks provided where the Statement AM was modified to a Number AM. These were:

- Location of Occupant Car Parks

- Quantity of Occupant Car Parking

- Location of Visitor Car Parks

- Quantity of Visitor Car Parking

- Location of Rubbish \& Recycling Facilities

- Frequency of Removal of Rubbish \& Recycling

- Cold Water Quality \& Supply

- Hot Water Supply \& Quality

Table G-7, Review of Assessment Methods Identified for Building Services and Amenities

\begin{tabular}{|c|c|c|c|c|}
\hline $\begin{array}{l}\text { Level } 4 \\
\text { Feature }\end{array}$ & $\begin{array}{l}\text { Level } 5 \\
\text { Aspect }\end{array}$ & $\begin{array}{l}\text { Level } 6 \\
\text { Indicator-Assessment } \\
\text { Question }\end{array}$ & $\begin{array}{l}\text { Assessment } \\
\text { Method } \\
\text { Version } 1 \\
\end{array}$ & $\begin{array}{l}\text { Modified } \\
\text { Assessment } \\
\text { Method }\end{array}$ \\
\hline \multirow{3}{*}{ Drainage } & Black Water & $\begin{array}{l}\text { Is black water adequately } \\
\text { removed from site? }\end{array}$ & $\begin{array}{l}\text { Assessment } \\
\text { (Drainage) }\end{array}$ & Yes/No \\
\hline & Grey Water & $\begin{array}{l}\text { Is grey water adequately } \\
\text { removed from site? }\end{array}$ & $\begin{array}{l}\text { Assessment } \\
\text { (Drainage) }\end{array}$ & Yes/No \\
\hline & Storm Water & $\begin{array}{l}\text { Is storm water adequately } \\
\text { removed from site? }\end{array}$ & $\begin{array}{l}\text { Assessment } \\
\text { (Drainage) }\end{array}$ & Yes/No \\
\hline \multirow{7}{*}{$\begin{array}{l}\text { Emergency } \\
\text { Escape }\end{array}$} & \multirow{5}{*}{$\begin{array}{l}\text { Fire Safety } \\
\text { Features }\end{array}$} & Are there smoke detectors? & Choose Yes or No & Yes/No \\
\hline & & Are there sprinklers? & Choose Yes or No & Yes/No \\
\hline & & Is there an alarm? & Choose Yes or No & Yes/No \\
\hline & & Are there switches? & Choose Yes or No & Yes/No \\
\hline & & $\begin{array}{l}\text { Are there fire extinguishers } \\
\text { and/or fire hose reels? }\end{array}$ & Choose Yes or No & Yes/No \\
\hline & $\begin{array}{l}\text { Emergency } \\
\text { Lighting \& } \\
\text { Signage }\end{array}$ & $\begin{array}{l}\text { Is there emergency lighting } \\
\& \text { signage that is clear and } \\
\text { prominent? }\end{array}$ & Choose Yes or No & Yes/No \\
\hline & Egress Routes & $\begin{array}{l}\text { Are the egress routes clear } \\
\text { and well maintained? }\end{array}$ & Choose Yes or No & Yes/No \\
\hline \multirow{2}{*}{ Facilities } & $\begin{array}{l}\text { Communal } \\
\text { Outdoor Areas } \\
\end{array}$ & $\begin{array}{l}\text { Are there communal } \\
\text { outdoor areas? }\end{array}$ & Choose Yes or No & Yes/No \\
\hline & Eateries & provided? & Choose Yes or No & Yes/No \\
\hline
\end{tabular}




\begin{tabular}{|c|c|c|c|c|}
\hline & $\begin{array}{l}\text { Exercise/Health } \\
\text { Facilities }\end{array}$ & $\begin{array}{l}\text { Are there exercise/health } \\
\text { facilities? }\end{array}$ & Choose Yes or No & Yes/No \\
\hline \multirow{4}{*}{ Lifts } & $\begin{array}{l}\text { Provision of } \\
\text { Lifts }\end{array}$ & Are there lifts provided? & Choose Yes or No & Yes/No \\
\hline & Quality & Are they good quality? & $\begin{array}{l}\text { Personal } \\
\text { Perception } \\
\text { (Quality) }\end{array}$ & Scale \\
\hline & $\begin{array}{l}\text { Secondary } \\
\text { Access }\end{array}$ & Is there secondary access? & Choose Yes or No & Yes/No \\
\hline & Size & Are they an adequate size? & $\begin{array}{l}\text { Measurement } \\
\text { (Lift Size) }\end{array}$ & Yes/No \\
\hline \multirow{9}{*}{ Parking } & $\begin{array}{l}\text { Provision of } \\
\text { Occupant } \\
\text { Parking }\end{array}$ & Is parking available? & Choose Yes or No & Yes/No \\
\hline & $\begin{array}{l}\text { Location of } \\
\text { Occupant } \\
\text { Parking }\end{array}$ & Where is it located? & $\begin{array}{l}\text { Statement } \\
\text { (Location) }\end{array}$ & List \\
\hline & $\begin{array}{l}\text { Quality of } \\
\text { Occupant } \\
\text { Parking }\end{array}$ & Is it good quality parking? & $\begin{array}{l}\text { Personal } \\
\text { Perception } \\
\text { (Quality) }\end{array}$ & Scale \\
\hline & $\begin{array}{l}\text { Quantity of } \\
\text { Occupant } \\
\text { Parking }\end{array}$ & $\begin{array}{l}\text { How many parks are } \\
\text { provided? }\end{array}$ & $\begin{array}{l}\text { Statement } \\
\text { (Number) }\end{array}$ & Number \\
\hline & $\begin{array}{l}\text { Size of } \\
\text { Occupant } \\
\text { Parking }\end{array}$ & How big are parks? & $\begin{array}{l}\text { Measurement } \\
\text { (Car Park Size) }\end{array}$ & List \\
\hline & \multirow{4}{*}{$\begin{array}{l}\text { Provision of } \\
\text { Visitor Parking }\end{array}$} & Is visitor parking provided? & Choose Yes or No & Yes/No \\
\hline & & $\begin{array}{l}\text { How many parks are } \\
\text { provided? }\end{array}$ & $\begin{array}{l}\text { Statement } \\
\text { (Number) }\end{array}$ & Number \\
\hline & & How big are parks? & $\begin{array}{l}\text { Measurement } \\
\text { (Car Park Size) }\end{array}$ & List \\
\hline & & Where is it located? & $\begin{array}{l}\text { Statement } \\
\text { (Location) }\end{array}$ & List \\
\hline \multirow{4}{*}{$\begin{array}{l}\text { Rubbish \& } \\
\text { Recycling }\end{array}$} & $\begin{array}{l}\text { Provision of } \\
\text { Rubbish \& } \\
\text { Recycling } \\
\text { Facilities }\end{array}$ & $\begin{array}{l}\text { Are rubbish and recycling } \\
\text { facilities provided? }\end{array}$ & Choose Yes or No & Yes/No \\
\hline & Location & Where are they located? & $\begin{array}{l}\text { Statement } \\
\text { (Location) }\end{array}$ & Scale \\
\hline & Quality & $\begin{array}{l}\text { Are these areas good } \\
\text { quality? }\end{array}$ & $\begin{array}{l}\text { Personal } \\
\text { Perception } \\
\text { (Quality) }\end{array}$ & Scale \\
\hline & $\begin{array}{l}\text { Frequency of } \\
\text { Removal }\end{array}$ & $\begin{array}{l}\text { How often is rubbish and } \\
\text { recycling removed? }\end{array}$ & $\begin{array}{l}\text { Statement } \\
\text { (Frequency) }\end{array}$ & List \\
\hline Water & Water Supply & $\begin{array}{l}\text { How is water supplied to the } \\
\text { building? }\end{array}$ & $\begin{array}{l}\text { Statement (Cold } \\
\text { Water) }\end{array}$ & List \\
\hline
\end{tabular}




\begin{tabular}{|l|l|l|l|l|}
\hline & $\begin{array}{l}\text { Hot Water } \\
\text { Supply \& } \\
\text { Storage }\end{array}$ & $\begin{array}{l}\text { How is hot water supplied } \\
\text { and stored? }\end{array}$ & $\begin{array}{l}\text { Statement (Hot } \\
\text { Water) }\end{array}$ & List \\
\hline \multirow{4}{*}{ Utilities } & Gas & $\begin{array}{l}\text { Is gas available with a choice } \\
\text { of providers? }\end{array}$ & Choose Yes or No & Yes/No \\
\cline { 2 - 5 } & $\begin{array}{l}\text { Internet \& } \\
\text { Telephone }\end{array}$ & $\begin{array}{l}\text { Is internet and telephone } \\
\text { available with a choice of } \\
\text { providers? }\end{array}$ & Choose Yes or No & Yes/No \\
\cline { 2 - 5 } & Television & $\begin{array}{l}\text { Is television available with a } \\
\text { choice of providers? }\end{array}$ & Choose Yes or No & Yes/No \\
\hline
\end{tabular}

\section{Materials Quality}

Table G-8 outlines the Assessment Methods identified for Materials Quality identified required some form of Assessment of the materials used in the construction, design and All of the Assessment Methods initially identified for Materials Quality were identified as being impractical assessments as the relied on understanding of materials and issues concerning durability, emissions and toxics. End-users would most probably lack the knowledge to undertake an accurate assessment of materials and the affect on liveability. The first AM identified for Materials Quality was for Durability. The assessment initially required as an AM for Durability was modified to a Scale as shown in Table G-8

Deterioration and Emissions were modified to become Yes/No choices.

$$
\text { ors within Toxic Materials (Lead and Asbestos) were modified to }
$$
determine the possibility of there being these toxic materials within a building. The modified AM became a number in the form of the year the building was constructed.

Table G-8, Review of Assessment Methods Identified for Materials Quality

\begin{tabular}{|l|l|l|l|l|}
\hline $\begin{array}{l}\text { Level } \mathbf{4} \\
\text { Feature }\end{array}$ & $\begin{array}{l}\text { Level 5 } \\
\text { Aspect }\end{array}$ & $\begin{array}{l}\text { Level 6 } \\
\text { Indicator -Assessment } \\
\text { Question }\end{array}$ & $\begin{array}{l}\text { Assessment } \\
\text { Method } \\
\text { Version 1 }\end{array}$ & $\begin{array}{l}\text { Modified } \\
\text { Assessment } \\
\text { Method }\end{array}$ \\
\hline $\begin{array}{l}\text { Deterioration } \\
\text { \& Durability }\end{array}$ & Durability & How durable are materials? & $\begin{array}{l}\text { Assessment } \\
\text { (Durability) }\end{array}$ & Scale \\
\cline { 2 - 5 } & Deterioration & Are materials deteriorating? & $\begin{array}{l}\text { Assessment } \\
\text { (Deterioration) }\end{array}$ & Yes/No \\
\hline Emissions & Emissions & Are there any emissions? & $\begin{array}{l}\text { Assessment } \\
\text { (Emissions) }\end{array}$ & Yes/No \\
\hline \multirow{2}{*}{$\begin{array}{l}\text { Toxic } \\
\text { Materials }\end{array}$} & Asbestos & Is there any asbestos? & $\begin{array}{l}\text { Assessment } \\
\text { (Asbestos) }\end{array}$ & Number \\
\cline { 2 - 5 } & Lead & Is there any lead? & $\begin{array}{l}\text { Assessment } \\
\text { (Lead) }\end{array}$ & Number \\
\hline
\end{tabular}


6. Credit Establishment

\section{Building Quality}

Table G-9 outlines the possible answers and awarding of credits for Building Quality. Seven

6 Indicator

Table G-9, Acceptability \& Awarding of Credits Identified for Building Quality

\begin{tabular}{|c|c|c|c|}
\hline $\begin{array}{l}\text { Level } 4 \\
\text { Feature }\end{array}$ & $\begin{array}{l}\text { Level } 5 \\
\text { Aspect }\end{array}$ & $\begin{array}{l}\text { Level } 6 \\
\text { Indicator - Modified } \\
\text { Assessment Question }\end{array}$ & Acceptability \& Awarding of Credits \\
\hline Airtightness & Draughts & $\begin{array}{l}\text { Are there any noticeable } \\
\text { draughts in the apartment? }\end{array}$ & Yes/No Version 2 \\
\hline \multirow{4}{*}{$\begin{array}{l}\text { Communal } \\
\text { Areas }\end{array}$} & \multirow{3}{*}{$\begin{array}{l}\text { Access \& } \\
\text { Entrance } \\
\text { Ways }\end{array}$} & $\begin{array}{l}\text { On a scale of } 1-10 \text {, how nice } \\
\text { and presentable are these } \\
\text { areas? }\end{array}$ & 110 Scale \\
\hline & & $\begin{array}{l}\text { Are these areas well } \\
\text { protected from the } \\
\text { weather? }\end{array}$ & Yes/No Version 1 \\
\hline & & $\begin{array}{l}\text { Are these areas well lit and } \\
\text { ventilated? }\end{array}$ & Yes/No Version 1 \\
\hline & $\begin{array}{l}\text { Storage } \\
\text { Areas }\end{array}$ & $\begin{array}{l}\text { On a scale of } 1-10 \text {, how nice } \\
\text { and presentable are these } \\
\text { areas? }\end{array}$ & 110 Scale \\
\hline \multirow{5}{*}{ Landscaping } & \multirow{2}{*}{$\begin{array}{l}\text { Building \& } \\
\text { Site } \\
\text { Boundaries }\end{array}$} & $\begin{array}{l}\text { On a scale of } 1-10 \text {, how nice } \\
\text { and presentable are these } \\
\text { areas? }\end{array}$ & 110 Scale \\
\hline & & $\begin{array}{l}\text { Is there a clear separation } \\
\text { between the site and public } \\
\text { boundaries? }\end{array}$ & Yes/No Version 1 \\
\hline & \multirow{3}{*}{$\begin{array}{l}\text { Communal } \\
\text { Outdoor } \\
\text { Areas }\end{array}$} & $\begin{array}{l}\text { On a scale of } 1-10 \text {, how nice } \\
\text { and presentable are these } \\
\text { areas? }\end{array}$ & 110 Scale \\
\hline & & $\begin{array}{l}\text { Are these areas well } \\
\text { protected from the } \\
\text { weather? }\end{array}$ & Yes/No Version 1 \\
\hline & & $\begin{array}{l}\text { Are these areas regularly } \\
\text { maintained? }\end{array}$ & Yes/No Version 1 \\
\hline \multirow{4}{*}{ Safety } & $\begin{array}{l}\text { Electrical } \\
\text { Safety }\end{array}$ & $\begin{array}{l}\text { Are all electrical fixtures in } \\
\text { good repair and safe? }\end{array}$ & Yes/No Version 1 \\
\hline & \multirow{3}{*}{$\begin{array}{l}\text { Injury } \\
\text { Prevention }\end{array}$} & $\begin{array}{l}\text { Are there any slippery or } \\
\text { unsafe surfaces? }\end{array}$ & Yes/No Version 2 \\
\hline & & $\begin{array}{l}\text { Are there adequate } \\
\text { handrails where required? }\end{array}$ & Yes/No Version 1 \\
\hline & & $\begin{array}{l}\text { Are there any windows that } \\
\text { people could fall from? }\end{array}$ & Yes/No Version 2 \\
\hline
\end{tabular}




\begin{tabular}{|c|c|c|c|c|}
\hline & \multirow[b]{2}{*}{$\begin{array}{l}\text { Structural } \\
\text { Safety }\end{array}$} & $\begin{array}{l}\text { What year was the building } \\
\text { constructed, OR when was it } \\
\text { last majorly refurbished? }\end{array}$ & $\begin{array}{l}\text { If building is: } \\
\text { Less than } 50 \text { years old } \\
\text { More than } 50 \text { years old }\end{array}$ & $\begin{array}{l}100 \% \\
0 \%\end{array}$ \\
\hline & & $\begin{array}{l}\text { Do you notice any } \\
\text { degradation, deformation } \\
\text { and/or vibrations in the } \\
\text { structure of the building? } \\
\text { (i.e. floor vibrations, } \\
\text { squeaking, sag, unevenness } \\
\text { or sloping) }\end{array}$ & Yes/No Version 2 & \\
\hline \multirow{13}{*}{ Security } & \multirow{8}{*}{$\begin{array}{l}\text { Access \& } \\
\text { Entrance } \\
\text { Ways }\end{array}$} & $\begin{array}{l}\text { What type of access is there } \\
\text { for occupants? }\end{array}$ & $\begin{array}{l}\text { Swipe Card/Tag } \\
\text { PIN/Code } \\
\text { Key Only } \\
\text { None }\end{array}$ & $\begin{array}{l}100 \% \\
75 \% \\
50 \% \\
0 \% \\
\end{array}$ \\
\hline & & $\begin{array}{l}\text { What type of access is there } \\
\text { for visitors? }\end{array}$ & $\begin{array}{l}\text { Intercom/Buzzer } \\
\text { None }\end{array}$ & $\begin{array}{l}100 \% \\
0 \% \\
\end{array}$ \\
\hline & & $\begin{array}{l}\text { Is there restricted floor } \\
\text { access? (i.e. } \\
\text { occupants/visitors can only } \\
\text { access their floor) }\end{array}$ & Yes/No Version 1 & \\
\hline & & Are there security cameras? & Yes/No Version 1 & \\
\hline & & $\begin{array}{l}\text { Is it individual or communal } \\
\text { access? }\end{array}$ & $\begin{array}{l}\text { Individual (enter apartment } \\
\text { from private entry) } \\
\text { Communal (enter apartment } \\
\text { from common circulation } \\
\text { route) }\end{array}$ & $50 \%$ \\
\hline & & $\begin{array}{l}\text { Is it horizontal or vertical } \\
\text { access? }\end{array}$ & $\begin{array}{l}\text { Horizontal (enter apartment } \\
\text { from corridor) } \\
\text { Vertical (enter apartment } \\
\text { from vertical core of building } \\
\text { i.e. stairs or lift) }\end{array}$ & $50 \%$ \\
\hline & & Is it residential only? & Yes/No Version 1 & \\
\hline & & $\begin{array}{l}\text { Are front doors facing each } \\
\text { other? }\end{array}$ & $\begin{array}{l}\text { Yes/No Version } 1 \\
\text { and } N / A=100 \%\end{array}$ & \\
\hline & \multirow[t]{2}{*}{$\begin{array}{l}\text { Garage \& } \\
\text { Parking } \\
\text { Areas }\end{array}$} & $\begin{array}{l}\text { What type of access is there } \\
\text { for occupants? }\end{array}$ & $\begin{array}{l}\text { Electronic Opener } \\
\text { Keypad with PIN/Code } \\
\text { None }\end{array}$ & $\begin{array}{l}100 \% \\
50 \% \\
0 \%\end{array}$ \\
\hline & & Are there security cameras? & Yes/No Version 1 & \\
\hline & \multirow{2}{*}{$\begin{array}{l}\text { Mailbox \& } \\
\text { Postal } \\
\text { Facilities }\end{array}$} & $\begin{array}{l}\text { What type of access is there } \\
\text { for occupants? }\end{array}$ & $\begin{array}{l}\text { Keypad with PIN/Code } \\
\text { Key Only } \\
\text { None }\end{array}$ & $\begin{array}{l}100 \% \\
50 \% \\
0 \% \\
\end{array}$ \\
\hline & & $\begin{array}{l}\text { Is there secure storage for } \\
\text { large post? }\end{array}$ & Yes/No Version 1 & \\
\hline & Storage & What type of access is there & Keypad with PIN/Code & $100 \%$ \\
\hline
\end{tabular}




\begin{tabular}{|l|l|l|l|}
\hline & Areas & for occupants? & $\begin{array}{l}\text { Key Only } \\
\text { None }\end{array}$ \\
\cline { 3 - 4 } & & Are there security cameras? & Yes/No Version 1 \\
\hline \multirow{2}{*}{$\begin{array}{l}\text { Weather- } \\
\text { tightness }\end{array}$} & $\begin{array}{l}\text { WT Issues } \\
\text { and/or } \\
\text { Claims to } \\
\text { WHRS }\end{array}$ & $\begin{array}{l}\text { Are there any WT issues or } \\
\text { claims that have been made } \\
\text { to WHRS? }\end{array}$ & Yes/No Version 2 \\
\hline
\end{tabular}

\section{Building Services \& Amenities}

Table G-10 shows the possible answers and credits awarded for Building Services \& Amenities. Lists were developed from minimum recommendations and guidelines on apartment design. Many of the Assessment Questions needed to be modified to ensure that they were asking for the correct information and could be applied to NZ ALI.

Table G-10, Acceptability \& Awarding of Credits Identified for Building Services \& Amenities

\begin{tabular}{|c|c|c|c|}
\hline $\begin{array}{l}\text { Level } 4 \\
\text { Feature }\end{array}$ & $\begin{array}{l}\text { Level } 5 \\
\text { Aspect }\end{array}$ & $\begin{array}{l}\text { Level } 6 \\
\text { Indicator - Modified } \\
\text { Assessment Question }\end{array}$ & Acceptability \& Awarding of Credits \\
\hline \multirow{3}{*}{ Drainage } & Black Water & $\begin{array}{l}\text { Is black water adequately } \\
\text { drained offsite? }\end{array}$ & Yes/No Version 1 \\
\hline & Grey Water & $\begin{array}{l}\text { Is grey water adequately } \\
\text { drained offsite? }\end{array}$ & Yes/No Version 1 \\
\hline & Storm Water & $\begin{array}{l}\text { Is storm water adequately } \\
\text { drained offsite? }\end{array}$ & Yes/No Version 1 \\
\hline \multirow{7}{*}{$\begin{array}{l}\text { Emergency } \\
\text { Escape }\end{array}$} & \multirow{5}{*}{$\begin{array}{l}\text { Fire Safety } \\
\text { Features }\end{array}$} & Are there smoke detectors? & Yes/No Version 1 \\
\hline & & Are there sprinklers? & Yes/No Version 1 \\
\hline & & Is there an alarm? & Yes/No Version 1 \\
\hline & & $\begin{array}{l}\text { Are there emergency fire } \\
\text { switches? }\end{array}$ & Yes/No Version 1 \\
\hline & & $\begin{array}{l}\text { Are there fire extinguishers, } \\
\text { and/or fire hose reels? }\end{array}$ & Yes/No Version 1 \\
\hline & $\begin{array}{l}\text { Emergency } \\
\text { Lighting \& } \\
\text { Signage }\end{array}$ & $\begin{array}{l}\text { Is there emergency lighting } \\
\& \text { signage that is clear and } \\
\text { prominent? }\end{array}$ & Yes/No Version 1 \\
\hline & Egress Routes & $\begin{array}{l}\text { Are egress routes clear and } \\
\text { well maintained? }\end{array}$ & Yes/No Version 1 \\
\hline \multirow{3}{*}{ Facilities } & $\begin{array}{l}\text { Communal } \\
\text { Outdoor Areas }\end{array}$ & $\begin{array}{l}\text { Do you have communal } \\
\text { outdoor areas? }\end{array}$ & Yes/No Version 1 \\
\hline & Eateries & $\begin{array}{l}\text { Are there eateries in the } \\
\text { building? (i.e. cafes or } \\
\text { restaurants) }\end{array}$ & Yes/No Version 1 \\
\hline & $\begin{array}{l}\text { Exercise/Health } \\
\text { Facilities }\end{array}$ & $\begin{array}{l}\text { Are there exercise facilities? } \\
\text { (i.e. gym, pool, sauna etc) }\end{array}$ & Yes/No Version 1 \\
\hline
\end{tabular}




\begin{tabular}{|c|c|c|c|c|}
\hline \multirow{4}{*}{ Lifts } & $\begin{array}{l}\text { Provision of } \\
\text { Lifts }\end{array}$ & Are lifts provided? & \multicolumn{2}{|l|}{ Yes/No Version 1} \\
\hline & Quality & $\begin{array}{l}\text { On a scale of } 1-10 \text {, are the } \\
\text { lifts in good condition? }\end{array}$ & \multicolumn{2}{|l|}{110 Scale } \\
\hline & $\begin{array}{l}\text { Secondary } \\
\text { Access }\end{array}$ & $\begin{array}{l}\text { Is there secondary access? } \\
\text { (i.e. if lift breaks down is } \\
\text { there other lifts, stairs, } \\
\text { maintenance elevator) }\end{array}$ & \multicolumn{2}{|l|}{ Yes/No Version 1} \\
\hline & Size & $\begin{array}{l}\text { Are the lifts a good size? (i.e. } \\
\text { can you easily move } \\
\text { furniture in them) }\end{array}$ & \multicolumn{2}{|l|}{ Yes/No Version 1} \\
\hline \multirow{18}{*}{ Parking } & $\begin{array}{l}\text { Provision of } \\
\text { Occupant } \\
\text { Parking }\end{array}$ & Is parking available to you? & \multicolumn{2}{|l|}{ Yes/No Version 1} \\
\hline & \multirow{3}{*}{$\begin{array}{l}\text { Location of } \\
\text { Occupant } \\
\text { Parking }\end{array}$} & \multirow{3}{*}{$\begin{array}{l}\text { Where is the parking } \\
\text { located? }\end{array}$} & $\begin{array}{l}\text { On-grade (i.e. uncovered, } \\
\text { open parking) }\end{array}$ & $0 \%$ \\
\hline & & & $\begin{array}{l}\text { Underground } \\
\text { Within Building (within } \\
\text { apartment building) }\end{array}$ & $\begin{array}{l}100 \% \\
75 \%\end{array}$ \\
\hline & & & $\begin{array}{l}\text { Within Building (within a } \\
\text { secondary }\end{array}$ & $50 \%$ \\
\hline & $\begin{array}{l}\text { Quality of } \\
\text { Occupant } \\
\text { Parking }\end{array}$ & $\begin{array}{l}\text { On a scale of } 1-10 \text {, how } \\
\text { good is the parking } \\
\text { provided? }\end{array}$ & \multicolumn{2}{|l|}{110 Scale } \\
\hline & \multirow{3}{*}{$\begin{array}{l}\text { Quantity of } \\
\text { Occupant } \\
\text { Parking }\end{array}$} & \multirow{3}{*}{ How many parks do you get? } & $>1$ & $100 \%$ \\
\hline & & & 1 & $50 \%$ \\
\hline & & & $<1$ & $0 \%$ \\
\hline & \multirow{3}{*}{$\begin{array}{l}\text { Size of } \\
\text { Occupant } \\
\text { Parking }\end{array}$} & \multirow{3}{*}{$\begin{array}{l}\text { What size car parks are } \\
\text { available to you? }\end{array}$} & $\begin{array}{l}\text { Large Car (i.e. 4WD, People } \\
\text { Mover, SUV, Truck) }\end{array}$ & $75 \%$ \\
\hline & & & $\begin{array}{l}\text { Medium Car (i.e. Station } \\
\text { Wagon, Sedan) }\end{array}$ & $100 \%$ \\
\hline & & & $\begin{array}{l}\text { Small Car (i.e. Hatchback, } \\
\text { Coupe, } 2 \text { Door) }\end{array}$ & $50 \%$ \\
\hline & \multirow{7}{*}{$\begin{array}{l}\text { Provision of } \\
\text { Visitor Parking }\end{array}$} & $\begin{array}{l}\text { Is parking available to for } \\
\text { visitors? }\end{array}$ & \multicolumn{2}{|l|}{ Yes/No Version 1} \\
\hline & & \multirow{5}{*}{$\begin{array}{l}\text { How many parks are } \\
\text { available? }\end{array}$} & $>10$ & $100 \%$ \\
\hline & & & $>7$ & $75 \%$ \\
\hline & & & $>5$ & $50 \%$ \\
\hline & & & $>2$ & $25 \%$ \\
\hline & & & $<2$ & $0 \%$ \\
\hline & & How big are parks? & $\begin{array}{l}\text { Large Car (i.e. 4WD, People } \\
\text { Mover, SUV, Truck) }\end{array}$ & $75 \%$ \\
\hline
\end{tabular}




\begin{tabular}{|c|c|c|c|c|}
\hline & & & $\begin{array}{l}\text { Medium Car (i.e. Station } \\
\text { Wagon, Sedan) } \\
\text { Small Car (i.e. Hatchback, } \\
\text { Coupe, } 2 \text { Door) }\end{array}$ & $50 \%$ \\
\hline & & \multirow{4}{*}{$\begin{array}{l}\text { Where is the parking } \\
\text { located? }\end{array}$} & $\begin{array}{l}\text { On-grade (i.e. uncovered, } \\
\text { open parking) }\end{array}$ & \\
\hline & & & Underground & $100 \%$ \\
\hline & & & $\begin{array}{l}\text { Within Building (within } \\
\text { apartment building) }\end{array}$ & $75 \%$ \\
\hline & & & $\begin{array}{l}\text { Within Building (within a } \\
\text { secondary }\end{array}$ & $50 \%$ \\
\hline \multirow{8}{*}{$\begin{array}{l}\text { Rubbish \& } \\
\text { Recycling }\end{array}$} & $\begin{array}{l}\text { Provision of } \\
\text { Rubbish \& } \\
\text { Recycling } \\
\text { Facilities }\end{array}$ & $\begin{array}{l}\text { Are rubbish and/or recycling } \\
\text { facilities provided? }\end{array}$ & Yes/No Version 1 & \\
\hline & Location & $\begin{array}{l}\text { On a scale of } 1-10 \text {, how } \\
\text { accessible are these } \\
\text { facilities? }\end{array}$ & 110 Scale & \\
\hline & Quality & $\begin{array}{l}\text { On a scale of } 1-10 \text {, how } \\
\text { good are these facilities? }\end{array}$ & 110 Scale & \\
\hline & \multirow{5}{*}{$\begin{array}{l}\text { Frequency of } \\
\text { Removal }\end{array}$} & \multirow{5}{*}{$\begin{array}{l}\text { How often is rubbish and } \\
\text { recycling removed? }\end{array}$} & Once a day & $100 \%$ \\
\hline & & & Once a week & $90 \%$ \\
\hline & & & Once a fortnight & $75 \%$ \\
\hline & & & Once a month & $50 \%$ \\
\hline & & & Whenever required & $50 \%$ \\
\hline \multirow{5}{*}{ Water } & \multirow{2}{*}{ Water Supply } & \multirow{2}{*}{$\begin{array}{l}\text { How is cold water supplied } \\
\text { to the building? }\end{array}$} & Mains & $100 \%$ \\
\hline & & & Rainwater Collection & $80 \%$ \\
\hline & \multirow{3}{*}{$\begin{array}{l}\text { Hot Water } \\
\text { Supply \& } \\
\text { Storage }\end{array}$} & \multirow{3}{*}{$\begin{array}{l}\text { How is hot water supplied } \\
\text { and stored in the building? }\end{array}$} & Electric & $80 \%$ \\
\hline & & & Gas & $100 \%$ \\
\hline & & & Instant & $100 \%$ \\
\hline \multirow{3}{*}{ Utilities } & Gas & $\begin{array}{l}\text { Is gas available with a choice } \\
\text { of providers? }\end{array}$ & Yes/No Version 1 & \\
\hline & $\begin{array}{l}\text { Internet \& } \\
\text { Telephone }\end{array}$ & $\begin{array}{l}\text { Are the internet and } \\
\text { telephone available with a } \\
\text { choice of providers? }\end{array}$ & \multicolumn{2}{|l|}{ Yes/No Version 1} \\
\hline & Television & $\begin{array}{l}\text { Is television available with a } \\
\text { choice of providers? }\end{array}$ & \multicolumn{2}{|l|}{ Yes/No Version 1} \\
\hline
\end{tabular}




\section{Materials Quality}

Table G-11 outlines how possible answers for awarding of credits for the assessment of Indicators within Materials Quality. The answer acceptability for Asbestos and Lead was based on when the use each of these materials was banned in New Zealand. Blue and brown asbestos (raw amphibole) was banned in 1984 and white asbestos (chrysotile) was banned in 2002 (Smartt, 2004). The use of white Lead was banned in 1979 although some red lead may still be in use today (BRANZ Ltd, N.D.) All Assessment Questions for Materials Quality were also modified (as shown in Table G-11, blue text) to be applicable for NZ ALI.

Table G-11, Acceptability \& Awarding of Credits Identified for Materials Quality

\begin{tabular}{|l|l|l|l|l|}
\hline $\begin{array}{l}\text { Level 4 } \\
\text { Feature }\end{array}$ & $\begin{array}{l}\text { Level 5 } \\
\text { Aspect }\end{array}$ & $\begin{array}{l}\text { Level 6 } \\
\text { Indicator - Modified } \\
\text { Assessment Question }\end{array}$ & Acceptability \& Awarding of Credits \\
\hline $\begin{array}{l}\text { Deterioration } \\
\text { \& Durability }\end{array}$ & Durability & $\begin{array}{l}\text { On a scale of } 1 \text { - 10, how } \\
\text { durable do the materials } \\
\text { seem? }\end{array}$ & $1 \quad 10$ Scale \\
\cline { 2 - 5 } & Deterioration & $\begin{array}{l}\text { Do you notice any signs of } \\
\text { materials deteriorating? }\end{array}$ & Yes/No Version 2 \\
\hline \multirow{2}{*}{ Emissions } & Emissions & $\begin{array}{l}\text { Do you notice any emissions } \\
\text { from materials? }\end{array}$ & Yes/No Version 2 \\
\hline \multirow{2}{*}{$\begin{array}{l}\text { Toxic } \\
\text { Materials }\end{array}$} & Asbestos & $\begin{array}{l}\text { What year was the building } \\
\text { constructed, OR when was } \\
\text { the last major } \\
\text { refurbishment? }\end{array}$ & $\begin{array}{l}\text { If the building was built: } \\
>2007 \\
>1984\end{array}$ \\
\cline { 2 - 5 } & Lead & $\begin{array}{l}\text { What year was the building } \\
\text { constructed, OR when was } \\
\text { the last major } \\
\text { refurbishment? }\end{array}$ & $\begin{array}{l}\text { If the building was built: } \\
>1979 \\
<1984\end{array}$ \\
\hline
\end{tabular}




\section{G.2 QUALITY CALIBRATION}

The information discussed here provides information on the Calibration of the Quality Components. The data analysed and used to develop weightings for this Category is from the NZ ALI Questionnaire. The Calibration process follows that discussed in Section 4.3 and The NZ ALI Questionnaire.

\section{G.2.1 NZ ALI QUESTIONNAIRE RESULTS \& ANALYSIS}

\section{Aspects}

Building Quality: Figure G-2and Figure G-3 shows the percentage of nominations that each of the Aspects within Building Quality received. No nominations were given for Storage Areas within Security.

Building Services \& Amenities: Figure G-4 and Figure G-5 shows the percentage of nominations that each of the Aspects within Building Services \& Amenities received. Lighting \& Signage received no nominations within Emergency Escape.

Materials Quality: Figure G-6 shows the percentage of nominations that each of the Aspects within Materials Quality received.

\section{Features}

Figure G-7 shows the weightings determined for the Quality Features which were determined from Equation 4-1.

\section{Sections}

Figure G-8 shows the weightings determined for the Quality Sections which were determined from Equation 4-1. 


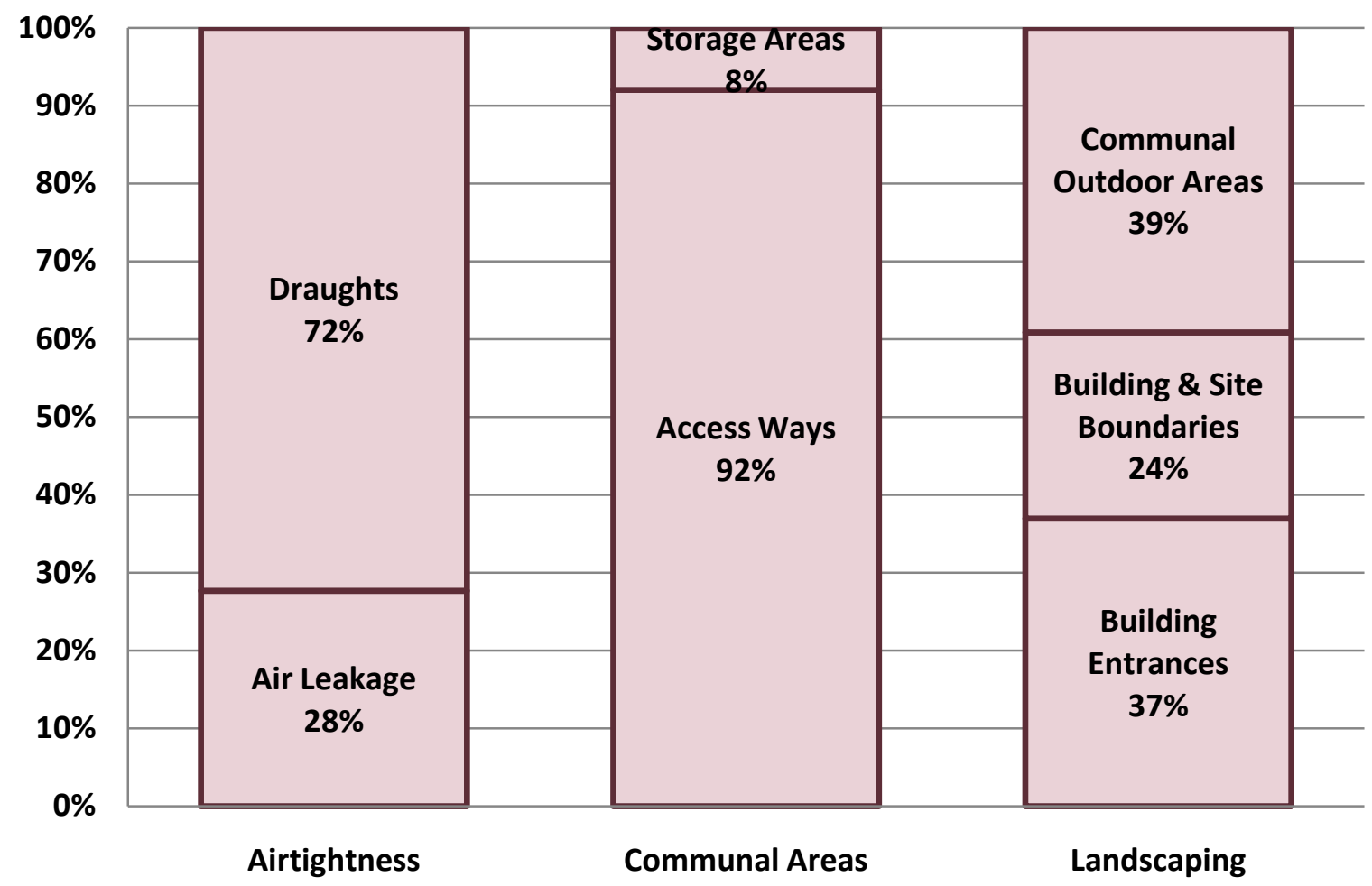

Figure G-2, Perceived Importance of Building Quality Aspects (1)

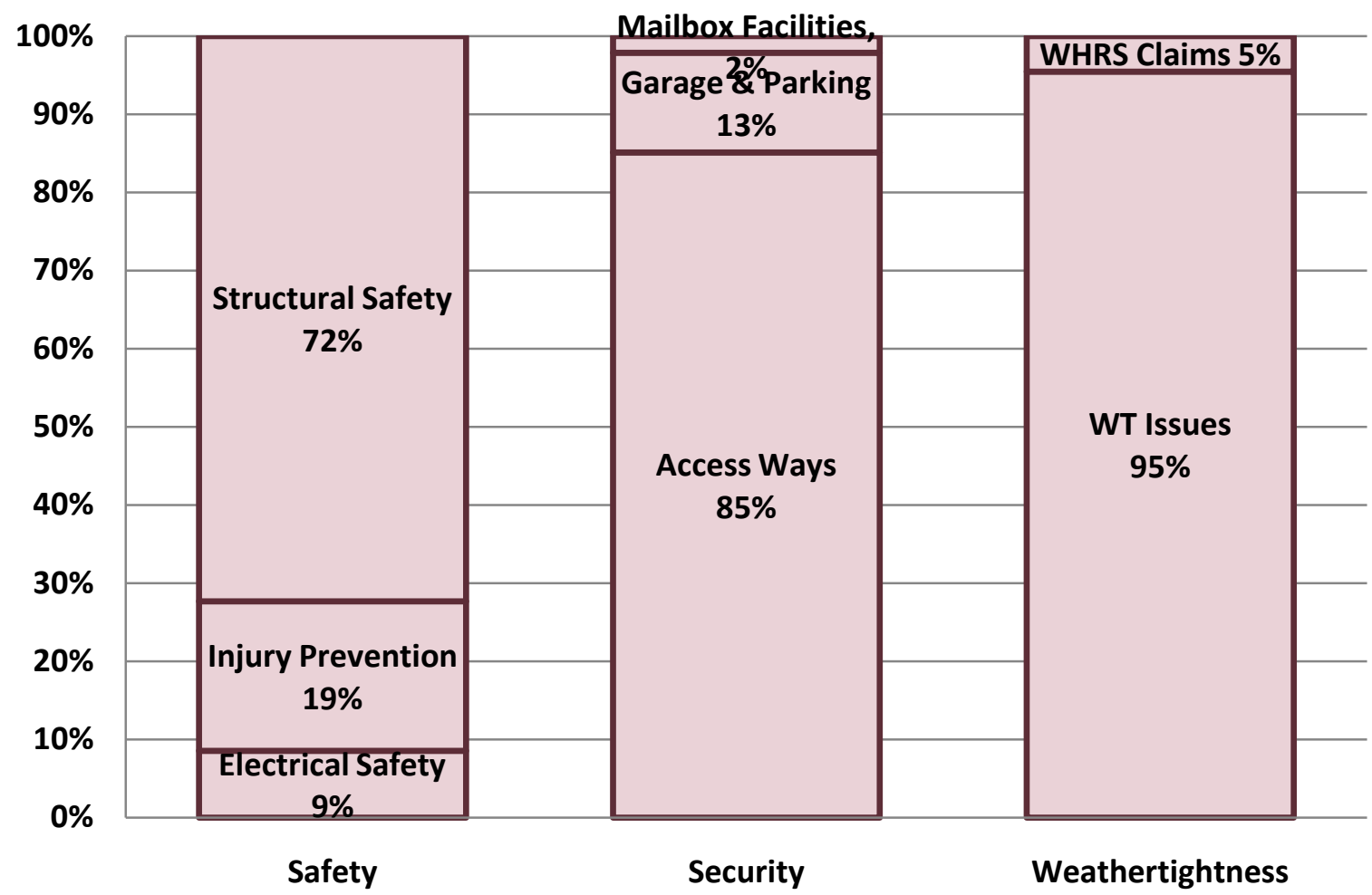

Figure G-3, Perceived Importance of Building Quality Aspects (2) 


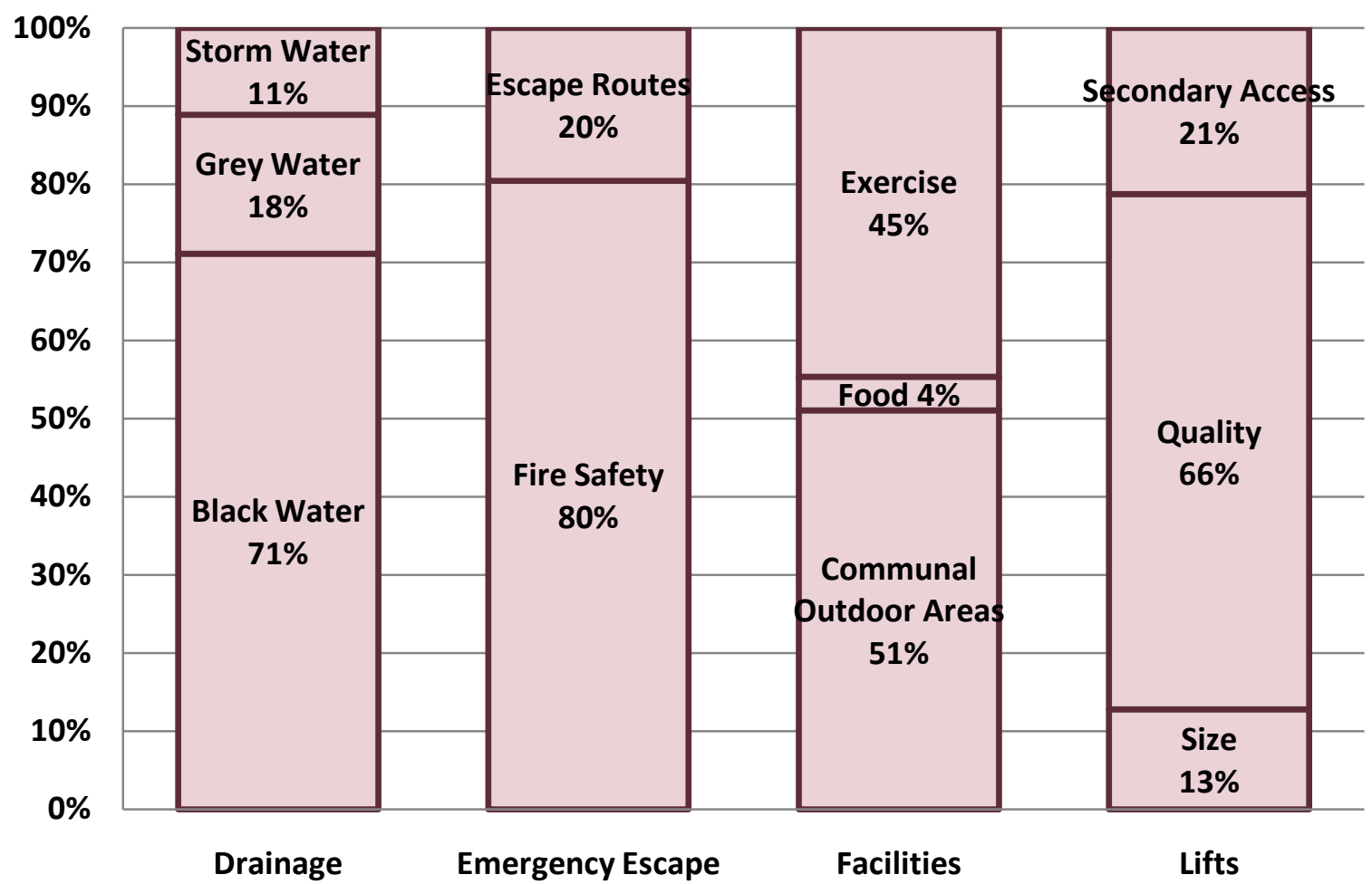

Figure G-4, Perceived Importance of Building Services \& Amenities Aspects (1)

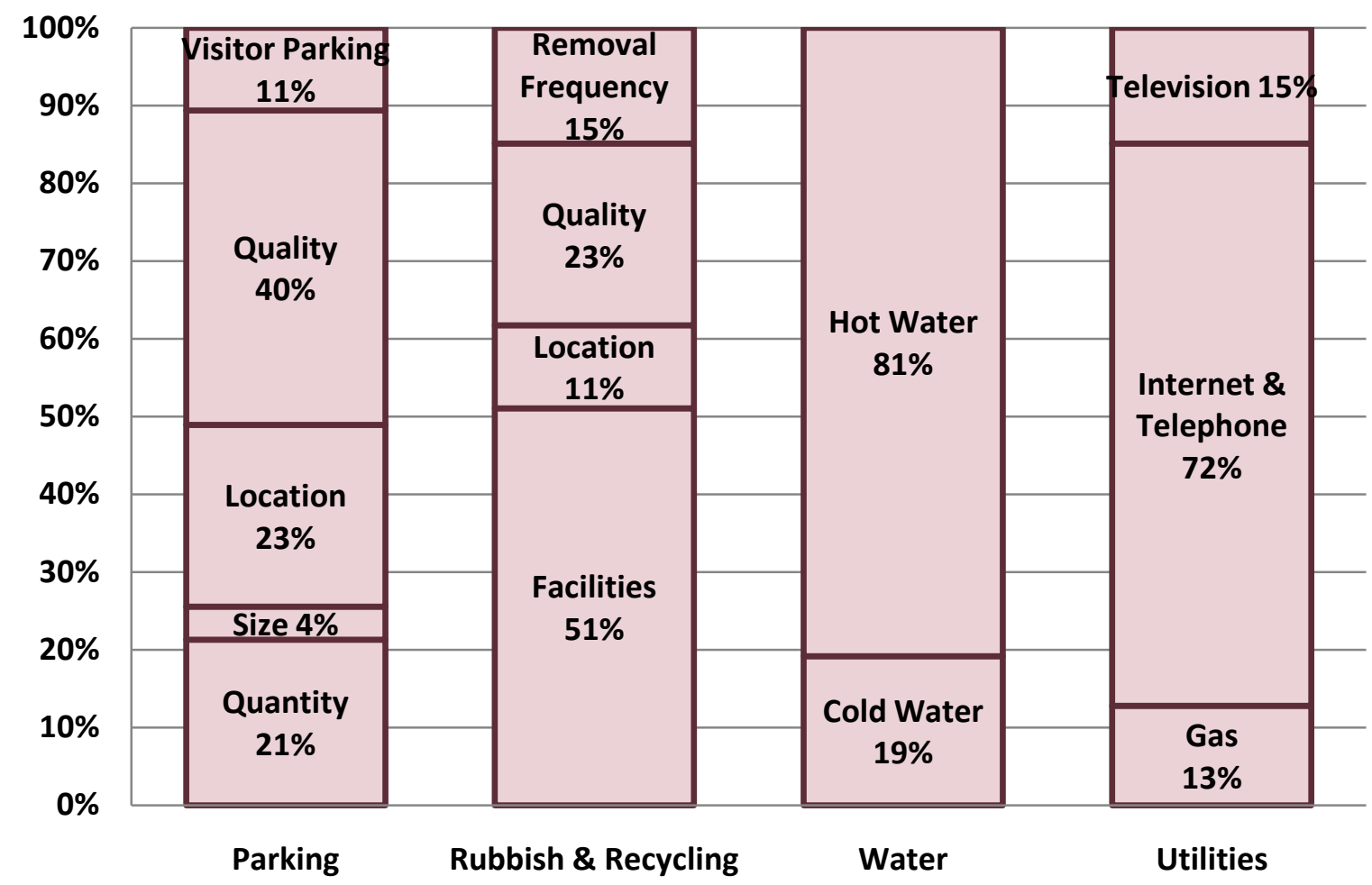

Figure G-5, Perceived Importance of Building Services \& Amenities Aspects (2) 


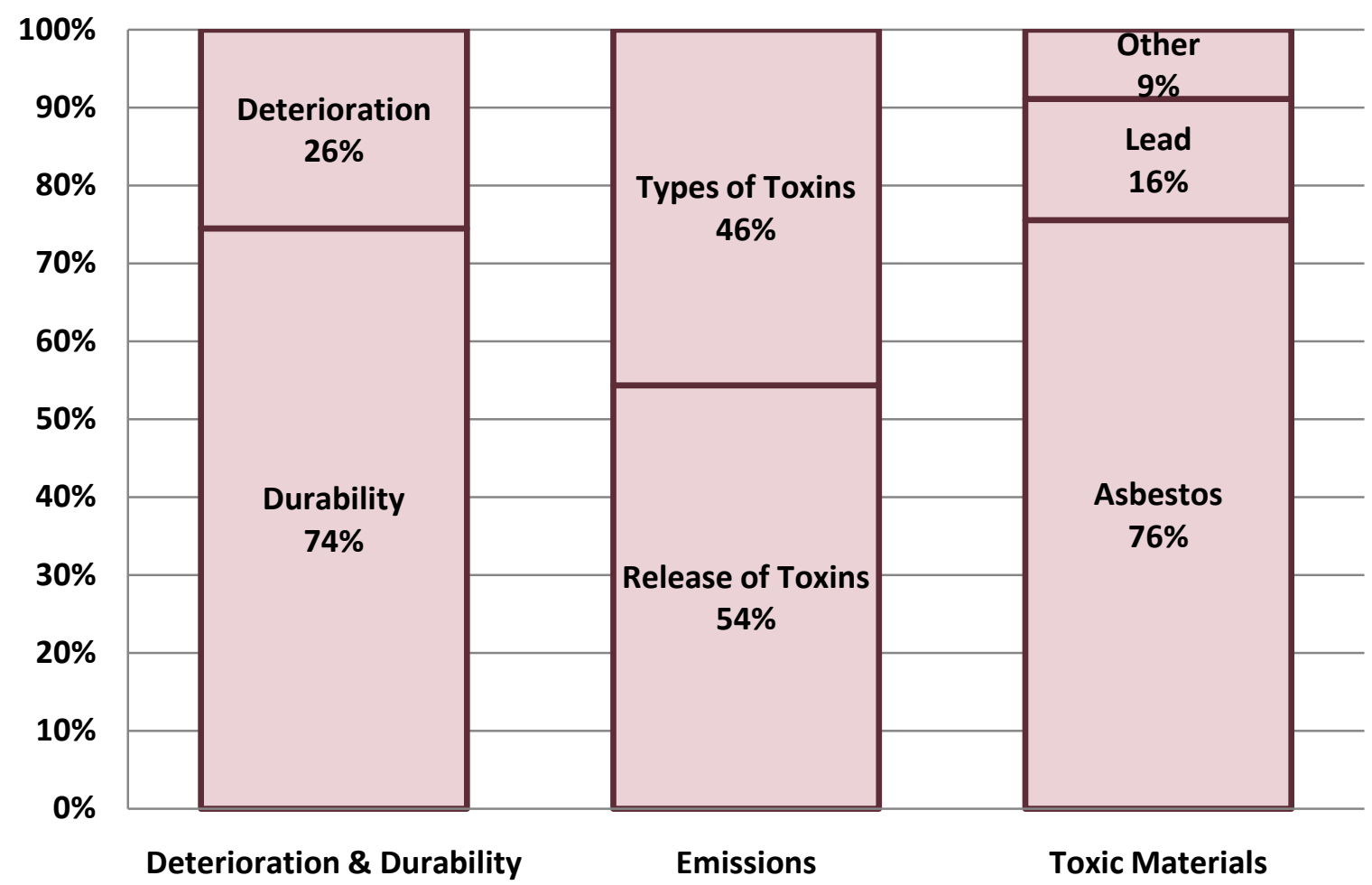

Figure G-6, Perceived Importance of Materials Quality Aspects

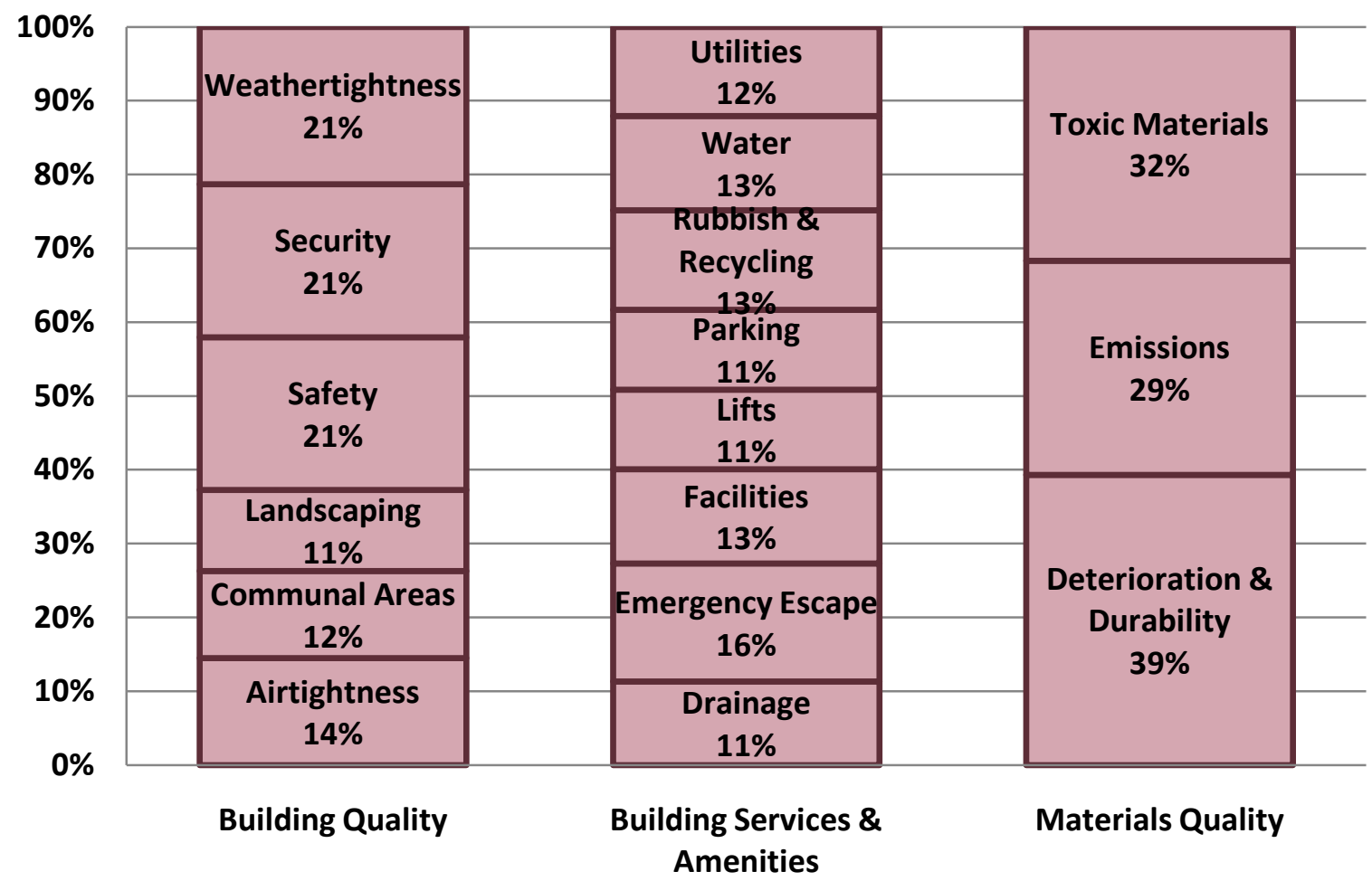

Figure G-7, Perceived Importance of Quality Features 


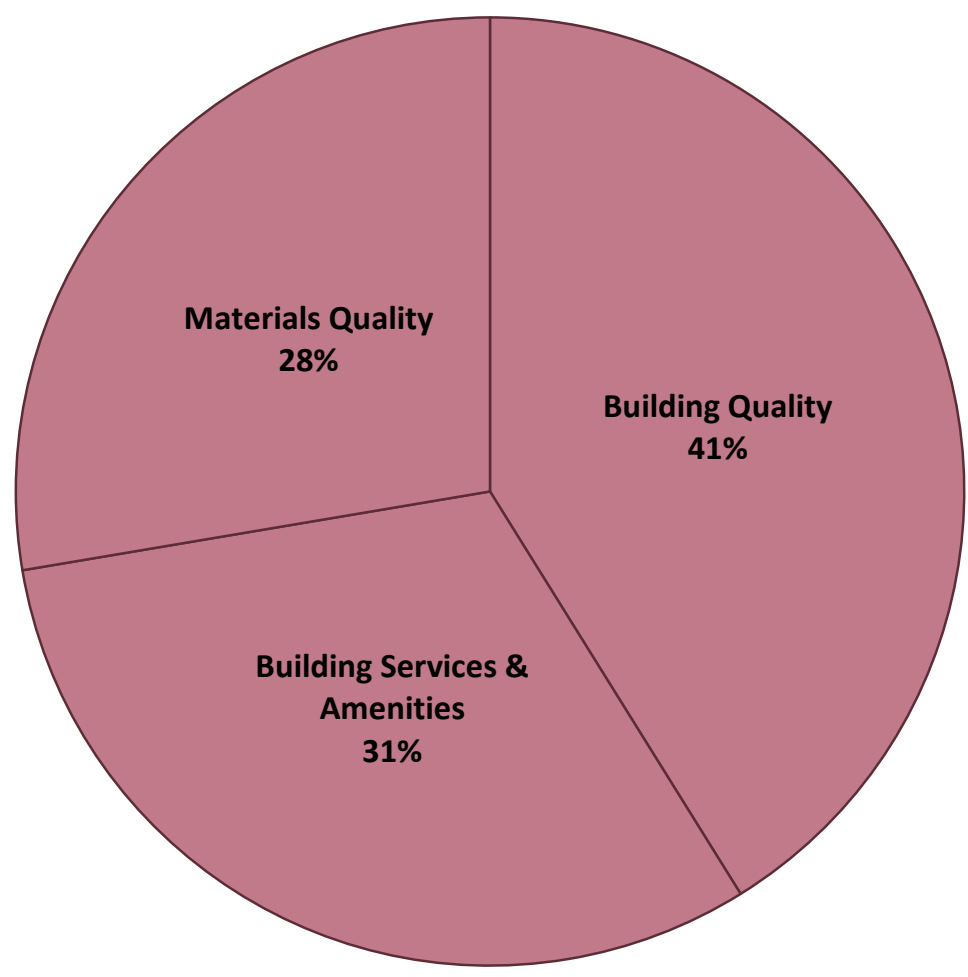

Figure G-8, Perceived Importance of Quality Sections

\section{G.2.2 APPLICATION OF PERCEIVED IMPORTANCE AS WEIGHTINGS}

\section{Rule \#1 - Perceived Importance of less than 3\%}

Within Quality three Features had Aspects that received a PI from the NZ Ali Questionnaire of less than 3\%. These were Mail \& Post Facilities (Security), Storage (Security) and Emergency Lighting \& Signage (Emergency Escape). Each of these three Aspects was removed from the index and the weightings shared around the remaining Aspects within its Feature grouping as shown in Table G-12 below.

Table G-12, Weightings Applied to NZ ALI Quality following Rule \#1

\begin{tabular}{|l|l|l|l|l|}
\hline Category & Feature & Aspects & $\begin{array}{l}\text { Perceived } \\
\text { Importance }\end{array}$ & NZ ALI Weighting \\
\hline \multirow{2}{*}{$\begin{array}{l}\text { Building } \\
\text { Quality }\end{array}$} & \multirow{2}{*}{ Security } & Access \& Entrance Ways & $85 \%$ & $86 \%$ \\
\cline { 3 - 5 } & & Garage \& Parking Areas & $13 \%$ & $14 \%$ \\
\cline { 3 - 5 } & & Mail \& Post Facilities & $2 \%$ & $0 \%$ \\
\cline { 3 - 5 } & Storage Areas & $0 \%$ & $0 \%$ \\
\hline $\begin{array}{l}\text { Building } \\
\text { Services \& } \\
\text { Amenities }\end{array}$ & \multirow{2}{*}{$\begin{array}{l}\text { Emergency } \\
\text { Escape }\end{array}$} & Fire Safety Features & $80 \%$ & $80 \%$ \\
\cline { 3 - 5 } & $\begin{array}{l}\text { Emergency Lighting \& } \\
\text { Signage }\end{array}$ & $0 \%$ & $0 \%$ \\
\cline { 3 - 5 } & Emergency Escape & $20 \%$ & $20 \%$ \\
\hline
\end{tabular}




\section{Rule \#2 - Indicator Weightings}

Within Quality there were 10 Aspects that had more than one Indicator. Therefore following Rule \#2 Indicator credits were spread evenly between them as shown in Table G-13.

Table G-13, Weightings Applied to NZ ALI Quality following Rule \#2

\begin{tabular}{|c|c|c|c|c|}
\hline Category & Feature & Aspect & Indicator & $\begin{array}{l}\text { Indicator } \\
\text { Weighting }\end{array}$ \\
\hline \multirow[t]{11}{*}{$\begin{array}{l}\text { Building } \\
\text { Quality }\end{array}$} & \multirow[t]{3}{*}{ Communal Areas } & \multirow[t]{3}{*}{$\begin{array}{l}\text { Access \& Entrance } \\
\text { Ways }\end{array}$} & $\begin{array}{l}\text { Are these areas } \\
\text { nice and } \\
\text { presentable? }\end{array}$ & $33 \%$ \\
\hline & & & $\begin{array}{l}\text { Are these areas } \\
\text { well protected } \\
\text { from the weather? }\end{array}$ & $33 \%$ \\
\hline & & & $\begin{array}{l}\text { Are these areas } \\
\text { well lit and } \\
\text { ventilated? }\end{array}$ & $33 \%$ \\
\hline & \multirow[t]{7}{*}{ Landscaping } & \multirow[t]{2}{*}{ Building Entrance } & $\begin{array}{l}\text { Are these areas } \\
\text { nice and } \\
\text { presentable? }\end{array}$ & $50 \%$ \\
\hline & & & $\begin{array}{l}\text { Is there a clear } \\
\text { separation } \\
\text { between the site } \\
\text { and public } \\
\text { boundaries? }\end{array}$ & $50 \%$ \\
\hline & & \multirow[t]{2}{*}{$\begin{array}{l}\text { Building \& Site } \\
\text { Boundaries }\end{array}$} & $\begin{array}{l}\text { Are these areas } \\
\text { nice and } \\
\text { presentable? }\end{array}$ & $50 \%$ \\
\hline & & & $\begin{array}{l}\text { Is there a clear } \\
\text { separation } \\
\text { between the site } \\
\text { and public } \\
\text { boundaries? }\end{array}$ & $50 \%$ \\
\hline & & \multirow[t]{3}{*}{$\begin{array}{l}\text { Communal } \\
\text { Outdoor Areas }\end{array}$} & $\begin{array}{l}\text { Are these areas } \\
\text { nice and } \\
\text { presentable? }\end{array}$ & $33 \%$ \\
\hline & & & $\begin{array}{l}\text { Are these areas } \\
\text { well protected } \\
\text { from the weather? }\end{array}$ & $33 \%$ \\
\hline & & & $\begin{array}{l}\text { Are these areas } \\
\text { regularly } \\
\text { maintained? }\end{array}$ & $33 \%$ \\
\hline & Safety & Injury Prevention & $\begin{array}{l}\text { Are there any } \\
\text { slippery or unsafe } \\
\text { surfaces? }\end{array}$ & $33 \%$ \\
\hline
\end{tabular}




\begin{tabular}{|c|c|c|c|c|}
\hline & & & $\begin{array}{l}\text { Are there adequate } \\
\text { handrails where } \\
\text { required? }\end{array}$ & $33 \%$ \\
\hline & & & $\begin{array}{l}\text { Are there any } \\
\text { windows that } \\
\text { people could fall } \\
\text { from? }\end{array}$ & $33 \%$ \\
\hline & & Structural Safety & $\begin{array}{l}\text { What year was the } \\
\text { building } \\
\text { constructed, OR } \\
\text { when was it last } \\
\text { majorly } \\
\text { refurbished? }\end{array}$ & $50 \%$ \\
\hline & & & $\begin{array}{l}\text { Do you notice any } \\
\text { degradation, } \\
\text { deformation } \\
\text { and/or vibrations } \\
\text { in the structure of } \\
\text { the building? }\end{array}$ & $50 \%$ \\
\hline & Security & $\begin{array}{l}\text { Access \& Entrance } \\
\text { Ways }\end{array}$ & $\begin{array}{l}\text { What type of } \\
\text { access is there for } \\
\text { occupants? }\end{array}$ & $12.5 \%$ \\
\hline & & & $\begin{array}{l}\text { What type of } \\
\text { access is there for } \\
\text { visitors? }\end{array}$ & $12.5 \%$ \\
\hline & & & $\begin{array}{l}\text { Is there restricted } \\
\text { floor access? }\end{array}$ & $12.5 \%$ \\
\hline & & & $\begin{array}{l}\text { Are there security } \\
\text { cameras? }\end{array}$ & $12.5 \%$ \\
\hline & & & $\begin{array}{l}\text { Is it individual or } \\
\text { communal access? }\end{array}$ & $12.5 \%$ \\
\hline & & & $\begin{array}{l}\text { Is it horizontal or } \\
\text { vertical access? }\end{array}$ & $12.5 \%$ \\
\hline & & & $\begin{array}{l}\text { Is it residential } \\
\text { only? }\end{array}$ & $12.5 \%$ \\
\hline & & & $\begin{array}{l}\text { Are front doors } \\
\text { facing each other? }\end{array}$ & $12.5 \%$ \\
\hline & & $\begin{array}{l}\text { Garage \& Parking } \\
\text { Areas }\end{array}$ & $\begin{array}{l}\text { What type of } \\
\text { access is there for } \\
\text { occupants? }\end{array}$ & $50 \%$ \\
\hline & & & $\begin{array}{l}\text { Are there security } \\
\text { cameras? }\end{array}$ & $50 \%$ \\
\hline $\begin{array}{l}\text { Building } \\
\text { Services \& }\end{array}$ & Emergency Escape & $\begin{array}{l}\text { Fire Safety } \\
\text { Features }\end{array}$ & $\begin{array}{l}\text { Are there smoke } \\
\text { detectors? }\end{array}$ & $20 \%$ \\
\hline Amenities & & & $\begin{array}{l}\text { Are there } \\
\text { sprinklers? }\end{array}$ & $20 \%$ \\
\hline & & & Is there an alarm? & $20 \%$ \\
\hline
\end{tabular}




\begin{tabular}{|c|c|c|c|}
\hline & & $\begin{array}{l}\text { Are there } \\
\text { switches? }\end{array}$ & $20 \%$ \\
\hline & & $\begin{array}{l}\text { Are there fire } \\
\text { extinguishers } \\
\text { and/or fire hose } \\
\text { reels? }\end{array}$ & $20 \%$ \\
\hline \multirow[t]{4}{*}{ Parking } & \multirow[t]{4}{*}{$\begin{array}{l}\text { Provision of Visitor } \\
\text { Parking }\end{array}$} & $\begin{array}{l}\text { Is visitor parking } \\
\text { provided? }\end{array}$ & $25 \%$ \\
\hline & & $\begin{array}{l}\text { How many parks } \\
\text { are provided? }\end{array}$ & $25 \%$ \\
\hline & & How big are parks? & $25 \%$ \\
\hline & & $\begin{array}{l}\text { Where is it } \\
\text { located? }\end{array}$ & $25 \%$ \\
\hline
\end{tabular}

\section{Rule \#3 - Modified Components}

Initially Weathertightness was assessed with two Aspects Claims made to the WHRS and Weathertightness Issues. It was identified that in some cases where a building may have Weathertightness issues, it is not always guaranteed that claims would be made to the WHRS. However for ease of use and minimising complicated questions, it was decided that these two Aspects would become one and a user asked if there are any Weathertightness Issues and/or WHRS Claims. This Aspect received a full weighting of $100 \%$.

Three other Features also required some modifying these were Lifts, Parking and Rubbish \& Recycling Facilities. As in the case for Private Outdoor Access, Building Management and Pets each of these three Features had one Feature that was required to be weighted $0 \%$ because it asked if this Feature was available. Weightings for the remaining Aspects were weighted as per the NZ ALI

awarded for that Features as shown in Table G-14. No other components within Quality required modification in any way so the PI determined from the NZ ALI Questionnaire was applied as their component weighting.

Table G-14, Weightings Applied to Building Services \& Amenities Aspects

\begin{tabular}{|c|c|c|c|c|c|c|}
\hline Category & Feature & Aspects & Weighting & Indicator & $\begin{array}{l}\text { Possible } \\
\text { Credits } \\
\text { if 'No' }\end{array}$ & $\begin{array}{l}\text { Possible } \\
\text { Credits } \\
\text { if 'Yes' }\end{array}$ \\
\hline \multirow{4}{*}{$\begin{array}{l}\text { Building } \\
\text { Services } \\
\text { \& } \\
\text { Amenities }\end{array}$} & \multirow[t]{4}{*}{ Lifts } & Provision of Lifts & $0 \%$ & $\begin{array}{l}\text { Are there lifts } \\
\text { provided? }\end{array}$ & \multirow{4}{*}{$0 \%$} & $\mathrm{~N} / \mathrm{A}$ \\
\hline & & Quality of Lifts & $66 \%$ & $\begin{array}{l}\text { Are they good } \\
\text { quality? }\end{array}$ & & $66 \%$ \\
\hline & & Secondary Access & $21 \%$ & $\begin{array}{l}\text { Is there secondary } \\
\text { access? }\end{array}$ & & $21 \%$ \\
\hline & & Size of Lifts & $13 \%$ & $\begin{array}{l}\text { Are they an } \\
\text { adequate size? }\end{array}$ & & $13 \%$ \\
\hline
\end{tabular}




\begin{tabular}{|c|c|c|c|c|c|}
\hline \multirow[t]{9}{*}{ Parking } & $\begin{array}{l}\text { Provision of } \\
\text { Occupant } \\
\text { Parking } \\
\end{array}$ & $0 \%$ & Is parking available? & \multirow{9}{*}{$0 \%$} & N/A \\
\hline & $\begin{array}{l}\text { Location of } \\
\text { Parking }\end{array}$ & $23 \%$ & Where is it located? & & $23 \%$ \\
\hline & $\begin{array}{l}\text { Quality of } \\
\text { Parking }\end{array}$ & $40 \%$ & $\begin{array}{l}\text { Is it good quality } \\
\text { parking? }\end{array}$ & & $40 \%$ \\
\hline & $\begin{array}{l}\text { Quantity of } \\
\text { Parking }\end{array}$ & $21 \%$ & $\begin{array}{l}\text { How many parks are } \\
\text { provided? }\end{array}$ & & $21 \%$ \\
\hline & Size of Parking & $4 \%$ & How big are parks? & & $4 \%$ \\
\hline & \multirow[t]{4}{*}{ Visitor Parking } & \multirow[t]{4}{*}{$12 \%$} & $\begin{array}{l}\text { Is visitor parking } \\
\text { provided? }\end{array}$ & & \multirow[t]{4}{*}{$12 \%$} \\
\hline & & & $\begin{array}{l}\text { How many parks are } \\
\text { provided? }\end{array}$ & & \\
\hline & & & How big are parks? & & \\
\hline & & & Where is it located? & & \\
\hline \multirow[t]{4}{*}{$\begin{array}{l}\text { Rubbish \& } \\
\text { Recycling } \\
\text { Facilities }\end{array}$} & $\begin{array}{l}\text { Provision of } \\
\text { Rubbish \& } \\
\text { Recycling } \\
\text { Facilities }\end{array}$ & $0 \%$ & $\begin{array}{l}\text { Are rubbish and } \\
\text { recycling facilities } \\
\text { provided? }\end{array}$ & \multirow{4}{*}{$0 \%$} & N/A \\
\hline & $\begin{array}{l}\text { Location of } \\
\text { Facilities }\end{array}$ & $22 \%$ & $\begin{array}{l}\text { How accessible are } \\
\text { the rubbish } \& \\
\text { recycling facilities? }\end{array}$ & & $22 \%$ \\
\hline & $\begin{array}{l}\text { Quality of } \\
\text { Facilities }\end{array}$ & $47 \%$ & $\begin{array}{l}\text { Are these areas } \\
\text { good quality? }\end{array}$ & & $47 \%$ \\
\hline & $\begin{array}{l}\text { Removal } \\
\text { Frequency }\end{array}$ & $31 \%$ & $\begin{array}{l}\text { How often is } \\
\text { rubbish and } \\
\text { recycling removed? }\end{array}$ & & $31 \%$ \\
\hline
\end{tabular}




\section{G.2.3 QUALITY COMPONENT WEIGHTINGS}

The following tables present the final weightings applied to all Quality components.

Table G-15, Component and Global Weightings for Building Quality Indicators

\begin{tabular}{|c|c|c|c|c|c|c|}
\hline $\begin{array}{l}\text { Level } 2 \\
\text { Category }\end{array}$ & $\begin{array}{l}\text { Level } 3 \\
\text { Section }\end{array}$ & $\begin{array}{l}\text { Level } 4 \\
\text { Feature } \\
\end{array}$ & $\begin{array}{l}\text { Level } 5 \\
\text { Aspect } \\
\end{array}$ & $\begin{array}{l}\text { Level } 6 \\
\text { Indicator }\end{array}$ & $\begin{array}{l}\text { Component } \\
\text { Weighting }\end{array}$ & $\begin{array}{l}\text { Global } \\
\text { Weighting }\end{array}$ \\
\hline \multirow{29}{*}{ Quality } & \multirow{29}{*}{$\begin{array}{l}\text { Building } \\
\text { Quality }\end{array}$} & Airtightness & Airtightness & Draughts & $100 \%$ & $1.44 \%$ \\
\hline & & \multirow{4}{*}{$\begin{array}{l}\text { Communal } \\
\text { Areas }\end{array}$} & \multirow{3}{*}{$\begin{array}{l}\text { Access \& } \\
\text { Entrance } \\
\text { Ways }\end{array}$} & Nice & $33 \%$ & $0.38 \%$ \\
\hline & & & & Protection & $33 \%$ & $0.38 \%$ \\
\hline & & & & Lit \& Vent & $33 \%$ & $0.38 \%$ \\
\hline & & & $\begin{array}{l}\text { Storage } \\
\text { Areas }\end{array}$ & Nice & $100 \%$ & $0.10 \%$ \\
\hline & & \multirow{7}{*}{ Landscaping } & \multirow{2}{*}{$\begin{array}{l}\text { Building } \\
\text { Entrances }\end{array}$} & Nice & $50 \%$ & $0.21 \%$ \\
\hline & & & & Protection & $50 \%$ & $0.21 \%$ \\
\hline & & & \multirow{2}{*}{$\begin{array}{l}\text { Building\& } \\
\text { Site } \\
\text { Boundaries }\end{array}$} & Nice & $50 \%$ & $0.14 \%$ \\
\hline & & & & Separation & $50 \%$ & $0.14 \%$ \\
\hline & & & \multirow{3}{*}{$\begin{array}{l}\text { Communal } \\
\text { Outdoor } \\
\text { Areas }\end{array}$} & Nice & $33 \%$ & $0.15 \%$ \\
\hline & & & & Protection & $33 \%$ & $0.15 \%$ \\
\hline & & & & Maintain & $33 \%$ & $0.15 \%$ \\
\hline & & \multirow{6}{*}{ Safety } & Electrical & Maintain & $100 \%$ & $0.19 \%$ \\
\hline & & & \multirow{3}{*}{ Injuries } & Surfaces & $33 \%$ & $0.14 \%$ \\
\hline & & & & Handrails & $33 \%$ & $0.14 \%$ \\
\hline & & & & Windows & $33 \%$ & $0.14 \%$ \\
\hline & & & \multirow{2}{*}{ Structural } & Age & $50 \%$ & $0.77 \%$ \\
\hline & & & & Degradation & $50 \%$ & $0.77 \%$ \\
\hline & & \multirow{10}{*}{ Security } & \multirow{8}{*}{$\begin{array}{l}\text { Access \& } \\
\text { Entrance } \\
\text { Ways }\end{array}$} & Occupants & $13 \%$ & $0.23 \%$ \\
\hline & & & & Visitors & $13 \%$ & $0.23 \%$ \\
\hline & & & & Access & $13 \%$ & $0.23 \%$ \\
\hline & & & & Cameras & $13 \%$ & $0.23 \%$ \\
\hline & & & & Access & $13 \%$ & $0.23 \%$ \\
\hline & & & & Access & $13 \%$ & $0.23 \%$ \\
\hline & & & & Residential & $13 \%$ & $0.23 \%$ \\
\hline & & & & Doors & $13 \%$ & $0.23 \%$ \\
\hline & & & \multirow{2}{*}{$\begin{array}{l}\text { Garage \& } \\
\text { Parking }\end{array}$} & Access & $50 \%$ & $0.15 \%$ \\
\hline & & & & Cameras & $50 \%$ & $0.15 \%$ \\
\hline & & $\begin{array}{l}\text { Weather- } \\
\text { tightness }\end{array}$ & $\begin{array}{l}\text { Weather- } \\
\text { tightness }\end{array}$ & Issues & $100 \%$ & $2.15 \%$ \\
\hline
\end{tabular}


Table G-16, Component and Global Weightings for Building Services \& Amenities Indicators

\begin{tabular}{|c|c|c|c|c|c|c|}
\hline $\begin{array}{l}\text { Level } 2 \\
\text { Category }\end{array}$ & $\begin{array}{l}\text { Level } 3 \\
\text { Section }\end{array}$ & $\begin{array}{l}\text { Level } 4 \\
\text { Feature }\end{array}$ & $\begin{array}{l}\text { Level } 5 \\
\text { Aspect }\end{array}$ & $\begin{array}{l}\text { Level } 6 \\
\text { Indicator }\end{array}$ & $\begin{array}{l}\text { Component } \\
\text { Weighting }\end{array}$ & $\begin{array}{l}\text { Global } \\
\text { Weighting }\end{array}$ \\
\hline \multirow{32}{*}{ Quality } & \multirow{32}{*}{$\begin{array}{l}\text { Building } \\
\text { Services \& } \\
\text { Amenities }\end{array}$} & \multirow{3}{*}{ Drainage } & $\begin{array}{l}\text { Black } \\
\text { Water }\end{array}$ & Remove & $100 \%$ & $0.61 \%$ \\
\hline & & & $\begin{array}{l}\text { Grey } \\
\text { Water }\end{array}$ & Remove & $100 \%$ & $0.15 \%$ \\
\hline & & & $\begin{array}{l}\text { Storm } \\
\text { Water }\end{array}$ & Remove & $100 \%$ & $0.09 \%$ \\
\hline & & \multirow{6}{*}{$\begin{array}{l}\text { Emergency } \\
\text { Escape }\end{array}$} & \multirow{5}{*}{$\begin{array}{l}\text { Fire Safety } \\
\text { Features }\end{array}$} & $\begin{array}{l}\text { Smoke } \\
\text { Detectors }\end{array}$ & $20 \%$ & $0.20 \%$ \\
\hline & & & & Sprinklers & $20 \%$ & $0.20 \%$ \\
\hline & & & & Alarm & $20 \%$ & $0.20 \%$ \\
\hline & & & & Switches & $20 \%$ & $0.20 \%$ \\
\hline & & & & Extinguishers & $20 \%$ & $0.20 \%$ \\
\hline & & & Escape & Routes & $100 \%$ & $0.25 \%$ \\
\hline & & \multirow[t]{3}{*}{ Facilities } & $\begin{array}{l}\text { Communal } \\
\text { Outdoor } \\
\text { Areas }\end{array}$ & Provided & $100 \%$ & $0.51 \%$ \\
\hline & & & Eateries & Provided & $100 \%$ & $0.04 \%$ \\
\hline & & & Exercise & Provided & $100 \%$ & $0.45 \%$ \\
\hline & & \multirow{4}{*}{ Lifts } & Lifts & Provided & $100 \%$ & $0.00 \%$ \\
\hline & & & Quality & Condition & $100 \%$ & $0.56 \%$ \\
\hline & & & $\begin{array}{l}\text { Secondary } \\
\text { Access }\end{array}$ & Access & $100 \%$ & $0.18 \%$ \\
\hline & & & Size & Size & $100 \%$ & $0.11 \%$ \\
\hline & & \multirow{9}{*}{ Parking } & Parking & Provided & $100 \%$ & $0.00 \%$ \\
\hline & & & Location & Access & $100 \%$ & $0.20 \%$ \\
\hline & & & Quality & Quality & $100 \%$ & $0.34 \%$ \\
\hline & & & Quantity & Quantity & $100 \%$ & $0.18 \%$ \\
\hline & & & Size & Size & $100 \%$ & $0.03 \%$ \\
\hline & & & \multirow{4}{*}{$\begin{array}{l}\text { Visitor } \\
\text { Parking }\end{array}$} & Provided & $25 \%$ & $0.03 \%$ \\
\hline & & & & Quantity & $25 \%$ & $0.03 \%$ \\
\hline & & & & Size & $25 \%$ & $0.03 \%$ \\
\hline & & & & Access & $25 \%$ & $0.03 \%$ \\
\hline & & \multirow{4}{*}{$\begin{array}{l}\text { Rubbish \& } \\
\text { Recycling } \\
\text { Facilities }\end{array}$} & Facilities & Provided & $100 \%$ & $0.00 \%$ \\
\hline & & & Location & Access & $100 \%$ & $0.22 \%$ \\
\hline & & & Quality & Quality & $100 \%$ & $0.47 \%$ \\
\hline & & & Removal & Removal & $100 \%$ & $0.31 \%$ \\
\hline & & \multirow{2}{*}{ Water Supply } & Cold Water & Supply & $100 \%$ & $0.19 \%$ \\
\hline & & & Hot Water & Hot Water & $100 \%$ & $0.82 \%$ \\
\hline & & Utilities & Gas & Gas & $100 \%$ & $0.12 \%$ \\
\hline
\end{tabular}




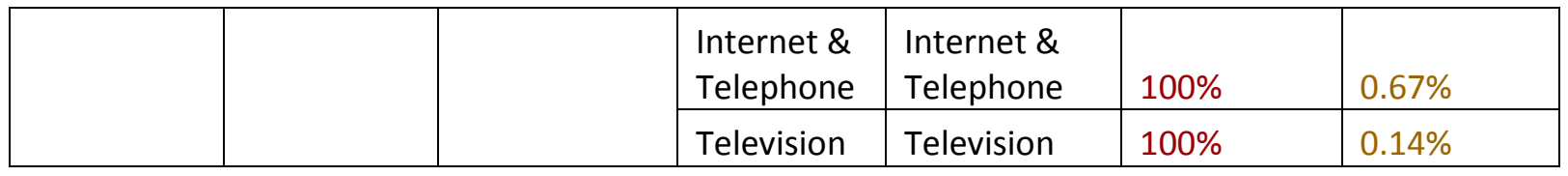

Table G-17, Component and Global Weightings for Materials Quality Indicators

\begin{tabular}{|c|c|c|c|c|c|c|}
\hline $\begin{array}{l}\text { Level } 2 \\
\text { Category }\end{array}$ & $\begin{array}{l}\text { Level } 3 \\
\text { Section } \\
\end{array}$ & $\begin{array}{l}\text { Level } 4 \\
\text { Feature } \\
\end{array}$ & $\begin{array}{l}\text { Level } 5 \\
\text { Aspect } \\
\end{array}$ & $\begin{array}{l}\text { Level } 6 \\
\text { Indicator }\end{array}$ & $\begin{array}{l}\text { Component } \\
\text { Weighting }\end{array}$ & $\begin{array}{l}\text { Global } \\
\text { Weighting }\end{array}$ \\
\hline \multirow{5}{*}{ Quality } & \multirow{5}{*}{$\begin{array}{l}\text { Materials } \\
\text { Quality }\end{array}$} & \multirow{2}{*}{$\begin{array}{l}\text { Deterioration } \\
\text { \& Durability }\end{array}$} & Durability & Durability & $100 \%$ & $2.02 \%$ \\
\hline & & & Deterioration & Deterioration & $100 \%$ & $0.71 \%$ \\
\hline & & Emissions & Emissions & Emissions & $100 \%$ & $2.03 \%$ \\
\hline & & \multirow{2}{*}{$\begin{array}{l}\text { Toxic } \\
\text { Materials }\end{array}$} & Asbestos & Age & $100 \%$ & $1.77 \%$ \\
\hline & & & Lead & Age & $100 \%$ & $0.47 \%$ \\
\hline
\end{tabular}

Table G-18, Component and Global Weightings for Quality Aspects

\begin{tabular}{|c|c|c|c|c|c|c|}
\hline $\begin{array}{l}\text { Level } 2 \\
\text { Category }\end{array}$ & $\begin{array}{l}\text { Level } 3 \\
\text { Section }\end{array}$ & $\begin{array}{l}\text { Level } 4 \\
\text { Feature }\end{array}$ & $\begin{array}{l}\text { Level } 5 \\
\text { Aspect }\end{array}$ & $\begin{array}{l}\text { Component } \\
\text { Weighting }\end{array}$ & $\begin{array}{l}\text { Global } \\
\text { Weighting }\end{array}$ & $\begin{array}{l}\text { Level } 6 \\
\text { Indicators }\end{array}$ \\
\hline \multirow{15}{*}{ Quality } & \multirow{12}{*}{$\begin{array}{l}\text { Building } \\
\text { Quality }\end{array}$} & Airtightness & Airtightness & $100 \%$ & $1.44 \%$ & 1 \\
\hline & & \multirow{2}{*}{$\begin{array}{l}\text { Communal } \\
\text { Areas }\end{array}$} & $\begin{array}{l}\text { Access \& } \\
\text { Entrance } \\
\text { Ways }\end{array}$ & $92 \%$ & $1.13 \%$ & 3 \\
\hline & & & $\begin{array}{l}\text { Storage } \\
\text { Areas }\end{array}$ & $8 \%$ & $0.10 \%$ & 1 \\
\hline & & \multirow{3}{*}{ Landscaping } & $\begin{array}{l}\text { Building } \\
\text { Entrances }\end{array}$ & $37 \%$ & $0.42 \%$ & 2 \\
\hline & & & $\begin{array}{l}\text { Building\& } \\
\text { Site } \\
\text { Boundaries }\end{array}$ & $24 \%$ & $0.27 \%$ & 2 \\
\hline & & & $\begin{array}{l}\text { Communal } \\
\text { Outdoor } \\
\text { Areas }\end{array}$ & $39 \%$ & $0.44 \%$ & 3 \\
\hline & & \multirow{3}{*}{ Safety } & Electrical & $9 \%$ & $0.19 \%$ & 1 \\
\hline & & & Injuries & $19 \%$ & $0.41 \%$ & 3 \\
\hline & & & Structural & $72 \%$ & $1.55 \%$ & 2 \\
\hline & & \multirow[t]{2}{*}{ Security } & $\begin{array}{l}\text { Access \& } \\
\text { Entrance } \\
\text { Ways }\end{array}$ & $86 \%$ & $1.85 \%$ & 8 \\
\hline & & & $\begin{array}{l}\text { Garage \& } \\
\text { Parking }\end{array}$ & $14 \%$ & $0.30 \%$ & 2 \\
\hline & & $\begin{array}{l}\text { Weather- } \\
\text { tightness }\end{array}$ & $\begin{array}{l}\text { Weather- } \\
\text { tightness }\end{array}$ & $100 \%$ & $2.15 \%$ & 1 \\
\hline & \multirow{3}{*}{$\begin{array}{l}\text { Building } \\
\text { Services \& } \\
\text { Amenities }\end{array}$} & \multirow{3}{*}{ Drainage } & Black Water & $71 \%$ & $0.61 \%$ & 1 \\
\hline & & & Grey Water & $18 \%$ & $0.15 \%$ & 1 \\
\hline & & & Storm Water & $11 \%$ & $0.09 \%$ & 1 \\
\hline
\end{tabular}




\begin{tabular}{|c|c|c|c|c|c|}
\hline & \multirow{2}{*}{$\begin{array}{l}\text { Emergency } \\
\text { Escape }\end{array}$} & $\begin{array}{l}\text { Fire Safety } \\
\text { Features }\end{array}$ & $80 \%$ & $0.99 \%$ & 5 \\
\hline & & Escape & $20 \%$ & $0.25 \%$ & 1 \\
\hline & \multirow[t]{3}{*}{ Facilities } & $\begin{array}{l}\text { Communal } \\
\text { Outdoor } \\
\text { Areas }\end{array}$ & $51 \%$ & $0.51 \%$ & 1 \\
\hline & & Eateries & $4 \%$ & $0.04 \%$ & 1 \\
\hline & & Exercise & $45 \%$ & $0.45 \%$ & 1 \\
\hline & \multirow{4}{*}{ Lifts } & Lifts & $0 \%$ & $0.00 \%$ & 1 \\
\hline & & Quality & $66 \%$ & $0.56 \%$ & 1 \\
\hline & & $\begin{array}{l}\text { Secondary } \\
\text { Access }\end{array}$ & $21 \%$ & $0.18 \%$ & 1 \\
\hline & & Size & $13 \%$ & $0.11 \%$ & 1 \\
\hline & \multirow{6}{*}{ Parking } & Parking & $0 \%$ & $0.00 \%$ & 1 \\
\hline & & Location & $23 \%$ & $0.20 \%$ & 1 \\
\hline & & Quality & $40 \%$ & $0.34 \%$ & 1 \\
\hline & & Quantity & $21 \%$ & $0.18 \%$ & 1 \\
\hline & & Size & $4 \%$ & $0.03 \%$ & 1 \\
\hline & & Visitor & $12 \%$ & $0.10 \%$ & 4 \\
\hline & \multirow{4}{*}{$\begin{array}{l}\text { Rubbish \& } \\
\text { Recycling } \\
\text { Facilities }\end{array}$} & Facilities & $0 \%$ & $0.00 \%$ & 1 \\
\hline & & Location & $22 \%$ & $0.22 \%$ & 1 \\
\hline & & Quality & $47 \%$ & $0.47 \%$ & 1 \\
\hline & & Removal & $31 \%$ & $0.31 \%$ & 1 \\
\hline & \multirow{2}{*}{ Water Supply } & Cold Water & $19 \%$ & $0.19 \%$ & 1 \\
\hline & & Hot Water & $81 \%$ & $0.82 \%$ & 1 \\
\hline & \multirow{3}{*}{ Utilities } & Gas & $13 \%$ & $0.12 \%$ & 1 \\
\hline & & $\begin{array}{l}\text { Internet \& } \\
\text { Telephone }\end{array}$ & $72 \%$ & $0.67 \%$ & 1 \\
\hline & & Television & $15 \%$ & $0.14 \%$ & 1 \\
\hline \multirow{5}{*}{$\begin{array}{l}\text { Materials } \\
\text { Quality }\end{array}$} & \multirow{2}{*}{$\begin{array}{l}\text { Deterioration } \\
\text { \& Durability }\end{array}$} & Durability & $74 \%$ & $2.02 \%$ & 1 \\
\hline & & Deterioration & $26 \%$ & $0.71 \%$ & 1 \\
\hline & Emissions & Emissions & $100 \%$ & $2.03 \%$ & 1 \\
\hline & \multirow{2}{*}{$\begin{array}{l}\text { Toxic } \\
\text { Materials }\end{array}$} & Asbestos & $79 \%$ & $1.77 \%$ & 1 \\
\hline & & Lead & $21 \%$ & $0.47 \%$ & 1 \\
\hline
\end{tabular}


Table G-19, Component and Global Weightings for Quality Features

\begin{tabular}{|c|c|c|c|c|c|c|}
\hline $\begin{array}{l}\text { Level } 2 \\
\text { Category }\end{array}$ & $\begin{array}{l}\text { Level } 3 \\
\text { Section }\end{array}$ & $\begin{array}{l}\text { Level } 4 \\
\text { Feature } \\
\end{array}$ & $\begin{array}{l}\text { Component } \\
\text { Weighting }\end{array}$ & $\begin{array}{l}\text { Global } \\
\text { Weighting }\end{array}$ & $\begin{array}{l}\text { Level } 5 \\
\text { Aspect }\end{array}$ & $\begin{array}{l}\text { Level } 6 \\
\text { Indicators }\end{array}$ \\
\hline \multirow{17}{*}{ Quality } & \multirow{6}{*}{$\begin{array}{l}\text { Building } \\
\text { Quality }\end{array}$} & Airtightness & $14 \%$ & $1.44 \%$ & 1 & 1 \\
\hline & & $\begin{array}{l}\text { Communal } \\
\text { Areas }\end{array}$ & $12 \%$ & $1.23 \%$ & 2 & 4 \\
\hline & & Landscaping & $11 \%$ & $1.13 \%$ & 3 & 7 \\
\hline & & Safety & $21 \%$ & $2.15 \%$ & 3 & 6 \\
\hline & & Security & $21 \%$ & $2.15 \%$ & 2 & 12 \\
\hline & & $\begin{array}{l}\text { Weather- } \\
\text { tightness }\end{array}$ & $21 \%$ & $2.15 \%$ & 1 & 1 \\
\hline & \multirow{8}{*}{$\begin{array}{l}\text { Building } \\
\text { Services \& } \\
\text { Amenities }\end{array}$} & Drainage & $11 \%$ & $0.85 \%$ & 3 & 3 \\
\hline & & $\begin{array}{l}\text { Emergency } \\
\text { Escape }\end{array}$ & $16 \%$ & $1.24 \%$ & 2 & 6 \\
\hline & & Facilities & $13 \%$ & $1.01 \%$ & 3 & 3 \\
\hline & & Lifts & $11 \%$ & $0.85 \%$ & 4 & 4 \\
\hline & & Parking & $11 \%$ & $0.85 \%$ & 6 & 9 \\
\hline & & $\begin{array}{l}\text { Rubbish \& } \\
\text { Recycling } \\
\text { Facilities } \\
\end{array}$ & $13 \%$ & $1.01 \%$ & 4 & 4 \\
\hline & & Water Supply & $13 \%$ & $1.01 \%$ & 2 & 2 \\
\hline & & Utilities & $12 \%$ & $0.93 \%$ & 3 & 3 \\
\hline & \multirow{3}{*}{$\begin{array}{l}\text { Materials } \\
\text { Quality }\end{array}$} & $\begin{array}{l}\text { Deterioration } \\
\text { \& Durability }\end{array}$ & $39 \%$ & $2.73 \%$ & 2 & 2 \\
\hline & & Emissions & $29 \%$ & $2.03 \%$ & 1 & 1 \\
\hline & & $\begin{array}{l}\text { Toxic } \\
\text { Materials }\end{array}$ & $32 \%$ & $2.24 \%$ & 2 & 2 \\
\hline
\end{tabular}

Table G-20, Component and Global Weightings for Quality Sections

\begin{tabular}{|c|c|c|c|c|c|c|}
\hline $\begin{array}{l}\text { Level } 2 \\
\text { Category }\end{array}$ & $\begin{array}{l}\text { Level } 3 \\
\text { Section }\end{array}$ & $\begin{array}{l}\text { Component } \\
\text { Weighting }\end{array}$ & $\begin{array}{l}\text { Global } \\
\text { Weighting }\end{array}$ & $\begin{array}{l}\text { Level } 4 \\
\text { Feature }\end{array}$ & $\begin{array}{l}\text { Level } 5 \\
\text { Aspect }\end{array}$ & $\begin{array}{l}\text { Level } 6 \\
\text { Indicators }\end{array}$ \\
\hline \multirow{3}{*}{ Quality } & $\begin{array}{l}\text { Building } \\
\text { Quality }\end{array}$ & $41 \%$ & $10.25 \%$ & 6 & 12 & 31 \\
\hline & $\begin{array}{l}\text { Building } \\
\text { Services \& } \\
\text { Amenities }\end{array}$ & $31 \%$ & $7.75 \%$ & 8 & 27 & 34 \\
\hline & $\begin{array}{l}\text { Materials } \\
\text { Quality }\end{array}$ & $28 \%$ & $7.00 \%$ & 3 & 5 & 5 \\
\hline
\end{tabular}




\section{APPENDIX H OTHER}

The information presented in this Appendix discusses the sixth Category identified in the literature review (discussed in Section 2.2) and the development of these factors in regards to inclusion within the NZ ALI hierarchy. The framework development discussed here follows the same process as that discussed in Section 3.2, Section 4.1 and Figure 4-2.

\section{Factor Assessment}

Other, the sixth Category created from the literature review was developed from factors that were not directly related to liveability in the built environment, or were reasons why people choose to live in a space that did not impact their well-being. Initially there were six factors (Figure 2-8, Chapter 2.2); however assessment showed that there were four repeated factors Lifestyle and Sustainability. These are shown in Figure $\mathrm{H}-1$ where the blue factors are from the academic literature, red from the popular press and green are repeated factors identified in both sets of literature.

\begin{tabular}{|l|}
\hline Other \\
Considers non building, design or site related \\
factors \\
\\
Affordability \\
Availability \\
Energy Efficiency/Use \\
Finance \\
Lifestyle \\
Sustainability
\end{tabular}

Figure H-1, Other - Associated Factors

As discussed in Section 3.1, all factors considered should be directly related to the health, comfort wellbeing and safety of occupants, users and visitors. Because these four factors are not liveability issues and they are instead reasons why people make a dwelling choice (i.e. affordability and sustainability) they did not meet the requirements of Criterion \#1. Because of this, they were removed from future inclusion in the Apartment Liveability Index because they are not relevant to liveability. While these issues are important, they cannot be included due to the irrelevance to the scope at hand. It is considered that at a later stage these may be included should NZ ALI become a more comprehensive assessment of liveability and sustainability.

Therefore, no further development of this Category was required and only five Categories were included with NZ ALI: Community; Configuration; Governance; Indoor Environmental Quality; and Quality. 


\section{APPENDIX I THE NZ ALI QUESTIONNAIRE}

The information presented in Appendix I: NZ ALI Calibration provides information on the NZ ALI Questionnaire including survey development $\&$ design, data collection and statistical data analysis. Analysis of Part 1, 2 and 3 data is presented in Appendices C G as it applies to those Categories.

\section{I.1 QUESTIONNAIRE DEVELOPMENT}

A survey was used to gain data required to develop component weightings and calibrate NZ ALI

This Section will discuss the NZ ALI Questionnaire particularly the instrument itself, data collection and the analysis procedure. A survey was determined to be the most appropriate instrument to gain the required data for the research for two reasons. Firstly a survey is useful because it allows for participant anonymity, lack of bias from interviewers and the ability to collect large amounts of information from participants. Secondly it would follow the method used for BQA, BQI and HPMFRB.

\section{I.1.1 SURVEY INTERFACE}

It was decided that in order to undertake the survey within the time available, two survey tools would be required. The first was an online survey, and the second a traditional postal survey. The online survey was chosen because it is effective and efficient at surveying large amounts of people quickly and can provide the responses digitally for ease of analysis. However it was accepted that this type of survey may exclude some people from participating due to restricted or no internet access, a postal survey would also be required.

Selected people were initially contacted to ask if they would like to participate in the survey. This was done via email and post (where email addresses were not available). Those who responded where then also asked to indicate which survey form they would like to complete online or postal.

\section{I.1.1.1 WEB SURVEY}

Undertaking a web based survey was advantageous for a number of reasons the results could be collected easily and efficiently in a useable format, survey layout and interface could be standardised easily and manual data entry and possible errors could also be minimised.

A number of online survey tools were evaluated to determine which would be the best for this work as shown in Table I-1. 
Table I-1, Online Survey Tool Requirements

\begin{tabular}{|l|l|}
\hline Online Survey Tool Criteria & Requirement \\
\hline Number of questions allowed & 91 in total \\
\hline Number of answers allowed per question & 8 maximum \\
\hline Number of respondents allowed & 60 or more \\
\hline Price & No more than \$40/month \\
\hline Question Types & $\begin{array}{l}\text { Ranking, Multiple Choice, Single } \\
\text { Answer and Text/Comment }\end{array}$ \\
\hline End data format & $\begin{array}{l}\text { Microsoft Excel. Or importable } \\
\text { data format }\end{array}$ \\
\hline The ability to include images & For Part 2 and VUW logo \\
\hline The ability to have a password or unique coding for each survey & 60 or more \\
\hline The ability to have one response per survey code & Highly Important \\
\hline IP address or cookie storage & If unable to have a unique code \\
\hline The ability to have a survey end date & Highly Important \\
\hline The ability for respondents to save and complete at a later date & Important \\
\hline Send invitations online & Important \\
\hline $\begin{array}{l}\text { Send reminder notice to respondents who have not yet } \\
\text { participated or are part way through }\end{array}$ & Highly Important \\
\hline
\end{tabular}

The final online survey tool that was chosen for this research was ZapSurvey (ZapSurvey, 2009) because it was deemed to be able to provide each of the above criteria the best. While it could not provide a unique code for each survey it stores IP addresses which allowed a survey to be completed only once on a computer.

\section{I.1.1.2 POSTAL SURVEY}

The postal survey was simply a hard copy, Microsoft Word formatted version of the online survey. Each of these surveys was also uniquely coded so that these surveys could also only be recorded once. Participants were again informed that should they wish to complete online they could do so by going to the internet address and using the unique code provided.

Participants were encouraged to undertake the survey online is possible due to the fast reporting and turn around time in comparison to the postal survey. A copy of this survey is provided in this Appendix.

\section{I.1.2 SURVEY PROCEDURE}

Undertaking the questionnaire occurred in the following stages:

- Email/letter sent to selected people asking for their participation

- Call or email response from interested participants, stating how they would prefer to complete survey (via post or online) 
- Survey conducted over four week period, online survey closed after this time, postal surveys mailed after this not included

- Online Participants

- Email sent to each respondent, providing link to website and unique questionnaire code

- Reminder email sent to each participant one week prior to closing of survey

- Online survey closed

- Postal Participants

- Survey mailed to each respondent, with hard copy of survey (each having unique code), and pre-paid, addressed reply envelope

- Participants invited again to complete survey online via website with unique code

- Participant to complete and return via attached envelope within one month

Directly following the questionnaire completion, post survey work included:

- Data collation (between online and postal surveys)

- Preliminary data analysis \& evaluation

\section{I.1.3 SURVEY DESIGN}

The rankings questionnaire was modelled from that used by researchers who developed the Building Quality Assessment (BQA) tool for office and retail buildings (Baird, Gray, Isaacs, Kernohan, \& McIndoe, 1995). The survey consisted of 4 parts as follows and can be viewed in this Appendix:

1. Aspects \& Features

a. Aspects

i. Aspects listed under each Feature were considered and participants were required to choose one Aspect they considered the most important

b. Features

i. Features listed under each Section were considered and participants were required to rank each in order of importance.

ii. If a participant felt a Feature was not important in any way they could also select N/A

2. Sections

a. Sections were listed under each Category and participants were required to rank each in order of importance.

b. N/A was not an option.

3. Categories

a. Categories were listed under the Objective and participants were require to rank each in order of importance

b. N/A was not an option.

4. Demographics 
a. Participants were asked a series of questions concerning their demographics (i.e. age, gender, location, occupation, dwelling type) to determine where difference in opinions may occur across groups

\section{I.1.4 TARGET POPULATION}

The target population of the NZ ALI Questionnaire was aimed at the end users previously identified (Section 3.2). These were:

- Body Corporate Members or Building Managers

- Building Owners and Property Developers

- Designers, Architects, Consultants and Engineers

- Government Organisations (such as Council, T Building and Housing [DBH])

- Apartment Occupants (Past or Present)

- Researchers \& Academics

As this research is a pilot study of the methodology it was determined that approximately 10 participants from each group would be required. In total 60 participants were required. Ethics Approval was granted by the Victoria University of Wellington Human Ethics Committee Ethics Approval No. 16260. 


\section{I.2 NZ ALI QUESTIONNAIRE DESIGN}

\section{NZ ALI QUESTIONNAIRE} Jessica Bennett, MBSc Candidate, VUW

\section{NEW ZEALAND APARTMENT LIVING: Developing a Liveability Index}

\section{NZ ALI QUESTIONNAIRE}

In the past two decades more apartments have been built around New Zealand. Unfortunately a number of issues with apartment design, construction and lifestyle are now coming to light.

The Apartment Liveability Index (ALI) is being developed for apartment occupants to use in order to evaluate (and compare) how apartments may affect their liveability (health, comfort, safety and well-being). A hierarchy of building features has been developed so that each building feature relates to the overall objective - Occupant Liveability in Apartments. This is shown in Figure 1 on the second page of this questionnaire.

The purpose of this questionnaire is for assigning weights to each of the categories and sections so that ALI may provide a standardised 'score' of an apartment. This will enable one apartment to be compared to another. The development of ALI would benefit from your opinions and knowledge of New Zealand apartments. Please complete this survey from your opinion considering;

How important is each issue to you when considering liveability in apartments?

You will consider four levels of the hierarchy, Level 2 - Categories, Level 3 -Sections, Level 4 - Subsections and Level 5 - Building Features.

There are three parts to the questionnaire. Please refer to the beginning of each for instructions. This questionnaire should take you approximately $20-25$ mins to complete. Thank-you for your time. 


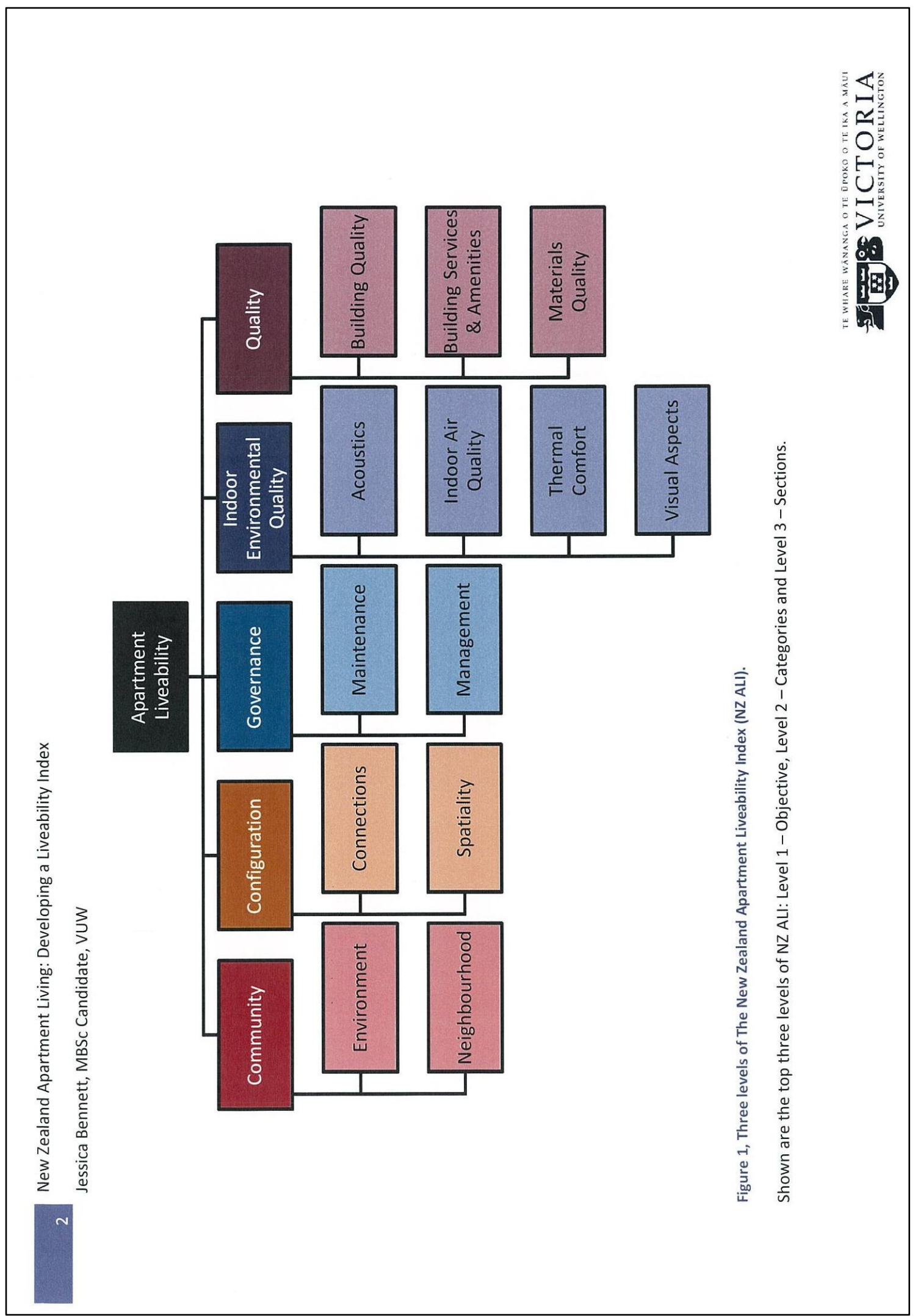

Figure I-2, NZ ALI Questionnaire Page 2 


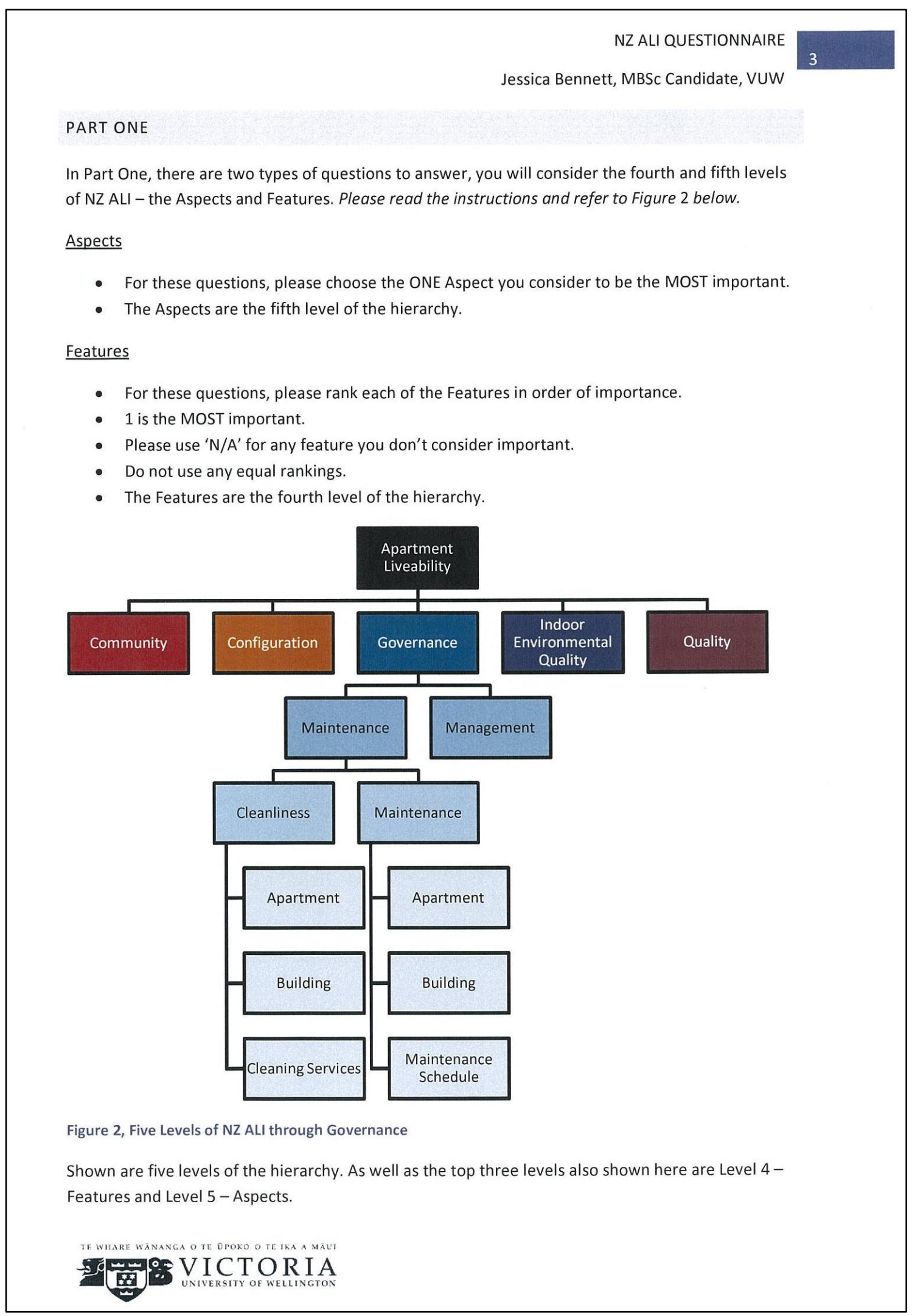

Figure I-3, NZ ALI Questionnaire Page 3 
Jessica Bennett, MBSc Candidate, VUW

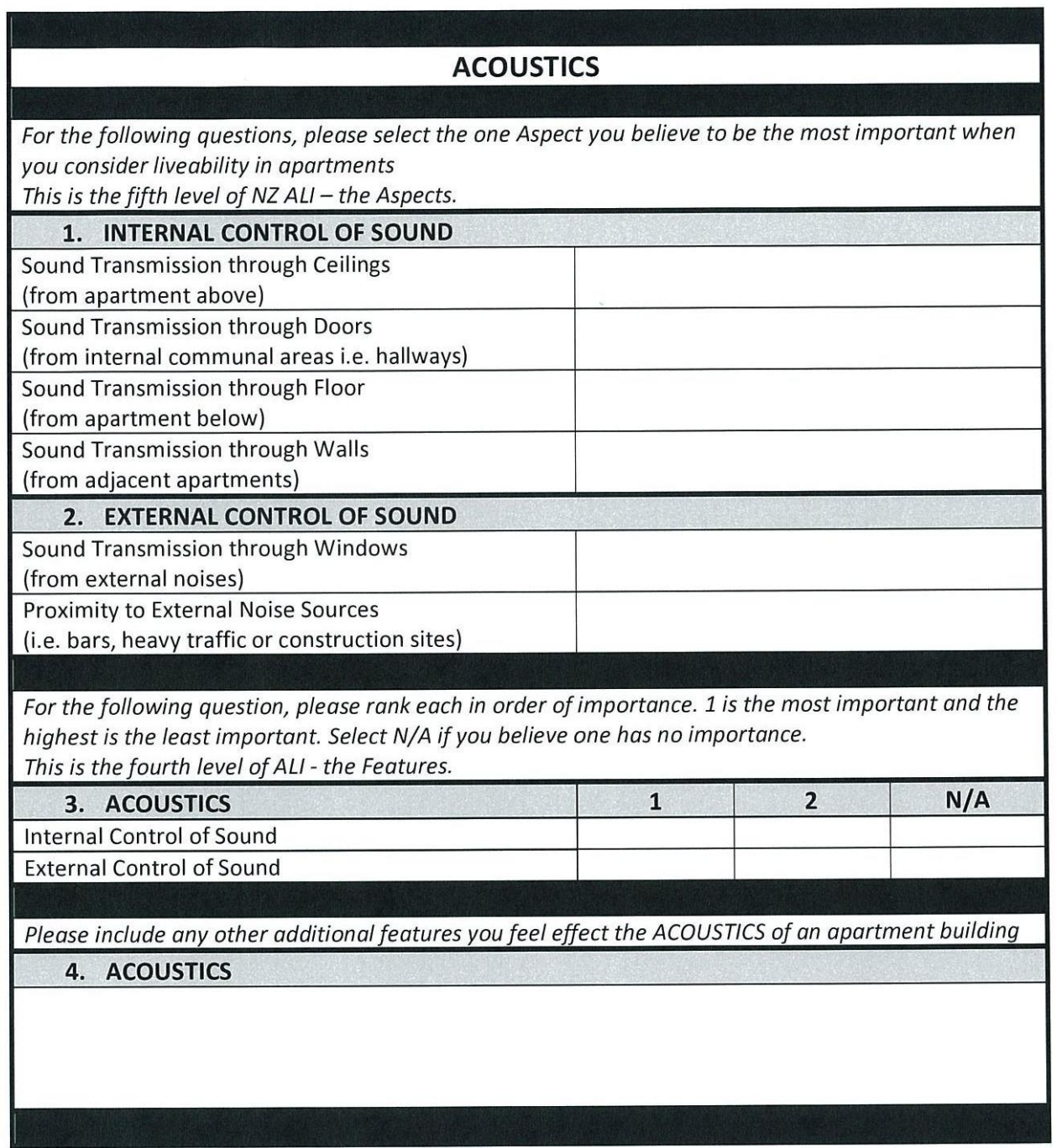

Figure I-4, NZ ALI Questionnaire Page 4 
NZ ALI QUESTIONNAIRE

Jessica Bennett, MBSc Candidate, VUW

\section{BUILDING QUALITY}

For the following questions, please select the one Aspect you believe to be the most important when you consider liveability in apartments

This is the fifth level of NZ ALI - the Aspects.

\section{AIRTIGHTNESS}

Air Leakage

(i.e. passive infiltration \& ventilation through building envelope)

Draughts

(i.e. unwanted and nuisance air movement through

windows and doors)

\section{COMMUNAL AREAS}

Access Ways

Garages \& Parking Areas

Lifts \& Stairs

Storage Areas

3. LANDSCAPING

Building Entrances

Building \& Site Boundaries

Communal Outdoor Areas

4. SAFETY

Electrical Safety

(i.e. from unsafe electrical points)

Injury Prevention

(i.e. from slips, trips, falls and collisions)

Structural Safety

(i.e. building collapse)

5. SECURITY

Entrance \& Access Ways

Garages \& Parking Areas

Mailbox Facilities

Storage Areas

6. WEATHERTIGHTNESS

Leaky Building Issues

(i.e. issues but no WHRS claims made)

Claims made to WHRS

(Weathertightness Home Resolution Service)

Figure I-5, NZ ALI Questionnaire Page 5 
New Zealand Apartment Living: Developing a Liveability Index

Jessica Bennett, MBSc Candidate, VUW

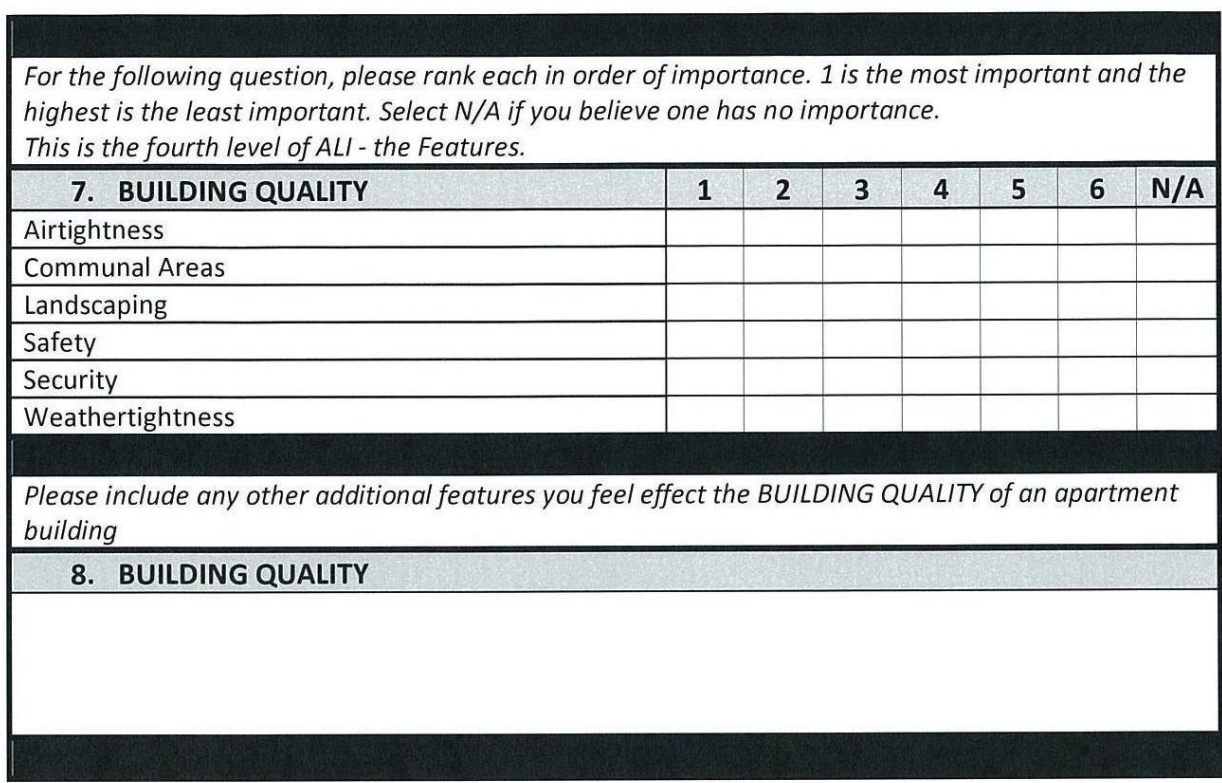




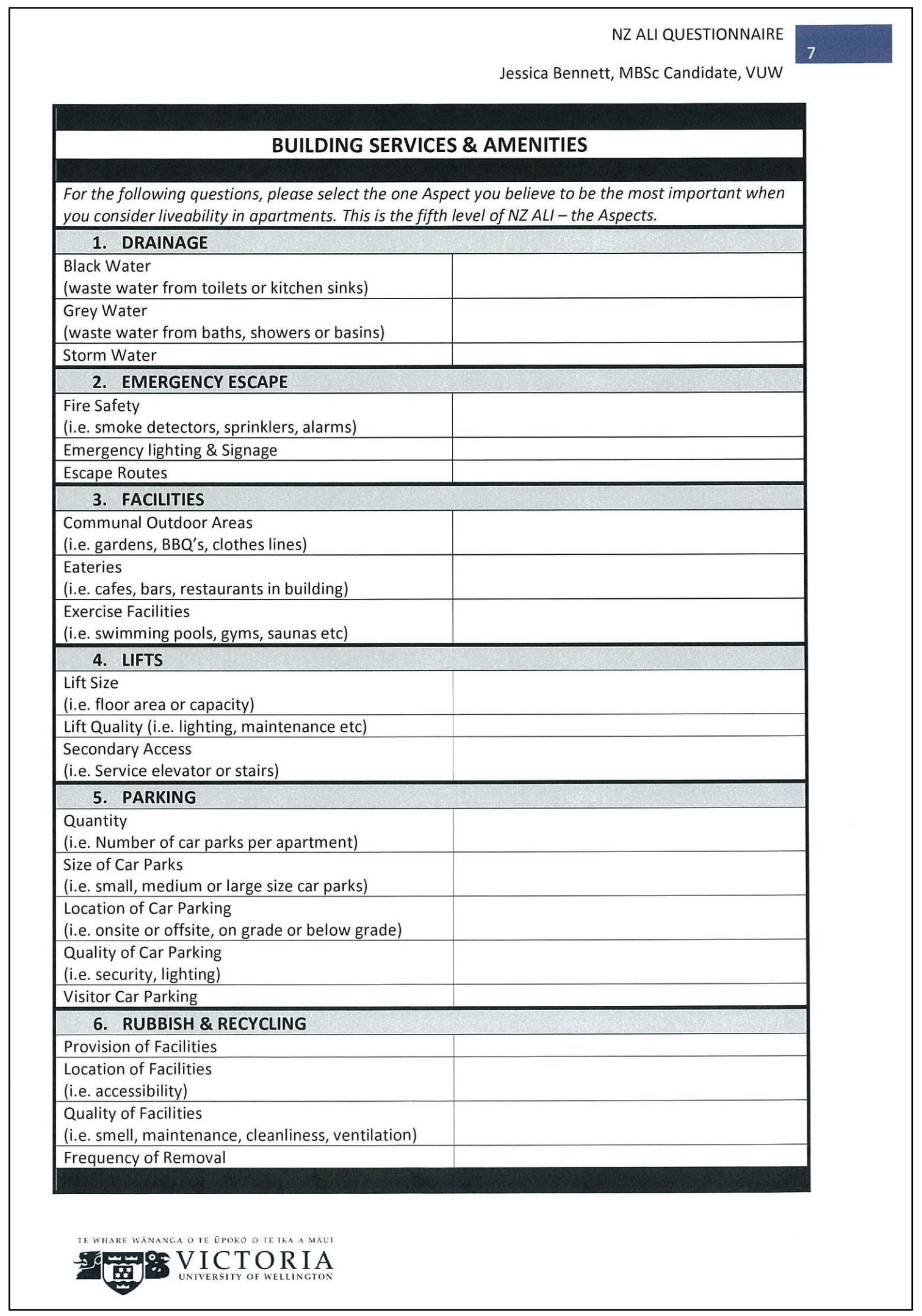

Figure I-7, NZ ALI Questionnaire Page 7 


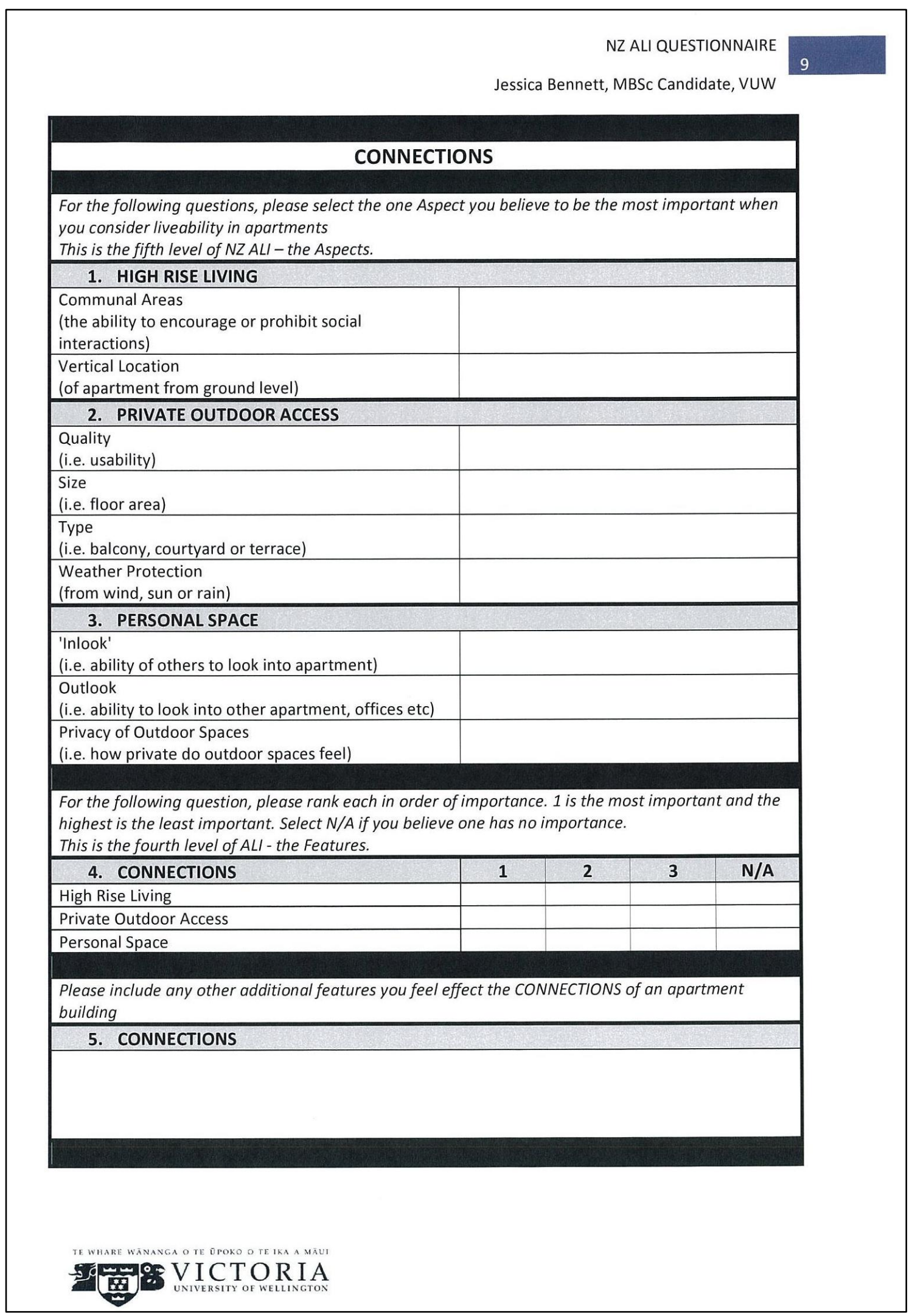

Figure I-9, NZ ALI Questionnaire Page 9 


\section{ENVIRONMENT}

For the following questions, please select the one Aspect you believe to be the most important when you consider live ability in apartments

This is the fifth level of $N Z A L I-$ the Aspects.

\section{LOCATION}

Site Typology

(i.e. sunny, cold, short building, hilly etc)

Surrounding Use

(i.e. residential, commercial, open space)

Outdoor Air Quality

(i.e. smell from industrial sites, traffic, fast food

outlets like MacDonald's or KFC)

\section{URBAN DENSITY}

Present Building Heights

(if buildings in area stayed at current heights)

Future Building Heights

(if buildings in area were allowed to be taller by

District Plan)

\section{WIND}

Downwash from Buildings

(wind forced down the windward face of a building to

pedestrian level)

Corner Effect

(severe winds around corners of buildings)

Funnelling/Channelling

(wind is channelled down streets, gathering

momentum as it goes)

For the following question, please rank each in order of importance. 1 is the most important and the highest is the least important. Select N/A if you believe one has no importance.

This is the fourth level of $A L I$ - the Features.

\begin{tabular}{|c|c|c|c|c|}
\hline 4. ENVIRONMENT & 1 & 2 & 3 & $\mathrm{~N} / \mathrm{A}$ \\
\hline \multicolumn{5}{|l|}{ Location } \\
\hline \multicolumn{5}{|l|}{ Urban Density } \\
\hline \multicolumn{5}{|l|}{ Wind Environment } \\
\hline \multicolumn{5}{|c|}{$\begin{array}{l}\text { Please include any other additional features you feel effect the ENVIRONMENT of an apartment } \\
\text { building }\end{array}$} \\
\hline 5. ENVIRONMENT & & & & \\
\hline
\end{tabular}

Figure I-10, NZ ALI Questionnaire Page 10 


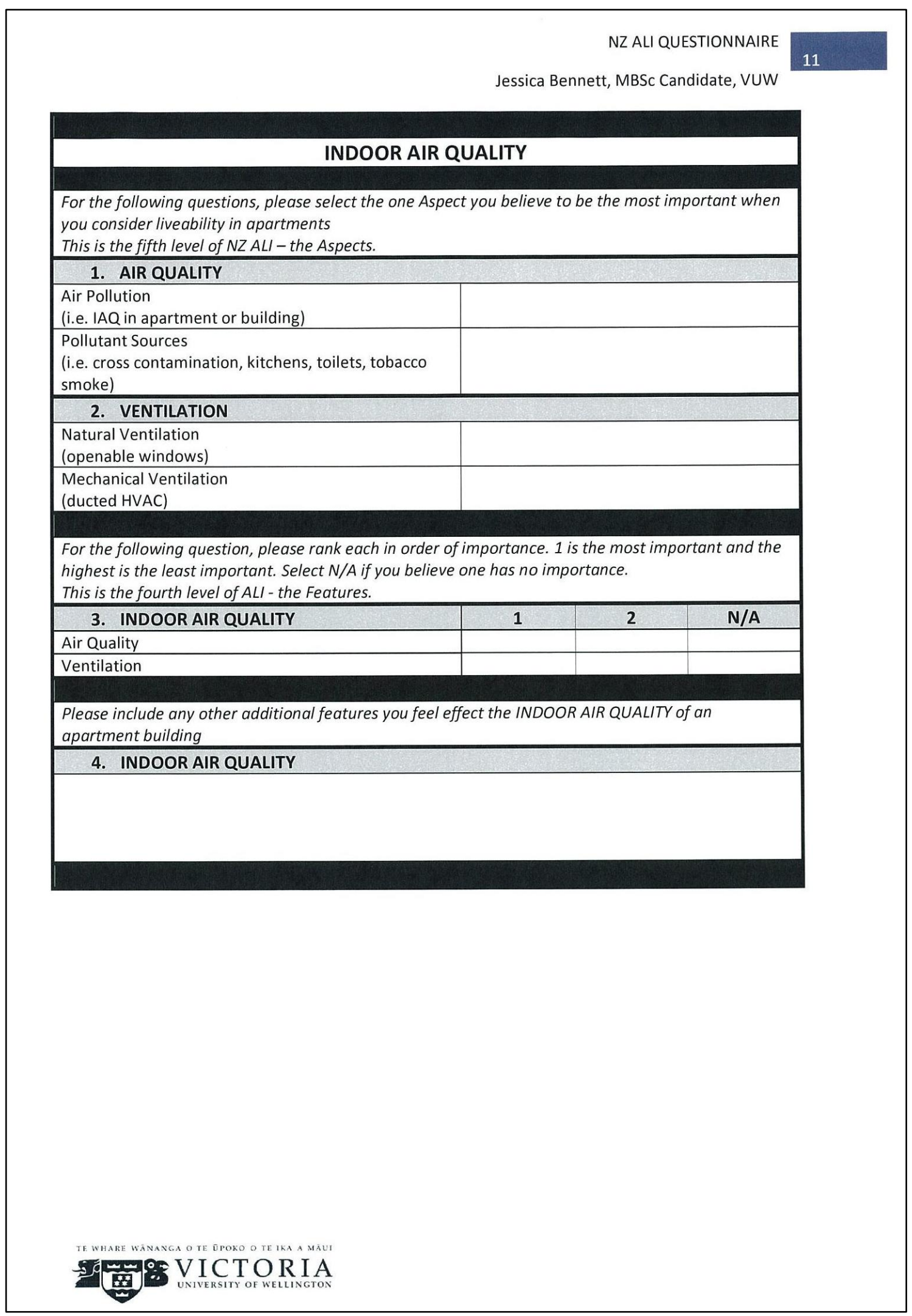

Figure I-11, NZ ALI Questionnaire Page 11 


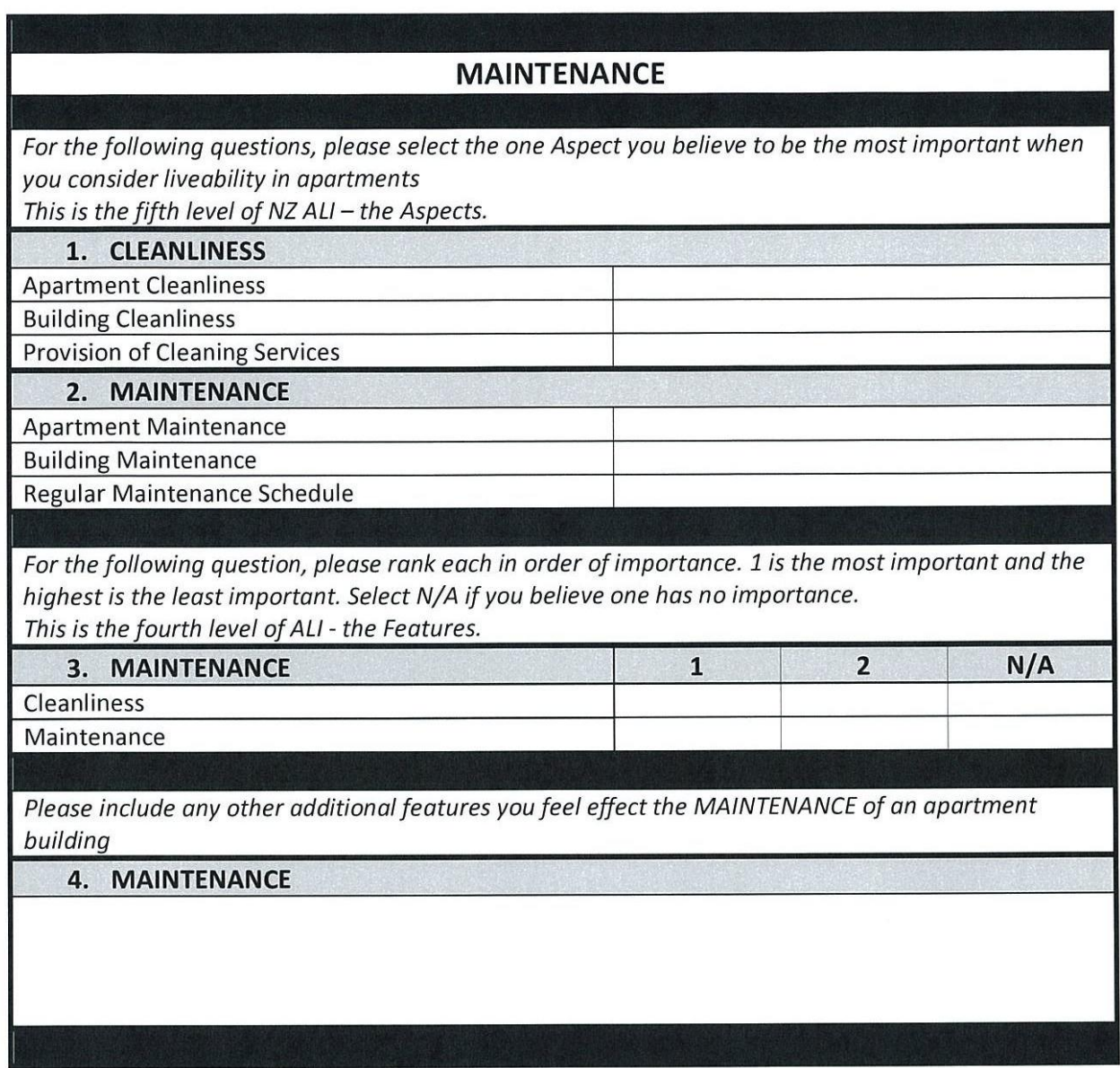




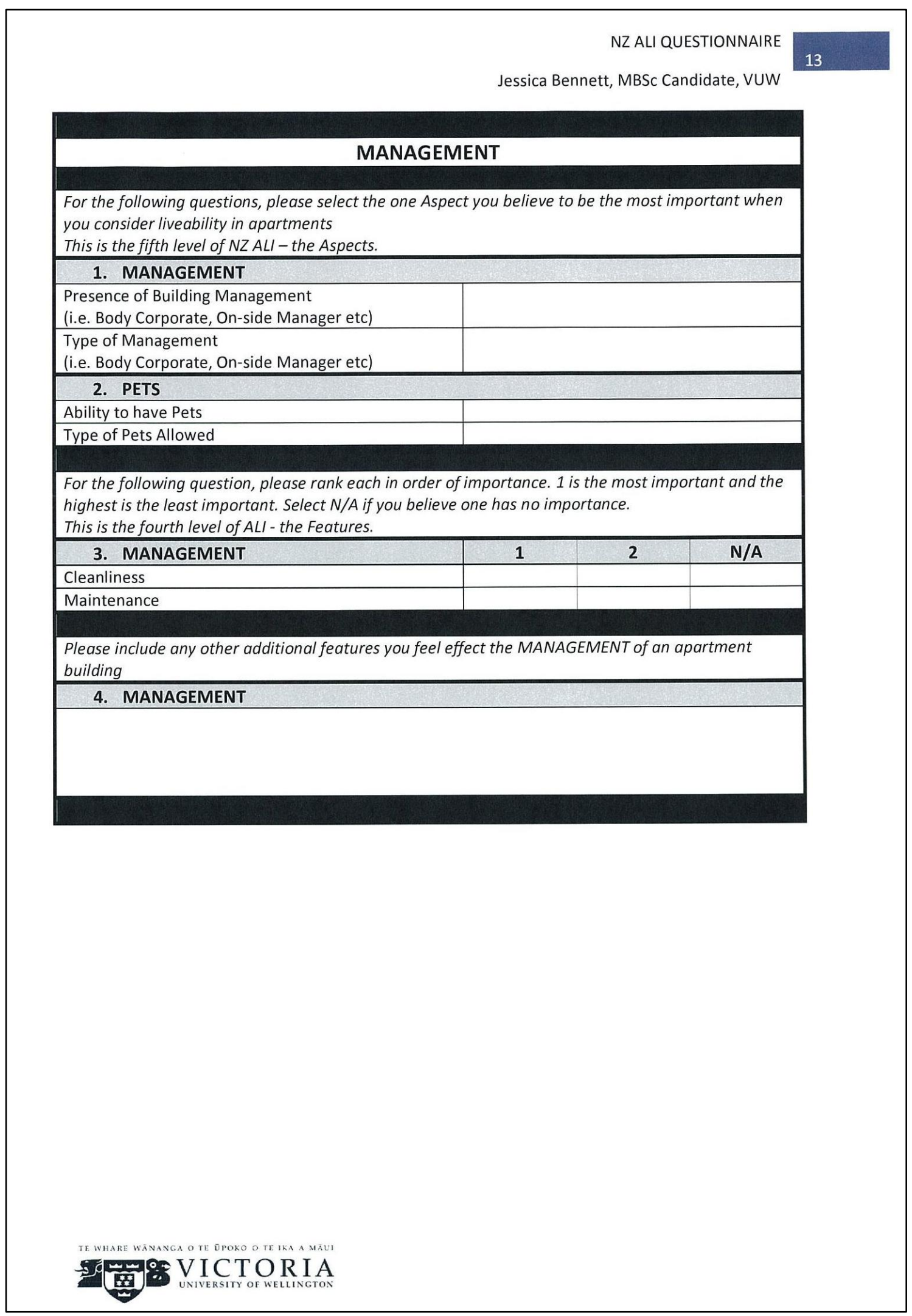

Figure I-13, NZ ALI Questionnaire Page 13 
Jessica Bennett, MBSc Candidate, VUW

\section{MATERIALS QUALITY}

For the following questions, please select the one Aspect you believe to be the most important when you consider liveability in apartments

This is the fifth level of NZ ALI - the Aspects.

\section{DURABILITY \& DETERIORATION}

\begin{tabular}{l} 
Deterioration \\
\hline Durability
\end{tabular}

\section{EMISSIONS}

Release of toxins

(i.e. off-gassing)

Type of Toxins released

(i.e. VOC's, biocides, particulates etc)

\section{TOXIC MATERIALS} Asbestos

Lead

Other (please state)

For the following question, please rank each in order of importance. 1 is the most important and the highest is the least important. Select N/A if you believe one has no importance.

This is the fourth level of ALI - the Features.

\begin{tabular}{|l|l|l|l|l|}
\hline \multicolumn{1}{|c|}{ 4. MATERIALS QUALITY } & $\mathbf{1}$ & $\mathbf{2}$ & $\mathbf{3}$ & N/A \\
\hline Durability \& Deterioration & & & & \\
\hline Emissions & & & & \\
\hline Toxic Materials & & & & \\
\hline $\begin{array}{l}\text { Please include any other additional features you feel effect the MATERIALS QUALITY of an apartment } \\
\text { building }\end{array}$ \\
\hline 5. MATERIALS QUALITY
\end{tabular}




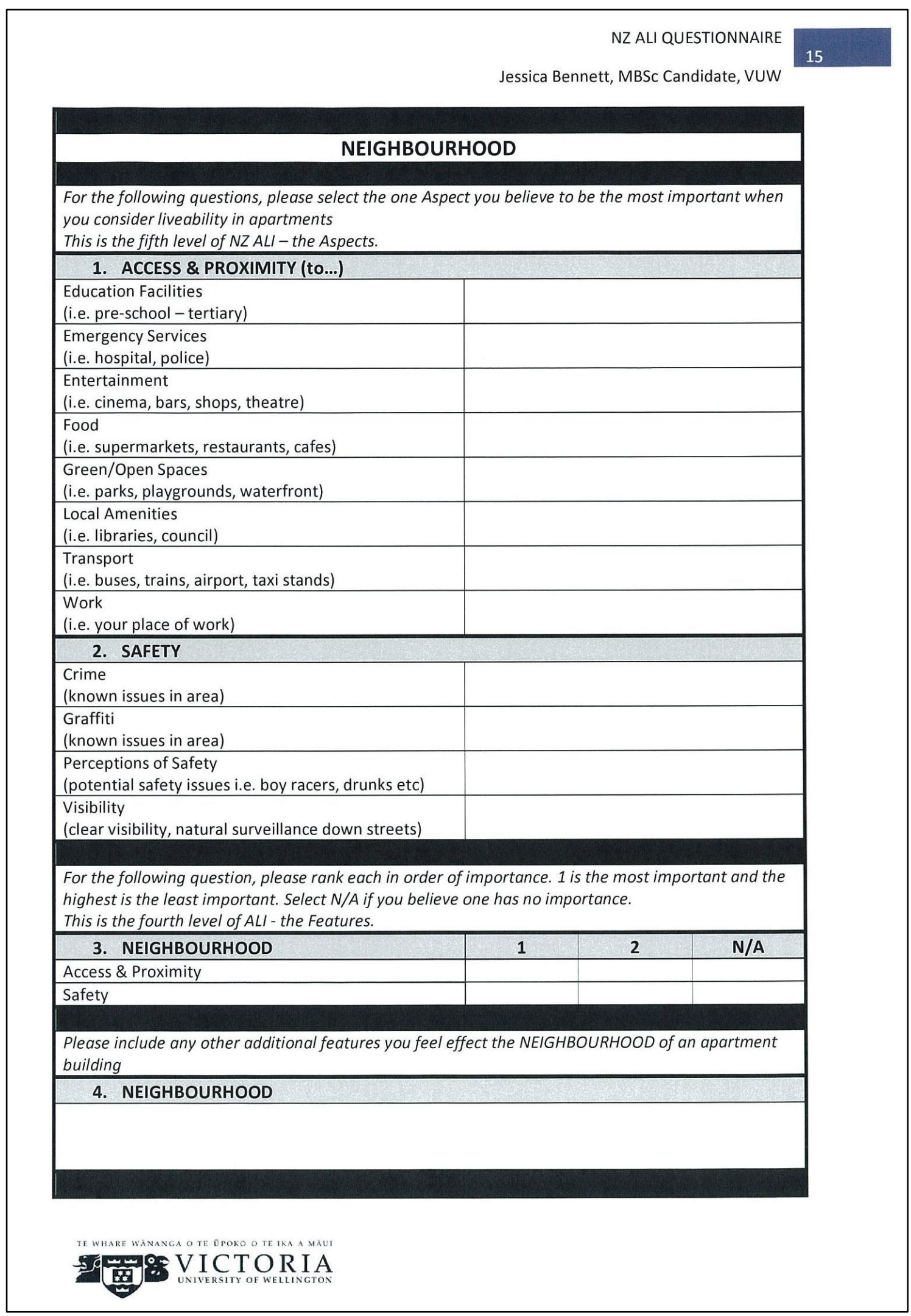

Figure I-15, NZ ALI Questionnaire Page 15 


\section{SPATIALITY}

For the following questions, please select the one Aspect you believe to be the most important when you consider liveability in apartments

This is the fifth level of NZ ALI - the Aspects.

1. OCCUPANCY \& DENSITY

Number of occupants per unit

Number of occupants within building

\section{APARTMENT SIZE}

Floor Area

Headroom (floor to ceiling height)

3. SHAPE \& CONFIGURATION

Number of external walls $(1,2,3 \ldots)$

Number of external walls with windows $(1,2,3 \ldots)$

\section{SPATIAL ORGANISATION}

Apartment Layout

Proximity of Living Spaces to Kitchens and Bathrooms

\section{STORAGE}

Location (within apartment, within building or offsite)

Quality (free of mould, well ventilated)

Size

Large Item Storage (excess furniture)

For the following question, please rank each in order of importance. 1 is the most important and the highest is the least important. Select N/A if you believe one has no importance.

This is the fourth level of ALI - the Features.

\begin{tabular}{|l|l|l|l|l|l|l|}
\hline \multicolumn{1}{|c|}{ 6. SPATIALITY } & $\mathbf{1}$ & $\mathbf{2}$ & $\mathbf{3}$ & $\mathbf{4}$ & $\mathbf{5}$ & N/A \\
\hline Occupancy \& Density & & & & & & \\
\hline Apartment Size & & & & & & \\
\hline Shape \& Configuration & & & & & & \\
\hline Spatial Organisation & & & & & & \\
\hline Storage & & & & & \\
\hline \\
Please include any other additional features you feel effect the SPATIALITY of an apartment building \\
\hline 7. SPATIALITY
\end{tabular}

Figure I-16, NZ ALI Questionnaire Page 16 


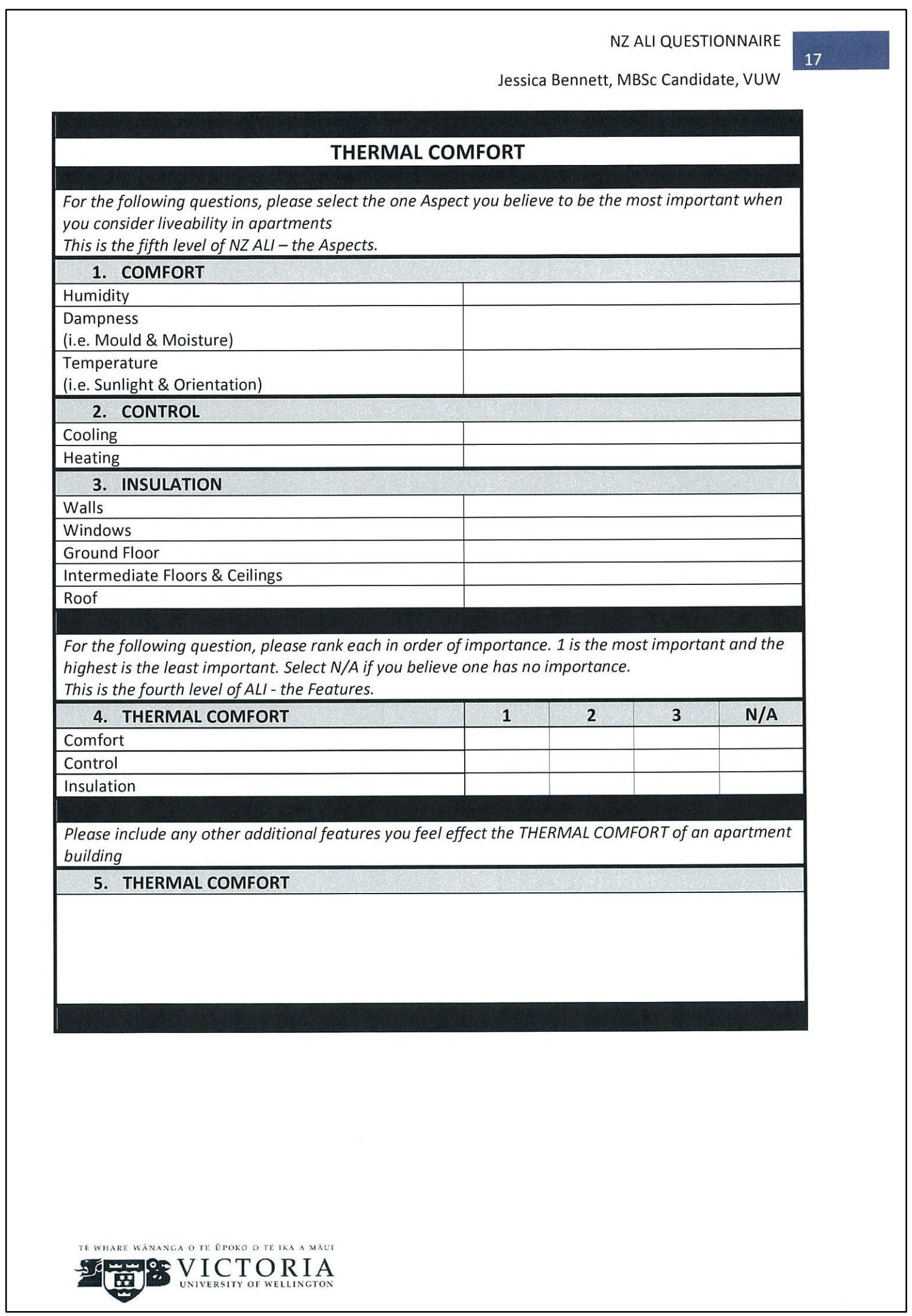

Figure I-17, NZ ALI Questionnaire Page 17 


\begin{tabular}{|l|l|}
\hline \multicolumn{2}{|c|}{ VISUAL ASPECTS } \\
\hline $\begin{array}{l}|c| \\
\text { For the following questions, please select the one Aspect you believe to be the most important when } \\
\text { you consider liveability in apartments } \\
\text { This is the fifth level of NZ ALI - the Aspects. }\end{array}$ \\
\hline 1. ADEQUATE TASK LIGHT & \\
\hline Orientation, Safety \& Walking & \\
\hline Eating \& Cooking & \\
\hline Reading \& Studying & \\
\hline 2. ARTIFICIAL LIGHT & \\
\hline Colour & \\
\hline Flicker \& Humming & \\
\hline Glare & \\
\hline 3. NATURAL LIGHT & \\
\hline Glare & \\
\hline Internal Bedrooms & \\
\hline Shading & \\
\hline 4. VIEWS & \\
\hline Views \\
\hline Visual Obstructions \\
\hline
\end{tabular}

For the following question, please rank each in order of importance. 1 is the most important and the highest is the least important. Select N/A if you believe one has no importance.

This is the fourth level of ALI - the Features.

\begin{tabular}{|l|c|c|c|c|c|}
\hline \multicolumn{1}{|c|}{ 5. VISUAL ASPECTS } & $\mathbf{1}$ & $\mathbf{2}$ & $\mathbf{3}$ & $\mathbf{4}$ & N/A \\
\hline Adequate Task Light & & & & & \\
\hline Artificial Light & & & & & \\
\hline Natural Light & & & & & \\
\hline Views & & & & & \\
\hline
\end{tabular}

Please include any other additional features you feel effect the VISUAL ASPECTS of an apartment building
6. VISUAL ASPECTS

Figure I-18, NZ ALI Questionnaire Page 18 


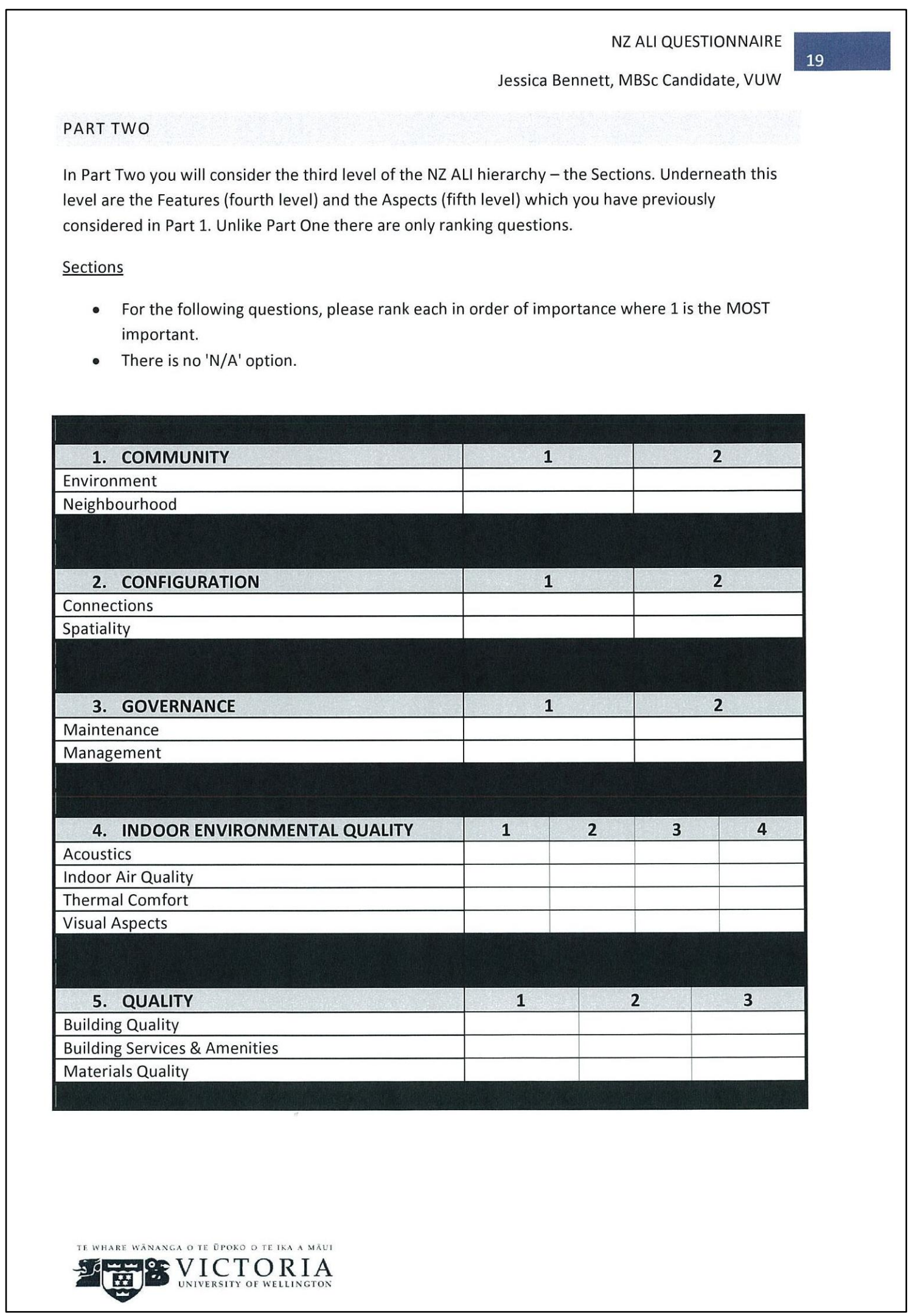

Figure I-19, NZ ALI Questionnaire Page 19 
New Zealand Apartment Living: Developing a Liveability Index

Jessica Bennett, MBSc Candidate, VUW

\section{PART THREE}

In Part Three you will consider the second level of the NZ ALI hierarchy - the Categories. Underneath this level are the Sections (third level), Features (fourth level) and the Aspects (fifth level). Like Part Two there are only ranking questions.

\section{Categories}

- For the following questions, please rank each in order of importance where 1 is the MOST important.

- There is no ' $N / A^{\prime}$ ' option.

\begin{tabular}{|l|c|c|c|c|c|}
\hline \multicolumn{1}{|c|}{ 1. NZ ALI } & $\mathbf{1}$ & $\mathbf{2}$ & $\mathbf{3}$ & $\mathbf{4}$ & $\mathbf{5}$ \\
\hline Community & & & & & \\
\hline Configuration & & & & & \\
\hline Governance & & & & & \\
\hline Indoor Environmental Quality & & & & & \\
\hline Quality & & & & & \\
\hline
\end{tabular}




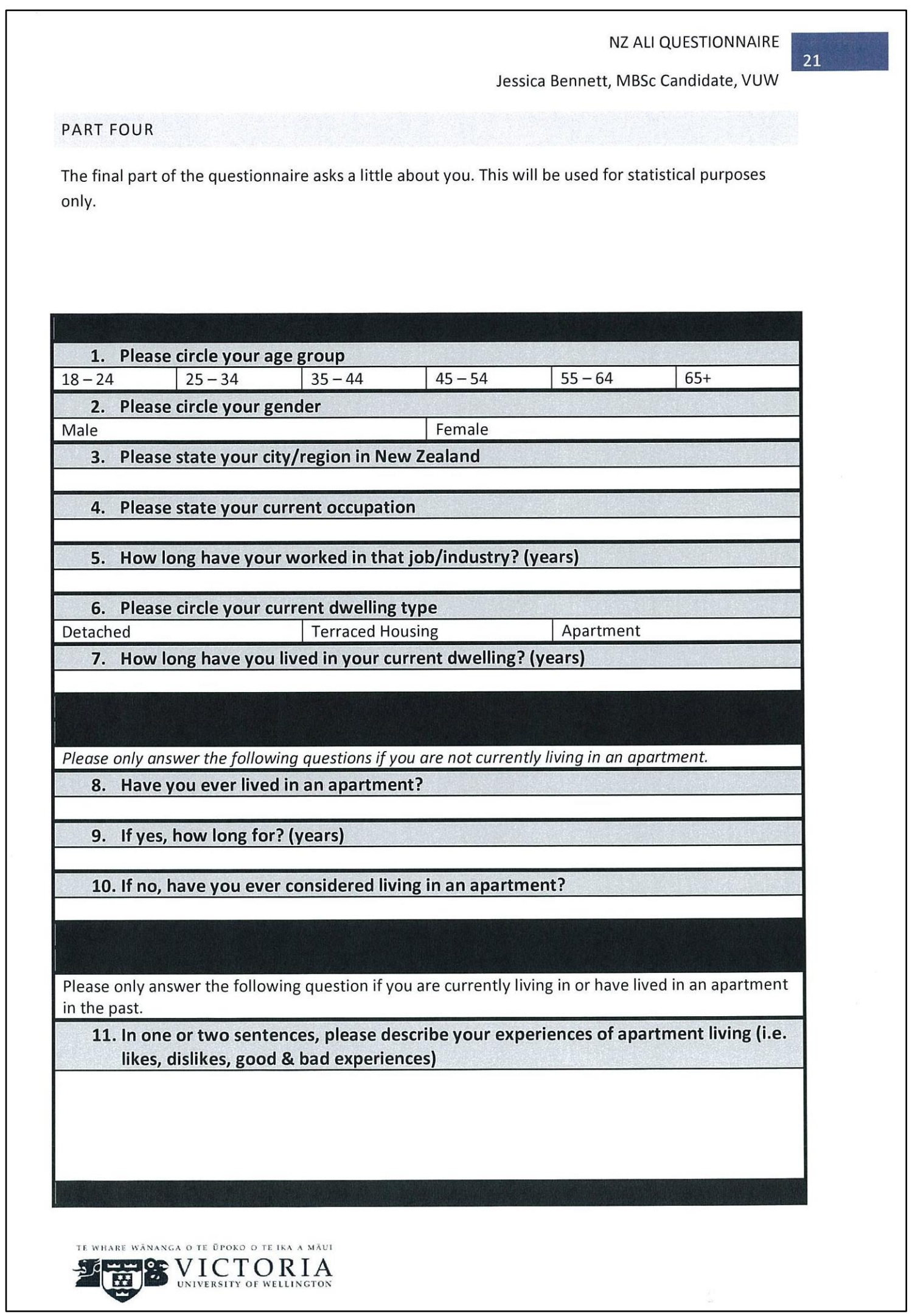

Figure I-21, NZ ALI Questionnaire Page 21 
New Zealand Apartment Living: Developing a Liveability Index

Jessica Bennett, MBSc Candidate, VUW

END OF SURVEY

Thank you for your time. The results from this survey will be available in May 2009.

If you would like feedback from this survey or are interested in the research outcomes, please include a forwarding address, or an email address below. Your contact information will remain confidential and will be destroyed upon the completion of this research. You can also use this space to add further comments on any questions in this survey.

Thank you for your time,

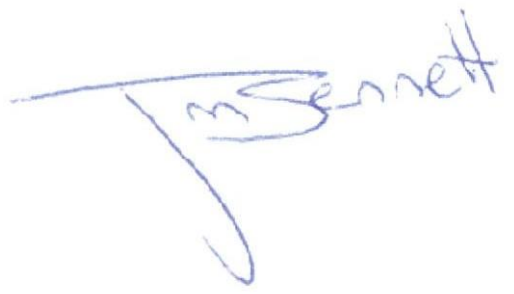

Jessica Bennett

Masters of Building Science Student

School of Architecture, Victoria University of Wellington

Email: bennetjess@myvuw.ac.nz

Phone: (04) 4636253

Figure I-22, NZ ALI Questionnaire Page 22 


\section{I.3 DATA COLLECTION}

The majority of participants responded via the web based survey instrument (83\%). This data was stored within ZapSurvey and was able to be collected in a variety of formats. For the data analysis the most useable format was data with the exact text of participant answers. This was stored as a comma separated value file, compatible with Microsoft Excel which was used to collate the data and undertake analysis. Once the postal surveys were obtained this data was entered into the Microsoft Excel file in the same format collected from ZapSurvey.

Once the survey data was collected it was stored electronically in a password protected file and will be destroyed after two years from completion of the research. Any hard copy postal surveys were also stored in a locked filing cabinet and will also be destroyed two years from completion of the research. For ethical reasons this data cannot be stored indefinitely however I needs to remain available for checking, review and further development. 
Discussed here is the analysis of the NZ ALI Questionnaire data. Two sets of data were obtained statistical data about the 47 participants and NZ ALI component data. Discussion regarding the analysis of component data is given in Section 4.3 and Appendices C G as they apply to those

Statistical questions such as age, gender, location and dwelling history were all asked so that

understanding of liveability in apartments. The NZ ALI Questionnaire data was analysed in two ways firstly as a whole to obtain component weightings and secondly the data was grouped by end user and dwelling history to understand how this may or may not affect participant responses.

\section{I.4.1 SURVEY RESPONSE}

The survey received a total of 47 responses, made up from five predetermined groups. Originally the survey aimed to question six end user groups, however due to low response rates from two groups (Building Management and Owners/Developers) they were combined into one group for analysis purposes as they have similarities. Refer to Table I-2 and Figure I-23 for response make up.

Table I-2, Response Rate for End-User and Stakeholder Groups

\begin{tabular}{|l|l|l|}
\hline Stakeholder Group & Abbreviation/Key & Response Rate \\
\hline $\begin{array}{l}\text { Management, Owners and } \\
\text { Developers }\end{array}$ & BMOD & $43 \%$ \\
\hline Architects & ARCH & $100 \%$ \\
\hline Government & GOVT & $64 \%$ \\
\hline Occupants & OCPT & $85 \%$ \\
\hline Academics & ACDM & $82 \%$ \\
\hline
\end{tabular}

It can be seen from Table I-2 that over half (53.2\%) of the survey responses were from two groups OCPT and ACDM. The response rate for the survey as a whole was $73 \%$. In total 64 people across the six stakeholder groups were contacted to participate in the survey with only 47 actually responding and completing the survey ${ }^{34}$. ARCH was by far the best group of respondents, followed by OCPT and

\footnotetext{
${ }^{34}$ Some survey responses were not completed correctly however if the participant had completed the majority of the survey correctly they were still included in the sample. Incomplete answers were not included.
} 
ACDM. The high response rate for these three groups was expected because of the knowledge of and interest in apartments that these groups have. BMOD and GOVT were both groups that were much harder to contact, so the low rate of response is not surprising here. Often participants had to be contacted multiple times to first agree to participate then to actually complete the survey.

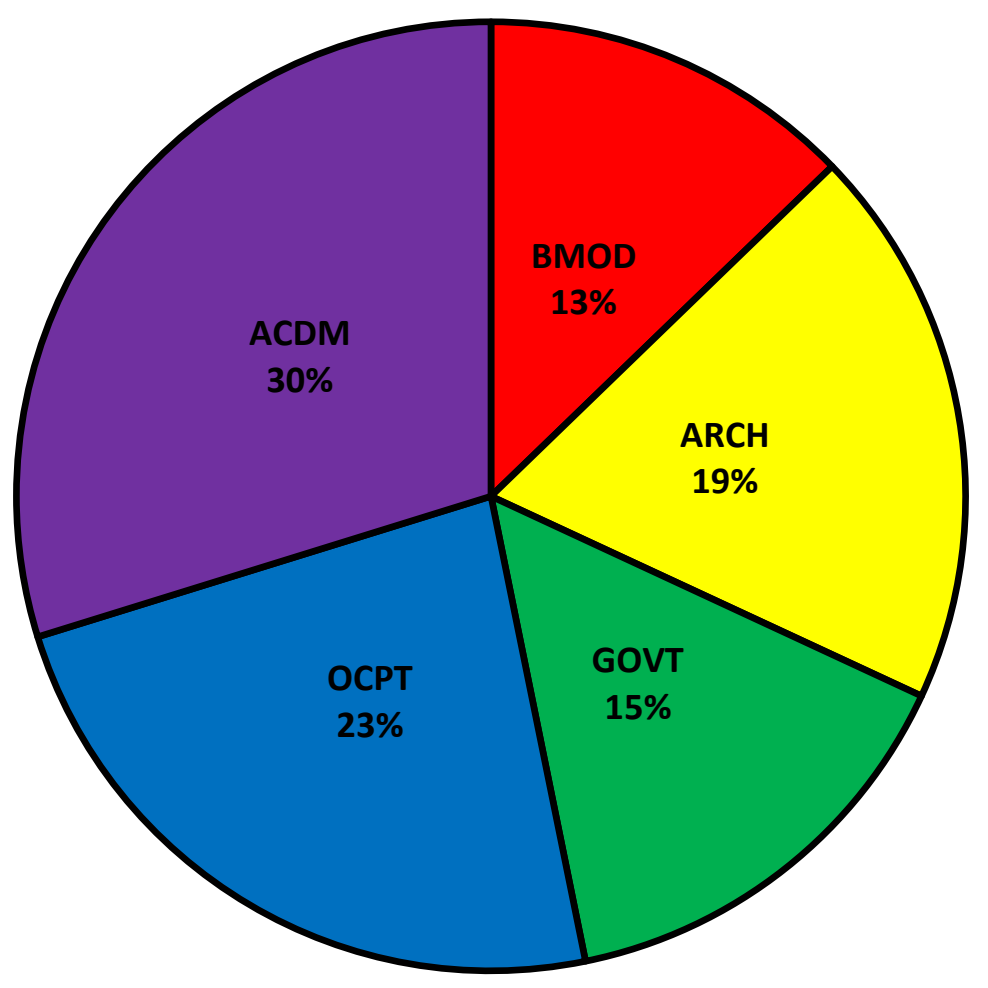

Figure I-23, Survey Responses by End User and Stakeholder Groups

Some survey responses were incomplete but were still included in the survey results. These were only postal surveys ${ }^{35}$ and there were only 3 that were incomplete. It was determined that it was possibly a misunderstanding in the instructions and the ability to simply not fill out an answer on the postal survey. Surveys completed online did not allow participants to complete questions incorrectly or to move on till all answers had been given.

Where these surveys were incomplete, any answers for those questions were removed from the data and all others remained.

\footnotetext{
${ }^{35}$ In total there were 8 postal surveys, mostly from the GOVT group. The other 39 surveys completed were all completed online.
} 


\section{I.4.2 RESPONDENT \& STATISTICAL DATA}

In total, there were 47 participants in the survey. Statistical questions such as age, gender, location and dwelling history were all asked so that answers to questions could be put into context to the

\section{Gender and Location}

Of the 47 participants, $64 \%$ were male and $36 \%$ were female, perhaps reflecting the often male dominated building and construction industry in New Zealand. $87 \%$ of participants were from Wellington, $9 \%$ from Auckland and $4 \%$ from Christchurch. The large proportion of Wellington participants is not surprising due to the fact that the study is being carried out in Wellington and the survey sample was not chosen randomly.

\section{Age}

Participants were asked to state their age group to determine how well represented each age group was. As shown in Figure I-24, two thirds of the participants were aged 18 34, and one third were aged 35 or over. There were 11 apartment occupants that participated and 9 of them were between 1832 years of age which mirrors the typical New Zealand apartment dweller age.

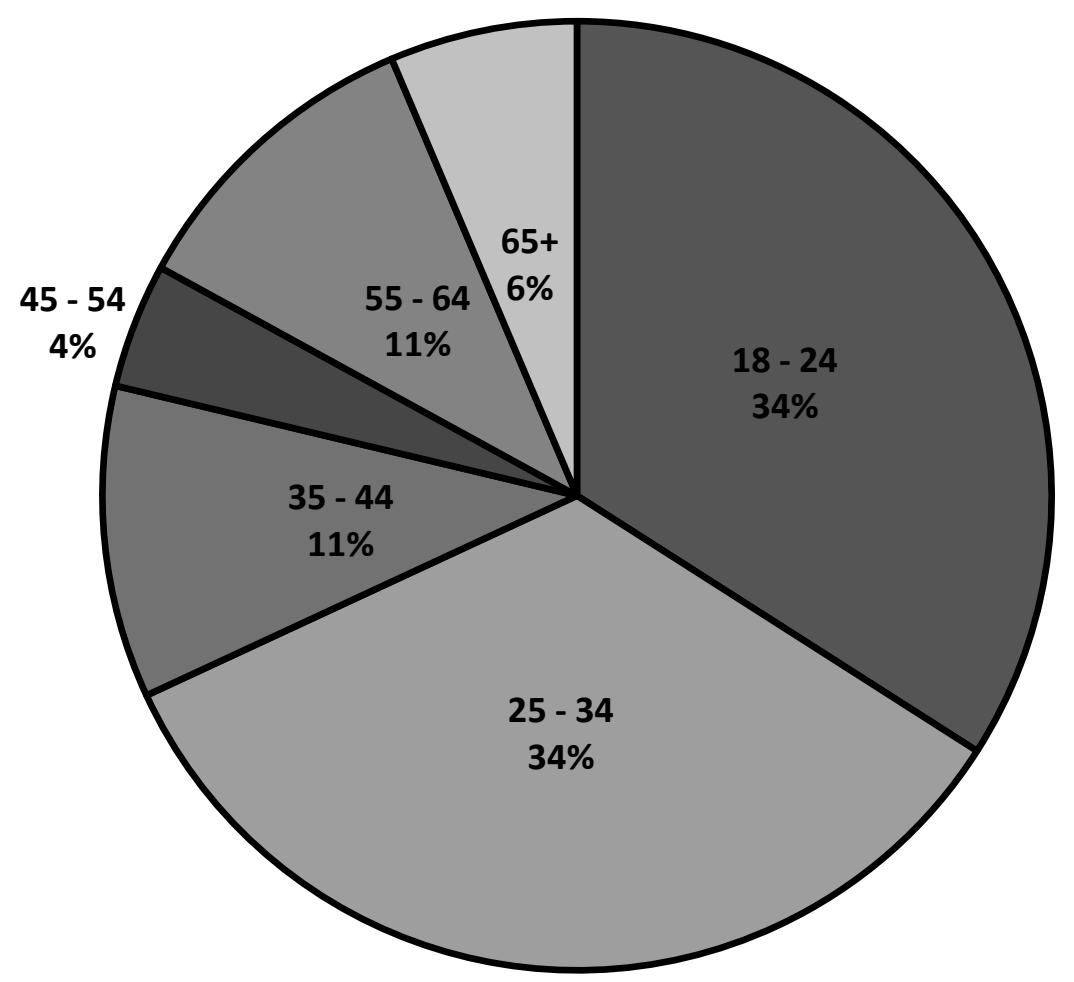

Figure I-24, Survey Responses by Age Group 


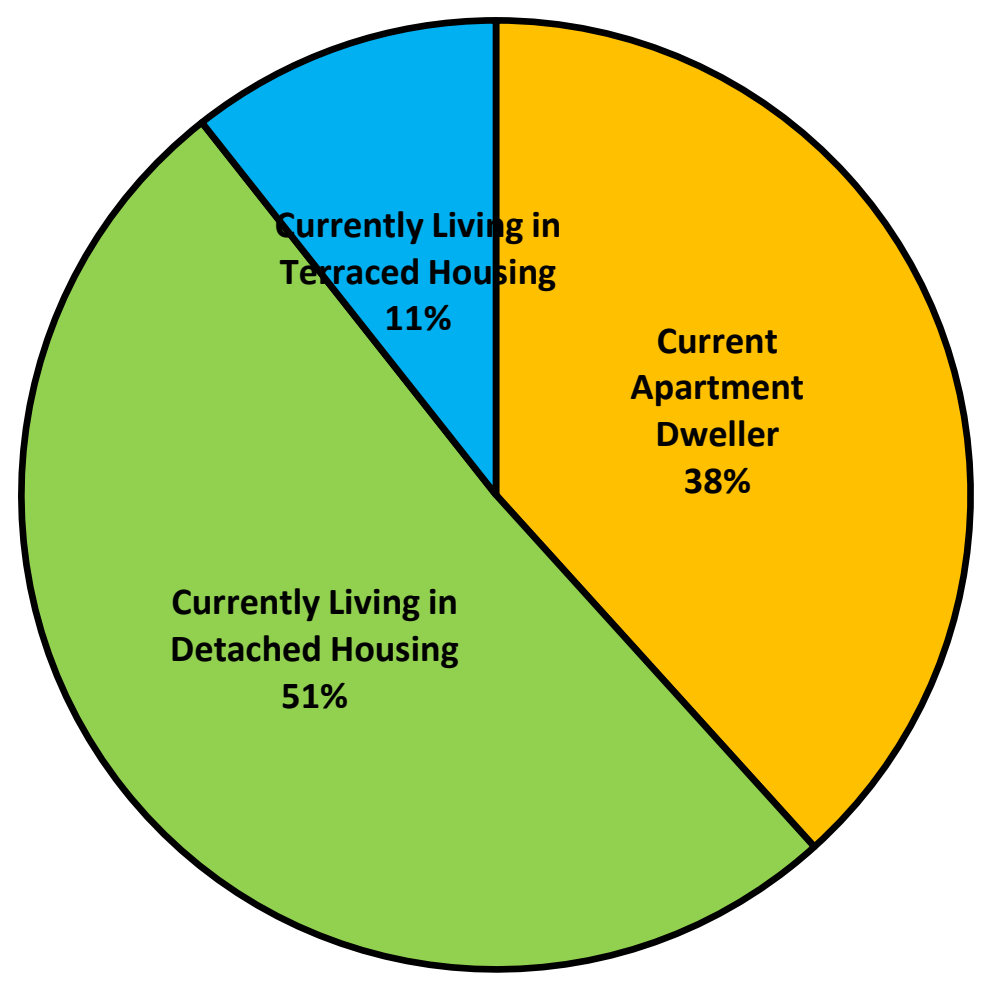

Figure I-25, Survey Responses by Current Dwelling Type

\section{Dwelling History}

Participants were asked a series of questions to determine what type of dwelling they currently lived in, whether they had ever lived in an apartment, or if they had not if they had ever considered living in an apartment before. Figure I-25 shows that just over one third of the participants currently live in apartments and over half currently live in detached housing. However, when participants who were not currently living in apartments were asked if they had ever lived in apartments, nearly $80 \%$ answered yes (as shown in Figure I-26). The participants who had never previously lived in an apartment were then also asked if they had ever considered living in an apartment, of the 6 participants, 4 four answered yes.

Participants who had at some point lived in an apartment were also asked how long they had lived in them for. Figure I-27 shows that the majority of the participants have lived in apartments for 02 years (61\%). Very few had lived in an apartment over 6 years only $10 \%$. This seems to follow trends shown in previous apartment dwellers surveys, that apartment occupants tend to be younger and due to that generations more transient nature tend to live in them for shorter periods of time.

Data in the following sections that is analysed by dwelling history will be analysed by participants who are currently living in apartments, those who have previously and those who have never lived in apartments (as shown in Figure I-26). 


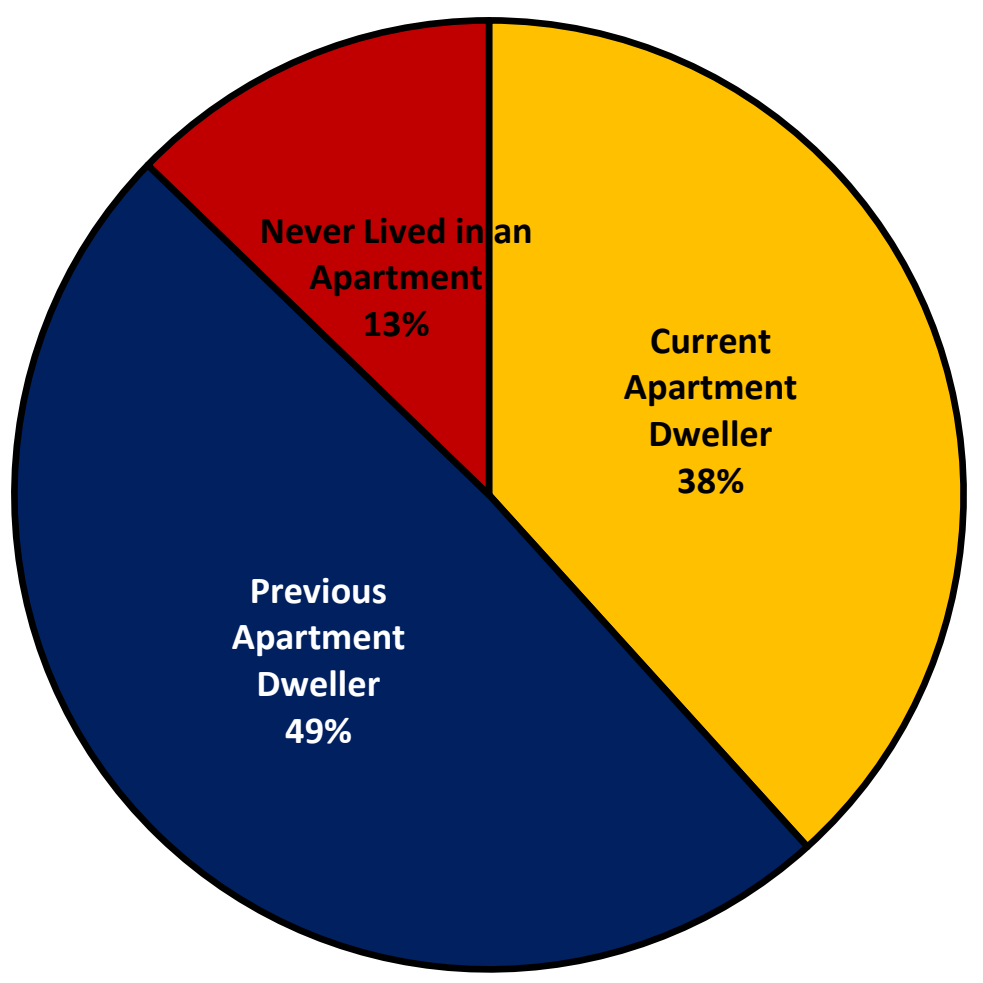

Figure I-26, Survey Responses by Apartment Dwelling History

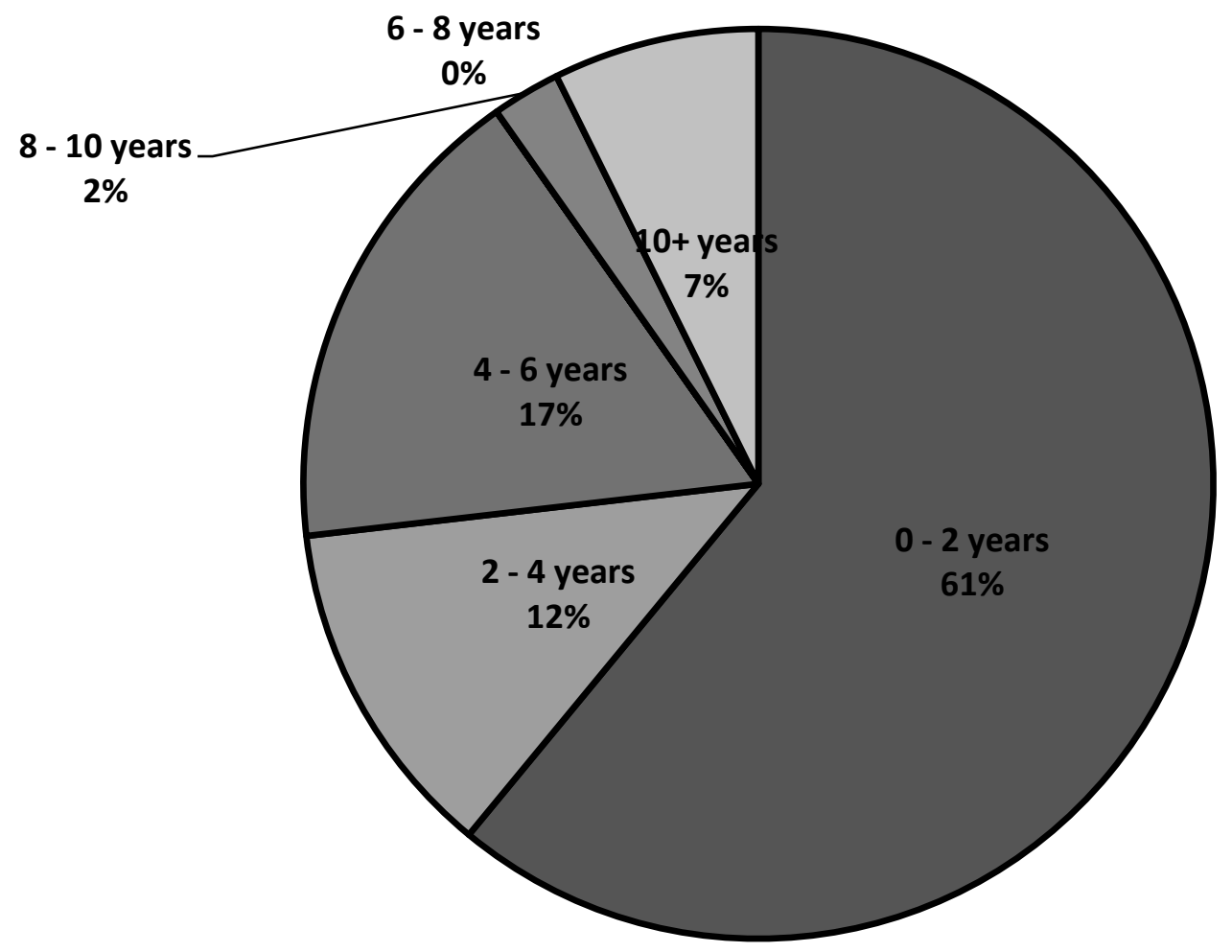

Figure I-27, Length of Time as Apartment Dweller 
New Zealand Apartment Living: Developing a Liveability Index 


\section{APPENDIX J NZ ALI TRIAL \& CRITIQUE}

The information presented in Appendix J: NZ ALIU Validation provides information on the NZ ALI Trial \& Critique which was carried out to ensure that NZ ALI met all development criteria and was fit for purpose. Information on the NZ ALI Trial on four apartments and Interviews with six occupants is given as is information regarding the NZ ALI Critique undertaken by the same six apartment occupants. Information regarding the occupants is given in Section 5.1.

\section{J.1 NZ ALI TRIAL \& INTERVIEWS}

\section{J.1.1 TRIAL RESULTS}

Table J-1, NZ ALI Liveability Ratings for NZ ALI Trial Apartments

\begin{tabular}{|c|c|c|c|c|}
\hline NZ ALI Profile & Apartment & Apartment & Apartment & Apartment \\
NZ ALI Liveability Rating & 1 & 2 & 3 & 4 \\
\hline
\end{tabular}

Table J-2, NZ ALI Category Liveability Profiles for NZ ALI Trial Apartments

\begin{tabular}{|c|c|c|c|c|c|}
\hline \multirow[b]{3}{*}{ NZ ALI } & NZ ALI Category Profile & $\begin{array}{c}\text { Apartment } \\
1\end{array}$ & $\begin{array}{c}\text { Apartment } \\
2 \\
\end{array}$ & $\begin{array}{c}\text { Apartment } \\
3 \\
\end{array}$ & $\begin{array}{c}\text { Apartment } \\
4 \\
\end{array}$ \\
\hline & Community & $85 \%$ & $66 \%$ & $76 \%$ & $77 \%$ \\
\hline & Configuration & $36 \%$ & $74 \%$ & $56 \%$ & $88 \%$ \\
\hline & Governance & $62 \%$ & $71 \%$ & $17 \%$ & $82 \%$ \\
\hline & Indoor Environmental Quality & $61 \%$ & $63 \%$ & $59 \%$ & $79 \%$ \\
\hline & Quality & $53 \%$ & $64 \%$ & $59 \%$ & $85 \%$ \\
\hline
\end{tabular}


Table J-3, NZ ALI Section Liveability Profiles for NZ ALI Trial Apartments

\begin{tabular}{|c|c|c|c|c|c|c|}
\hline & \multicolumn{2}{|c|}{ NZ ALI Section Profile } & $\begin{array}{c}\text { Apartment } \\
1\end{array}$ & $\begin{array}{c}\text { Apartment } \\
2\end{array}$ & $\begin{array}{c}\text { Apartment } \\
3\end{array}$ & $\begin{array}{c}\text { Apartment } \\
4\end{array}$ \\
\hline & \multirow{2}{*}{ Community } & Environment & $81 \%$ & $60 \%$ & $75 \%$ & $86 \%$ \\
\hline & & Neighbourhood & $90 \%$ & $73 \%$ & $77 \%$ & $66 \%$ \\
\hline & \multirow{2}{*}{ Configuration } & Connections & $9 \%$ & $74 \%$ & $9 \%$ & $82 \%$ \\
\hline & & Spatiality & $53 \%$ & $75 \%$ & $88 \%$ & $92 \%$ \\
\hline & \multirow{2}{*}{ Governance } & Maintenance & $71 \%$ & $75 \%$ & $29 \%$ & $95 \%$ \\
\hline & & Management & $50 \%$ & $65 \%$ & $0 \%$ & $65 \%$ \\
\hline \multirow[t]{7}{*}{ NZ ALI } & \multirow{4}{*}{$\begin{array}{c}\text { Indoor } \\
\text { Environmental } \\
\text { Quality }\end{array}$} & Acoustics & $48 \%$ & $23 \%$ & $62 \%$ & $54 \%$ \\
\hline & & $\begin{array}{c}\text { Indoor Air } \\
\text { Quality }\end{array}$ & $80 \%$ & $84 \%$ & $41 \%$ & $88 \%$ \\
\hline & & Thermal Comfort & $49 \%$ & $83 \%$ & $82 \%$ & $83 \%$ \\
\hline & & Visual Aspects & $74 \%$ & $60 \%$ & $42 \%$ & $96 \%$ \\
\hline & \multirow{3}{*}{ Quality } & Building Quality & $49 \%$ & $57 \%$ & $70 \%$ & $88 \%$ \\
\hline & & $\begin{array}{c}\text { Building Services } \\
\text { \& Amenities } \\
\end{array}$ & $44 \%$ & $65 \%$ & $42 \%$ & $82 \%$ \\
\hline & & Materials Quality & $68 \%$ & $72 \%$ & $63 \%$ & $83 \%$ \\
\hline
\end{tabular}

J.1.2 NZ ALI INTERVIEWS

\section{J.1.2.1 INTERVIEW QUESTIONS}

The following questions occupants were asked verbally and answer were recorded by the researcher.

\section{Statistical Questions}

1. Gender

2. Age

3. Occupation

4. Ethnicity

5. How long has occupant been living in apartment?

6. Do they rent or own?

a. If Own

i. Did they buy from plans, a show or as built?

b. If from Plans or Show Home

i. Are they satisfied that what they brought matched their expectations?

ii. Why/Why not?

7. Have they ever lived in other apartments?

a. If Yes

i. Where? (I.e. Wellington, Auckland, Christchurch. City not suburb) 
ii. How does this apartment compare to other apartment they have lived in?

iii. Do they feel more or less satisfied/happy in this apartment compared to others?

8. Do they enjoy apartment living?

9. Why/Why not?

10. What are the 3 things they like most about living in this apartment?

11. What are the 3 things they dislike most about living in this apartment?

\section{Apartment Liveability Questions}

The following were used to start an open discussion with the occupants. Each of the NZ ALI Sections was used as topics for participants to consider and discuss openly in relation to their apartment, liveability and how satisfied they are. NZ ALI Features and at time Aspects were given as keywords to trigger discussion as required. No other advice or discussion was given from the researcher except where clarification on a term or key word was needed. This was done to avoid bias in the discussion.

Table J-4, NZ ALI Interview, Discussion Topics \& Prompts

\begin{tabular}{|l|l|}
\hline Discussion Topic & Keywords \\
\hline 1. Acoustics & Sound Transfer, Internal noise, External noise \\
\hline 2. Architecture & High Rise Living, Outdoor Access, Privacy \\
\hline 3. Building Quality & $\begin{array}{l}\text { Airtightness, Communal Areas, Landscaping, } \\
\text { Safety/Security, Weathertightness }\end{array}$ \\
\hline 4. Building Services \& Amenities & $\begin{array}{l}\text { Drainage, Emergency Escape, Building Facilities, Lifts, } \\
\text { Parking, Rubbish \& Recycling, Water, Utilities }\end{array}$ \\
\hline 5. Environment & Location, Urban Density, Wind \\
\hline 6. Indoor Air Quality & $\begin{array}{l}\text { Air Quality, Ventilation Natural or Mechanical, } \\
\text { Pollutants \& Sources) }\end{array}$ \\
\hline 7. Maintenance & Cleanliness, Maintenance \\
\hline 8. Management & Management, Pets \\
\hline 9. Materials Quality & Deterioration, Durability, Emissions, Toxic Materials \\
\hline 10. Neighbourhood & Access \& Proximity, Safety \\
\hline 11. Spatiality & Occupancy, Size, Shape, Spatial Organisation, Storage \\
\hline 12. Thermal Comfort & Comfort, Control, Insulation \\
\hline 13. Visual Aspects & Adequate Light, Artificial Light, Natural Light, Views \\
\hline
\end{tabular}




\section{J.1.2.2 INTERVIEWS}

Table J-5, NZ ALI Interview - Occupant A Statistical Questions

\begin{tabular}{|c|c|}
\hline Question & Occupant A Answer \\
\hline Gender & Female \\
\hline Age & 23 \\
\hline Occupation & Pharmacist \\
\hline Ethnicity & NZ European \\
\hline $\begin{array}{l}\text { How long have you lived in this } \\
\text { apartment? }\end{array}$ & 2 months \\
\hline Do you rent or own? & Rent \\
\hline $\begin{array}{l}\text { (IF OWN) Did you buy off plans, from a } \\
\text { show home or as built? }\end{array}$ & N/A \\
\hline $\begin{array}{l}\text { (IF OFF PLANS OR SHOW HOME) Were } \\
\text { you satisfied that what you } \\
\text { brought/now live in matched your } \\
\text { expectations? }\end{array}$ & $\mathrm{N} / \mathrm{A}$ \\
\hline $\begin{array}{l}\text { (IF OFF PLANS OR SHOW HOME) } \\
\text { Why/Why not? }\end{array}$ & $\mathrm{N} / \mathrm{A}$ \\
\hline $\begin{array}{l}\text { Have you ever lived in other } \\
\text { apartments? }\end{array}$ & No \\
\hline (IF YES) Only in Wellington? (Where) & $\mathrm{N} / \mathrm{A}$ \\
\hline $\begin{array}{l}\text { (IF YES) How does this apartment } \\
\text { compare to other apartments you have } \\
\text { lived in? }\end{array}$ & N/A \\
\hline $\begin{array}{l}\text { Do you feel more satisfied/happy in this } \\
\text { apartment? }\end{array}$ & $\mathrm{N} / \mathrm{A}$ \\
\hline Do you enjoy living in an apartment? & Yes \\
\hline Why/Why not? & $\begin{array}{l}\text { Reduced/No maintenance and am able to live by herself } \\
\text { because of price and security. }\end{array}$ \\
\hline $\begin{array}{l}\text { What are } 3 \text { things you most like about } \\
\text { this apartment? }\end{array}$ & $\begin{array}{l}\text { Size } \\
\text { Modern Fittings } \\
\text { Proximity to Town \& Motorway for work }\end{array}$ \\
\hline $\begin{array}{l}\text { What are } 3 \text { things you most dislike } \\
\text { about this apartment? }\end{array}$ & $\begin{array}{l}\text { Noise from above } \\
\text { Security \& Warmth issues with transparency of front } \\
\text { door } \\
\text { Lack of Sunlight }\end{array}$ \\
\hline
\end{tabular}


Table J-6, NZ ALI Interview Occupant A - Liveability Questions

\begin{tabular}{|c|c|}
\hline Question & Occupant A Answer \\
\hline Acoustics & $\begin{array}{l}\text { Acoustics are very bad particularly from upstairs. It makes the } \\
\text { occupant uncomfortable at times that she may be heard or her visitors } \\
\text { may be heard. Disturbs her sleeping and quiet times. }\end{array}$ \\
\hline Building Quality & $\begin{array}{l}\text { up a driveway, all external access with no cover } \\
\text { over her access. } \\
\text { She wishes there were more smaller windows she could leave open } \\
\text { during the day for ventilation } \\
\text { Happy with key access only as she has external access only. }\end{array}$ \\
\hline $\begin{array}{l}\text { Building Services \& } \\
\text { Amenities }\end{array}$ & $\begin{array}{l}\text { Drainage } \\
\text { storm water runoff } \\
\text { through it to get to her apartment. } \\
\text { The smoke alarm always goes off when cooking because of open plan } \\
\text { and little natural ventilation and no mechanical ventilation in kitchen. } \\
\text { No extra facilities } \\
\text { No lifts } \\
\text { Glad she has parking, but no cover and not near front door tricky } \\
\text { access. } \\
\text { Has rubbish \& recycling facilities, but there could be more (only } 3 \\
\text { wheelie bins for whole building) and only emptied once a week. } \\
\text { Hot water runs out after one shower size of tank issue } \\
\text { Power meters outside her house for whole building which makes her } \\
\text { feel a little insecure with people always standing in her front door to } \\
\text { check their meters. } \\
\text { An older building so some internet issues with wiring. }\end{array}$ \\
\hline Connections & $\begin{array}{l}\text { There is no privacy all windows including lunge, kitchen, } \\
\text { bathroom/toilet and bedroom have windows that people can look into. } \\
\text { No POA which she finds very annoying } \\
\text { can use the washing lines not that they get any sun anyway }\end{array}$ \\
\hline Environment & $\begin{array}{l}\text { Not a hugely populated area lots of buildings but road seems semi } \\
\text { private. } \\
\text { Wind issues leaves in porch. }\end{array}$ \\
\hline Indoor Air Quality & $\begin{array}{l}\text { Natural ventilation everywhere except in bathroom where } \\
\text { mechanical ventilation also (not in kitchen). }\end{array}$ \\
\hline Maintenance & $\begin{array}{l}\text { Exterior is cared for by Body Corporate which is great. However her } \\
\text { apartment needs to be looked at ASAP by her property manager. }\end{array}$ \\
\hline Management & She has nothing to do with Body Corporate \\
\hline Materials Quality & Is concerned there may be asbestos. \\
\hline
\end{tabular}




\begin{tabular}{|c|c|}
\hline & $\begin{array}{l}\text { The exterior needs painting. } \\
\text { Possible leak in bathroom wall } \\
\text { Front door \& windows need to be looked at may be needs new seals, } \\
\text { they are very draughty. }\end{array}$ \\
\hline Neighbourhood & $\begin{array}{l}\text { However she does think that in reality it is probably safer than people } \\
\text { realise and it is getting better as it is a lot } \\
\text { Too far to really walk from town. Bus is close. Work is out of town but } \\
\text { is very close to motorway which is good. }\end{array}$ \\
\hline Spatiality & $\begin{array}{l}\text { It is a bit small, but she does comment that for a one bedroom place it } \\
\text { e looked at. } \\
\text { She would prefer if the kitchen is more separate due to smells \& smoke } \\
\text { detector. } \\
\text { Would prefer if front entrance was more of an entrance not just a } \\
\text { small opening. } \\
\text { fixtures, feels cramped, germs/hygiene etc. } \\
\text { Not really enough storage particularly for big things without them }\end{array}$ \\
\hline Thermal Comfort & $\begin{array}{l}\text { Warm enough but draughty. She does use heating during winter but } \\
\text { was not there during the summer. }\end{array}$ \\
\hline Visual Aspects & $\begin{array}{l}\text { Lighting levels are fine. } \\
\text { No glare. } \\
\text { Sometimes visitors have commented on flickering and humming from } \\
\text { the lights in the bathroom but she has never noticed it. Natural light is } \\
\text { fine. Plenty of windows. } \\
\text { Does not like view. }\end{array}$ \\
\hline
\end{tabular}


Table J-7, NZ ALI Interview Occupant B\&C - Statistical Questions

\begin{tabular}{|c|c|c|}
\hline Question & Occupant B Answer & Occupant C Answer \\
\hline Gender & Male & Female \\
\hline Age & 40 & 36 \\
\hline Occupation & Student & building consents officer \\
\hline Ethnicity & NZ European & NZ European/Maori \\
\hline $\begin{array}{l}\text { How long have you lived in this } \\
\text { apartment? }\end{array}$ & 5 years & 3 years \\
\hline Do you rent or own? & Own & Own/Rent \\
\hline $\begin{array}{l}\text { (IF OWN) Did you buy off plans, from a } \\
\text { show home or as built? }\end{array}$ & As built & $\mathrm{N} / \mathrm{A}$ \\
\hline $\begin{array}{l}\text { (IF OFF PLANS OR SHOW HOME) Were } \\
\text { you satisfied that what you } \\
\text { brought/now live in matched your } \\
\text { expectations? }\end{array}$ & N/A & $\mathrm{N} / \mathrm{A}$ \\
\hline $\begin{array}{l}\text { (IF OFF PLANS OR SHOW HOME) } \\
\text { Why/Why not? }\end{array}$ & N/A & $\mathrm{N} / \mathrm{A}$ \\
\hline $\begin{array}{l}\text { Have you ever lived in other } \\
\text { apartments? }\end{array}$ & No & No \\
\hline (IF YES) Only in Wellington? (Where) & N/A & $\mathrm{N} / \mathrm{A}$ \\
\hline $\begin{array}{l}\text { (IF YES) How does this apartment } \\
\text { compare to other apartments you have } \\
\text { lived in? }\end{array}$ & $\mathrm{N} / \mathrm{A}$ & $\mathrm{N} / \mathrm{A}$ \\
\hline $\begin{array}{l}\text { Do you feel more satisfied/happy in this } \\
\text { apartment? }\end{array}$ & N/A & $\mathrm{N} / \mathrm{A}$ \\
\hline Do you enjoy living in an apartment? & Yes and No & Yes \\
\hline Why/Why not? & $\begin{array}{l}\text { Has been living in an } \\
\text { apartment for five years } \\
\text { is ready for some land \& } \\
\text { space again proper } \\
\text { BUT the place is a } \\
\text { reasonable size, } \\
\text { convenient location, } \\
\text { close } 2 \text { conveniences, can }\end{array}$ & $\begin{array}{l}\text { Space, closer to facilities, can } \\
\text { get up for work later } \\
\text { because she is closer to }\end{array}$ \\
\hline $\begin{array}{l}\text { What are } 3 \text { things you most like about } \\
\text { this apartment? }\end{array}$ & $\begin{array}{l}\text { Comfortable } \\
\text { Good Size } \\
\text { Convenience/Proximity }\end{array}$ & $\begin{array}{l}\text { Size } \\
\text { Warmth } \\
\text { Westerly Aspect } \\
\text { Deck }\end{array}$ \\
\hline $\begin{array}{l}\text { What are } 3 \text { things you most dislike } \\
\text { about this apartment? }\end{array}$ & $\begin{array}{l}\text { Outdoor noise at night } \\
\text { Noise from upstairs } \\
\text { Lack of real outdoor } \\
\text { space }\end{array}$ & $\begin{array}{l}\text { Noise from upstairs } \\
\text { Carpet gets filthy from traffic } \\
\text { pollution } \\
\text { Lack of real outdoor space }\end{array}$ \\
\hline
\end{tabular}


Table J-8, NZ ALI Interview Occupant B\&C - Liveability Questions

\begin{tabular}{|c|c|}
\hline Question & Occupant Answer (B\&C) \\
\hline Acoustics & $\begin{array}{l}\text { Noise from outside affects sleep } \\
\text { annoying. } \\
\text { Very aware of themselves making noise. }\end{array}$ \\
\hline Building Quality & $\begin{array}{l}\text { There are Weathertightness issues but it is not a leaky building bad } \\
\text { workmanship not design. } \\
\text { No draughts because of deck } \\
\text { Security is good up to a point more to with occupant stupidity i.e. let } \\
\text { Mormons in, people let anybody in. } \\
\text { Lands } \\
\text { better. } \\
\text { Communal areas needs a lot of work, they are not presentable. } \\
\text { Carpets needs to be replaced but not urgent. }\end{array}$ \\
\hline $\begin{array}{l}\text { Building Services \& } \\
\text { Amenities }\end{array}$ & $\begin{array}{l}\text { Drainage is fine, just affected by occupant stupidity } \\
\text { Emergency escape wise, everything fine except no sprinklers. } \\
\text { No lifts } \\
\text { Parking again } \\
\text { good to have more parks and visitor parking. Easy to get parking tickets } \\
\text { in the area. } \\
\text { Rubbish \& recycling fine, taken away twice a week sufficient } \\
\text { Water excellent, done by communal boiler. } \\
\text { Happy with utilities. }\end{array}$ \\
\hline Connections & $\begin{array}{l}\text { No better or worse than living in a detached house. Neighbours come } \\
\text { and go, you just have more. } \\
\text { house though. } \\
\text { Never see people in the communal areas. }\end{array}$ \\
\hline Environment & Fine except Outdoor Air Quality this affects carpet. \\
\hline Indoor Air Quality & $\begin{array}{l}\text { Natural Ventilation everywhere, except in kitchen \& bathroom which } \\
\text { have mechanical ventilation also. }\end{array}$ \\
\hline Maintenance & \\
\hline Management & Body Corporate and Building Manager are good. \\
\hline Materials Quality & $\begin{array}{l}\text { Everything is currently ok it was a bit old when brought. Traffic } \\
\text { pollution ruins carpet \& upholstery. }\end{array}$ \\
\hline Neighbourhood & $\begin{array}{r}\text { Too many students but close to university area. } \\
\text { ct }\end{array}$ \\
\hline Spatiality & $\begin{array}{l}\text { Minimal storage had to make up extra storage in car parking area. } \\
\text { Size is good for three people, could fit four if required. } \\
\text { Single aspect is ok enough light and visual stimulus has an internal } \\
\text { room. }\end{array}$ \\
\hline
\end{tabular}




\begin{tabular}{|l|l|}
\hline Thermal Comfort & \multicolumn{1}{c|}{ ok } \\
& $\begin{array}{l}\text { The odd day in summer it does need to be cooled } \\
\text { need to heat. }\end{array}$ \\
\hline Visual Aspects & $\begin{array}{l}\text { Not enough natural light. Shading from deck above. Glare on deck but } \\
\text { not in apartment. Adequate views for price. } \\
\text { Really enjoy lights on old museum at night-time. }\end{array}$ \\
\hline
\end{tabular}

Table J-9, NZ ALI Interview Occupant D - Statistical Questions

\begin{tabular}{|c|c|}
\hline Question & Occupant D Answer \\
\hline Gender & Female \\
\hline Age & 23 \\
\hline Occupation & Barista/Student \\
\hline Ethnicity & NZ European \\
\hline $\begin{array}{l}\text { How long have you lived in this } \\
\text { apartment? }\end{array}$ & 4 months \\
\hline Do you rent or own? & Rent \\
\hline $\begin{array}{l}\text { (IF OWN) Did you buy off plans, from a } \\
\text { show home or as built? }\end{array}$ & N/A \\
\hline $\begin{array}{l}\text { (IF OFF PLANS OR SHOW HOME) Were } \\
\text { you satisfied that what you } \\
\text { brought/now live in matched your } \\
\text { expectations? }\end{array}$ & $\mathrm{N} / \mathrm{A}$ \\
\hline $\begin{array}{l}\text { (IF OFF PLANS OR SHOW HOME) } \\
\text { Why/Why not? }\end{array}$ & $\mathrm{N} / \mathrm{A}$ \\
\hline $\begin{array}{l}\text { Have you ever lived in other } \\
\text { apartments? }\end{array}$ & Yes \\
\hline (IF YES) Only in Wellington? (Where) & Yes \\
\hline $\begin{array}{l}\text { (IF YES) How does this apartment } \\
\text { compare to other apartments you have } \\
\text { lived in? }\end{array}$ & $\begin{array}{l}\text { It is bigger, but colder and has no balcony which is } \\
\text { annoying }\end{array}$ \\
\hline $\begin{array}{l}\text { Do you feel more satisfied/happy in this } \\
\text { apartment? }\end{array}$ & Yes \\
\hline Do you enjoy living in an apartment? & Yes \\
\hline Why/Why not? & Location and modern feel \\
\hline $\begin{array}{l}\text { What are } 3 \text { things you most like about } \\
\text { this apartment? }\end{array}$ & $\begin{array}{l}\text { Location } \\
\text { Sun/Warmth } \\
\text { Size }\end{array}$ \\
\hline $\begin{array}{l}\text { What are } 3 \text { things you most dislike } \\
\text { about this apartment? }\end{array}$ & $\begin{array}{l}\text { Noise from outside } \\
\text { Number of people in apartment } \\
\text { Draughts through windows }\end{array}$ \\
\hline
\end{tabular}


Table J-10, NZ ALI Interview Occupant D - Liveability Questions

\begin{tabular}{|c|c|}
\hline Question & Occupant D Answer \\
\hline Acoustics & $\begin{array}{l}\text { Noise disturbances from exterior are really bad. } \\
\text { Never hear adjacent apartments or apartment below unless their music } \\
\text { is really loud or they are having a party }\end{array}$ \\
\hline Building Quality & $\begin{array}{l}\text { Security is good access, can drop keys to friends out } \\
\text { window } \\
\text { Can get very cold but is easy to heat }\end{array}$ \\
\hline $\begin{array}{l}\text { Building Services \& } \\
\text { Amenities }\end{array}$ & $\begin{array}{l}\text { Could do with more means of escape though only one floor up. } \\
\text { No lifts, but not an issue } \\
\text { No recycling or rubbish facilities }\end{array}$ \\
\hline Connections & $\begin{array}{l}\text { Like floor level } \\
\text { People can look into her room and flatmates rooms from across road, } \\
\text { but not into living. This is an issue for her. }\end{array}$ \\
\hline Environment & $\begin{array}{l}\text { Like density of area always people around. } \\
\text { Sunny but buildings block out more sun (not hills) } \\
\text { Not a damp area }\end{array}$ \\
\hline Indoor Air Quality & Ventilation is fine $I A Q$ issues come from smelly flatmate \\
\hline Maintenance & $\begin{array}{l}\text { Easy to clean, big but can clean easily. } \\
\text { Some maintenance issues }\end{array}$ \\
\hline Management & \\
\hline Materials Quality & Very old and deteriorated \\
\hline Neighbourhood & $\begin{array}{l}\text { Love location close to everything. } \\
\text { apartment but not on street at night }\end{array}$ \\
\hline Spatiality & $\begin{array}{l}\text { Occupancy ok } \\
\text { Wish she has a balcony } \\
\text { Size is a bit small } \\
\text { Shape is fine } \\
\text { Layout fine } \\
\text { Not enough storage none }\end{array}$ \\
\hline Thermal Comfort & $\begin{array}{l}\text { Not too humid, no dampness, some mould I bathroom but not in } \\
\text { bedrooms that she knows off. } \\
\text { Need to warm not cool }\end{array}$ \\
\hline Visual Aspects & $\begin{array}{l}\text { Lighting fine except for makeup in her bedroom. } \\
\text { No glare, one internal bedroom. } \\
\text { Average views new building across street }\end{array}$ \\
\hline
\end{tabular}


Table J-11, NZ ALI Interview Occupant E\&F - Statistical Questions

\begin{tabular}{|c|c|c|}
\hline Question & Occupant E Answer & Occupant F Answer \\
\hline Gender & Male & Female \\
\hline Age & 60 & 55 \\
\hline Occupation & IT Specialist & Academic \\
\hline Ethnicity & NZ European & NZ European \\
\hline $\begin{array}{l}\text { How long have you lived in this } \\
\text { apartment? }\end{array}$ & 5 years & 5 years \\
\hline Do you rent or own? & Own & Own \\
\hline $\begin{array}{l}\text { (IF OWN) Did you buy off plans, from a } \\
\text { show home or as built? }\end{array}$ & As built & As built \\
\hline $\begin{array}{l}\text { (IF OFF PLANS OR SHOW HOME) Were } \\
\text { you satisfied that what you } \\
\text { brought/now live in matched your } \\
\text { expectations? }\end{array}$ & N/A & $\mathrm{N} / \mathrm{A}$ \\
\hline $\begin{array}{l}\text { (IF OFF PLANS OR SHOW HOME) } \\
\text { Why/Why not? }\end{array}$ & N/A & $\mathrm{N} / \mathrm{A}$ \\
\hline $\begin{array}{l}\text { Have you ever lived in other } \\
\text { apartments? }\end{array}$ & No & No \\
\hline (IF YES) Only in Wellington? (Where) & $\mathrm{N} / \mathrm{A}$ & $\mathrm{N} / \mathrm{A}$ \\
\hline $\begin{array}{l}\text { (IF YES) How does this apartment } \\
\text { compare to other apartments you have } \\
\text { lived in? }\end{array}$ & $\mathrm{N} / \mathrm{A}$ & $\mathrm{N} / \mathrm{A}$ \\
\hline $\begin{array}{l}\text { Do you feel more satisfied/happy in this } \\
\text { apartment? }\end{array}$ & $\mathrm{N} / \mathrm{A}$ & $\mathrm{N} / \mathrm{A}$ \\
\hline Do you enjoy living in an apartment? & Yes & Yes \\
\hline Why/Why not? & $\begin{array}{l}\text { Location \& convenience } \\
\text { that apartment living } \\
\text { affords. }\end{array}$ & $\begin{array}{l}\text { Security, minimal } \\
\text { maintenance \& community } \\
\text { in building. }\end{array}$ \\
\hline $\begin{array}{l}\text { What are } 3 \text { things you most like about } \\
\text { this apartment? }\end{array}$ & $\begin{array}{l}\text { Location } \\
\text { Size } \\
\text { Outdoor Access }\end{array}$ & $\begin{array}{l}\text { Size } \\
\text { Storage } \\
\text { Light }\end{array}$ \\
\hline $\begin{array}{l}\text { What are } 3 \text { things you most dislike } \\
\text { about this apartment? }\end{array}$ & $\begin{array}{l}\text { Proximity to bars } \\
\text { External Noise } \\
\text { Safety in Area }\end{array}$ & $\begin{array}{l}\text { Proximity to bars } \\
\text { External Noise } \\
\text { Safety in Area }\end{array}$ \\
\hline
\end{tabular}


Table J-12, NZ ALI Interview Occupant E\&F - Liveability Questions

\begin{tabular}{|c|c|}
\hline Question & Occupant Answer (E\&F) \\
\hline \multicolumn{2}{|l|}{ Acoustics } \\
\hline Building Quality & $\begin{array}{l}\text { Very good quality apartment and building. No real issues identified } \\
\text { despite all keywords offered. }\end{array}$ \\
\hline $\begin{array}{l}\text { Building Services \& } \\
\text { Amenities }\end{array}$ & $\begin{array}{l}\text { Both love the parking facilities (they get } 2 \text { parks), good lifts, security } \\
\text { (pin number and intercom system). Have a gym, swimming pool and } \\
\text { communal garden/courtyard area. Very happy although the comment }\end{array}$ \\
\hline Connections & $\begin{array}{l}\text { Despite outlook over communal areas both occupants feel that they } \\
\text { are able to define their personal space both inside and outside. They } \\
\text { did comment that some communal areas are not conducive to social } \\
\text { interactions, but this is only concerned with hallways. Entrances and } \\
\text { other areas are fine. }\end{array}$ \\
\hline Environment & $\begin{array}{l}\text { Occupant } F \text { the siting of the building is good in relation to other } \\
\text { buildings, sunlight availability is not adversely affected. Wind is not a } \\
\text { bad } \\
\text { considering the major roads near them. } \\
\text { Although it is only an average height building in the area, the building } \\
\text { in front of theirs did not interfere with views and sunlight access into } \\
\text { the apartment. }\end{array}$ \\
\hline Indoor Air Quality & $\begin{array}{l}\text { Occupant } F \text { noted that they hardly get any cooking smells in the } \\
\text { hallways due to the placement of kitchens, entrances to apartments } \\
\text { and extract fans in all kitchens. Extract fans are available in both } \\
\text { bathrooms also and cross ventilation allows for removal of smelly air } \\
\text { naturally. Because they are on the } 7^{\text {th }} \text { floor they can also leave windows } \\
\text { open for much of the day helping to supply fresh air much of the time. }\end{array}$ \\
\hline Maintenance & $\begin{array}{l}\text { The building is always well maintained and clean. The apartment is } \\
\text { (Occupant F) }\end{array}$ \\
\hline Management & $\begin{array}{l}\text { Very happy with management (Occupant } \mathrm{E} \text { is on Body Corporate). } \\
\text { Can have pets although both are happy with this } \\
\text { kind of have pets in an } \\
\text { apartment building due to high-rise issues, limited outdoor access and }\end{array}$ \\
\hline Materials Quality & $\begin{array}{l}\text { Few issues identified with materials, Occupant } F \\
\text { very durable, which is great as we often had very active grandchildren } \\
\text { either. }\end{array}$ \\
\hline Neighbourhood & $\begin{array}{l}\text { Occupant E said he felt comfortable in the area and that while there } \\
\text { are some crime issues due to bars and intoxicated people in the area } \\
\text { often he generally felt fairly safe due to police presence and walk wise } \\
\text { Occupant F said she was able to easily access many things in the area } \\
\text { including public transport, supermarkets and open space. }\end{array}$ \\
\hline Spatiality & $\begin{array}{l}\text { Both commented on how good the storage wa } \\
\text { are only two of us in a three bedroom apartment we have lots of space }\end{array}$ \\
\hline
\end{tabular}




\begin{tabular}{|l|l|}
\hline & Great spatial design \& layout, love the outdoor access. \\
\hline Thermal Comfort & $\begin{array}{l}\text { Thermally there is little wrong with the apartment (Occupant F), the } \\
\text { northern aspect means that there is a large amount of sunlight most } \\
\text { days of the year and when overheating does occur openable windows } \\
\text { allow for cross ventilation throughout the entire apartment. }\end{array}$ \\
\hline Visual Aspects & $\begin{array}{l}\text { Both occupants stated that visually they are very pleased with the } \\
\text { apartment. The large amount of natural light let in by the high levels of } \\
\text { glazing in the living area means that they rarely need to use artificial } \\
\text { lighting during the daytime. The views are wonderful of the } \\
\text { harbour/waterfront area (Occupant E). }\end{array}$ \\
\hline
\end{tabular}




\section{J.2 NZ ALI CRITIQUE}

\section{J.2.1 METHOD}

Participants were asked to trial using NZ ALI for around half an hour and provide feedback on the once they were finished. Feedback was required on three issues:

- The usability of the tool,

- Objectivity of questions,

- Practicality of NZ ALI.

The first (Usability) was required so that Criterion \#6 could be assessed. The second two (Objectivity \& Practicality) were required so that Criteria \#2 \& \#3 could be reassessed to ensure that the tool is fit for purpose and meet all development criteria. Feedback was given verbally and recorded by the researcher.

The specific questions participants were asked were:

\section{Usability}
a. How user-friendly is NZ ALI in your opinion? (How/why?)
b. How easy is NZ ALI to understand? (provide examples is possible)
c. How straightforward is NZ ALI to use?

\section{Objectivity}

a. How objective do you feel the questions answers required in NZ ALI are?

b.

\section{Practicality}

a. How practical is NZ ALI? (Do you think you would use it in the future?)

b. Are the assessment procedures simple and any information required easily

c. Is any of the information required for NZ ALI too specialist in any way? (Is there 


\section{J.2.2 RESULTS}

The following tables present the NZ ALI Critique results and summarises the critiques to determine the main issues identified for each aspect.

Table J-13, NZ ALI Critique, Usability

\begin{tabular}{|c|c|c|c|c|c|c|}
\hline \multirow{2}{*}{$\begin{array}{l}\text { Usability } \\
\text { Questions }\end{array}$} & \multicolumn{6}{|c|}{ Apartment Occupant Participants } \\
\hline & A & B & C & D & $\mathbf{E}$ & $\mathbf{F}$ \\
\hline $\begin{array}{l}\text { a) How } \\
\text { user- } \\
\text { friendly is } \\
\text { NZ ALI? }\end{array}$ & $\begin{array}{l}\text { Fine, but too } \\
\text { long and } \\
\text { therefore } \\
\text { boring }\end{array}$ & $\begin{array}{l}\text { Fairly user- } \\
\text { friendly }\end{array}$ & $\begin{array}{l}\text { Fine, } \\
\text { although } \\
\text { programme } \\
\text { is 'naff', not } \\
\text { dynamic }\end{array}$ & $\begin{array}{l}\text { Yes, } \\
\text { definitely } \\
\text { very user- } \\
\text { friendly }\end{array}$ & Very & $\begin{array}{l}\text { Quite user- } \\
\text { friendly }\end{array}$ \\
\hline $\begin{array}{l}\text { b) How } \\
\text { easy is NZ } \\
\text { ALI to } \\
\text { understand? }\end{array}$ & Easy & $\begin{array}{l}\text { Fine, except } \\
\text { the } 1 \text { - } 10 \\
\text { scale }\end{array}$ & Fine & $\begin{array}{l}\text { Very easy to } \\
\text { understand, } \\
\text { types of } \\
\text { questions } \\
\text { and answers } \\
\text { make it very } \\
\text { easy to use } \\
\& \\
\text { understand }\end{array}$ & $\begin{array}{l}\text { Fairly easy } \\
\text { to } \\
\text { understand } \\
\text { - } \\
\text { instructions } \\
\text { and } \\
\text { guidance } \\
\text { help a lot }\end{array}$ & $\begin{array}{l}\text { Good - } \\
\text { except scale } \\
\text { is confusing }\end{array}$ \\
\hline $\begin{array}{l}\text { c) How } \\
\text { straight } \\
\text { forward is } \\
\text { NZ ALI to } \\
\text { use? }\end{array}$ & Fine & $\begin{array}{l}\text { Fairly } \\
\text { straight- } \\
\text { forward }\end{array}$ & $\begin{array}{l}\text { Straight } \\
\text { forward, } \\
\text { layout } \\
\text { needs } 2 \text { be } \\
\text { clearer but } \\
\text { boxes are } \\
\text { good }\end{array}$ & $\begin{array}{l}\text { Fairly - lots } \\
\text { to do, but } \\
\text { not a lot of } \\
\text { 'thinking' to } \\
\text { do, drop } \\
\text { down } \\
\text { menus are } \\
\text { great and } \\
\text { very broad }\end{array}$ & Very & $\begin{array}{l}\text { Very - layout } \\
\text { is good, } \\
\text { clear } \\
\text { stepping } \\
\text { through } \\
\text { hierarchy }\end{array}$ \\
\hline
\end{tabular}


Table J-14, Summary of Usability Issues

\begin{tabular}{|c|c|c|c|c|}
\hline $\begin{array}{l}\text { Usability } \\
\text { Questions }\end{array}$ & Critique Summary & Bad points & Good points & $\begin{array}{l}\text { Main Issues } \\
\text { Identified }\end{array}$ \\
\hline $\begin{array}{l}\text { a) How } \\
\text { user- } \\
\text { friendly is } \\
\text { NZ ALI? }\end{array}$ & $\begin{array}{l}\text { Seems to be fairly } \\
\text { user-friendly }\end{array}$ & $\begin{array}{l}\text { A: Too long \& } \\
\text { boring } \\
\text { C: } \\
\text { Program/Interface } \\
\text { used is not nice, } \\
\text { very 'naff' }\end{array}$ & $\begin{array}{l}\text { D: 'Definitely very } \\
\text { user-friendly }\end{array}$ & \multirow{3}{*}{$\begin{array}{l}\text { Length } \\
\text { Program/Interface } \\
\text { Scale }\end{array}$} \\
\hline $\begin{array}{l}\text { b) How } \\
\text { easy is NZ } \\
\text { ALI to } \\
\text { understand? }\end{array}$ & $\begin{array}{l}\text { Seems to be easy to } \\
\text { understand }\end{array}$ & B \& F: 1 - 10 scale & $\begin{array}{l}\text { D: 'Types of } \\
\text { questions \& } \\
\text { answers make it } \\
\text { very easy to use \& } \\
\text { understand. } \\
\text { E: Instructions \& } \\
\text { Guidance provided } \\
\text { help a lot }\end{array}$ & \\
\hline $\begin{array}{l}\text { c) How } \\
\text { straight } \\
\text { forward is } \\
\text { NZ ALI to } \\
\text { use? }\end{array}$ & $\begin{array}{l}\text { Seems to be fairly } \\
\text { straightforward }\end{array}$ & $\begin{array}{l}\text { C: Layout needs to } \\
\text { be clearer }\end{array}$ & $\begin{array}{l}\text { C: Boxes are good at } \\
\text { showing hierarchy } \\
\text { D: Lots to do but } \\
\text { not a lot of 'thinking } \\
\text { involved. Drop } \\
\text { down menus are } \\
\text { great and very } \\
\text { broad range of } \\
\text { answers possible } \\
\text { F: Layout is good, } \\
\text { clear stepping } \\
\text { through hierarchy }\end{array}$ & \\
\hline
\end{tabular}


Table J-15, NZ ALI Critique, Objectivity

\begin{tabular}{|c|c|c|c|c|c|c|}
\hline \multirow{2}{*}{$\begin{array}{l}\text { Objectivity } \\
\text { Questions }\end{array}$} & \multicolumn{6}{|c|}{ Apartment Occupant Participants } \\
\hline & A & B & C & D & $\mathbf{E}$ & $\mathbf{F}$ \\
\hline $\begin{array}{l}\text { a) How } \\
\text { objective do } \\
\text { you feel the } \\
\text { questions } \\
\text { answers } \\
\text { required in } \\
\text { NZ ALI are? }\end{array}$ & $\begin{array}{l}\text { Generally } \\
\text { objective }\end{array}$ & $\begin{array}{l}\text { Generally } \\
\text { objective }\end{array}$ & $\begin{array}{l}\text { About half } \\
\text { and half, the } \\
\text { scale } \\
\text { questions } \\
\text { are very } \\
\text { subjective } \\
\text { although } \\
\text { instructions } \\
\text { and } \\
\text { guidance } \\
\text { generally } \\
\text { help this }\end{array}$ & They are ok & Seem to be & $\begin{array}{l}\text { Fine } \\
\text { although } \\
\text { some are } \\
\text { blatantly } \\
\text { subjective }\end{array}$ \\
\hline $\begin{array}{l}\text { b) Are NZ } \\
\text { ALI } \\
\text { components } \\
\text { easily } \\
\text { measure- } \\
\text { able? }\end{array}$ & $\begin{array}{l}\text { Yes - except } \\
\text { the } 1 \text { - } 10 \\
\text { scale is hard } \\
\text { to work as } \\
\text { there is no } \\
\text { neutral }\end{array}$ & $\begin{array}{l}\text { Yes, when } \\
\text { instructions } \\
\text { are clear }\end{array}$ & $\begin{array}{l}\text { When } \\
\text { instructions } \\
\text { are clear } \\
\text { enough yes - } \\
\text { perhaps } \\
\text { clarify } \\
\text { some? }\end{array}$ & Yes & Yes & $\begin{array}{l}\text { Yes - except } \\
\text { scale }\end{array}$ \\
\hline
\end{tabular}

Table J-16, Summary of Objectivity Issues

\begin{tabular}{|l|l|l|l|l|}
\hline $\begin{array}{l}\text { Objectivity } \\
\text { Questions }\end{array}$ & Critique Summary & \multicolumn{1}{|c|}{ Bad points } & \multicolumn{1}{|c|}{ Good points } & \multicolumn{1}{|c|}{$\begin{array}{l}\text { Main Issues } \\
\text { Identified }\end{array}$} \\
\hline $\begin{array}{l}\text { a) How } \\
\text { objective do } \\
\text { you feel the } \\
\text { questions } \\
\text { answers } \\
\text { required in } \\
\text { NZ ALI are? }\end{array}$ & $\begin{array}{l}\text { They seem to be } \\
\text { objective }\end{array}$ & $\begin{array}{l}\text { C \& F: Some } \\
\text { questions are very } \\
\text { subjective }\end{array}$ & $\begin{array}{l}\text { C: Instructions \& } \\
\text { guidelines help to } \\
\text { limit subjectiveness }\end{array}$ & \\
\hline $\begin{array}{l}\text { b) Are NZ } \\
\text { ALI } \\
\text { components } \\
\text { easily } \\
\text { measure- } \\
\text { able? }\end{array}$ & In general yes & $\begin{array}{l}\text { A\& F: } 1 \text { - 10 scale } \\
\text { hard to work } \\
\text { because there is no } \\
\text { neutral } \\
\text { B \& C: When } \\
\text { instructions aren't } \\
\text { clear is an issue for } \\
\text { measurability of } \\
\text { components }\end{array}$ & $\begin{array}{l}\text { B \& C: When } \\
\text { instructions are } \\
\text { clear there is not } \\
\text { problem }\end{array}$ & Scale \\
\hline
\end{tabular}


Table J-17, NZ ALI Critique, Practicality

\begin{tabular}{|c|c|c|c|c|c|c|}
\hline \multirow{2}{*}{$\begin{array}{l}\text { Practicality } \\
\text { Questions }\end{array}$} & \multicolumn{6}{|c|}{ Apartment Occupant Participants } \\
\hline & A & B & C & D & $E$ & $\mathbf{F}$ \\
\hline $\begin{array}{l}\text { a) How } \\
\text { practical is } \\
\text { NZ ALI? }\end{array}$ & $\begin{array}{l}\text { Fairly } \\
\text { practical - } \\
\text { except } \\
\text { length issue }\end{array}$ & Very & Very & $\begin{array}{l}\text { Some } \\
\text { technical } \\
\text { terms are } \\
\text { confusing }\end{array}$ & $\begin{array}{l}\text { Very. } \\
\text { Although I } \\
\text { have no } \\
\text { background } \\
\text { in the } \\
\text { building } \\
\text { industry I } \\
\text { am sure that } \\
\text { most of the } \\
\text { questions } \\
\text { and factors } \\
\text { in the tool } \\
\text { could be } \\
\text { understood } \\
\text { by anybody }\end{array}$ & Very \\
\hline $\begin{array}{l}\text { b) Are the } \\
\text { assessment } \\
\text { procedures } \\
\text { simple and } \\
\text { any } \\
\text { information } \\
\text { required } \\
\text { easily } \\
\text { acquired? }\end{array}$ & $\begin{array}{l}\text { Generally } \\
\text { yes except } \\
\text { perhaps the } \\
\text { building age } \\
\text { (if not new) } \\
\text { and the } \\
\text { question } \\
\text { about the } \\
\text { building } \\
\text { heights }\end{array}$ & Yes & $\begin{array}{l}\text { Some } \\
\text { questions } \\
\text { would be } \\
\text { hard if you } \\
\text { hadn't lived } \\
\text { in an } \\
\text { apartment } \\
\text { before - } \\
\text { perhaps } \\
\text { need } 2 \\
\text { versions } \\
\text { where you } \\
\text { buy off } \\
\text { plans and } \\
\text { for as built. } \\
\text { No }\end{array}$ & $\begin{array}{l}\text { Yes, easily } \\
\text { acquirable } \\
\text { except for } \\
\text { perhaps } \\
\text { building } \\
\text { heights }\end{array}$ & Seem to be & $\begin{array}{l}\text { Yes, except } \\
\text { perhaps } \\
\text { building } \\
\text { heights? }\end{array}$ \\
\hline $\begin{array}{l}\text { c) Is any of } \\
\text { the } \\
\text { information } \\
\text { required for } \\
\text { NZ ALI too } \\
\text { specialist in } \\
\text { any way? }\end{array}$ & $\begin{array}{l}\text { No - except } \\
\text { some words } \\
\text { are too } \\
\text { specialist. } \\
\text { Emissions? } \\
\text { Egress? }\end{array}$ & No & No & $\begin{array}{l}\text { No, except } \\
\text { for perhaps } \\
\text { building } \\
\text { heights }\end{array}$ & No & No \\
\hline
\end{tabular}


Table J-18, Summary of Practicality Issues

\begin{tabular}{|c|c|c|c|c|}
\hline $\begin{array}{l}\text { Practicality } \\
\text { Questions }\end{array}$ & Critique Summary & Bad points & Good points & $\begin{array}{l}\text { Main Issues } \\
\text { Identified }\end{array}$ \\
\hline $\begin{array}{l}\text { a) How } \\
\text { practical is } \\
\text { NZ ALI? }\end{array}$ & Very practical & $\begin{array}{l}\text { A: Except for length } \\
\text { issue } \\
\text { D: Some technical } \\
\text { terms are confusing }\end{array}$ & No quote & \\
\hline $\begin{array}{l}\text { b) Are the } \\
\text { assessment } \\
\text { procedures } \\
\text { simple and } \\
\text { any } \\
\text { information } \\
\text { required } \\
\text { easily } \\
\text { acquired? }\end{array}$ & Yes, seem to be & $\begin{array}{l}\text { A: Building Age \& } \\
\text { Building Heights, } \\
\text { where can I find this } \\
\text { info? } \\
\text { C: Some questions } \\
\text { would be hard if } \\
\text { you had never lived } \\
\text { in an apartment } \\
\text { before - } 2 \text { versions? } \\
\text { D \& F: Building } \\
\text { Heights? }\end{array}$ & No quote & $\begin{array}{l}\text { Length } \\
\text { Technical Terms i.e. } \\
\text { emissions \& egress } \\
\text { Acquiring some } \\
\text { info i.e. building } \\
\text { age \& building } \\
\text { heights }\end{array}$ \\
\hline $\begin{array}{l}\text { c) Is any of } \\
\text { the } \\
\text { information } \\
\text { required for } \\
\text { NZ ALI too } \\
\text { specialist in } \\
\text { any way? }\end{array}$ & No & $\begin{array}{l}\text { A: Specialist words? } \\
\text { Egress? Emissions? } \\
\text { D: Building Heights }\end{array}$ & No quote & $\begin{array}{l}\text { New apartment } \\
\text { dwellers }\end{array}$ \\
\hline
\end{tabular}


New Zealand Apartment Living: Developing a Liveability Index 
APPENDIX K NZ ALI

For a working example of NZ ALI for Existing Buildings and NZ ALI for New Buildings please open this $\mathrm{CD}$. Please follow the instructions and compare results for different apartments. 
New Zealand Apartment Living: Developing a Liveability Index 


\section{APPENDIX L VICTORIA UNIVERSITY OF WELLINGTON ETHICS APPROVAL}

The following documents are copies of Victoria University of Wellington Ethics Approval. A brief explanation of each is given below explaining why they were needed and how the data supported the research.

\section{Ethics Approval No. 16260}

Ethics approval was required from the Victoria University of Human Ethics Committee for the NZ ALI Questionnaire. Participants of the NZ ALI Questionnaire were required to select components of NZ ALI which they considered to be the most important in regard to liveability. 47 people participated from a range of backgrounds although consent was given for up to 60 people. Five groups of people participated, these were:

- ACAD Academics \& Researchers

- $\quad$ ARCH Architects, Designers, Consultants \& Engineers

- BMOD Building Managers, Owners \& Developers

- GOVT

- OCPT Apartment Occupants (past and present)

The data from the NZ ALI Questionnaire was used to calibrate the NZ ALI components so that weightings could be applied and NZ ALI could be a functioning evaluation and rating tool.

\section{Ethics Approval No. 16431}

Ethics Approval was required from the Victoria for the NZ ALI Trial \& Critique. This work was done in three stages: NZ ALI was trialled on apartments; the apartment occupants participated in an open discussion regarding affects on liveability in the apartment; and trialled NZ ALI themselves and critiqued it. The results of the NZ ALI Critique \& Trial helped to validate the tool first by ensuring that the results were accurate (by comparing the trial and interview) and then by ensuring that it is user friendly (by assessing the critiques). Consent was given for this process to be carried out in four apartments with a maximum of two occupants form each. Four apartments were trialled with six occupants participating. 


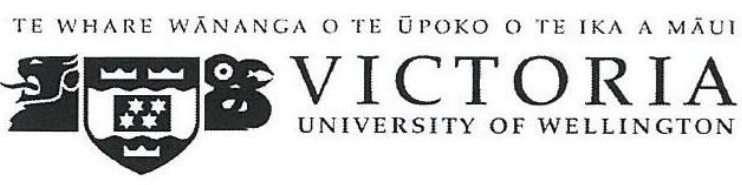
MEMORANDUM
$\begin{array}{ll}\text { Phone } & 0-4-4635676 \\ \text { Fax } & 0-4-4635209 \\ \text { Email } & \text { Allison.kirkman@vuw.ac.nz }\end{array}$

\begin{tabular}{l|l}
\hline TO & Jessica Bennett \\
\hline COPY TO & Nigel Isaacs \\
\hline FROM & Dr Allison Kirkman, Convener, Human Ethics Committee \\
\hline
\end{tabular}

\begin{tabular}{l|l}
\hline DATE & December 20,2008 \\
\hline PAGES & 1 \\
\hline
\end{tabular}

SUBJECT Ethics Approval: No 16260, New Zealand apartment living: developing a liveability index

Thank you for your application for ethical approval, which has now been considered by the Standing Committee of the Human Ethics Committee.

Your application has been approved from the above date and this approval continues until 30 July 2009. If your data collection is not completed by this date you should apply to the Human Ethics Committee for an extension to this approval.

Best wishes with the research.

Allison Kirkman

Convener

Figure L-1, VUW Ethics Approval No. 16260 
TE WHARE WÃNANGA O TE ŪPOKO O TE IKA A MÃUI
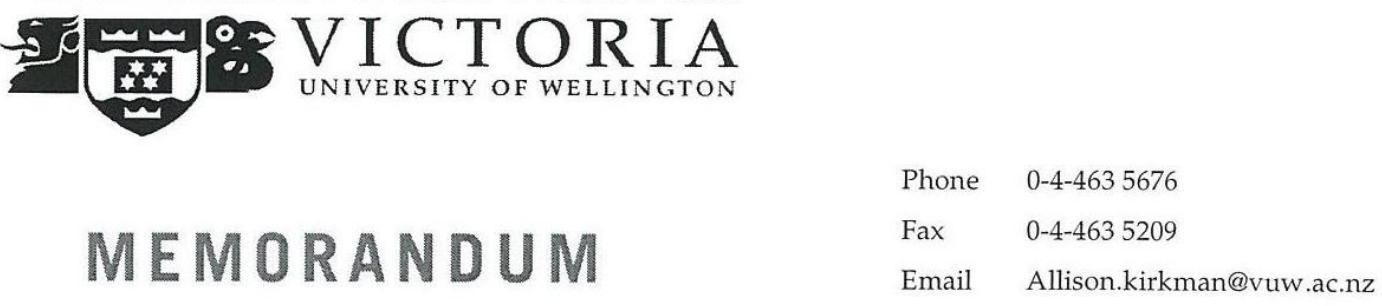

\begin{tabular}{l|l}
\hline TO & Jessica Bennett \\
\hline COPY TO & Nigel Isaacs, Supervisor \\
\hline FROM & Dr Allison Kirkman, Convener, Human Ethics Committee \\
\hline
\end{tabular}

\begin{tabular}{l|l}
\hline DATE & April 6, 2009 \\
\hline PAGES & 1 \\
\hline
\end{tabular}

SUBJECT Ethics Approval: No 16431, New Zealand apartment living: Developing a Liveability Index.

Thank you for your application for ethical approval, which has now been considered by the Standing Committee of the Human Ethics Committee.

Your application has been approved from the above date and this approval continues until 30 July 2009. If your data collection is not completed by this date you should apply to the Human Ethics Committee for an extension to this approval.

Best wishes with the research.

Allison Kirkman

Convener

Figure L-2, VUW Ethics Approval No. 16431 
New Zealand Apartment Living: Developing a Liveability Index 